Development and validation of diagnostic and pharmacodynamic cancer biomarker methods and their (pre)clinical application

Derk Pluim 
Printing of this thesis was financially supported by

o Utrecht Institute of Pharmaceutical Sciences (UIPS)

o The Netherlands Cancer Institute (NKI)

The research described in this thesis was conducted at the Department of Pharmacology, and the Division of Molecular Pathology of the Netherlands Cancer Institute, and the Clinical Research Unit of the Antoni van Leeuwenhoek hospital

ISBN: 978-94-93197-92-3

https://doi.org/10.33540/900

Printing: Off Page

Cover, artwork, and layout design: Derk Pluim, Amsterdam

Copyright@ 2021, Derk Pluim, Amsterdam

All rights reserved. No parts of this book may be reproduced or transmitted, in any form or by any means, without written permission from the author. 


\title{
Development and validation of diagnostic and pharmacodynamic cancer biomarker methods and their (pre)clinical application
}

\author{
Ontwikkeling en validatie van diagnostische en \\ pharmacodynamische kanker biomarker methoden \\ en hun (pre)klinische toepassing \\ (met een samenvatting in het Nederlands)

\section{Proefschrift} \\ ter verkrijging van de graad van doctor aan de \\ Universiteit Utrecht \\ op gezag van de \\ rector magnificus prof. dr. H.R.B.M. Kummeling \\ ingevolge van het besluit van het college van promoties \\ in het openbaar te verdedigen op
}

maandag 20 december 2021 des middags te 2:15 uur

door

\section{Derk Pluim}

geboren op 11 september 1970

te Groningen 
PROMOTOR:

Prof. dr. J. H. Beijnen

COPROMOTOR:

Dr. D. Brandsma 


\section{CONTENTS}

\section{General introduction and thesis outline}

Chapter 1 Development and validation of biomarker methods

$1.1 \quad$ Analytical validation of quantitative pharmacodynamic methods used in clinical cancer studies Int Arch Clin Pharmacol 2021; 7

Correction of peripheral blood mononuclear cell cytosolic protein for hemoglobin contamination Analytical Bioanalytical Chemistry 2013;405:2391-2395

1.3 Pharmacodynamic assay of thymidylate synthase activity in peripheral blood mononuclear cells Analytical Bioanalytical Chemistry 2013;405:2495-2503

1.4 Improved pharmacodynamic assay of dihydropyrimidine dehydrogenase activity in peripheral blood mononuclear cells Bioanalysis 2015; 7:519-529

1.5 Development and validation of a quantitative method for thymidine phosphorylase activity in peripheral blood mononuclear cells Nucleosides, Nucleotides and Nucleic Acids 2018;37:436-454

$1.6 \quad$ Improved pharmacodynamic (PD) assessment of low dose PARP inhibitor PD activity for radiotherapy and chemotherapy combination trials Radiotherapy and Oncology 2018;126:443-449

1.7 Multiparameter flow cytometry assay for quantification of immune cell subsets, PD-1 expression levels and PD-1 receptor occupancy by nivolumab and pembrolizumab Cytometry Part A 2019;95:1053-1065

$1.8 \quad$ Validation of a Multiparameter Flow Cytometry Method for the Determination of Phosphorylated Extracellular-SignalRegulated Kinase and DNA in Circulating Tumor Cells Cytometry Part A 2012;81A:664-671 
Chapter 2 (Pre)clinical application of biomarker methods

2.1 Pronounced between-subject and circadian variability in

199

thymidylate synthase and dihydropyrimidine

dehydrogenase enzyme activity in human volunteers

British Journal of Clinical Pharmacology 2016;82:706-716

2.2 Phase I pharmacological study of continuous

chronomodulated capecitabine treatment

Pharmaceutical Research 2020;37:89-99

2.3 EpCAM-based assays for epithelial tumor cell detection in cerebrospinal fluid

Journal of Neuro-Oncology 2017;137:1-10

2.4 Circulating epithelial tumor cell analysis in CSF in patients

with leptomeningeal metastases

Neurology 2020;94:521-528

2.5 Circulating melanoma tumor cell analysis in CSF in patients with leptomeningeal metastases

Manuscript in preparation

Conclusions and perspectives 


\section{General introduction and thesis outline}

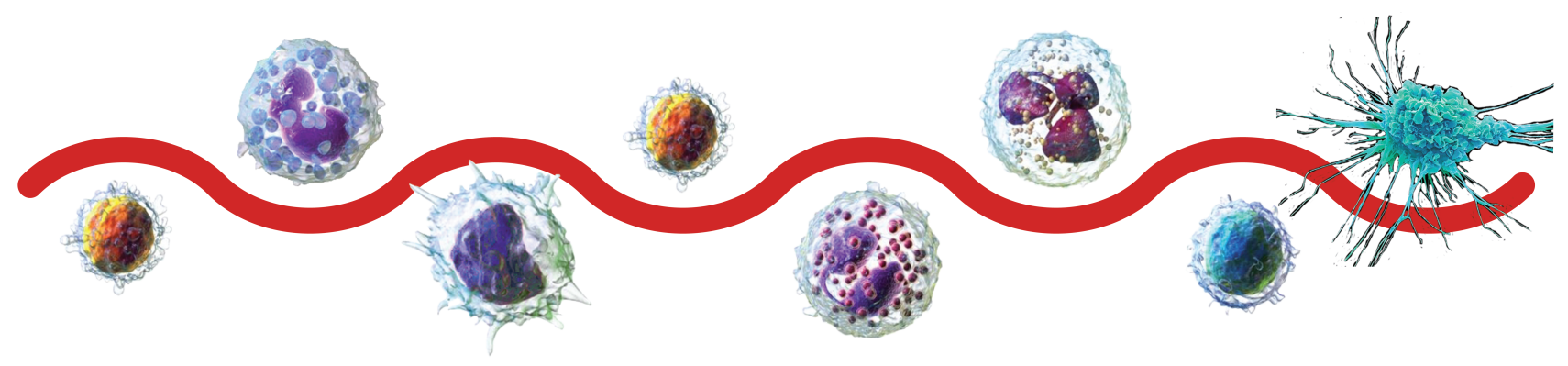

\section{GENERAL INTRODUCTION}

Biomarkers play an important role in the treatment of cancer by functioning as signposts of the pathogenic process (1). In clinical cancer trials, biomarkers are used for the selection of patients most likely to benefit from a certain (personalized) treatment (2). Biomarkers can also facilitate the early detection of treatment outcome, which may provide essential guidance for treatment modification or discontinuation $(3,4)$. For these reasons, the interest in the use of biomarkers in cancer trials has grown considerably over the past 60 years. In 1959 , there were just $0.02 \%$ of papers with mentions of the words "cancer" and "biomarker" listed in Pubmed, whereas by 2019 this had increased to $13.8 \%$ (5). Of all oncology trials in 2018, 55\% involved the use of biomarkers, as compared with 15 percent in 2000 (6). Almost half of the total trials with biomarkers specifically highlighted interrogation of two or more biomarkers in 2018, compared with just about 14 percent in 2000. Interestingly, the increased use of biomarkers in oncology coincides with a rise in drug approvals from nine out of 41 (about 22\%) in 2014 of the U.S. Food and Drug Administration's (FDA) new molecular entity approvals to 16 out of 59 (about 27\%) in 2018 (6). It is nowadays 
generally recognized that the use of biomarkers in clinical trials leads to a higher drug approval rate (7).

The biomarkers used in clinical cancer trials mostly have molecular (chemicals, proteins, or genes) characteristics. Less frequently they have histologic (cells), radiographic (X-ray, CT, PET or MRI features), or physiologic (heart rate, blood pressure etc.) characteristics (8). Based on their clinical application, biomarkers can be subdivided into pharmacodynamic, diagnostic, predictive, prognostic, monitoring, safety, and risk/tolerability categories (9). Pharmacodynamic biomarkers are used to provide proof of target engagement by a treatment drug. Diagnostic biomarkers are used to detect or confirm the presence of cancer, or to classify the cancer based on subtypes. Predictive biomarkers are used to select the most appropriate patients for (personalized) treatment. Prognostic biomarkers provide information about the likely clinical outcome. Monitoring biomarkers provide insight into the disease progress or the therapeutic effect. Safety biomarkers are used to assess and monitor toxicities. Risk/susceptibility biomarkers can be used to predict the chance of developing cancer in an individual who does not yet have this disease (10). Sometimes a biomarker can be used for more than one clinical application (9).

Many challenges are encountered in the development of the methods used for the measurement of molecular biomarkers $(11,12)$. Firstly, molecular biomarkers need to be detected in patient material such as body fluids and tissues that contain a complex mixture (the matrix) of similar endogenous molecules. Secondly, endogenous enzymes may affect the stability of a biomarker, or the biomarker is susceptible to post-translational modification (PTM). Thirdly, obtaining biomarker-free matrices for the method development is often impossible because biomarkers are endogenous compounds. Lastly, sometimes a pure and certified biomarker is not available to serve as reference standard. Therefore, the reference standards are often isolated from cell lines, and the extent of their purification may differ between manufacturers, resulting in high lot-to-lot deviations of up to $76 \%$ in an European Bioanalysis Forum (EBF) case study (13). These challenges complicate the design of reliable and robust biomarker methods.

After the method development, biomarker methods need to be validated to establish whether they are reliable and robust, which gives biomarker methods the best chance to live up to their expectations in clinical trials. For this purpose, the FDA in their 2018 guideline for bioanalytical method validation recommends 
full analytical validation of biomarker methods used in clinical trials (14). A draft guideline similar to this 2018 FDA validation guideline has existed since 2013. The FDA guideline recommends to establish the method specificity, sensitivity, accuracy (mean \% deviation from nominal concentration), linearity, dilution integrity, upper and lower limits of quantification, precision (\% coefficient of variation (CV), and reagents and sample storage stability.

\section{THESIS OUTLINE}

This thesis will focus on the development, analytical validation, and (pre)clinical application of molecular biomarker methods for pharmacodynamic and diagnostic purposes. We demonstrate their full analytical validation, in accordance with the recommendations from the FDA 2018 validation guideline (14). Furthermore, we demonstrate the preclinical and clinical application of these validated methods.

In chapter 1 of this thesis, we show the development and analytical validation of several novel or improved molecular pharmacodynamic biomarker methods. These methods are based on a broad spectrum of common analytical techniques, such as flow cytometry, radio-isotope scintillation, enzyme linked-immunosorbent assays (ELISA), and high performance liquid chromatography (HPLC).

Chapter 1.1 of this thesis provides a review of the validation quality of quantitative biomarker methods used in clinical cancer trials over the past seven years. The recommendations for biomarker method validation from the 2018 FDA validation guideline were used as a reference (14).

Chapter 1.2 describes a new method to correct for the variable and large amounts of hemoglobin contamination found in peripheral blood mononuclear cell (PBMC) lysates. If left uncorrected, hemoglobin negatively influences the accuracy and variability of methods used for the determination of enzyme activities in PBMC.

Chapters 1.3 - 1.5 describe 3 novel biomarker methods that we developed for the quantification of thymidylate synthase (TS), dihydropyrimidine dehydrogenase (DPD), and thymidine phosphatase (TP) enzyme activities in PBMC. These enzymes are involved in the metabolism of fluoropyrimidines, which are the most widely used chemotherapeutic agents for the treatment of many solid tumors, including gastrointestinal, head and neck, pancreas, and breast cancers (15).

Chapter 1.6 describes an improved biomarker method for the quantification of poly-ADP-ribose polymerase (PARP) activity in PBMC. The main role of PARP 
is to detect and initiate an immediate cellular response to metabolic, chemical, or radiation-induced single-strand DNA breaks (SSB) by signaling the enzymatic machinery involved in the SSB repair. In the clinic, PARP inhibitors have shown synergistic toxicity in combination with DNA damaging agents, and they show synthetic lethality against tumors deficient for double strand break repair.

Chapter 1.7 present a novel biomarker method for measuring the amount of nivolumab or pembrolizumab bound to their biological target, programmed death-1 (PD-1), on the surface of different immune cell subsets. Nivolumab and pembrolizumab are commonly used immunotherapeutic antibodies that act as PD-1 checkpoint inhibitors, and are both approved by the FDA for treatment of several cancers like melanoma, non-small cell lung cancer (NSCLC), and urothelial cancer (16).

Chapter 1.8 presents a new method for the enumeration of epithelial circulating tumor cells (CTC) in blood, which can also be used for the quantification of phosphorylated Extracellular-Signal-Regulated Kinase ( $p$-ERK) in CTC.

Chapter 2 describes four pre(clinical) human studies in which the validated biomarker methods from chapter 1 and 2.5 of this thesis have been applied.

Chapter 2.1 describes the application of our new and validated biomarker methods for quantification of DPD, TS, and TP enzyme activities in a healthy volunteer study to investigate possible circadian variability in these biomarkers.

Chapter 2.2 describes the application of our DPD, TS, and TP biomarker methods in a phase I clinical study using continuous chronomodulated capecitabine treatment. Capecitabine is an oral administered prodrug of the active metabolite 5-fluorouracil (5-FU) and is frequently used for the treatment of colorectal, breast and gastric cancer. Other investigators have shown that the biological activities of DPD and TS are subject to circadian rhythmicity in healthy volunteers. In this study, we assessed the maximum tolerated dose and safety of chronomodulated treatment with capecitabine. We investigated the circadian rhythms of TS and DPD, and also established whether capecitabine affects TP phenotype.

Chapter 2.3 provides a literature review of the sensitivity and specificity of the reported EpCAM based analysis methods available for the quantification of epithelial CTC in cerebrospinal fluid (CSF).

Chapters 2.4 and 2.5 describe the results of two clinical studies performed to establish the diagnostic value of circulating epithelial and melanoma cancer cells 
for the early detection of leptomeningeal metastases (LM) in the CSF. For this purpose, we present a novel analysis method for the enumeration of circulating melanoma cells in human blood in chapter 2.5. In these two clinical studies, the results of our CTC analysis methods were cross-validated against CSF cytology, which is still the golden standard method for LM diagnosis.

Lastly, we highlight some of the most important aspects of the design of biomarker methods, and we draw conclusions and give our perspective on the importance of analytical validation of biomarker methods for their successful application in (pre)clinical studies. 


\section{REFERENCES}

1. Srinivas PR, Kramer BS, and Srivastava

S. Trends in biomarker research for cancer detection; Lancet Oncol 2001;2:698-704.

2. Chau $\mathrm{CH}$, Rixe $\mathrm{O}$, McLeod $\mathrm{H}$, and Figg WD. Validation of Analytical Methods for Biomarkers Employed in Drug; Clin Cancer Res 2008;14:5967-5976.

3. Sarker D, and Workman P; Pharmacodynamic biomarkers for molecular cancer therapeutics. Adv Cancer Res 2007; 96:213-268.

4. Sarker D et al. Use of pharmacokinetic/ pharmacodynamic biomarkers to support rational cancer drug development. Biomark Med 2007; 1:1-18.

5. Vadas A., Bilodeau, TJ, and Oza C. The evolution of biomarker use in clinical trials for cancer treatments; J. Precision Medicine 2019 special report:1-25.

6. Pritchard D, Wells C. Raising the Bar: FDA Accelerates the Push Toward Personalized Medicine; J Precision Medicine 2019;5:3639.

7. Paul SM, Mytelka DS, Dunwiddie, CT, Persinger CC, Munos, BH, Lindborg SR, et al. How to improve R\&D productivity: the pharmaceutical industry's grand challenge. Nature reviews Drug Discovery 2010; 9:203214.

8. Atkinson AJ, Colburn WA, DeGruttola VG, DeMets DL, Downing GJ, Hoth DF, Oates JA, Peck CC, Schooley RT, Spilker BA, Woodcock J, and Zeger SL. Biomarkers and surrogate endpoints: Preferred definitions and conceptual framework; Clinical pharmacology and Therapeutics 2001; 69:89-95.

9. Califf RM. Biomarker definitions and their applications; Experimental Biology and Medicine 2018;243:213-221.

10. Dumbrava El, Meric-Bernstam F, and Yap TA, Challenges with biomarkers in cancer drug discovery and development. Epert Opinion on Drug Discovery 2018;13:685690.

11. Goossens N, Nakagawa $S$, Sun $X$, and Hoshida $Y$. Cancer biomarker discovery and validation. Transl Cancer Res 2015;4:256269.

12. $\mathrm{Wu} \mathrm{L}$, and $\mathrm{Qu} \mathrm{X}$. Cancer biomarker detection: recent achievements and challenges. Chem Soc Rev 2015;44:29632997.

13. Kunz U, Goodman J, Loevgren U, Piironen $\mathrm{T}$, Elsby $\mathrm{K}$, Robinson $\mathrm{P}$, Pihl $\mathrm{S}$, Versteilen $A$, Companjen $A$, Scheel Fjording $M$, and Timmerman P. Addressing the challenges of biomarker calibration standards in ligandbinding assays: a European Bioanalysis Forum perspective. Bioanalysis 2017;9:14931508.

14. Food and Drug Administration; Bioanalytical Method Validation Guidance for Industry 2018; http://www.fda.gov/ Drugs/GuidanceComplianceRegulatroy Information/Guidances/default.htm 15. Del Re M, Cinieri, S., Michelucci, A., Salvadori, S., Loupakis, F., Schirripa, M., Cremolini, C., Crucitta, S., Barbara, C., Di Leo, A., Pia Latiano, T., Pietrantonio, F., Di Donato, S., Simi, P., Passardi, A., De Braud, F., Altavilla, G., Zamagni, C., Bordonaro, R., Butera, A., Maiello, E., Pinto, C., Falcone, A., Mazzotti, V., Morganti, R., Danesi, R.; DPYD*6 plays an important role in fluoropyrimidine toxicity in addition to DPYD*2A and c.2846A $>$ T: a comprehensive analysis in 1254 patients; 
The Pharmacogenomics Journal 2019;19: 556-563.

16. Cui, P., Li, R., Huang, Z., Wu, Z., Tao, H., Zhang, S., Hu, Y.; Comparative effectiveness of pembrolizumab vs. nivolumab in patients with recurrent or advanced NSCLC; Nature Scientific Reports 2020;10:13160. 
General introduction and thesis outline 


\section{CHAPTER 1}

Development and validation of pharmacodynamic and diagnostic cancer biomarker methods

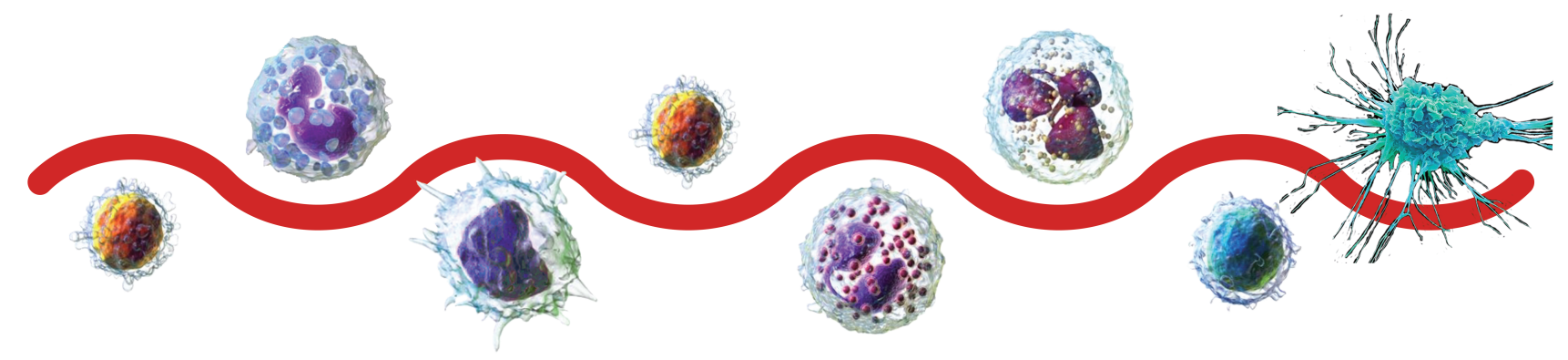

1.1

Analytical validation of quantitative pharmacodynamic methods used in clinical cancer studies

Dick Pluim, Jos H. Beijnen

Int Arch Clin Pharmacol 2021; 7: 


\section{ABSTRACT}

Quantitative pharmacodynamic (PD) methods are used to assess the effect of a drug on its target. The use of these methods in clinical cancer studies has increased enormously with the advent of targeted therapies in the past years. To ensure that quantitative PD methods meet their expectations, methods need to be validated according to internationally recognized standards for amongst others specificity, accuracy, sensitivity, precision and stability. We show that $87 \%$ of our selected clinical cancer studies, published in the last 7 years, used quantitative PD methods that were on average only validated for half of the 10 main validation parameters. Here, we offer our view on the quality of, and the challenges encountered in validation of quantitative PD methods. Finally, we provide future directions and considerations for improvement of the method validation quality. 


\section{INTRODUCTION}

The need for pharmacodynamic (PD) biomarker methods continues to grow with the explosive increase of targeted agents in clinical cancer therapy. PD biomarkers are endogenous biological indicators that can be measured objectively and provide insight about the target engagement, and proof of concept i.e. the extent of the biological effect of a drug. Poor target validation or insufficient target engagement is the main reason for failure of $42 \%$ of clinical phase I and $63 \%$ of phase II clinical cancer trials (1). Early recognition of these failures is important, which can be accomplished by using PD biomarkers to provide proof of mechanism for the drug-target engagement. PD biomarkers may include molecular, histologic, radiographic, or physiologic characteristics. Most PD biomarkers are, however, molecular biomarkers, which encompass among others protein modifications, enzyme activities, receptor expression and occupancies, and cell counts. In early clinical trials, PD biomarkers can provide useful information for patient management, e.g., whether to continue treatment or to adjust dose (schedule) (2). They can also help to guide drug dose individualization in targeted/personalized cancer therapy with the aim of treating cancer more effectively and with less toxicity (3). An illustrative example of the potential usefulness of PD evaluations is the monitoring of B-lymphocyte suppression as PD biomarker in clinical trials to find doses of anti-CD20 monoclonal antibodies required to maximally reduce this cell population. The reduction of the amount of B-cells is presumed to underlie the clinical benefits of these drugs in treating cancer, and has become an established indicator for treatment success (4). Another example is the monitoring of the inhibition of PARP (target) enzyme activity in white blood cells as PD biomarker for the target engagement of the anticancer drug olaparib (5).

Quantitative PD biomarker methods are used to determine biomarker activity or concentration in different biological matrices such as blood, bile, serum, plasma, urine, tumor cells, and tissue such as skin. For this purpose, these methods need calibration standards prepared in biomarker-free surrogate matrices that are fully defined and representative for the measured biomarkers and their biological matrices. Full analytical validation of these methods is essential to assure accurate and specific biomarker quantification to prevent interference from other compounds in these matrices. Often biomarkers can fail not because of the underlying science, but because of poor choice of methods and 
lack of analytical validation (2). The development and validation of quantitative biomarker methods is, however, more complicated than that of bioanalytical drug methods used for pharmacokinetics due to the following complications. Firstly, sometimes biomarkers need to be detected in more complex biological matrices such as tumor tissues. Secondly, the stability of biomarkers and other endogenous compounds in the biological matrix is often poor. Thirdly, biomarkers are endogenous substances, thus obtaining biomarker-free surrogate matrices for validation of method specificity, and preparation of the calibration curve may be more difficult. Lastly, the biomarker molecule is often not available to act as a certified calibration standard (6).

The last decade has seen significant progress in harmonisation of acceptance criteria, definitions, and guidelines for bioanalytical method validation (BMV) of chromatography and ligand binding methods (7). For this purpose, the International Council for Harmonisation of Technical Requirements for Pharmaceuticals for Human Use $(\mathrm{ICH})$ recently released BMV Guidance M10 (8). Fundamentally, ICH-M10 validation involves demonstration of bioanalytical method specificity, accuracy (mean \% deviation from nominal concentration), linearity, dilution integrity, sensitivity, limit of quantification, precision (\% coefficient of variation (CV), and stability for drugs (Table 1). However, international harmonization of guidelines for biomarker method validation is lacking. In their BMV 2018 guideline, the Food and Drug Administration (FDA) recommends to "conduct a full validation of any new bioanalytical method for the analysis of a new drug entity, its metabolite(s), or biomarkers." (9). The validation of biomarkers thus needs to be consistent with the validation principles applied to bioanalytical drug methods validation (9). This guideline further states that exploratory quantitative biomarker methods, that are not used to support regulatory decision making, may not require such stringent validation. Exploratory biomarker methods are for instance used to better understand the mechanism of action of drugs, which may ultimately lead to improved future cancer treatments. However, in light of their importance, and to make sure that these methods life up to their expectations, we would argue that also exploratory quantitative biomarker methods, used in clinical trials, need to be fully validated.

Herein, we present our viewpoint on the degree of compliance with the FDA BMV 2018 guideline of quantitative PD biomarker methods used in our selection of clinical cancer trials. Challenges encountered in the process of PD biomarker method development and validation are discussed. 
Table 1. Definition and main criteria of the biomarker validation parameters from the Food and Drug Administration (FDA) Bioanalytical Method Validation (BMV) guideline 2018 (5).

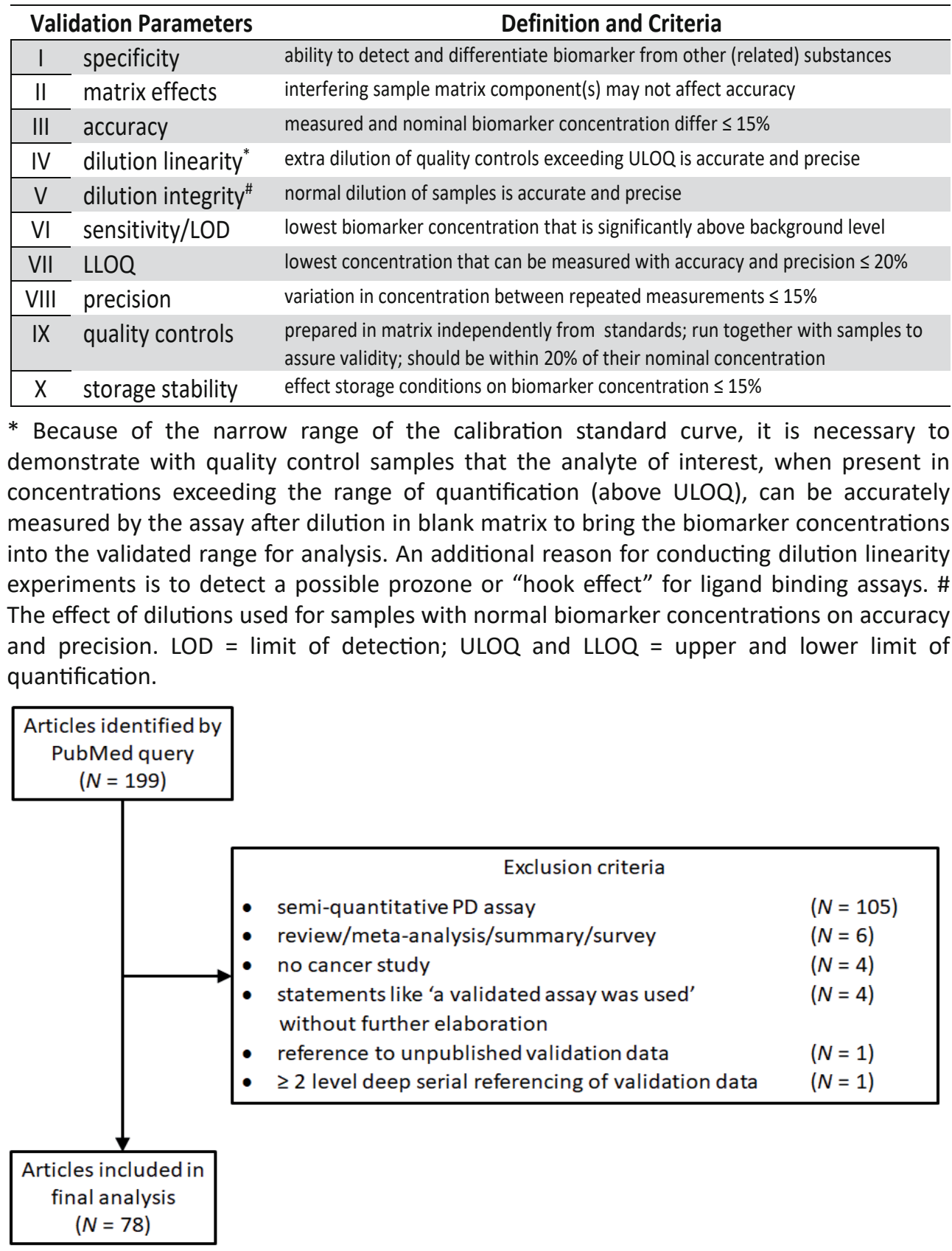

Figure 1. Flow diagram of the published articles selection process 
The implications of poorly validated methods used for assessment of drug effects are described. In the final section, we offer some considerations and suggestions that may help to improve the quality of PD biomarker methods and consequently their usefulness in clinical cancer trials.

\section{Analytical methods validation}

For the assessment of the status of analytical validation of quantitative PD methods used in clinical cancer trials, a focused PubMed literature query was performed on the 8th of December 2020, including the keywords "2013/04/12" [PDAT] : "2020/12/08" [PDAT] AND "humans" [MeSH Terms] AND ("Clinical Trials, Phase I as Topic" [Mesh] OR "Clinical Trials, Phase II as Topic" [Mesh] OR "Clinical Trials, Phase III as Topic" [Mesh] OR "Clinical Trials, Phase IV as Topic" [Mesh] OR phase I [tiab] OR phase 1 [tiab] OR phase II [tiab] OR phase 2 [tiab] OR phase III [tiab] OR phase 3 [tiab] OR phase IV [tiab] OR phase 4 [tiab] OR "Clinical Trials, Phase I as Topic" [Mesh] OR "Clinical Trials, Phase II as Topic" [Mesh] OR "Clinical Trials, Phase III as Topic" [Mesh] OR "Clinical Trials, Phase IV as Topic" [Mesh]) AND (pharmacodynamic* [tiab] AND method AND methods AND cancer NOT modeling [tiab] NOT review [tiab]). The query returned 199 articles. After review, 4 articles were excluded for failure to provide details about used validation criteria and guidelines. Another article was excluded for referencing to validation data in a submitted, but never published, other article from the authors. Yet another article was excluded for serial referencing. After applying additional exclusion criteria, 78 (39\%) of articles were found suitable for our evaluation using quantitative PD methods in human clinical cancer studies (Fig. 1.) $(10,11,20-29,12,30-39,13,40-$ $49,14,50-59,15,60-69,16,70-79,17,80-87,18,19)$. From each of these articles one quantitative PD method was evaluated and qualitatively scored for compliance with the 10 main validation criteria defined by the FDA BMV 2018 guideline (Tables 1 and 2).

We found, that 10 PD biomarker methods (13\%) were fully validated in accordance with all 10 main FDA BMV 2018 validation parameters. However, 53 PD methods (68\%) were validated for just on average 5 parameters. Total absence of PD method validation was found for 17 (22\%) of published clinical studies. Compared to chromatographic and ligand binding methods, flow cytometry (FC) methods were relatively less well validated. FC methods were validated for on average just 2 parameters and 50\% lacked any validation. In order to effectively utilize biomarkers to draw meaningful conclusions, it is imperative that the 
measured concentration or activity of the biomarker in study samples is as close as possible to the actual value at the time of sample collection. The FDA guideline states that investigators should always evaluate their PD methods for stability themselves, referencing the limited sample stability data published in literature is not considered sufficient (9). For this purpose, stability needs to be assessed for all stocks and reagents used, and for biomarkers during all different parts of the experimental procedure: 1 . From sample collection in the clinic to the start of the sample work-up in the lab 2. On the bench-top or in the autosampler after sample work-up 3. Long term storage 4. Freeze-thaw stability. Stability during the sample work-up procedure is by definition not part of the validation, but should be assessed during method development. Nevertheless, only 26 PD methods (33\%) were evaluated for reagent and stock solution stability, and biomarker stability during one or more parts of the experimental procedure.

\section{Challenges and considerations}

Commercial immuno-assay kits were used in 33 (77\%) of PD methods. These kits are usually developed for general use and therefore may need some level of optimisation, such as adding more calibrators and/or replacing the kit controls in a buffer with controls that mimic the sample matrices. This may prevent accuracy problems from a lack of parallelism between standard curves prepared in buffer and matrix. Many reagents are "research use only" (RUO) with considerable batch to batch variation. The use of good manufacturing practice (GMP) reagents or pooled RUO batches should be preferred if possible. A common complaint from scientists is that suppliers do not provide the data required to evaluate a given antibody's specificity or its lot-to-lot variability (88). Companies might ship a batch of antibodies with characterization information derived from a previous batch (88). And any validation data that are given are often derived under ideal conditions that do not reflect typical experiments (89). Investigators should be aware that certain suppliers are releasing with a fast pace antibodies and ELISA kits of questionable quality (88). The largest vendors often buy antibodies from smaller suppliers, relabel them and offer them for sale (88). Such products can lead to unfounded conclusions, waste of many months of research and publications that subsequently need to be retracted. In one illustrative example, the investigators spent 2 years and $\$ 500.000$ because the commercial kit they were using did not recognize Zona Pellucida-like domains protein 1 but cancer antigen 125 (90). Investigators should realise that validation of specificity is the 
Table 2. Qualitative validation scores for PD assays from 78 phase 1-3 clinical cancer studies.

\begin{tabular}{|c|c|c|c|c|c|c|c|c|c|c|c|c|c|c|c|c|}
\hline \multirow{2}{*}{$\begin{array}{c}\text { Biomarkers } \\
\text { (alphabetically) }\end{array}$} & Assay & Origin & & & & Jalic & tio & par & met & & & & Drug & Phase & Year & Ref.\# \\
\hline & & & $I$ & II & III & IV & v & VI & VII & VIII & IX & $\mathbf{x}$ & & & & \\
\hline ADA & ELISA & LDA & + & + & + & + & + & + & + & $+/+$ & + & + & Blinatumomab & 1 & 2018 & 34 \\
\hline ADA & LBA & Comm. & + & + & + & + & + & - & + & $+/+$ & + & + & Regorafenib & 1 & 2016 & 13 \\
\hline ADA & ELISA & LDA & - & - & - & - & - & + & - & $-/-$ & - & - & TAS-266 & 1 & 2015 & 75 \\
\hline ADA & ELISA & LDA & - & - & - & - & - & + & - & $-/-$ & - & - & Angiocal & 1 & 2013 & 67 \\
\hline Ang2 & ELISA & Comm. & + & + & + & + & + & + & + & $+/+$ & + & + & Docetaxel & 2 & 2014 & 52 \\
\hline B/T-cells & FC & LDA & - & - & - & - & - & - & - & $-/-$ & - & - & Birinapant & 2 & 2016 & 86 \\
\hline BTK & LBA & LDA & + & - & + & + & - & + & + & $+/+$ & - & + & Tirabrutinib & 1 & 2018 & 26 \\
\hline BTK & ELISA & LDA & + & - & - & - & - & + & - & $-/$ & - & - & Acalabrutinib & 1 & 2018 & 25 \\
\hline ccK18 & ELISA & Comm. & + & + & + & + & + & + & - & $+/+$ & + & + & SOR-C13 & 1 & 2017 & 51 \\
\hline CD137 & xMAP ELISA & Comm. & + & - & + & + & + & + & + & $+/+$ & + & + & Utomilumab & 1 & 2018 & 56 \\
\hline CD26 & FC & LDA & + & - & - & - & - & - & - & $-/-$ & - & - & YS-110 & 1 & 2017 & 58 \\
\hline CD3/14/20 cells & FC & LDA & - & - & - & + & - & - & - & $-/-$ & - & - & CC-223 & 1 & 2015 & 45 \\
\hline CEC & FC & LDA & + & - & + & - & - & - & - & $+/-$ & - & - & Pazopanib & 1 & 2014 & 36 \\
\hline $\mathrm{CgA}$ & RIA & Comm. & - & - & - & - & - & - & + & $+/+$ & - & - & Lanreotide & 3 & 2016 & 31 \\
\hline Collagen IV & ELISA & Comm. & + & - & - & + & - & + & - & $-1-$ & - & - & Cediranib & 1 & 2015 & 35 \\
\hline CRP & LBA & n.d. & - & - & - & - & - & - & + & $-/-$ & - & - & Siltuximab & 1 & 2013 & 21 \\
\hline CTC & FC & Comm. & + & - & + & + & + & + & + & $+1+$ & + & + & ASP-9521 & $1 / 2$ & 2014 & 85 \\
\hline CTC & FC & Comm. & + & - & + & + & + & + & + & $+/+$ & + & + & ARN-509 & 1 & 2013 & 44 \\
\hline CTC & FC & LDA & - & - & - & - & - & + & - & $-/-$ & - & - & Alisertib & $1 / 2$ & 2017 & 79 \\
\hline CTC & FC & LDA & - & - & - & - & - & - & - & $-/-$ & - & - & TRC105 & 2 & 2016 & 61 \\
\hline $\mathrm{mCTC}$ & FC & LDA & + & + & + & + & + & + & + & $+/+$ & + & + & $5-F-2^{\prime}-d C$ & 1 & 2020 & 24 \\
\hline CTX1 & ELISA & Comm. & + & - & - & + & - & + & + & $+/+$ & + & - & GLPG-0187 & 1 & 2016 & 17 \\
\hline Cytokines & XMAP ELISA & Comm. & + & - & + & + & + & + & + & $+/+$ & + & + & TMX-101 & 1 & 2015 & 10 \\
\hline dFdC-TP & LC-MS/MS & LDA & + & - & + & + & + & + & + & $+/+$ & + & + & Gemcitabine & $1 / 2$ & 2015 & 38 \\
\hline DNA & LC-MS/MS & LDA & + & + & + & + & + & + & + & $+/+$ & + & + & LY2603618 & 2 & 2017 & 62 \\
\hline EGF & LBA & LDA & - & - & - & - & - & - & - & $-/-$ & - & - & Sorafenib & 1 & 2015 & 37 \\
\hline EPO & LBA & Comm. & + & + & + & + & - & + & - & $+/+$ & + & - & PT2385 & 1 & 2018 & 66 \\
\hline FGF & ELISA & Comm. & + & - & - & + & - & - & + & $+/+$ & - & - & S49076 & 1 & 2017 & 70 \\
\hline FGFR & ELISA & LDA & - & - & - & - & - & - & - & $-/-$ & - & - & JNJ-42756493 & 1 & 2015 & 71 \\
\hline G-CSF & ELISA & Comm. & + & + & + & + & + & + & + & $+/+$ & + & - & Lenvatinib & 1 & 2013 & 43 \\
\hline GSH-GSSH & Spectrometry & Comm. & - & - & - & - & - & + & - & $-/-$ & - & - & IACS-010759 & 1 & 2020 & 30 \\
\hline$\gamma-H 2 A X$ & FC & LDA & - & - & - & - & - & - & - & $-/-$ & - & - & MK-8776 & 1 & 2015 & 42 \\
\hline HSP7O & ELISA & n.d. & - & - & - & - & - & - & - & $-/-$ & - & - & NVP-AUY922 & 2 & 2014 & 77 \\
\hline$\gamma$-IF & FC & LDA & - & - & - & - & - & - & - & $-/-$ & - & - & Cixutumumab & 2 & 2014 & 12 \\
\hline IGF1 & ELISA & Comm. & + & - & + & + & - & + & - & $+/+$ & + & - & Polyphenon E & 2 & 2017 & 39 \\
\hline IGF1 & ELISA & Comm. & + & - & + & + & - & - & + & $+/+$ & + & - & MEDI-573 & 1 & 2015 & 54 \\
\hline IGF1R & FC & LDA & - & - & - & - & - & - & - & $-/-$ & - & - & BIIB-022 & 1 & 2014 & 72 \\
\hline IGFBP2 & ELISA & Comm. & + & + & + & + & + & + & - & $+/+$ & + & - & CNF-1010 & 1 & 2013 & 65 \\
\hline II-2 & ELISA & n.d. & - & - & - & - & - & - & - & $-/-$ & - & - & RO4929097 & 2 & 2015 & 29 \\
\hline $1 \mid 2-10$ & ELISA & Comm. & - & - & - & - & - & - & - & $-1-$ & - & - & Ponatinib & 2 & 2019 & 74 \\
\hline II-8 & ELISA & Comm. & + & + & + & + & + & + & + & $+/+$ & + & + & Sunitinib & 3 & 2013 & 87 \\
\hline LFA102 & ELISA & LDA & - & - & - & + & - & - & - & $-/-$ & - & - & LFA-102 & 1 & 2016 & 83 \\
\hline lymphocytes & FC & LDA & - & - & - & - & - & - & - & $-1-$ & - & - & Dinaciclib & 1 & 2013 & 33 \\
\hline monocytes & FC & LDA & - & - & - & - & - & - & - & $-/-$ & - & - & Emactuzumab & 1 & 2019 & 19 \\
\hline p-AKT & ELISA & Comm. & - & + & + & + & + & + & - & $+/+$ & + & - & PX-866 & 2 & 2019 & 82 \\
\hline p-AKT & XMAP ELISA & Comm. & + & - & + & + & - & + & - & $+/+$ & - & - & Pictilisib & 1 & 2016 & 41 \\
\hline p-AKT & XMAP ELISA & Comm. & + & - & + & + & + & + & + & $+/+$ & + & + & Pictilisib & 1 & 2015 & 59 \\
\hline PAR & ELISA & Comm. & + & + & + & + & + & + & + & $+/+$ & + & + & Olaparib & 1 & 2018 & 16 \\
\hline PAR & ELISA & Comm. & + & + & + & + & + & + & + & $+/+$ & + & + & ABT -888 & 1 & 2017 & 57 \\
\hline p-BAD & ELISA & Comm. & + & - & - & + & - & + & - & $+/-$ & - & - & AZD1208 & 1 & 2018 & 46 \\
\hline $\mathrm{p}$-CREB & FC & LDA & + & - & - & - & - & - & - & $+/-$ & - & - & AB-928 & 1 & 2018 & 80 \\
\hline PD1 & ELISA & LDA & + & + & + & + & + & + & + & $+/+$ & + & + & SHR-1210 & 1 & 2018 & 18 \\
\hline PDGF & LBA & Comm. & + & - & - & + & + & - & + & $+/+$ & + & - & Motesanib & 2 & 2015 & 48 \\
\hline PDGF & XMAP ELISA & Comm. & + & - & + & + & + & + & + & $+/+$ & + & + & MEDI-575 & 1 & 2014 & 40 \\
\hline PDGF & ELISA & Comm. & + & + & + & + & + & + & - & $+/+$ & + & - & Pazopanib & 1 & 2013 & 47 \\
\hline PD-L1 & FC & LDA & + & - & - & - & - & - & - & $-/-$ & - & - & Velumab & $1 a$ & 2017 & 53 \\
\hline p-ERK & FC & LDA & - & - & - & - & - & - & - & $-1-$ & - & - & TAK-733 & 1 & 2016 & 73 \\
\hline p-FAK & ELISA & Comm. & + & - & + & + & + & + & - & $+/+$ & + & - & BI 853520 & 1 & 2019 & 60 \\
\hline $\mathrm{PI} 3 \mathrm{~K}$ & $\mathrm{FC}$ & LDA & - & - & - & - & - & - & - & $-1-$ & - & - & Temsirolimus & 1 & 2017 & 78 \\
\hline p-RAD50 & MRM-MS & LDA & + & - & + & + & + & + & + & $+/+$ & + & + & AZD0156 & 1 & 2018 & 14 \\
\hline PRAS40 & ELISA & Comm. & + & - & + & + & + & + & - & $+/+$ & + & - & Azacitidine & 1 & 2017 & 32 \\
\hline $\mathrm{p}-\mathrm{SCR}$ & ELISA & Comm. & + & - & - & - & - & - & - & $-1-$ & - & - & Dasatinib & 2 & 2019 & 23 \\
\hline Rhodamine & Spectrometry & LDA & + & - & + & - & - & - & - & $+/+$ & - & - & Tariquidar & 1 & 2015 & 68 \\
\hline RON8 & ELISA & Comm. & + & - & - & + & - & - & - & $-1-$ & - & - & Narnatumab & 1 & 2017 & 55 \\
\hline Serum IgG & xMAP ELISA & Comm. & + & - & + & + & + & + & + & $+/+$ & + & + & Sipuleucel-T & 3 & 2015 & 15 \\
\hline serum proteins & xMAP ELISA & Comm. & + & + & + & + & + & + & + & $+/+$ & + & + & Cediranib & 3 & 2014 & 84 \\
\hline s-VEGF & ELISA & Comm. & + & - & + & + & - & + & + & $+/+$ & + & - & Bevacizumab & 2 & 2014 & 81 \\
\hline s-VEGF1/2 & ELISA & n.d. & - & - & - & - & - & - & - & $-/-$ & - & - & Lenvatinib & 1 & 2014 & 69 \\
\hline s-VEGF1/2 & ELISA & Comm. & + & + & + & + & + & + & + & $+/+$ & + & + & Ramucirumab & 3 & 2020 & 22 \\
\hline s-VEGFR2 & ELISA & n.d. & - & - & - & - & - & - & - & $-/-$ & - & - & $X L-647$ & 1 & 2018 & 49 \\
\hline Testosterone & HPLC & LDA & + & - & + & + & + & + & + & $+/+$ & + & + & Abiraterone & 2 & 2018 & 64 \\
\hline Testosterone & LC-MS/MS & LDA & + & + & + & + & + & + & + & $+/+$ & + & + & Relugolix & 1 & 2015 & 11 \\
\hline Testosterone & LC-MS/MS & LDA & - & - & - & - & - & - & + & $-1-$ & - & - & Orteronel & 1 & 2015 & 27 \\
\hline TSA & radio-assay & LDA & + & + & + & + & + & + & + & $+/+$ & + & + & Capecitabine & 1 & 2020 & 63 \\
\hline VEGF & ELISA & Comm. & + & - & + & + & - & + & + & $+/+$ & + & + & Cediranib & 1 & 2015 & 76 \\
\hline VEGF & ELISA & Comm. & + & - & + & + & - & - & + & $+/+$ & + & - & TRC105 & 1 & 2015 & 20 \\
\hline VEGF-A & LBA & LDA & - & - & - & - & - & - & - & $-/-$ & - & - & Ramucirumab & 1 & 2015 & 50 \\
\hline virus infectivity & Microscopy & LDA & - & - & - & - & - & - & - & $-/-$ & + & - & Enadenotucirev & $1 / 2 a$ & 2019 & 28 \\
\hline
\end{tabular}


basis of every reliable method. Ideally, researchers would refuse to buy antibodies and immune-assays without extensive validation and quality control data, or would perform the validation themselves. Antibodies should be tested for offtarget binding using positive and negative controls e.g. control experiments that involve engineering cell lines to both express and stop expressing the protein of interest. We recommend additional in-house validation before using commercial antibodies and kits, also when obtained from suppliers with a proven track-record, and subsequent entry of the in-house validation data in centralized antibody validation registries such as CiteAb (www.citeab.com) (91). CiteAb mines the scientific literature for publications citing the use of individual antibodies, to generate a comprehensive searchable database of literature citations, together with suppliers, blog and news.

Establishing methods "fit for purpose" requires extensive validation and is a continuous process. Scientists, however, often claim that their methods are validated in a very casual way, often without explaining which guidelines were followed or any reference to experimental data to back up their claim. The validation process should start with a description of the purpose of the method, followed by method development and the definition of the performance characteristics. It continues with documentation of the methodology and the validation results. Once the method has been validated, it is crucial that the method is consistently executed as it was validated. The same materials should be used, and system suitability and method controls are applied with the same specifications as during the validation process. During the in-use phase of the methods, there is continuous monitoring to assure that the method still generates results in accordance with the performance characteristics as originally determined. Revalidation is needed if the method is changed, or has been out of use for a while, when it is applied for another material or for a new purpose. For this, the validated method is carefully documented in a procedure or a standard protocol often called a Standard Operating Procedure or 'SOP'. The documentation is not limited to a general description of the methods, but preferably includes all relevant aspects that contribute to the performance of the method.

\section{Future directions and outstanding questions}

Validation of PD biomarker methods is a necessary component for obtaining high-quality PD biomarker data from clinical studies. For this purpose, FDA draft guidelines for the validation of quantitative PD biomarker methods have 
existed since 2013 (9). In this light, the incomplete and sometimes total absence of validation for $87 \%$ of quantitative PD biomarker methods in phase 1-3 clinical cancer trials, published in the last 7 years, is quite disturbing. A possible explanation for this lack of validation may be that most quantitative biomarkers used in clinical trials originate from preclinical research in laboratories that are not used to working in accordance with good laboratory practice (GLP). GLP guidelines mandate full validation of quantitative bioanalytical drug methods. For quantitative biomarker methods these guidelines did not exist till the FDA recommended them in their 2013 draft BMV guideline, which became final in 2018 (9).

The FDA BMV 2018 guideline is, however, limited to recommendations for chromatographic and ligand binding method validation (9). This may explain why we found that validation was most often lacking for quantitative FC biomarker methods (92). These FC methods are used to quantify cell subpopulations and antigen expression per cell (93). Quantitative FC methods are used in many clinical biomarker studies, and their importance is increasing (93). Several factors complicate the validation of these FC methods (94). One of the most important limitations is lack of standardization in methods, instrument setup, and quality controls. There is an urgent need to address these limitations by establishing internationally harmonized guidelines for quantitative FC biomarker methods used for clinical trials.

Currently, journals apparently do not mandate the use of properly validated quantitative PD methods for clinical studies. Investigators should, however, realize that quantitative PD methods used in clinical trials can only generate reliable and robust results if these methods are fully validated, reliable and robust. In that respect, it does not matter whether these methods are used for regulatory decision making, or for exploratory purposes. Full validation will increase the credibility of PD studies and may increase the discovery rate of qualified clinical PD biomarkers. For this purpose, we recommend that all quantitative PD methods used in clinical trials are fully validated as in the international guidelines for bioanalytical method validation (9). 


\section{REFERENCES}

1. Wong $\mathrm{CH}$, Siah KW, Lo AW. Estimation of clinical trial success rates and related parameters. Biostatistics 2019;20:273-286.

2. Carden $C P$, Sarker $D$, Postel-Vinay $S$, Yap TA, Attard G, Banerji U, Garrett MD, Thomas G V., Workman P, Kaye SB, de Bono JS. Can molecular biomarker-based patient selection in Phase I trials accelerate anticancer drug development? Drug Discov Today 2010;15:88-97.

3. Ileana Dumbrava E, Meric-Bernstam F, Yap TA. Challenges with biomarkers in cancer drug discovery and development. Expert Opin Drug Discov. 2018;13:685-690.

4. Gelfand JM, Cree BAC, Hauser SL. Ocrelizumab and Other CD20+ B-CellDepleting Therapies in Multiple Sclerosis. Neurotherapeutics 2017;14:835-841.

5. de Haan R, Pluim D, van Triest $B$, van den Heuvel $M$, Peulen $H$, van Berlo $D$, George J, Verheij M, Schellens JHM, Vens C. Improved pharmacodynamic (PD) assessment of low dose PARP inhibitor PD activity for radiotherapy and chemotherapy combination trials. Radiother Oncol 2018;126:443-449.

6. Miller KJ, Bowsher RR, Celniker A, Gibbons J, Gupta S, Lee JW, Swanson SJ, Smith WC, Weiner RS, Crommelin DJA, Das I, DeSilva BS, Dillard RF, Geier M, Gunn H, Khan MN, Knuth DW, Kunitani MK, Nordblom GD, Paulussen RJA, Sailstad JM, Tacey RL, Watson A. Workshop on bioanalytical methods validation for macromolecules: Summary report. Pharm Res 2001;18:1373-1383.

7. Lowes S, Brown M. Bioanalytical method validation guidance language and a decade of progress. Bioanalysis 2019;11:587-593.

8. Adoption C, Release C. ICH guideline M10 on bioanalytical method validation. 2019;44. 9. U.S. Department of Health and Human Services - Food and Drug Administration. Bioanalytical method validation guidance for industry 2018. https://www.fda.gov/ downloads/drugs/guidances/ucm070107. Pdf.

10. Arends TJH, Lammers RJM, Falke J, Van Der Heijden AG, Rustighini I, Pozzi R, Ravic $M$, Eisenhardt $A$, Vergunst $H$, Witjes JA. Pharmacokinetic, pharmacodynamic, and activity evaluation of TMX-101 in a multicenter phase 1 study in patients with papillary non-muscle-invasive bladder cancer. Clin Genitourin Cancer 2015;13:204209.

11. MacLean DB, Shi H, Faessel HM, Saad F. Medical castration using the investigational oral GnRH antagonist TAK-385 (Relugolix): Phase 1 study in healthy males. J Clin Endocrinol Metab 2015;100:4579-4587.

12. Rajan A, Carter CA, Berman A, Cao L, Ph D, Kelly J, Thomas A, Khozin S, Chavez AL, Bergagnini I, Scepura B, Szabo E, Lee $M$, Ph D, Trepel JB, Browne SK, Rosen LB, Yu Y, Steinberg SM, Ph D, Chen HX, Riely GJ, Ph D. Cixutumumab - TET, p2. Lancet Oncol 2014;15:191-200.

13. Zopf D, Fichtner I, Bhargava A, Steinke W, Thierauch KH, Diefenbach K, Wilhelm S, Hafner FT, Gerisch M. Pharmacologic activity and pharmacokinetics of metabolites of regorafenib in preclinical models. Cancer Med 2016;5:3176-3185.

14. Jones GN, Rooney C, Griffin N, Roudier M, Young LA, Garcia-Trinidad A, Hughes GD, 
Whiteaker JR, Wilson Z, Odedra R, Zhao L, Ivey RG, Howat WJ, Harrington EA, Barrett JC, Ramos-Montoya A, Lau A, Paulovich AG, Cadogan EB, Pierce AJ. pRAD50: a novel and clinically applicable pharmacodynamic biomarker of both ATM and ATR inhibition identified using mass spectrometry and immunohistochemistry. $\mathrm{Br} J$ Cancer 2018;119:1233-1243.

15. Thakurta DG, Sheikh NA, Fan LQ, Kandadi $\mathrm{H}$, Meagher TC, Hall SJ, Kantoff PW, Higano CS, Small EJ, Gardner TA, Bailey K, Vu T, Devries T, Whitmore JB, Frohlich MW, Trager JB, Drake CG. Humoral immune response against nontargeted tumor antigens after treatment with sipuleucel-T and its association with improved clinical outcome. Clin Cancer Res 2015;21:3619-3630.

16. de Haan R, Pluim D, van Triest B, van den Heuvel $M$, Peulen $H$, van Berlo D, George J, Verheij M, Schellens JHM, Vens C. Improved pharmacodynamic (PD) assessment of low dose PARP inhibitor PD activity for radiotherapy and chemotherapy combination trials. Radiother Oncol 2018;126:443-449.

17. Cirkel GA, Kerklaan BM, Vanhoutte F, Der Aa A Van, Lorenzon G, Namour F, Pujuguet $P$, Darquenne S, De Vos FYF, Snijders TJ, Voest EE, Schellens JHM, Lolkema MP. A dose escalating phase i study of GLPG0187, a broad spectrum integrin receptor antagonist, in adult patients with progressive high-grade glioma and other advanced solid malignancies. Invest New Drugs 2016;34:184-192.

18. Mo H, Huang J, Xu J, Chen X, Wu D, Qu D, Wang $X$, Lan B, Wang $X$, X J J, Zhang $H$, Chi Y, Yang Q, Xu B. Safety, anti-tumour activity, and pharmacokinetics of fixed-dose SHR1210, an anti-PD-1 antibody in advanced solid tumours: a dose-escalation, phase 1 study. Br J Cancer 2018;119:538-545.

19. Gomez-Roca CA, Italiano A, Le Tourneau C, Cassier PA, Toulmonde M, D'Angelo SP, Campone M, Weber KL, Loirat D, Cannarile $M A$, Jegg $A M$, Ries $C$, Christen R, MenesesLorente G, Jacob W, Klaman I, Ooi CH, Watson C, Wonde K, Reis B, Michielin F, Rüttinger $D$, Delord JP, Blay JY. Phase $i$ study of emactuzumab single agent or in combination with paclitaxel in patients with advanced/metastatic solid tumors reveals depletion of immunosuppressive $\mathrm{M} 2$-like macrophages. Ann Oncol 2019;30:13811392.

20. Karzai FH, Apolo AB, Cao L, Madan RA, Adelberg DE, Parnes H, McLeod DG, Harold N, Peer C, Yu Y, Tomita Y, Lee MJ, Lee S, Trepel JB, Gulley JL, Figg WD, Dahut WL. A phase i study of TRC105 anti-endoglin (CD105) antibody in metastatic castration-resistant prostate cancer. BJU Int 2015;116:546-555.

21. Hudes G, Tagawa ST, Whang YE, Qi M, Qin X, Puchalski TA, Reddy M, Cornfeld M, Eisenberger $M$. A phase 1 study of a chimeric monoclonal antibody against interleukin-6, siltuximab, combined with docetaxel in patients with metastatic castrationresistant prostate cancer. Invest New Drugs 2013;31:669-676.

22. Van Cutsem E, Muro $K$, Cunningham D, Bodoky G, Sobrero A, Cascinu S, Ajani J, Oh SC, Al-Batran SE, Wainberg ZA, Wijayawardana SR, Melemed S, Ferry D, Hozak RR, Ohtsu A. Biomarker analyses of second-line ramucirumab in patients with advanced gastric cancer from RAINBOW, a 
global, randomized, double-blind, phase 3 study. Eur J Cancer 2020;127:150-157.

23. Ocana A, Gil-Martin M, Antolín S, Atienza M, Montaño Á, Ribelles N, Urruticoechea A, Falcón A, Pernas S, Orlando J, Montero JC, Escudero MJ, Benito S, Caballero R, Carrasco E, Rojo F, Pandiella A, Ruiz-Borrego $M$. Efficacy and safety of dasatinib with trastuzumab and paclitaxel in first line HER2positive metastatic breast cancer: results from the phase II GEICAM/2010-04 study. Breast Cancer Res Treat 2019;174:693-701.

24. Coyne GO 'Sulliva., Wang L, Zlott J, Juwara L, Covey JM, Beumer JH, Cristea MC, Newman EM, Koehler S, Nieva JJ, Garcia AA, Gandara DR, Miller B, Khin S, Miller SB, Steinberg SM, Rubinstein L, Parchment RE, Kinders RJ, Piekarz RL, Kummar S, Chen AP, Doroshow JH. Intravenous 5-fluoro2'-deoxycytidine administered with tetrahydrouridine increases the proportion of p16-expressing circulating tumor cells in patients with advanced solid tumors. Cancer Chemother Pharmacol 2020;85:979-993.

25. Patel VK, Lamothe B, Ayres ML, Gay J, Cheung JP, Balakrishnan K, Ivan C, Morse J, Nelson M, Keating MJ, Wierda WG, Marszalek JR, Gandhi V. Pharmacodynamics and proteomic analysis of acalabrutinib therapy: Similarity of on-target effects to ibrutinib and rationale for combination therapy. Leukemia 2018;32:920-930.

26. Yu $H$, Truong $H$, Mitchell SA, Liclican A, Gosink JJ, Li W, Lin J, Feng JY, Jürgensmeier $J M$, Billin A, Xu R, Patterson S, Pagratis N. Homogeneous BTK Occupancy Assay for Pharmacodynamic Assessment of Tirabrutinib (GS-4059/ONO-4059) Target Engagement. SLAS Discov 2018;23:919-929.
27. Suzuki K, Ozono S, Yamaguchi A, Koike $H$, Matsui $\mathrm{H}$, Nagata M, Takubo T, Miyashita K, Matsushima T, Akaza H. A phase 1 multipledose study of orteronel in Japanese patients with castration-resistant prostate cancer. Cancer Chemother Pharmacol 2015;75:373380.

28. Machiels JP, Salazar R, Rottey S, Duran I, Dirix L, Geboes K, Wilkinson-Blanc C, Pover G, Alvis S, Champion B, Fisher K, McElwaineJohnn H, Beadle J, Calvo E. A phase 1 dose escalation study of the oncolytic adenovirus enadenotucirev, administered intravenously to patients with epithelial solid tumors (EVOLVE). J Immunother Cancer 2019;7:410.

29. Sylvia M. Lee, James Moon, Bruce G. Redman, Tarek Chidiac, Lawrence E. Flaherty, Yuanyuan Zha, Megan Othus, Antoni Ribas, Vernon K. Sondak, Thomas F. Gajewski and KAM. A Phase II Study of R04929097 Gamma-Secretase Inhibitor in Metastatic Melanoma: SWOG 0933. Cancer 2015;121:432-440.

30. Gammon ST, Pisaneschi F, Bandi ML, Smith MG, Sun Y, Rao Y, Muller F, Wong F, De Groot J, Ackroyd J, Mawlawi O, Davies MA, Gopal YNV, Di Francesco ME, Marszalek JR, Dewhirst M, Piwnica-Worms D. MechanismSpecific Pharmacodynamics of a Novel Complex-I Inhibitor Quantified by Imaging Reversal of Consumptive Hypoxia with $\left[{ }^{18} \mathrm{~F}\right]$ FAZA PET In Vivo. Cells 2019;8:1-23.

31. Buil-Bruna $N$, Dehez $M$, Manon $A$, Nguyen TXQ, Trocóniz IF. Establishing the quantitative relationship between lanreotide autoge ${ }^{\circledR}$, chromogranin $A$, and progressionfree survival in patients with nonfunctioning gastroenteropancreatic neuroendocrine 
tumors. AAPS J 2016;18:703-712.

32. Abaza YM, Kadia TM, Jabbour EJ, Konopleva MY, Borthakur G, Ferrajoli A, Estrov Z, Wierda WG, Alfonso A, Chong TH, Chuah C, Koh LP, Goh BC, Chang JE, Durkes $D E$, Foudray MC, Kantarjian HM, Dong $X Q$, Garcia-Manero G. Phase 1 dose escalation multicenter trial of pracinostat alone and in combination with azacitidine in patients with advanced hematologic malignancies. Cancer 2017;123:4851-4859.

33. Nemunaitis JJ, Small KA, Kirschmeier $P$, Zhang D, Zhu Y, Jou YM, Statkevich P, Yao SL, Bannerji R. A first-in-human, phase 1, doseescalation study of dinaciclib, a novel cyclindependent kinase inhibitor, administered weekly in subjects with advanced malignancies. J Transl Med 2013;11:1.

34. Hijazi $Y$, Klinger $M$, Kratzer $A$, Wu $B$, Baeuerle PA, Kufer P, Wolf A, Nagorsen D, Zhu M. Pharmacokinetic and Pharmacodynamic Relationship of Blinatumomab in Patients with Non-Hodgkin Lymphoma. Curr Clin Pharmacol 2018;13:55-64.

35. Gerstner ER, Ye X, Duda DG, Levine MA, Mikkelsen T, Kaley TJ, Olson JJ, Nabors BL, Ahluwalia MS, Wen PY, Jain RK, Batchelor TT, Grossman S. A phase i study of cediranib in combination with cilengitide in patients with recurrent glioblastoma. Neuro Oncol 2015;17:1386-1392.

36. Hamberg $P$, Boers-Sonderen MJ, Van Der Graaf WTA, De Bruijn P, Suttle AB, Eskens FALM, Verweij J, Van Herpen CML, Sleijfer S. Pazopanib exposure decreases as a result of an ifosfamide-dependent drug-drug interaction: Results of a phase I study. $\mathrm{Br} J$ Cancer 2014;110:888-893.

37. Do K, Cao L, Kang Z, Turkbey B,
Lindenberg $\mathrm{ML}$, Larkins $\mathrm{E}$, Holkova $\mathrm{B}$, Steinberg SM, Raffeld M, Peer CJ, Figg WD, Eugeni $\mathrm{M}$, Jacobs P, Choyke P, Wright JJ, Doroshow JH, Kummar S. A Phase II Study of Sorafenib Combined With Cetuximab in EGFR-Expressing, KRAS-Mutated Metastatic Colorectal Cancer. Clin Colorectal Cancer 2015;14:154-161.

38. Leijen $S$, Burgers $S A$, Baas $P$, Pluim $D$, Tibben M, Van Werkhoven E, Alessio E, Sava G, Beijnen JH, Schellens JHM. Phase I/ Il study with ruthenium compound NAMI-A and gemcitabine in patients with non-small cell lung cancer after first line therapy. Invest. New Drugs 2015;33:201-214.

39. Gee JR, Saltzstein DR, Kim KM, Kolesar J, Huang W, Havighurst TC, Wollmer BW, Stublaski J, Downs T, Mukhtar H, House MG, Parnes HL, Bailey HH. A phase II randomized, double-blind, presurgical trial of polyphenon e in bladder cancer patients to evaluate pharmacodynamics and bladder tissue biomarkers. Cancer Prev Res 2017;10:298307.

40. Becerra $C R$, Conkling $P$, Vogelzang $N, W u$ $\mathrm{H}$, Hong $\mathrm{S}$, Narwal R, Liang M, Tavakkoli $\mathrm{F}$, Pandya N. A phase I dose-escalation study of MEDI-575, a PDGFR(alpha) monoclonal antibody, in adults with advanced solid tumors. Cancer Chemother Pharmacol 2014;74:917-925.

41. Ang JE, Pandher R, Ang JC, Asad YJ, Henley AT, Valenti M, Box G, De Brandon AH, Baird $R D$, Friedman L, Derynck $M$, Vanhaesebroeck B, Eccles SA, Kaye SB, Workman P, De Bono JS, Raynaud FI. Plasma metabolomic changes following PI3K inhibition as pharmacodynamic biomarkers: Preclinical discovery to phase I trial evaluation. Mol 
Cancer Ther 2016;15:1412-1424.

42. Daud Al, Ashworth MT, Strosberg J, Goldman JW, Mendelson D, Springett G, Venook AP, Loechner S, Rosen LS, Shanahan F, Parry D, Shumway S, Grabowsky JA, Freshwater T, Sorge C, Kang SP, Isaacs R, Munster PN. Phase I dose-escalation trial of checkpoint kinase 1 inhibitor MK-8776 as monotherapy and in combination with gemcitabine in patients with advanced solid tumors. J Clin Oncol 2015;33:1060-1066.

43. Nishio $M$, Horai $T$, Horiike $A$, Nokihara H, Yamamoto N, Takahashi T, Murakami $\mathrm{H}$, Yamamoto N, Koizumi F, Nishio K, Yusa W, Koyama N, Tamura T. Phase 1 study of lenvatinib combined with carboplatin and paclitaxel in patients with non-small-cell lung cancer. Br J Cancer 2013;109:538-544.

44. Rathkopf DE, Morris MJ, Fox JJ, Danila DC, Slovin SF, Hager JH, Rix PJ, Maneval EC, Chen I, Gönen M, Fleisher M, Larson SM, Sawyers CL, Scher HI. Phase I study of ARN509, a novel antiandrogen, in the treatment of castration-resistant prostate cancer. J Clin Oncol 2013;31:3525-3530.

45. Bendell JC, Kelley RK, Shih KC, Grabowsky $J A$, Bergsland $E$, Jones $S$, Martin $T$, Infante $J R$, Mischel PS, Matsutani T, Xu S, Wong L, Liu Y, Wu X, Mortensen DS, Chopra R, Hege K, Munster PN. A phase i doseescalation study to assess safety, tolerability, pharmacokinetics, and preliminary efficacy of the dual mTORC1/mTORC2 kinase inhibitor CC-223 in patients with advanced solid tumors or multiple myeloma. Cancer 2015;121:3481-3490.

46. Cortes J, Tamura K, Deangelo DJ, De Bono J, Lorente D, Minden M, Uy GL, Kantarjian H, Chen LS, Gandhi V, Godin R, Keating
K, McEachern K, Vishwanathan K, Pease JE, Dean E. Phase i studies of AZD1208, a proviral integration Moloney virus kinase inhibitor in solid and haematological cancers. Br J Cancer 2018;118:1425-1433.

47. Bender JLG, Lee A, Reid JM, Baruchel S, Roberts $\mathrm{T}$, Voss $\mathrm{SD}$, Wu $\mathrm{B}$, Ahern $\mathrm{CH}$, Ingle AM, Harris P, Weigel BJ, Blaney SM. Phase i pharmacokinetic and pharmacodynamic study of pazopanib in children with soft tissue sarcoma and other refractory solid tumors: A children's oncology group phase i consortium report. J Clin Oncol 2013;31:3034-3043.

48. Bass MB, Yao B, Hei YJ, Ye Y, Davis GJ, Davis MT, Kaesdorf BA, Chan SS, Patterson SD. Challenges in developing a validated biomarker for angiogenesis inhibitors: The motesanib experience. PLoS One 2014;9.

49. Das M, Padda SK, Frymoyer A, Molina J, Adjei A, Lensing JL, Miles D, Sikic BI, Wakelee HA. A safety, tolerability, and pharmacokinetic analysis of two phase I studies of multitargeted small molecule tyrosine kinase inhibitor XL647 with an intermittent and continuous dosing schedule in patients with advanced solid malignancies. Cancer Chemother Pharmacol 2018;82:541-550.

50. Chiorean EG, Hurwitz $\mathrm{HI}$, Cohen RB, Schwartz JD, Dalal RP, Fox FE, Gao L, Sweeney CJ. Phase I study of every 2- or 3-week dosing of ramucirumab, a human immunoglobulin G1 monoclonal antibody targeting the vascular endothelial growth factor receptor- 2 in patients with advanced solid tumors. Ann Oncol 2015;26:12301237.

51. Fu S, Hirte H, Welch $S$, Ilenchuk TT, Lutes 
T, Rice C, Fields N, Nemet A, Dugourd D, Piha-Paul S, Subbiah V, Liu L, Gong J, Hong D, Stewart JM. First-in-human phase I study of SOR-C13, a TRPV6 calcium channel inhibitor, in patients with advanced solid tumors. Invest New Drugs 2017:1-10.

52. Derosa L, Galli L, Orlandi P, Fioravanti A, Di Desidero T, Fontana A, Antonuzzo A, Biasco E, Farnesi A, Marconcini R, Francia G, Danesi R, Falcone A, Bocci G. Docetaxel plus oral metronomic cyclophosphamide: A phase ii study with pharmacodynamic and pharmacogenetic analyses in castrationresistant prostate cancer patients. Cancer 2014;120:3923-3931.

53. Heery CR, O'Sullivan-Coyne G, Madan RA, Cordes L, Rajan A, Rauckhorst M, Lamping $E$, Oyelakin I, Marté JL, Lepone LM, Donahue RN, Grenga I, Cuillerot JM, Neuteboom B, Heydebreck A von, Chin K, Schlom J, Gulley JL. Avelumab for metastatic or locally advanced previously treated solid tumours (JAVELIN Solid Tumor): a phase 1a, multicohort, dose-escalation trial. Lancet Oncol 2017;18:587-598.

54. Iguchi $H$, Nishina $T$, Nogami $N$, Kozuki T, Yamagiwa $Y$, Yagawa K. Phase i doseescalation study evaluating safety, tolerability and pharmacokinetics of MEDI573, a dual IGF-I/II neutralizing antibody, in Japanese patients with advanced solid tumours. Invest New Drugs 2015;33:194200.

55. LoRusso PM, Gounder M, Jalal SI, André V, Kambhampati SRP, Loizos N, Hall J, Holzer TR, Nasir A, Cosaert J, Kauh J, Chiorean EG. Phase 1 study of narnatumab, an anti-RON receptor monoclonal antibody, in patients with advanced solid tumors. Invest New
Drugs 2017;35:442-450.

56. Segal NH, He AR, Doi T, Levy R, Bhatia $S$, Pishvaian MJ, Cesari R, Chen $Y$, Davis $C B$, Huang B, Thall AD, Gopal AK. Phase i study of single-agent utomilumab (PF05082566), a 4-1bb/cd137 agonist, in patients with advanced cancer. Clin Cancer Res 2018;24:1816-1823.

57. Stoller R, Schmitz JC, Ding F, Puhalla $S$, Belani CP, Appleman L, Lin $Y$, Jiang $Y$, Almokadem S, Petro D, Holleran J, Kiesel $B F$, Ken Czambel R, Carneiro BA, Kontopodis E, Hershberger PA, Rachid M, Chen A, Chu E, Beumer JH. Phase I study of veliparib in combination with gemcitabine. Cancer Chemother Pharmacol 2017;80:631-643.

58. Angevin $E$, Isambert $N$, Trillet-Lenoir $V$, You B, Alexandre J, Zalcman G, Vielh P, Farace $F$, Valleix F, Podoll T, Kuramochi $Y$, Miyashita I, Hosono O, Dang NH, Ohnuma K, Yamada T, Kaneko Y, Morimoto C. First-in-human phase 1 of YS110, a monoclonal antibody directed against CD26 in advanced CD26-expressing cancers. Br J Cancer 2017;116:1126-1134.

59. Sarker D, Ang JE, Baird R, Kristeleit R, Moreno V, Clarke PA, Raynaud FI, Levy G, Joseph A, Mazina K, Lin R, Wu J, Fredrickson J, Spoerke JM, Mark R, Yan Y, Friedman LS, Kaye SB, Derynck MK, Bono JS De, Levy G, Wu J, Kaye S. First-in-human Phase I study of Pictilisib ( GDC-0941), a potent panclass I phosphatidylinositol-3-kinase ( PI3K ) inhibitor, in patients with advanced solid tumors. Clin Cancer Res 2015;21:77-86.

60. de Jonge MJA, Steeghs N, Lolkema MP, Hotte SJ, Hirte HW, van der Biessen DAJ, Abdul Razak AR, De Vos FYFL, Verheijen RB, Schnell D, Pronk LC, Jansen M, Siu LL. Phase I Study of BI 853520, an Inhibitor 
of Focal Adhesion Kinase, in Patients with Advanced or Metastatic Nonhematologic Malignancies. Target Oncol 2019;14:43-55. 61. Apolo AB, Karzai FH, Trepel JB, Alarcon S, Lee S, Lee MJ, Tomita Y, Cao L, Yu Y, Merino MJ, Madan RA, Parnes HL, Steinberg SM, Rodriguez BW, Seon BK, Gulley JL, Arlen PM, Dawson NA, Figg WD, Dahut WL. A Phase II Clinical Trial of TRC105 (Anti-Endoglin Antibody) in Adults With Advanced/ Metastatic Urothelial Carcinoma. Clin Genitourin Cancer 2017;15:77-85.

62. Laquente B, Lopez-Martin J, Richards D, Illerhaus G, Chang DZ, Kim G, Stella P, Richel D, Szcylik C, Cascinu S, Frassineti GL, Ciuleanu T, Hurt K, Hynes S, Lin J, Lin AB, Hoff D, Calvo E. A phase II study to evaluate LY2603618 in combination with gemcitabine in pancreatic cancer patients. BMC Cancer 2017;17:1-9.

63. Roosendaal J, Jacobs BAW, Pluim D, Rosing $H$, de Vries $N$, van Werkhoven $E$, Nuijen B, Beijnen JH, Huitema ADR, Schellens JHM, Marchetti S. Phase I pharmacological study of continuous chronomodulated capecitabine treatment. Pharm Res 2020;37:89.

64. Szmulewitz RZ, Peer C, Ibraheem A, Martinez E, Kozloff MF, Carthon B, Donald Harvey R, Fishkin P, Yong WP, Chiong E, Nabhan C, Karrison T, Figg WD, Stadler WM, Ratain MJ. Prospective International Randomized Phase II Study of Low-Dose Abiraterone With Food Versus Standard Dose Abiraterone In Castration-Resistant Prostate Cancer. J Clin Oncol 2018;36:13891395.

65. Saif MW, Erlichman C, Dragovich T, Mendelson D, Toft D, Burrows F,
Storgard C, Von Hoff D. Open-label, doseescalation, safety, pharmacokinetic, and pharmacodynamic study of intravenously administered CNF1010 (17-(allylamino)-17demethoxygeldanamycin

[17-AAG]) in patients with solid tumors. Cancer Chemother Pharmacol 2013;71:1345-1355.

66. Courtney KD, Infante JR, Lam ET, Figlin RA, Rini BI, Brugarolas J, Zojwalla NJ, Lowe AM, Wang K, Wallace EM, Josey JA, Choueiri TK. Phase I dose-escalation trial of PT2385, a first-in-class hypoxia-inducible factor$2 a$ antagonist in patients with previously treated advanced clear cell renal cell carcinoma. J Clin Oncol 2018;36:867-874.

67. Mross K, Richly $H$, Fischer $R$, Scharr D, Büchert M, Stern A, Gille H, Audoly LP, Scheulen ME. First-in-human phase i study of PRS-050 (Angiocal), an anticalin targeting and antagonizing VEGF-A, in patients with advanced solid tumors. PLoS One 2013;8:111.

68. Fox E, Widemann BC, Pastakia D, Chen CC, Yang SX, Cole D, Balis FM. Pharmacokinetic and pharmacodynamic study of tariquidar (XR9576), a P-glycoprotein inhibitor, in combination with doxorubicin, vinorelbine, or docetaxel in children and adolescents with refractory solid tumors. Cancer Chemother Pharmacol 2015;76:1273-1283.

69. Koyama N, Saito K, Nishioka Y, Yusa W, Yamamoto N, Yamada Y, Nokihara H, Koizumi F, Nishio K, Tamura T. Pharmacodynamic change in plasma angiogenic proteins: $A$ dose-escalation phase 1 study of the multikinase inhibitor lenvatinib. BMC Cancer 2014;14:1-8.

70. Rodon J, Postel-Vinay $S$, Hollebecque A, Nuciforo P, Azaro A, Cattan V, Marfai L, 
Sudey I, Brendel K, Delmas A, Malasse S, Soria JC. First-in-human phase I study of oral S49076, a unique MET/AXL/FGFR inhibitor, in advanced solid tumours. Eur J Cancer 2017;81:142-150.

71. Tabernero J, Bahleda $R$, Dienstmann $R$, Infante JR, Mita A, Italiano A, Calvo E, Moreno V, Adamo B, Gazzah A, Zhong B, Platero SJ, Smit JW, Stuyckens K, ChatterjeeKishore M, Rodon J, Peddareddigari V, Luo FR, Soria JC. Phase I dose-escalation study of JNJ-42756493, an oral pan-fibroblast growth factor receptor inhibitor, in patients with advanced solid tumors. J. Clin. Oncol. 2015;33:3401-3408.

72. Von Mehren $M$, Britten $C D$, Pieslor $P$, Saville W, Vassos A, Harris S, Galluppi GR, Darif $M$, Wainberg $Z A$, Cohen RB, Leong S. A phase 1 , open-label, dose-escalation study of BIIB022 (anti-IGF-1R monoclonal antibody) in subjects with relapsed or refractory solid tumors. Invest. New Drugs 2014;32:518-525.

73. Adjei $A A$, LoRusso $P$, Ribas $A$, Sosman JA, Pavlick A, Dy GK, Zhou X, Gangolli E, Kneissl M, Faucette S, Neuwirth R, Bózon V. A phase I dose-escalation study of TAK733, an investigational oral MEK inhibitor, in patients with advanced solid tumors. Invest. New Drugs 2017;35:47-58.

74. Lee EQ, Muzikansky A, Duda DG, Gaffey S, Dietrich J, Nayak L, Chukwueke UN, Beroukhim R, Doherty L, Laub CK, LaFrankie D, Fontana B, Stefanik J, Ruland S, Caruso V, Bruno J, Ligon K, Reardon DA, Wen PY. Phase II trial of ponatinib in patients with bevacizumab-refractory glioblastoma. Cancer Med. 2019;8:5988-5994.

75. Papadopoulos KP, Isaacs R, Bilic $S$,
Kentsch K, Huet $\mathrm{H}$ a., Hofmann M, Rasco D, Kundamal N, Tang Z, Cooksey J, Mahipal A. Unexpected hepatotoxicity in a phase I study of TAS266, a novel tetravalent agonistic Nanobody $\left({ }^{\circledR}\right)$ targeting the DR5 receptor. Cancer Chemother. Pharmacol. 2015:887-895.

76. Mark W. Kieran, Susan Chi, Stewart Goldman, Arzu Onar-Thomas, Tina Young Poussaint, Sridhar Vajapeyam, Frederic Fahey, Shengjie Wu, David C. Turner, Clinton F. Stewart, Marsha Moses4, Roger J. Packer, Regina Jakacki10, Anu Banerjee, James M. Boyett6, Mary and LK. A Phase I trial and PK Study of Cediranib (AZD2171), an Orally Bioavailable Pan-VEGFR Inhibitor, in Children with Recurrent or Refractory Primary CNS Tumors. Childs Nerv Syst 2015;31:14331445.

77. Gaykema SBM, Schröder CP, VitfellRasmussen J, Chua S, Munnink THO, Brouwers $A H$, Bongaerts $A H H$, Akimov $M$, Fernandez-Ibarra C, Lub-De Hooge MN, De Vries EGE, Swanton C, Banerji U. 89Zrtrastuzumab and 89Zr-bevacizumab PET to evaluate the effect of the HSP90 inhibitor NVP-AUY922 in metastatic breast cancer patients. Clin. Cancer Res. 2014;20:39453954.

78. Rheingold SR, Tasian SK, Whitlock JA, Teachey DT, Borowitz MJ, Liu X, Minard CG, Fox E, Weigel BJ, Blaney SM. A phase 1 trial of temsirolimus and intensive re-induction chemotherapy for 2 nd or greater relapse of acute lymphoblastic leukaemia: a Children's Oncology Group study (ADVL1114). Br. J. Haematol. 2017;177:467-474.

79. Lin J, Patel SA, Sama AR, Hoffman-Censits $\mathrm{JH}$, Kennedy B, Kilpatrick D, Ye Z, Yang H, Mu 
Z, Leiby B, Lewis N, Cristofanilli M, Kelly WK. A Phase I/II Study of the Investigational Drug Alisertib in Combination With Abiraterone and Prednisone for Patients With Metastatic Castration-Resistant Prostate Cancer Progressing on Abiraterone. Oncologist 2016;21:1296.

80. Seitz $L$, Jin $L$, Leleti $M$, Ashok $D$, Jeffrey J, Rieger A, Tiessen RG, Arold G, Tan JBL, Powers JP, Walters MJ, Karakunnel J. Safety, tolerability, and pharmacology of AB928, a novel dual adenosine receptor antagonist, in a randomized, phase 1 study in healthy volunteers. Invest New Drugs 2019;37:711721.

81. Mahalingam D, Malik L, Beeram $M$, Rodon J, Sankhala K, Mita A, Benjamin D, Ketchum N, Michalek J, Tolcher A, Wright J, Sarantopoulos J. Phase II study evaluating the efficacy, safety, and pharmacodynamic correlative study of dual antiangiogenic inhibition using bevacizumab in combination with sorafenib in patients with advanced malignant melanoma. Cancer Chemother Pharmacol 2014;74:77-84.

82. Hotte SJ, Chi KN, Joshua AM, Tu D, Macfarlane RJ, Gregg RW, Ruether JD, Basappa NS, Finch D, Salim M, Winquist EW, Torri V, North S, Kollmannsberger C, Ellard SL, Eigl BJ, Tinker A, Allan AL, Beja K, Annala M, Powers J, Wyatt AW, Seymour L. A Phase II Study of PX-866 in Patients With Recurrent or Metastatic Castration-resistant Prostate Cancer: Canadian Cancer Trials Group Study IND205. Clin Genitourin Cancer 2019;17:201-208.e1.

83. Damiano JS, Rendah KG, Karim C, Embry MG, Ghoddusi M, Holash J, Fanidi A, Abrams TJ, Abraham JA. Neutralization of prolactin receptor function by monoclonal antibody LFA102, a novel potential therapeutic for the treatment of breast cancer. Mol Cancer Ther 2013;12:295-305.

84. Pommier AJC, Shaw R, Spencer SKM, Morgan SR, Hoff PM, Robertson JD, Barry ST, Jürgensmeier JM. Serum protein profiling reveals baseline and pharmacodynamic biomarker signatures associated with clinical outcome in $\mathrm{MCRC}$ patients treated with chemotherapy \pm cediranib. Br J Cancer 2014;111:1590-1604.

85. Loriot $Y$, Fizazi K, Jones RJ, Van Den Brande J, Molife RL, Omlin A, James ND, BaskinBey E, Heeringa M, Baron B, Holtkamp GM, Ouatas T, De Bono JS. Safety, tolerability and anti-tumour activity of the androgen biosynthesis inhibitor ASP9521 in patients with metastatic castration-resistant prostate cancer: Multi-centre phase I/II study. Invest New Drugs 2014;32:995-1004.

86. Anne M. Noonan, Kristen P. Bunch, Jin-Qiu Chen, Michelle A. Herrmann, Jung-min Lee, Elise C. Kohn, Ciara C. O'Sullivan, Elizabeth Jordan, Nicole Houston, Naoko Takebe, Robert J. Kinders, Liang Cao, Cody J. Peer, W. Douglas Figg and CMA. Pharmacodynamic markers and clinical results from the Phase II Study of the SMAC-Mimetic Birinapant in Women with Relapsed Platinum-Resistant or Refractory Epithelial Ovarian Cancer. Cancer 2016;122:588-597.

87. Harmon CS, Deprimo SE, Figlin RA, Hudes GR, Hutson TE, Michaelson MD, Négrier S, Kim ST, Huang X, Williams JA, Eisen T, Motzer RJ. Circulating proteins as potential biomarkers of sunitinib and interferon- $\alpha$ efficacy in treatment-naïve patients with metastatic renal cell carcinoma. Cancer 
Chemother Pharmacol 2014;73:151-161.

88. Baker M. Blame it on the antibodies. Nature 2015;521:274-276.

89. Taussig MJ, Fonseca C, Trimmer JS. Antibody validation: a view from the mountains. N Biotechnol 2018;45:1-8.

90. Prassas I, Diamandis EP. Translational researchers beware! Unreliable commercial immunoassays (ELISAs) can jeopardize your research. Clin Chem Lab Med 2014;52:765766.

91. Helsby MA, Leader PM, Fenn JR, Gulsen T, Bryant C, Doughton G, Sharpe B, Whitley $P$, Caunt $C$, James $K$, Pope $A D$, Kelly $D H$, Chalmers AD. CiteAb: A searchable antibody database that ranks antibodies by the number of times they have been cited. BMC Cell Biol 2014;15:1-12.

92. Davis BH, Wood B, Oldaker T, Barnett D. Validation of cell-based fluorescence assays: Practice guidelines from the ICSH and ICCS - Part i - ale and aims. Cytom Part B - Clin Cytom 2013;84:282-285.

93. Olga Millán and Mercè Brunet. Flow Cytometry as a Platform for Biomarker Discovery and Clinical Validation. Gen Methods Biomark Res their Appl 2015;12:1-1316.

94. Mizrahi O, Ish Shalom E, Baniyash M, Klieger Y. Quantitative Flow Cytometry: Concerns and Recommendations in Clinic and Research. Cytom Part B - Clin Cytom 2018;94:211-218. 


\section{CHAPTER 1}

Development and validation of

pharmacodynamic and diagnostic cancer biomarker methods

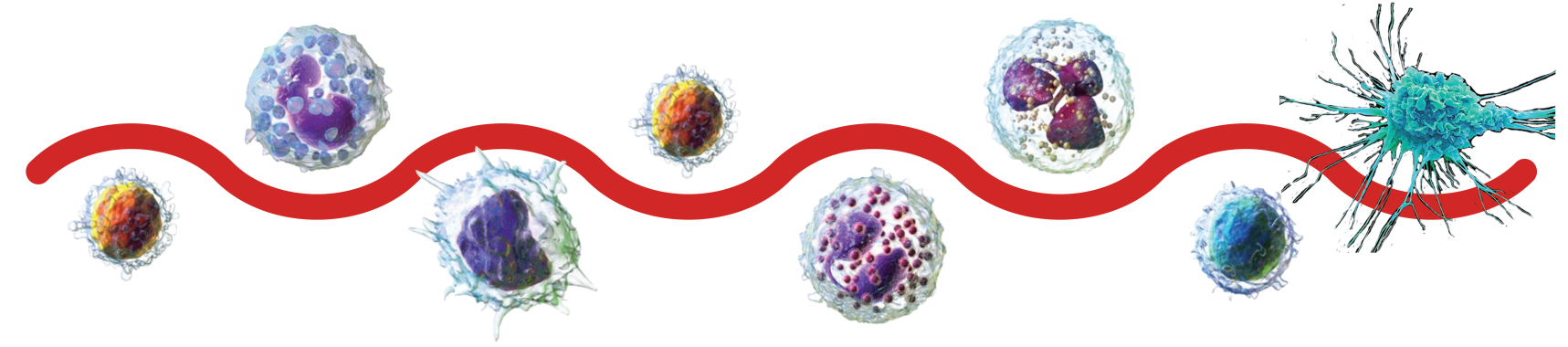

1.2

Correction of peripheral blood mononuclear cell cytosolic protein for hemoglobin contamination

Dick Pluim, Bart A. W. Jacobs, Martin D. Krähenbühl, Anna E. M. Ruijter, Jos H. Beijnen, Jan H. M. Schellens

Analytical Bioanalytical Chemistry 2013;405:2391-2395 


\section{ABSTRACT}

Pharmacodynamic (PD) analysis requires accurate and precise quantification of enzyme activity targeted by anticancer agents in surrogate cells like peripheral blood mononuclear cells (PBMCs). Enzyme activity is normally reported per mass unit of protein input. However, high and fluctuating hemoglobin $(\mathrm{Hb})$ contamination strongly influences the protein content of PBMC cytosolic lysate. We present the development and validation of a spectrophotometrical $\mathrm{Hb}$ quantification method to correct for this contamination. The applicability of $\mathrm{Hb}$ correction was demonstrated by determination of the dihydropyrimidine dehydrogenase enzyme activity in PBMC cytosolic lysates. 


\section{INTRODUCTION}

Peripheral blood mononuclear cells (PBMCs) are used extensively in pharmacodynamic (PD) assays as surrogate tissue for predicting the effect of anticancer agents on their molecular target in tumor cells [1;2]. Surrogate tissues or cells like PBMCs have several advantages over tumor biopsies for monitoring the PD effects of targeted anticancer agents, including minimally invasive sample collection and the ability to collect multiple samples for longitudinal assessment of drug effect.

Most protocols used today for isolation of PBMCs from peripheral blood are based on Ficoll density gradient centrifugation that allows separation of PBMCs from granulocytes and red blood cells [3;4].

An accurate measurement of the amount of protein from the isolated PBMCs is critical since the result is used in the calculation of a selected enzyme activity, which is usually expressed relative to the amount of isolated protein [5]. In most protocols for the quantification of enzyme activity in PBMCs protein content is used as a marker for the number of PBMCs isolated.

Manufacturers of Ficoll and the methodologically related cell preparation tubes (CPT) report an average of $6.3 \%$ and $16.9 \%$ red blood cell (RBC) contamination, respectively [6;7]. In this technical note we present contamination levels of PBMC cytosolic lysates with variable and high amounts (1 - 59\% range, average $20.3 \%$ ) of hemoglobin ( $\mathrm{Hb})$. When applying the Bradford assay for protein quantification, the amount of PBMC cytosolic lysate protein is overestimated due to the amount of $\mathrm{Hb}$, which can not be discriminated. We and others have reported this problem before and subsequently developed relatively laborious DNA based methods for quantification of PBMCs [8], or a RBC lysis buffer is sometimes used to eliminate RBCs [9]. We now present data indicating that the $\mathrm{Hb}$ contamination is not significantly reduced after treatment of samples with RBC lysis buffer, thus intact $\mathrm{RBC}$ are probably not the main cause of the $\mathrm{Hb}$ contamination.

In this technical note we present the validation of a spectrophotometric method for the correction of the total protein concentration for the amount of $\mathrm{Hb}$ contamination in PBMC cytosolic lysates. This method is useful in those cases where the PD parameter of interest is absent or low in RBCs as compared to PBMCs [9]. The applicability of the method is demonstrated by a PD enzyme activity assay of dihydropyrimidine dehydrogenase (DPD), which is extensively expressed in PBMCs and can be determined ex vivo [9]. 
DPD enzyme activity in PBMCs from 12 healthy volunteers was compared before and after $\mathrm{Hb}$ correction to illustrate the implications of the presented $\mathrm{Hb}$ correction method.

\section{EXPERIMENTAL}

PBMC isolation and cytosolic lysate preparation

Peripheral blood was drawn at 9:00 am from 18 healthy volunteers into $10 \mathrm{ml}$ heparin blood collection tubes. PBMCs were isolated immediately after blood collection using Ficoll-Paque ${ }^{\mathrm{TM}}$ PLUS (GE Healthcare, Little Chalfont, UK) gradient centrifugation. Briefly, $8 \mathrm{ml}$ of peripheral blood was mixed with an equal volume of phosphate buffered saline (PBS) at room temperature (RT) and carefully layered on top of a $12.5 \mathrm{ml}$ Ficoll Paque ${ }^{\mathrm{TM}}$ PLUS layer in a $50 \mathrm{ml}$ tube. After centrifugation at $720 \mathrm{~g}$ for $20 \mathrm{~min}$ at RT, the PBMC layer was transferred to a new $50 \mathrm{ml}$ tube, washed with $50 \mathrm{ml}$ ice-cold PBS, and centrifuged at $1000 \mathrm{~g}$ for $10 \mathrm{~min}$ at $4^{\circ} \mathrm{C}$. In addition, the PBMC pellet from 6 volunteers was suspended on ice in $10 \mathrm{ml}$ icecold PBS and $40 \mathrm{ml} \mathrm{RBC}$ lysis buffer consisting of 0.83 (w/v\%) ammoniumchloride, 0.1 (w/v\%) sodiumbicarbonate and $1 \mathrm{mM}$ ethylenediaminetetraacetatic acid. After incubation for $20 \mathrm{~min}$ on ice, samples were centrifuged at $1000 \mathrm{~g}$ for $10 \mathrm{~min}$ at $4^{\circ} \mathrm{C}$. The supernatant was discarded. Next, the PBMCs from all volunteers were washed with another $50 \mathrm{ml}$ of ice-cold PBS and centrifuged at $1000 \mathrm{~g}$ for $10 \mathrm{~min}$ at $4^{\circ} \mathrm{C}$. The supernatant was discarded, the PBMCs were suspended in $1 \mathrm{ml}$ ice-cold PBS and transferred to a $1.5 \mathrm{ml}$ cryo vial. After centrifugation at $1000 \mathrm{~g}$ for $5 \mathrm{~min}$ at $4^{\circ} \mathrm{C}$ the supernatant was discarded and the PBMC pellet was snap frozen in liquid nitrogen and subsequently stored at $-80^{\circ} \mathrm{C}$.

PBMC cytosolic lysates were prepared by resuspending the $-80^{\circ} \mathrm{C}$ stored PBMCs, after defrosting on ice, in $300 \mu$ of PBS pH 7.4, which was subsequently equally divided over three $1.5 \mathrm{ml}$ vials on ice. Next, the cell membranes were disrupted by stick sonication using 15 pulses with a Branson 250 tip sonicator (Branson, Danbury, CT, USA) at power input setting level 3 and a $50 \%$ duty cycle on ice. After centrifugation at $11000 \mathrm{~g}$ for $20 \mathrm{~min}$ at $4^{\circ} \mathrm{C}$, the cytosolic lysate was transferred to a new $1.5 \mathrm{ml}$ vial on ice for immediate determination of protein amount, $\mathrm{Hb}$ content and determination of DPD enzyme activity. 


\section{Protein determination}

Total protein concentrations were determined using the Bio-Rad protein assay (Bio-Rad, Hercules, CA, USA). Briefly, $10 \mu \mathrm{l}$ of PBMC cytosolic lysate was diluted with $90 \mu \mathrm{l}$ of MilliQ water (Millipore, Billerica, MA, USA). Five bovine serum albumin standards were prepared in concentrations ranging from 32.5 to 500 $\mathrm{mg} / \mathrm{ml}$. In duplicate $10 \mu \mathrm{l}$ of diluted cytosolic lysate and the standard curve were transferred to a clear 96-well flat bottom plate. After the addition of 200 $\mu$ dye solution, the plate was incubated for $15 \mathrm{~min}$ at RT and subsequently the absorption was measured at $590 \mathrm{~nm}$ using an EL340 microplate reader (Bio-Tek, Winooski, VT, USA).

\section{Hb determination and correction}

The oxygenation of $\mathrm{Hb}$ in the PBMC cytosolic lysates was determined with a Rapidpoint 405 (Siemens, Tarrytown, NY, USA).

The molar extinction coefficient of $\mathrm{Hb}$ at $413 \mathrm{~nm}$ was determined by using lysed RBCs from a healthy volunteer, isolated as the precipitate of $10 \mathrm{ml}$ peripheral blood centrifuged for $5 \mathrm{~min}$ at $1500 \mathrm{~g}$. The RBCs were washed twice with $50 \mathrm{ml}$ icecold PBS and centrifuged at 1000g for $10 \mathrm{~min}$. After suspending the RBCs in $10 \mathrm{ml}$ ice-cold PBS, the total volume was adjusted to $50 \mathrm{ml}$ with RBC lysis buffer. After incubation for $20 \mathrm{~min}$ on ice the sample was centrifuged at $1000 \mathrm{~g}$ for $10 \mathrm{~min}$ at $4^{\circ} \mathrm{C}$. The lysation was successful if only a clear RBC lysate remained. A $10 \mu$ l aliquot of the RBC lysate was diluted 100 times with Milli-Q water and subsequently used for determining the protein concentration as described. The complete 50 $\mathrm{ml} \mathrm{RBC}$ lysate was freeze-dried and the dry mass of the RBCs was determined by subtracting the freeze-dried mass of a blank sample containing $10 \mathrm{ml}$ PBS and 40 $\mathrm{ml} \mathrm{RBC} \mathrm{lysis} \mathrm{buffer.}$

A $10 \mu \mathrm{l}$ aliquot of the RBC lysate was diluted 20 times with Milli-Q water and subsequently used for the measurement of the $\mathrm{Hb}$ absorption at the Soret peak at $413 \mathrm{~nm}$ using a Nanodrop 1000 (Thermo Scientific, Ashville, NC, USA). The molar extinction coefficient of $\mathrm{Hb}$ at $413 \mathrm{~nm}$ was determined with the formula:

$\varepsilon H b=(A 413 n m \cdot M w H b) /(c H b \cdot I)$

$\varepsilon \mathrm{Hb}=$ molar extinction coefficient of $\mathrm{Hb}\left(\mathrm{A} 413 \mathrm{~nm} \cdot \mathrm{M}^{-1} \cdot \mathrm{cm}^{-1}\right)$ 
A413nm $=$ Absorption of $\mathrm{Hb}$ at $413 \mathrm{~nm}$

$\mathrm{MwHb}=64500$ (g/mol)

$\mathrm{c} \mathrm{Hb}=\mathrm{Hb}$ protein concentration $(\mathrm{mg} / \mathrm{ml})$

I = path length Nanodrop $1000(0.1 \mathrm{~cm})$

Next, the concentration of $\mathrm{Hb}$ in 10-fold diluted PBMC lysates, left-over from the Bradford assay, was calculated by substitution of this $\varepsilon \mathrm{Hb}$ and the measured absorption of these samples at $413 \mathrm{~nm}$ in this formula. The correction for $\mathrm{Hb}$ contamination was performed by subtracting the $\mathrm{Hb}$ concentration from the total protein concentration.

\section{DPD activity}

DPD activity was determined according to the method adapted from Van Kuilenburg et al. [9]. Briefly, $60 \mu \mathrm{g}$ of PBMC cytosolic lysate was adjusted to a total volume of $100 \mu \mathrm{l}$ with $35 \mathrm{mM}$ potassium phosphate ( $\mathrm{pH} 7.4)$ containing $250 \mu \mathrm{M}$ $\beta$-NADPH, $12.5 \mathrm{mM} \mathrm{MgCl}_{2}, 1 \mathrm{mM}$ dithiotreitol, and $12.5 \mu \mathrm{M}$ thymine. The thymine solution consisted of radio-labeled $3 \mathrm{H}$-thymine plus thymine (in a ratio of 1:125). After incubation for $1 \mathrm{~h}$ at $37^{\circ} \mathrm{C}$, reactions were stopped by heatshock treatment for $3 \mathrm{~min}$ at $100{ }^{\circ} \mathrm{C}$. Thymine and the reaction product dihydrothymine were chromatographically separated by isocratic elution with $50 \mathrm{mM} \mathrm{KH}_{2} \mathrm{PO}_{4}(\mathrm{pH}$ 4.5) in $2 \%$ methanol through an Interchrom C18-column (150 x $4.6 \mathrm{~mm}, 5 \mu \mathrm{m}$ particle size, Interchim) for 15 minutes. The flow rate was maintained at $0.8 \mathrm{~mL} / \mathrm{min}$, reaching typical retention times of 13.0 minutes for thymine, and 10.5 minutes for dihydrothymine. ${ }^{3} \mathrm{H}$-thymine and ${ }^{3} \mathrm{H}$-dihydrothymine were detected by online radioactivity detection using a flow scintillation analyzer (Canberra Packard, Meridan, USA) with a $500 \mu \mathrm{L}{ }^{3} \mathrm{H}$-LSC cell (Canberra Packard, Meridan, USA) and Ultima-Flow M scintillation fluid (Perkin Elmer Inc., Waltham, USA) at a 1:1 ratio of column effluent to scintillation fluid. The DPD activity was expressed as nmol of thymine degraded per $\mathrm{mg}$ protein per $\mathrm{h}$.

\section{Effect of hemoglobin on DPD activity}

DPD activity was determined in samples containing $80 \mu \mathrm{g}$ of PBMC cytosolic lysate spiked with $0,25,50$, and $100 \mu \mathrm{g}$ of human hemoglobin (Sigma, St. Louis, USA), corresponding to $0,24,38$, and $56 \%$ of hemoglobin relative to total protein. 
Linearity and lower limit of quantification (LLOQ)

Ten hemoglobin standards were prepared from RBC lysate in the range of 0.020 $-2.00 \mathrm{mg} / \mathrm{ml}$ in PBS pH 7.4. The absorption was measured at $413 \mathrm{~nm}$ using the Nanodrop 1000. Linearity was assessed using weighted $\left(x^{-1}\right)$ least square linear regression analysis. A Pearson coefficient $\geq 0.95$ was considered significant.

The LLOQ was defined as the lowest $\mathrm{Hb}$ concentration that could be determined with an accuracy and precision better than $20 \%$.

Within- and between day precision and accuracy

PBMC cytosolic lysates from a healthy volunteer were spiked with $0.100,0.250$, and $1.000 \mathrm{mg} / \mathrm{ml}$ hemoglobin using RBC lysate and the $\mathrm{Hb}$ content was assessed on three different days $(n=5)$. The within- and between day precision were determined using one way ANOVA with the run day as classification variable.

\section{Stability}

The stability of the hemoglobin concentration was assessed in threefold in nonlysed PBMC pellets. The same batch of PBMC was used to prepare cytosolic lysates containing $0.123 \mathrm{mg} / \mathrm{ml} \mathrm{Hb}$, which were stored at $-80^{\circ} \mathrm{C}$ for $0,1,2,4,8$, and 16 weeks. The stability of the cytosolic lysates was also tested during storage at RT for $0,1,2$, and $4 \mathrm{~h}$, and after 3 freeze $\left(-80^{\circ} \mathrm{C}\right)$-thaw cycles.

\section{Statistics}

Statistical significance calculations were performed using SPSS statistics version 17.0 (Chicago, IL, USA). Paired student t-tests were used, except when stated differently, $\mathrm{P}$ values $\leq 0.05$ were considered significant. Accuracy and stability of the method of between $85-115 \%$, and a precision better than $15 \%$, were considered acceptable. 


\section{RESULTS}

Hb determination

We measured a Soret peak for $\mathrm{Hb}$ in the PBMC cytosolic lysates at $413 \mathrm{~nm}$, corresponding with oxygen (O2) saturated $\mathrm{Hb}$, which was confirmed by a $99.1 \%$ $\mathrm{O}_{2}$ saturation as determined with a Rapidpoint 405. In freshly prepared RBC lysate we determined an $\varepsilon \mathrm{Hb}$ of $483031 \mathrm{M}^{-1} \cdot \mathrm{cm}^{-1}$ by combining the results of freeze drying, protein analysis, and absorption at $413 \mathrm{~nm}$. The $\mathrm{Hb}$ concentration in PBMC cytosolic lysates was determined by using this $\varepsilon \mathrm{Hb}$.

Linearity and lower limit of quantification (LLOQ)

$\mathrm{Hb}$ concentrations in the range of $0.040-2.00 \mathrm{mg} / \mathrm{ml}$ were linearly related with the absorption at $413 \mathrm{~nm}$ (Pearson coefficient $=0.9998$ ). The back-calculated $\mathrm{Hb}$ concentrations deviated in the range of $0.3-12.8 \%$ from the nominal concentrations, and the precision was better than $9.2 \%$ at all calibration levels. The lower limit of quantification was $0.040 \mathrm{mg} / \mathrm{ml}$.

\section{Within- and between day precision and accuracy}

The precision and accuracy of the $\mathrm{Hb}$ determination were better than $9.0 \%$, and $107 \%$, respectively, in $\mathrm{Hb}$ spiked cytosolic lysates at nominal concentrations of $0.100,0.250$, and $1.00 \mathrm{mg} / \mathrm{ml}$, which correspond to the low, mid and high region of the linear range of the $\mathrm{Hb}$ determination (Table 1 ).

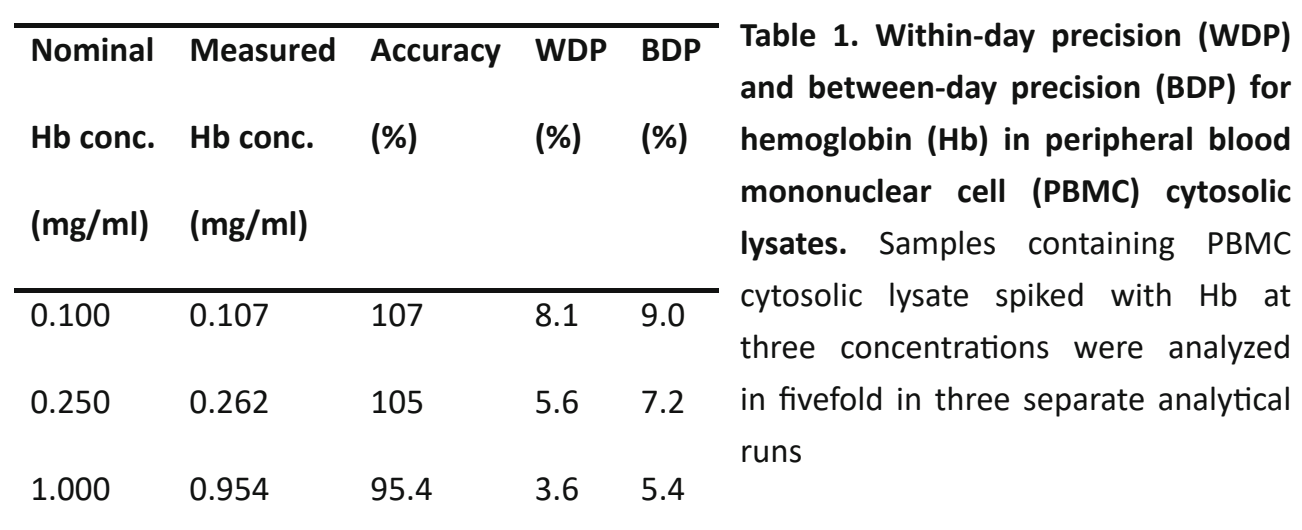


Table 2. Stability of hemoglobin $(\mathrm{Hb})$ in lysed and non-lysed peripheral blood mononuclear cells (PBMCs) stored under three different conditions. Results are the mean of three replicate samples.

\begin{tabular}{llllll}
\hline Matrix & Condition & Initial & Measured & CV & Dev \\
& & concentration & concentration & (\%) & (\%) \\
& & $(\mathbf{m g} / \mathbf{m l})$ & $(\mathbf{m g} / \mathbf{m l})$ & & \\
\hline Non-lysed & $\mathbf{3}$ months $-\mathbf{8 0}^{\circ} \mathbf{C}$ & 0.123 & 0.120 & 8.2 & 2.4 \\
lysate & $\mathbf{3}$ months $\mathbf{- 8 0 ^ { \circ } \mathbf { C }}$ & 0.118 & 0.110 & 9.3 & 6.8 \\
lysate & $\mathbf{4 ~ h ~ R T ~}$ & 0.119 & 0.111 & 11.2 & 6.7 \\
lysate & $\mathbf{3}$ freeze $\left(-80^{\circ} \mathbf{C}\right)-$ thaw cycles & 0.121 & 0.114 & 6.4 & 5.8 \\
\hline
\end{tabular}

$\mathrm{CV}=$ coefficient of variation, $\mathrm{Dev}=$ deviation

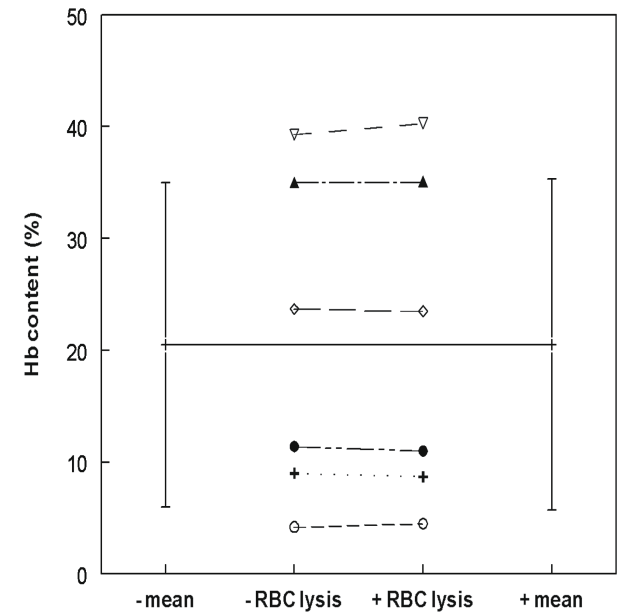

Figure 1. The effect of red blood cell (RBC) lysis buffer on the relative hemoglobin (Hb) contamination (\%) in peripheral blood mononuclear cell (PBMC) cytosolic lysates isolated from whole blood drawn at 9:00 am from 6 healthy volunteers. Results are the mean \pm inter-individual SD of the $\mathrm{Hb}$ contamination before (-) and after (+) RBC lysis of three replicate samples.

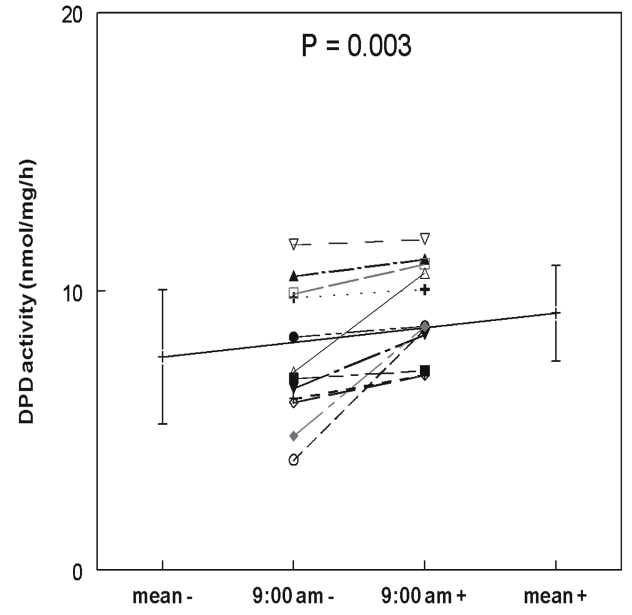

Figure 2. The effect of hemoglobin $(\mathrm{Hb})$ correction on the mean and spread in dihydropyrimidine dehydrogenase (DPD) activity determined in PBMC cytosolic lysates from peripheral blood collected at 9:00 am from 12 healthy volunteers. Results are the mean \pm SD of three replicate samples without (-) or with (+) $\mathrm{Hb}$ correction. 
Stability

$\mathrm{Hb}$ levels were stable under the tested storage conditions (Table 2 ) in both nonlysed PBMC as well as PBMC cytosolic lysate samples. The measured $\mathrm{Hb}$ levels deviated less than $15 \%$ from the initial concentration.

\section{Effect of RBC lysis on Hb contamination}

PBMCs isolated from 6 healthy volunteers were treated with or without RBC lysis buffer. No effect of this additional treatment on the $\mathrm{Hb}$ contamination was found (Fig. 1).

\section{Effect of hemoglobin on DPD activity}

The DPD activity was not affected by addition of $0,25,50$, and $100 \mu \mathrm{g}$ of $\mathrm{Hb}$ to samples containing $80 \mu \mathrm{g}$ of PBMC cytosolic lysate (Supplementary Material Fig. 1). The lysate contained an endogenous $\mathrm{Hb}$ background level of only $1 \%$, which amounts to $0.08 \mu \mathrm{g}$ of $\mathrm{Hb}$ per sample.

\section{Utility $\mathrm{Hb}$ correction in DPD activity determination}

The DPD activity in PBMC cytosolic lysate from 12 volunteers was determined with and without correction for $\mathrm{Hb}$ contamination (Fig. 2). After correction the average DPD activity was significantly $(P=0.003)$ increased by $20.3 \%$ (range 1 $59 \%, w / w \%)$ due to an equal percentage of $\mathrm{Hb}$ contamination present in the isolated PBMCs. Furthermore, the coefficient of variation (\%CV) in the DPD activity decreased from $31.5 \%$ to $18.6 \%$ after $\mathrm{Hb}$ correction.

\section{DISCUSSION}

Blood plasma and PBMC cytosolic lysates from clinical samples were sometimes colored red, which seemed to correlate with high protein levels in the PBMC cytosolic lysates. We investigated the possibility of contamination by RBCs. For quantification of the amount of RBC contamination we developed and validated a spectrophotometrical $\mathrm{Hb}$ determination method. We found an average of 20.3\% (range 1 - 59\%, w/w\%) Hb contamination in the PBMC cytosolic lysates of 12 healthy volunteers. The DPD activity was not directly affected by hemoglobin. By examining PBMC cytosolic lysates before and after RBC lysis we discovered 
that the amount of $\mathrm{Hb}$ contamination was not altered. Therefore, intact RBCs are most likely not responsible for the $\mathrm{Hb}$ contamination. We assume that RBCs, which have a dry mass that consists for $97.1 \%$ of $\mathrm{Hb}$ [10], are partly lysed during and after blood collection releasing the $\mathrm{Hb}$ into the plasma, which explains the red colorization of some samples. The free $\mathrm{Hb}$ in the plasma possibly binds to haptoglobin ( $\mathrm{Hp}$ ) [11], and is subsequently internalized as $\mathrm{Hb}-\mathrm{Hp}$ complex by monocytes, which constitute about $13.6 \%$ of the total cells after isolation by Ficoll [7]. With the $\mathrm{Hb}$ correction method we demonstrate an increase in the accuracy of the DPD activity determination in PBMCs. We believe that application of the $\mathrm{Hb}$ correction method is important and will result in an increase of the accuracy of most protein based biomarker assays in PBMCs. 


\section{REFERENCES}

1. Kummar $S$, Kinders $R$, Gutierrez $M E$, Rubinstein L, Parchment RE, Phillips LR, Ji J, Monks A, Low JA, Chen A, Murgo AJ, Collins J, Steinberg SM, Eliopoulos $\mathrm{H}$, Giranda VL, Gordon G, Helman L, Wiltrout $\mathrm{R}$, Tomaszewski JE, and Doroshow JH. J Clin Oncol 2009;27:2705-2711.

2. Burczynski ME, Twine NC, Dukart G, Marshall B, Hidalgo $M$, Stadler WM, Logan T, Dutcher J, Hudes G, Trepicchio WL, Strahs A, Immermann F, Slonim DK, and Dorner AJ . Clin Cancer Res 2005;11:1181-1189.

3. Boyum A. Scand J Clin Lab Invest Suppl 1968;97:77-89.

4. Boyum A. Scand J Clin Lab Invest Suppl 1968;97:9-29.

5. Olson BJ and Markwell J (2007) Curr Protoc Protein Sci Chapter 3.4.1-3.4.29.

6. Ficoll-Paque ${ }^{\mathrm{TM}}$ PLUS product insert 2012. https://www. gelifesciences. com/gehcls_images/GELS/Related $\% 20$ Content/Files/1314823637792/ litdoc11003135AC_20110831231429. pdf.

7. BD vacutainer ${ }^{\circledR}$ CPT product insert 2012. http://www. bd. com/vacutainer/pdfs/bd_ cpt_VDP40104. pdf.

8. Jansen RS, Rosing $H$, Schellens $J H$, and Beijnen JH. Anal Bioanal Chem 2009; 395:863-867.

9. van Kuilenburg $A B$, van Lenthe $H$, Blom MJ, Mul EP, and Van Gennip AH. Br J Cancer 1999;79:620-626.

10. Vajpayee N, Graham SS, and Bem S. Henry's Clinical Diagnosis and Management by Laboratory Methods 2011;30:509-535.

11. Weaver LK, Hintz-Goldstein KA, Pioli PA, Wardwell K, Qureshi N, Vogel SN, and Guyre PM. J Leukoc Biol 2012;80:26-35. 


\section{SUPPLEMENTARY MATERIAL}

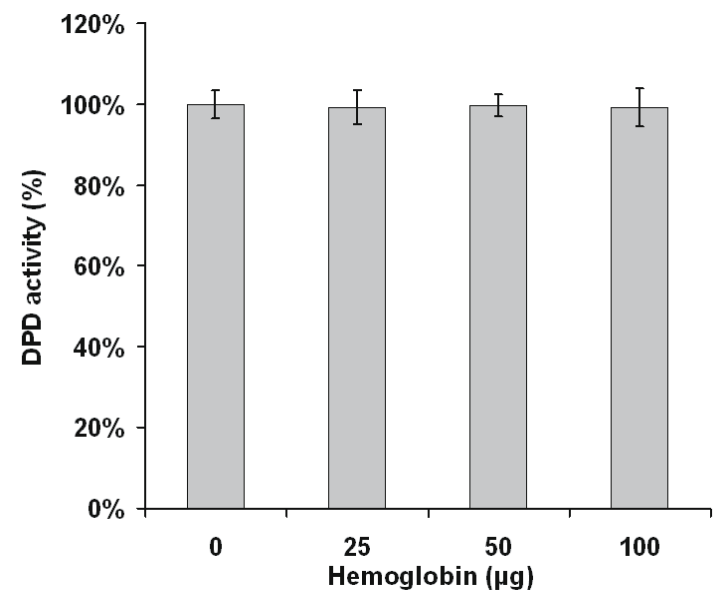

Figure S1. The effect of spiking indicated amount of hemoglobin $(\mathrm{Hb})$ on the dihydropyrimidine dehydrogenase (DPD) activity determined in samples containing $\mathbf{8 0}$ $\mu \mathrm{g}$ of PBMC cytosolic lysate. Results are the mean \pm RSD of three replicate samples and were expressed relative to the unspiked samples. 
Development and validation of pharmacodynamic and diagnostic biomarker methods 


\section{CHAPTER 1}

Development and validation of pharmacodynamic and diagnostic cancer biomarker methods

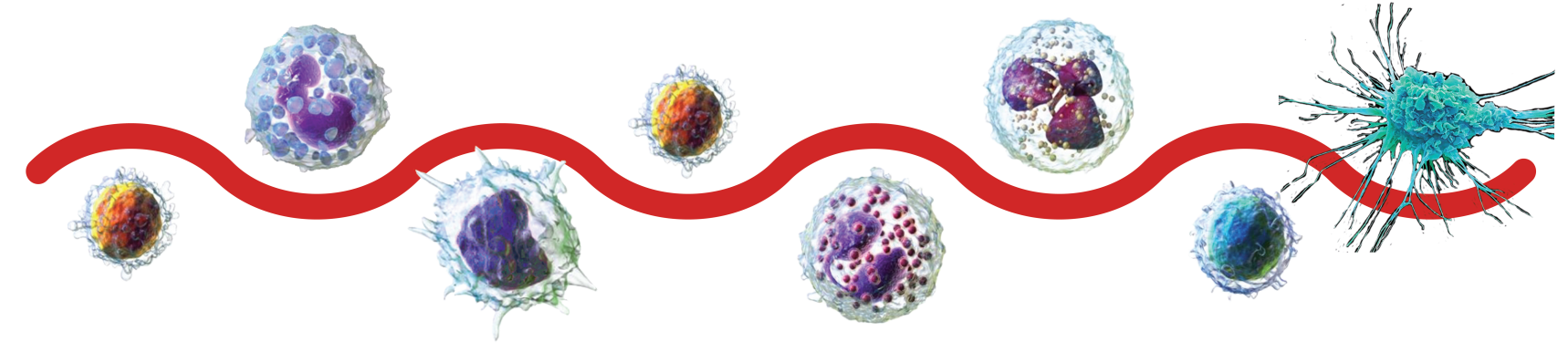

1.3

Pharmacodynamic assay of thymidylate synthase activity in peripheral blood mononuclear cells

Dick Pluim, Kim A. A. Schilders, Bart. A. W. Jacobs, Daniëlle Vaartjes, Jos H. Beijnen, Jan H. M. Schellens

Analytical Bioanalytical Chemistry 2013;405:2495-2503 


\section{ABSTRACT}

We developed and validated a simple, selective and sensitive method utilizing tritium $\left({ }^{3} \mathrm{H}\right)$ release from ${ }^{3} \mathrm{H}$-dUMP substrate for accurate and precise determination of the low basal Thymidylate synthase activity (TSA) in normal healthy peripheral blood mononuclear cells (PBMCs). The method is based on the removal of the remaining substrate after the TSA reaction by absorption onto activated carbon and measurement of the supernatant fluid by liquid scintillation counting. The method background was substantially decreased by using lyophilized substrate and optimized binding conditions of remaining substrate onto carbon after TSA reaction. The concentration of cofactor N5,N10 methylene-(6R,S)-tetrahydrofolate (MTHF) was increased to obtain maximal TS activity. Method sensitivity was further increased by omission of EDTA from the reaction mix (RM), and by using longer reaction times. The validation parameters included specificity, linearity, sensitivity, precision and stability. The lower limit of quantification was $25 \mu \mathrm{g}$ PBMC cytosolic lysate, which released $1.4 \mathrm{pmol}{ }^{3} \mathrm{H} / \mathrm{h}$. TSA was stable in PBMC pellets stored for 6 months at $-80^{\circ} \mathrm{C}$. The applicability of the method was demonstrated by the successful determination of TSA in PBMC cytosolic lysates from 10 healthy volunteers with and without the specific TSA inhibitor FdUMP. 


\section{INTRODUCTION}

Thymidylate synthase (TS) is the unique enzyme capable of de novo synthesis of 2'-deoxythymidine 5'-monophosphate (dTMP), which is essential for DNA biosynthesis. Therefore, TS is an important target of anticancer agents such as 5-Fluorouracil and its derivatives [1]. The level of TS expression is increased in highly proliferative cells, and an increased abundance in a broad range of tumors is associated with a poor treatment response and clinical outcome [2]. Thymidylate synthase activity (TSA) is highest in actively dividing cells, and low basal TSA is found in non dividing cells [3]. There is growing interest in the use of surrogate tissue to determine anti-cancer drug response. Thus far, most methods for determining TSA are applied on leukocyte populations that are isolated from whole blood, but failed to demonstrate TSA above background levels [4;5]. We decided to use peripheral blood mononuclear cells (PBMCs) instead, because PBMCs, in contrast to total leukocyte populations, are a more homogenous cell population consisting mostly of lymphocytes. Therefore, TSA determinations in PBMCs are possibly less distorted by differences in relative cellular composition. Furthermore, PBMCs are used extensively in pharmacodynamic (PD) studies as a source of surrogate markers for predicting the effect of anticancer agents on their molecular target in tumor cells [6;7]. Surrogate cells like PBMCs have several advantages over tumor biopsies for monitoring the PD effects of targeted anticancer agents, including minimally invasive sample collection and the ability to collect multiple samples for longitudinal assessment of drug effect.

In this paper we present the development and validation of the first radioisotopic method for the quantification of TSA in non cultured human PBMCs by tritium release from the substrate $5^{-3} \mathrm{H}-2^{\prime}$-deoxyuridine $5^{\prime}$-monophosphate $\left(5-{ }^{3} \mathrm{H}\right.$-dUMP). TSA assays can be divided in spectrophotometric [8] and radioisotopic methods [9]. Although the radioisotopic TSA methods possess the highest sensitivity, TSA quantification in human PBMCs has remained impossible. We based our method on the tritium release method, with subsequent binding of excess substrate by carbon, first reported by Dewayne Roberts [10]. The sensitivity of that method was increased by preparing PBMC cytosolic lysates directly in the reaction mix (RM) enabling higher protein input per sample. A further increase of sensitivity was obtained by using the recently available pure N5,N10 methylene(6R,S)-tetrahydrofolate (MTHF) cofactor in a 20 to 1 ratio relative to substrate, which resulted in increased TSA that was independent of MTHF concentration. By omitting ethylenediaminetetraacetic acid (EDTA) from the reaction mix sensitivity 
was also increased due to an increase of TSA in combination with a decrease of background. An additional increase of method sensitivity was reached by prolonging the reaction times.

The applicability of the method was demonstrated in PBMCs from healthy volunteers with or without ex vivo exposure to the specific TS inhibitor dFdUMP.

Although we report results in PBMC, we believe that this method will be more widely applicable for the quantification of TSA in other cell types with low TSA, or for the accurate determination of the effect of TS inhibitors.

\section{MATERIALS AND METHODS}

\section{Reagents and chemicals}

N5,N10 methylene-(6R,S)-tretrahydrofolate-sodium (MTHF) salt was a kind gift from Merck Eprova (Schaffhausen, Switserland). Ficoll-paquetmPLUS was procured from General Electric Healthcare (Little Chalfont, UK). Phosphate buffered saline (PBS) was purchased from GIBCO BRL (Gaithersburg, MD, USA). Tris- $\mathrm{HCl}$ was obtained from Roche (Woerden, the Netherlands). Ethylenediaminetetraacetic acid (EDTA), $\mathrm{MgCl}_{2} \cdot 6 \mathrm{H}_{2} \mathrm{O}$, DL-dithiotreitol (DTT), NaF, 2-mercaptoethanol (BME), carbon, and 2'-deoxyuridine 5'-monophosphate (dUMP) were purchased from Sigma (St. Louis, MO, USA). 5- ${ }^{3} \mathrm{H}$-dUMP was purchased from Moravek (Brea, CA, USA). Dextran T500 was procured from Pharmacia (Uppsula, Sweden). Ultima Gold was purchased from Canberra Packard (Meriden, CT, USA). Buffers and water were deoxygenized by a $1 \mathrm{~L} / \mathrm{min}$ bubble stream of nitrogen for $40 \mathrm{~min}$ [11]. Reaction mix (RM) consisted of $20 \mathrm{mM} \mathrm{MgCl}_{2}, 1.5 \mathrm{mM} \mathrm{NaF}, 1 \mathrm{mM}$ DTT in $50 \mathrm{mM}$ Tris- $\mathrm{HCl}$ $\mathrm{pH} 7.5$, after deoxygenation 0.47 (v/v\%) BME was added. The substrate consisted of a mixture of $1 \mathrm{ml} 1 \mathrm{mM}$ dUMP and $500 \mathrm{kBq}$ of lyophilized $5-{ }^{3} \mathrm{H}$-dUMP. A $10 \mathrm{mM}$ MTHF solution was prepared in water and $500 \mu$ aliquots were lyophilized in 500 $\mu \mathrm{l}$ vials, closed under an atmosphere of nitrogen. Carbon suspension (CS) was prepared by vigorously shaking of $5 \mathrm{~g}$ carbon, and $20 \mathrm{mg}$ Dextran T500 in $50 \mathrm{ml}$ PBS.

\section{Cell culture}

The human breast cancer cell line T47D (ATCC, Rockvile, USA) was cultured as monolayer in RPMI medium supplemented with $10 \%$ fetal calf serum. Exponentially growing cells were harvested by trypsinization and subsequently 
washed with $50 \mathrm{ml}$ of ice-cold PBS. After centrifugation at $1000 \mathrm{~g}$ for $10 \mathrm{~min}$ at $4^{\circ} \mathrm{C}$ the supernatant was discarded. Subsequently, dry cell pellets for storage at $-80^{\circ} \mathrm{C}$ and cytosolic lysates were prepared as described next for PBMCs.

\section{PBMC isolation and cytosolic lysate preparation}

Peripheral blood was drawn between 9:00 and 10:00 am from 10 healthy volunteers into $10 \mathrm{ml}$ heparin blood collection tubes. Study participants were informed of the investigational nature of this analysis and had given written informed consent in accordance with institutional and national guidelines. PBMCs were isolated immediately after blood collection using Ficoll gradient centrifugation [12]. Briefly, $8 \mathrm{ml}$ of peripheral blood was mixed with an equal volume of PBS at room temperature (RT) and carefully layered on top of a $12.5 \mathrm{ml}$ Ficoll layer in a $50 \mathrm{ml}$ tube. After centrifugation at $720 \mathrm{~g}$ for $20 \mathrm{~min}$ at RT, the PBMC layer was transferred to a new $50 \mathrm{ml}$ tube, washed with $50 \mathrm{ml}$ of ice-cold PBS, and centrifuged at $1000 \mathrm{~g}$ for $10 \mathrm{~min}$ at $4^{\circ} \mathrm{C}$. The supernatant was discarded. Next, the pellet was washed with another $50 \mathrm{ml}$ of ice-cold PBS and centrifuged at $500 \mathrm{~g}$ for $10 \mathrm{~min}$ at $4^{\circ} \mathrm{C}$. The supernatant was discarded, and the pellet was suspended in $1 \mathrm{ml}$ of ice-cold PBS and transferred to a $1.5 \mathrm{ml}$ cryo vial. After centrifugation at $500 \mathrm{~g}$ for $5 \mathrm{~min}$ at $4^{\circ} \mathrm{C}$, the supernatant was discarded and the PBMC pellet was snap frozen in liquid nitrogen and subsequently stored at $-80^{\circ} \mathrm{C}$.

After defrosting PBMC pellets were suspended in $300 \mu$ ice-cold RM. The PBMC suspension was subsequently equally divided into three separate vials on ice. Next, PBMC lysates were prepared on ice by applying 15 pulses with a Branson 250 tip sonicator (Branson, Danbury, CT, USA) at power input setting level 3 with a $50 \%$ duty cycle. After centrifugation at $11000 \mathrm{~g}$ for 20 min at $4{ }^{\circ} \mathrm{C}$, $95 \mu \mathrm{l}$ of supernatant was transferred to a clean $1.5 \mathrm{ml}$ vial on ice for immediate determination of protein followed by TSA analysis.

\section{Protein assay}

Protein concentrations in PBMC cytosolic lysates were determined using the BioRad protein assay (Bio-Rad, Hercules, CA, USA). Briefly, $5 \mu$ of PBMC cytosolic lysate was diluted with $45 \mu$ l of MilliQ water (Millipore, Billerica, MA, USA). Five bovine serum albumin standards were prepared in concentrations ranging from 32.5 to $500 \mathrm{mg} / \mathrm{ml}$ to obtain a standard curve. In duplicate $10 \mu \mathrm{l}$ of diluted lysate and the standard curve were transferred to a clear 96-well flat bottom plate. After 
the addition of $200 \mu \mathrm{l}$ dye solution, the plate was incubated for $15 \mathrm{~min}$ at RT and subsequently the absorption was measured at $590 \mathrm{~nm}$ using an EL340 microplate reader (Bio-Tek, Winooski, VT, USA).

\section{Carbon binding of substrate}

Samples were prepared at RT with a total volume of $100 \mu \mathrm{l}$, containing $85 \mu \mathrm{l}$ of $\mathrm{RM}, 10 \mu \mathrm{l}$ of $10 \mathrm{mM}$ MTHF, and $5 \mu \mathrm{l}$ of $1 \mathrm{mM}{ }^{3} \mathrm{H}$-dUMP (100.000 DPM/sample). Next, 200, 400, and $800 \mu$ of CS was added, followed by vortex mixing for $5 \mathrm{~s}$ at full speed setting and subsequent vertical disk rotation mixing at $50 \mathrm{rpm}$ and $4^{\circ} \mathrm{C}$. After $0,0.25,0.5,1,4$, and $24 \mathrm{~h} 100 \mu \mathrm{l} 6.5 \mathrm{~N}$ of $\mathrm{HCl}$ was added to three samples at each CS input level. Subsequently, the samples containing 200,400, and $800 \mu \mathrm{l}$ of CS containing samples were centrifuged at $11,000 \mathrm{~g}$ for $5 \mathrm{~min}$ at $4^{\circ} \mathrm{C}$, followed by transfer of 200,300 , and $500 \mu \mathrm{l}$ of clear supernatant to a $20 \mathrm{ml}$ polyethylene vial, respectively. After mixing with $10 \mathrm{ml}$ of Ultima Gold, samples were assayed for radioactivity for $10 \mathrm{~min}$ using a LSC2800 Tri-Carb liquid scintillation counter (Packard, Meriden, CT, USA).

\section{Thymidylate Synthase activity assay}

The assay was carried out according to the method described by Dewayne Roberts [10] with modifications. Immediately before the start of the reaction a vial containing $2.51 \mathrm{mg}$ of lyophilized MTHF was reconstituted in $500 \mu \mathrm{l}$ of deoxygenized water and $10 \mu \mathrm{l}$ was added to a $1.5 \mathrm{ml}$ vial on ice. To this vial $85 \mu \mathrm{l}$ of ice-cold PBMC or T47D cytosolic lysate, or in case of background controls 85 $\mu \mathrm{l}$ of ice-cold RM was added. Next, $5 \mu \mathrm{l}$ of $1 \mathrm{mM}$ ice-cold substrate was added, and after mixing, the samples were incubated for $3 \mathrm{~h}$ at $37^{\circ} \mathrm{C}$ in a shaking water bath. The reaction was terminated by adding $100 \mu \mathrm{l}$ of $6.5 \mathrm{~N} \mathrm{HCl}$, and the remaining substrate was bound onto $400 \mu \mathrm{CS}$ by vertical disk rotation mixing of the samples at $50 \mathrm{rpm}$ at $4^{\circ} \mathrm{C}$. After centrifugation at $11,000 \mathrm{~g}$ for $5 \mathrm{~min}$ at $4^{\circ} \mathrm{C}, 300$ $\mu \mathrm{l}$ of clear supernatant was transferred to a $20 \mathrm{ml}$ polyethylene vial, mixed with 10 $\mathrm{ml}$ of Ultima Gold, and subsequently assayed for radioactivity for 10 min using a LSC2800 Tri-Carb liquid scintillation counter.

TS enzyme kinetics

All samples concerning TSA kinetics were prepared on ice and analyzed in 
threefold. All samples were adjusted with RM to a total volume of $100 \mu \mathrm{l}$. Samples were incubated for $3 \mathrm{~h}$ at $37^{\circ} \mathrm{C}$, unless indicated differently. Reactions were terminated and TSA was determined as described above. The influence of MTHF concentration on the TSA reaction was determined in samples containing $0.05,0.1,0.5,1,2.5$, and $5 \mathrm{mM}$ MTHF, $50 \mu \mathrm{g}$ of T47D cytosolic lysate, and $50 \mu \mathrm{M}$ substrate. The time dependency of the TSA reaction was assessed in samples containing $50 \mu \mathrm{g}$ of T47D cytosolic protein, $50 \mu \mathrm{M}$ of ${ }^{3} \mathrm{H}$-dUMP and $1 \mathrm{mM}$ MTHF. After incubation for $0.5,1,2,3,4,6$ and $24 \mathrm{~h}$ at $37^{\circ} \mathrm{C}$, reactions were terminated and TSA was determined as described above. The concentration dependency of the TSA reaction was determined in samples containing $1,2,5,10,25,50$, and 100 $\mu \mathrm{M}$ of ${ }^{3} \mathrm{H}$-dUMP, $1 \mathrm{mM}$ of MTHF, and $50 \mu \mathrm{g}$ of T47D cytosolic lysate. The results were displayed in a Eadie Hofstee Plot for determination of $\mathrm{Km}$ and Vmax.

pH optimum

The $\mathrm{pH}$ optimum of TSA using $100 \mu \mathrm{g}$ T47D cytosolic protein was determined using $50 \mu \mathrm{M}$ of ${ }^{3} \mathrm{H}$-dUMP and $1 \mathrm{mM}$ of MTHF. RM prepared with $50 \mathrm{mM}$ of potassium phosphate was used from $\mathrm{pH} 5.0$ to 6.5 , and $50 \mathrm{mM}$ of Tris- $\mathrm{HCl}$ from $\mathrm{pH} 7.0$ to 9.0, both in $\mathrm{pH} 0.5$ increments.

\section{Specificity}

The background signal from three separate blank control samples containing RM instead of cytosolic cell lysate was assessed during each batch analysis. TSA was also determined in threefold in samples from 10 healthy volunteers containing 200 $\mu \mathrm{g}$ of PBMC cytosolic lysates with and without $100 \mu \mathrm{M}$ of the strong and specific TS inhibitor FdUMP [13].

\section{Linearity and Lower limit of quantification (LLOQ)}

The linearity and LLOQ were determined in threefold in samples spiked with 5, 10, $15,20,25,30,50,75,100,150,200$, and $300 \mu \mathrm{g}$ of PBMC cytosolic lysate protein from a healthy volunteer. TSA in samples at the highest linear spike level was defined as nominal. The LLOQ and linear range were defined as the protein input level or protein input range, respectively, at which TSA could be determined with precision $\leq 20 \%$, and accuracy between $80-120 \%$ of the nominal TSA. 
Within- and between-day precision

Samples containing 50, 100 or $200 \mu \mathrm{g}$ of PBMC cytosolic lysate were measured in triplicate on three consecutive days. The between-day (BDP) and within-day precision (WDP) were calculated by one-way analysis of variance (ANOVA) for each spike level with the run day as classification variable using the software package SPSS v15.0 for windows (SPSS, Chicago, USA). The day mean square (DayMS), error mean square (ErrMS) and the grand mean (GM) of the observed cell concentrations across run days were used. The WDP\% and BDP\% for each spike level was calculated using the formulas:

WDP\% $=(\text { ErrMS })^{0.5} / \mathrm{GM} \times 100 \%$

$\mathrm{BDP} \%=\left[(\text { DayMS }- \text { ErrMS) } / \mathrm{n}]^{0.5} / \mathrm{GM} \times 100 \%\right.$

(Where $\mathrm{n}$ is the number of replicates within each run).

\section{Stability}

All PBMCs used for stability tests originated from a single volunteer. The stability of TSA in PBMCs isolated from whole blood stored ex vivo at RT for $6 \mathrm{~h}$ was assessed. Next, we determined the stability of TSA in PBMC cytosolic lysates stored for $24 \mathrm{~h}$ on ice. Long term storage stability of TSA was assessed in a single batch of PBMCs and T47D tumor cells after 180 days of storage at $-80^{\circ} \mathrm{C}$ as dry cell pellets. RM and ${ }^{3} \mathrm{H}$-dUMP solution stored for 6 months at $-20^{\circ} \mathrm{C}$, and lyophilized MTHF stored for 6 months at $-80^{\circ} \mathrm{C}$ was used for the determination of TSA in lysates prepared from stably stored T47D dry cell pellets at $-80^{\circ} \mathrm{C}$.

\section{Statistical Analysis}

Statistical evaluation was performed using the unpaired two-tailed student $t$-test unless indicated otherwise. P-values of 0.05 were considered to be significant. 


\section{RESULTS}

\section{RM development}

The reaction mix of typical tritium release methods contains $20 \mathrm{mM} \mathrm{Mg}^{2+}, 1.5$ $\mathrm{mM} \mathrm{NaF}, 1 \mathrm{mM}$ DTT, 0.47\% (v,v\%) BME, and 2 mM EDTA, which are necessary for an optimal release of tritium from the substrate as reported by others [14]. We tested the influence of these components on the background and TSA using RM from which one of these components was omitted (Fig. 1). Omission of $\mathrm{Mg}^{2+}$ and $\mathrm{NaF}$ had no effect on the background, however, TSA was reduced by $11.8 \%$ ( $\mathrm{P}=$ 0.028 ) and $12.6 \%(P=0.0021)$, respectively. Omission of DTT, and BME increased the background by $9.6 \%(P=0.036)$ and $15.8 \%(P=0.013)$, respectively, and a decrease of TSA by $16.0 \%(P=0.0014)$ and $52.3 \%(P=0.0009)$, respectively. The omission of EDTA caused a $22 \%(P=0.0012)$ decrease of the background, and a $56.8 \%(P=0.0008)$ increase in TSA. Based on these results we decided to use RM containing $20 \mathrm{mM} \mathrm{Mg}{ }^{2+}, 1.5 \mathrm{mM} \mathrm{NaF}, 1 \mathrm{mM}$ DTT, and $0.47 \%$ (v,v\%) BME for low background and high TSA. Compared to the original RM described by others [14], EDTA was omitted from the RM.
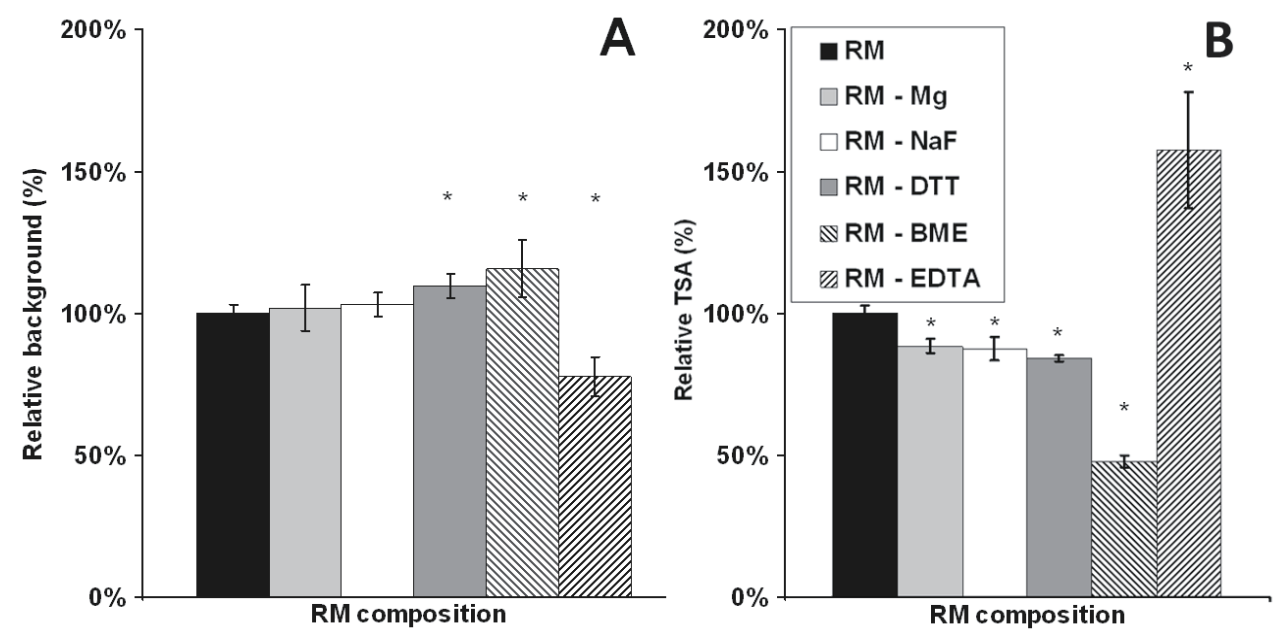

Figure 1. Influence of different reaction mix (RM) components on background after substrate binding to carbon suspension (A), and thymidylate synthase activity (B). Samples with a total volume of $100 \mu \mathrm{l}$ were prepared, containing $300 \mu \mathrm{g}$ of peripheral blood mononuclear cell cytosolic lysate with RM containing all components or RM without one of the indicated components, and incubated for $3 \mathrm{~h}$ at $37^{\circ} \mathrm{C}$. Results $\pm \mathrm{SD}$ of 3 different samples are shown relative to samples prepared with RM containing all components, which was set at $100 \%$. 


\section{Carbon binding of substrate}

No significant difference in carbon binding of substrate was found between samples processed with 400 and $800 \mu \mathrm{l}$ of CS (Supplementary Fig. 7). However, samples processed with $200 \mu \mathrm{l}$ of CS contained significantly more remaining substrate. The binding of substrate was maximal at $99.92 \%$ after $15 \mathrm{~min}$ of incubation using $400 \mu \mathrm{l}$ of CS. Longer incubations and/or using more CS did not result in significantly increased binding of remaining substrate.

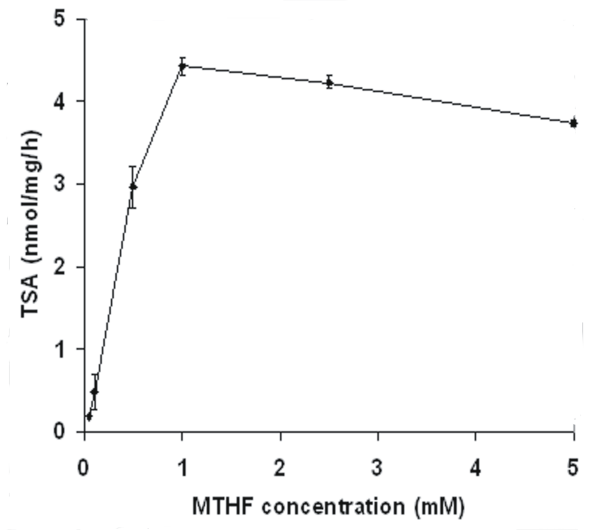

Figure 2. Linearity between thymidylate synthase activity and protein input. Indicated amounts of cell line T47D cytosolic lysate protein were incubated in a total volume of $100 \mu \mathrm{l}$ for $3 \mathrm{~h}$ at $37^{\circ} \mathrm{C}$. Results are expressed as means \pm S.D. of 3 different samples.

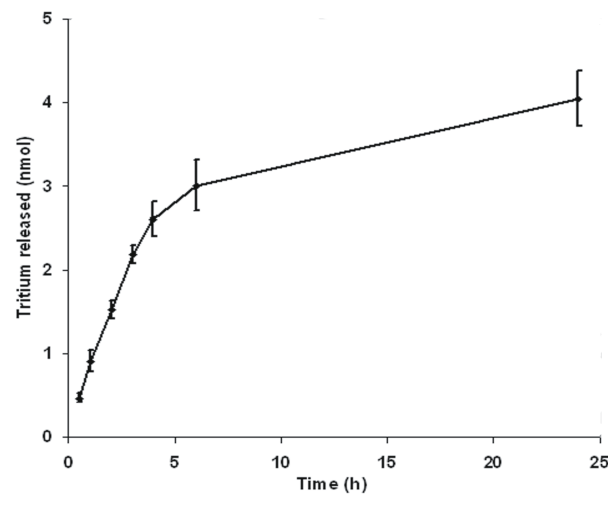

Figure 3. Time dependency of TSA. Samples, containing $50 \mu \mathrm{g}$ of T47D cytosolic lysate in a total volume of $100 \mu \mathrm{l}$, were incubated for the indicated time at $37^{\circ} \mathrm{C}$. Results are expressed as the means \pm S.D. of 3 different samples. 

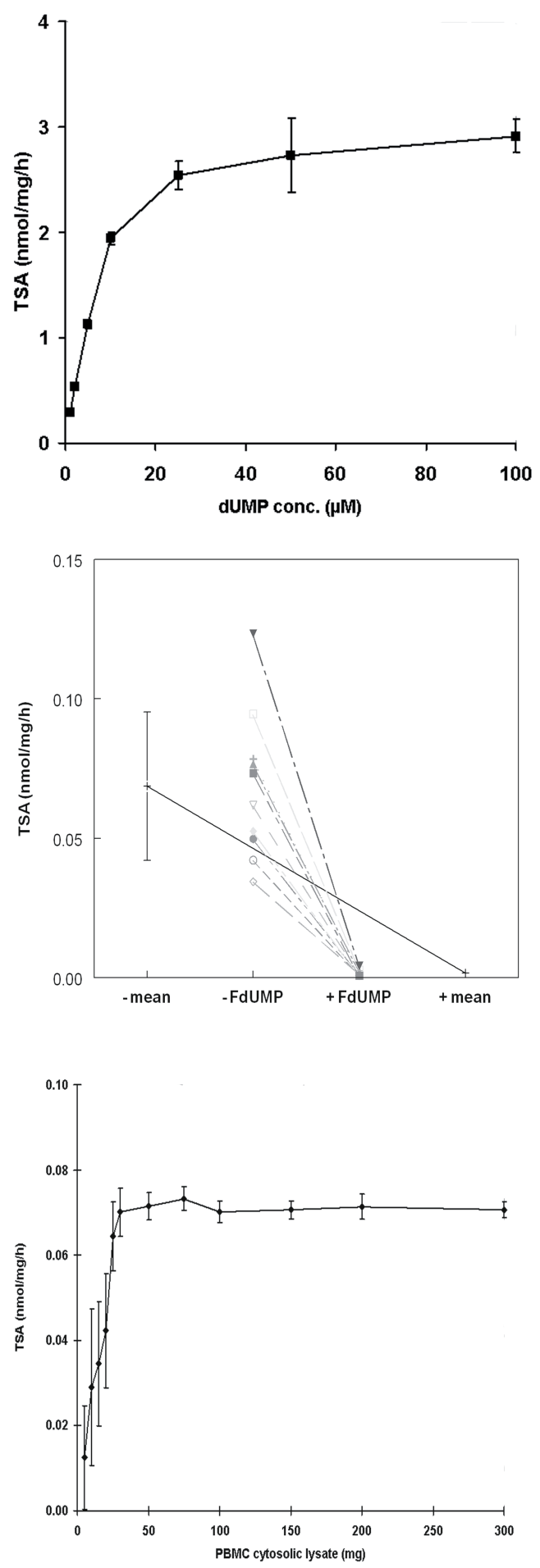

Figure 4. MTHF dependency of thymidylate synthase activity. Samples, containing $50 \mu \mathrm{g}$ of cell line T47D cytosolic lysate protein and indicated concentration of MTHF in a total volume of $100 \mu \mathrm{l}$, were incubated for $3 \mathrm{~h}$ at $37^{\circ} \mathrm{C}$. Results are expressed as the means \pm S.D. of 3 different samples.

\section{3}

Figure 5. Effect of the specific thymidylate synthase inhibitor FdUMP on thymidylate synthase activity (TSA) from 10 healthy volunteers. Samples, containing $300 \mu \mathrm{g}$ of peripheral blood mononuclear cell cytosolic lysate, were incubated in the absence ( - ) or presence $(+)$ of $100 \mu \mathrm{M}$ FdUMP in a total reaction volume of $100 \mu \mathrm{l}$ for $3 \mathrm{~h}$ at $37^{\circ} \mathrm{C}$. Results are shown as the mean TSA of 3 separate samples for 10 healthy volunteers, as well as the interindividual mean \pm S.D.

Figure 6. Linearity of thymidylate synthase activity (TSA) with protein input. TSA was assessed after incubation of samples containing indicated amounts of peripheral blood mononuclear cell cytosolic lysate protein in a total volume of $100 \mu \mathrm{l}$ for $3 \mathrm{~h}$ at $37^{\circ} \mathrm{C}$. Data are expressed as the means \pm S.D. of 3 different samples. 


\section{TS enzyme kinetics}

We determined the dependency of the TSA reaction on the cofactor MTHF, which acts as 'one-carbon donor' during the reaction, using $50 \mu \mathrm{M}$ of substrate (Fig. 2). An increase in MTHF concentration from $50 \mu \mathrm{M}$ to $1 \mathrm{mM}$ resulted in an increase of TSA from 0.189 to $4.43 \mathrm{nmol} / \mathrm{mg} / \mathrm{h}$, respectively. TSA was maximal at $1 \mathrm{mM} \mathrm{MTHF}$ and decreased at higher MTHF concentrations e.g. a decrease of $16 \%(P=0.018)$ in TSA was found using $5 \mathrm{mM}$ of MTHF.

The time dependency of the TSA reaction was determined in reactions containing $1 \mathrm{mM}$ of MTHF and $50 \mu \mathrm{M}$ of substrate (Fig. 3). Although TSA decreased over time, the total amount of released $3 \mathrm{H} 2 \mathrm{O}$ increased from 0.47 to $2.18 \mathrm{nmol}$ in reactions incubated for 0.5 and $3 \mathrm{~h}$, respectively. We decided to use 3 $h$ incubations for all subsequent TSA reactions as a compromise between maximal method sensitivity and time needed for analysis of sample batches during a standard $8 \mathrm{~h}$ working day.

In order to determine the substrate concentration dependency, TSA reactions were performed using different concentrations of substrate, and $1 \mathrm{mM}$ of MTHF (Fig. 4).

The $\mathrm{Km}$ of TS was $8.49 \mu \mathrm{M}$ and $10.03 \mu \mathrm{M}$ as determined from the substrate dependency curve (Fig. 4.) and Eadie Hofstee Plot (Supplementary Fig. 8), respectively. TSA was saturated at substrate concentrations higher than $25 \mu \mathrm{M}$, which is demonstrated by a decrease of only $6.9 \%$ in TSA after $50 \%$ of the initial 50 $\mu \mathrm{M}$ of substrate has been used by the reaction. Therefore we decided to perform all subsequent TSA reactions using $50 \mu \mathrm{M}$ substrate, allowing for a maximum of $50 \%$ conversion of substrate with only a small negative effect on TSA.

\section{pH optimum}

RM with $50 \mathrm{mM}$ potassium phosphate or $50 \mathrm{mM}$ Tris- $\mathrm{HCl}$ was used containing $\mathrm{Mg}^{2+}, \mathrm{NaF}, \mathrm{DTT}$, and BME. RM with potassium phosphate was used to assess TSA from $\mathrm{pH} 4.0$ to 6.5 and Tris- $\mathrm{HCl}$ based $\mathrm{RM}$ was used from $\mathrm{pH} 7.0$ to 9.0. We prepared $1 \mathrm{M} \mathrm{MgCl}_{2}$ stock solutions in Tris- $\mathrm{HCl} \mathrm{pH} \mathrm{7.5}$, because the $\mathrm{MgCl}_{2}$ we used had a high acidity of $\mathrm{pH} 4$ at $1 \mathrm{M}$ concentration in water resulting in a significant decrease of the final $\mathrm{pH}$ of the RM (data not shown). The pH dependency of TSA shows a hyperbolic curve (Supplementary Fig. 9) with lowest TSA levels of 0 and $0.772 \mathrm{nmol} / \mathrm{mg} / \mathrm{h}$ at $\mathrm{pH} 4.0$ and 9.0 , respectively. TSA peaked at $\mathrm{pH} 7.5$ with no significant difference in TSA from $\mathrm{pH} 6.5$ to 8.0. 


$\begin{array}{llll}\begin{array}{l}\text { Nominal } \\ \text { cytosolic }\end{array} & \begin{array}{l}\text { Measured } \\ \text { TSA }\end{array} & \begin{array}{l}\text { WDP } \\ (\%)\end{array} & \begin{array}{l}\text { BDP } \\ (\%)\end{array} \\ \begin{array}{l}\text { lysate } \\ \text { input level } \\ (\mu \mathrm{g})\end{array} & \begin{array}{l}\mathrm{nmol} / \mathrm{mg} / \mathrm{h}) \\ \end{array} & & \\ & & & \end{array}$

\begin{tabular}{llll}
\hline 50 & 0.0589 & 6.8 & 2.2 \\
100 & 0.0639 & 2.9 & 1.5 \\
200 & 0.0618 & 9.2 & 6.0 \\
\hline
\end{tabular}

Table 1. Within-day precision (WDP) and between-day precision (BDP) for Thymidylate Synthase activity (TSA) determination at three peripheral blood mononuclear cell (PBMC) cytosolic lysate input levels. Three replicate measurements were performed at each spike level. Within- and between-day precision were calculated using one-way analysis of variance (ANOVA).

Table 2. Stability of different components of the Thymidylate Synthase activity (TSA) reaction under various storage conditions. Results for initial and measured TSA are the average of three replicate measurements \pm SD ( ${ }^{*}$ indicates a significant difference).

\begin{tabular}{|c|c|c|c|c|c|}
\hline component & $\begin{array}{c}\text { storage } \\
\text { temperature }\left({ }^{\circ} \mathrm{C}\right)\end{array}$ & $\begin{array}{l}\text { storage } \\
\text { period }\end{array}$ & $\begin{array}{c}\text { initial TSA } \\
\text { (nmol/mg/h) }\end{array}$ & $\begin{array}{l}\text { measured TSA } \\
(\mathrm{nmol} / \mathrm{mg} / \mathrm{h})\end{array}$ & $\begin{array}{c}\text { change } \\
\text { (\%) }\end{array}$ \\
\hline whole blood & 0 & $6 \mathrm{~h}$ & $0.0541 \pm 0.0043$ & $0.022 \pm 0.0021$ & $-60.3^{*}$ \\
\hline whole blood & RT & $6 \mathrm{~h}$ & $0.140 \pm 0.013$ & $0.146 \pm 0.026$ & -4.4 \\
\hline $\begin{array}{c}\text { PBMC cytosolic } \\
\text { lysate }\end{array}$ & 0 & $24 \mathrm{~h}$ & $0.0701 \pm 0.0039$ & $0.068 \pm 0.0027$ & -2.5 \\
\hline T47D dry pellet & -80 & 180 days & $4.97 \pm 0.215$ & $5.11 \pm 0.198$ & 5.8 \\
\hline PBMC dry pellet & -80 & 180 days & $0.078 \pm 0.0037$ & $0.084 \pm 0.0035$ & 7.7 \\
\hline RM & -20 & 180 days & $4.68 \pm 0.306$ & $4.85 \pm 0.193$ & 3.6 \\
\hline dUMP & -20 & 180 days & $4.52 \pm 0.127$ & $4.38 \pm 0.265$ & -3.1 \\
\hline MTHF & -80 & 180 days & $4.69 \pm 0.265$ & $4.45 \pm 0.290$ & -5.1 \\
\hline
\end{tabular}


Specificity

Removal of free ${ }^{3} \mathrm{H}_{2} \mathrm{O}$ from the substrate by freeze drying resulted in a 4.33 fold reduction of background level of control samples prepared without cytosolic lysate to $170 \pm 25$ DPM $(n=12)$, which was $0.162 \%$ of the total radioactivity input, or $0.0077 \mathrm{nmol} / \mathrm{mg} / \mathrm{h}$ using $300 \mu \mathrm{g}$ of PBMC cytosolic lysate. The average TSA in samples from 10 healthy volunteers was $0.0687 \pm 0.0266 \mathrm{nmol} / \mathrm{mg} / \mathrm{h}$ (range: $0.0345-0.123 \mathrm{nmol} / \mathrm{mg} / \mathrm{h}$ ). In the presence of $100 \mu \mathrm{M}$ FdUMP the TSA activity in these samples was significantly reduced by $98.7 \%$ (range: $97.5-99.3 \%, \mathrm{P}<$ 0.001 ), indicating that the radioactive signal minus background originated almost completely from TSA (Fig. 5).

Linearity and Lower limit of quantification (LLOQ)

The TSA levels in samples containing 25 to $300 \mu \mathrm{g}$ of PBMC cytosolic lysate did not differ significantly which indicated good linear correlation between the amount of protein input and TSA (Fig. 6). The amount of tritium release using 5, 10, or 20 $\mu \mathrm{g}$ of PBMC cytosolic lysate was too low for an accurate determination of TSA. The LLOQ was 287 DPM, corresponding to $0.28 \%$ of total radioactivity input, or $25 \mu \mathrm{g}$ of PBMC cytosolic lysate with a TSA of $0.0706 \mathrm{nmol} / \mathrm{mg} / \mathrm{h}$. At the LLOQ the accuracy was $8.9 \%$, and the precision was $12.6 \%$. The LLOQ of $25 \mu \mathrm{g}$ corresponded on average to 1 million PBMCs which can be isolated from approximately $0.8 \mathrm{ml}$ of whole blood.

\section{Within- and between-day precision}

The WDP and BDP precisions of the TSA determination were better than 9.2\%, and $6.0 \%$, respectively, in samples spiked with PBMC cytosolic lysate at nominal concentrations of 50,100 , and $200 \mu \mathrm{g}$. These protein levels corresponded to the low, mid and high region of the linear range of the TSA determination (Table 1). The precisions of all selected cases were well within the limits that are considered acceptable for bio-analytical methods [15].

\section{Stability}

We tested the stability of different components of the TSA reaction under various storage conditions (Table 2). Whole blood was stored on ice for $6 \mathrm{~h}$ prior to PBMC isolation, which resulted in a significant reduction of TSA by $60.3 \%(P=0.0014)$. 
However, stable TSA levels were found in PBMCs isolated from whole blood stored at RT for $6 \mathrm{~h}$. Cytosolic lysates could be stored on ice for $24 \mathrm{~h}$ without a significant deterioration in TSA. The long term storage at $-80^{\circ} \mathrm{C}$ of T47D and PBMCs dry cell pellets was possible for 7 months without significant deterioration of TSA. Furthermore, TSA was not affected when RM, dUMP, and MTHF were stored for 180 days at $-20^{\circ},-80^{\circ} \mathrm{C}$, and $-80^{\circ} \mathrm{C}$, respectively. We noticed a $52 \%$ reduction ( $P$ $<0.001$ ) in TSA using MTHF solutions stored on ice for $24 \mathrm{~h}$ under exposure to white fluorescent tube light. Therefore we recommend immediate preparation of the MTHF solution, on ice and shielded from light, just before start of the TSA reaction.

\section{DISCUSSION}

We applied several sensitivity increasing modifications to the tritium release method described by Dewayne Roberts et al. [10], that enabled the determination of TSA in non dividing cells like PBMC. By preparing PBMC cytosolic lysates in RM we were able to increase the amount of lysate per sample resulting in more tritium release per sample, which consequently increased method sensitivity. Next, we optimized the RM composition by determining the effect of the RM components $\mathrm{Mg}^{2+}, \mathrm{NaF}, \mathrm{DTT}, \mathrm{BME}$, and EDTA on TSA and background signal. Our results confirmed other findings [16] about the importance of $\mathrm{Mg}^{2+}, \mathrm{DTT}$, and $\mathrm{BME}$ for TSA. However, omission of the RM component EDTA had a large positive effect of $56.8 \%$ on TSA, which is in agreement with the findings of Dewayne Roberts et al., but it is in disagreement with a negative effect reported by Silber et al. [14]. We assume that EDTA inhibits TSA by the chelation of $\mathrm{Mg}^{2+}$. DTT and BME had a small but significant effect on the background, possibly caused by the scavenging of oxygen radicals that might otherwise have reacted with labile tritium on the 5-carbon of the substrate [17].

Earlier developed tritium release methods depend $[9 ; 10]$ on the spontaneous formation of MTHF from a mixture of formaldehyde and tetrahydrofolate during the TSA reaction. This reaction is, however, very oxygen sensitive and possibly the cause of inconsistent results reported with previous tritium release methods [18]. Therefore, we used the recently available p.a. grade MTHF. We showed a linear 23-fold increase in TSA over a MTHF concentration range from 0.05 to $1 \mathrm{mM}$. At MTHF concentrations above $1 \mathrm{mM}$ saturation of TSA occurred, which was possibly caused by binding of formaldehyde, which could be formed as a result of MTHF degradation, to TS [19]. We further increased the sensitivity of the method by 
applying $3 \mathrm{~h}$ instead of $1 \mathrm{~h}$ TSA time, which resulted in the release of 2.4 times more tritium. Prolongation of incubation times beyond $3 \mathrm{~h}$ would probably increase the method sensitivity even further, but batch analysis of samples during a normal $8 \mathrm{~h}$ working day would be impossible.

In our studies and possibly those of others [20-23] we have noted a potential problem associated with the tritium release assay, described by the inability to demonstrate either low levels or complete inhibition of TSA due to incomplete binding of remaining substrate after the TSA reaction. Armstrong et al. [24] showed that incubations of $48 \mathrm{~h}$ using $200 \mu \mathrm{l}$ CS per $500 \mu \mathrm{l}$ of total reaction volume resulted in $99.5 \%$ binding of remaining substrate in no enzyme containing control samples. We showed, however, maximal binding of $99.84 \%$ of remaining substrate after just 15 min by using $400 \mu \mathrm{l}$ CS per $100 \mu \mathrm{l}$ of total reaction volume for binding of remaining substrate in negative control samples.

Our method is very specific for TSA, since TSA is inhibited by $98.7 \%$ in samples containing $100 \mu \mathrm{M}$ of the specific TS inhibitor FdUMP [13] and $300 \mu \mathrm{g}$ of PBMC cytosolic lysate. Therefore, we believe only a small part of the released tritium is caused by non enzymatic nucleophilic attack on the labile 5-carbon of the substrate [25].

In conclusion, a method has been developed and validated for the determination of TSA in PBMCs isolated from whole blood. The sensitivity was increased substantially over existing tritium release assays. The method is simple, sensitive, precise, robust, and shows long-term TSA stability, using standard laboratory equipment and techniques. We have shown that the method enables reproducible determination of TSA in PBMCs isolated from 10 healthy volunteers. We have successfully applied the method in a volunteer study for determining the circadian rhythm of TSA, as described earlier [26], in PBMCs (for submission). We believe that application of the method in clinical trials for monitoring the inhibitory effect of TS inhibitors is possible. 


\section{REFERENCES}

1. Takezawa K, Okamoto I, Tsukioka S, Uchida J, Kiniwa M, Fukuoka M, and Nakagawa K. Identification of thymidylate synthase as a potential therapeutic target for lung cancer. Br J Cancer 2010;103:354-361.

2. Costi MP, Ferrari S, Venturelli A, Calo S, Tondi D, and Barlocco D. Thymidylate synthase structure, function and implication in drug discovery. Curr Med Chem 2005;12: 2241-2258.

3. Derenzini $M$, Montanaro $L$, Trere $D$, Chilla A, Tazzari PL, Dall'Olio F, and Ofner D. Thymidylate synthase protein expression and activity are related to the cell proliferation rate in human cancer cell lines. Mol Pathol 2002;55:310-314.

4. Bertino JR, Silber R, Freeman M, Alenty A, Albrecht M, Gabrio BW, and Huenekens FM, studies on normal and leukemic leukocytes. IV. tetrahydrofolate-dependent enzyme systems and dihydrofolicreductase. J Clin Invest 1963;42:1899-1907.

5. Rao KN, Bhattacharya RK, and Venkatachalam SR. Thymidylate synthase activity and the cell growth are inhibited by the beta-carboline-benzoquinolizidine alkaloid deoxytubulosine. J Biochem Mol Toxicol 1998;12:167-173.

6. Kummar S, Kinders R, Gutierrez ME, Rubinstein L, Parchment RE, Phillips LR, Ji J, Monks A, Low JA, Chen A, Murgo AJ, Collins J, Steinberg SM, Eliopoulos $H$, Giranda VL, Gordon G, Helman L, Wiltrout $\mathrm{R}$, Tomaszewski JE, and Doroshow JH. Phase 0 clinical trial of the poly (ADP-ribose) polymerase inhibitor $\mathrm{ABT}-888$ in patients with advanced malignancies. J Clin Oncol 2009;27:2705-2711.
7. Burczynski ME, Twine NC, Dukart G, Marshall B, Hidalgo $M$, Stadler WM, Logan T, Dutcher J, Hudes G, Trepicchio WL, Strahs A, Immermann F, Slonim DK, and Dorner AJ, Transcriptional profiles in peripheral blood mononuclear cells prognostic of clinical outcomes in patients with advanced renal cell carcinoma. Clin Cancer Res 2005;11:1181-1189.

8. Leary RP, Beaudette N, and Kisliuk RL. Interaction of deoxyuridylate with thymidylate synthetase. J Biol Chem 1975 250:4864-4868.

9. Lomax MI and Greenberg GR. A new assay of thymidylate synthetase activity based on the release of tritium from deoxyuridylate5-3-H. J Biol Chem 1967;242:109-113.

10. Roberts D. An isotopic assay for thymidylate synthetase. Biochemistry 1966; 5:3546-3548.

11. I.B.Butler, M.A.Schoonen, and D.T.Rickard. Removal of dissolved oxygen from water: A comparison of four common techniques. Talanta 1994;41:211-215.

12. Boyum A. Isolation of mononuclear cells and granulocytes from human blood. Isolation of monuclear cells by one centrifugation, and of granulocytes by combining centrifugation and sedimentation at $1 \mathrm{~g}$. Scand J Clin Lab Invest Suppl 1968;97 :77-89.

13. Rode W, Kulikowski T, Kedzierska B, and Shugar D. Studies on the interaction with thymidylate synthase of analogues of 2'-deoxyuridine-5'-phosphate and 5-fluoro2'-deoxyuridine-5'-phosphate with modified phosphate groups. Biochem Pharmacol 1987;36:203-210.

14. Silber R, Gabrio BW, and Huenekens 
FM. Studies on normal and leukemic leukocytes VI. Thymidylate synthase and deoxycytidylate deaminase. J Clin Invest 1963;42:1913-1921.

15. Chandran S and Singh RS. Comparison of various international guidelines for analytical method validation. Pharmazie 2007;62:4-14.

16. Jastreboff $M$, Kedzierska $B$, and Rode W. Properties of thymidylate synthetase from Ehrlich ascites carcinoma cells. Effect of Mg2/ and MgATP2-. Biochem Pharmacol 1982;31:217-223.

17. Kawai $M$ and Hillcoat BL. Nonenzymatic exchange of tritium from $(5-3 \mathrm{H})$ deoxyuridylate in the thymidylate synthetase assay. Anal Biochem 1974;58:404-413.

18. Vandiver VV and Fites RC. Thymidylate synthase activity from chlamydomonas cells and cultured tissues of Nicotiana, pinus, and daucus. Plant Physiol 1979;64:668-670.

19. De Brouwer V, Zhang GF, Storozhenko S, Straeten DV, and Lambert WE. pH stability of individual folates during critical sample preparation steps in prevision of the analysis of plant folates. Phytochem Anal 2007;18: 496-508.

20. Ardalan B, Cooney DA, Jayaram HN, Carrico CK, Glazer RI, Macdonald J, and Schein PS. Mechanisms of sensitivity and resistance of murine tumors to 5-fluorouracil. Cancer Res 1980;40:1431-1437.

21. Diasio RB, Bennett JE, and Myers CE. Mode of action of 5-fluorocytosine. Biochem Pharmacol 1978;27:703-707.

22. Evans RM, Laskin JD, and Hakala MT. Assessment of growth-limiting events caused by 5-fluorouracil in mouse cells and in human cells. Cancer Res
1980;40:4113-4122.

23. Armstrong RD and Diasio RB. Metabolism and biological activity of 5'-deoxy-5fluorouridine, a novel fluoropyrimidine. Cancer Res 1980;40:3333-3338.

24. Armstrong RD and Diasio RB. Improved measurement of thymidylate synthetase activity by a modified tritium-release assay. J Biochem Biophys Methods 1982;6:141-147.

25. Kawai $M$ and Hillcoat BL. Nonenzymatic exchange of tritium from $(5-3 \mathrm{H})$ deoxyuridylate in the thymidylate synthetase assay. Anal Biochem 1974;58:404-413.

26. Wood PA, Du-Quiton J, You S, and Hrushesky WJ. Circadian clock coordinates cancer cell cycle progression, thymidylate synthase, and 5-fluorouracil therapeutic index. Mol Cancer Ther 2006;5:2023-2033. 


\section{SUPPLEMENTARY MATERIAL}

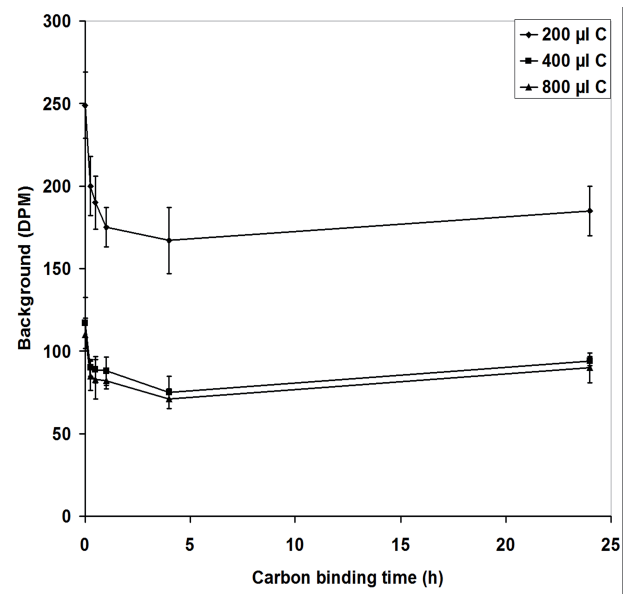

Figure 7. Remaining background after binding of substrate to carbon suspension (CS). Samples containing $50 \mu \mathrm{M}$ substrate (100.000 DPM) were incubated with 200, 400 , and $800 \mu$ l of CS for the indicated times on a rotation mixer at $4^{\circ} \mathrm{C}$. Data is expressed as the means \pm S.D. of 3 different samples.

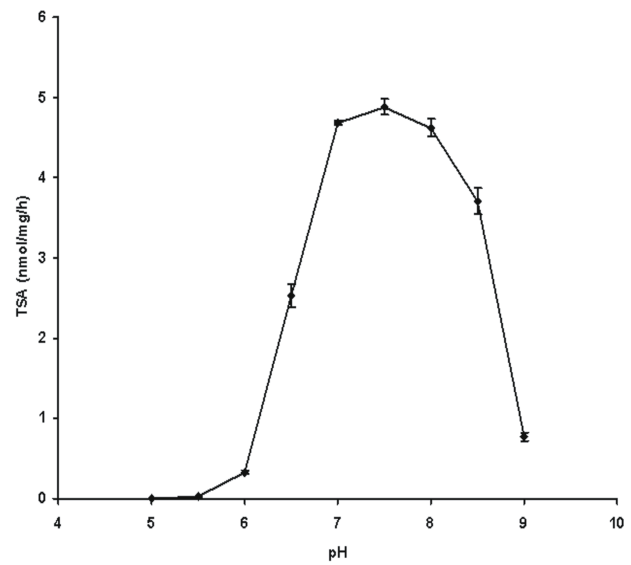

Figure 9. pH dependency of TSA. RM containing $50 \mathrm{mM}$ of potassium phosphate was used between pH $\mathbf{5 . 0}$ and 7.0, and $\mathbf{5 0}$ $\mathrm{mM}$ of Tris- $\mathrm{HCl}$ was used between $\mathbf{7 . 0}$ and 9.0. Data is expressed as the means \pm S.D. of 3 different samples.

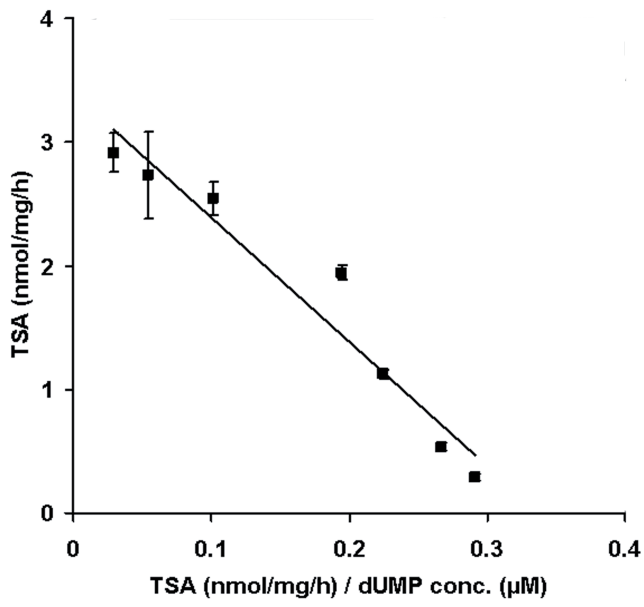

Figure 8. Eadie Hofstee Plot of thymidylate synthase activity. Samples containing $50 \mu \mathrm{g}$ of cell line T47D cytosolic lysate were incubated with indicated substrate concentrations in a total volume of $100 \mu \mathrm{l}$ for $3 \mathrm{~h}$ at $37^{\circ} \mathrm{C}$. Data are expressed as the means \pm S.D. of 3 different samples. 
Development and validation of pharmacodynamic and diagnostic biomarker methods 


\section{CHAPTER 1}

Development and validation of pharmacodynamic and diagnostic cancer biomarker methods

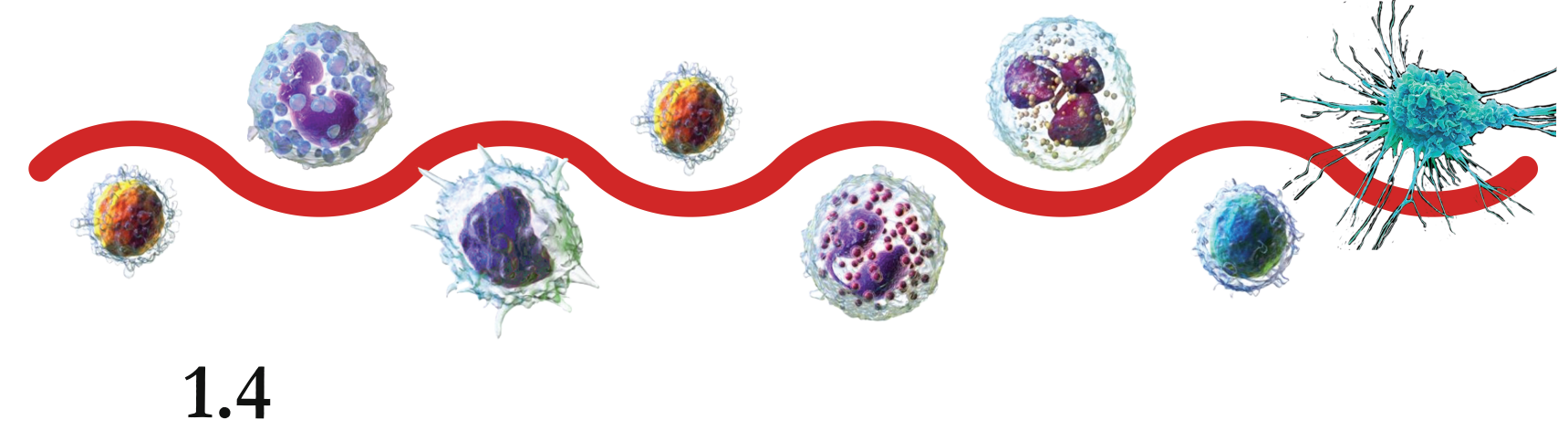

Improved pharmacodynamic assay for dihydropyrimidine dehydrogenase activity in peripheral blood mononuclear cells

Dick Pluim, Bart A. W. Jacobs, Maarten J. Deenen, Anneloes E. M. Ruijter, Robin M. J. M. van Geel, Artur M. Burylo, Didier Meulendijks, Jos H. Beijnen, Jan H. M. Schellens

Bioanalysis 2015;7:519 - 529. 


\section{ABSTRACT}

Background: Dihydropyrimidine dehydrogenase (DPD) activity determination in peripheral blood mononuclear cells of DPD deficient patients was hitherto very inaccurate due to hemoglobin $(\mathrm{Hb})$ contamination.

Results: DPD activity was determined by high performance liquid chromatography with online radio-isotope detection using liquid scintillation counting. $\mathrm{Hb}$ was determined spectrophotometrically. Method accuracy and precision were significantly improved by using cumulative area of all peaks as internal standard. PBMC lysates from DPD deficient patients were highly contaminated with on average $23.3 \%$ (range $2.7-51 \%$ ) of $\mathrm{Hb}$ resulting in up to twofold underestimated DPD activity. DPD activities were corrected for $\mathrm{Hb}$ contamination. The method was validated and showed good long term sample stability.

Conclusion: This method has increased specificity allowing accurate identification of DPD deficient patients. 


\section{INTRODUCTION}

Dihydropyrimidine dehydrogenase (DPD) catalyzes the reduction of the pyrimidine bases uracil and thymine into 5,6-dihydrouracil and 5,6-dihydrothymine, respectively [1]. DPD also facilitates the rate-limiting step in the metabolism of the anti-cancer drug 5-fluorouracil (5-FU). Approximately $85 \%$ of the administered $5-F U$ is metabolized into inactive metabolites by DPD. Because reduced DPD activity results in a higher exposure to 5-FU, patients with a complete or partial DPD deficiency who are treated with 5-FU or capecitabine are at high risk for developing severe, and sometimes fatal, fluoropyrimidine-induced toxicity [2-4].

Severe fluoropyrimidine related toxicity due to decreased DPD activity can be caused by point mutations, such as c.1905+1G>A (IVS $14+1 G>A$, DPYD*2A) in the $5^{\prime}$ splicing site of intron 14, c.2846A $>T$, or c.1679T>G [5]. So far, an additional 50 polymorphisms spread over the entire DPYD coding region have been identified [6], but their clinical relevance is uncertain. Other genetic and epigenetic regulations such as promoter hypermethylation or variations in transcriptional factor expression may play a critical role in DPYD expression [7,8]. In addition, also non-genetic causes, such as drug-drug interactions and circadian variations might explain the large inter-patient variability in DPD activity [9].

For these reasons, phenotypic testing of DPD activity is likely to be a more sensitive way to detect DPD deficiency in patients compared to genetic screening for DPYD polymorphisms alone. In fact, recent studies using phenotypic screening have evidenced reduced DPD enzyme activity in between $36-71 \%$ of the patients with fluoropyrimidine-induced severe toxicities [10]. Phenotypic screening for DPD deficiency is most often performed in peripheral blood mononuclear cells (PBMCs) [11]. Only methods for determining DPD activity using radio-isotopic substrates of DPD have high enough sensitivity to establish the presence of a complete DPD deficiency [12]. However, several technical challenges limit the applicability of these methods. The original method by van Kuilenburg et al. $[13,14]$ is based on the conversion of $\left[{ }^{14} \mathrm{C}\right]$-thymine into $\left[{ }^{14} \mathrm{C}\right]$-dihydrothymine with subsequent detection by high performance liquid chromatography and online liquid scintillation counting (HPLC-LSC). This method is relatively expensive and requires a laborious and hazardous purification process. Second, precision of the method is likely to be less than optimal due to experimental errors which are not corrected for. In addition, previous studies reported highly variable red colorization of PBMC lysates [15]. Recently, we demonstrated that the accuracy of the DPD activity was strongly affected by this hemoglobin $(\mathrm{Hb})$ contamination 
in PBMC lysates, by $20.3 \%$ (range $1-59 \%, n=12$ ) [16]. We evidenced that this contamination is exclusively caused by hemoglobin $(\mathrm{Hb})$ and introduced a simple spectrophotometrical method for the quantification of $\mathrm{Hb}$ in PBMC lysates.

Here we developed and validated an improved radio-isotopic method for the quantification of DPD activity in human PBMCs using the substrate $\left[{ }^{3} \mathrm{H}\right]$-thymine, eliminating the need of hazardous $\left[{ }^{14} \mathrm{C}\right]$-thymine. We based our DPD activity method on the method first reported by van Kuilenburg et al. [13,14], with modifications.

DPD activity was quantified using the peak area of the DPD enzyme reaction product $\left[{ }^{3} \mathrm{H}\right]$-dihydrothymine (DHT). We demonstrate, that DPD activity can also be quantified using the area of the substrate $\left[{ }^{3} \mathrm{H}\right]$-thymine. This opens the possibility for determining DPD activity in e.g. liver extracts and other tissues containing, in contrast to PBMCs, DHT metabolizing enzymes.

We improved method precision and accuracy by using the ratio between the average total peak area of five negative controls and total sample peak area to compensate for experimental errors in measurement of DPD activity.

Our improved method was applied for the determination of DPD activity in PBMCs from eight patients experiencing severe capecitabine-induced toxicity in order to establish the effect of $\mathrm{Hb}$ contamination on the accuracy of DPD phenotyping. Lastly, since data on long-term storage stability of these samples is missing, we performed stability experiments and validated different storage conditions to allow batch analysis of stored samples.

\section{MATERIALS AND METHODS}

\section{Reagents and chemicals}

Ficoll-paquetmPLUS was obtained from General Electric Healthcare (Little Chalfont, UK). Phosphate buffered saline (PBS) was purchased from GIBCO BRL (Gaithersburg, MD, USA). Complete ${ }^{\circledR}$ EDTA-free Protease Inhibitor was from Roche (Woerden, the Netherlands). Ammonium chloride $\left(\mathrm{NH}_{4} \mathrm{CL}\right)$, sodium bicarbonate

$\left(\mathrm{NaHCO}_{3}\right)$, ethylenediaminetetraacetate (EDTA), $\beta$-nicotinamide adenine dinucleotide phosphate (NADPH), dipotassium hydrogenphophate $\left(\mathrm{K}_{2} \mathrm{HPO}_{4}\right)$, potassium dihydrogenphosphate $\left(\mathrm{KH}_{2} \mathrm{PO}_{4}\right)$, magnesium chloride hexahydrate $\left(\mathrm{MgCl}_{2} \cdot 6 \mathrm{H}_{2} \mathrm{O}\right)$, dithiotreitol (DTT-DL), and thymine were purchased from Sigma (St. Louis, MO, USA). $\left[{ }^{3} \mathrm{H}\right.$-methyl]-thymine $(1.85-2.59 \mathrm{TBq} / \mathrm{mmol})$ was purchased from Moravek (Brea, CA, USA). Ultima Flow M was from Canberra Packard 
(Meriden, CT, USA). Cofactor solution consisted of $2.5 \mathrm{mM} \mathrm{NADPH}$ in water, and was stored in $500 \mu \mathrm{l}$ aliquots at $-80{ }^{\circ} \mathrm{C}$. PBS Complete ${ }^{\circledR}$ buffer consisted of 17.5 $\mathrm{mM} \mathrm{K}_{2} \mathrm{HPO}_{4} \mathrm{pH} 7.4$ and $2 \mathrm{mM}$ DTT-DL in PBS supplemented with 1 Complete $^{\circledR}$ EDTA-free Protease Inhibitor tablet per $10 \mathrm{ml}$, and was stored in $1 \mathrm{ml}$ aliquots at $-20{ }^{\circ} \mathrm{C}$. Thymine mix consisted of $125 \mu \mathrm{M}$ thymine, $2 \mu \mathrm{M}\left[{ }^{3} \mathrm{H}\right.$-methyl]-thymine and $12.5 \mathrm{mM} \mathrm{MgCl}_{2}$ in water, and was stored at $-20^{\circ} \mathrm{C}$. Reaction mix was freshly prepared on ice each day shielded from light by aluminium foil, and consisted of a $1: 1(\mathrm{v} / \mathrm{v})$ mixture of cofactor solution and thymine mix.

\section{Subjects}

Subjects asked for study participation included 19 healthy volunteers aged $\geq 18$ years of age, not known with cancer, not treated with investigational or other drugs within 30 days before start of the study, and who had not undergone surgery within the past six months.

Blood samples of eight patients who experienced severe capecitabine-induced toxicity (grade III/IV) were used for testing the accuracy of the developed DPD activity method. Patients had not been on treatment for at least 4 weeks before blood was drawn for determination of DPD activity. The study received approval from the institutional medical ethical review board and subjects provided whole blood after written informed consent.

\section{Pharmacogenetics}

From all volunteers and patients participating in this study a volume of $3 \mathrm{~mL}$ blood was collected in EDTA blood tubes at the same time blood for DPD activity analysis was drawn. Genomic DNA was isolated using the QIAamp DNA mini kit (Qiagen, Inc. Valencia, CA). Polymorphisms for DPYD IVS14+1G>A (DPYD*2A), c.496A>G, c.1236G >A, c.2194G >A, c.2846A>T, c.1601G >A, and c.1679T>G were determined using real-time PCR (RT-PCR) assays using allele-specific TaqMan probes (Applied Biosystems, Bleijswijk, The Netherlands), and polymorphisms for DPYD 1627A>G were determined by sequencing [17].

\section{PBMC isolation and cytosolic lysate preparation}

Peripheral blood was drawn from subjects between 9:00 and 10:00 am into 10 $\mathrm{ml}$ heparin containing blood collection tubes. PBMCs were isolated immediately 
after blood collection using Ficoll gradient centrifugation [18,19]. Briefly, $8 \mathrm{ml}$ of peripheral blood was mixed with an equal volume of PBS at room temperature (RT) and carefully layered on top of a $12.5 \mathrm{ml}$ Ficoll layer in a $50 \mathrm{ml}$ tube. After centrifugation at $720 \mathrm{~g}$ for $20 \mathrm{~min}$ at RT, the PBMC layer was transferred to a new $50 \mathrm{ml}$ tube, washed with $50 \mathrm{ml}$ of ice-cold PBS, and centrifuged at $500 \mathrm{~g}$ for 10 min at $4^{\circ} \mathrm{C}$. Next, the supernatant was discarded, and the pellet was washed with another $50 \mathrm{ml}$ of ice-cold PBS. After centrifugation at $500 \mathrm{~g}$ for $10 \mathrm{~min}$ at $4^{\circ} \mathrm{C}$, the supernatant was discarded. Next, the pellet was suspended in $1 \mathrm{ml}$ of ice-cold PBS and transferred to a $1.5 \mathrm{ml}$ cryo vial. After centrifugation at $500 \mathrm{~g}$ for $5 \mathrm{~min}$ at $4^{\circ} \mathrm{C}$, the supernatant was discarded and the PBMC pellet was snap frozen in liquid nitrogen and subsequently stored at $-80^{\circ} \mathrm{C}$.

PBMC lysates were prepared by resuspending the stored PBMC pellet in $100 \mu \mathrm{l}$ of ice-cold PBS Complete ${ }^{\circledR}$ buffer after defrosting on ice and applying 15 pulses with a Branson 250 tip sonicator (Branson, Danbury, CT, USA) at power input setting level 3 with a 50\% duty cycle. After centrifugation at 11,000g for 20 min at $4^{\circ} \mathrm{C}, 95 \mu \mathrm{l}$ of supernatant was transferred to a clean $1.5 \mathrm{ml}$ vial on ice for immediate determination of protein content and DPD activity.

\section{Protein assay}

Protein concentrations in the PBMC lysates were determined using the Bio-Rad protein assay (Bio-Rad, Hercules, CA, USA). Briefly, $5 \mu$ l of PBMC lysate was diluted with $45 \mu \mathrm{l}$ of MilliQ water (Millipore, Billerica, MA, USA). Five bovine serum albumin standards were prepared in concentrations ranging from 32.5 to $500 \mathrm{mg} /$ $\mathrm{ml}$. In duplicate, $10 \mu \mathrm{l}$ of diluted lysate and the standard curve were transferred to a clear 96-well flat bottom plate. After the addition of $200 \mu$ dye solution, the plate was incubated for $15 \mathrm{~min}$ at RT and subsequently the absorption was measured at $590 \mathrm{~nm}$ using an EL340 microplate reader (Bio-Tek, Winooski, VT, USA).

\section{Determination of and correction for hemoglobin content}

Hemoglobin concentration was determined spectrophotometrically at $413 \mathrm{~nm}$ with a Nanodrop1000 (Thermo Scientific, Ashville, NC, USA) in ten-fold diluted PBMC lysate [16]. Next, the corrected protein concentration in the PBMC lysate was calculated by subtracting the contaminating $\mathrm{Hb}$ concentration from the total protein concentration. DPD activity was expressed relative to the protein 
concentration after correction for $\mathrm{Hb}$.

\section{DPD activity assay}

The assay was a modification of the method described by Van Kuilenburg et al. [13], with modifications. A volume of PBMC lysate, typically corresponding to 60 $100 \mu \mathrm{g}$ of protein, was diluted on ice with PBS complete buffer to a total volume of $80 \mu \mathrm{l}$. Five negative control samples containing $80 \mu \mathrm{l}$ of PBS complete buffer were prepared for each batch analysis. Next, $20 \mu \mathrm{l}$ of ice-cold reaction mix was added to the samples, and after mixing, the samples were incubated for $60 \mathrm{~min}$ at $37^{\circ} \mathrm{C}$ in a shaking water bath. The reactions were terminated by boiling for $3 \mathrm{~min}$ at $100^{\circ} \mathrm{C}$. After centrifugation at $11,000 \mathrm{~g}$ for $5 \mathrm{~min}$ at $4^{\circ} \mathrm{C}, 90 \mu \mathrm{l}$ of clear supernatant was transferred to a reversed phase high pressure liquid chromatography (HPLC) vial.

\section{High performance liquid chromatography analysis}

Separation and quantification of $\left[{ }^{3} \mathrm{H}\right]$-thymine and the reaction product $\left[{ }^{3} \mathrm{H}\right]-\mathrm{DHT}$ was performed using HPLC (Beckman Coulter, CA, USA). A C18 HDO Uptisphere ${ }^{\circledR}$ column (Interchim, Montluçon Cedex, France), particle size $5 \mu \mathrm{m}, 150 \times 4.6 \mathrm{~mm}$ was used at ambient temperature at an eluent flow of $0.8 \mathrm{ml} / \mathrm{min}$, which was mixed 1:1 $(v, v)$ with Ultima-Flow $M$ for on-line tritium radioisotope detection (Packard Instrument Co, CT, USA). The mobile phase consisted of eluent A (50 mM $\mathrm{KH}_{2} \mathrm{PO}_{4} \mathrm{pH} 4.5$, and $1.0 \%(\% \mathrm{v}, \mathrm{v}) \mathrm{MeOH}$ ) and eluent $\mathrm{B}\left(50 \mathrm{mM} \mathrm{KH}_{2} \mathrm{PO}_{4} \mathrm{pH} 4.5\right.$, and $40 \%(\% \mathrm{v}, \mathrm{v}) \mathrm{MeOH})$. The following gradient was used: t0 - t20 min $100 \%$ eluent $A$, t20 - t30 min $100 \%$ eluent $B, t 30-t 35$ min $100 \%$ eluent $A$.

\section{Calculation of DPD activity}

Formulas 1 and 2 were used for calculation of the DPD activity $(\mathrm{nmol} / \mathrm{mg} / \mathrm{h})$ using the $\left[{ }^{3} \mathrm{H}\right]-\mathrm{DHT}$ and $\left[{ }^{3} \mathrm{H}\right]$-thymine peak, respectively:

1. $((\mathrm{A} 1-\mathrm{A} 2) * \mathrm{~A} 3 * \mathrm{nmol} \mathrm{T}) /(\mathrm{A} 4 * \mathrm{~A} 5 * \mathrm{mg} * \mathrm{t})$

2. $((\mathrm{nmolT}-(\mathrm{A} 6 * \mathrm{~A} 3 * \mathrm{nmolT} / \mathrm{A} 4 * \mathrm{~A} 5)) /(\mathrm{mg} * \mathrm{t})$

$\mathrm{A} 1$ = area of the DHT peak in the sample in counts per minute (cpm)

$\mathrm{A} 2$ = average area of the DHT peaks in the 5 negative control samples (cpm)

$\mathrm{A} 3=$ average area of the sum of all peaks in the 5 negative control samples (cpm)

$\mathrm{A} 4=$ average area of all thymine peaks in the 5 negative control samples (cpm) 
A5 = sum of the area of all peaks in the sample (cpm)

A6 = area of the thymine peak in the sample in counts per minute (cpm)

$\mathrm{nmol} \mathrm{T}=$ input level of thymine $(=1.27 \mathrm{nmol})$

$\mathrm{mg}=$ amount of $\mathrm{Hb}$ corrected protein $(\mathrm{mg})$

$t=$ incubation time in hours $(h)$

\section{DPD enzyme kinetics}

The dependency of the DPD reaction on the concentration of the cofactor NADPH was determined in threefold in samples containing $0,0.05,0.1,0.25,0.5,1.25$, and $2.5 \mathrm{mM}$ of $\mathrm{NADPH}, 100 \mu \mathrm{g}$ of PBMC lysate protein, and $12.5 \mu \mathrm{M}$ of thymine in a total volume of $100 \mu \mathrm{l}$.

To determine at which concentration of thymine the method would discriminate best between DPD poor and extensive metabolizers, the MichaelisMenten constant $(\mathrm{Km})$ and maximum DPD enzyme velocity (Vmax) were determined in blood obtained from a genetically-confirmed partial DPD-deficient (DPYD*2A, heterozygous) volunteer, and in PBMCs from a patient who was wild type for all tested mutations. The $\mathrm{Km}$ and Vmax were determined in triplicate in samples containing $0,0.25,2.5,5.0$, and $25 \mu \mathrm{M}$ of thymine, $2.5 \mathrm{mM}$ of NADPH, and $100 \mu \mathrm{g}$ of PBMC lysate protein in a total volume of $100 \mu \mathrm{l}$.

\section{Specificity and limit of detection}

Five negative control samples containing $80 \mu \mathrm{l}$ PBS complete and $20 \mu \mathrm{l}$ RM were assessed during each batch analysis. The limit of detection of the DPD method was defined as the DPD activity $(\mathrm{nmol} / \mathrm{h})$ that resulted in a DHT peak area that was equal to the average DHT background signal from these five negative control samples plus three times the standard deviation (SD). The specificity of the DPD reaction was determined in triplicate from the effect on DPD activity of 200 and $1000 \mathrm{nM}$ of the specific DPD inhibitor gimeracil [20] in samples containing $80 \mu \mathrm{g}$ of PBMC lysate protein obtained from a healthy volunteer. The $50 \%$ inhibitory concentration of gimeracil was earlier estimated to be $95 \mathrm{nM}$ [20].

Linearity and lower limit of quantification (LLOQ)

The linearity and LLOQ were determined in triplicate in samples spiked with 
$5,9.3,19,29,40,48,60,79,100,100,120$, and $140 \mu \mathrm{g}$ of PBMC lysate protein from a healthy volunteer. DPD activities were determined using the peak areas of thymine and DHT with and without using the total sample peak area as internal standard. The DPD activity determined at the highest linear spike level was defined as nominal. The LLOQ and linear range were defined as the protein input level or protein input range, respectively, at which DPD activity could be determined with a precision of $\leq 20 \%$, and an accuracy of $80-120 \%$ of the nominal DPD activity.

Within- and between-day precision

Samples containing 20,60 or $100 \mu \mathrm{g}$ of PBMC lysate protein were measured in triplicate on 7 consecutive days. The between-day (BDP) and within-day precision (WDP) were calculated by one-way analysis of variance (ANOVA) for each spike level using the run day as classification variable using the software package SPSS v15.0 for windows (Chicago, USA). The day mean square (DayMS), error mean square (ErrMS) and the grand mean (GM) of the observed cell concentrations across run days were used. The WDP\% and BDP\% for each spike level was calculated using the formulas:

WDP\% $=(\text { ErrMS })^{0.5} / \mathrm{GM} \times 100 \%$

BDP\% $=\left[(\text { DayMS }- \text { ErrMS) } / \mathrm{n}]^{0.5} / \mathrm{GM} \times 100 \%\right.$

(Where $\mathrm{n}$ is the number of replicates within each run).

\section{Stability}

The stability of DPD activity in PBMCs, isolated from whole blood of a healthy volunteer stored ex vivo at RT for $0,0.5,1,2$ and $3 \mathrm{~h}$, was determined. In addition the stability of DPD activity in PBMC lysates stored for $0,2,3,5,6,24$ and $28 \mathrm{~h}$ on ice was determined. Long term storage stability of DPD activity was assessed in triplicate in a single batch of PBMCs stored as dry cell pellets at $-80^{\circ} \mathrm{C}$ for $0,1,7$, $14,45,120,180$, and 1020 days. For these stability experiments $500 \mu$ laliquots of $2.5 \mathrm{mM} N A D P H$ in water were prepared at day 0 and immediately stored at $-80^{\circ} \mathrm{C}$. NADPH was thawed on ice in the dark, and immediately refrozen after use. After two freeze/thaw cycles the NADPH was discarded. Furthermore, we determined the stability of processed samples in the HPLC autosampler during 0, 24, 48 and 72 h of storage at RT. 


\section{Clinical applicability}

A total of 19 healthy volunteers (nine female, ten male) of Caucasian race provided blood on one occasion between 09:00 and 10:00 a.m. for the determination of the average DPD activity in the control population. Their median age (range) was 28.7 (22.9 - 39.8) years.

We also tested the DPD activity of eight cancer patients ( 4 female / 4 male). All patients experienced severe grade III / IV capecitabine-induced toxicity.

\section{Statistical Analysis}

Statistical evaluation was performed using Student's t-test, unless indicated otherwise. DPD activities in PBMCs from healthy volunteers were tested for normal Gaussian distribution using the Kolmogorov-Smirnov test. DPD deficiency was defined as a DPD deficiency was defined as a DPD activity within the lower quartile (25th percentile) determined by quartile analysis of DPD activities in the control population. Analysis was performed with the Statistical Package for the Social Sciences (SPSS, Chicago, USA)

\section{RESULTS}

\section{Method development}

The original method of Van Kuilenburg was based on $\left[{ }^{14} \mathrm{C}\right]$-thymine as substrate for DPD. Our DPD activity method is based on [ $\left.{ }^{3} \mathrm{H}\right]$-thymine for cost and safety reasons. The cost of an equal amount of $\left[{ }^{3} \mathrm{H}\right]$-thymine is approximately seven times less than the cost of $\left[{ }^{14} \mathrm{C}\right]$-thymine. $\left[{ }^{3} \mathrm{H}\right]$-thymine is also less dangerous as indicated by the annual limit of intake that is forty times higher than for $\left[{ }^{14} \mathrm{C}\right.$ ]-thymine [21].

Furthermore, the original method uses $25 \mu$ of perchloric acid for reaction termination. This, however, lowers the $\mathrm{pH}$-values of the final samples to below the advised working range of most HPLC columns, which strongly reduces column lifespan. Therefore, in our method the DPD reactions are terminated by boiling for 3 min. There proved to be no significant loss of thymine and DHT during this boiling step (data not shown).

The separation of DHT and thymine by HPLC was optimised by testing different 


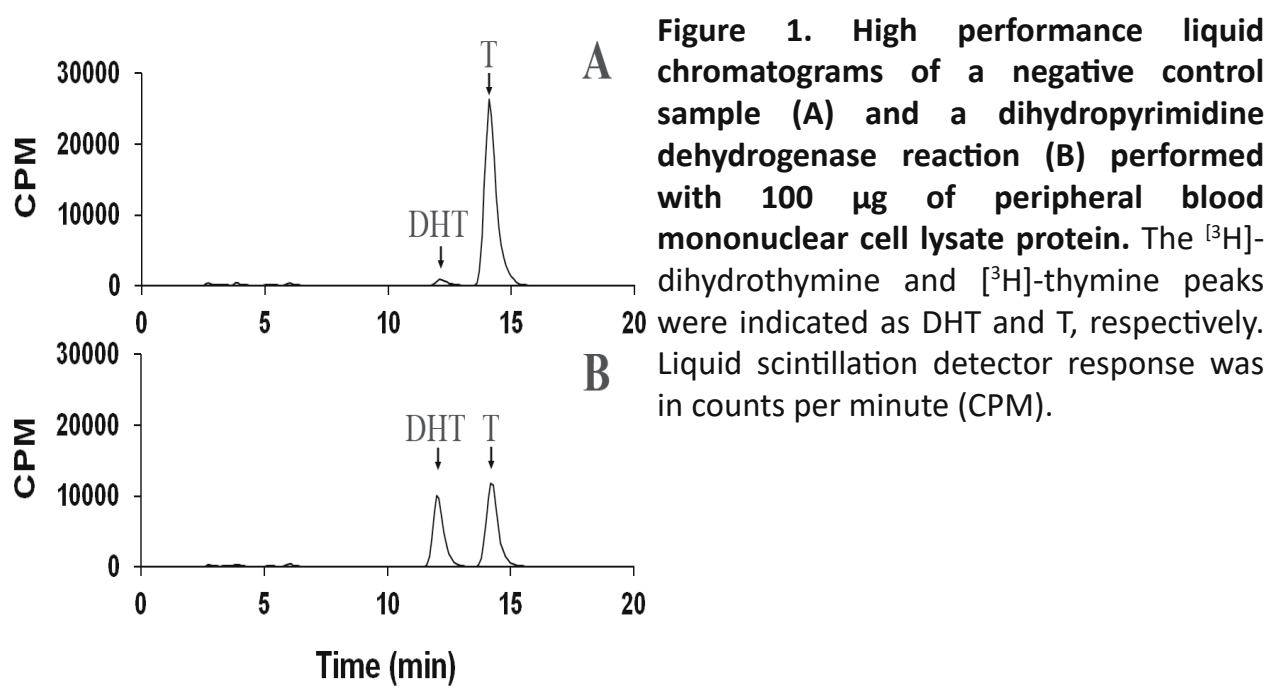

eluents A containing $0,0.5,1.0,1.5$ and $2.0(\% \mathrm{v}, \mathrm{v})$ of methanol. Complete baseline separation of DHT from thymine was only achieved using eluent $A$ containing $1 \%$ of methanol (Fig. 1).

Immediately after purchase the radiochemical impurities of the $\left[{ }^{3} \mathrm{H}\right]$-thymine stock were $5 \%$ and $4 \%$, consisting of unknown compounds eluting between 2 and $7 \mathrm{~min}$, and $\left[{ }^{3} \mathrm{H}\right]-\mathrm{DHT}$ at $12.5 \mathrm{~min}$, respectively (Fig.1.). The radiochemical purity of the $\left[{ }^{3} \mathrm{H}\right]$-thymine stock further deteriorated at $1 \%$ per month resulting in an increase of the area of the peaks between 2 and $7 \mathrm{~min}$, however, [ $\left.{ }^{3} \mathrm{H}\right]$-DHT content remained stable at about $4 \%$.

\section{DPD enzyme kinetics}

The dependence of the DPD reaction on the NADPH concentration is depicted in figure $2 \mathrm{~A}$. The $\mathrm{Km}$ and $\mathrm{Vmax}$ were $4.3 \mu \mathrm{M}$ and $8.24 \mathrm{nmol} / \mathrm{mg} / \mathrm{h}$, respectively, as calculated from the Eadie-Hofstee plot (Fig. 2B). DPD activity did not significantly increase at NADPH concentrations above $125 \mu \mathrm{M}$. 

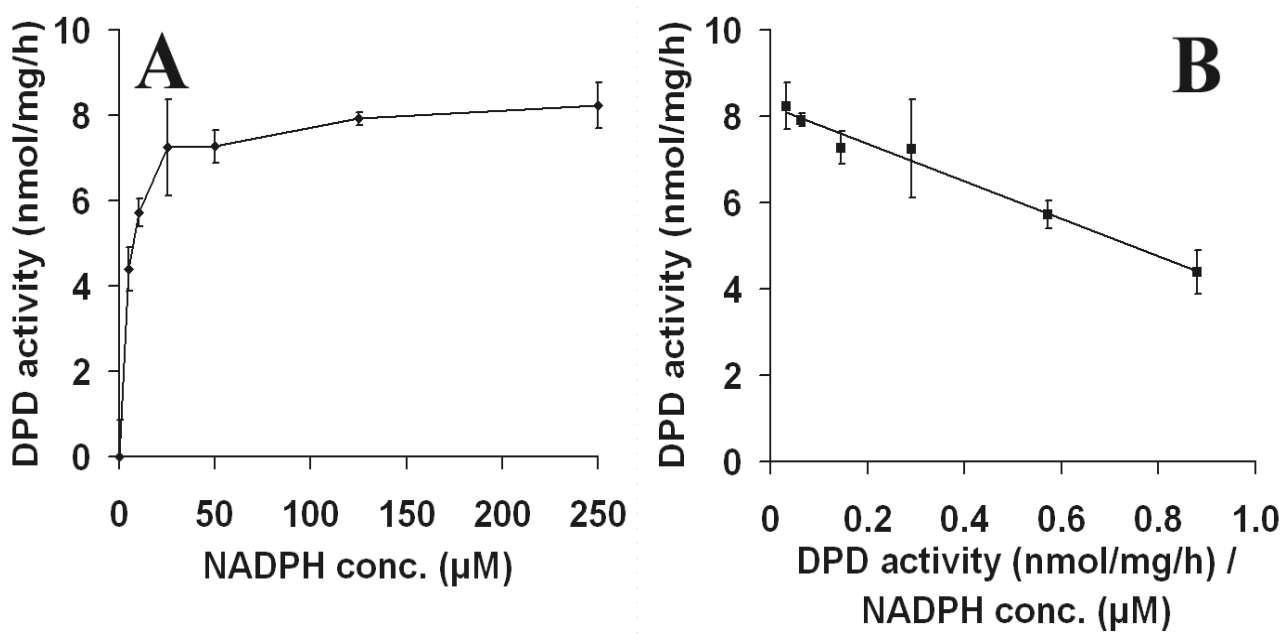

Figure 2. Effect of $\beta$-nicotinamide adenine dinucleotide phosphate (NADPH) concentration on dihydropyrimidine dehydrogenase (DPD) activity in peripheral blood mononuclear cell lysate from a healthy volunteer. Data are shown as Michaelis-Menten (A) and Eadie-Hofstee plots (B). Results are expressed as means \pm S.D. of 3 different samples.
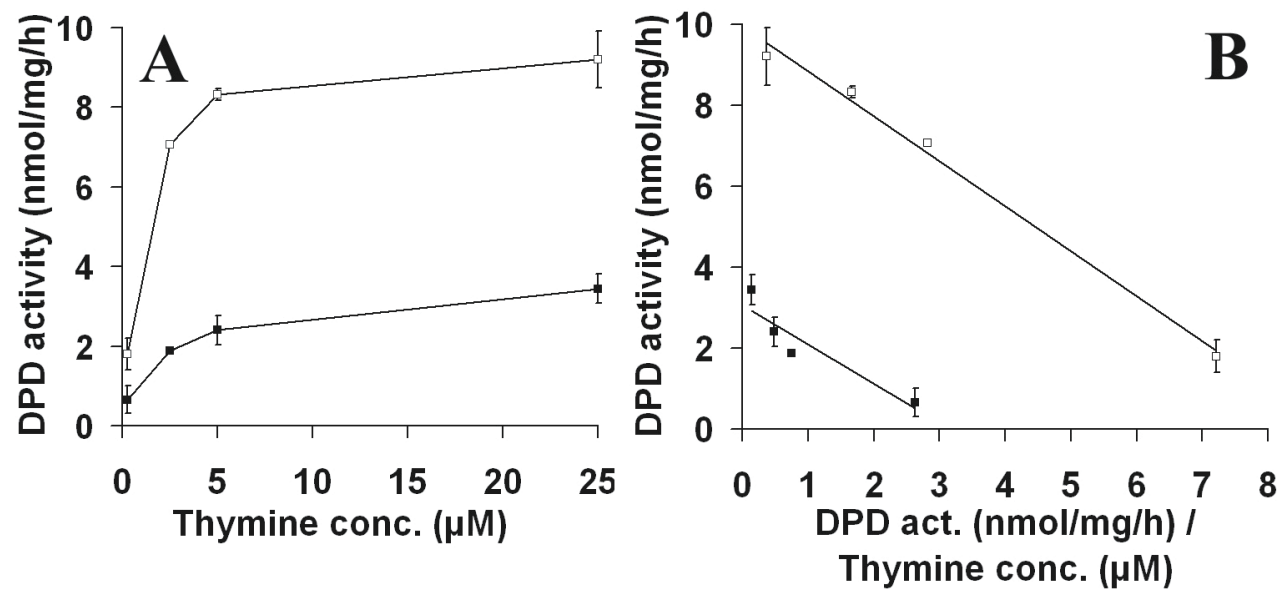

Figure 3. Enzyme kinetics of the dihydropyrimidine dehydrogenase (DPD) activity in peripheral blood mononuclear cell lysate from a genetically-determined partial DPD-deficient (DPYD*2A) volunteer (- - ), and in lysate from a subject who was wild type for $D P Y D^{*} 2 A(-\square-$, extensive metabolizer).

Data are shown as Michaelis Menten (A) and Eadie Hofstee plots (B). Results are expressed as means \pm S.D. of 3 different samples. 
Table 1. Effect of determination of dihydropyrimidine dehydrogenase (DPD) activity using thymine and DHT with or without internal standard correction on the lower limit of quantification (LLOQ), mean DPD activity, precision, and linear range.

\begin{tabular}{ccccc}
\cline { 2 - 5 } & \multicolumn{2}{c}{ Thymine based } & \multicolumn{2}{c}{ DHT based } \\
& - IS & + IS & - IS & + IS \\
\hline $\begin{array}{c}\text { mean DPD act. } \\
(\mathrm{nmol} / \mathrm{mg} / \mathrm{h})\end{array}$ & $7.62 \pm 0.57$ & $8.18 \pm 0.35$ & $8.57 \pm 0.44$ & $8.12 \pm 0.28$ \\
\hline LLOQ $(\mu \mathrm{g})$ & 60 & 40 & 9.3 & 9.3 \\
\hline linear range $(\mu \mathrm{g})$ & $60-120$ & $40-120$ & $9.3-120$ & $9.3-120$ \\
\hline linear thymine & $37.1 \pm 1.2-$ & $23.7 \pm 1.0-$ & $6.6 \pm 1.0-$ & $6.1 \pm 0.8-$ \\
conversion range $(\%)$ & $73.5 \pm 3.0$ & $74.6 \pm 2.7$ & $80.5 \pm 5.1$ & $77.1 \pm 3.8$ \\
\hline
\end{tabular}

${ }^{a}$ mean DPD activity over the linear range

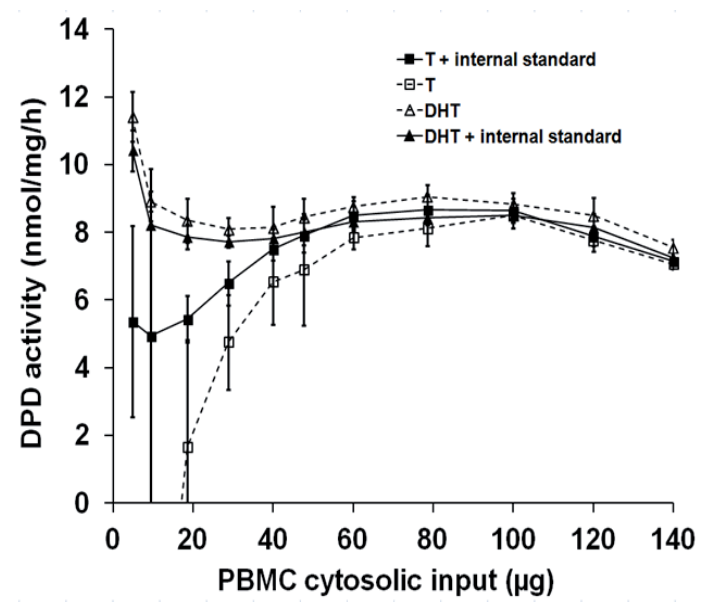

Figure 4. Correlation between the amount of peripheral blood mononuclear cells (PBMC) lysate protein and the dihydropyrimidine dehydrogenase (DPD) activity calculated using the thymine (T) peak and dihydrothymine (DHT) peak. Both calculations were performed with or without using the total peak area as an internal standard for correction of experimental errors. Results are expressed as means \pm S.D. of 3 different samples. 
The substrate dependency of the DPD reaction is depicted in figure $3 \mathrm{~A}$. Vmax for the extensive and poor metabolizer were 9.96 and $3.51 \mathrm{nmol} / \mathrm{mg} / \mathrm{h}$, and $\mathrm{Km}$ was 1.11 and $0.97 \mu \mathrm{M}$, respectively, as determined from the Eadie-Hofstee plot (Fig. 3B). DPD activity did not significantly increase at thymine concentrations above $5 \mu \mathrm{M}$, which indicates saturation of DPD activity. Based on this, we decided to perform all future DPD reactions with $12.5 \mu \mathrm{M}$ of thymine ( 10 times $\mathrm{Km}$ ), which would theoretically results in only $8 \%$ reduction of enzyme activity after $50 \%$ of substrate is consumed [22].

\section{Specificity}

The lower limit of detection of the method determined from five background control samples was $16.25 \mathrm{pmol} \mathrm{DHT}$, which corresponds to $1.3 \%$ of the total thymine input of 1267 pmol per sample. The DPD reaction was inhibited by $67 \%$ and $96 \%$ using 200 and $1000 \mathrm{nM}$ of gimeracil, respectively.

\section{Linearity and lower limit of quantification}

The nominal DPD activity using the DHT peak and internal standard correction was $8.12 \pm 0.28 \mathrm{nmol} / \mathrm{mg} / \mathrm{h}$ (Table 1 ). The linear range was from 9.3 to $120 \mu \mathrm{g}$ PBMC lysate (Fig. 4) corresponding with a thymine conversion of $6.1 \pm 0.3 \%$ to $77.1 \pm$ $3.8 \%$, respectively. At the LLOQ of $9.3 \mu \mathrm{g}$ accuracy and precision were 102.3 and $13.4 \%$, respectively. Internal standard correction had no effect on the linear range, however average precision improved from $5.0 \%$ to $3.1 \%$.

The DPD activity method using the thymine peak and internal standard correction was $8.18 \pm 0.35 \mathrm{nmol} / \mathrm{mg} / \mathrm{h}$ (Table 1 ). The linear range was from 40 to $120 \mu \mathrm{g}$ PBMC lysate (Fig. 4) corresponding with a thymine conversion of 23.7 $\pm 1.2 \%$ to $74.6 \pm 2.7 \%$, respectively. At the LLOQ of $40 \mu \mathrm{g}$ accuracy and precision were $97.4 \%$ and $3.6 \%$, respectively. Internal standard correction extended the lower part of the linear range from 60 to $40 \mu \mathrm{g}$ of PBMC lysate protein and improved the average precision from $9.3 \%$ to $4.3 \%$. Furthermore, internal standard correction reduced the difference in mean DPD activity between both methods from a significant $12 \%(P=0.003)$ to a non significant $0.8 \%$.

\section{Within- and between-day precision}

DPD activity based on DHT with internal standard correction was determined at 
20,40 , and $60 \mu \mathrm{g}$ of PBMC lysate protein input. The average DPD activity was $8.5 \pm$ $0.4 \mathrm{nmol} / \mathrm{mg}^{*} \mathrm{~h}$. BDP was $4.2,3.8$, and $5.1 \%$ and WDP was $4.7,3.6$ and $2.4 \%$ at 20 , 40 , and $60 \mu \mathrm{g}$ of PBMC lysate protein input, respectively.

DPD activity based on thymine with internal standard correction was $8.3 \pm 0.5$ $\mathrm{nmol} / \mathrm{mg}^{*} \mathrm{~h}$. BDP was 6.3, 4.8, and $4.7 \%$ and WDP was 4.0, 2.9 and 5.4\% at 20, 40, and $60 \mu \mathrm{g}$ of PBMC lysate protein input, respectively.

Internal standard correction had no significant effect on BDP, however WDP was significantly improved by on average $46 \%(P=0.004)$ and $34 \%(P=0.01)$ using the DHT and thymine based methods, respectively.

\section{Stability}

The stability of different components of the DPD reaction under various storage conditions was determined (Table 2). Whole blood was stored on ice for $3 \mathrm{~h}$ prior to PBMC isolation and subsequent lysate preparation, which resulted in stable DPD activity levels. In addition, PBMC lysates could be stored on ice for 24 $\mathrm{h}$ without a significant deterioration in DPD activity. Long term storage of PBMC dry cell pellets at $-80^{\circ} \mathrm{C}$ was possible for 1020 days without significant reduction of DPD activity. NADPH was stable when stored as a $2.5 \mathrm{mM}$ solution at $-80^{\circ} \mathrm{C}$ for 1020 days. We noticed, however, a significantly lower DPD activity after 30 days of storage of the NADPH solution at $-20^{\circ} \mathrm{C}(\mathrm{P}=0.018$, data not shown).

\section{Clinical applicability of DPD phenotyping}

The average DPD activity before and after $\mathrm{Hb}$ correction in the healthy volunteers was $8.0 \pm 2.6$ (range $5.0-11.8, \mathrm{n}=19$ ) and $9.6 \pm 2.2 \mathrm{nmol} / \mathrm{mg} / \mathrm{h}$ (range $6.0-14.0$, $\mathrm{n}=19$ ), respectively. No significant difference was found between the average $\mathrm{Hb}$ contamination of $19.4 \%$ (range $2.0-54.3$ ) and $23.3 \%$ (range $2.7-51, n=8$ ) in PBMC lysates from healthy volunteers and patients, respectively. 
Table 2. Stability of dihydropyrimidine dehydrogenase (DPD) activity in samples at different processing stages under various storage conditions. Results for initial and measured DPD activity are the average of three replicate measurements \pm SD.

\begin{tabular}{cccccc}
\hline processing stages & storage & storage & initial DPD & measured & change \\
& temperature & period & activity & DPD activity & (\%) \\
& $\left({ }^{\circ} \mathrm{C}\right)$ & & $(\mathrm{nmol} / \mathrm{mg} / \mathrm{h})$ & $(\mathrm{nmol} / \mathrm{mg} / \mathrm{h})$ & \\
\hline whole blood & RT & $3 \mathrm{~h}$ & $5.17 \pm 0.18$ & $4.78 \pm 0.13$ & -7.6 \\
PBMC cytosolic lysate & 0 & $28 \mathrm{~h}$ & $9.10 \pm 0.70$ & $8.01 \pm 0.35$ & -11.9 \\
PBMC dry pellet & -80 & $1020 \mathrm{~d}$ & $4.99 \pm 0.31$ & $4.91 \pm 0.39$ & 2.5 \\
autosampler & RT & $72 \mathrm{~h}$ & $4.54 \pm 0.10$ & $4.61 \pm 0.16$ & 1.5 \\
& & & & & \\
\hline
\end{tabular}


Table 3. Summary of patients suspected of experiencing capecitabine induced toxicity. Measured dihydropyrimidine dehydrogenase (DPD) activities were compared to DPD activity in healthy volunteers ( $n=19)$.

\begin{tabular}{|c|c|c|c|c|c|}
\hline $\begin{array}{l}\text { Patient \# } \\
\text { (Gender } \\
\text { (f/m) / } \\
\text { Age } \\
\text { (years)) }\end{array}$ & $\begin{array}{l}\text { Treatment } \\
\text { regimen } \\
\text { (conventional } \\
\text { capecitabine } \\
\text { dose) }\end{array}$ & $\begin{array}{c}\text { Grade } 3-4 \\
\text { CAP related } \\
\text { toxicities }\end{array}$ & $\begin{array}{c}\text { DPD activity a } \\
\text { (nmol/mg/h) } \\
+/- \\
\text { (s.d.) }\end{array}$ & $\begin{array}{c}\text { DPD activity }{ }^{b} \\
\text { (nmol/mg/h) } \\
+/- \\
\text { (s.d.) }\end{array}$ & $\begin{array}{c}\text { DPYD } \\
\text { Polymorphism(s) }\end{array}$ \\
\hline 1 (f / 39) & $\begin{array}{c}\text { CAP } \\
\left(1000 \mathrm{mg} / \mathrm{m}^{2}\right. \\
\text { BID })\end{array}$ & Mucositis & $3.80(0.07)^{1}$ & $7.56(0.10)^{1}$ & $\begin{array}{c}1627 \mathrm{~A}>\mathrm{G} \\
\text { (heterozygous) }\end{array}$ \\
\hline $2(f / 71)$ & $\begin{array}{c}\mathrm{EP}+\mathrm{CIS}+\mathrm{CAP} \\
\left(500 \mathrm{mg} / \mathrm{m}^{2} \mathrm{BID}\right)\end{array}$ & Mucositis & $5.68(0.27)^{1}$ & $8.61(0.39)^{2}$ & $\begin{array}{c}1236 \mathrm{G}>\mathrm{A} \\
\text { (heterozygous) }\end{array}$ \\
\hline $3(f / 73)$ & $\begin{array}{c}\text { CAPOX } \\
\left(1000 \mathrm{mg} / \mathrm{m}^{2}\right. \\
\text { BID) }\end{array}$ & Mucositis & $10.06(0.08)^{2}$ & $10.56(0.11)^{2}$ & None detected \\
\hline 4 (f / 61) & $\begin{array}{c}\text { CAPOX } \\
\left(1000 \mathrm{mg} / \mathrm{m}^{2}\right. \\
\text { BID) }\end{array}$ & Mucositis & $5.51(0.12)^{1}$ & $6.05(0.13)^{1}$ & $\begin{array}{c}2194 \mathrm{G}>\mathrm{A} \\
496 \mathrm{~A}>\mathrm{G} \\
\text { (heterozygous) }\end{array}$ \\
\hline $5(\mathrm{~m} / 69)$ & $\begin{array}{c}\text { CAP + RT } \\
\left(825 \mathrm{mg} / \mathrm{m}^{2} \mathrm{BID}\right)\end{array}$ & Diarrhea & $3.37(0.16)^{1}$ & $4.36(0.21)^{1}$ & None detected \\
\hline $6(\mathrm{~m} / 65)$ & $\begin{array}{c}\text { CAP } \\
\left(1000 \mathrm{mg} / \mathrm{m}^{2}\right. \\
\text { BID })\end{array}$ & $\begin{array}{c}\text { Yes } \\
\text { (type } \\
\text { unknown) }\end{array}$ & $3.51(0.05)^{1}$ & $4.23(0.06)^{1}$ & $\begin{array}{c}\text { IVS14+1G>A } \\
\text { (heterozygous) }\end{array}$ \\
\hline 7 (m / 67) & $\begin{array}{c}\text { CAPOX } \\
\left(1000 \mathrm{mg} / \mathrm{m}^{2}\right. \\
\text { BID) }\end{array}$ & Mucositis & $4.75(0.17)^{1}$ & $5.64(0.21)^{1}$ & None detected \\
\hline $8(\mathrm{~m} / 56)$ & $\begin{array}{l}\text { CAP + OX + Doc } \\
\left(850 \mathrm{mg} / \mathrm{m}^{2} \text { BID }\right)\end{array}$ & $\begin{array}{c}\text { Mucositis } \\
\text { Neutropenia }\end{array}$ & $6.94(0.81)^{1}$ & $10.03(1.03)^{3}$ & $\begin{array}{c}2194 \mathrm{G}>\mathrm{A} \\
\text { (heterozygous) }\end{array}$ \\
\hline
\end{tabular}


The findings with respect to DPD activity measurements in cancer patients, their DPYD genotypes, and the experienced toxicity are presented in table 3. DPD deficiency was found in seven out of eight patients (88\%) if no correction for $\mathrm{Hb}$ contamination was applied. However, two out of these seven patients (29\%) with higher than average $\mathrm{Hb}$ contamination levels (31\% and 34\%, respectively), were shown to have normal DPD activity levels after correction for $\mathrm{Hb}$. The lowest DPD activity was found in patient 6 who was heterozygous for the IVS14+1G>A (DPYD*2A) polymorphism. We measured DPD deficiency in two out of three patients that tested negative for any tested genetic DPYD mutation. The other three DPD deficient patients had point mutations at c.1627A>G, c.1236G>A, and c. $496 \mathrm{~A}>\mathrm{G}$.

\section{DISCUSSION}

We developed a simple, accurate and precise method for the determination of DPD activity in PBMCs. The method was substantially simplified by using commercially available $\left[{ }^{3} \mathrm{H}\right]$-thymine without additional HPLC removal of remaining traces of $\left[{ }^{3} \mathrm{H}\right]-\mathrm{DHT}$. The method showed to be highly specific for DPD, since 200 and $1000 \mathrm{nM}$ of the specific DPD inhibitor gimeracil inhibited the DPD reaction by $67 \%$ and $96 \%$, respectively. This level of inhibition of DPD by gimeracil is in line with the $50 \%$ inhibitory concentration of $95 \mathrm{nM}$ [20].

Method accuracy and precision were significantly improved by using the ratio of the average total peak area of five controls and total peak area of samples as internal standard to correct for experimental errors. After applying this internal standard correction DPD activities calculated based on thymine and DHT were the same over the linear ranges of $40-120$, and $9.3-120 \mu \mathrm{g}$ of PBMC lysate, respectively. The DHT based method had the highest sensitivity with a lower limit of quantification of $9.3 \mu \mathrm{g}$ PBMC lysate, which corresponds to an amount of 500.000 PBMCs. The WDP and BDP precisions were both well within the limit of $15 \%$ which is common for analytical assays [23]. Our innovative way of using the cumulative area of all peaks in the chromatogram as internal standard can also be applied for the development and optimization of other HPLC-based radioassays.

We demonstrated the clinical applicability of our improved method in eight cancer patients. Although DPD activity was determined in PBMCs, which is used as a surrogate marker for systemic 5-FU catabolising capacity, the results provide information that could explain the observed capecitabine-induced toxicities such 
as mucositis, diarrhea, and neutropenia in these patients. Earlier studies already demonstrated a highly significant correlation between DPD activity in PBMCs and liver cells [11], illustrating that DPD activity in PBMCs is a valid marker for systemic DPD activity.

All patients treated with fluoropyrimidine anti-cancer agents in the Antoni van Leeuwenhoek Hospital are prospectively screened for DPYD IVS14+ $1 G>A$ (DPYD*2A) prior to start of treatment. Although this strategy proves to significantly reduce the incidence of severe toxicity in mutation carriers and is cost-effective [24], there are many more polymorphisms in DPYD that may result in fluoropyrimidine-induced severe toxicity [6]. By phenotyping DPD activity, the consequences of all possible polymorphisms in DPYD are taken into account.

The results from this case series show the importance of correction of DPD activity for $\mathrm{Hb}$ contamination in PBMC lysates. We and others $[15,16]$ have reported about wide inter-individual variability in red colorization of PBMCs isolated by Ficoll. Recently, we evidenced that the origin of this red color was $\mathrm{Hb}$ instead of intact RBCs [16]. As expected, we found an equal mean amount and range of $\mathrm{Hb}$ contamination in PBMC lysates from volunteers and patients. Importantly, we found that above average $\mathrm{Hb}$ contamination can result in significant underestimation of DPD activity and consequently lead to misidentification of DPD deficient patients. In our case series, two out of seven patients were wrongfully identified as being DPD deficient. The chance of underestimating DPD activity is, of course, higher in samples containing above average $\mathrm{Hb}$ contamination. After $\mathrm{Hb}$ correction five out of eight $(=63 \%)$ patients were identified as DPD deficient. Patient 6 with a DPYD*2A mutation was DPD deficient with the lowest DPD activity, which is in line with literature [25]. Patients 1,4 , and 8 were DPD deficient and had mutations at c.1627A $>$ G, c.2194G $>A$ + c.496A>G, and c.2194G $>A$, respectively. However, the association of these mutations with DPD deficiency is questionable [5]. Interestingly, patient 2 had the c.1236G >A mutation, but no DPD deficiency. Although this mutation has been associated with severe toxicity, little is known about the effect of this mutation on DPD activity $[5,26]$. Three patients screened wild type for all tested mutations. However, two of these patients were found to be DPD deficient, which indicates that other genetic alterations in DPYD might be involved and confirms the added value of DPD phenotyping compared with genetic screening alone. The limitation of these observations is of course the small sample size of the case series. Other factors, such as co-medication, epigenetic factors and polymorphisms within other 
genes were not taken into account. To determine whether upfront phenotyping of DPD activity has any clinical implications, and if this is possibly linked to other polymorhisms in DPYD, a well-powered controlled clinical trial is warranted, a study, which will be performed at the Antoni van Leeuwenhoek hospital.

\section{CONCLUSION}

We developed and validated an improved method for the determination of DPD activity in PBMCs isolated from whole blood. The method is simple, sensitive, precise, and robust. We showed long-term stability of samples, thereby making the method suitable for batch analysis. Importantly, this DPD activity method is more accurate than previously developed methods, due to the application of an internal standard and by correcting for highly variable levels of $\mathrm{Hb}$ contamination that are found in Ficoll isolated PBMCs lysates. We have successfully applied our method in a volunteer study for determining the circadian rhythm of DPD activity, as described earlier [27], in PBMC (for submission). Our method has increases precision and accuracy, enabling better identification of DPD deficient patients in the clinical setting.

\section{FUTURE PERSPECTIVE}

We believe that this improved method for establishing DPD deficiency can help in the identification of DPD deficient patients with increased specificity. Furthermore, false positive identification of DPD deficient patients due to above average hemoglobin contamination of the PBMC lysates can possibly be prevented using our method. This may prevent the treating physician from lowering the dose of fluoropyrimidine anti-cancer agent based on wrongfully identified DPD deficiency, which can negatively affect treatment outcome. 


\section{REFERENCES}

1. Yen JL, McLeod HL. Should DPD analysis be required prior to prescribing fluoropyrimidines? Eur J Cancer 2007;43: 1011-1016.

2. Milano G, Etienne $M C$, Pierrefite $V$, Barberi-Heyob M, Deporte-Fety R, Renee N. Dihydropyrimidine dehydrogenase deficiency and fluorouracil-related toxicity. Br J Cancer 1999;79: 627-630.

3. Johnson MR, Diasio RB. Importance of dihydropyrimidine dehydrogenase (DPD) deficiency in patients exhibiting toxicity following treatment with 5-fluorouracil 8. Adv Enzyme Regul 2001;41:151-157.

4. van Kuilenburg $A B$. Dihydropyrimidine dehydrogenase and the efficacy and toxicity of 5-fluorouracil 8. Eur J Cancer 2004;40: 939-950.

5. Rosmarin D, Palles C, Church D et al. Genetic markers of toxicity from capecitabine and other fluorouracil-based regimens: investigation in the QUASAR2 study, systematic review, and meta-analysis. J Clin Oncol 2014; 32:1031-1039.

6. Ciccolini J, Gross E, Dahan L, Lacarelle B, Mercier C. Routine dihydropyrimidine dehydrogenase testing for anticipating 5-fluorouracil-related severe toxicities: hype or hope? 1. Clin Colorectal Cancer 2010; 9: 224-228.

7. Zhang X, Li L, Fourie J, Davie JR, Guarcello $\mathrm{V}$, Diasio RB. The role of Sp1 and Sp3 in the constitutive DPYD gene expression 1. Biochim Biophys Acta 2006; 1759:247-256.

8. Etienne MC, Lagrange $\mathrm{JL}$, Dassonville $\mathrm{O}$ et al. Population study of dihydropyrimidine dehydrogenase in cancer patients. J Clin
Oncol 1994;12:2248-2253 (1994).

9. Mercier C, Ciccolini J. Profiling dihydropyrimidine dehydrogenase deficiency in patients with cancer undergoing 5-fluorouracil/capecitabine therapy. Clin Colorectal Cancer 2006;6: 288296.

10. Ciccolini J, Mercier C, Evrard A et al. A rapid and inexpensive method for anticipating severe toxicity to fluorouracil and fluorouracil-based chemotherapy 1 . Ther Drug Monit 2006;28:678-685.

11. Ostapowicz A, Dolegowska B. [Review of methods for determination of dihydropyrimidine dehydrogenase and possible application in screening previous chemotheraphy with 5-fluorouracil]. Przeglad lekarski 2012; 69:694-697.

12. van Staveren $M C$, Guchelaar $H J$, van Kuilenburg AB, Gelderblom H, Maring JG. Evaluation of predictive tests for screening for dihydropyrimidine dehydrogenase deficiency. The pharmacogenomics journal 2013; 13:389-395.

13. van Kuilenburg $A B$, van Lenthe $H$, Zoetekouw L, Kulik W. HPLC-electrospray tandem mass spectrometry for rapid determination of dihydropyrimidine dehydrogenase activity. Clin Chem 2007; 53:528-530.

14. Van Kuilenburg $A B$, Van Lenthe $H$, Van Gennip AH. Identification and tissue-specific expression of a NADHdependent activity of dihydropyrimidine dehydrogenase in man. Anticancer research 1996;16:389-394.

15. van Kuilenburg $A B$, van Lenthe $H$, Tromp A, Veltman PC, van Gennip AH. 
Pitfalls in the diagnosis of patients with a partial dihydropyrimidine dehydrogenase deficiency. Clin Chem 2000;46: 9-17.

16. Jansen RS, Rosing $H$, Schellens JH, Beijnen JH. Protein versus DNA as a marker for peripheral blood mononuclear cell counting 3. Anal Bioanal Chem 2009; 395: 863-867.

17. Pluim D, Jacobs BA, Krahenbuhl MD, Ruijter AE, Beijnen JH, Schellens $\mathrm{JH}$. Correction of peripheral blood mononuclear cell cytosolic protein for hemoglobin contamination 1. Anal Bioanal Chem 2013;405:2391-2395.

18. Boyum A. Isolation of mononuclear cells and granulocytes from human blood. Isolation of monuclear cells by one centrifugation, and of granulocytes by combining centrifugation and sedimentation at $1 \mathrm{~g} 4$. Scand J Clin Lab Invest Suppl 1968;97:77-89.

19. Boyum A. Isolation of leucocytes from human blood. A two-phase system for removal of red cells with methylcellulose as erythrocyte-aggregating agent 2 . Scand J Clin Lab Invest Suppl 1968;97:9-29.

20. Matt $P$, Zwieten-Boot B, Calvo Rojas G et al. The European Medicines Agency review of Tegafur/Gimeracil/Oteracil (Teysuno) for the treatment of advanced gastric cancer when given in combination with cisplatin: summary of the Scientific Assessment of the Committee for medicinal products for human use (CHMP) 4. Oncologist, 16(10), 1451-1457 (2011).

21. Deenen MJ, Tol J, Burylo AM et al. Relationship between single nucleotide polymorphisms and haplotypes in DPYD and toxicity and efficacy of capecitabine in advanced colorectal cancer. Clin Cancer Res 2011;17:3455-3468.

22. ICRP Publication 61: Annual Limits on Intake of Radionuclides by Workers Based on the 1990 Recommendations. Protection 1991.

23. Scopes RK. Enzyme Activity and Assays. (Ed.^(Eds) (John Wiley \& Sons Ltd, 2002)

24. Chandran S, Singh RS. Comparison of various international guidelines for analytical method validation. Die Pharmazie 2007;62:4-14.

25. Deenen MJ, Cats $A$, Sechterberger $M K$ et al. Safety, pharmacokinetics (PK), and cost-effectiveness of upfront genotyping of DPYD in fluoropyrimidine therapy. J Clin Oncol 2011;29.

26. Offer SM, Fossum CC, Wegner NJ, Stuflesser AJ, Butterfield GL, Diasio RB. Comparative functional analysis of DPYD variants of potential clinical relevance to dihydropyrimidine dehydrogenase activity. Cancer Res 2014;74:2545-2554.

27. van Kuilenburg $A B$, Meijer J, Mul $A N$ et al. Intragenic deletions and a deep intronic mutation affecting pre-mRNA splicing in the dihydropyrimidine dehydrogenase gene as novel mechanisms causing 5-fluorouracil toxicity. Human genetics 2010;128:529-538.

28. Tod PA, Du-Quiton J, You S, Hrushesky WJ. Circadian clock coordinates cancer cell cycle progression, thymidylate synthase, and 5-fluorouracil therapeutic index 5. Mol Cancer Ther 2006; 5:2023-2033. 


\section{CHAPTER 1}

Development and validation of pharmacodynamic and diagnostic cancer biomarker methods

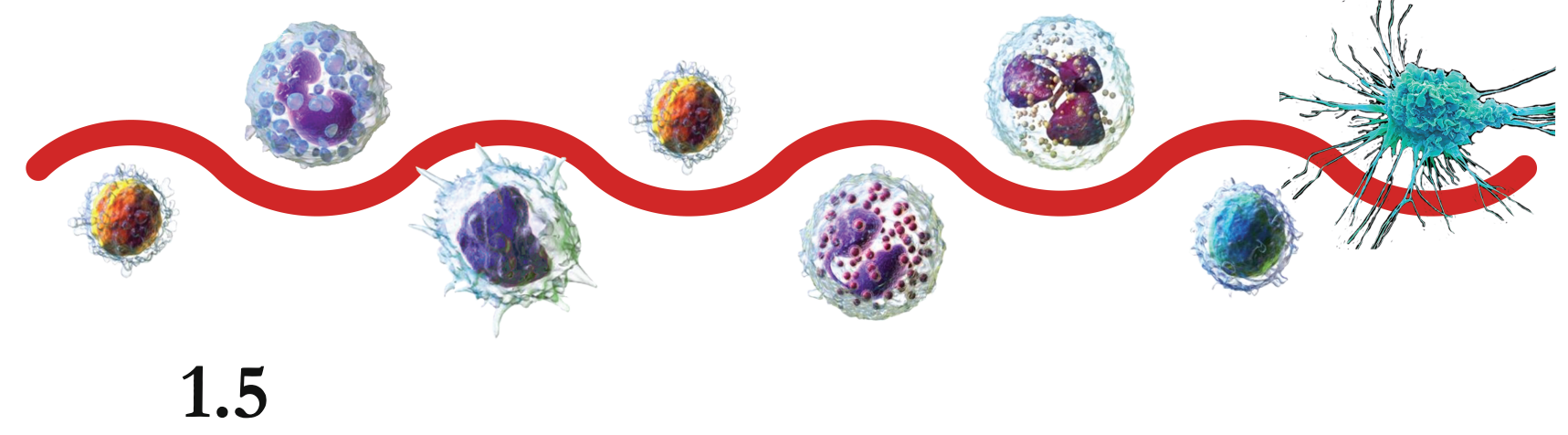

Development and validation of a quantitative method for thymidine phosphorylase activity in peripheral blood mononuclear cells

Bart A.W. Jacobs, Dick Pluim, Pia van der Laan, Anna Tzani, Jos H. Beijnen, Jan H.M. Schellens

Nucleosides Nucleotides Nucleic Acids 2018;37:436-454 


\section{ABSTRACT}

The enzyme thymidine phosphorylase (TP) is important for activation of capecitabine and 5-fluorouracil. Assessment of TP phenotype might be suitable for identification of patients at risk of fluoropyrimidine-induced toxicity. In this paper, we describe the development and validation an assay for TP activity in peripheral blood mononuclear cells (PBMCs). The assay was based on ex vivo conversion of the TP substrate thymidine to thymine. The amount of thymine formed was determined by high-performance liquid chromatography - ultraviolet detection (HPLC-UV) with 5-bromouracil as internal standard. Lymphocytes and monocytes were purified from isolated PBMCs to examine cell-specific TP activity. TP activity in PBMCs demonstrated Michaelis-Menten kinetics. The lower limit of quantification was $2.3 \mu \mathrm{g}$ PBMC protein and assay linearity was demonstrated up to $22.7 \mu \mathrm{g}$ PBMC protein. Within-day and between-day precisions were $\leq 9.2 \%$ and $\leq 6.0 \%$, respectively. Adequate stability TP activity was demonstrated after longterm storage of PBMC dry pellets and lysates at $-80{ }^{\circ} \mathrm{C}$. In monocytes, TP activity was approximately 3 times higher than in lymphocytes. Clinical applicability was demonstrated in samples that were collected from five cancer patients. A simple, precise and sensitive HPLC-UV assay for quantification of TP activity in PBMCs was developed that can be applied for clinical research. 


\section{INTRODUCTION}

Capecitabine is an orally available pre-prodrug of 5-fluorouracil (5-FU) that is used for treatment of colorectal, gastric and breast cancer. After administration, capecitabine is rapidly absorbed and enzymatically converted to subsequently 5'-deoxy-5-fluorocytidine (dFCR) and 5'-deoxy-5-fluoro-uridine (dFUR) [1-5]. Conversion of dFUR to $5-\mathrm{FU}$ is catalyzed by thymidine phosphorylase (TP) and uridine phosphorylase (UP) [6, 7]. Because of relatively high TP and UP expression, formation of 5-FU preferentially occurs within tumor and liver tissue $[4,8,9]$. Approximately $80 \%$ of $5-\mathrm{FU}$ is catabolized to inactive metabolites by the enzyme dihydropyrimidine dehydrogenase (DPD) and about $1-3 \%$ of $5-\mathrm{FU}$ is intracellularly anabolized to active metabolites. The metabolite 5-fluoro-2'-deoxyuridine$5^{\prime}$-monophosphate (FdUMP) possesses the highest anticancer potency. This metabolite inhibits the enzyme thymidylate synthase (TS), which leads to disrupted DNA synthesis and cell death [10]. Formation of FdUMP also depends on TP, since TP catalyzes intracellular conversion of 5-FU to 5-fluoro-2-deoxyuridine (FdUrd), which, in turn, is converted to FdUMP by thymidine kinase. The activation pathway of capecitabine is illustrated in more detail in Figure 1.

About $10-30 \%$ of the patients treated with capecitabine develop severe, sometimes even lethal, toxicity [11]. Recent studies by us and others showed that some single nucleotide polymorphisms (SNPs) in the gene encoding DPD (DPYD) are associated with capecitabine-induced toxicity $[12,13]$. Genotyping for relevant SNPs in DPYD alone, however, has limited sensitivity for identification of patients at risk of severe toxicity [13].

Recently, a single nucleotide mutation (1412C $>T$, rs11479) in the gene for TP (TYMP) was found to be associated with relatively high expression of TP and capecitabine-induced diarrhea and hand-foot syndrome in patients [14, 15]. In vitro studies have demonstrated that the cytotoxic effects of the TP substrate dFUR are increased after upregulation of TP [16]. Furthermore, upregulation of TP has been found in tumor tissue of patients after treatment with docetaxel, adriamycin and epirubicin [17-19]. Studies of xenograft models and in vitro experiments also demonstrated TP induction after exposure to vorinostat, vinorelbine, lidamycin and X-ray irradiation [20-23]. Based on these findings, it seems likely that the availability of a marker for the TP phenotype could attribute to the identification of patients at risk of capecitabine-induced toxicity. Since TP activity seems to be affected by other treatments, the ideal TP phenotype marker should allow for longitudinal assessments of TP activity. 


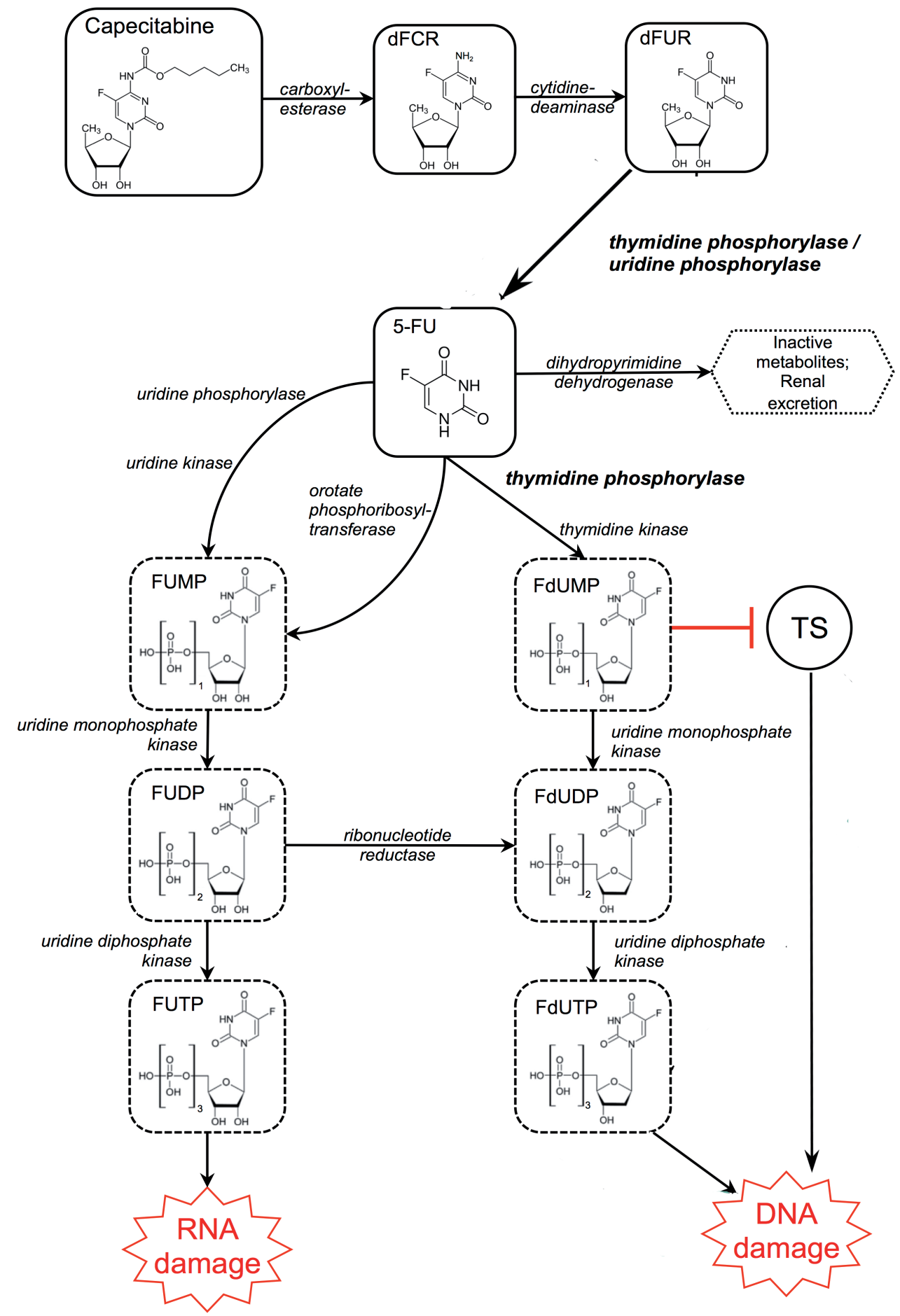


Figure 1. Activation pathway of capecitabine. The role of thymidine phosphorylase is highlighted in bold.

Abbreviations: dFCR, 5'-deoxy-5-fluorocytidine; dFUR, 5'-deoxy-5-fluorouridine; 5-FU, 5-fluorouracil, FdUMP, 5-fluoro-2'-deoxyuridine-5'-monophosphate; TS, thymidylate synthase; FUMP, 5-fluorouridine-5'-monophosphate; FUDP, 5-fluorouridine-5'diphosphate; FUTP, 5-fluorouridine-5'-triphosphate; FdUDP, 5-fluoro-2'-deoxyuridine-5'diphosphate; FdUTP, 5-fluoro-2'-deoxy-5'-triphosphate

Peripheral blood mononuclear cells (PBMCs) are extensively used as a source of surrogate tissue for quantification of a phenotype marker $[6,7]$. Collection of PBMCs is minimally invasive and can be repeated at several time points in order to assess treatment effects. A method for phenotyping TP activity in total leukocytes has previously been described [24]. This method is based on quantification of the amount of thymine formed after ex vivo incubation with the TP substrate thymidine. Importantly, TP activity significantly differed among leukocyte subpopulations [25]. The PBMC population mainly consists of lymphocytes and a small percentage of monocytes. Therefore, the PBMC population is more homogenous than the total leukocyte population and is possibly less distorted by alterations in relative sample composition.

The primary objective was to develop and validate a simple assay for quantification of TP activity in PBMCs (TPApbmc). In addition, we explored the TP activity in the purified lymphocytes and monocytes.

\section{MATERIALS AND METHODS}

\subsection{Chemicals}

Thymidine, thymine, 5-bromouracil (5-BU), dithiothreitol (DTT), potassium dihydrogenphosphate $\left(\mathrm{KH}_{2} \mathrm{PO}_{4}\right)$, dipotassium hydrogenphosphate $\left(\mathrm{K}_{2} \mathrm{HPO}_{4}\right)$, high-performance liquid chromatography (HPLC)-grade methanol, bovine serum albumin (BSA) and Hoechst33258 were purchased from Sigma (St. Louis, MO, USA). The water used for the experiments was Milli-Q grade (Millipore, Billerica, MA, USA). Ficoll-paquetm PLUS was obtained from General Electric Healthcare (Little Chalfont, UK). Phosphate buffered saline (PBS) was purchased from Gibco BRL (Gaithersburg, MD, USA). Perm/Washtm was obtained from Becton Dickinson (Heidelberg, Germany) and formaldehyde was purchased from Merck (Darmstadt, 
Germany). Magnetic antibody cell sorting (MACS) columns, anti-CD14 microbeads, anti-CD45 fluorescein isothiocyanate (FITC), anti-CD14 allophycocyanin (APC) were obtained from Miltenyi (Bergisch Gladbach, Germany).

\subsection{Isolation of PBMCs}

Heparinized blood $(8 \mathrm{~mL})$ was mixed with an equal volume PBS. Isolation of PBMCs was achieved using Ficoll density gradient centrifugation at $720 \mathrm{~g}$ for 20 $\mathrm{min}$ at room temperature. The leukocyte layer containing PBMCs was transferred to a clean $50 \mathrm{~mL}$ tube, washed with PBS and centrifuged at $1000 \mathrm{~g}$ for $10 \mathrm{~min}$ at $4{ }^{\circ} \mathrm{C}$. Then, PBMCs were washed twice with PBS, centrifuged at 500g for $10 \mathrm{~min}$ at $4{ }^{\circ} \mathrm{C}$ and transferred to a $1.5 \mathrm{~mL}$ cryovial. After centrifugation, supernatant was removed and the PBMCs were snap-frozen in liquid nitrogen and stored at $-80{ }^{\circ} \mathrm{C}$ until further processing.

\subsection{Sample preparation for TP activity measurement}

After defrosting, PBMCs were resuspended in $300 \mu \mathrm{L}$ assay buffer $(35 \mathrm{mM}$ potassium phosphate, $1 \mathrm{mM}$ DTT; pH 7.4) and divided into three $100 \mu \mathrm{L}$ aliquots that were independently processed. Samples were sonicated for 15 pulses using a Branson 250 tip sonicator (Branson, Danbury, USA) that was set on program 3 and $50 \%$ duty. PBMC cytosolic lysate was isolated after centrifugation at 11,000g for 20 min at $4{ }^{\circ} \mathrm{C}$. Protein concentration was determined using the Bradford assay (BioRad protein assay kit, Bio-Rad, Hercules, CA, USA) [26]. The amount of hemoglobin contamination in PBMC cytosolic lysate was quantified using a validated spectrophometrical method and subtracted from the total PBMC cytosolic protein [27].

\subsection{TP enzyme activity assay}

The assay was based on a method for TP activity of the total leukocyte population, with modifications [24]. TPApbmc was expressed by the amount of thymine formed after incubation of the TP substrate thymidine. Incubation started when PBMC cytosolic lysate was added to $2 \mathrm{mM}$ thymidine in assay buffer in a total reaction volume of $500 \mu \mathrm{L}$. Three negative control samples consisting of 2 $\mathrm{mM}$ thymidine in assay buffer were freshly prepared for each run. Samples were incubated for 1 hour at $37^{\circ} \mathrm{C}$. Directly after incubation, $50 \mu \mathrm{L}$ of the ice-cold 
internal standard solution (100 $\mathrm{gg} / \mathrm{mL} 5-\mathrm{BU}$ in Milli-Q water) was added and the reaction was terminated by placing the samples on a heat block for $4 \mathrm{~min}$ at $100{ }^{\circ} \mathrm{C}$. After centrifugation at $11,000 \mathrm{~g}$ for 5 minutes at $4^{\circ} \mathrm{C}$, clear supernatant was transferred to a glass vials and a volume of $60 \mu \mathrm{L}$ was injected into the HPLC system coupled with ultraviolet detection (HPLC-UV).

\subsection{HPLC-UV analysis}

Thymine and 5-BU concentrations were quantified using an UltiMate 3000 HPLC-UV system (Dionex, Sunnyville, CA, USA). Chromatographic separation was achieved on an Interchrom C18 column (150 x $4.6 \mathrm{~mm}$ ID, particle size $5 \mu \mathrm{m}$; Interchim, Montluçon Cedex, France). The autosampler and the column were at room temperature. Eluent $A$ consisted of $50 \mathrm{mM} \mathrm{KH}_{2} \mathrm{PO}_{4}(\mathrm{pH} 4.5)$ and $1.0 \%(\mathrm{v} / \mathrm{v})$ methanol in water and eluent $B$ consisted of $50 \mathrm{mM} \mathrm{KH}_{2} \mathrm{PO}_{4}(\mathrm{pH} \mathrm{4.5)}$ and $40 \%(\mathrm{v} / \mathrm{v})$ methanol in water. The following gradient was used: $20 \%$ B from 0-8 min, $20-100 \%$ B from 8-9 min, 100\% B from 9-14 min, 20\% B from 14-20 min. The flow rate was $0.8 \mathrm{~mL} / \mathrm{min}$. Thymine and 5-BU were quantified at $265 \mathrm{~nm}$. An external calibration curve was prepared in duplicate with thymine concentrations ranging from 0.76 to $500 \mu \mathrm{M}$. The amount of thymine in the negative control samples was subtracted from the amount of thymine in study samples. Chromeleon software (Dionex, Sunnyville, CA, USA; version 6.8) was used to control the HPLC-UV system and for data processing.

\subsection{Method validation}

\subsubsection{TP enzyme kinetics}

The influence of thymidine concentration on TPApbmc was investigated by running the assay with $0.98,1.95,3.9,7.8,15.6,31.2,62.5,125,250,500$ and $1000 \mu \mathrm{M}$ thymidine. For all reactions, the amount of PBMC cytosolic protein was $10 \mu \mathrm{g}$. Non-linear regression, using the Michealis-Menten equation, was performed to determine the Vmax and $\mathrm{Km}$. A linearized model of MichealisMenten, the Eadie-Hofstee model, was used for data visualization.

Assay linearity and the lower limit of quantification (LLOQ) were determined by running the assay with $0.9,2.3,4.5,9.1,18.2$ and $22.7 \mu \mathrm{g}$ of PBMC cytosolic protein. Linear regression of TPApbmc versus protein input was performed. TPApbmc values were back-calculated from the regression line and deviations from the measured TP activities were determined. Back-calculated TPApbmc 
should not deviate from the observed TPApbmc by more than $\pm 20 \%$ at the LLoQ level and $\pm 15 \%$ for higher protein input levels. Assay precision of $\leq 20 \%$ at the LLoQ level and $\leq 15 \%$ at the higher cytosolic protein input levels was considered acceptable. The limit of detection (LoD) of the TP method was defined as the average thymine background $(\mu \mathrm{M})$ signal from three negative control samples plus three times the standard deviation.

Time dependency of the TP reaction was assessed in samples that were incubated for $15,30,60,90,120$ and 210 minutes at $37{ }^{\circ} \mathrm{C}$ using $12.5 \mu \mathrm{g}$ PBMC cytosolic protein. The effect of temperature on TPApbmc was assessed by running the assay at $0,25,37,50,60$ and $70{ }^{\circ} \mathrm{C}$ with $10 \mu \mathrm{g}$ of PBMC cytosolic protein. Samples were equilibrated for 15 minutes at the different temperatures before thymidine was added. Kinetics of TP was assessed using pooled PBMCs from three healthy volunteers.

\subsubsection{Within-day and between-day precision}

Within-day precision (WDP) and between-day precision (BDP) were determined from quantification of TPApbmc in 5 consecutive analytical runs. PBMCs of one healthy volunteer were aliquoted in 5 cryovials and stored at $-80{ }^{\circ} \mathrm{C}$. On each day, one sample was thawed, prepared and analyzed in triplicate using 5 and 15 $\mu \mathrm{g}$ of PBMC cytosolic protein for the enzymatic reaction. One-way analysis of variance (ANOVA) with run day as classification variable was performed in order to calculate WDP and BDP [26]. Assay precision was considered acceptable in case WDP and BDP were $<15 \%$.

\subsubsection{Specificity}

Specificity was determined using three batches of blank PBMCs. Samples with $20 \mu \mathrm{g}$ of PBMC cytosolic protein were subsequently spiked with 2.5, 12.5 and $50 \mu \mathrm{M}$ of thymine. Deviations from the nominal thymine concentrations were determined.

\subsubsection{Stability}

The stability of TPApbmc was examined after storage of whole blood for 4 and 24 hours at room temperature and for 4 hours on ice-water. Long-term stability of TPApbmc was assessed after storage of PBMC dry pellets and PBMC cytosolic 
protein lysates for 60 days at $-80{ }^{\circ} \mathrm{C}$. The stability of processed samples in the HPLC autosampler was assessed after 24 hours of storage at room temperature. Assay buffer and thymidine $(50 \mathrm{mM})$ stock solution were stored for 2 months at $-20{ }^{\circ} \mathrm{C}$, before the effect on TPApbmc was determined. Stability of TPApbmc was considered acceptable if $85-115 \%$ of the initial activity was obtained.

\subsection{Clinical applicability}

Clinical applicability of the developed assay was assessed by quantification of TPApbmc in patient samples. The samples were collected from cancer patients who participated in a phase I clinical study of chronomodulated capecitabine therapy (http://www.trialregister.nl, study identifier: NTR4639). From each patient, $4 \mathrm{~mL}$ of blood was drawn within 3 days prior to treatment with capecitabine (screening sample), at the 7th day of capecitabine treatment and at the end of treatment. Samples were collected at 9:00 $\mathrm{h}$ to avoid possible interference of circadian variability in enzyme kinetics. Immediately after blood collection, PBMCs were isolated and stored as dry pellets at $-80{ }^{\circ} \mathrm{C}$ until further processing. The study was approved by the Ethics Committee of the Antoni van Leeuwenhoek Hospital, Amsterdam, The Netherlands.

\subsection{TP activity PBMC subpopulations}

\subsubsection{Isolation of monocytes and lymphocytes}

TP activities in the monocyte and lymphocyte subpopulations were explored in samples that were obtained from six healthy volunteers. PBMCs were isolated from $24 \mathrm{~mL}$ of heparinized blood using Ficoll density gradient. After washing the PBMCs three times with PBS, the cells were resuspended in $1 \mathrm{~mL}$ of beads buffer (BB) that consisted of $0.5 \%$ BSA and 2 mM EDTA in PBS. A total of $15 \times 10^{6}$ PBMCs were used for separation and isolation of the monocyte and lymphocyte subpopulations. The remaining PBMCs were used for assessment of TP activity in the total PBMC population. A volume of $8 \mu \mathrm{L}$ of anti-CD14 microbeads, which was used for positive selection of monocytes, was added to the $15 \times 10^{6}$ PBMCs in a total volume of $200 \mu \mathrm{L}$ and incubated for 30 minutes at room temperature. After incubation, PBMCs were washed three times with $1 \mathrm{~mL} B B$ in order to remove unbound anti-CD14 microbeads. The PBMCs were resuspended in $500 \mu \mathrm{L} \mathrm{BB}$ and the cell suspension was loaded on a MACS column for magnetic enrichment. The lymphocytes, which are CD14-negative, were collected by rinsing the MACS 
column three times with $500 \mu \mathrm{L} \mathrm{BB}$. After removal from the magnetic field, the column was flushed twice with $1 \mathrm{~mL}$ of $B B$ in order to elute the monocytes. The samples were centrifuged at $1000 \mathrm{~g}$ for $4 \mathrm{~min}$ at $4{ }^{\circ} \mathrm{C}$. After centrifugation, the supernatant was removed, leaving $100 \mu \mathrm{L}$ buffer on the pellets. Sample purity was assessed by analyzing $5 \mu \mathrm{L}$ of each sample by flow cytometry. The isolated monocytes, lymphocytes and the sample containing the total PBMC population were washed twice with PBS and once with TP assay buffer, before the TP activity was assessed. Differences in TP activity among monocytes, lymphocytes and total PBMC populations were assessed by one-way analysis of variance and Tukey's post-hoc tests.

\subsubsection{Flow cytometry analysis}

Fluorescence-activated cell sorting (FACS) analysis was performed to assess the amount of monocytes and lymphocytes in the processed samples. From each sample, a $5 \mu \mathrm{L}$ aliquot was fixed in $1 \mathrm{~mL}$ of $2 \%$ formaldehyde in BB (v/v) for 15 minutes at room temperature. The samples were centrifuged for 4 minutes at $1000 \mathrm{~g}$ at $4^{\circ} \mathrm{C}$ and washed twice with $1 \mathrm{~mL} \mathrm{BB}$. After discarding the supernatant, 1 $\mathrm{mL}$ of Perm/Washtm was added and the samples were inverted 10 times, followed by centrifugation at $1000 \mathrm{~g}$ for 4 minutes at $4{ }^{\circ} \mathrm{C}$. Supernatants were carefully removed, leaving $100 \mu \mathrm{L}$ on the cell pellets. The cells were stained with $3 \mu \mathrm{L}$ antiCD45-FITC, $1.5 \mu \mathrm{L}$ anti-CD14-APC and Hoechst33258. After incubation for 1 hour at room temperature, the cells were washed twice with $1 \mathrm{~mL}$ Perm/Wash ${ }^{\mathrm{tm}}$. Samples were centrifuged at $1000 \mathrm{~g}$ for 4 minutes at $4{ }^{\circ} \mathrm{C}$ and supernatants were removed, leaving $100 \mu \mathrm{L}$ on the cell pellets. A volume of $300 \mu \mathrm{L}$ BB was added. Flow cytometry was performed with a CyAn ADP Analyzer (Beckman Coulter, Brea, CA, USA). Summit software (Dakota Cytomation, Fort Collins, CO, USA; version 4.3) was used for data analysis.

\subsection{Statistics}

Statistical analyses were performed using Prism 6 (GraphPad, La Jolla, CA, USA). P-values $\leq 0.05$ were considered statistically significant. 


\section{RESULTS}

\subsection{Method development}

Quantification of TPApbmc was achieved by determining the amount of thymine formed after incubation of thymidine in the presence of PBMC cytosolic protein

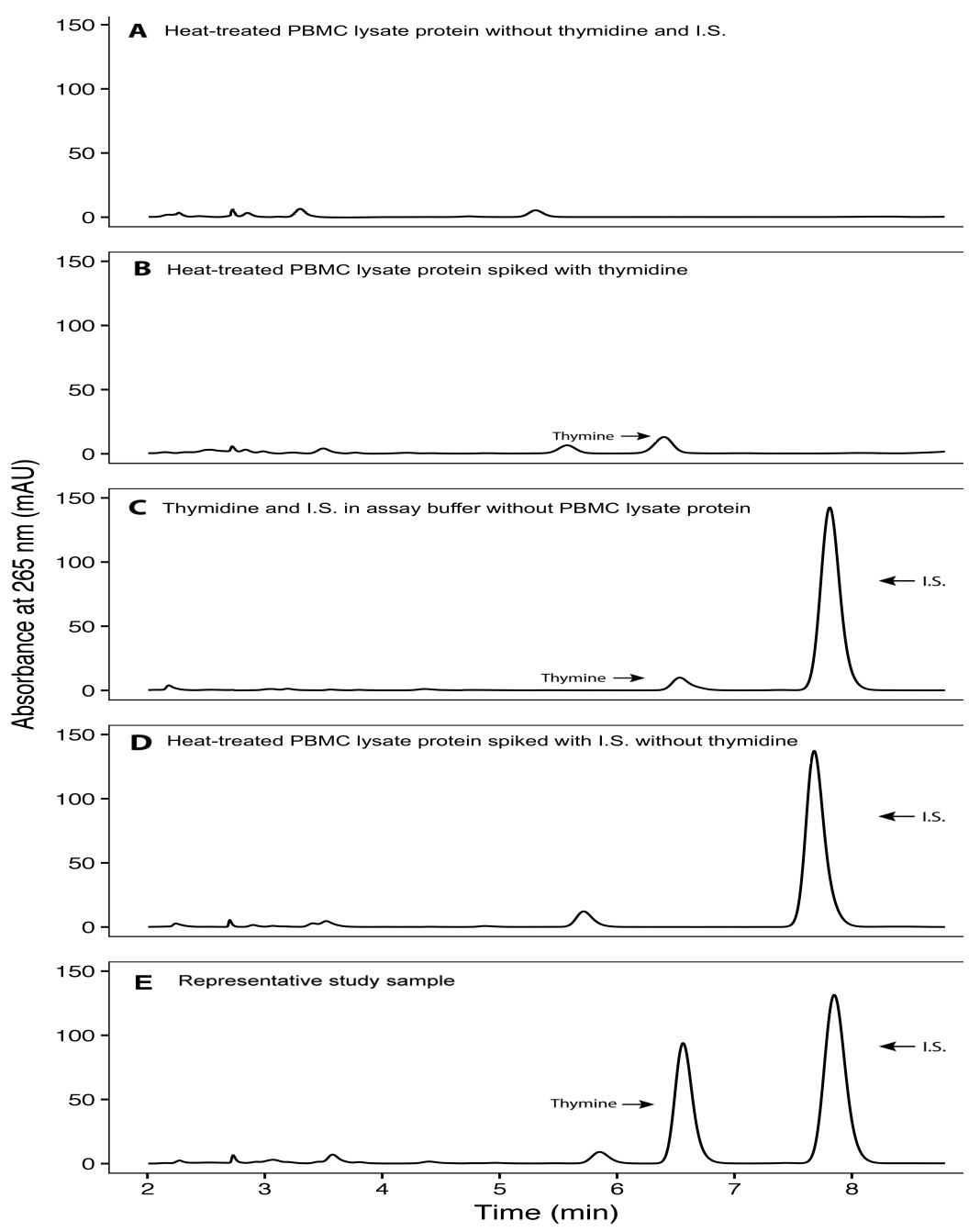

Figure 2. Representative chromatograms of thymine and the internal standard 5-bromouracil in A) a negative control sample of $20 \mu \mathrm{g}$ PBMC cytosolic protein in assay buffer B) a negative control sample of $20 \mu \mathrm{g}$ of PBMC protein spiked with thymidine C) a negative control sample of $2 \mathrm{mM}$ thymidine and internal standard in assay buffer D) a control sample of $20 \mu \mathrm{g}$ PBMC cytosolic protein and internal standard E) a study sample incubated with $15 \mu \mathrm{g}$ of PBMC cytosolic protein and $2 \mathrm{mM}$ thymidine in assay buffer. Abbreviations: PBMC, peripheral blood mononuclear cells; I.S., internal standard 
and the co-factor phosphate. We used a previously optimized method for isolation of PBMC cytosolic lysate $[26,28]$. For the current method, we adapted the same procedures for processing PBMCs.

In order to quantify DPD activity in PBMCs, we previously established a HPLC method for chromatographic separation of thymine and dihydrothymine [28]. The same HPLC column was used for the current assay. We used 5-BU as an internal standard because this substance closely resembles the physicochemical properties of thymine. The proportion of eluent B was titrated up to a level that allowed for adequate separation of thymine and 5-BU. Typical retention times for thymine and 5-BU were 6.6 and $7.8 \mathrm{~min}$, respectively. Thymidine eluted after 12.1 min and was not quantified during the HPLC-UV analysis, since the reduction in thymidine levels after incubation with PBMC cytosolic lysate was relatively small and could not be accurately quantified. The chromatogram of a sample that was processed with $20 \mu \mathrm{g}$ of PBMC cytosolic protein without thymidine and internal standard did not reveal interfering peaks at the retention times of thymine and 5-BU (Figure 2A). A small peak was observed at the expected retention time of thymine in a sample with heat-treated PBMC lysate $(20 \mu \mathrm{g})$ that was spiked with $2 \mathrm{mM}$ thymidine (Figure 2B). In addition, this small peak was also observed at the expected retention time of thymine in a sample that only contained $2 \mathrm{mM}$ thymidine in assay buffer (Figure $2 \mathrm{C}$ ). There was no thymine peak in the sample that only contained heat-treated PBMC cytosolic protein and 5-BU (Figure 2D). The chromatogram of a representative study sample that was incubated with 15 $\mu \mathrm{g}$ PBMC cytosolic protein resulted in a relatively large increase of the thymine peak (Figure 2E). Because of the background signal in control samples of $2 \mathrm{mM}$ thymidine in assay buffer and heat-treated PBMC lysate (Figure 2B-C), three negative control samples were freshly prepared for each analytical run. The average thymine concentration in the background samples was subtracted from the thymine levels in the study samples.

\subsection{Method validation}

\subsubsection{TP enzyme kinetics}

The kinetics of TPApbmc with varying thymidine concentrations is illustrated in Figure 3. TPApbmc clearly demonstrated Michaelis-Menten kinetics. The estimated $V \max$ and $\mathrm{Km}$ were $1278 \mathrm{nmol} / \mathrm{mg} / \mathrm{h}$ (95\% confidence interval $(\mathrm{Cl})=$ $1255-1301 \mathrm{nmol} / \mathrm{mg} / \mathrm{h})$ and $78.1 \mu \mathrm{M}(95 \% \mathrm{Cl}=73.2-83.0 \mu \mathrm{M})$, respectively. 


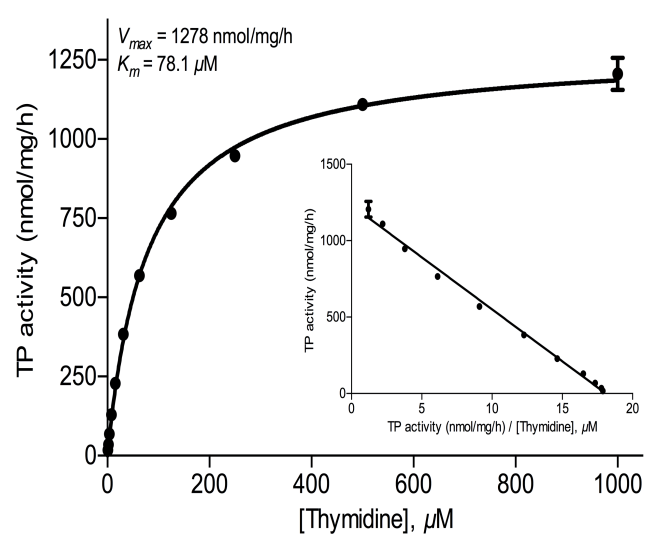

Figure 3. The effect of thymidine concentration on thymidine phosphorylase activity in peripheral blood mononuclear cells that were pooled from 3 volunteers. Data are visualized by a Michaelis-Menten and linearized (Eadie-Hofstee) plot (insert). Results are expressed by the average \pm s.d. of three samples. Abbreviations: TP, thymidine phosphorylase; Vmax, maximum enzyme velocity; Km, Michaelis-Menten constant
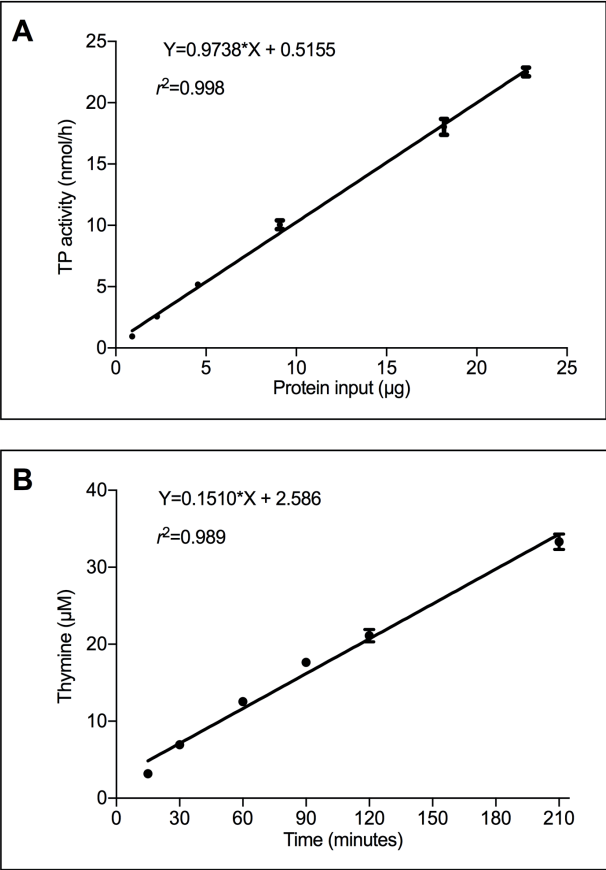

Figure 4. Linearity of thymidine phosphorylase activity in peripheral blood mononuclear cells with protein input (A) incubation time (B) and the effect of incubation temperature (C). Thymidine phosphorylase activity was determined in pooled samples from three volunteers. Results are expressed by the average \pm s.d. of three samples. Abbreviation: TP, thymidine phosphorylase

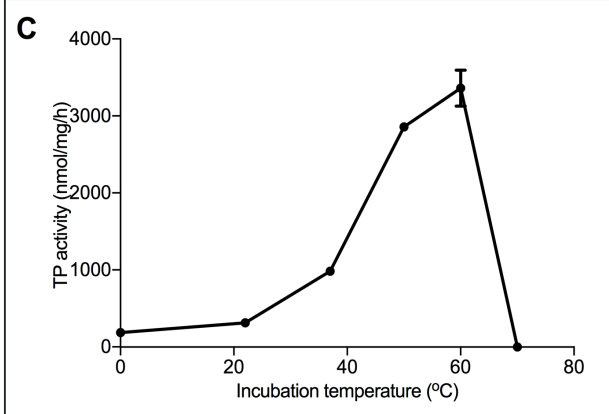


The amount of thymine increased linearly between 2.3 and $22.7 \mu \mathrm{g}$ of PBMC cytosolic protein that was used for the enzymatic reaction (Figure 4A). At the LLoQ level of $2.3 \mu \mathrm{g}$ protein input level, the average ( \pm s.d.) thymine concentration was $6.78 \pm 0.13 \mu \mathrm{M}$ and highly exceeded thymine levels in blank control samples $(1.61 \pm 0.02 \mu \mathrm{M})$. The assay LoD was $1.67 \mu \mathrm{M}$. Assay accuracy and precision were 94.4\% and $2.8 \%$ at the LLoQ level. At protein input levels of 4.5, 9.1, 18.2 and $22.7 \mu \mathrm{g}$, the accuracy and precision ranged between $98.8-107.5 \%$ and $1.6-3.6 \%$, respectively.

There was a linear association between the amount of thymine formed and the duration of incubation (Figure 4B). TPApbmc was highly temperature-dependent and peaked at $60^{\circ} \mathrm{C}$ (Figure $4 \mathrm{C}$ ). Incubation at this temperature resulted in a 3-fold increase of TPApbmc compared to incubation at $37^{\circ} \mathrm{C}$. There was no significant TPApbmc observed at $70{ }^{\circ} \mathrm{C}$.

\subsubsection{Within-day and between-day precision}

Average TPApbmc in samples spiked with 5 and $15 \mu \mathrm{g}$ of PBMC cytosolic protein were $910 \mathrm{nmol} / \mathrm{mg} / \mathrm{h}$ and $916 \mathrm{nmol} / \mathrm{mg} / \mathrm{h}$, respectively. The WDP and BDP of the TP assay were $8.1 \%$ and $4.6 \%$ in samples that were spiked with $5 \mu \mathrm{g}$ protein. For samples spiked with $15 \mu \mathrm{g}$, the WDP and BDP were $9.2 \%$ and $6.0 \%$.

\subsubsection{Specificity}

No significant interferences were observed. The deviations from the nominal thymine concentrations were between -0.3 and $6.5 \%$ (Supplementary table 1), showing that the specificity of this assay is acceptable.

\subsubsection{Stability}

Results of stability experiments are shown in Table 1. TPApbmc was stable in whole blood that was stored for 24 hours at room temperature. Storage of whole blood for 4 hours on ice-water resulted in significant reduction of TPApbmc. Long-term stability of PBMC dry pellets and cytosolic lysates was demonstrated for at least 6 months at $-80^{\circ} \mathrm{C}$. There was no significant change in TPApbmc after storage of assay buffer and thymidine stock solutions for two months at $-20^{\circ} \mathrm{C}$. Furthermore, re-injection analysis showed that final extracts were adequately stored in the HPLC autosampler for at least 24 hours at room temperature. 


\subsection{Clinical applicability}

Figure 5 illustrates the TPApbmc of five patients. These analyses demonstrated the feasibility of quantification of TPApbmc in samples that were collected from cancer patients. TPApbmc demonstrated between-subject variability but did not seem to be altered after seven days of capecitabine treatment or at the end of treatment.

\subsection{TP activity in monocyte and lymphocyte subpopulations}

The TP activities in monocytes, lymphocytes and PBMCs of six volunteers are shown in Figure 6. Average ( \pm s.d.) TP activity in monocytes was $2710 \pm 490 \mathrm{nmol} /$ $\mathrm{mg} / \mathrm{h}$ and in lymphocytes $906 \pm 134 \mathrm{nmol} / \mathrm{mg} / \mathrm{h}(\mathrm{P}<0.001)$. The average TPApbmc was $1286 \pm 190 \mathrm{nmol} / \mathrm{mg} / \mathrm{h}$ and was significantly different from TP activity in lymphocytes and monocytes $(P<0.01)$. Purity of the monocyte and lymphocyte populations ranged between $93.5-98.6 \%$. The percentage of monocytes in the total PBMC fractions ranged between 14.8-21.9\%.

\subsection{TP activity in monocyte and lymphocyte subpopulations}

The TP activities in monocytes, lymphocytes and PBMCs of six volunteers are shown in Figure 6. Average ( \pm s.d.) TP activity in monocytes was $2710 \pm 490 \mathrm{nmol} /$ $\mathrm{mg} / \mathrm{h}$ and in lymphocytes $906 \pm 134 \mathrm{nmol} / \mathrm{mg} / \mathrm{h}(\mathrm{P}<0.001)$. The average TPApbmc was $1286 \pm 190 \mathrm{nmol} / \mathrm{mg} / \mathrm{h}$ and was significantly different from TP activity in lymphocytes and monocytes $(\mathrm{P}<0.01)$. Purity of the monocyte and lymphocyte populations ranged between $93.5-98.6 \%$. The percentage of monocytes in the total PBMC fractions ranged between 14.8-21.9\%. 


\begin{tabular}{|c|c|c|c|c|c|}
\hline Component & Condition & $\begin{array}{c}\text { Initial TP } \\
\text { activity } \\
\text { (nmol/mg/h) }\end{array}$ & $\begin{array}{c}\text { Measured TP } \\
\text { activity } \\
\text { (nmol/mg/h) }\end{array}$ & $\begin{array}{c}\text { Deviation } \\
\text { (\%) }\end{array}$ & $\begin{array}{l}\text { CV } \\
(\%)\end{array}$ \\
\hline Whole blood & Ice-water, 4 hours & 1020 & 792 & -22.3 & 9.7 \\
\hline Whole blood & Ambient, 4 hours & 1020 & 987 & -3.2 & 5.9 \\
\hline Whole blood & Ambient, 24 hours & 1020 & 1015 & -0.5 & 2.0 \\
\hline PBMC dry pellet & $-80^{\circ} \mathrm{C}, 6$ months & 934 & 856 & -8.4 & 5.5 \\
\hline PBMC cytosolic lysate & $-80^{\circ} \mathrm{C}, 6$ months & 950 & 871 & -8.3 & 4.1 \\
\hline $\begin{array}{l}\text { Re-injection stability } \\
\text { (final extract) }\end{array}$ & Ambient, 24 hours & 1020 & 1060 & 3.9 & 5.9 \\
\hline Assay buffer & $-20^{\circ} \mathrm{C}, 2$ months & 1129 & 1118 & -1.0 & 3.8 \\
\hline $\begin{array}{l}\text { Thymidine stock } \\
\text { solution }\end{array}$ & $-20^{\circ} \mathrm{C}, 2$ months & 1041 & 1118 & 7.4 & 3.8 \\
\hline
\end{tabular}

Table 1. Stability of thymidine phosphorylase activity in peripheral blood mononuclear cells at different processing stages and storage conditions.

Abbreviations: TP, thymidine phosphorylase; CV, coefficient of variation; PBMC, peripheral blood mononuclear cell 


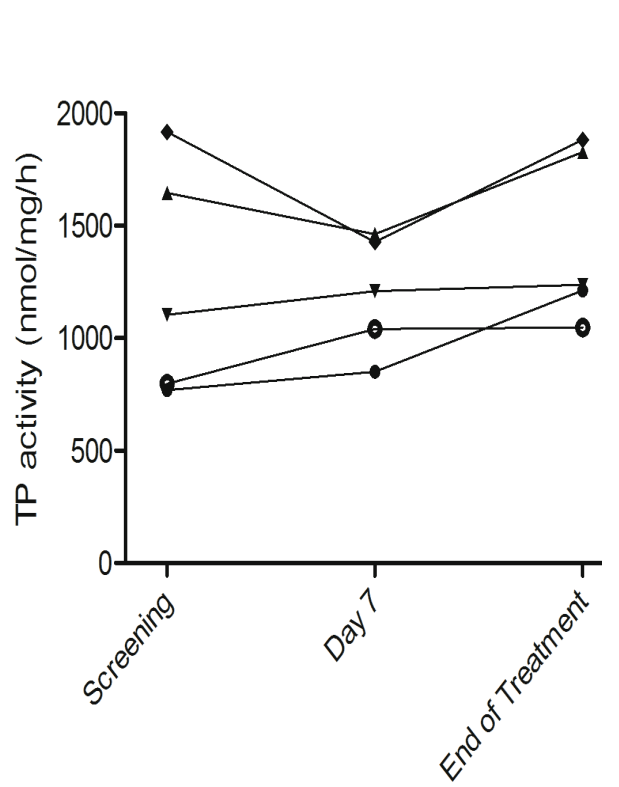

Figure 5. Thymidine phosphorylase activity in peripheral blood mononuclear cells of five cancer patients before treatment (Screening) with capecitabine, on the 7th day of capecitabine treatment and at the end of treatment. The patients participated in a phase I clinical trial of chronomodulated capecitabine therapy. Abbreviation: TP, thymidine phosphorylase

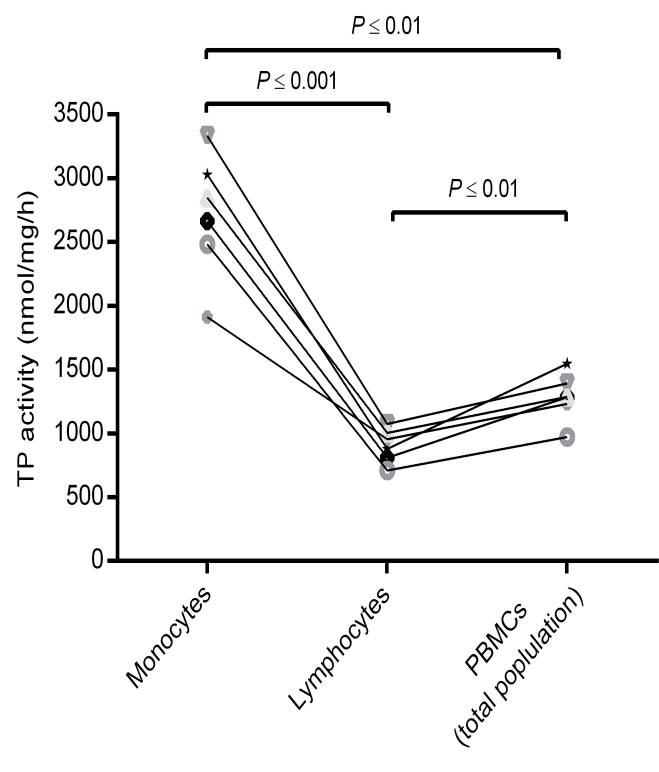

Figure 6. Thymidine phosphorylase activity in purified monocytes, purified lymphocytes and peripheral blood mononuclear cells of six volunteers. Abbreviation: TP, thymidine phosphorylase

\section{DISCUSSION}

The primary aim was to develop and validate a simple and accurate method for the quantification of TPApbmc. We successfully developed a method that is based on ex vivo conversion of the TP substrate thymidine to the reaction product thymine. By applying the widely available HPLC-UV technique, this method can be implemented in most laboratories. The use of the internal standard 5-BU helps to reduce variation due to sample preparation. 
We found a small background signal at the retention time of thymine in the chromatogram of a sample of $2 \mathrm{mM}$ thymidine. The thymine background signal was not noticeable in samples that did not contain the thymidine stock solution. Based on these results it can be concluded that thymine is an impurity in the thymidine dry powder, which is $\geq 99 \%$ pure, and directly causes the background signal. By quantifying the amount of thymine in three negative control samples, thymine background signals can be easily quantified and corrected for in study samples.

Validation experiments showed that assay linearity was observed for PBMC cytosolic protein levels between $2.3-22.7 \mu \mathrm{g}$. Within this range, assay accuracy and precision met the predefined criteria and were considered acceptable. Using only $2.3 \mu \mathrm{g}$ PBMC cytosolic protein, the amount of thymine formed highly exceeds background levels. The minimum amount of PBMC protein needed for quantification of TPApbmc can be extracted from approximately 125,000 cells, which can already be isolated from about $0.1 \mathrm{~mL}$ of whole blood. Since only a limited amount of blood is required, the developed assay can be easily implemented for sequential quantification of TPApbmc in cancer patients. Clinical applicability of the assay was confirmed by the quantification of TPApbmc in five patients that were sampled at 3 time points during the treatment course.

The estimated $\mathrm{Km}$ was $78.1 \mu \mathrm{M}$ and is comparable to the previously determined $\mathrm{Km}$ of TP activity in the total leukocyte population [24]. It can be anticipated that a thymidine concentration of $2 \mathrm{mM}$, which corresponds to approximately $\sim 25$ times the estimated $\mathrm{Km}$, saturation of the TP enzymes occurs. Therefore, a thymidine concentration of $2 \mathrm{mM}$ can be considered adequate for quantification of TP in PBMCs. The Vmax of TP activity is approximately 3-fold higher in PBMCs compared to TP activity in total leukocytes [24].

Assay precision was tested using 5 and $15 \mu \mathrm{g}$ PBMC protein. These protein input levels were at the lower and higher end, respectively, of the established linear range. For both protein input levels, the within-day and between-day precision met the predefined criteria for adequate precision. Therefore, we conclude that the assay shows good precision within the validated linear range of protein input levels.

Changes in temperature highly affect TPApbmc. Shaw et al. previously found that incubation at a temperature slightly above $40{ }^{\circ} \mathrm{C}$ increases the conversion of thymidine to thymine compared to samples that were incubated at $37{ }^{\circ} \mathrm{C}$ [29]. We also determined TPApbmc at temperatures above $40{ }^{\circ} \mathrm{C}$ and found the 
highest TPApbmc at $60^{\circ} \mathrm{C}$. In order to obtain reliable and reproducible results, it is of major importance to keep the incubation temperature constant. We choose to maintain the incubation temperature at $37{ }^{\circ} \mathrm{C}$ because this best resembles the in vivo physiological conditions, and may better predict the role of TP inducers or inhibitors on TP activity. In addition, future experiments might be performed to study the role of TP inducers or inhibitors on TP activity. Such experiments normally require incubation at a temperature that resembles the in vivo situation.

Previous studies demonstrated that changes in $\mathrm{pH}$ might affect TP enzyme kinetics $[24,29]$. Therefore, all experiments were performed using an assay buffer with a fixed $\mathrm{pH}$ of 7.4. The $\mathrm{pH}$ of the freshly prepared assay buffer should be examined before usage.

Other assays have been described for quantification of TP activity of the total leukocyte population [24, 30]. Leukocyte subpopulations, however, showed high variability in TP activity [25]. A more homogenous population, like PBMCs, is most probably more appropriate for longitudinal observation of TP activity than the total leukocyte population. The PBMC fraction consists for $70-90 \%$ of lymphocytes and for $10-30 \%$ of monocytes. We found that TP activity was $~ 3$ times higher in monocytes than in lymphocytes. Other researchers previously found that monocytes also possess higher DPD activity in comparison with lymphocytes [31]. Although the proportion of monocytes in PBMCs is relatively low, changes in the sample composition with respect to the relative amount of monocytes could affect the TP activity. Our analysis by flow cytometry provides a simple way for monitoring the amount of monocytes in the PBMC samples and their potential effect on TPApbmc.

A limitation of the method is that it is focused on the enzyme TP. The activities of other enzymes that are involved in the activation and degradation of capecitabine, such as DPD, TS and UP, are not determined using the current assay and warrant the use of other methods.

The applicability for quantification of TP might not be limited to prediction of fluoropyrimidine-induced toxicity. Fairbanks et al. previously described a quality control (QC) method for a pharmaceutical formulation of erythrocytes that were encapsulated with TP [32]. This QC method also employs the conversion of thymidine to thymine in order to quantify TP activity. The TP-loaded erythrocytes can be administered to patients with TP deficiency, a mutation that causes mitochondrial neurogastrointestinal encephalomyopathy.

Other researchers demonstrated the potential role of TP protein and gene 
expression as a predictor for patient prognosis [33, 34] and sensitivity to capecitabine treatment $[35,36]$. TP expression is therefore a promising biomarker for the treatment of cancer patients. Additional clinical research is needed to determine the clinical validity and applicability of TP phenotyping methods.

In conclusion, we successfully developed and validated a simple, accurate and precise assay for quantification of TPApbmc. Clinical applicability of the assay was demonstrated. Therefore, we believe that the developed assay is suitable for quantification of TPApbmc in clinical studies.

\section{ACKNOWLEDGEMENT}

The study was funded by the Netherlands Cancer Institute 


\section{REFERENCES}

1. Mackean $M$, Planting $A$, Twelves $C$, et al. Phase I and pharmacologic study of intermittent twice-daily oral therapy with capecitabine in patients with advanced and/or metastatic cancer. J Clin Oncol 1998; 16:2977-2985.

2. Judson IR, Beale PJ, Trigo JM, et al. A human capecitabine excretion balance and pharmacokinetic study after administration of a single oral dose of 14C-labelled drug. Invest New Drugs 1999;17:49-56.

3. Budman DR, Meropol NJ, Reigner B, et al. Preliminary studies of a novel oral fluoropyrimidine carbamate: capecitabine. J Clin Oncol 1998;16:1795-802.

4. Miwa M, Ura M, Nishida M, et al. Design of a novel oral fluoropyrimidine carbamate, capecitabine, which generates 5 fluorouracil selectively in tumours by enzymes concentrated in human liver and cancer tissue. Eur J Cancer 1998;34:1274-1281.

5. Tabata $\mathrm{T}$, Katoh $\mathrm{M}$, Tokudome $\mathrm{S}$, et al. Bioactivation of capecitabine in human liver: involvement of the cytosolic enzyme on 5'-deoxy-5-fluorocytidine formation. Drug Metab Dispos 2004;32:762-7.

6. Walko CM, Lindley C. Capecitabine: a review. Clin Ther 2005;27:23-44.

7. Wilson PM, Danenberg P V., Johnston PG, et al. Standing the test of time: targeting thymidylate biosynthesis in cancer therapy. Nat Rev Clin Oncol 2014;11:282-98.

8. Ishikawa $T$, Sekiguchi $F$, Fukase $Y$, et al. Positive correlation between the efficacy of capecitabine and doxifluridine and the ratio of thymidine phosphorylase to dihydropyrimidine dehydrogenase activities in tumors in human cancer xenografts. Cancer Res 1998;58:685-90.

9. Schüller J, Cassidy J, Dumont $E$, et al. Preferential activation of capecitabine in tumor following oral administration to colorectal cancer patients. Cancer Chemother Pharmacol 2000;45:291-7.

10. Longley DB, Harkin DP, Johnston PG. 5-fluorouracil: mechanisms of action and clinical strategies. Nat Rev Cancer 2003; 3:330-8.

11. Midgley R, Kerr DJ. Capecitabine: have we got the dose right? Nat Clin Pract Oncol 2009;6:17-24.

12. Deenen MJ, Meulendijks D, Cats A, et al. Upfront Genotyping of DPYD*2A to Individualize Fluoropyrimidine Therapy: A Safety and Cost Analysis. J Clin Oncol 2016;34:227-34.

13. Meulendijks D, Henricks LM, Sonke $\mathrm{GS}$, et al. Clinical relevance of DPYD variants c.1679T>G, c.1236G >A/HapB3, and c.1601G $>A$ as predictors of severe fluoropyrimidine-associated toxicity: a systematic review and meta-analysis of individual patient data. Lancet Oncol 2015;16:1639-50.

14. Jennings BA, Loke YK, Skinner J, et al. Evaluating predictive pharmacogenetic signatures of adverse events in colorectal cancer patients treated with fluoropyrimidines. PLoS One 2013;8:e78053.

15. Milano G, Etienne-Grimaldi M-C, Mari $M$, et al. Candidate mechanisms for capecitabine-related hand-foot syndrome. 
Development and validation of pharmacodynamic and diagnostic biomarker methods

Br J Clin Pharmacol 2008;66:88-95.

16. Evrard A, Cuq P, Ciccolini J, et al. Increased cytotoxicity and bystander effect of 5-fluorouracil and 5-deoxy-5-fluorouridine in human colorectal cancer cells transfected with thymidine phosphorylase. Br J Cancer 1999;80:1726-33.

17. Toi $M$, Bando $H$, Horiguchi $S$, et al. Modulation of thymidine phosphorylase by neoadjuvant chemotherapy in primary breast cancer. Br J Cancer 2004;90:23382343.

8. Han J-Y, Hong EK, Lee SY, et al. Thymidine phosphorylase expression in tumour cells and tumour response to capecitabine plus docetaxel chemotherapy in non-small cell lung cancer. J Clin Pathol 2005;58:650-4.

19. Puglisi F, Andreetta C, Valent F, et al. Anthracyclines and taxanes induce the upregulation of thymidine phosphorylase in breast cancer cells. Anticancer Drugs 2007;18:883-8.

20. Zhang J, Gu SY, Gan Y, et al. Vinorelbine and capecitabine in anthracycline- and/or taxane-pretreated metastatic breast cancer: Sequential or combinational? Cancer Chemother Pharmacol 2013;71:103-113.

21. Sawada N, Ishikawa T, Sekiguchi F, et al. X-ray irradiation induces thymidine phosphorylase and enhances the efficacy of capecitabine (Xeloda) in human cancer xenografts. Clin Cancer Res 1999;5:2948-53.

22. Zhang $\mathrm{S}-\mathrm{H}$, Zhang $\mathrm{H}, \mathrm{He} H-W$, et al. Lidamycin up-regulates the expression of thymidine phosphorylase and enhances the effects of capecitabine on the growth and pulmonary metastases of murine breast carcinoma. Cancer Chemother Pharmacol 2013;72:777-88.

23. Di Gennaro E, Piro G, Chianese MI, et al. Vorinostat synergises with capecitabine through upregulation of thymidine phosphorylase. Br J Cancer 2010;103:168091.

24. van Kuilenburg $A B P$, Zoetekouw L Determination of thymidine phosphorylase activity by a non-radiochemical assay using reversed-phase high-performance liquid chromatography. J Chromatogr B Analyt Technol Biomed Life Sci 2005;820:271-275.

25. van Kuilenburg $A B P$, Zoetekouw $L$ Determination of thymidine phosphorylase activity in human blood cells and fibroblasts by a nonradiochemical assay using reversed-phase high-performance liquid chromatography. Nucleosides Nucleotides Nucleic Acids 2006;25:1261-4.

26. Pluim D, Schilders KAA, Jacobs BAW, et al. Pharmacodynamic assay of thymidylate synthase activity in peripheral blood mononuclear cells. Anal Bioanal Chem 2013; 405:2495-2503.

27. Pluim D, Jacobs BAW, Krähenbühl $M D$, et al. Correction of peripheral blood mononuclear cell cytosolic protein for hemoglobin contamination. Anal Bioanal Chem 2013; 405:2391-2395.

28. Pluim D, Jacobs BAW, Deenen MJ, et al. Improved pharmacodynamic assay for dihydropyrimidine dehydrogenase activity in peripheral blood mononuclear cells. Bioanalysis 2015;7:519-29.

29. Shaw T, Smillie RH, MacPhee DG. The role of blood platelets in nucleoside metabolism: 
assay, cellular location and significance of thymidine phosphorylase in human blood. Mutat Res 1988;200:99-116.

30. Martí R, López LC, Hirano M. Assessment of thymidine phosphorylase function: measurement of plasma thymidine (and deoxyuridine) and thymidine phosphorylase activity. Methods Mol Biol 2012;837:12133.

31. Van Kuilenburg $A B$, Van Lenthe $H$, Tromp A, et al. Pitfalls in the diagnosis of patients with a partial dihydropyrimidine dehydrogenase deficiency. Clin Chem 2000;46:9-17.

32. Fairbanks LD, Levene $M$, Bax $B E$. Validation of a HPLC method for the measurement of erythrocyte encapsulated thymidine phosphorylase (EE-TP) activity. J Pharm Biomed Anal 2013;76:8-12.

33. Minisini AM, Pascoletti G, Intersimone D, et al. Expression of thymidine phosphorylase and cyclooxygenase- 2 in melanoma. Melanoma Res 2013;23:96-101.

34. Bonotto M, Bozza C, Di Loreto C, et al. Making capecitabine targeted therapy for breast cancer: which is the role of thymidine phosphorylase? Clin Breast Cancer 2013; 13:167-72.

35. Andreetta C, Puppin C, Minisini A, et al. Thymidine phosphorylase expression and benefit from capecitabine in patients with advanced breast cancer. Ann Oncol 2009 20:265-71.

36. Puglisi F, Cardellino GG, Crivellari D, et al. Thymidine phosphorylase expression is associated with time to progression in patients receiving low-dose, docetaxel- modulated capecitabine for metastatic breast cancer. Ann Oncol 2008;19:1541-6.

\section{5}




\section{SUPPLEMENTARY MATERIAL}

Table S1. The specificity of thymine in heat-treated PBMC lysate protein $(20 \mu \mathrm{g})$. Abbreviation: PBMC, peripheral blood mononuclear cells; CV, coefficient of variation

\begin{tabular}{cccc}
$\begin{array}{c}\text { Nominal thymine concentration } \\
(\mu \mathrm{M})\end{array}$ & $\begin{array}{c}\text { Average measured thymine concentration } \\
(\mu \mathrm{M})\end{array}$ & $\begin{array}{c}\text { Deviation } \\
(\%)\end{array}$ & $\begin{array}{c}\mathrm{CV} \\
(\%)\end{array}$ \\
2.5 & 2.49 & -0.3 & 0.2 \\
12.5 & 13.28 & 6.3 & 0.4 \\
50 & & & \\
& 53.24 & 6.5 & 0.2 \\
\hline
\end{tabular}




\section{CHAPTER 1}

Development and validation of pharmacodynamic and diagnostic cancer biomarker methods

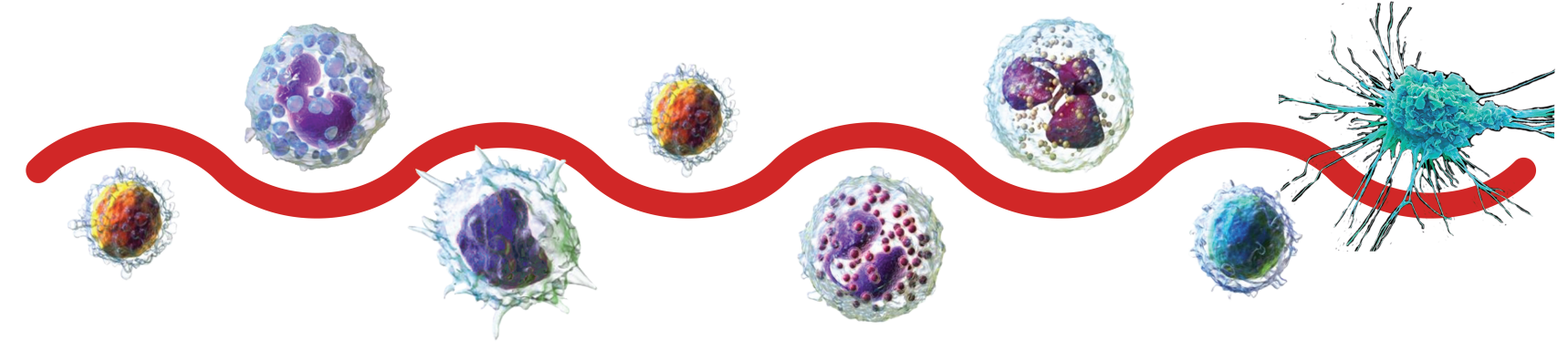

\section{6}

Improved pharmacodynamic (PD) assessment of low dose PARP inhibitor PD activity for radiotherapy and chemotherapy combination trials

Rosemarie de Haan*, Dick Pluim*, Baukelien van Triest, Michel van den Heuvel, Heike Peulen, Damien van Berlo, Jay George, Marcel Verheij, Jan H.M. Schellens, Conchita Vens

* authors contributed equally and share first authorship

Radiotherapy and Oncology 2018;126:443-449 


\section{ABSTRACT}

Background: PARP inhibitors are currently evaluated in combination with radiotherapy and/or chemotherapy. As sensitizers, PARP inhibitors are active at very low concentrations therefore requiring highly sensitive pharmacodynamic (PD) assays. Current clinical PD-assays partly fail to provide such sensitivities. The aim of our study was to enable sensitive PD evaluation of PARP inhibitors for clinical sensitizer development.

Material and methods: PBMCs of healthy individuals and of olaparib and radiotherapy treated lung cancer patients were collected for ELISA-based PDassays.

Results: PAR-signal amplification by ex vivo irradiation enabled an extended quantification range for PARP inhibitory activities after ex vivo treatment with inhibitors. This "radiation-enhanced-PAR" (REP) assay provided accurate IC50 values thereby also revealing differences among healthy individuals. Implemented in clinical radiotherapy combination Phase I trials, the REP-assay showed sensitive detection of PARP inhibition in patients treated with olaparib and establishes strong PARP inhibitory activities at low daily doses.

Conclusions: Combination trials of radiotherapy and novel targeted agent(s) often require different and more sensitive PD assessments than in the monotherapy setting. This study shows the benefit and relevance of sensitive and adapted PDassays for such combination purposes and provides proof of clinically relevant cellular PARP inhibitory activities at low daily olaparib doses. 


\section{INTRODUCTION}

Pharmacodynamic (PD) assays that measure the effect(s) of a drug on its specific biological target(s) are essential for clinical drug development. PD data support clinical decision making concerning the optimal dose and duration of a drug therapy and, in case of combination treatment strategies, the optimal dosing and sequence of the different components [1, 2]. Furthermore, it may allow individualized treatment selection or adaptation if drug responses vary among patients.

Next to established monotherapy indications in certain cancers, PARP (poly(ADPribose) polymerase) inhibitors are promising anti-cancer drugs to be combined with chemotherapy and/or radiotherapy. A range of different PARP inhibitors is currently under clinical evaluation, of which olaparib (LynparzaTM) is the first FDA and EMA approved drug. PARP is an enzyme involved in the repair of DNA lesions such as single-strand breaks. Upon its activation, PARP produces poly(ADP-ribose)polymers (PAR) at the expense of nicotinamide adenine dinucleotide (NAD). PARP inhibition by pharmaceutical drugs decreases PAR levels in cells. Several PD assays that measure PARP activity in tumour cells and in peripheral blood mononuclear cells (PBMCs) have been used in clinical studies [3-12].

Currently, there is only one clinically validated PD assay that quantifies basal PAR levels (generated by PARP through endogenously induced DNA damage), both in PBMCs and tumour cells, using an ELISA based method [6-8]. Through extensive $\mathrm{NCl}$ (US National Cancer Institute) studies optimizing its clinical application, this assay was able to support the clinical development of PARP inhibitors [13-17]. Especially in PBMCs, however, basal PAR levels can be low with a high day-to-day variation within the same individual [6, 7], making sensitive quantification of PAR levels upon PARP inhibition difficult. Applicability of this PD assay is therefore limited to patients with sufficiently high PAR levels and it can be difficult to detect clinically relevant reductions in PAR levels. This is particularly important in the development as sensitizer in combination treatments, as PARP inhibitors have been shown to be effective chemo- and radiosensitizers at much lower concentrations and shorter duration $[18,19]$. Thus, sensitive and robust PD assessments are needed in such combination trials.

The aim of our study was to evaluate PARP inhibition at low drug dose levels for novel combination trials and therefore to achieve highly sensitive quantification of PAR levels and PAR reduction due to PARP inhibition by a clinically applicable PD assay. 


\section{MATERIAL \& METHODS}

Healthy individual \& clinical trial patient material

Healthy individual ( $\mathrm{HI}$ ) blood was drawn in the morning after $1 \mathrm{~h}$ fasting; informed consent was obtained. Clinical PD data are from non-small cell lung cancer (NSCLC) patients included in a clinical Phase I trial (NCT01562210). Patients were treated with a radical standard of care chemoradiotherapy schedule (66 Gy with daily cisplatin at $6 \mathrm{mg} / \mathrm{m}^{2}$ ) combined with olaparib $25 \mathrm{mg}$ bidaily (tablet formulation). The study was performed according to ICH-GCP guidelines after approval by the hospital's ethics committee and national regulatory body. All patients gave written, informed consent prior to undergoing study-related procedures. Patient blood samples were collected prior and during treatment at a steady-state minimal concentration (C-min) level of olaparib and after completion.

\section{Radiation and reagents}

PBMCs were exposed to radiation using the Gammacell ${ }^{\circledR} 40$-Exactor (Best Theratronics Ltd., Ottawa, Canada). Olaparib for the ex vivo analyses in $\mathrm{HI}$ was purchased from Sequoia Research Products (Pangbourne, UK). Niraparib was kindly provided by the Slotervaart-Pharmacy (Amsterdam, Netherlands). Stocksolutions were prepared in dimethylsulfoxide at a concentration of $5 \mathrm{mM}$ (olaparib) and $0.31 \mathrm{mM}$ (niraparib).

\section{PBMC lysate preparation}

Cell lysates were prepared following the $\mathrm{NCl}$ advised protocol for clinical use [8] with some minor adaptations as listed in Sup. Table S1. Samples prepared in the 'REP-assay' (Radiation Enhanced Assay) were irradiated with 8 Gy on ice and incubated for $1 \mathrm{~h}$ on ice. Intact PBMCs in plasma of healthy (and untreated) individuals were incubated ex vivo with olaparib and niraparib at $37^{\circ} \mathrm{C} 1 \mathrm{~h}$ before irradiation. Olaparib plasma levels and protein-binding after ex vivo incubation were comparable to the clinical situation, as determined by HPLC-MS/MS (Sup. Fig. S1). 
PAR assay

Cellular PAR levels were measured by using the HT-PARP in vivo Pharmacodynamic Assay II, following the $\mathrm{NCl}$ protocol [8] using a Tecan-Infinite-200-Pro. Plates and kits were provided by Trevigen ${ }^{\circledR}$.

\section{Data analysis and statistics}

PAR levels (presented in $\mathrm{pg} / 1 \mathrm{E}^{7} \mathrm{PBMCs}$ ) were calculated from the linear fits of the PAR standard curves. All further quality control steps and criteria were followed as recommended in the $\mathrm{NCl}$ protocol [8] and are specified in Sup. Table 1 together with lower limit of quantification (LLOQ) definition and IC50 (half maximal inhibitory concentration) and E-max (maximal effect) calculations [20]. One-way ANOVA tests and Tukey's multiple comparison test were used and differences were considered significant if P-value $<0.05$.

\section{RESULTS}

Basal PAR levels in PBMCs

PAR levels in peripheral blood mononuclear cells (PBMCs) of 10 healthy individuals (HIs, Sup. Table S2) were quantified following the clinically validated $\mathrm{NCI}$ developed method [8], herein termed $\mathrm{NCl}$-protocol. Consistent with literature [6, 16], using this $\mathrm{NCl}$-protocol (i.e. without an ex vivo irradiation step) we found a wide range of PAR levels among different HIs: $52-145 \mathrm{pg} / 1 \mathrm{E}^{7}$ cells with a median of $107 \mathrm{pg} / 1 \mathrm{E}^{7}$. Basal PAR levels were quantifiable in all. It has been suggested that a minimum of $90 \%$ inhibition is required for efficient monotherapy activity [3]. Assuming efficient inhibition, a simulated $90 \%$ reduction of PAR levels would only be quantifiable in one out of ten HIs. Our data suggest that basal PAR levels in PBMCs are often too low and too close to background levels to quantify PAR reduction accurately.

\section{PAR amplification after ex vivo irradiation}

To amplify the low basal PAR signal, which is based on low levels of endogenous DNA damage, we induced DNA damage by ex vivo irradiation. PAR levels increased after irradiation and rapidly decreased with increasing incubation times (Fig. 1A). 

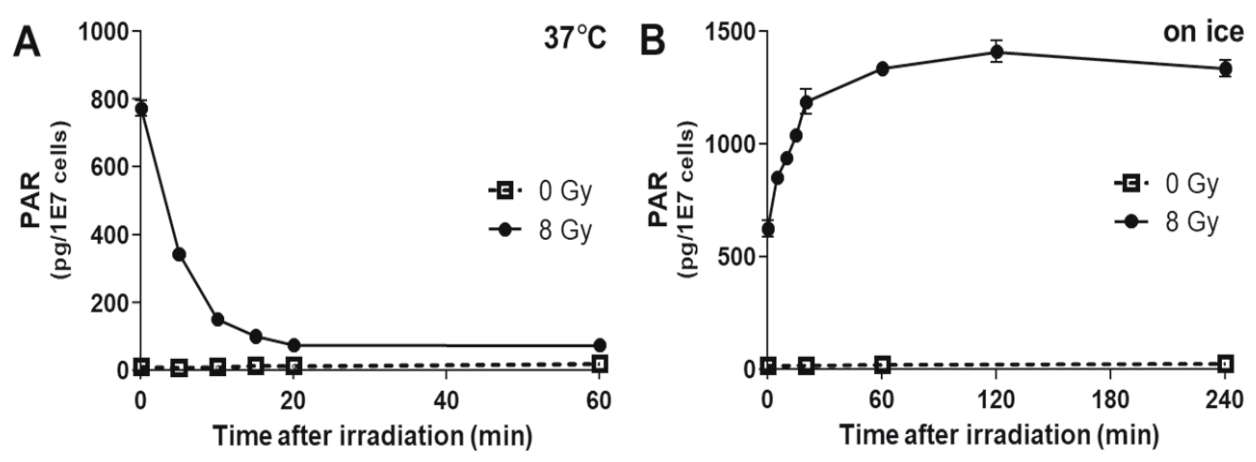

Figure 1. PAR level kinetics after ex vivo irradiation and incubation, and linear radiation dose dependent induction of PAR. (A and B) PAR levels at indicated incubation times at $37^{\circ} \mathrm{C}$ and on ice after 0 Gy and 8 Gy ex vivo irradiation (C). PAR levels after different radiation doses and $1 \mathrm{~h}$ incubation on ice (linear regression $\mathrm{P}$ $<0.0001)$. Data represent mean \pm SD of triplicate ELISA measurements.

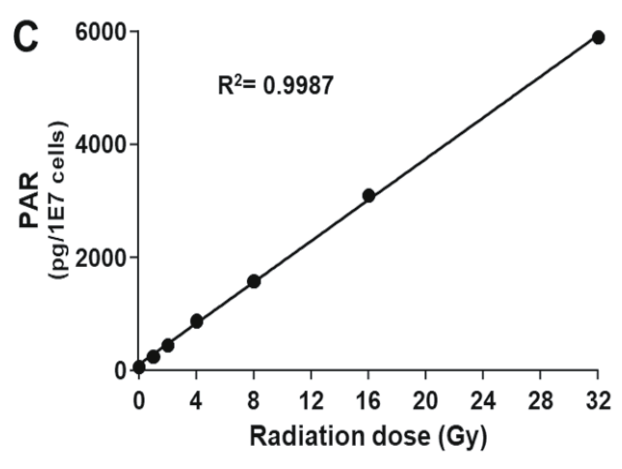

After incubation on ice, however, PAR level values increased and stabilized after 1 h (Fig. 1B). Radiation increased PAR levels in a dose-dependent and linear manner up to $32 \mathrm{~Gy}$ (Fig. 1C). Ex vivo irradiation of PBMCs did not negatively influence the stability of PAR levels in cell lysates (Sup. Fig. S2). For subsequent analyses with this assay, termed REP (Radiation-Enhanced-PAR) assay, we chose a radiation dose of $8 \mathrm{~Gy}$ followed by an $1 \mathrm{~h}$ incubation on ice that provides sufficient PAR signal amplification within a reasonable radiation time-frame. We conclude that this strongly amplifies PAR signal in a strictly linear manner in PBMCs and could therefore enable the sensitive quantification of changes in PAR levels by inhibitors. 


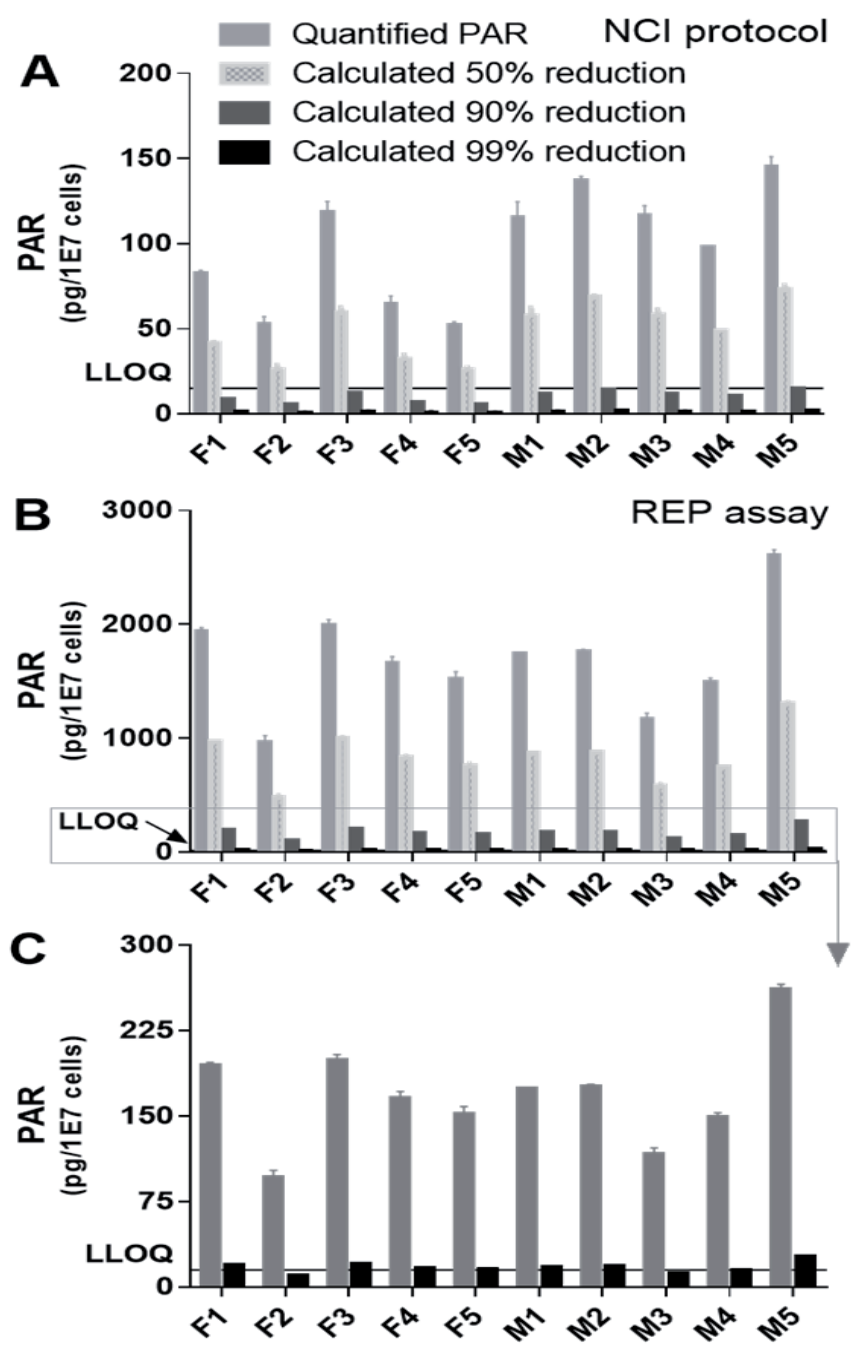

Figure 2. PAR signal amplification by irradiation enables better the quantification of its inhibition. (A) PAR levels in PBMCs are often too low to quantify a reduction by PARP inhibitor treatment. Quantified PAR levels in PBMCs of $10 \mathrm{HI}$ ( $\mathrm{F}=$ female, $\mathrm{M}=$ male). Simulated $50 \%$, $90 \%$ and $99 \%$ inhibition and the lower limit of quantification (LLOQ) are also depicted. All $99 \%$ inhibition values fall under the LLOQ. (B) The REP-assay was tested in parallel to the NCIprotocol in PBMCs isolated from the same blood samples of the same ten HIs as shown in (A) Quantified PAR levels in PBMCs after 8Gy (i.e. according to the REP-assay) varied among the HIs (median: 1696, range $962-2607 \mathrm{pg} / 1 \mathrm{E}^{7}$ cells). Simulated inhibition values of $90 \%$ and $99 \%$ can be detected and quantified in all HIs and 8 and $10 \mathrm{His}$, respectively. (C) Reduction of Y-axis scale with data from Fig. $2 \mathrm{~B}$ to visualize the lower limit of quantification (LLOQ). Using the REP-assay, PAR reduction of $90 \%$ and $99 \%$ would be quantifiable (i.e. above the LLOQ) in all HIs and in eight out of the ten HIs, respectively. Data represent mean \pm SD of triplicate ELISA measurements. 

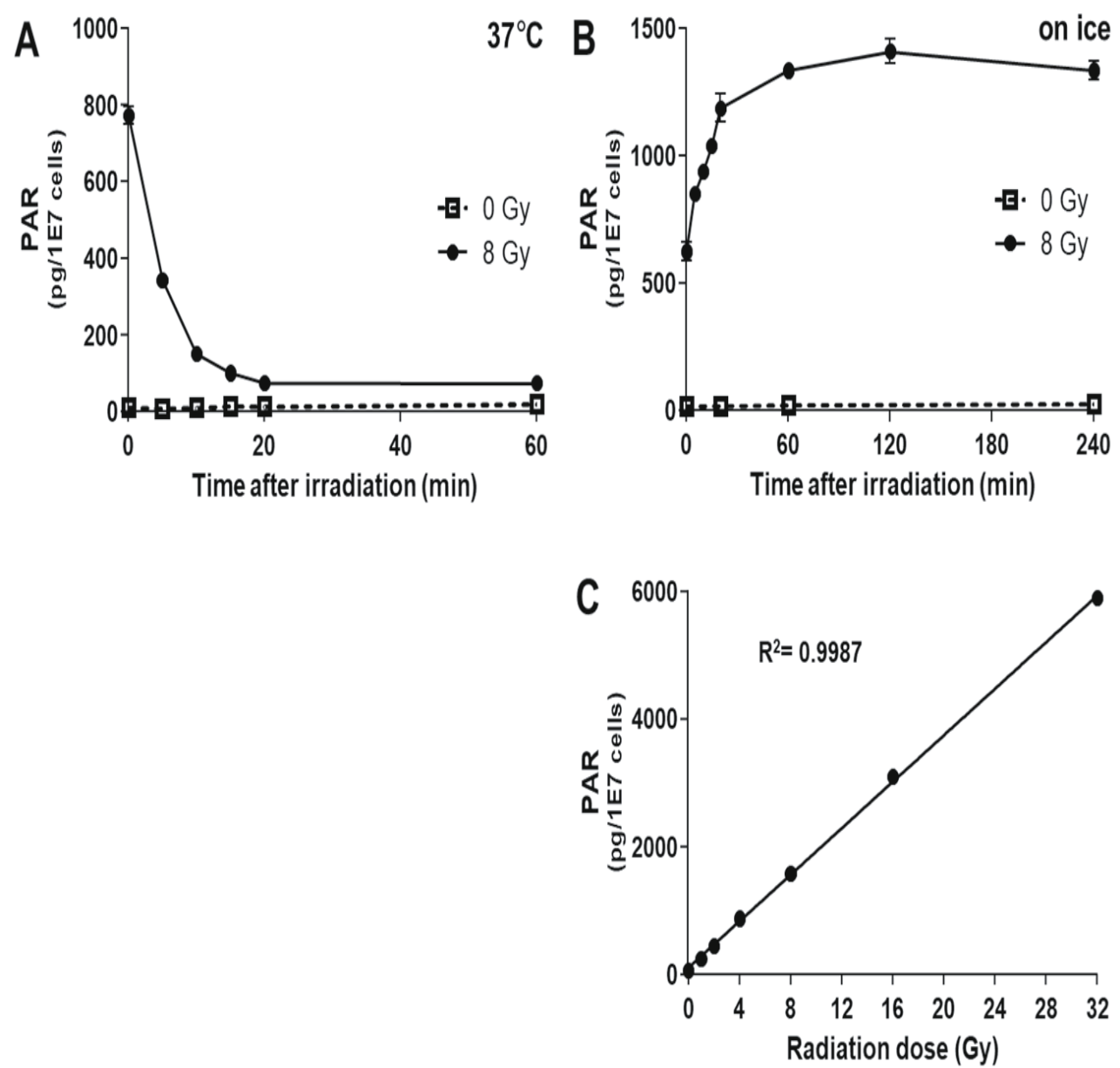

Figure 3. Determination of the maximal inhibitory effect of olaparib. (A) PAR levels determined in PBMCs of a $\mathrm{HI}$ after $1 \mathrm{~h}$ ex vivo pre-incubation with olaparib at indicated concentrations, ex vivo irradiation with $0,8,16$ and $32 \mathrm{~Gy}$ and $1 \mathrm{~h}$ incubation on ice. (B) PAR levels as of Fig. 3A, normalized to the PAR levels of the control treated samples ( 0 $\mathrm{nM}$ olaparib). At $33 \mathrm{nM}, \mathrm{PAR}$ levels were reduced to $34 \%$ in non-irradiated and to $11 \%$ in irradiated PBMCs with similar relative inhibition levels at higher radiation doses. (C) To enable the quantification of maximal inhibitory effect of olaparib and such extensively reduced PAR levels by PARP inhibition, PBMCs were irradiated ex vivo with 32 Gy for maximal PAR induction. PAR levels of six HIs determined after $1 \mathrm{~h}$ ex vivo pre-incubation with olaparib at different concentrations, ex vivo irradiation with $32 \mathrm{~Gy}$ and $1 \mathrm{~h}$ incubation on ice are shown. The grey bar indicates the plasma concentration range of olaparib that was found in plasma of patients that were treated at monotherapy doses in clinical trials [5]. PAR levels were reduced to $0.7 \%$ (range $0.6-1.0 \%$ ) at $10 \mu \mathrm{M}$ olaprib. Data represent mean \pm SD of triplicate ELISA measurements. Note, PAR levels of control-treated ( $0 \mathrm{nM}$ olaparib) samples are plotted at $0.1 \mathrm{nM}$. 

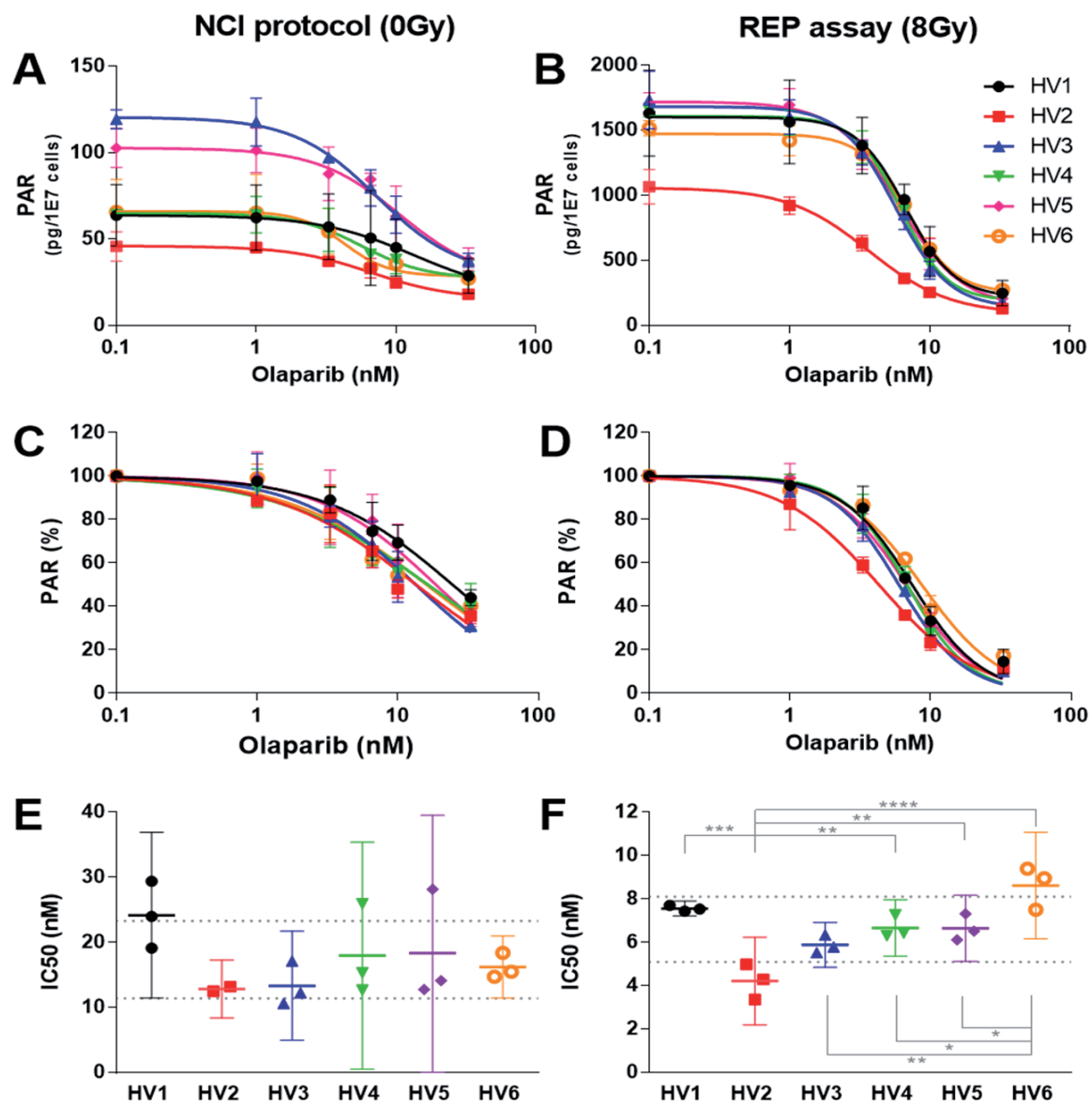

Figure 4. PARP inhibitor activity is largely consistent but the effectiveness can differ two-fold among healthy individuals. ( $A$ and $B$ ). PBMCs were isolated from $6 \mathrm{HIs}$ at three different days and treated ex vivo at increasing olaparib concentrations. PAR levels after ex vivo incubation with olaparib $1 \mathrm{~h}$ before (sham-)irradiation determined with the $\mathrm{NCl}$ protocol and the REP-assay are shown. Data represent mean \pm SD of three independent blood samples. ( $C$ and D) To compare relative olaparib responses PAR levels were normalized. PAR levels of Fig. A and B minus the relative E-max of that individual $\mathrm{HI}$ and normalized to control treated samples ( $0 \mathrm{nM}$ olaparib) are shown. (E and F) IC50 as calculated from Fig. C and D. The REP-assay revealed up to 2 -fold significant differences in absolute IC50s between individuals (range 4.2-8.6 nM). Dotted lines indicate mean \pm SD of IC50s of all HIs. Level of significance as tested by one-way ANOVA: ${ }^{*} \mathrm{P}<0.05,{ }^{* *} \mathrm{P}<$ $0.01, * * * \mathrm{P}<0.001 * * * * \mathrm{P}<0.0001$. Data represent mean $\pm \mathrm{SD}(\mathrm{A}$ and $\mathrm{D})$ or mean $\pm 95 \% \mathrm{Cl}$ ( $E$ and $F$ ) of three independent blood samples. Note, PAR levels of $0 \mathrm{nM}$ olaparib treated samples are set at $0.00001 \mathrm{nM}$ to calculate fits, however, are plotted at $0.1 \mathrm{nM}$. 

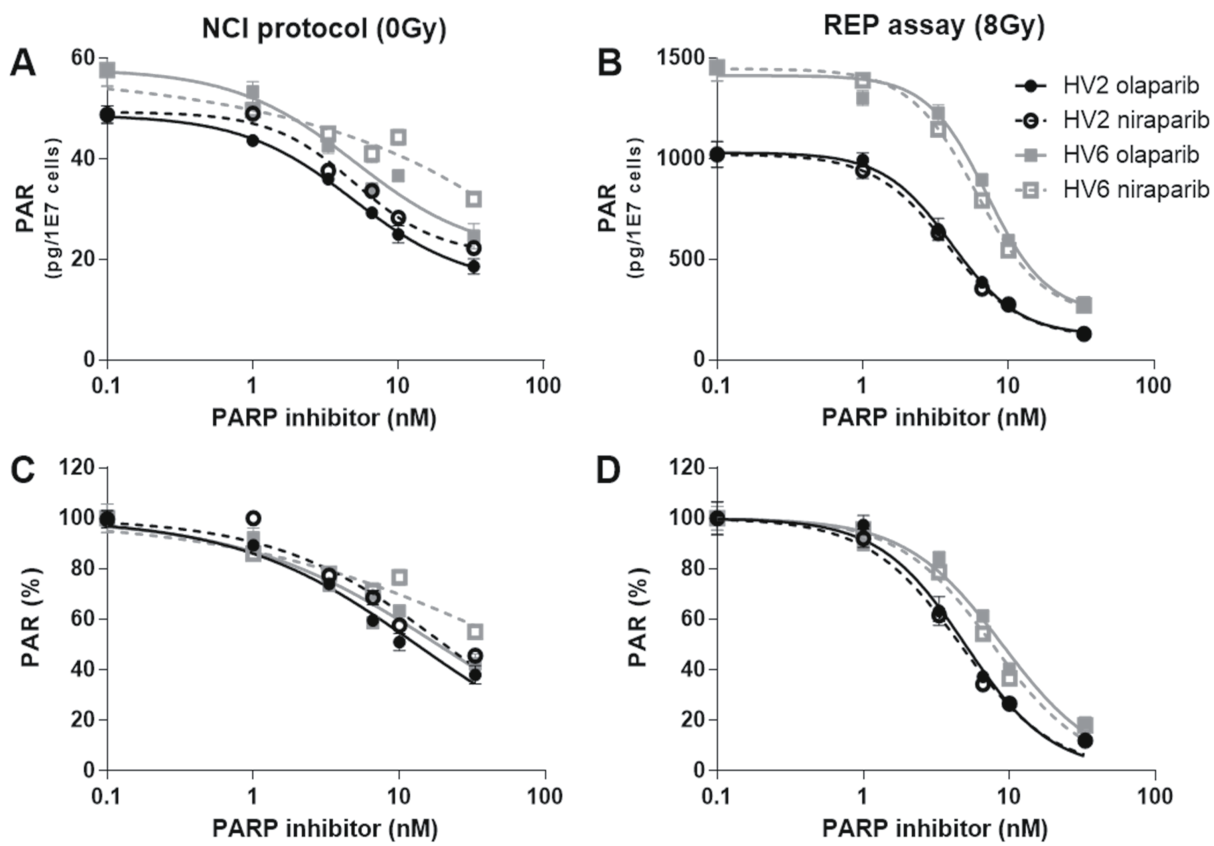

Figure 5. Comparison of individual ex vivo responses to different PARP inhibitors incubation. ( $A$ and $B$ ) PAR levels in PBMCs of two HIs after ex vivo incubation with the PARP inhibitors olaparib and niraparib at different concentrations $1 \mathrm{~h}$ before (sham-) irradiation, as determined with the $\mathrm{NCl}$-protocol and REP-assay. All samples for both, olaparib and niraparib treatment, were taken from the same blood sample. ( $C$ and $D$ ) PAR levels of figures $A$ and $B$ minus the relative $E$-max of that individual $\mathrm{HI}$ normalized to control treated samples ( $0 \mathrm{nM}$ olaparib). Data represent mean \pm SD of triplicate ELISA measurements. Note, PAR levels of $0 \mathrm{nM}$ olaparib treated samples are set at $0.00001 \mathrm{nM}$ to calculate fits, however, are plotted at $0.1 \mathrm{nM}$. 
Development of the REP-assay

We next compared PAR levels induced by ex vivo radiation in a panel of HIs and in different blood samples of the same HI. We found a strong induction of PAR levels in all HIs (Fig. 2A and B). PAR induction rates varied among HIs (range 114 pg-308 pg PAR/1E'cells per Gy, Sup. Fig. S3). Nevertheless, the day-to-day variation in PAR levels was smaller in all but one $\mathrm{HI}$ in the REP-assay than when following the $\mathrm{NCl}$ protocol (Sup. Fig. S4). PAR reduction of $90 \%$ would be quantifiable in all $\mathrm{HI}$ and of $99 \%$ in some $\mathrm{HI}$ (Fig. 2C). From this we predict that ex vivo irradiation enables accurate quantification of PAR levels in PBMCs even upon efficient PARP inhibition in almost all individuals.

\section{PARP inhibition dynamics after ex vivo irradiation}

To explore this further, we incubated intact PBMCs from HIs ex vivo with the PARP inhibitor olaparib at different concentrations. Olaparib inhibits radiation-induced PAR formation at all tested radiation doses (Fig. 3A). The relative inhibition values are similar in non-irradiated and irradiated PBMCs. There is also no apparent difference in the inhibition values at different radiation doses (Fig. 3B). Hence, there is no apparent interaction between radiation dose and PARP inhibitor activity.

\section{Maximal PARP inhibition by olaparib}

As calculated above, following the $\mathrm{NCl}$-protocol, determination of inhibition levels above $90 \%$ are not possible in most individuals. To assess the maximal inhibitory effect of olaparib, we treated PBMCs ex vivo with up to $10 \mu \mathrm{M}$ olaparib (comparable to the maximum concentration at monotherapy doses, [5]) at maximal PAR induction (32 Gy). We found that we could still quantify remaining PAR-levels in all His, which were reduced to $0.7 \%$ (Fig. 3C). Overall, cellular PARP inhibition was high at this concentration for all $\mathrm{HI}$ (>99\%), therefore also suggesting consistently strong activities at olaparib concentrations that are clinically relevant for monotherapy settings. 

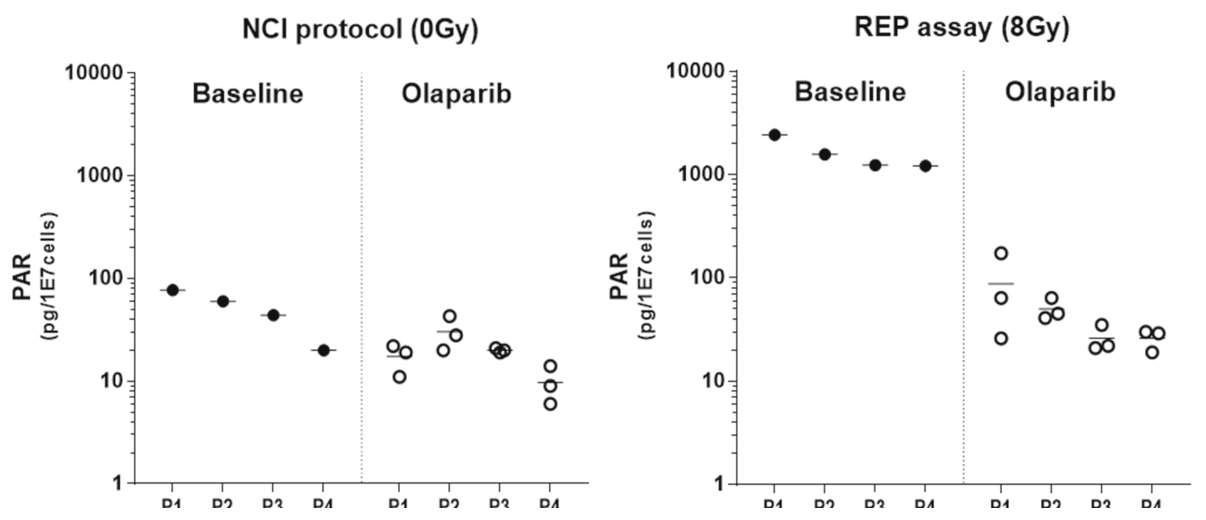

Figure 6. REP-assay detects strong inhibitor activity at low olaparib doses in NSCLC patients treated with olaparib combined with concurrent chemoradiation in clinic. Blood was drawn from four NSCLC trial patients and assayed in parallel according to the $\mathrm{NCl}$ protocol (A) or REP-assay (B) that applies $8 \mathrm{~Gy}$ irradiation as indicated. PAR levels of three blood samples from patients 1 to 4 under $25 \mathrm{mg}$ bidaily olaparib treatment (open circles) compared to two baseline values (closed circles) are shown. Similar as in the healthy individuals, baseline PAR levels in patients varied (20 to $77 \mathrm{pg} / 1 \mathrm{E}^{7}$ cells in the $\mathrm{NCl}$-protocol) and were strongly induced in all patients (1214 to $2426 \mathrm{pg}$ PAR/1E $/ \mathrm{E}^{7}$ cells per Gy) in the REPassay, with an average PAR-induction of 195 pg PAR/1Ecells per Gy. The REP-assay was able to detect strong inhibitory activity in this patient cohort with a $25 \mathrm{mg}$ bidaily dose.

\section{Olaparib activities among $\mathrm{HI}$}

The previous data (Fig. 3), suggested some difference in the PD response in different individuals. To investigate this further, we next determined the olaparib concentration dependent PAR response in a group of HIs while directly comparing the performance of the REP-assay with the $\mathrm{NCl}$-protocol. In all HIs, olaparib reduced PAR levels in a concentration dependent manner (Fig. 4A and D). We further determined absolute half maximal inhibitory concentrations (IC50s; Sup. Table S3, Fig. 4E and F). We found that IC50 determinations are inaccurate or impossible when omitting the ex vivo irradiation (Sup. Table S3), thereby demonstrating the improvement over the $\mathrm{NCl}$-protocol. The day-to-day variation in the IC50 values of each $\mathrm{HI}$ was also lower in the REP-assay. Importantly, the REP-assay revealed significant differences in IC50s between individuals. This 
remained undetected using the $\mathrm{NCl}$-protocol. Sensitivity analysis, e.g. calculation of a relative IC50 instead of an absolute IC50 [20], confirms this (Sup. Fig. S5) and shows that by optimizing the assay we were able to accurately determine olaparib responses in all HIs and to detect individual differences.

\section{Comparison of different PARP inhibitors}

This prompted us to test whether this was drug/compound-dependent. To compare within the same individual, we added different concentrations of olaparib and niraparib ex vivo to the PBMCs and chose the HIs with the highest and lowest olaparib IC50s. Consistent with the prior results only the REPassay yielded accurate IC50 determinations (Sup. Table S3). We found that the concentration dependent response of olaparib and niraparib was similar (Fig. 5 and Sup. Table S3) and confirmed a significant difference in IC50 between the two HIs (1.8/1.7-fold for olaparib/niraparib) thereby showing a yet unidentified significant variable response to PARP inhibition between different individuals.

\section{REP-assay in patients treated with olaparib}

Confirmation of efficient cellular PARP inhibition has been in particular challenging at low drug dose levels such as administrated in Phase I trials and tested in combination treatments. We therefore implemented the REP-assay in a Phase I trial (NCT01562210) for PD analyses on blood samples from NSCLC patients at the lowest dose level of olaparib (i.e. $25 \mathrm{mg}$ bidaily) and treated with concurrent chemoradiation (Sup. Table S4).

Standard $\mathrm{NCl}$-protocol PD revealed a reduction in PAR during $25 \mathrm{mg}$ bidaily olaparib treatment (Fig. 6). The same blood samples assayed according to the REPassay, however, show strong reductions in all patients. The REP-assay revealed a strong median inhibition capacity of $97 \%$ (range 96-98\%) compared to 53\% (range 49-77\%) by the $\mathrm{NCl}$-protocol. Using the REP-assay we are able to affirm $25 \mathrm{mg}$ olaparib as biologically effective dose (Fig. 6). Together these data, enabled by the REP-assay, demonstrate a strong cellular inhibition of PARP at low doses in the clinic. 


\section{DISCUSSION}

We developed and validated a clinical pharmacodynamic assay for the sensitive quantification of PAR levels and PAR reduction upon PARP inhibition in peripheral blood mononuclear cells (PBMCs). As radiation induces DNA damage which consequently increases PAR levels [19, 21], we hypothesized that ex vivo irradiation of PBMCs will amplify the PAR signal allowing sensitive quantification of PAR levels and explored this further. Indeed, ex vivo irradiation strongly induced PAR levels in PBMCs and thereby allowed sensitive and otherwise difficult quantifications of olaparib and niraparib responses in healthy individuals ( $\mathrm{HI}$ ) and patients. Due to the increased sensitivity, we were able to detect yet unidentified differences in PARP inhibitor responses among individuals. The REP-assay also extends the applicability to almost all patients. The greatly increased sensitivity enables clinical studies that could correlate individual patient PD values with individual PARP inhibitor drug responses such as toxicity and efficacy. Importantly, the REP-assay provided evidence of high inhibitory activity at low olaparib dose levels in clinical trials developing chemoradiotherapy combinations.

PAR induction by ex vivo irradiation proved to be a crucial element in the assay optimization. We found a consistent linear PAR-induction in all HIs and observed inter- and intra-individual variations in the slope of the linear PAR-induction upon irradiation (median $\% \mathrm{CV}$ of $23 \%$ and $20 \%$ respectively). PARP inhibition responses by two different drugs is, however, very similar further confirming the consistent performance of the REP-assay. Minimizing technical variation in our REP-assay while taking into account day-to-day variations, we discovered different responses to PARP inhibition in healthy individuals upon ex vivo PARP inhibitor treatment. Possible explanations for this variability include: differences in metabolic state [22], differences in PARP-1 protein expression levels [23], single nucleotide polymorphisms affecting PARP activity [24, 25] and differences in DNA damage response efficiency or in the expression of the drug efflux pump P-glycoprotein [26]. Consistent with our findings, individual differences have been found in a study assessing olaparib treatment in breast cancer patients. Using an extracellular PARP activation assay and different from assessing PAR formation in intact cells, Bundred et al [4] reported a considerable variation in PARP pharmacodynamics at similar pharmacokinetic values, suggesting such a differential individual response. It remained unclear whether these differences were due to technical or day-to-day variation or true significant differences in PARP inhibitor response. Notably, these differences in IC50, that we observed 
here, translate to different inhibitor doses required for full inhibition (Fig. 3C). Used as sensitizer, we have also shown a gradual and potent olaparib concentration dependent potentiation of radiation induced kill before [19], further arguing for personalized treatment.

The REP-assay enabled us to show high drug activity (up to 90\%) at low PARP inhibitor concentrations as low as $33 \mathrm{nM}$ that translates to a dose of just $10 \mathrm{mg}$ olaparib in clinic (after a single capsule administration)[5]. Indeed the clinical trial data confirm that an olaparib dose of $25 \mathrm{mg}$ bi-daily (tablet formulation) can reach inhibition levels of over $95 \%$ in patients, a dose 10 -fold lower than the recommended monotherapy dose [27]. Our findings are of clinical importance as they warrant careful dose escalation in combination trials. Furthermore, this stresses the necessity of highly sensitive PD assays, such as this REP-assay, in the clinical development of combination treatments, in particular, in choosing optimal schedules and doses. Future application opportunities of the REP-assay include the possibility to monitor drug uptake issues that can be caused by food/ absorption differences (e.g. due to gastrointestinal toxicities during treatment) and clinical studies that associate individual patient pharmacodynamics with toxicities. The same principle of signal enhancement by ex vivo irradiation could be applied to tumour cells, enabling clinical association studies with tumour response.

In summary, due to its increased sensitivity and quantification accuracy the REP-assay revealed individual differences in pharmacodynamic responses of PARP inhibitors and showed high activities at low drug doses in clinic. These results therefore support clinical development of combination treatments with PARP inhibitors at lower doses.

\section{ACKNOWLEDGEMENTS}

The authors wish to acknowledge the $\mathrm{NCl}$ for their development and clinical validation of the ELISA PAR assay that were the base of this optimization study. Furthermore, we would like to thank Trevigen ${ }^{\circledR}$ for providing additional plates and kits for the ELISA assay, the Pharmacy of the Slotervaart Hospital (Amsterdam, the Netherlands) for providing niraparib and $M$. Marsman for her assistance in the patent filing. We wish to acknowledge Wilma Uyterlinde and Manon VerwijsJanssen for their support in trial logistics and patient sample preparation. We would like to thank AstraZeneca and Ozlem Ataman, Susan Galbraith and Mark 
Development and validation of pharmacodynamic and diagnostic biomarker methods

O'Connor's for their past and continued support for our PARP inhibitor and radiotherapy combination efforts. 


\section{REFERENCES}

1. Kinders RJ, Hollingshead $M$, Khin S et al. Preclinical modeling of a phase 0 clinical trial: qualification of a pharmacodynamic assay of poly (ADP-ribose) polymerase in tumor biopsies of mouse xenografts. Clin Cancer Res 2008;14:6877-6885.

2. Yap TA, Sandhu SK, Workman P, de Bono JS. Envisioning the future of early anticancer drug development. Nat Rev Cancer 2010; 10: 514-523.

3. PARP Inhibitors for Cancer Therapy. Humana Press 2015.

4. Bundred N, Gardovskis J, Jaskiewicz J et al. Evaluation of the pharmacodynamics and pharmacokinetics of the PARP inhibitor olaparib: a phase I multicentre trial in patients scheduled for elective breast cancer surgery. Invest New Drugs 2013;31: 949-958.

5. Fong $P C$, Boss DS, Yap TA et al. Inhibition of poly(ADP-ribose) polymerase in tumors from BRCA mutation carriers. N Engl J Med 2009;361:123-134.

6. Ji J, Kinders RJ, Zhang $Y$ et al. Modeling pharmacodynamic response to the poly(ADP-Ribose) polymerase inhibitor ABT888 in human peripheral blood mononuclear cells. PLoS One 2011;6:e26152.

7. Kummar S, Kinders R, Gutierrez ME et al. Phase 0 clinical trial of the poly (ADP-ribose) polymerase inhibitor ABT-888 in patients with advanced malignancies. J Clin Oncol 2009;27:2705-2711.

8. NCl DoCTaD. [cited 2015 20-10-2015]; Available from: <http://dctd.cancer.
gov/ResearchResources/biomarkers/ PolyAdenosylRibose.htm>.

9. Plummer ER, Middleton MR, Jones $C$ et al. Temozolomide pharmacodynamics in patients with metastatic melanoma: dna damage and activity of repair enzymes 06alkylguanine alkyltransferase and poly(ADPribose) polymerase-1. Clin Cancer Res 2005; 11:3402-3409.

10. Plummer $R$, Jones $C$, Middleton $M$ et al. Phase I study of the poly(ADP-ribose) polymerase inhibitor, AG014699, in combination with temozolomide in patients with advanced solid tumors. Clin Cancer Res 2008;14:7917-7923.

11. Redon CE, Nakamura AJ, Zhang YW et al. Histone gammaH2AX and poly(ADP-ribose) as clinical pharmacodynamic biomarkers. Clin Cancer Res 2010;16:4532-4542.

12. Sandhu SK, Schelman WR, Wilding G et al. The poly(ADP-ribose) polymerase inhibitor niraparib (MK4827) in BRCA mutation carriers and patients with sporadic cancer: a phase 1 dose-escalation trial. Lancet Oncol 2013;14:882-892.

13. Kummar S, Chen A, Ji J et al. Phase I study of PARP inhibitor ABT-888 in combination with topotecan in adults with refractory solid tumors and lymphomas. Cancer Res 2011;71:5626-5634.

14. LoRusso PM, Li J, Burger A et al. Phase I safety, pharmacokinetic and pharmacodynamic study of the poly (ADPribose) polymerase inhibitor veliparib with irinotecan in patients with advanced tumors. Clin Cancer Res 2016.

15. Rajan A, Carter CA, Kelly RJ et al. A phase I 
combination study of olaparib with cisplatin and gemcitabine in adults with solid tumors. Clin Cancer Res 2012;18:2344-2351.

16. Rodler $E T$, Kurland $B F$, Griffin $M$ et al. Phase I Study of Veliparib (ABT-888) Combined with Cisplatin and Vinorelbine in Advanced Triple-Negative Breast Cancer and/or BRCA Mutation-Associated Breast Cancer. Clin Cancer Res 2016.

17. Su JM, Thompson $P$, Adesina $A$ et al. A phase I trial of veliparib (ABT-888) and temozolomide in children with recurrent CNS tumors: a pediatric brain tumor consortium report. Neuro Oncol 2014;16: 1661-1668.

18. Thomas HD, Calabrese CR, Batey MA et al. Preclinical selection of a novel poly(ADPribose) polymerase inhibitor for clinical trial. Mol Cancer Ther 2007;6:945-956.

19. Verhagen $C V$, de Haan $R$, Hageman $F$ et al. Extent of radiosensitization by the PARP inhibitor olaparib depends on its dose, the radiation dose and the integrity of the homologous recombination pathway of tumor cells. Radiother Oncol 2015;116:358365.

20. Sebaugh JL. Guidelines for accurate EC50/IC50 estimation. Pharm Stat 2011;10: 128-134.

21. Althaus FR, Richter C. ADP-ribosylation of proteins. Enzymology and biological significance. Mol Biol Biochem Biophys 1987;37:1-237.

22. Loetscher $P$, Alvarez-Gonzalez $R$, Althaus FR. Poly(ADP-ribose) may signal changing metabolic conditions to the chromatin of mammalian cells. Proc Natl Acad Sci U S A
1987;84:1286-1289.

23. Tentori $L$, Leonetti $C$, Scarsella $M$ et al. Inhibition of poly(ADP-ribose) polymerase prevents irinotecan-induced intestinal damage and enhances irinotecan/ temozolomide efficacy against colon carcinoma. FASEB J 2006;20:1709-1711.

24. Lockett $K L$, Hall $M C, X u J$ et al. The ADPRT V762A genetic variant contributes to prostate cancer susceptibility and deficient enzyme function. Cancer Res 2004;64: 6344-6348.

25. Wang $X G$, Wang ZQ, Tong $W M$, Shen $Y$. PARP1 Val762Ala polymorphism reduces enzymatic activity. Biochem Biophys Res Commun 2007;354:122-126.

26. Rottenberg $\mathrm{S}$, Jaspers JE, Kersbergen A et al. High sensitivity of BRCA1-deficient mammary tumors to the PARP inhibitor AZD2281 alone and in combination with platinum drugs. PNAS 2008;105:17079-84.

27. Pujade-Lauraine E, Ledermann JA, Sell $F$ et al. Olaparib tablets as maintenance therapy in patients with platinum-sensitive, relapsed ovarian cancer and a BRCA1/2 mutation (SOLO2/ENGOT-Ov21): a doubleblind, randomised, placebo-controlled, phase 3 trial. Lancet Oncol 2017; published online Jul 25. 


\section{SUPPLEMERARY MATERIAL}

TABLES1

\begin{tabular}{|c|c|}
\hline $\begin{array}{l}\text { PBMC lysate } \\
\text { preparation }\end{array}$ & $\begin{array}{l}\text { Cell lysates from PBMCs (peripheral blood mononuclear cells ) were prepared following the NCl advised protocol for clinical use } \\
\text { with some minor adaptations as explained here briefly. PBMCs were isolated from whole blood, chilled on ice and } \\
\text { subsequently suspended in PBS at a concentration of } 4 \text { E6 cells/ml. Samples containing 2E6 intact PMBCs were irradiated ex } \\
\text { vivo and incubated, followed by cell lysate preparation. Different temperatures and incubation times were tested to find } \\
\text { optimal conditions. In this study, samples that were prepared according to the 'NCI-protocol' were sham-irradiated and } \\
\text { incubated for } 1 \text { h on ice. }\end{array}$ \\
\hline Ex vivo treatments & $\begin{array}{l}\text { Samples that were prepared in the 'REP (Radiation Enhanced PAR) assay' were irradiated with 8Gy on ice and incubated for } 1 \mathrm{~h} \\
\text { on ice. In experiments that test the quantification capacity of the assay to determine PARP inhibition, intact PBMCs in plasma } \\
\text { of healthy (and untreated) individuals were incubated ex vivo with increasing concentrations of the PARP inhibitors olaparib } \\
\text { and niraparib at } 37^{\circ} \mathrm{C} \text { 1h before irradiation on ice. In this setting, olaparib plasma levels and protein-binding after ex vivo } \\
\text { incubation were comparable to the clinical situation, as determined by high performance liquid chromatography-tandem mass } \\
\text { spectrometry (HPLC-MS/MS, Supplementary Fig. S1). }\end{array}$ \\
\hline Data analysis & $\begin{array}{l}\text { PAR levels (presented in pg/1E7 PBMCS) were calculated from the linear fits of the PAR standard curves, as a wide range of cell } \\
\text { lysate dilutions were used to cover the large PAR signal range. All further quality control steps and criteria were followed as } \\
\text { recommended in the NCl protocol. } \\
\text { The lower limit of quantification (LLOO) was defined as the lowest concentration of PAR standard that passes all criteria of the } \\
\text { NCl protocol [6], i.e. mean RLU above the mean RLU of standard Opg/ } \mathrm{ml}+3^{*} \mathrm{SD} \text { of standard Opg/ml at a signal to noise ratio } \\
\geq 1.1 \text {. }\end{array}$ \\
\hline IC50 determinations & $\begin{array}{l}\text { The relative PAR reduction at 10uM olaparib in 32Gy irradiated samples was defined as the maximal effect of PARP inhibition } \\
\text { (E-max). For absolute IC50 (half maximal inhibitory concentration) calculations [20], PAR values minus the relative E-max of } \\
\text { that individual HI were normalized to untreated samples. These normalized PAR values were fitted using the 'log/inhibitor) } \\
\text { versus normalized response - variable slope' equation in GraphPad Prism to obtain IC50 values for each blood sample of each } \\
\text { H. Average IC50 values were tested for significant differences between HIs using a one-way ANOVA test with a subsequent } \\
\text { Tukey's multiple comparison test without assuming sphericity in GraphPad Prism. Differences were considered significant if } P \text { - } \\
\text { value }<0.05 \text {. }\end{array}$ \\
\hline
\end{tabular}


Table S2. Characteristics of healthy individuals contributing blood. In vitro radiation and PARP inhibitor incubations were performed on multiple independent blood draws from 10 different healthy individuals (HI) from our research departments with no apparent pathologies. Due to the associated high costs of repeated assays and depending on the research question and statistical requirements, the panel size of individuals was reduced to 6 individuals whom were randomly selected from the 10 according to their availabilities. The two individuals with the largest difference in the evaluated ex vivo inhibitor activity parameters were purposely selected when comparing different compounds to be able to test the consistency of this observation.

\begin{tabular}{l|l|l|}
\hline HI & $\mathbf{N = 1 0}$ & $\mathbf{N = 6}$ \\
\hline $\begin{array}{l}\text { Age (years) median- } \\
\text { range }\end{array}$ & $5(50 \%)$ & $1(10 \%)$ \\
\hline Ethnic origin & $33(26-50)$ & $34(26-50)$ \\
\hline $\begin{array}{l}\text { Asian 2 (20\%) } \\
\text { Caucasian } 8 \\
(80 \%)\end{array}$ & $\begin{array}{l}\text { Asian 2 (40\%) } \\
\text { Caucasian 4 } \\
(60 \%)\end{array}$ \\
\hline
\end{tabular}

Table S3. Comparison of olaparib and niraparib IC50s as determined ex vivo by the REP-assay or following the $\mathrm{NCl}$-protocol. Individual blood samples were treated and prepared simultaneously, following either the NCI-protocol or REPassay protocol, while adding olaparib or niraparib to the PBMC samples; see M\&M and Supplementary Table S1 for further specifications. IC50s values are in nM and were calculated for each healthy individual (HI) on PAR values as determined following the protocols as indicated above. In the first blood sample of $\mathrm{HI}$, the IC50 could not be determined (ND) by the NCI-protocol as there were too few data points above the lower limit of quantification (LLOQ). Using the NCl-protocol, the IC50 could not be calculated in one of the blood samples in HI2, while applying the REP-assay IC50s could be calculated in all blood samples of all HIs. In all the 17 blood samples in which both assays could calculate an IC50, the $95 \% \mathrm{Cl}$ were greatly smaller in the REP-assay, 6-fold on average with a range of 2.8-fold to 10fold with a range of 2.8 -fold to 10 -fold. The day-to-day variation in the IC50 values of each $\mathrm{HI}$ was also lower when in the REP-assay was used than when the $\mathrm{NCl}$ protocol was followed (median \%CV: $8 \%$ versus and $25 \%$ respectively). IC50 $=$ half maximal inhibitory concentration, $\mathrm{Cl}=$ confidence interval, $\mathrm{NA}=$ not assessed. 


\begin{tabular}{|c|c|c|c|c|c|c|c|c|}
\hline \multirow{3}{*}{$\begin{array}{c}\mathrm{NCl}- \\
\text { protocol }\end{array}$} & \multirow{2}{*}{\multicolumn{2}{|c|}{$\begin{array}{c}\text { Blood sample } 1 \\
\text { olaparib }\end{array}$}} & \multirow{2}{*}{\multicolumn{2}{|c|}{$\begin{array}{c}\text { Blood sample } 2 \\
\text { olaparib }\end{array}$}} & \multicolumn{4}{|c|}{ Blood sample 3} \\
\hline & & & & & \multicolumn{2}{|c|}{ olaparib } & \multicolumn{2}{|c|}{ niraparib } \\
\hline & IC50 & $95 \% \mathrm{Cl}$ & IC50 & $95 \% \mathrm{Cl}$ & IC50 & $95 \% \mathrm{Cl}$ & IC50 & $95 \% \mathrm{Cl}$ \\
\hline HI1 & 24.0 & $16.1-35.8$ & 29.4 & $26.1-33.1$ & 19.1 & $15.3-23.9$ & NA & \\
\hline HI2 & $N D$ & & 12.5 & $9.9-15.7$ & 13.2 & $11.4-15.3$ & 20.4 & $16.0-26.0$ \\
\hline HI3 & 10.6 & $7.0-16.1$ & 12.3 & $9.5-15.7$ & 17.1 & $15.9-18.3$ & NA & \\
\hline HI4 & 25.9 & $15.5-43.4$ & 15.3 & $11.7-20.1$ & 12.6 & $11.2-14.3$ & NA & \\
\hline HI5 & 12.8 & $9.5-17.1$ & 14.1 & $12.2-16.3$ & 28.2 & $22.2-35.8$ & NA & \\
\hline HI6 & 14.7 & $9.7-22.4$ & 15.5 & $11.4-21.1$ & 18.4 & $14.0-24.1$ & 63.4 & $34.7-116$ \\
\hline
\end{tabular}

S3B

\begin{tabular}{|c|c|c|c|c|c|c|c|c|}
\hline \multirow{3}{*}{ REP-assay } & \multirow{2}{*}{\multicolumn{2}{|c|}{$\begin{array}{c}\text { Blood sample } 1 \\
\text { olaparib }\end{array}$}} & \multirow{2}{*}{\multicolumn{2}{|c|}{$\begin{array}{c}\text { Blood sample } 2 \\
\text { olaparib }\end{array}$}} & \multicolumn{4}{|c|}{ Blood sample 3} \\
\hline & & & & & \multicolumn{2}{|c|}{ olaparib } & \multicolumn{2}{|c|}{ niraparib } \\
\hline & IC50 & $95 \% \mathrm{Cl}$ & IC50 & $95 \% \mathrm{Cl}$ & IC50 & $95 \% \mathrm{Cl}$ & IC50 & $95 \% \mathrm{Cl}$ \\
\hline HI1 & 7.5 & $6.3-9.1$ & 7.4 & $7.1-7.8$ & 7.7 & $7.1-8.4$ & NA & \\
\hline HI2 & 3.4 & $2.6-4.4$ & 4.3 & $3.9-4.7$ & 5.0 & $4.4-5.6$ & 4.6 & $4.2-5.1$ \\
\hline HI3 & 5.8 & $4.9-6.9$ & 5.5 & $5.1-6.0$ & 6.3 & $5.9-6.8$ & NA & \\
\hline HI4 & 6.4 & $5.2-8.0$ & 6.3 & $5.8-6.9$ & 7.3 & $6.7-7.8$ & NA & \\
\hline HI5 & 6.1 & $5.0-7.4$ & 6.5 & $6.1-7.0$ & 7.3 & $6.6-8.1$ & NA & \\
\hline HI6 & 7.5 & $6.2-9.1$ & 9.4 & $8.6-10.3$ & 9.0 & $8.0-10.0$ & 7.7 & $7.0-8.4$ \\
\hline Ratio IC5O HI6/HI2 & 2.2 & & 2.2 & & 1.8 & & 1.7 & \\
\hline
\end{tabular}


Table S4. Patient characteristics of clinical trial PD data. Clinical details from the four NSCLC patients of whom blood was drawn for the PD evaluation of the clinical study (Clinicaltrials.gov: NCT01562210, Materials and Methods, Supplementary Table S1). Multiple blood draw samples were acquired for PD analysis before, during and after olaparib-chemoradiotherapy combination treatment of these patients. All samples were acquired and prepared as planned and indicated in the material and methods section. $\mathrm{C}=$ Caucasian, M=Male, F=Female.

Patient number
$N$ of PD samples total
$N$ of PD samples within treatment
$N$ of PD samples without olaparib
Ratio lymphocytes to monocytes (with olaparib)
Ratio lymphocytes to monocytes (w/o olaparib)
Gender
Age (years)
Ethnic origin

\begin{tabular}{|c|c|c|c|}
\hline 1 & $\mathbf{2}$ & $\mathbf{3}$ & $\mathbf{4}$ \\
\hline 5 & 5 & 5 & 5 \\
\hline 3 & 3 & 3 & 3 \\
\hline 2 & 2 & 2 & 2 \\
\hline 1.35 & 1.62 & 2.14 & 2.92 \\
\hline 0.89 & 2.54 & 3.10 & 5.25 \\
\hline M & F & M & F \\
\hline 73 & 55 & 61 & 72 \\
\hline C & C & C & C \\
\hline
\end{tabular}
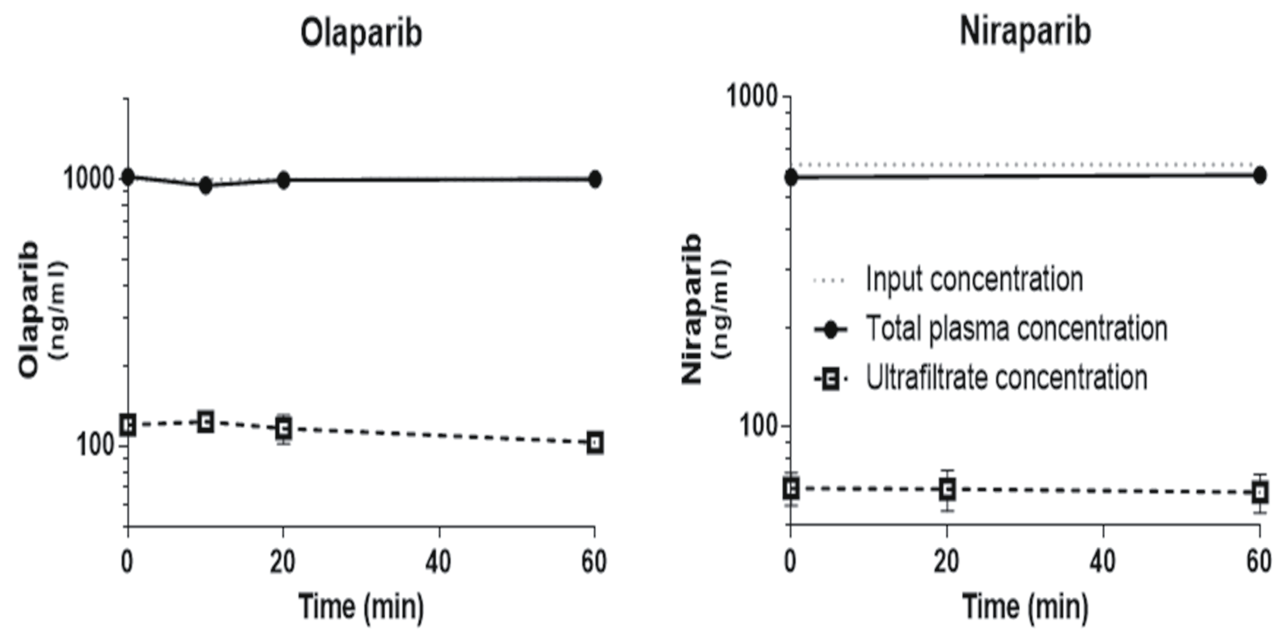

Figure S1. Olaparib and niraparib concentrations in plasma and ultra filtrates after ex vivo incubation. To check whether PARP inhibitor concentrations in the ex vivo incubations of plasma containing PBMCs resemble the clinically observed (in vivo) PARP inhibitor concentrations, we determined olaparib and niraparib concentrations in plasma and ultrafiltrates after different incubation times in $1000 \mathrm{ng} / \mathrm{ml}$ olaparib and $625 \mathrm{ng} / \mathrm{ml}$ niraparib, respectively. PARP inhibitor concentrations were measured as validated for human plasma in Nijenhuis et al (J Chromatogr B Technol Biomed Life Sci, 2013) and in Van Andel et al (J Chromatogr B Analyt Technol Biomed Life Sci, 2017) using high performance 
liquid chromatography-tandem mass spectrometry (HPLC-MS/MS). Stable total plasma concentrations with an average of $992 \mathrm{ng} / \mathrm{ml}$ olaparib (99.2\% of input concentration) and $577 \mathrm{ng} / \mathrm{ml}$ niraparib (92\% of input concentration) were found. Protein-unbound concentrations, i.e. the free fraction of the drug, were measured in ultrafiltrates that were prepared from plasma filtered through $30 \mathrm{kDa}$ cut-off filters. Olaparib and niraparib both bind fast, immediately reaching a steady state between bound and unbound concentrations at $\mathrm{t}=0$ (note, includes 10 minutes centrifugation time). In average, $12 \%$ of olaparib and $11 \%$ of niraparib was found to be unbound. This fraction of unbound olaparib and niraparib is comparable to clinical data (data on file). Dotted line reflects input concentration.

\section{A Whole blood at room temperature}

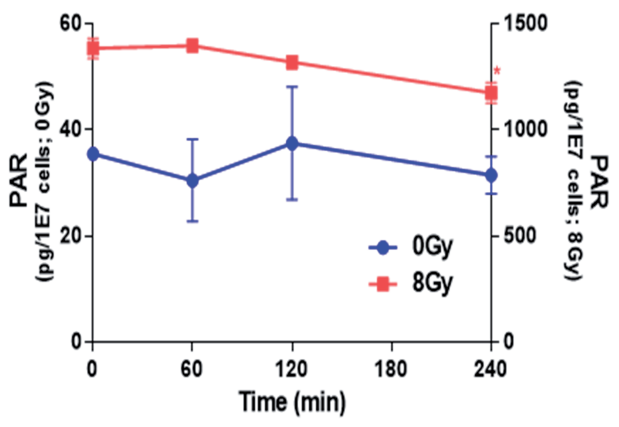

C

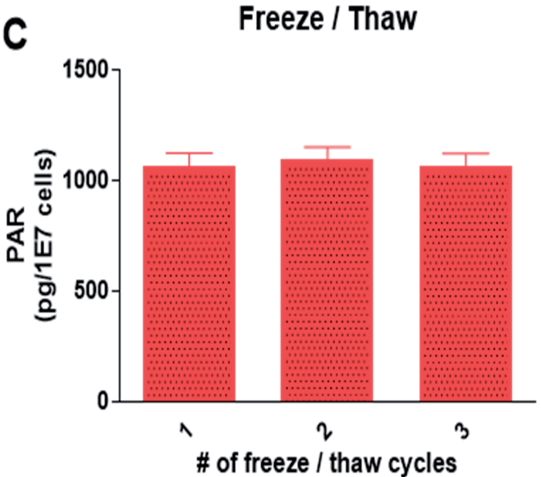

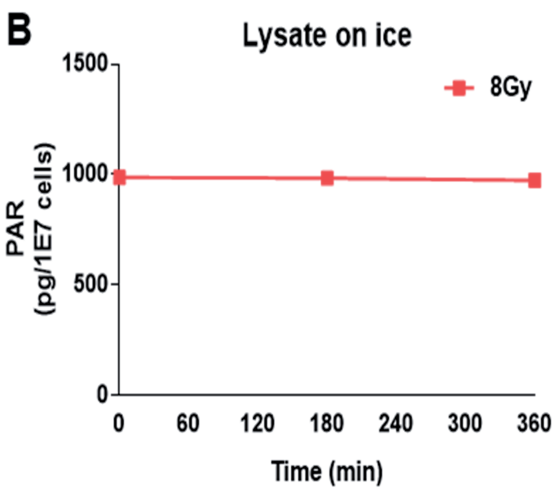

Long term stability

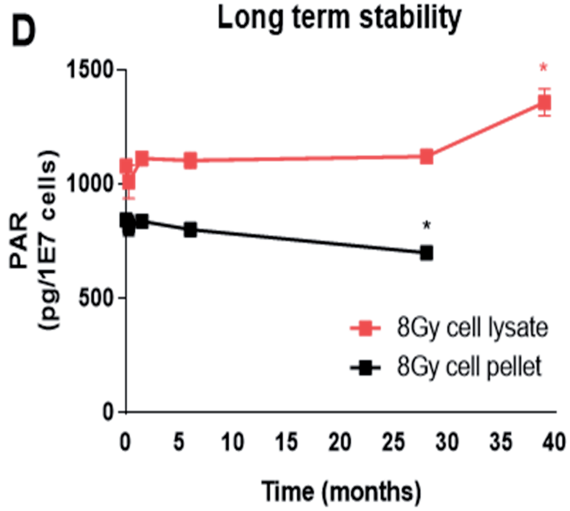

Figure S2. Stability of PAR levels after ex vivo irradiation of PBMCs. Ex vivo irradiation of PBMCs did not negatively influence the stability of PAR levels in cell lysates, e.g. after long term storage at $-80^{\circ} \mathrm{C}$ or after multiple freeze/thaw cycles. (A) Extended storage of whole blood samples prior to ex vivo irradiation has little influence on the PAR induction capacity, therefore allowing for large time margins prior to sample preparation. Whole blood was kept in CPTTM tubes at room temperature for different time intervals 
prior PBMC isolation, irradiation, $1 \mathrm{~h}$ incubation on ice and lysate preparation. PAR levels remained relatively stable throughout. A significant decrease in PAR levels was only observed in the irradiated samples at $4 \mathrm{~h}\left(15 \%\right.$ decrease from $1385 \mathrm{pg} / 1 \mathrm{E}^{7}$ cells at $\mathrm{t}=0$ to $1175 \mathrm{pg} / 1 \mathrm{E}^{7}$ cells, t-test, $\mathrm{P}<0.0001$ ) indicating a small reduction in the PAR induction capacity in these older blood draw samples. (B) Radiation-induced PAR levels remain stable in lysates on ice. Fully prepared lysates, as prepared in the REP-assay, were stored on ice for the indicated times. PAR levels remained stable for a minimum period of three hours. (C) Thawing and re-freezing does not affect PAR levels. PAR levels, as determined with the REP-assay, remained stable after multiple rounds of freeze $\left(-80^{\circ} \mathrm{C}\right)$ and thaw cycles of the lysates. D. REP-assay determined PAR level stability allows long term storage. PAR levels in cell lysates remained stable, no significant difference were observed for a minimal period of 28 months. To assess long term storage and test alternative long term storage options, we determined PAR level stabilities in PBMCs that were stored at $-80^{\circ} \mathrm{C}$ after centrifugation, removal of PBS and snap freezing in liquid nitrogen as a cell pellet (i.e. after irradiation at $8 \mathrm{~Gy}$ and $1 \mathrm{~h}$ incubation on ice) compared to a storage as lysates from these cells. Overall, PAR levels remained high and stable for a minimal period of 28 months. However, storage as cell pellets resulted in a $22 \%$ drop of the PAR levels and a further decrease in PAR levels at 28 months. We therefore recommend the preparation of lysates for long term storage. All data represent mean \pm SD of triplicate ELISA measurements. * indicates a significant difference compared to control $(t=0)$ sample with $\mathrm{P}<0.05$ (t-test, corrected for multiple testing by Dunnett's).

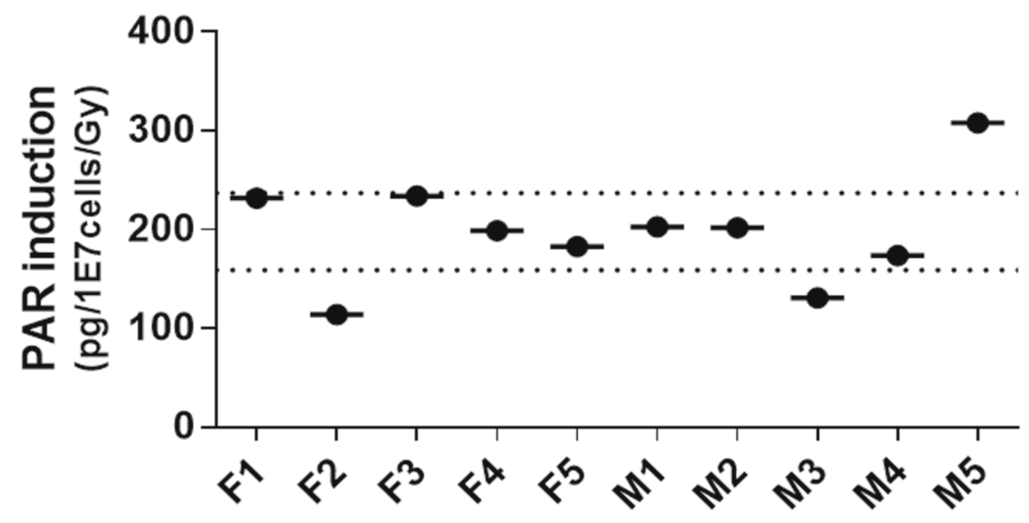

Figure S3. PAR induction varies among individuals. PAR induction values, i.e. pg PAR induced by $1 \mathrm{~Gy}$ in $1 \mathrm{E} 7$ cells, (pg/1E7 cells/Gy) as calculated from individual radiation dose response curves in the 10 healthy individuals ( $F=$ female, $M=$ male) represent the efficacy of radiation to induce PAR in the PBMCs in different individuals (Figure 2). Dotted lines represent $95 \% \mathrm{Cl}$ around the mean PAR induction value of the tested population. 

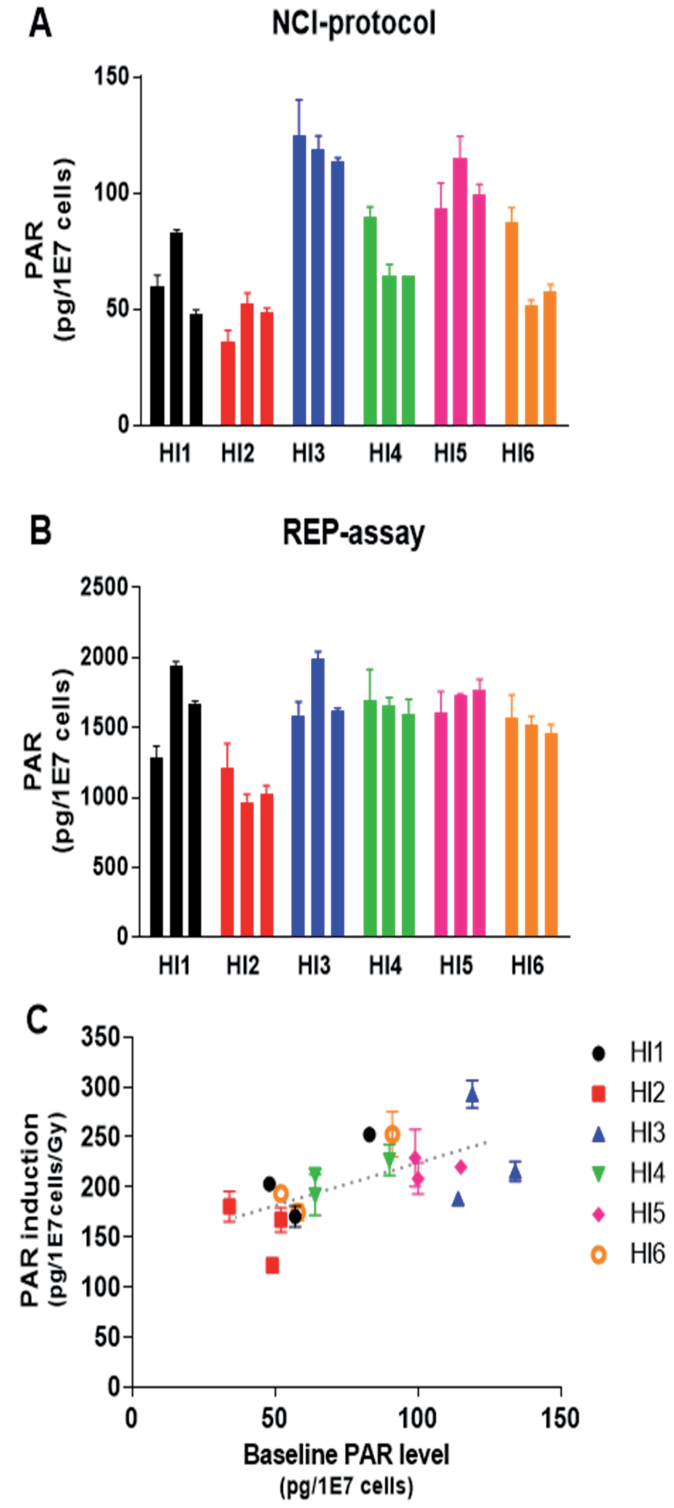

Figure 4S. Biological variation in the tested protocols. (A and B). PAR levels determined following the $\mathrm{NCl}$ protocol and according to the REPassay in 6 healthy individuals (HIs) on three different days as indicated. The day-to-day coefficient of variation $(\% \mathrm{CV})$ in the samples ranged from $5 \%$ to $29 \%$ with a median of $20 \%$ when prepared according to the $\mathrm{NCl}$ protocol. The day-to-day \%CV in the samples prepared according to the REP-assay ranged from $3 \%$ to $20 \%$ with a median of $9 \%$. In all but one $\mathrm{HI}$, the day-to-day \%CV was lower in the samples that were prepared according to the REP-assay than in the samples that were prepared following the $\mathrm{NCl}$ protocol. The difference is, however, not statistically significant (Wilcoxon matched-pairs signed rank test: $p=$ 0.19). Data represent the mean $\pm S D$ of triplicate ELISA measurements. C. Exploration of the relationships between baseline PAR levels (nonirradiated samples) and the PAR induction values (as calculated from individual radiation dose response curves) in the HIs. There is a significant correlation between baseline PAR levels and PAR induction (Pearson correlation $\mathrm{P}=0.006$, dotted

line). Little of the intra-individual variation in PAR induction is however explained by the differences in the baselines $\left(R^{2}=0.39\right)$. Most of the variation in PAR baseline levels seemed to be explained by inter-individual variation (see also Supplementary Fig. S3). When evaluating the day-to-day variation in the PAR induction values (PAR/Gy), we found that the median \%CV of PAR induction was $20 \%$ (range 5-23\%). Data represent the mean \pm SD of triplicate ELISA measurements. 

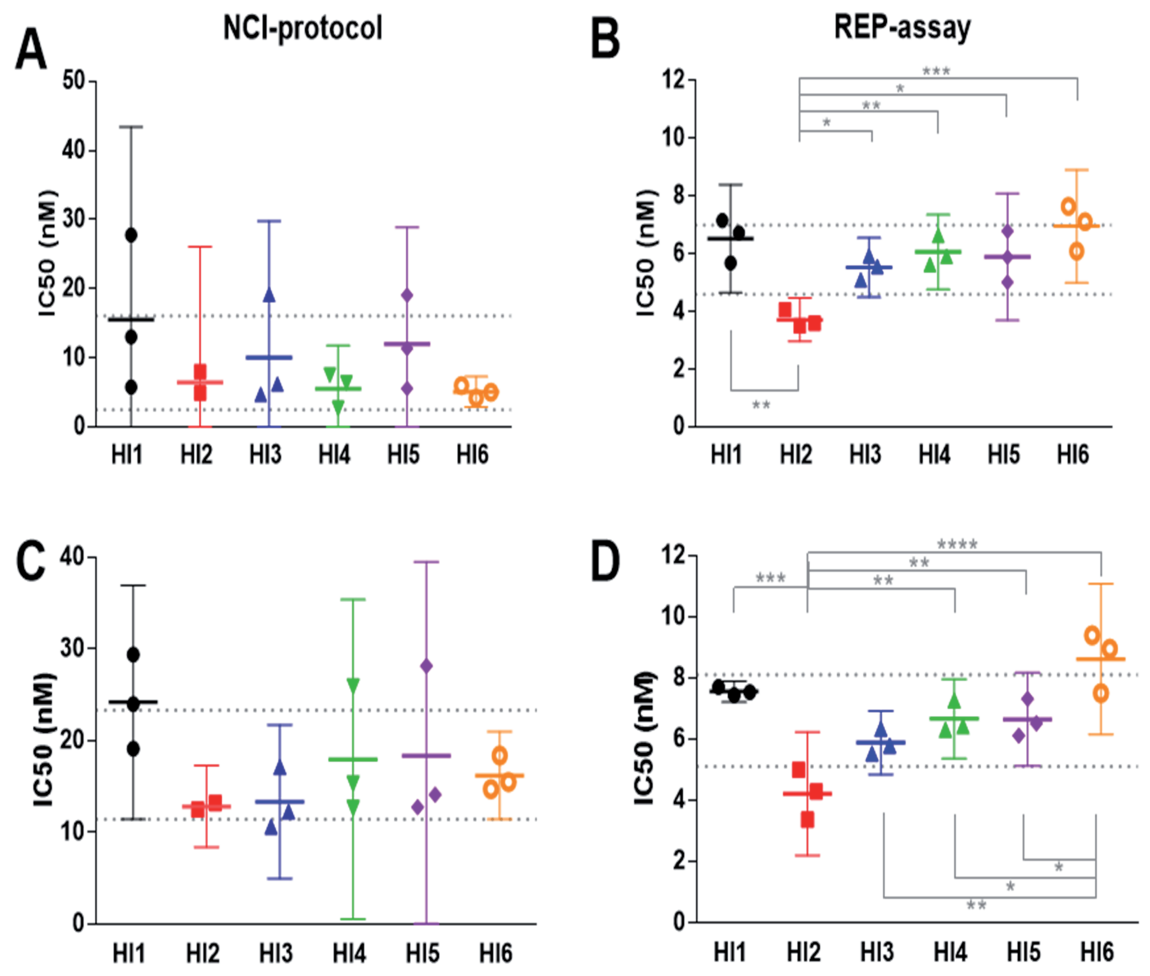

Figure 5S. Sensitivity analysis of IC50 determination. IC50 values, and their $95 \%$ confidence intervals, can change depending on the IC50 calculation method. Different IC50 determination methods did not alter the determined IC50 values or the observed inter-individual differences in the REP-assay but did so when using the currently used NCl-protocol. (A and B). "Relative" IC50s for olaparib (relative half maximal inhibitory concentrations; i.e. the value halfway between the fitted top and bottom of the inhibition curve) of 6 healthy individuals (HIs) as calculated from non-normalized PAR levels that were determined following the $\mathrm{NCl}$ protocol (A) or according to the REP-assay (B), respectively, using a 4-parameter fit (i.e. $\log$ (inhibitor) versus response - variable slope function in GraphPad Prism). Note, PAR levels of $0 \mathrm{nM}$ olaparib treated samples are set at $0.00001 \mathrm{nM}$ to calculate fits, however, for clarity they are plotted at $0.1 \mathrm{nM}$ in the graphs in Figure 4. (C and D). "Absolute" IC50s calculations (i.e. top and bottom of the inhibition curve are pre-defined). Absolute IC50s are shown for olaparib of $6 \mathrm{HIs}$ as calculated from PAR levels after subtraction of the relative E-max of that individual $\mathrm{HI}$ and normalization against untreated samples in $\mathrm{NCl}$-protocol and REPassay samples, respectively. Values of the untreated samples $(0 \mathrm{nM})$ were set at 0.00001 $\mathrm{nM}$ on the logarithmic concentration scale for IC50 determination. Excluding the values from the untreated samples $(0 \mathrm{nM})$ from the inhibition curve fits and therefore from the IC50 determinations resulted in the same overall conclusions as in Figure 4, i.e. up to 2-fold differences in IC50s. Data represent the mean $\pm 95 \% \mathrm{Cl}$ of three independent blood samples. Dotted lines indicate the mean \pm SD of IC50s of all HIs. Level of significance as tested by oneway ANOVA is: ${ }^{*} \mathrm{P}<0.05,{ }^{* *} \mathrm{P}<0.01, * * * \mathrm{P}<0.001, * * * * \mathrm{P}<0.0001$. 


\section{CHAPTER 1}

Development and validation of pharmacodynamic and diagnostic cancer biomarker methods

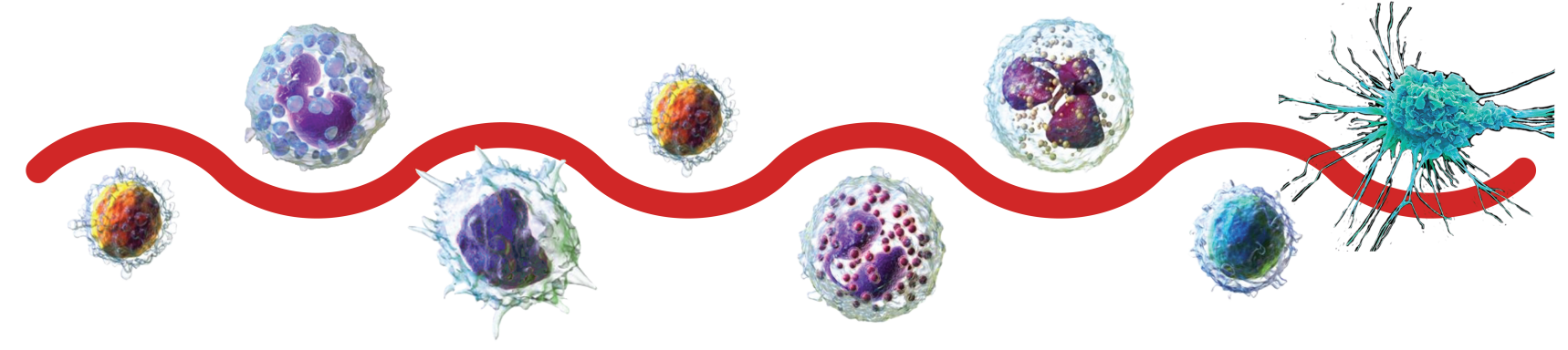

1.7

Multiparameter flow cytometry assay for quantification of immune cell subsets, PD-1

expression levels and PD-1 receptor occupancy

by nivolumab and pembrolizumab

Dick Pluim*, Willeke Ros*, Iris H.C. Miedema, Jos H. Beijnen, and Jan H. M. Schellens

* authors contributed equally and share first authorship

Cytometry Part A 2019;95:1053-1065 


\section{ABSTRACT}

We report the development and validation of a twelve parameter fluorescence activated cell sorting method for the sensitive determination of cell concentrations, their expression of PD-1, and PD-1 receptor occupancy. Cell subsets include CD4 ${ }^{+}$ and $\mathrm{CD}^{+}{ }^{+}$-T-cells, B-cells, natural killer cells, classical-, intermediate- and non-classical monocytes, and myeloid- and plasmacytoid dendritic cells. Cells were isolated from peripheral blood by density gradient centrifugation. The validation parameters included specificity, linearity, sensitivity, precision, biological within- and between subject variation, and storage stability. The lower limit of quantification was $5.0 \%$ of PD- $1^{+}$cells. Samples were stable for at least 153 days of storage at $80^{\circ} \mathrm{C}$. The clinical applicability of the method was demonstrated in 11 advanced cancer patients by the successful determination of immune cell concentrations, relative number of PD-1+ immune cells, and number of PD-1 molecules per immune cell. Shortly after infusion of nivolumab, receptor occupancy on CD8+-T-cells was $98 \%$. Similar values were found predose cycle 2 , suggesting receptor occupancy remained high throughout the entire cycle. 


\section{INTRODUCTION}

Checkpoint blockade therapy has demonstrated remarkable efficacy against numerous cancer types. The monoclonal antibodies nivolumab and pembrolizumab have shown anti-tumor activity in melanoma, non-small cell lung cancer (NSCLC), urothelial cancer, head and neck cancer, gastric cancer, renal cell carcinoma (RCC), Hodgkin's Lymphoma, cervical cancer and mismatch repair deficient tumors (dMMR) (1-9). Overall response rates have been up to $30-40 \%$ for melanoma, up to $20 \%$ for NSCLC, and up to $25 \%$ in RCC treated with programmed cell death protein 1 (PD-1) inhibitor monotherapy $(3,4,10)$.

Both nivolumab and pembrolizumab block PD-1, a protein on the surface of immune cells acting as a receptor checkpoint molecule. Upon binding of PD-1 to its ligand PD-L1, expressed on tumor cells, activated T-cells become anergic, which makes them unable to eradicate cancer cells. The therapeutic anti-PD-1 $\operatorname{lgG}_{4}$ antibodies nivolumab and pembrolizumab can block this interaction, thereby preventing T-cell inhibition and allowing effective anti-tumor immune responses. Whereas pembrolizumab is a humanized antibody, nivolumab is a fully human antibody. Pembrolizumab and nivolumab bind at partly overlapping sites of the extracellular domain of PD-1. Nivolumab binding is dominated by interactions with the PD-1 N-loop, whereas for pembrolizumab this is with the PD-1 CD loop (11). Both antibodies bind PD-1 with high affinity: Nivolumab binds PD-1 with an half maximal effective concentration (EC50) of 3.06 pM, and pembrolizumab with 29 pM $(12,13)$.

Much effort has been put into identifying biomarkers which help select those patients who are likely to respond to treatment. Approved biomarkers include PDL1 expression and mismatch repair deficient/microsatellite instability high tumors $(14,15)$. Other biomarkers correlating to response include tumor infiltrating lymphocytes, number of $\mathrm{CD}^{+}-\mathrm{T}$-cells, T-cell receptor clonality, and IFN- $\gamma$ signature expression (16-20). Furthermore, absolute lymphocyte and monocyte counts have shown to predict time to reponse, time to progression, overall survival, and immune related adverse effects of immunotherapy $(21,22)$.

Potential other pharmacodynamic biomarkers which may require further investigation are the receptor occupancy (RO) of PD-1 upon treatment with anti-PD-1 immunotherapeutic antibodies, and PD-1 expression on immune cell subtypes other than T-cells (23). PD-1 RO has been described during the phase I study of nivolumab (24). RO was determined on $\mathrm{CD}^{+}$-peripheral blood mononuclear cells (PBMCs) from patients receiving $0.3,1,3$ or $10 \mathrm{mg} / \mathrm{kg}$. In this 
study, the mean RO was $85 \%$ (70 - 97\%) at the end of infusion (EOI), and $72 \%$ (59$81 \%)$ after 57 days of infusion. RO was dose-independent and the half-life was 150 days. The method which was used to assess RO is in brief: PBMCs were incubated with either an isotype control or nivolumab, followed by incubation with a murine biotin-labelled anti-human- $\operatorname{lgG}_{4}$. RO was estimated as the ratio of the percent of $\mathrm{CD}^{+}$-cells stained with isotype control to that stained with nivolumab.

Thus far, the main focus of PD-1 expression in relationship to anti-PD-1 treatment has been on $\mathrm{CD}^{+}$and $\mathrm{CD}^{+}$-T-cells (25). In cancer patients, naïve T-cells show low ( 1\%) percentages of PD-1 expression, whereas for central memory and effector memory T-cells this percentage lies substantially higher (40 - 60\%) (26-28). However, PD-1 is not solely expressed on T-cells. PD-1 also appears to play roles on B-cells, natural killer (NK)-cells, monocytes and dendritic cells (2933 ). Approximately $25 \%$ ( $5-45 \%)$ of B-cells, and up to $8 \%(2-13 \%)$ of NK-cells express PD-1 (34-36). PD-1 expression on monocytes and dendritic cells has been described as well, but results are inconsistent $(30,31)$.

A high variability is seen across studies regarding PD-1 expression on immune cell subsets. This variability may have been caused by clinical factors such as disease status and disease type (26,31). Another possible source of variability could have been the use of methods that were not robust or thoroughly validated.

Here, we report the development and validation of a sensitive pharmacodynamic assay for the determination of the concentration of $\mathrm{CD}^{+}$and CD8 ${ }^{+}$-T-cells, B-cells, NK-cells, classical monocytes (CM), intermediate monocytes (IM), non-classical monocytes (NCM), myeloid dendritic cells (mDC), and plasmacytoid dendritic cells (pDC) in blood, number of PD-1+ immune cells, and number of PD-1 molecules per immune cell. Our method does not rely on isotype controls, which can result in an erroneous estimation of the background level (37). Within- and between subject biological variation in the relative number of PD- $1^{+}$cells and PD-1 expression were determined in 10 healthy volunteers. Clinical applicability was demonstrated in 11 advanced cancer patients who were treated with nivolumab $(n=6)$ or pembrolizumab $(n=5)$.

\section{MATERIALS AND METHODS}

\section{Reagents and chemicals}

The water used was of Milli-Q grade (Millipore, USA). Ficoll-paque ${ }^{\text {tm }}$ PLUS was obtained from General Electric Healthcare (Little Chalfont, UK). Phosphate 
buffered saline (PBS) was purchased from GIBCO BRL (Gaithersburg, MD, USA). Eppendorf ${ }^{\circledR}$ LoBind microcentrifuge $2.0 \mathrm{~mL}$ tubes, bovine serum albumin (BSA), fetal calf serum (FCS), and human IgG1k were purchased from Sigma (St. Louis, MO, USA). Beads buffer (BB) and BB-5\%BSA consisted of PBS with 2 $\mathrm{mM}$ EDTA, and respectively $0.5 \%$ and $5 \%$ (w/v\%) BSA. All buffers were filtered through $0.22 \mu \mathrm{m}$ filters. PBS and buffers were chilled on ice before use. Neutral methanol-free $40 \%$ (w/v\%) formaldehyde in physiological salt was prepared from paraformaldehyde purchased from Merck (Darmstadt, Germany). Live/Dead ${ }^{\text {TM }}$ Fixable Violet Dead Cell Stain and Spherotech rainbow beads were purchased from ThermoFisher (Landsmeer, the Netherlands). Live-dead stain was diluted 500-fold in PBS immediately before use. Ionomycin, phorbol-12-myristate13-acetate, and Cryosofree ${ }^{\mathrm{TM}}$ were from Sigma (St. Louis, USA). Quantum ${ }^{\mathrm{TM}}$ Simply Cellular ${ }^{\circledR}$ mouse IgG (QSC) beads were from Bio-Rad (Veenendaal, the Netherlands). Antibody cocktail consisted of $8 \mu \mathrm{l}$ of human IgG1k from Sigma and the following anti-human antibodies: $0.5 \mu \mathrm{l}$ of CD3-APC-Cy7 (clone Hit3a), $1 \mu \mathrm{l}$ of CD8-PerCP-Cy5.5 (clone SK1), $2 \mu$ of CD14-BV510 (clone M5E2) and $0.5 \mu$ of CD16-AF700 (clone 3G8) from ITK (Uithoorn, the Netherlands), $1 \mu$ of CD4-APC (clone VIT4) from Miltenyi (Leiden, the Netherlands), $0.5 \mu$ of CD11C-BV650 (BLy6), $2 \mu$ of CD19-BV711 (clone SJ25C1), $0.5 \mu$ of CD56-FITC (clone TULY56), 0.5 $\mu$ of CD123-BV605 (clone 7G3), and $0.5 \mu$ of HLA-DR-BV786 (clone G46-6) from Becton Dickinson (Heidelberg, Germany). PD-L2 was from Sino Biological (Beijing, China). Anti-human PD-1 (clone PD1.3.1.3) was from Miltenyi. Anti-human IgG4-PE (clone HP6025) was from ITK (Uithoorn, the Netherlands). Ipilimumab (Yervoy ${ }^{\circledR}$ ), nivolumab (Opdivo ${ }^{\circledR}$ ) and pembrolizumab (Keytruda ${ }^{\circledR}$ ) were a kind gift from the Antoni van Leeuwenhoek hospital pharmacy. To remove protein aggregates all antibodies were centrifuged at $10,000 \mathrm{~g}$ for $8 \mathrm{~min}$, after which the supernatant was used.

\section{Subjects and sample collection}

Subjects asked for study participation included 10 healthy volunteers not known with cancer, and 11 patients with advanced cancer. Blood samples from healthy volunteers were used to assess number and variability of immune cells and their PD-1 expression, and blood samples from patients were used for demonstrating the clinical applicability of the method. From each subject $10 \mathrm{~mL}$ of blood was collected in a heparin tube. Blood was kept at room temperature (RT) and within $30 \mathrm{~min}, 7.0 \mathrm{~mL}$ of blood was transferred to a $\mathrm{CPT}^{\mathrm{TM}}$-citrate vacutainer tube (BD). 
Total volume was adjusted to $8 \mathrm{~mL}$ with PBS.

All study participants had given written informed consent in accordance with institutional and national guidelines. The study protocol was approved by the ethical committee of the Netherlands Cancer Institute.

\section{Centrifugation}

Unless stated otherwise, all centrifugations were performed in $2 \mathrm{~mL}$ Lo-bind eppendorf tubes in a centrifuge equipped with a swing-out rotor at $500 \mathrm{~g}$ for $4 \mathrm{~min}$ at $4^{\circ} \mathrm{C}$. After centrifugation the supernatant was removed by aspiration, leaving $100 \mu \mathrm{L}$ on the pellet.

\section{PBMC pre-processing}

Unless stated otherwise, the assay development and validation were performed with unstimulated PBMCs, which may provide a good representation of the actual in vivo patient PD-1 levels on these immune cells at the time of blood sampling. Each CPT tube, containing $7.0 \mathrm{~mL}$ whole blood, was centrifuged in a swing-out rotor at 1,500g for $25 \mathrm{~min}$ at RT. Next, the layer of plasma was aspirated and the layer of PBMCs was poured into a $15 \mathrm{ml}$ tube on ice. The CPT tube was washed with $5 \mathrm{~mL}$ of ice-cold BB, which was pooled with the PBMCs in the $15 \mathrm{~mL}$ tube. The sample volume was adjusted to $15 \mathrm{~mL}$ with ice-cold $\mathrm{BB}$ and inverted 5 times before centrifugation. The supernatant was aspirated and the pellet was resuspended in $1 \mathrm{~mL}$ of $B B$, which was completely transferred to a $2 \mathrm{~mL}$ tube using a second wash with $0.5 \mathrm{~mL}$ of $\mathrm{BB}$. After centrifugation, the supernatant was aspirated and the pellet washed twice with $1 \mathrm{~mL}$ of PBS. Samples were again centrifuged, after which the total volume was adjusted to $690 \mu \mathrm{L}$. After addition of $10 \mu \mathrm{L}$ of 500 -fold diluted Live-Dead marker, samples were incubated on ice for $15 \mathrm{~min}$. Next, aliquots of $25 \mu \mathrm{L}$ of cell suspension were transferred in triplicate, unless otherwise specified, to $2 \mathrm{~mL}$ tubes on ice, containing $54 \mu \mathrm{L}$ of BB-5\%BSA and $16 \mu \mathrm{L}$ of antibody cocktail and samples were incubated vertically for $1 \mathrm{~h}$ on ice at 300 rpm using a Heidolph Vibramax ${ }^{\mathrm{TM}}$ 100. After that, samples were incubated for an additional $1 \mathrm{~h}$ with $10 \mu \mathrm{g} / \mathrm{mL}$ nivolumab or pembrolizumab, washed three times with $1 \mathrm{~mL}$ of $\mathrm{BB}$, and centrifuged. Subsequently, samples were fixed for 15 $\min$ at RT by addition of $1 \mathrm{~mL} 2 \%(\mathrm{w} / \mathrm{v})$ of formaldehyde. After centrifugation, pellets were washed with $1 \mathrm{~mL} \mathrm{BB}$ and aspirated to leave $50 \mu \mathrm{L}$ on the pellets. For cryopreservation, $500 \mu \mathrm{L}$ of Cryosofree ${ }^{\mathrm{TM}}$ was added before samples were snap- 


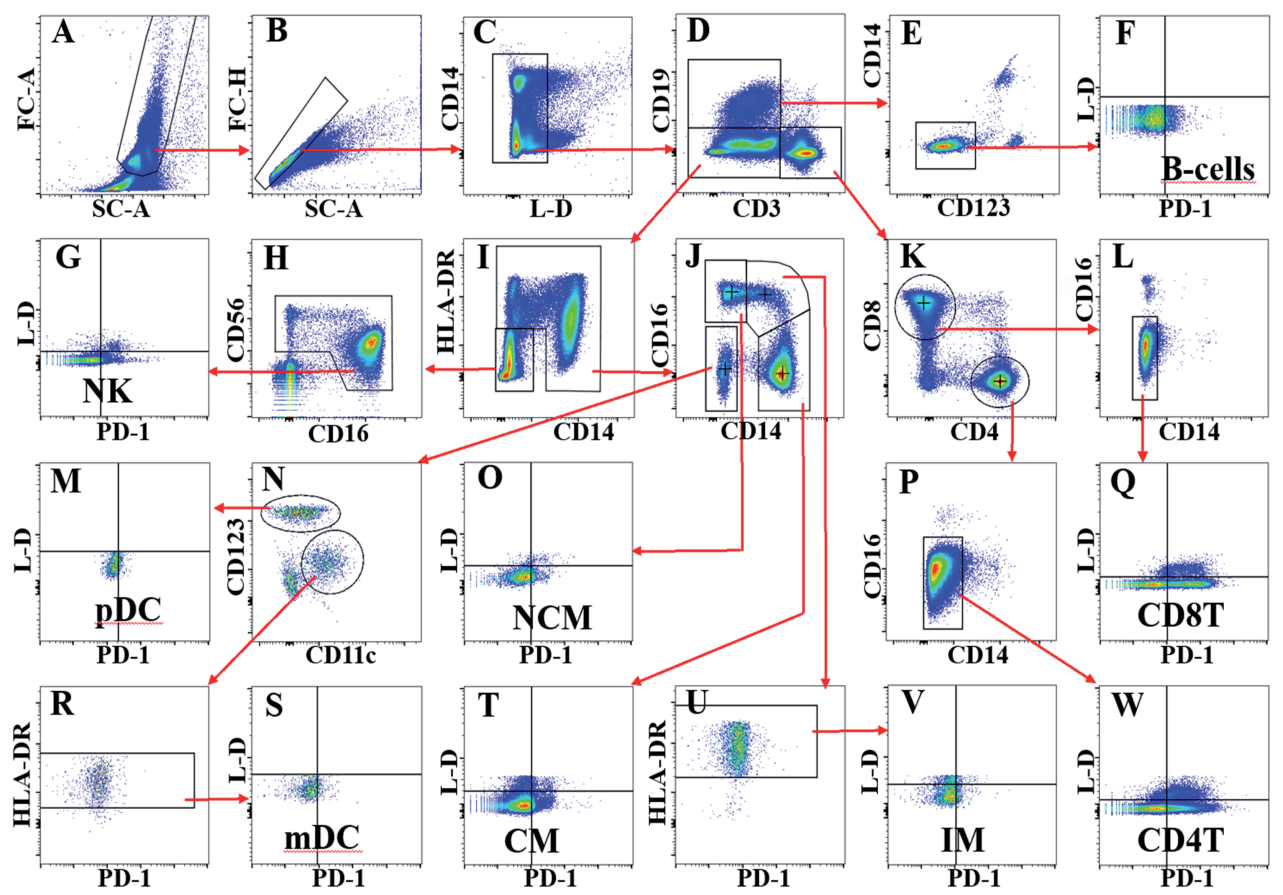

Figure 1. Gating strategy to discriminate 9 immune cell populations. Red arrows indicate the gating direction. Peripheral blood mononuclear cells are gated (A) using forward (FS) and sideward scatter (SC), with subsequent elimination of doublets by FS-height (FS-H) against FS-area (FS-A) gating (B). After rough elimination of dead cells (C) by live-dead protein stain (L-D), the negative dendritic-monocyte-natural killer cells (NK) are separated (D) from B-cells $\left(C D 19^{+}\right)$and T-cells $\left(C D 3^{+}\right)$. $\mathrm{CD}^{+}$T-cells were further differentiated into $\mathrm{CD} 4^{+}$ and $C D 8^{+}$-T-cells $(K)$. NK-cells differentiated from dendritic cells and monocytes as HLA-DR', $\mathrm{CD} 14, \mathrm{CD}^{-} 6^{-/+}, \mathrm{CD}^{+/ \pm}(\mathrm{H}, \mathrm{I})$. Dendritic cells are identified in plots $\mathrm{J}$ and $\mathrm{N}$ as CD14, CD16

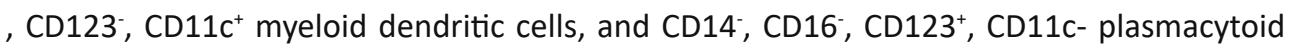
dendritic cells ( $\mathrm{PDC}$ ). Monocytes are divided into classical, non-classical and intermediate monocytes $(\mathrm{J})$ based on their relative amount of $\mathrm{CD} 14$ and 16 expression. After removal of the last remaining contaminating cells $(E, L, P, R, U), P D-1$ is detected in the final plots ( $F$, $\mathrm{G}, \mathrm{M}, \mathrm{O}, \mathrm{Q}, \mathrm{S}, \mathrm{T}, \mathrm{V}, \mathrm{W}$ ) using quadrant gating to eliminate remaining dead cells. Background samples that have not been treated with nivolumab or pembrolizumab were used to set the position of the quadrant gate at exactly $5.0 \%$ PD- $1^{+}$cells for each of the viable immune cell populations. 
frozen in liquid nitrogen and stored at $-80^{\circ} \mathrm{C}$.

Detection of PD-1

Samples were defrosted in a $37^{\circ} \mathrm{C}$ water bath until the remaining volume of ice was about halve the initial sample volume. After almost complete defrosting under constant manual shaking at RT, samples were put on ice for complete defrosting.

Samples were washed once with $1 \mathrm{~mL} \mathrm{BB}$, and once with BB-5\%BSA, respectively. After centrifugation, $8 \mu \mathrm{g} / \mathrm{mL}$ of anti-lgG $-\mathrm{PE}$ in $\mathrm{BB}-5 \% \mathrm{BSA}$ was added and vials were incubated standing upright in an ice box at $300 \mathrm{rpm}$ using a Heidolph Vibramax 100 plate mixer (Essex, UK). Next, samples were washed twice with $1 \mathrm{~mL} \mathrm{BB}$, centrifuged, and kept on ice until analysis by flow cytometry.

\section{Fluorescent-activated cell sorting and PD-1 determination}

Samples were measured using twelve-color flow cytometry on a Becton Dickinson Fortessa LSR2. Sequential gating (Fig. 1) was applied for the enumeration of 9 immune cell subsets with subsequent quantification of their PD-1 expression using FlowJo v10.0.7 software (Ashland, USA). The threshold for qualifying cells as PD- $1^{+}$was set at $5.0 \%$ of the cells with the highest median fluorescent intensity (MFI) of PE in background control samples. The used fluorochrome, voltage, laser, filter, and compensation settings for each detection antibody are listed in supplementary Table 1.

\section{Optimization of PD-1 signal to noise ratio}

Samples containing 400k PBMCs were incubated for $1 \mathrm{~h}$ in BB-5\%BSA with or without $10 \mu \mathrm{g} / \mathrm{mL}$ nivolumab, washed extensively with $\mathrm{BB}$, and incubated at RT for $1 \mathrm{~h}$ with $8 \mu \mathrm{g} / \mathrm{mL}$ of anti- $\operatorname{lgG}_{4}-\mathrm{PE}$ in $\mathrm{BB}$ containing $0.5,2.0$, and $5 \% \mathrm{BSA}$, and at $0^{\circ} \mathrm{C}$ with BB-5\%BSA (supplementary Fig. 1).

\section{Effect of formaldehyde and cryopreservation}

Samples containing 400k PBMCs from a healthy volunteer were incubated without (negative control, NC) or with $10 \mu \mathrm{g} / \mathrm{mL}$ of nivolumab or pembrolizumab for $1 \mathrm{~h}$ on ice, after which they were washed three times with $1 \mathrm{~mL}$ BB. Next, samples were left unfixed (NC) on ice, or fixed with $4 \%(\mathrm{w} / \mathrm{v} \%)$ formaldehyde for $15 \mathrm{~min}$ 
at RT, washed with $1 \mathrm{~mL} \mathrm{BB}$, centrifuged, and snap-frozen in liquid nitrogen after addition of $500 \mu \mathrm{L}$ of Cryosofree ${ }^{\mathrm{TM}}$. Same day, snap-frozen samples were defrosted and washed twice with $1 \mathrm{~mL} \mathrm{BB}$, centrifuged, and incubated for $1 \mathrm{~h}$ at $0^{\circ} \mathrm{C}$ with $8 \mu \mathrm{g} / \mathrm{mL}$ of anti-lgG 4 -PE. Different samples containing 400k PBMCs were similarly incubated with nivolumab or pembrolizumab, washed, and left unfixed on ice (0\%) or fixed with 1,2 and $4 \%(\mathrm{w} / \mathrm{v} \%)$ formaldehyde for $15 \mathrm{~min}$ at RT. After 1 wash with $1 \mathrm{~mL} \mathrm{BB}$, samples were incubated for $1 \mathrm{~h}$ at $0^{\circ} \mathrm{C}$ with $8 \mu \mathrm{g} / \mathrm{mL}$ of anti-IgG $-\mathrm{PE}$. Cells were kept on ice and PD-1 on CD8 ${ }^{+}$T-cells was analyzed the same day by flow cytometry.

\section{Antibody target saturation curves}

In order to determine PD-1 target saturation, samples containing 400k PBMCs from a healthy volunteer were incubated for $1 \mathrm{~h}$ with $0,0.02,0.05,0.1,0.2,0.5,1$, $2,5,10$, and $20 \mu \mathrm{g} / \mathrm{mL}$ nivolumab or pembrolizumab in BB-5\%BSA. Subsequently, PD-1 was detected using $8 \mu \mathrm{g} / \mathrm{mL}$ of anti- $\operatorname{lgG}_{4}-\mathrm{PE}$, as described previously. Growth stimulated PBMCs, which were cultured as described in the specificity section, were used for this nivolumab experiment. PBMCs from another healthy volunteer were pre-incubated for $1 \mathrm{~h}$ with $10 \mu \mathrm{g} / \mathrm{mL}$ nivolumab to saturate the PD-1 targets, followed by detection with $0,0.67,1,1.3,2,2.7,4,5.3,6.7,13.3,20 \mu \mathrm{g} / \mathrm{mL}$ of anti-lgG - -PE.

Next, the effect of different amounts of PBMC input per sample on PD-1 staining and cell recovery was assessed in samples containing $100 \mathrm{k}, 200 \mathrm{k}, 300 \mathrm{k}$, 400k, and 500k PBMC. These samples were incubated for $1 \mathrm{~h}$ on ice without (background controls) and with $10 \mu \mathrm{g} / \mathrm{mL}$ nivolumab. After extensive washing, PD-1 was detected with $8 \mu \mathrm{g} / \mathrm{mL}$ of anti-lgG $-P E$ as described for our preprocessing and PD-1 detection method.

\section{Quantification of the number of PD-1 molecules per cell}

The threshold for qualifying cells as PD-1+ was set at $5.0 \%$ of the cells with the highest median fluorescent intensity (MFI) of PE in background control samples. The negative contribution of these $5.0 \%$ background cells to the MFI of nivolumab or pembrolizumab treated cells (supplementary Fig. 2), was corrected for according to the following formula:

$$
\text { Corrected net MFI }=\text { MFIniv }+(\text { MFIniv }- \text { MFIbckg }) * \frac{\% b c k g}{(\% \text { PD1niv }-\% b c k g)}
$$


MFIniv = MFI of nivolumab or pembrolizumab treated cells

MFIbckg $=$ MFI of the $5.0 \%$ most PE positive background cells

$\%$ bckg $=$ background threshold level $=5.0 \%$

$\% P D 1$ niv = percentage of $P D-1^{+}$cells in nivolumab or pembrolizumab treated samples

A mix of five different QSC beads, each with a manufacturer determined known amount of anti-mouse $\operatorname{lgG}_{1}$ binding sites (ABS), was incubated in triplicate for 1 $\mathrm{h}$ on ice with $8.0 \mu \mathrm{g} / \mathrm{mL}$ of anti-lgG $-\mathrm{PE}$ in BB-BB-5\%BB. After two washes with 1 $\mathrm{mL} \mathrm{BB}$, samples were centrifuged and measured by flow cytometry using the same settings as used for PD-1 detection in cells. $\log (\mathrm{ABS})$ against $\log$ (net MFI-PE) linear regression analysis was used, according to the manufacturer's instructions, for samples incubated with $8 \mu \mathrm{g} / \mathrm{mL}$ of anti-lgG $-\mathrm{PE}$, in order to calculate the number of anti-lgG $-\mathrm{PE}$ per cell from the corrected net MFI of PE in samples.

Next, the number of PE bound per anti- $\lg _{4}$ antibody (PE labeling ratio) was determined spectrophotometrically using the following formula:

$P E$ labeling ratio $=\frac{\varepsilon \operatorname{IgG} 4}{\varepsilon \mathrm{PE}} * \frac{A b s 566}{(A b s 280-C F * A b s 566)}$

عlgG4 = molar extinction coefficient of IgG4 $=210.000$

$\varepsilon P E=$ molar extinction coefficient of $P E=1.863 .000$

Abs280 = Absorbance of total protein at 280 $\mathrm{nm}$

Abs566 = Absorbance of PE at 566nm

$\mathrm{CF}=$ Correction factor of $\mathrm{PE}$ contribution to $\mathrm{Abs} 280=0.17$

The number of PD-1 per cell was calculated by dividing the number of anti-lgG $-\mathrm{PE}$ per cell by the PE labeling ratio.

Specificity of PD-1 detection

PBMCs from a healthy volunteer were cultured for $8 \mathrm{~h}$ in RPMI supplemented with $10 \%$ (v/v\%) FCS, $1 \mu \mathrm{g} / \mathrm{mL}$ ionomycin and $25 \mathrm{ng} / \mathrm{mL}$ phorbol-12-myristate-13acetate. Cells were washed twice with PBS and resuspended at 1 million cells $/ \mathrm{mL}$ in PBS. Next, $25 \mu \mathrm{L}$ aliquots were incubated on ice with $8 \mu \mathrm{g} / \mathrm{mL}$ of anti-lgG $-\mathrm{PE}$ for $1 \mathrm{~h}$, according to the previously described sample pre-processing method. An 
additional incubation was performed on ice for $1 \mathrm{~h}$ with $10 \mu \mathrm{g} / \mathrm{mL}$ of PD-L2 and 40 $\mu \mathrm{g} / \mathrm{mL}$ PD-1 blocking antibody clone PD1313 in BB-5\%BSA, immediately prior to incubation with nivolumab or pembrolizumab.

Interference of the PD-1 detection by ipilimumab was assessed in samples containing 400k PBMCs from a healthy volunteer. Samples were incubated on ice with 0,10 and $50 \mu \mathrm{g} / \mathrm{mL}$ ipilimumab in BB-5\%BSA for $1 \mathrm{~h}$, after which $10 \mu \mathrm{g} / \mathrm{mL}$ of nivolumab or pembrolizumab were added. After another $1 \mathrm{~h}$ of incubation on ice, samples were washed three times with $1 \mathrm{ml} \mathrm{BB}$, centrifuged, and stained with 8 $\mu \mathrm{g} / \mathrm{mL}$ anti-lgG $\mathrm{G}_{4}-\mathrm{PE}$, as described for sample pre-processing.

\section{Storage stability}

Stability of PD-1 and cell numbers was assessed in blood from a healthy volunteer stored for $0,0.5,1,2$, and $4 \mathrm{~h}$ at room temperature in heparin tubes. After isolation PBMCs were spiked at $250 \mathrm{k}$ cells per sample and incubated with nivolumab or pembrolizumab, as described for sample pre-processing.

To assess the stability of cell numbers and PD-1 detection during long term storage at $-80^{\circ} \mathrm{C}$, PBMCs from a healthy volunteer were spiked at $200 \mathrm{k}$ cells per sample. After incubation with nivolumab or pembrolizumab, samples were processed, snap-frozen in liquid nitrogen and stored at $-80^{\circ} \mathrm{C}$, as described for our pre-processing method. After 0, 53, and 153 days of storage, samples were, in triplicate, defrosted and incubated with anti-lgG - PE for detection of PD-1 by flow cytometry, as described for our PD-1 detection method.

\section{Healthy volunteer study}

Peripheral blood from 10 different healthy volunteers ( 5 male, 5 female, age range 25 - 48) was collected between 9:00 and 10:00 AM on three different days with weekly intervals. PBMCs were isolated from $7.0 \mathrm{~mL}$ of blood, and incubated, in triplicate, with $10 \mu \mathrm{g} / \mathrm{mL}$ of nivolumab or pembrolizumab, and further processed as described in PBMC pre-processing and PD-1 detection. In order to determine the cell recovery of our method, total initial PBMC cell concentrations were measured using a Roche Innovatis Casy ${ }^{\mathrm{TM}}$ Coulter counter.

\section{Clinical applicability}

In order to determine the clinical applicability of our method, blood was drawn from advanced cancer patients (supplementary Table 6) who received nivolumab 
( $n=6$ ) or pembrolizumab $(n=5)$ in 2, 3 or 4 weekly course intervals ( $q 2 W, q 3 W$, or q4W). Blood was drawn at baseline, at the end of the first infusion (EOI), and predose of cycle 2. PBMCs were isolated from $7.0 \mathrm{ml}$ of blood and incubated with $10 \mu \mathrm{g} / \mathrm{mL}$ of nivolumab or pembrolizumab, i.e. the same antibody as administered to the respective patient. Samples were further processed as described in PBMC pre-processing and PD-1 detection.

\section{Statistical Analysis}

Specificity of PD-1 detection was defined as the difference in PD-1 signal between background control samples and samples incubated with PD-1 blocking agents before incubation with nivolumab and pembrolizumab. Linearity of PD-1 $1^{+}$cell recovery of immune cell subsets, and between MFI and number of PD-1 per QSC bead were tested using linear regression analysis in Graphpad Prism 6.01. The lower limit of quantification (LLOQ) of the percentage of PD-1+-cells was defined as the percentage of PE positive background cells \pm 5 times standard deviation (SD).

For determination of assay precision and biological variation, data from the volunteer study was checked for normal distribution using the Shapiro-Wilk test. The assay within- and between day precision (WDP and BDP) were determined using one-way analysis of variance (ANOVA) using the run day as classification variable, using Excel, and should not exceed $15 \%$ of the coefficient of variation (CV). Within subject biological variation (WSBV) was defined as the coefficient of variation between three independent weekly results for each subject. Between subject biological variation (BSBV) was defined as coefficient of variation between the mean within subject results. Statistical evaluation using Student's t-test, and Quartile analysis was performed in Excel. Differences in biomarker levels between patient sampling points were evaluated using Wilcoxon matched pair signed rank tests in Graphpad Prism 6.01. P-values smaller than 0.05 were considered to be significant.

\section{RESULTS}

\section{Optimization of PD-1 signal to noise ratio}

The signal to noise ratio (S/N) of PD-1 detection on PD- $1^{+} \mathrm{CD} 8^{+}-\mathrm{T}$-cells at $\mathrm{RT}$ in $\mathrm{BB}$ with $0.5 \%(w / v \%)$ BSA was $2.9 \pm 0.1$. $\mathrm{S} / \mathrm{N}$ ratios significantly increased to $3.1 \pm 0.1$ $(P=0.04)$ and $3.7 \pm 0.1(P=0.002)$ if $B B$ with $2.0 \%$ and $5.0 \%(w / v \%) B S A$ was used, respectively. Incubation at $0^{\circ} \mathrm{C}$ with $5 \% \mathrm{BSA}$ resulted in a significant additional 
increase of the $\mathrm{S} / \mathrm{N}$ ratio to $4.1 \pm 0.1$ (supplementary Fig. $1, \mathrm{P}=0.0001$ ).

\section{Effect of formaldehyde and cryopreservation}

In comparison with unfixed cells, fixation with $4 \%$ formaldehyde followed by cryopreservation had a negative effect on the percentage of PD1 ${ }^{+}$-cells of $-11.8 \%$ $\pm 5.2 \%(P=0.025)$ in samples treated with nivolumab (supplementary Fig. 3A). Fixation with $2 \%$ formaldehyde resulted in an increase of the PD-1 signal on CD8 ${ }^{+}$ T-cells by $15.0 \% \pm 1.8 \%(P=0.023)$ for nivolumab and $21.2 \% \pm 1.3 \%(P=0.006)$ for pembrolizumab treated samples. In nivolumab treated samples, the percentage of PD-1 $1^{+}$-cells was significantly higher after fixation with $2 \%$ formaldehyde $(P=$ 0.048). In pembrolizumab treated samples no significant change was detected (supplementary Fig. 3B)

\section{Linearity of PD-1 detection}

Flow cytometer PE MFI signals were linearly correlated to the number of PE molecules per QSC bead ( $r=0.999)$.

Antibody target saturation was assessed from curves of nivolumab, pembrolizumab, and anti-IgG - -PE (supplementary Fig. 4), using Eadie Hofstee plots constructed by linear regression. The $\mathrm{Km}$-values were respectively $0.127,0.117$, and $0.317 \mu \mathrm{g} / \mathrm{mL}$ for nivolumab, pembrolizumab, and anti-lgG $-\mathrm{PE}$ as determined from the slopes. The concentrations used in our PD-1 detection method are $10 \mu \mathrm{g} / \mathrm{ml}$ nivolumab and pembrolizumab, and $8 \mu \mathrm{g} / \mathrm{ml}$ anti-lgG $-\mathrm{PE}$. These concentrations resulted in PD-1 detection at, respectively 98.9\%, 101.3\%, and $96.9 \%$ of the maximum possible MFI signal strength calculated from the intercept of the Eadie Hofstee plots. The lowest antibody concentrations that did not result in significant lower PD-1 MFI, as compared to the concentrations chosen for our method, were $2 \mu \mathrm{g} / \mathrm{ml}$ nivolumab, $0.5 \mu \mathrm{g} / \mathrm{ml}$ pembrolizumab, and $2 \mu \mathrm{g} / \mathrm{ml}$ anti$\operatorname{lgG}_{4}$-PE.

The number of PD-1+ $1^{+}$cells recovered for the immune cell subsets correlated linearly over the tested spike range from 100k - 500k PBMCs input per sample ( $r$ $>0.997$ ). The slopes of these curves did not significantly differ from 1 indicating complete cell recovery over the tested concentration range. Furthermore, the difference in percentage of PD1 $1^{+}$and number of PD-1 per $\mathrm{CD}^{+}$and $\mathrm{CD} 8^{+}-\mathrm{T}$-cell was less than $6.9 \%$ between the $100 \mathrm{k}$ and 500k PBMC spike levels (supplementary Table 4A). 
Specificity of PD-1 detection

For determination of assay specificity, using PBMCs isolated from a healthy volunteer, it is necessary to ex vivo growth stimulate these cells to ensure detectable levels of PD-1 on all immune cell subsets. The average percentages of PD- $1^{+}$found on the subset was as follows: $38 \%$ for CD4+-T-cells, $41 \%$ for $\mathrm{CD} 8^{+}-$ T-cells, $21 \%$ for B-cells, $1 \%$ for NK-cells, $67 \%$ for CM, $18 \%$ for IM, $10 \%$ for NCM, $40 \%$ for $\mathrm{mDC}$ and $15 \%$ for $\mathrm{pDC}$. In samples that were pre-incubated with antiPD-1 clone PD1313 in combination with PD-L2, the percentage of PD- $1^{+}$cells was significantly decreased by more than $97.0 \pm 1.8 \%$, and the number of PD- $1^{+}-C D 4^{+}$ and $C D 8^{+}$-T-cells by more than $99.5 \% \pm 0.4 \%$ (Fig. 2 and supplementary Table 2 ). The MFI of PD-1 in all PD-1 blocked samples was not significantly different from the background control samples, which indicates highly specific detection of PD-1. Furthermore, the background signal, number of detected PD-1 per cell and percentage of $\mathrm{PD}-1^{+}-\mathrm{CD} 4^{+}$and $\mathrm{CD} 8^{+}-\mathrm{T}$-cells did not significantly change due to exposure to 10 and $50 \mu \mathrm{g} / \mathrm{mL}$ of ipilimumab before incubation with $10 \mu \mathrm{g} /$ $\mathrm{mL}$ of nivolumab or pembrolizumab (supplementary Table 3 ). This indicates no significant interference from ipilimumab with the detection of PD-1.

\section{Storage stability}

PD-1 expression and immune cell numbers were stable for $0.5 \mathrm{~h}$ in blood stored in heparin tubes. After 1, 2, and $4 \mathrm{~h}$ of storage both PD-1 expression and cell numbers were significantly decreased $(P<0.02$, Fig. 3$)$.

The difference in the number of cells between samples stored for 0 and 153 days was $14.1 \%$ or less (supplementary Table $5 \mathrm{~A}$ ). In addition, the percentage of PD-1 $1^{+}$cells and number of PD-1 $1^{+}$per cell were not significantly lower, and showed a decrease of $6.8 \%$ after 153 days of storage (supplementary Table $5 B C$ ). Therefore, we concluded that the number of immune subset cells, percentage of PD-1+ $1^{+}$cells and number of PD-1 per cell are at least stable for 153 days of storage at $-80^{\circ} \mathrm{C}$. The between day precision (BDP) was better than $9.0 \%$ for the determination of the number of cells, percentage of PD-1 $1^{+}$and number of PD-1 per cell. 


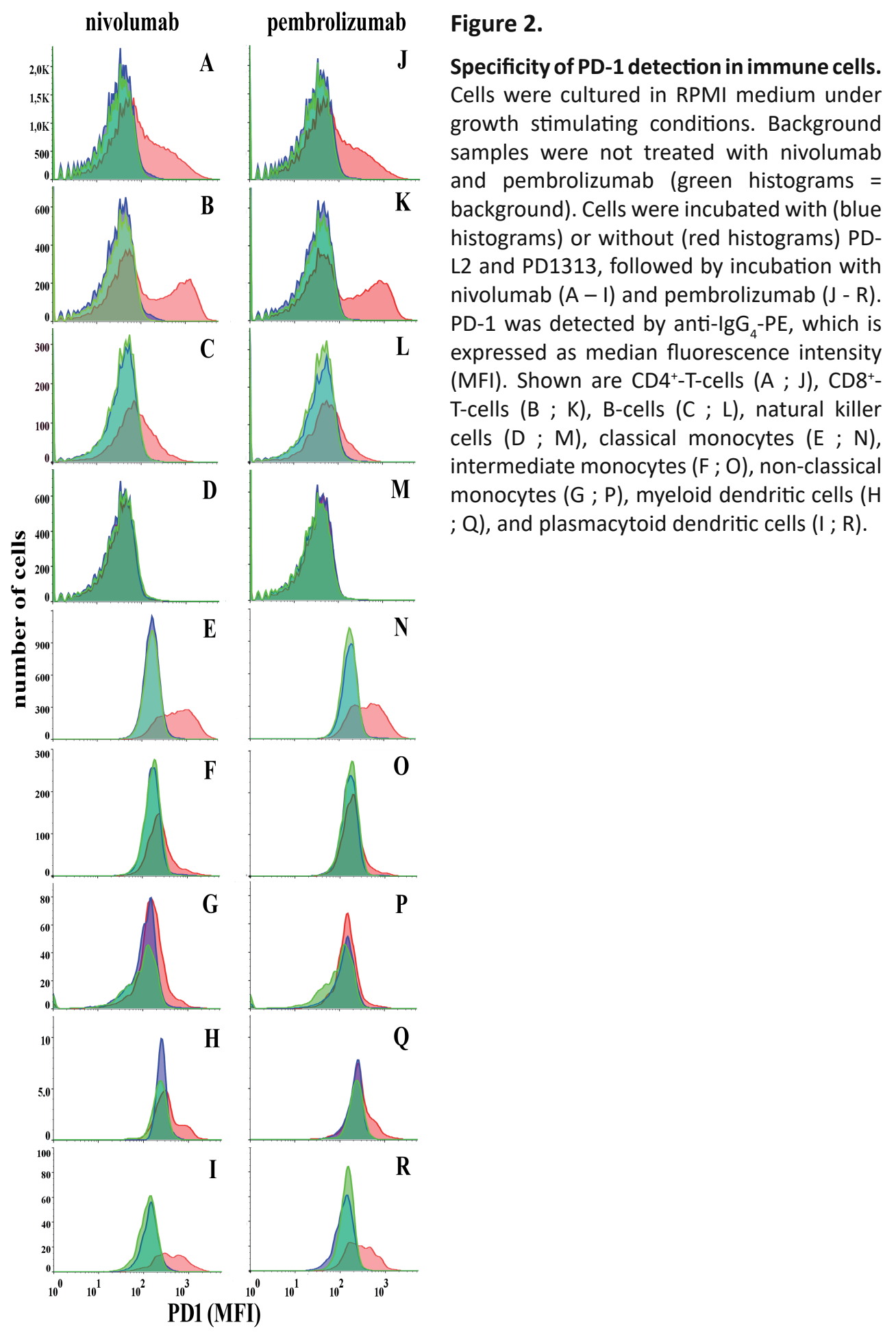



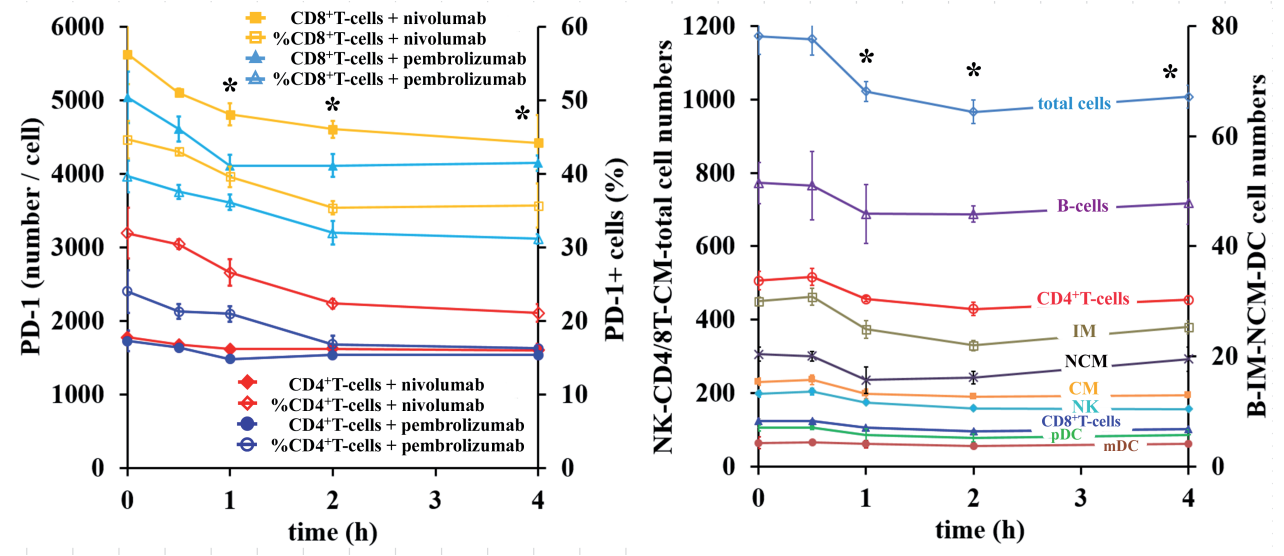

Figure 3. Stability of PD-1 in blood from a healthy volunteer stored for $0,0.5,1,2$ and $4 \mathrm{~h}$ at room temperature in heparin tubes before isolation of PBMC using cell preparation tubes. A. Shown are the results for nivolumab ( - - - ) and pembrolizumab (- - - - ) treated CD4 ${ }^{+}$-T-cells for the number of PD-1 per cell and percentage of PD- $1^{+}$cells, respectively. Results are shown for the number of PD-1 and percentage of PD-1 ${ }^{+} \mathrm{CD} 8^{+}-\mathrm{T}$-cells after nivolumab $\left(-{ }^{-}\right.$, $-\square$ ) and pembrolizumab (,$--\Delta$ ) treatment. B. The effect of storage on the total cell numbers (- $), \mathrm{CD}^{+}$and $\mathrm{CD}^{+}$- T-cells (CD4/8T, $-\mathbf{O},-\mathbf{-}$ ), B-cells ( $-\boldsymbol{-}$ ), natural killer cells $(\mathrm{NK},--)$, classical monocytes $(\mathrm{CM},--)$ ), intermediate monocytes $(\mathrm{IM},-\square-)$, nonclassical monocytes $(\mathrm{NCM},-\mathbf{X}$ ), plasmacytoid dendritic cells ( $\mathrm{pDC}, \longrightarrow$ ), and myeloid dendritic cells $(\mathrm{mDC},-$ ). Results are the mean of three separate samples \pm standard deviation (SD). * indicates a significant decrease relative to $\mathrm{t}=0$.

Table 1. Biological variation of PD-1 in healthy volunteers. Blood from healthy volunteers ( $n=10$ ) was drawn on three different days with weekly intervals. Shown are the results for cell concentrations per $\mu \mathrm{l}$ blood $(1 \mathrm{~A})$, percentage of PD-1 $1^{+}$cells, and number of PD-1 per cell for nivolumab (1B) and pembrolizumab (1C), for CD4 and CD8 T-cells (CD4T and $\mathrm{CD} 8 \mathrm{~T}), \mathrm{B}$-cells (B), natural killer cells (NK), classical monocytes (CM), intermediate monocytes (IM), non-classical monocytes (NCM), plasmacytoid dendritic cells ( $\mathrm{pDC}$ ), and myeloid dendritic cells (mDC). Q1 - 4 indicates whether the measured cell concentration was within the $1 \mathrm{st}, 2 \mathrm{nd}, 3 \mathrm{rd}$, or 4 th quartile $(=25,50,75,100$ percentile, respectively) of the reference healthy volunteer population $(n=10)$. LLOQ = lower limit of quantification and was defined as background + 5 times SD; WDP = within day precision; WSBV = within subject biological variation; $\mathrm{BSBV}=$ between subject biological variation); $\mathrm{ND}=$ not determined. Data are the mean of indicated number of volunteers $(n)$, each measured in triplicate, \pm standard deviation (SD). 

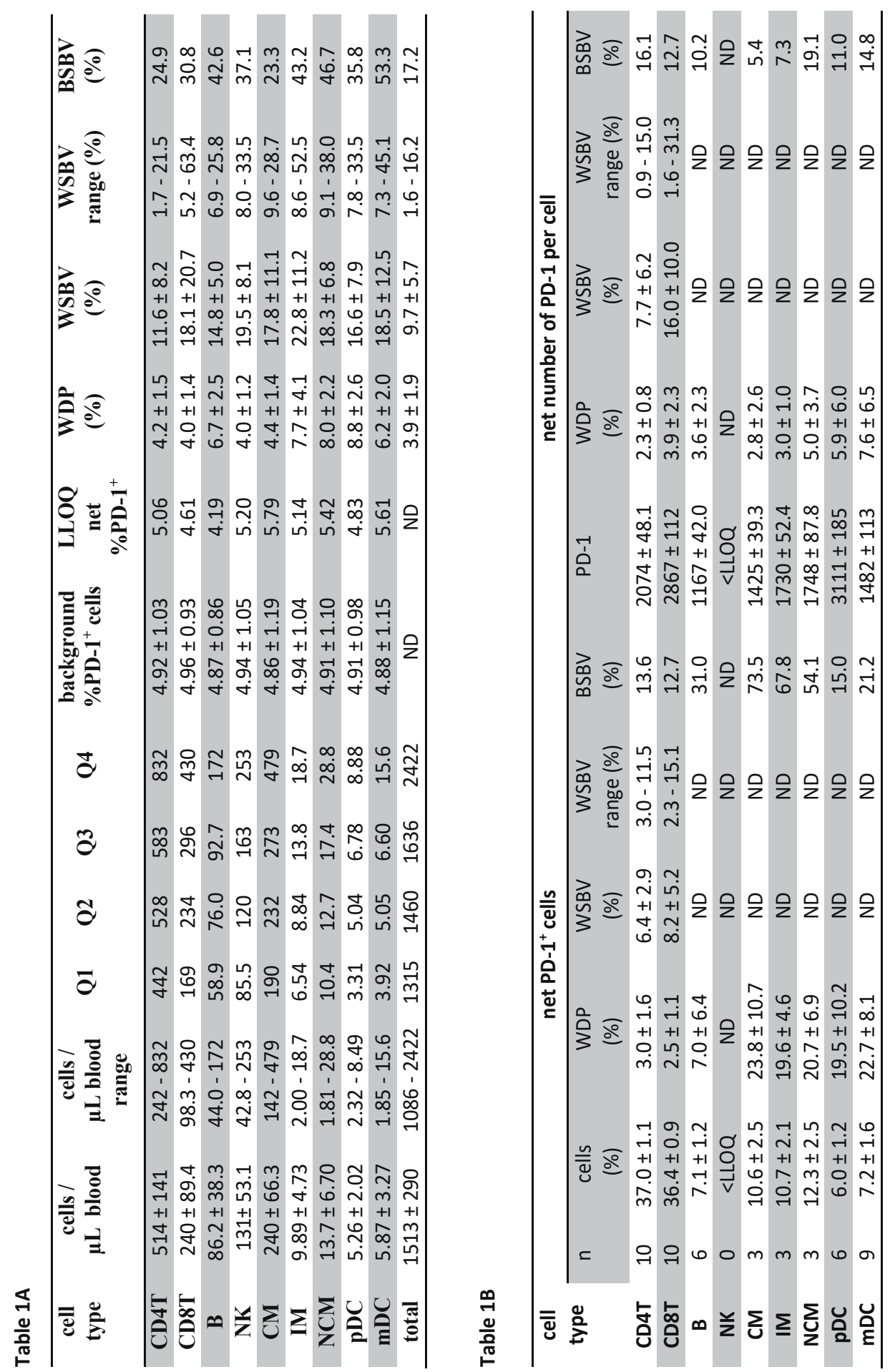


\section{Healthy volunteer study}

The cell recovery of single and live PBMCs by our method was $89.7 \% \pm 4.3 \%$ (range $85.1-92.6 \%, n=10$ ) of the total number of spiked PBMCs as determined by Coulter cell counting. Cell concentrations, percentage of PD- $1^{+}$cells, and number of PD-1 per cell were determined with a within day precision better than 15\% (Table 1A). The standard deviation in the predefined $5.0 \%$ background level was less than $1.0 \%$ and only slightly varied between immune cell subsets, which resulted in LLOQs of $4.19-5.79 \%$ for the percentage of PD- $1^{+}$cells (Table $1 \mathrm{~A}$ ). The cell concentrations of CD8 ${ }^{+}$-T-cells showed the highest WSBV of $18.1 \% \pm 20.7 \%$. The mean BSBV of the measured cell concentrations for each immune cell subset was about two-fold higher than the mean WSBV (Table 1A).

Table 2. Clinical applicability of the assay in patients administered with nivolumab (n $=6$ ) or pembrolizumab $(n=5)$. Blood was drawn during cycle 1 before administration (baseline) and immediately after end of infusion (EOI), and predose of cycle 2 (pre-C2). After isolation, peripheral blood mononuclear cells were either left on ice (background) or incubated with nivolumab or pembrolizumab, i.e. the same antibody type patients received therapeutically. Shown are the results for cell concentrations per $\mu$ l blood $(2 \mathrm{~A})$, percentage of $\mathrm{PD}-1^{+}$cells, and number of PD-1 per cell for nivolumab (2B) and pembrolizumab patients (2C), for CD4 and CD8 T-cells (CD4T and CD8T), B-cells (B), natural killer cells (NK), classical monocytes (CM), intermediate monocytes (IM), non-classical monocytes (NCM), plasmacytoid dendritic cells ( $\mathrm{PDC}$ ), and myeloid dendritic cells (mDC). delta is the relative difference as compared to the mean cell concentration found for the reference healthy volunteer population $(n=10)$. $Q$ indicates the quartile ( $=25$ percentile) of the reference healthy volunteer population to which the measured patient cell concentration corresponds. 
PD-1 expression levels and PD-1 receptor occupancy by nivolumab and pembrolizumab

Table 2A

\begin{tabular}{|c|c|c|c|c|c|c|c|c|c|c|}
\hline \multirow[b]{2}{*}{$\begin{array}{l}\text { cell } \\
\text { type }\end{array}$} & \multicolumn{4}{|c|}{ baseline } & \multicolumn{2}{|c|}{ EOI } & \multicolumn{4}{|c|}{ pre-C2 } \\
\hline & $\begin{array}{c}\text { cells / } \\
\mu L \text { blood }\end{array}$ & $\begin{array}{l}\text { cells / } \\
\mu \mathrm{L} \text { blood } \\
\text { range }\end{array}$ & $\Delta(\%)$ & Q & $\begin{array}{c}\text { cells / } \\
\mu L \text { blood }\end{array}$ & $\begin{array}{c}\text { cells / } \\
\mu \mathrm{L} \text { blood } \\
\text { range }\end{array}$ & $\begin{array}{c}\text { cells / } \\
\mu \text { L blood }\end{array}$ & $\begin{array}{l}\text { cells / } \\
\mu \mathrm{L} \text { blood } \\
\text { range }\end{array}$ & $\Delta(\%)$ & Q \\
\hline CD4T & $402 \pm 12.4$ & $69.4-719$ & $-16.8 \%$ & 1 & $425 \pm 19.2$ & $79.5-727$ & $429 \pm 14.9$ & $129-642$ & $-17.7 \%$ & 1 \\
\hline CD8T & $199 \pm 4.89$ & $55.1-593$ & $-21.8 \%$ & 1 & $206 \pm 6.11$ & $56.6-585$ & $197 \pm 7.21$ & $1.6-583$ & $-16.5 \%$ & 1 \\
\hline B & $60.0 \pm 2.7$ & $10.3-156$ & $-30.4 \%$ & 2 & $63.5 \pm 4.7$ & $10.9-132$ & $48.5 \pm 2.5$ & $25.5-90.7$ & $-43.8 \%$ & 1 \\
\hline NK & $127 \pm 41.2$ & $38.7-264$ & $-3.2 \%$ & 3 & $115 \pm 62.3$ & $53.0-233$ & $138 \pm 33.8$ & $68.8-223$ & $5.5 \%$ & 3 \\
\hline $\mathrm{CM}$ & $395 \pm 10.5$ & $254-747$ & $64.9 \%$ & 4 & $376 \pm 18.0$ & $202-727$ & $398 \pm 10.2$ & $242-473$ & $66.3 \%$ & 4 \\
\hline IM & $24.1 \pm 1.95$ & $7.50-100$ & $144.1 \%$ & 4 & $24.0 \pm 1.76$ & $10.1-84.6$ & $18.7 \pm 1.61$ & $10.6-54.5$ & $89.4 \%$ & 4 \\
\hline NCM & $20.1 \pm 1.19$ & $6.50-42.6$ & $46.7 \%$ & 4 & $19.5 \pm 2.03$ & $7.67-39.0$ & $4.2 \pm 1.82$ & $6.79-43.0$ & $76.6 \%$ & 4 \\
\hline $\mathrm{pDC}$ & $4.17 \pm 0.19$ & $1.83-8.07$ & $-20.7 \%$ & 2 & $3.78 \pm 0.29$ & $1.76-8.59$ & $3.75 \pm 0.22$ & $1.72-6.01$ & $-28.7 \%$ & 2 \\
\hline $\mathrm{mDC}$ & $6.82 \pm 0.30$ & $4.36-11.0$ & $16.2 \%$ & 4 & $7.36 \pm 0.52$ & $3.51-13.3$ & $7.87 \pm 0.37$ & $4.44-14.4$ & $34.2 \%$ & 4 \\
\hline total & $1,442 \pm 42.3$ & $887-2,227$ & $-4.7 \%$ & 2 & $1,430 \pm 58.2$ & $814-2013$ & $1,448 \pm 33.6$ & $964-1,911$ & $-4.3 \%$ & 2 \\
\hline
\end{tabular}

Table 2B

\begin{tabular}{cccccccccccc}
\hline $\begin{array}{c}\text { cell } \\
\text { type }\end{array}$ & \multicolumn{9}{c}{ net PD-1 $\mathbf{~}^{+}$cells (\%) } \\
\cline { 2 - 12 } & $\mathrm{n}$ & baseline & $\mathrm{n}$ & EOI & $\mathrm{n}$ & pre-C2 & baseline & EOI & RO (\%) & pre-C2 & RO (\%) \\
CD4T & 6 & $37.4 \pm 0.8$ & 6 & $40.0 \pm 0.8$ & 6 & $27.6 \pm 0.7^{*}$ & $2517 \pm 72$ & $2402 \pm 56$ & $98.9 \pm 2.5$ & $1949 \pm 35^{*}$ & $100 \pm 2.7$ \\
CD8T & 6 & $39.9 \pm 0.7$ & 6 & $41.7 \pm 0.8$ & 6 & $34.3 \pm 3.2^{*}$ & $2931 \pm 113$ & $2768 \pm 122$ & $98.2 \pm 2.5$ & $1788 \pm 57^{*}$ & $98.5 \pm 2.4$ \\
B & 4 & $5.5 \pm 1.1$ & 4 & $7.4 \pm 1.3$ & 1 & $15.2 \pm 0.7$ & $1141 \pm 76$ & $1080 \pm 33$ & $94.3 \pm 3.5$ & $1440 \pm 22$ & $98.0 \pm 2.5$ \\
NK & 0 & $<$ LLOQ & 2 & $5.6 \pm 1.1$ & 2 & $9.2 \pm 1.5$ & $<$ LLOQ & $1150 \pm 75$ & $94.3 \pm 2.8$ & $1330 \pm 40$ & $94.9 \pm 6.5$ \\
CM & 0 & $<$ LLOQ & 2 & $6.4 \pm 1.7$ & 3 & $13.0 \pm 2.2$ & $<$ LLOQ & $2593 \pm 464$ & $86.0 \pm 3.8$ & $2188 \pm 6$ & $101 \pm 3.2$ \\
IM & 0 & $<$ LLOQ & 1 & $7.6 \pm 1.7$ & 2 & $18.6 \pm 2.7$ & $<$ LLOQ & $1937 \pm 67$ & $113 \pm 9.1$ & $2020 \pm 25$ & $98.4 \pm 2.3$ \\
NCM & 1 & $5.4 \pm 1.4$ & 2 & $5.8 \pm 1.3$ & 2 & $17.8 \pm 2.3$ & $1948 \pm 194$ & $1916 \pm 90$ & $96.8 \pm 6.1$ & $1980 \pm 56$ & $97.1 \pm 1.0$ \\
pDC & 1 & $6.9 \pm 1.6$ & 0 & $<$ LLOQ & 4 & $9.5 \pm 0.7$ & $6084 \pm 298$ & $<L L O Q$ & ND & $2591 \pm 71$ & $95.6 \pm 2.6$ \\
mDC & 1 & $5.9 \pm 1.1$ & 3 & $6.0 \pm 1.5$ & 1 & $11.3 \pm 2.2$ & $1260 \pm 54$ & $1308 \pm 45$ & $95.8 \pm 7.8$ & $1119 \pm 4$ & $101 \pm 2.3$ \\
\hline & & & & & & & & & & & \\
\hline
\end{tabular}

Table 2C

\begin{tabular}{|c|c|c|c|c|c|c|c|c|c|c|c|}
\hline \multirow{2}{*}{$\begin{array}{l}\text { Cell } \\
\text { type }\end{array}$} & \multicolumn{6}{|c|}{ net PD-1 ${ }^{+}$cells (\%) } & \multicolumn{5}{|c|}{ net number of PD-1 per cell } \\
\hline & $\mathrm{n}$ & baseline & $\mathrm{n}$ & EOI & $\mathrm{n}$ & & ee & EOI & RO (\%) & pre-C2 & RO (\%) \\
\hline CD4T & 5 & $44.7 \pm 0.9$ & 5 & $47.7 \pm 1.9$ & 5 & $27.7 \pm 2$ & $53 \pm 47$ & & $5.0=$ & $1600 \pm 43^{*}$ & 98.5 \\
\hline CD8T & 5 & $50.4 \pm 1.2$ & 5 & $51.0 \pm 1.0$ & 5 & $42.5 \pm 1.0^{*}$ & 2761 & $2656 \pm 69$ & & & 90.6 \\
\hline B & 2 & $4.9 \pm 0.8$ & 2 & $6.0 \pm 1.1$ & 1 & $4.3 \pm$ & 1053 & $1091 \pm 58$ & 99.1 & $950 \pm 4$ & 102 \\
\hline NK & 0 & $<$ LLOQ & 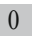 & $<$ LLOQ & 0 & SI & $<\mathrm{LL}$ & $<$ LLOQ & $<$ LLOQ & $<$ LLOQ & $<$ LLOQ \\
\hline CM & 2 & & 2 & & 1 & & & & & & \\
\hline IM & 1 & $6.4=$ & 1 & & 1 & & & & & & \\
\hline NCM & 1 & $5.8 \pm 0.9$ & 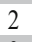 & $1.2 \pm 2.2$ & 1 & & & $2499 \pm 1$ & $99.2 \pm 4$ & $1480 \pm 10$ & $92.8 \pm 0.7$ \\
\hline pDC & 0 & $<$ LLOQ & 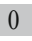 & $<$ LLOQ & 0 & $<$ LLOQ & $<$ LLOQ & $<$ LLOQ & $<$ LLOQ & $<$ LLOQ & $<$ LLOQ \\
\hline $\mathrm{mDC}$ & 1 & $6.3 \pm 0.8$ & 3 & $6.4 \pm 1.2$ & 0 & $<$ LLOQ & $1367 \pm 17$ & $1448 \pm 44$ & $101 \pm 5.3$ & $<$ LLOQ & $<$ LLOQ \\
\hline
\end{tabular}

* indicates a significant difference between baseline and predose cycle 2 . Data are the mean of indicated number of patients $(n)$, each measured in triplicate, \pm standard deviation (SD). 

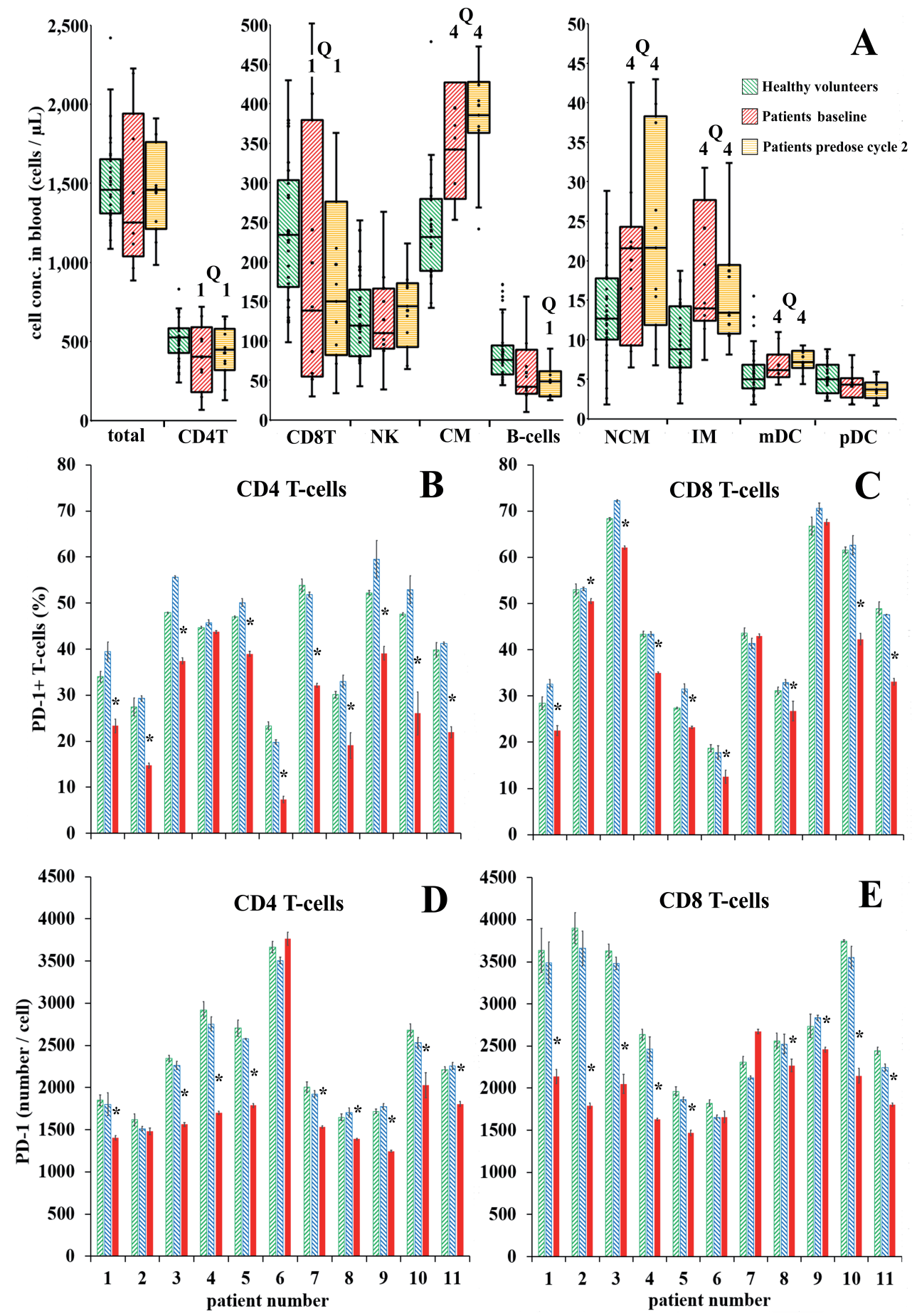

baseline $\mathbb{N}$ end of infusion cycle 1

predose cycle 2 
Figure 4. Clinical biomarker monitoring. Patients ( $n=11$, supplementary Table 6 ) were administered with nivolumab $(n=6)$ or pembrolizumab $(n=5)$ in $2-4$ weekly course intervals. Blood was drawn at baseline at the end of infusion of cycle 1 (EOI), and predose of cycle 2. Peripheral blood mononuclear cells were isolated, and ex vivo incubated with nivolumab or pembrolizumab for PD-1 saturation. A. Cell concentrations in blood of total immune cell subsets (total), $\mathrm{CD}^{+}$and $\mathrm{CD}^{+}$-T-cells (CD4/8T), B-cells, natural killer cells (NK), classical monocytes (CM), non-classical monocytes (NCM), intermediate monocytes (IM), myeloid dendritic cells (mDC), and plasmacytoid dendritic cells (pDC) in patients at baseline and predose of cycle $2(\mathbb{Q}, \mathrm{O}$, , respectively) in comparison with the reference healthy volunteer population $(\mathbb{Q}, \mathrm{n}=10)$. Quartile analysis was used to show whether cell concentrations were within Q1 (0 - 25 percentile) or Q4 (75 - 100 percentile) of the reference population. Percentage of PD- $1^{+}$cells and number of PD-1 per CD4 $4^{+}-\mathrm{T}$-cell (B and $D$, respectively) and $C D 8^{+}-T$-cell ( $C$ and $E$, respectively) at baseline $(\mathbb{Z}), E O I(\mathbb{N})$, and predose of cycle $2(\square) .{ }^{*}$ indicates a significant reduction. Results are the mean of 10 volunteers and 11 patients \pm between subject standard deviation $(A)$ or within subject standard deviation $(B-E)$.

\section{Clinical applicability}

The measured cell concentrations in patients were significantly $(P<0.001)$ higher by $64.9 \%, 46.7 \%, 144 \%$, and $16.2 \%$ in CM, NCM, IM, and $\mathrm{mDC}$ immune cell subsets, respectively, as compared to the reference healthy volunteer population (Fig 4A). However, measured $\mathrm{CD}^{+}$- and $\mathrm{CD}^{+}-\mathrm{T}$-cell, and $\mathrm{B}$-cell concentrations were significantly $(P<0.015)$ lower in patients by $21.8 \%, 16.8 \%$, and $30.4 \%$, respectively. Total cell concentrations in patients at baseline and predose cycle 2 were not significantly lower than in healthy volunteers (Table 2A).

The percentage of PD-1 $1^{+}$cells and number of PD-1 per cell at baseline and EOI were not significantly different from healthy volunteers. However, at predose of cycle 2 , the percentage of PD- $1^{+} \mathrm{CD} 4^{+}$and $\mathrm{CD} 8^{+}$-T-cells were significantly lower by $34.5 \%(n=10, P=0.001)$ and $16.4 \%(n=9, P=0.002)$, respectively, relative to baseline (Fig 4BC, Table 2BC). Furthermore, the number of PD-1 per cell was significantly decreased by $22.6 \%$ for $\mathrm{CD}^{+}$-T-cells $(\mathrm{n}=9, \mathrm{P}=0.003$ ) and $26.0 \%$ for CD8 ${ }^{+}$-T-cells $(n=9, P=0.007$ ) at predose of cycle 2 relative to baseline (Fig $4 \mathrm{DE}$, Table 2BC). The BSBV in the determination of percentage of PD-1 ${ }^{+}$cells and number of PD-1 per CD4 $4^{+}$-T-cell at baseline were $25.7 \%$ and $27.7 \%$, and for $\mathrm{CD}^{+}$T-cells BSBV was $37.7 \%$ and $26.2 \%$, respectively. PD-1 RO on CD4 ${ }^{+}$and CD8 ${ }^{+}$-T-cells of patients who were given nivolumab were $98.9 \% \pm 2.5 \%$ and $98.2 \% \pm 2.5 \%$, respectively. $\mathrm{RO}$ on $\mathrm{CD}^{+}-$-T-cells was $95.0 \% \pm 1.1 \%$ in patients who were given pembrolizumab. RO occupation on $\mathrm{CD}^{+}{ }^{+}$-T-cells by pembrolizumab and nivolumab 
showed no significant difference. However, RO on CD8 ${ }^{+}$-T-cells was significantly lower at $91.6 \% \pm 1.1 \%(P=0.014)$ in patients who were given pembrolizumab, as compared to nivolumab. PD-1 RO at EOI, in patients who were given nivolumab or pembrolizumab, was not significantly different from RO at predose cycle 2 (Table $2 \mathrm{~B}$ and $\mathrm{C})$.

\section{DISCUSSION}

We have described here a PD-1 detection method which is highly specific for PD-1. Background control samples are used for setting the gates that determine PD-1 positivity. Brahmer et al. used background controls containing human IgG4 isotype antibody as a control for non-specific binding of nivolumab and pembrolizumab (24). Others have reported that using isotype antibodies can give erroneous results, and have shown that adequate blocking of non-specific antibody interactions and using directly conjugated antibodies can most often prevent the use of isotypes in flow cytometry (37). By using anti-PD-1 antibody clone PD1313 and PD-L2, the interaction between nivolumab / pembrolizumab and PD-1 was completely blocked. This demonstrates that our method was $100 \%$ specific for PD-1 and that the use of an $\operatorname{lgG}_{4}$ isotype antibody was not necessary. After correction for $90 \%$ cell recovery, the average cell concentrations we found in healthy volunteers for different immune cell subsets were as follows: 1780 (1278 - 2849) PBMCs; 1156 (508 - 2013) lymphocytes; 310 (172 - 620) total monocytes; 101 (57 -202) B-cells; 154 (51 -202) NK-cells; 6.9 (2.2 - 18.4) mDCs; and 6.2 (2.7 -10) pDCs per $\mu \mathrm{l}$ blood. These values are in concordance with values reported by other investigators (38-40). Although the normal range for concentrations of immune cell subsets has been reported by many investigators, there is debate regarding both the percentage and the absolute numbers of cells constituting this range. Methods that depend on density gradient centrifugation rather than whole blood cell counting prior to enumeration of immune cells may lead to an underestimation of the absolute cell concentrations of (some) immune cell subsets.

Reproducibility over time and between instruments is crucial in longitudinal and multicenter studies. In flow cytometry, QSC beads allow comparison of experiments over time and between different instruments (41). We show that 
the use of QSC beads enabled the reproducible quantification of PD-1 levels in samples that were stored at $-80^{\circ} \mathrm{C}$ in Cryosofree ${ }^{\mathrm{TM}}$.

To our knowledge, this is the first indirect detection method for the quantification of the number of PD-1 molecules on, and number of PD-1+ B-cells, monocytes, and dendritic cells in peripheral human blood. For pharmacodynamic assays, indirect detection methods rather than direct methods are preferred, as they enable the determination of RO and changes in receptor expression separately. However, direct detection may potentially be more sensitive, as their sensitivity is not affected by non-specific binding of nivolumab and pembroluzimab (42). Other investigators reported detectable levels of PD$1^{+}$for B-cells, NK-cells, monocytes, and dendritic cells in peripheral blood from cancer patients and healthy volunteers using direct detection methods. However, results were often inconsistent, which may have been caused by the use of not thoroughly validated methods e.g. methods for which important validation parameters such as specificity and lower limit of quantification were not established. Other investigators have reported percentages of $40-60 \%$ of PD- $1^{+} \mathrm{CD}^{+}$and $\mathrm{PD}-1^{+} \mathrm{CD} 8^{+}$-T-cells in peripheral blood from cancer patients, which is similar to our findings (25-28). Wang et al. reported approximately 10,000 number of PD-1 receptors per growth activated human T-cell (43). This is in good agreement with the range of 2,000 - 3,000 PD-1 receptors per T-cell we found for unstimulated PBMCs from healthy volunteers, considering the 5-fold increase in PD-1 expression induced by anti-CD3 growth stimulation of PBMCs (supplementary Fig. 3).

Thus far, receptor occupancy by nivolumab and pembrolizumab has only been described in one study (24). PD-1 occupancy was described on CD3+-T-cells that were cryopreserved in DMSO, and was found to be dose-independent with maximal occupancy of $85 \%$ at the end of infusion. Nivolumab concentrations in plasma were $50 \mu \mathrm{g} / \mathrm{mL}$ at EOI for patients that received $3 \mathrm{mg} / \mathrm{kg}$. The investigators hypothesized that PD-1 occupancy analyses of cryopreserved PBMCs may underestimate occupancy on fresh PBMCs. However, for batch analysis of samples from clinical studies, cryopreservation is necessary. In order to keep nivolumab and pembrolizumab attached to PD-1 during the cryopreservation and wash steps, cells were fixed with $2 \%$ formaldehyde which resulted in $15 \%$ higher PD-1 signals. Instead of DMSO we used Cryosofree ${ }^{\mathrm{TM}}$ as cryopreservative, which is far superior for retaining cell vitality (44). Furthermore, DMSO infiltrates the cells and requires laborious removal during the slow thawing procedure, which compromises 
reproducibility and cell recovery. Cryosofree ${ }^{\mathrm{TM}}$ does not enter the cells and can simply be washed away after thawing, resulting in much higher vital cell recoveries with good reproducibility, as confirmed by our study. We found that the mean RO on $\mathrm{CD}^{+}$-T-cells from cancer patients that were given nivolumab or pembrolizumab was $99 \%$ and $91 \%$, respectively, after $2-4$ weekly courses of treatment. Similar RO values were found at baseline day 1 immediately after infusion. These results are in line with our in vitro experiments, indicating $>83 \%$ PD-1 occupancy on CD8 ${ }^{+}$-T-cells exposed for $1 \mathrm{~h}$ to a relatively low $0.05 \mu \mathrm{g} / \mathrm{mL}$ concentration of nivolumab.

The detection of PD-1 on CD4+ and CD8+-T-cells was on average 7\% lower in samples incubated with pembrolizumab compared to nivolumab. This is likely caused by the difference in binding sites on PD-1 for both antibodies (45). This may possibly explain the fact that RO of PD- 1 on $C D 8^{+}-$-T-cells was on average $7 \%$ lower in patients which were administered pembrolizumab, as compared to patients treated with nivolumab.

The discovery of factors that influence the clinical response to immunotherapy remains an area of active research and is important to maximize the benefit/ risk ratio of these agents in clinical practice. For that purpose, we tested the clinical applicability of our method in cancer patients. We reported a significant drop in the number of PD-1+ T-cells and the number of PD-1 receptors per T-cell after one course of nivolumab or pembrolizumab. This may potentially be a pharmacodynamic effect, which requires further investigation regarding predictive value for nivolumab and pembrolizumab immunotherapy outcome. Compared to other methods, our method offers efficient determination of multiple biomarkers on a large panel of immune cell subsets in a single experiment. 


\section{REFERENCES}

1. Le DT, Durham JN, Smith KN, Wang $H$, Bartlett BR, Aulakh LK, Lu S, Kemberling $\mathrm{H}$, Wilt C, Luber BS, Wong F, Azad NS, Rucki AA, Laheru $D$, Donehower $R$, Zaheer A, Fisher GA, Crocenzi TS, Lee JJ, Greten TF, Duffy AG, Ciombor KK, Eyring AD, Lam BH, Joe A, Kang SP, Holdhoff M, Danilova L, Cope L, Meyer C, Zhou S, Goldberg RM, Armstrong DK, Bever KM, Fader AN, Taube J, Housseau F, Spetzler D, Xiao N, Pardoll DM, Papadopoulos $\mathrm{N}$, Kinzler KW, Eshleman JR, Vogelstein B, Anders RA, Diaz LA. Mismatch repair deficiency predicts response of solid tumors to PD-1 blockade. Science 2017;357:409413.

2. Larkin J, Minor D, D’Angelo S, Neyns B, Smylie $M$, Miller WH, Gutzmer R, Linette G, Chmielowski B, Lao CD, Lorigan $P$, Grossmann K, Hassel JC, Sznol M, Daud A, Sosman J, Khushalani N, Schadendorf D, Hoeller C, Walker D, Kong G, Horak C, Weber J. Overall Survival in Patients With Advanced Melanoma Who Received Nivolumab Versus Investigator's Choice Chemotherapy in CheckMate 037: A Randomized, Controlled, Open-Label Phase III Trial. J Clin Oncol 2017.

3. Weber JS, D'Angelo SP, Minor D, Hodi FS, Gutzmer R, Neyns B, Hoeller C, Khushalani $\mathrm{NI}$, Miller WH, Lao CD, Linette GP, Thomas L, Lorigan P, Grossmann KF, Hassel JC, Maio M, Sznol M, Ascierto PA, Mohr P, Chmielowski B, Bryce A, Svane IM, Grob J-J, Krackhardt AM, Horak C, Lambert A, Yang AS, Larkin J. Nivolumab versus chemotherapy in patients with advanced melanoma who progressed after anti-CTLA-4 treatment (CheckMate 037): a randomised, controlled, open-label, phase 3 trial. Lancet Oncol 2015;16:375-
384.

4. Motzer RJ, Escudier B, McDermott DF, George S, Hammers HJ, Srinivas S, Tykodi SS, Sosman JA, Procopio G, Plimack ER, Castellano D, Choueiri TK, Gurney H, Donskov F, Bono P, Wagstaff J, Gauler TC, Ueda T, Tomita Y, Schutz FA, Kollmannsberger C, Larkin J, Ravaud A, Simon JS, Xu L-A, Waxman IM, Sharma P, CheckMate 025 Investigators. Nivolumab versus Everolimus in Advanced Renal-Cell Carcinoma. N Engl J Med 2015;373:1803-13.

5. Sul J, Blumenthal GM, Jiang $X, \mathrm{He} \mathrm{K}$, Keegan P, Pazdur R. FDA Approval Summary: Pembrolizumab for the Treatment of Patients With Metastatic Non-Small Cell Lung Cancer Whose Tumors Express Programmed DeathLigand 1. Oncologist 2016;21:643-650.

6. Kang Y-K, Boku N, Satoh T, Ryu M-H, Chao Y, Kato K, Chung HC, Chen J-S, Muro K, Kang WK, Yeh K-H, Yoshikawa T, Oh SC, Bai L-Y, Tamura T, Lee K-W, Hamamoto Y, Kim JG, Chin K, Oh D-Y, Minashi K, Cho JY, Tsuda M, Chen L-T. Nivolumab in patients with advanced gastric or gastro-oesophageal junction cancer refractory to, or intolerant of, at least two previous chemotherapy regimens (ONO4538-12, ATTRACTION-2): a randomised, double-blind, placebo-controlled, phase 3 trial. Lancet 2017;390:2461-2471.

7. Harrington KJ, Ferris RL, Blumenschein G, Colevas AD, Fayette J, Licitra L, Kasper S, Even C, Vokes EE, Worden F, Saba NF, Kiyota N, Haddad R, Tahara M, Grünwald V, Shaw JW, Monga M, Lynch M, Taylor F, DeRosa M, Morrissey L, Cocks K, Gillison ML, Guigay J. Nivolumab versus standard, single-agent therapy of investigator's choice in recurrent or metastatic squamous cell carcinoma 
of the head and neck (CheckMate 141): health-related quality-of-life results from a randomised, phase 3 trial. Lancet Oncol. 2017;18:1104-1115.

8. Ansell SM. Nivolumab in the Treatment of Hodgkin Lymphoma. Clin Cancer Res 2017;23:1623-1626.

9. Sharma $P$, Retz $M$, Siefker-Radtke $A$, Baron A, Necchi A, Bedke J, Plimack ER, Vaena D, Grimm M-O, Bracarda S, Arranz JÁ, Pal S, Ohyama C, Saci A, Qu X, Lambert A, Krishnan S, Azrilevich A, Galsky MD. Nivolumab in metastatic urothelial carcinoma after platinum therapy (CheckMate 275): a multicentre, single-arm, phase 2 trial. Lancet Oncol 2017;18:312-322.

10. Garon EB, Rizvi NA, Hui R, Leighl N, Balmanoukian AS, Eder JP, Patnaik A, Aggarwal C, Gubens M, Horn L, Carcereny E, Ahn M-J, Felip E, Lee J-S, Hellmann MD, Hamid O, Goldman JW, Soria J-C, DolledFilhart M, Rutledge RZ, Zhang J, Lunceford JK, Rangwala R, Lubiniecki GM, Roach C, Emancipator K, Gandhi L, KEYNOTE-001 Investigators. Pembrolizumab for the Treatment of Non-Small-Cell Lung Cancer. N Engl J Med 2015;372:2018-2028.

11. Fessas $P$, Lee $H$, Ikemizu $S$, Janowitz T. A molecular and preclinical comparison of the PD-1-targeted T-cell checkpoint inhibitors nivolumab and pembrolizumab. Semin Oncol 2017;44:136-140.

12. European Medicines Agency. Keytruda (pembrolizumab) Eur. Public Assess. Rep. 2016.

13. European Medicines Agency. Opdivo (nivolumab) Eur. Public Assess. Rep. 2016.

14. U.S. Food and Drug Administration. Opdivo (nivolumab) Prescribing information. 2015. Available at: https:// www.accessdata.fda.gov/drugsatfda_docs/ label/2018/125554s058lbl.pdf.

15. U.S. Food and Drug Administration. Keytruda (pembrolizumab) Prescribing information. 2015. Available at: https:// www.merck.com/product/usa/pi_ circulars/k/keytruda/keytruda_pi.pdf.

16. Nakamura $Y$, Kitano $S$, Takahashi $A$, Tsutsumida A. Nivolumab for advanced melanoma: pretreatment prognostic factors and early outcome markers during therapy. Oncotarget 2016;7:77404-15.

17. Loi S, Adams S, Schmid P, Cortes J, Cescon DW, Winer EP, Toppmeyer DL, Rugo $H$, De Laurentiis $M$, Nanda R, Iwata $H$, Awada A, Tan A, Wang A, Aktan G, Karantza $\mathrm{V}$, Salgado R. Relationship between tumor infiltrating lymphocyte (TIL) levels and response to pembrolizumab (pembro) in metastatic triple-negative breast cancer (mTNBC): Results from KEYNOTE-086. Ann Oncol 2017;28.

18. Tumeh PC, Harview CL, Yearley $\mathrm{JH}$, Shintaku IP, Taylor EJM, Robert L, Chmielowski B, Spasic M, Henry G, Ciobanu V, West AN, Carmona M, Kivork C, Seja E, Cherry G, Gutierrez AJ, Grogan TR, Mateus C, Tomasic G, Glaspy JA, Emerson RO, Robins $\mathrm{H}$, Pierce RH, Elashoff DA, Robert C, Ribas A. PD-1 blockade induces responses by inhibiting adaptive immune resistance. Nature 2014;515:568-571.

19. Ribas A, Robert C, Hodi FS, Wolchok JD, Joshua AM, Hwu W-J, Weber JS, Zarour HM, Kefford R, Loboda A, Albright A, Kang $S P$, Ebbinghaus $S$, Yearley J, Murphy E, Nebozhyn M, Lunceford JK, McClanahan T, Ayers M, Daud A. Association of response 
to programmed death receptor 1 (PD-1) blockade with pembrolizumab (MK-3475) with an interferon-inflammatory immune gene signature. J Clin Oncol 2015;33:3001.

20. Chow LQM, Haddad R, Gupta $S$, Mahipal A, Mehra R, Tahara M, Berger $\mathrm{R}$, Eder JP, Burtness B, Lee S-H, Keam B, Kang $\mathrm{H}$, Muro K, Weiss J, Geva R, Lin C-C, Chung HC, Meister A, Dolled-Filhart $M$, Pathiraja K, Cheng JD, Seiwert TY. Antitumor Activity of Pembrolizumab in BiomarkerUnselected Patients With Recurrent and/ or Metastatic Head and Neck Squamous Cell Carcinoma: Results From the Phase Ib KEYNOTE-012 Expansion Cohort. J Clin Oncol 2016;34:3838-3845.

21. Diehl A, Yarchoan M, Hopkins A, Jaffee E, Grossman SA. Relationships between lymphocyte counts and treatmentrelated toxicities and clinical responses in patients with solid tumors treated with PD-1 checkpoint inhibitors. Oncotarget 2017;8:114268-114280.

22. Parikh K, Kumar A, Ahmed J, Anwar A, Puccio C, Chun H, Fanucchi M, Lim SH. Peripheral monocytes and neutrophils predict response to immune checkpoint inhibitors in patients with metastatic nonsmall cell lung cancer. Cancer Immunol Immunother 2018;67:1365-1370.

23. Agrawal S, Feng Y, Roy A, Kollia G, Lestini B. Nivolumab dose selection: challenges, opportunities, and lessons learned for cancer immunotherapy. J Immunother Cancer 2016;4:72.

24. Brahmer JR, Drake CG, Wollner I, Powderly JD, Picus J, Sharfman WH, Stankevich E, Pons A, Salay TM, McMiller TL, Gilson MM, Wang C, Selby M, Taube
JM, Anders R, Chen L, Korman AJ, Pardoll DM, Lowy I, Topalian SL. Phase I study of single-agent anti-programmed death-1 (MDX-1106) in refractory solid tumors: safety, clinical activity, pharmacodynamics, and immunologic correlates. J Clin Oncol 2010;28:3167-75.

25. Choueiri TK, Fishman MN, Escudier B, McDermott DF, Drake CG, Kluger H, Stadler WM, Perez-Gracia JL, McNeel DG, Curti B, Harrison MR, Plimack ER, Appleman L, Fong L, Albiges L, Cohen L, Young TC, Chasalow SD, Ross-Macdonald P, Srivastava S, JureKunkel M, Kurland JF, Simon JS, Sznol M. Immunomodulatory activity of nivolumab in metastatic renal cell carcinoma. Clin Cancer Res 2016;22:5461-5471.

26. Zheng H, Liu X, Zhang J, Rice SJ, Wagman M, Kong Y, Zhu L, Zhu J, Joshi M, Belani CP. Expression of PD-1 on CD4+ $T$ cells in peripheral blood associates with poor clinical outcome in non-small cell lung cancer. Oncotarget 2016;7:56233-56240.

27. Kamphorst AO, Pillai RN, Yang S, Nasti TH, Akondy RS, Wieland A, Sica GL, Yu K, Koenig L, Patel NT, Behera M, Wu H, McCausland M, Chen Z, Zhang C, Khuri FR, Owonikoko TK, Ahmed R, Ramalingam SS. Proliferation of PD-1+ CD8 T cells in peripheral blood after PD-1-targeted therapy in lung cancer patients. Proc Natl Acad Sci 2017;114:49934998. A

28. van de Ven $R$, Niemeijer A-LN, Stam AGM, Hashemi SMS, Slockers CG, Daniels JM, Thunnissen E, Smit EF, de Gruijl TD, de Langen AJ. High PD-1 expression on regulatory and effector T-cells in lung cancer draining lymph nodes. ERJ Open Res 2017;3. 29. Asano T, Meguri Y, Yoshioka T, Kishi Y, 
Iwamoto M, Nakamura M, Sando Y, Yagita $H$, Koreth J, Kim HT, Alyea EP, Armand P, Cutler CS, Ho VT, Antin JH, Soiffer RJ, Maeda Y, Tanimoto M, Ritz J, Matsuoka KI. PD-1 modulates regulatory T-cell homeostasis during low-dose interleukin-2 therapy. Blood 2017;129:2186-2197.

30. Lim TS, Chew V, Sieow JL, Goh S, Yeong JPS, Soon AL, Ricciardi-Castagnoli P. PD-1 expression on dendritic cells suppresses CD8+T cell function and antitumor immunity. Oncoimmunology 2016;5.

31. MacFarlane AW, Jillab $M$, Plimack ER, Hudes GR, Uzzo RG, Litwin S, Dulaimi E, AlSaleem T, Campbell KS. PD-1 Expression on Peripheral Blood Cells Increases with Stage in Renal Cell Carcinoma Patients and Is Rapidly Reduced after Surgical Tumor Resection. Cancer Immunol Res 2014;2:320-331.

32. Ren Z, Peng H, Fu Y-X. PD-1 Shapes B Cells as Evildoers in the Tumor Microenvironment. Cancer Discov 2016;6:477-8.

33. Thibult M-L, Mamessier E, GertnerDardenne J, Pastor S, Just-Landi S, Xerri L, Chetaille B, Olive D. PD-1 is a novel regulator of human B-cell activation. Int. Immunol 2013;25:129-37.

34. Das R, Verma R, Sznol M, Boddupalli CS, Gettinger SN, Kluger $H$, Callahan $M$, Wolchok JD, Halaban R, Dhodapkar M V., Dhodapkar KM. Combination Therapy with Anti-CTLA-4 and Anti-PD-1 Leads to Distinct Immunologic Changes In Vivo. J Immunol 2015;194:950-959.

35. Thibult ML, Mamessier E, Gertnerdardenne J, Pastor S, Just-landi S, Xerri L, Chetaille $B$, Olive D. Pd-1 is a novel regulator of human B-cell activation. Int Immunol 2013;25:129-137.
36. Liu Y, Cheng Y, Xu Y, Wang Z, Du X, Li C, Peng J, Gao L, Liang X, Ma C. Increased expression of programmed cell death protein 1 on NK cells inhibits NK-cell-mediated anti-tumor function and indicates poor prognosis in digestive cancers. Oncogene 2017;36:61436153.

37. Keeney M, Gratama JW, Chin-Yee IH, Sutherland DR. Isotype controls in the analysis of lymphocytes and CD34+ stem and progenitor cells by flow cytometry-time to let go! Cytometry 1998;34:280-3.

38. Simmons A. The establishment of normal hematology values using the hemalog. Am J Med Technol 1974;40:321-5.

39. Comans-Bitter WM, de Groot R, van den Beemd R, Neijens HJ, Hop WCJ, Hooijkaas H, Groeneveld K, van Dongen JJM. Immunophenotyping of blood lymphocytes in childhoodReference values for lymphocyte subpopulations. J Pediatr 2005;130:388-393.

40. Chen $P$, Sun $Q$, Huang $Y, A t t a ~ M G$, Turban $S$, Segev DL, Marr KA, Naqvi FF, Alachkar $\mathrm{N}$, Kraus ES, Womer KL. Blood dendritic cell levels associated with impaired IL-12 production and T-cell deficiency in patients with kidney disease: implications for posttransplant viral infections. Transpl Int 2014;27:1069-1076.

41. Perfetto SP, Ambrozak D, Nguyen R, Chattopadhyay PK, Roederer M. Quality assurance for polychromatic flow cytometry using a suite of calibration beads. Nat Protoc 2012;7:2067-79.

42. Sternebring $O$, Alifrangis $L$, Christensen $T F$, Ji $H$, Hegelund AC, Högerkorp CM. A weighted method for estimation of receptor occupancy for pharmacodynamic 
measurements in drug development. Cytom Part B - Clin Cytom 2016;90:220-229.

43. Wang $C$, Thudium KB, Han M, Wang $X-T$, Huang $\mathrm{H}$, Feingersh D, Garcia C, Wu Y, Kuhne $M$, Srinivasan $M$, Singh $S$, Wong $S$, Garner $\mathrm{N}$, Leblanc $\mathrm{H}$, Bunch RT, Blanset D, Selby MJ, Korman AJ. In Vitro Characterization of the Anti-PD-1 Antibody Nivolumab, BMS936558, and In Vivo Toxicology in NonHuman Primates. Cancer Immunol Res 2014;2:846-856.

44. Matsumura K, Bae JY, Hyon SH. Polyampholytes as cryoprotective agents for mammalian cell cryopreservation. Cell Transplant 2010;19:691-699.

45. Ghiotto $M$, Gauthier L, Serriari N, Pastor $S$, Truneh A, Nunès JA, Olive D. PD-L1 and PD-L2 differ in their molecular mechanisms of interaction with PD-1. Int Immunol 2010;22:651-660. 


\section{SUPPLEMENTARY MATERIAL}

Table S1. FACS settings for detection of indicated biomarkers by 12 parameter flow cytometry. A. Overview of used fluorochromes, lasers, filters and voltages. B. compensation settings.

Table S1A

\begin{tabular}{ccccc}
\hline biomarker & fluorochrome & laser $(\mathbf{n m})$ & filter & voltage \\
\hline Live-dead & V450 & 405 & $450 / 50$ & 400 \\
\hline CD14 & BV525 & 405 & $530 / 30$ & 444 \\
CD123 & BV605 & 405 & $610 / 20$ & 600 \\
\hline CD11c & BV650 & 405 & $660 / 20$ & 555 \\
CD19 & BV710 & 405 & $710 / 50$ & 551 \\
HLA-DR & BV786 & 405 & $780 / 60$ & 629 \\
CD56 & FITC & 480 & $530 / 30$ & 400 \\
CD8 & PerCP-C5.5 & 480 & $710 / 50$ & 568 \\
PD-1 & PE & 561 & $585 / 15$ & 458 \\
\hline CD4 & APC & 640 & $670 / 14$ & 650 \\
CD16 & APC-AF700 & 640 & $730 / 45$ & 650 \\
\hline CD3 & APC-Cy7 & 640 & $780 / 60$ & 650 \\
\hline
\end{tabular}

Table S1B

\begin{tabular}{ccccccccccccc}
\hline $\begin{array}{c}\text { bio- } \\
\text { marker }\end{array}$ & L-D & CD14 & CD123 & CD11c & CD19 & HLA & CD56 & CD8 & PD-1 & CD4 & CD16 & CD3 \\
\hline L-D & 100 & 0 & 0 & 0 & 0 & 0 & 0 & 0 & 0 & 0 & 0 & 0 \\
CD14 & 7 & 100 & 0 & 0 & 0 & 0 & 0 & 0 & 0 & 0 & 0 & 0 \\
CD123 & 0 & 0 & 100 & 33 & 0.8 & 0 & 0 & 0 & 0 & 0 & 0 & 0 \\
CD11c & 0 & 0 & 25 & 100 & 17 & 10 & 0 & 0 & 0 & 0 & 0 & 0 \\
CD19 & 0 & 0 & 0 & 0 & 100 & 0 & 0 & 0 & 0 & 38 & 80 & 0 \\
HLA & 0 & 0 & 0 & 1 & 2 & 100 & 0 & 0 & 0 & 0 & 0 & 10 \\
CD56 & 0 & 0 & 0 & 0 & 0 & 0 & 100 & 0 & 0 & 0 & 0 & 0 \\
CD8 & 0 & 0 & 0 & 0 & 60 & 0 & 0 & 100 & 0 & 0 & 90 & 0 \\
PD-1 & 0 & 0 & 0 & 0 & 0 & 0 & 0 & 17 & 100 & 0 & 0 & 0 \\
CD4 & 0 & 0 & 0 & 0 & 0 & 0 & 0 & 0 & 0 & 100 & 80 & 15 \\
CD16 & 0 & 0 & 0 & 0 & 0 & 0 & 0 & 0 & 0 & 0.5 & 100 & 13 \\
CD3 & 0 & 0 & 0 & 0 & 0 & 0 & 0 & 0 & 0 & 3 & 7 & 100 \\
\hline
\end{tabular}

- indicates that the indicated percentage should be subtracted from the signal of the horizontally aligned biomarkers. L-D $=$ Live-dead ${ }^{\mathrm{TM}}$ protein fixable marker. 
Table S2. Specificity of PD-1 detection in immune cells from a healthy volunteer. Peripheral blood mononuclear cells were cultured in RPMI medium under growth stimulating conditions. Cells were incubated with PD-L2 and PD-1 blocking antibody clone PD1313, followed by incubation with nivolumab and pembrolizumab and detection with anti-IgG 4 -PE. Shown are the results for CD4 and CD8 ${ }^{+}-$T-cells (CD4T and CD8T), B-cells (B), natural killer cells (NK), classical monocytes (CM), intermediate monocytes (IM), nonclassical monocytes (NCM), plasmacytoid dendritic cells ( $\mathrm{pDC}$ ), and myeloid dendritic cells $(\mathrm{mDC})$. Data are represented as the mean percentage of PD-1 positive cells (\%PD-1+) and the mean number of PD-1 molecules per PD-1+ cell of three separate samples \pm standard deviation (SD).

\begin{tabular}{|c|c|c|c|c|c|c|c|c|}
\hline \multirow[b]{2}{*}{$\begin{array}{l}\text { cell } \\
\text { type }\end{array}$} & \multicolumn{4}{|c|}{ nivolumab } & \multicolumn{4}{|c|}{ pembrolizumab } \\
\hline & $\begin{array}{c}\text { net } \\
\% \text { PDI }^{+} \text {cells }\end{array}$ & $\begin{array}{c}\text { \%PD-1 } \\
\text { inhibition }\end{array}$ & $\begin{array}{l}\text { number of } \\
\text { PD-1/ cell }\end{array}$ & $\begin{array}{l}\text { PD-1/cell } \\
\text { inhibition }\end{array}$ & $\begin{array}{c}\text { net } \\
\% \text { PD1 }^{+} \text {cells }\end{array}$ & $\begin{array}{c}\text { \%PD-1 } \\
\text { inhibition }\end{array}$ & $\begin{array}{l}\text { number of } \\
\text { PD-1 / cell }\end{array}$ & $\begin{array}{l}\text { PD-1/cell } \\
\text { inhibition }\end{array}$ \\
\hline CDAT & $37.6 \pm 0.5$ & $99.9 \pm 1.9$ & $2397 \pm 94$ & $97.0 \pm 1.8$ & $31.1 \pm 0.6$ & $97.9 \pm 0.9$ & $2290 \pm 24$ & $99.5 \pm 0.4$ \\
\hline CD8T & $41.3 \pm 0.8$ & $99.0 \pm 2.3$ & $6105 \pm 231$ & $98.2 \pm 1.0$ & $36.4 \pm 0.2$ & $98.9 \pm 0.9$ & $5510 \pm 133$ & $99.6 \pm 0.1$ \\
\hline B & $27.7 \pm 0.5$ & $100 \pm 1.4$ & $1753 \pm 29$ & $98.0 \pm 6.2$ & $18.6 \pm 0.8$ & $95.9 \pm 4.6$ & $1631 \pm 11$ & $100.0 \pm 7.0$ \\
\hline NK & $1.2 \pm 0.7$ & $<L L O Q$ & $<L L O Q$ & $<L L O Q$ & $0.0 \pm 0.3$ & $<L L O Q$ & $<L L O Q$ & $<L L O Q$ \\
\hline$C M$ & $67.0 \pm 0.6$ & $100 \pm 1.3$ & $9126 \pm 91$ & $94.4 \pm 1.7$ & $56.2 \pm 0.8$ & $99.9 \pm 2.1$ & $7130 \pm 98$ & $94.4 \pm 1.5$ \\
\hline IM & $18.4 \pm 0.3$ & $99.5 \pm 4.0$ & $4902 \pm 116$ & $83.6 \pm 4.1$ & $10.4 \pm 0.7$ & $86.4 \pm 13.0$ & $4677 \pm 136$ & $80.3 \pm 4.1$ \\
\hline NCM & $10.1 \pm 2.0$ & $93.1 \pm 16.4$ & $2845 \pm 104$ & $80.9 \pm 3.7$ & $10.3 \pm 0.8$ & $88.1 \pm 9.3$ & $2569 \pm 20$ & $91.3 \pm 17.3$ \\
\hline$P D C$ & $39.7 \pm 6.2$ & $91.6 \pm 6.0$ & $5711 \pm 314$ & $86.3 \pm 4.3$ & $22.9 \pm 1.0$ & $101 \pm 6.3$ & $5462 \pm 270$ & $91.5 \pm 8.4$ \\
\hline $\mathrm{mDC}$ & $15.1 \pm 1.4$ & $93.4 \pm 1.6$ & $3863 \pm 283$ & $86.1 \pm 11.7$ & $15.4 \pm 1.7$ & $84.5 \pm 4.5$ & $3866 \pm 192$ & $85.6 \pm 10.0$ \\
\hline
\end{tabular}




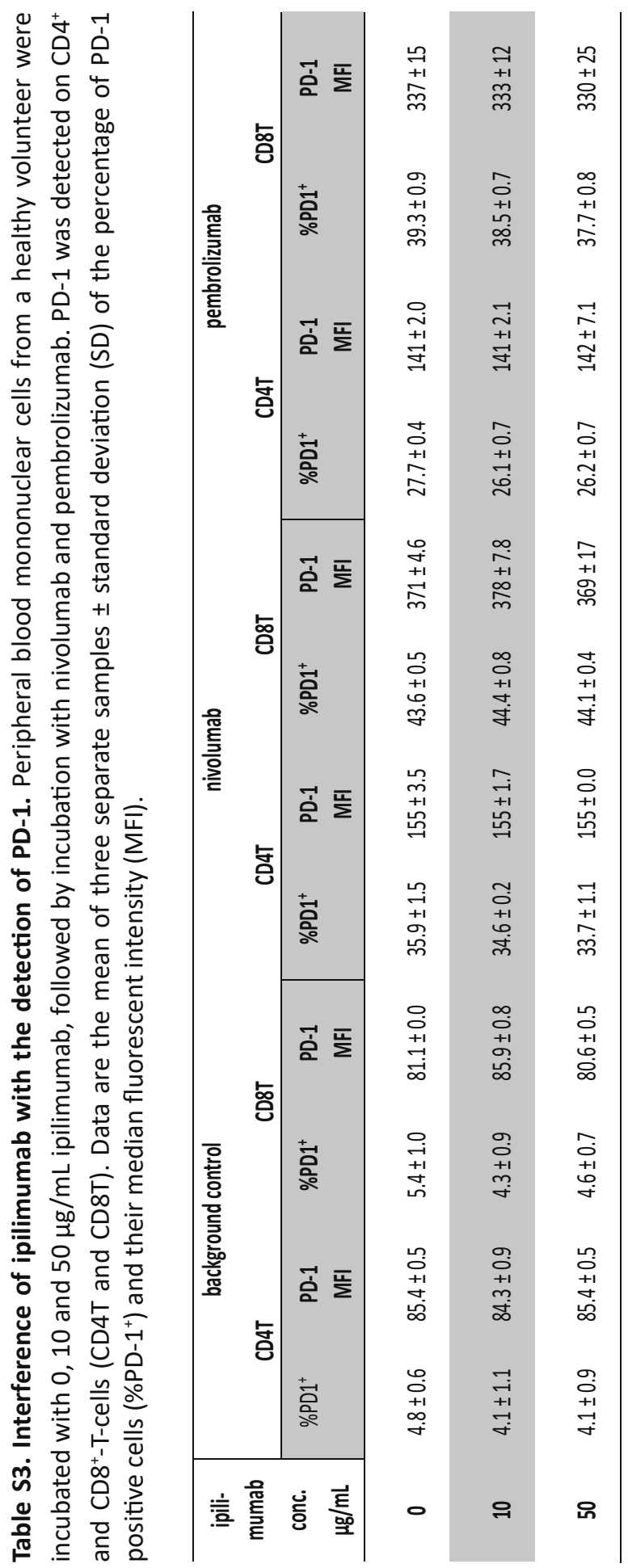


Table S4. Linearity of PD-1 detection in samples containing 100k and 500k PBMC from a healthy volunteer. Samples were incubation with nivolumab. 4A. Relative difference $(\Delta)$ in measured cells between samples spiked with 100k and 500k PBMC. Shown are the results for total live cells, $\mathrm{CD} 4^{+}$and $\mathrm{CD} 8^{+}-\mathrm{T}$-cells (CD4T and CD8T), B-cells (B), natural killer cells (NK), classical monocytes (CM), intermediate monocytes (IM), non-classical monocytes (NCM), plasmacytoid dendritic cells ( $\mathrm{pDC}$ ), and myeloid dendritic cells (mDC). 4B. Relative difference $(\Delta)$ between the percentage of PD- $1^{+}$and number of PD-1 per $C D 4^{+}$and $C D 8^{+}-$ T-cells in samples containing 100k and 500k PBMC. Data are represented as the mean of three separate samples \pm standard deviation (SD).

\section{Table S4A.}

\begin{tabular}{crrr}
\hline \multirow{2}{*}{$\begin{array}{c}\text { cell } \\
\text { type }\end{array}$} & \multicolumn{2}{c}{ number of measured cells at input level } \\
\cline { 2 - 4 } total & 100,000 & 500,000 & $\Delta(\%)$ \\
CD4T & 104865 & 529000 & 0.9 \\
\hline CD8T & 40,179 & 196,494 & 2.2 \\
B & 9,296 & 45,315 & 2.5 \\
NK & 3,581 & 19,637 & -9.7 \\
CM & 17,399 & 83,002 & 4.6 \\
\hline IM & 18,582 & 94,723 & -2.0 \\
\hline NCM & 2,887 & 14,366 & 0.5 \\
\hline pDC & 1,548 & 8,709 & -12.5 \\
mDC & 376 & 2,015 & -7.2 \\
\hline
\end{tabular}

Table S4B.

\begin{tabular}{ccccccc}
\hline \multirow{2}{*}{$\begin{array}{c}\text { cell } \\
\text { type }\end{array}$} & \multicolumn{2}{c}{ net number of PD1 ${ }^{+}$cells } & \multicolumn{3}{c}{ number of PD-1 / cell } \\
\cline { 2 - 7 } & 100,000 & 500,000 & $\Delta(\%)$ & 100,000 & 500,000 & $\Delta(\%)$ \\
CD4T & $27.6 \pm 1.8$ & $29.5 \pm 2.2$ & 6.9 & $1814 \pm 73$ & $1776 \pm 75$ & -2.1 \\
CD8T & $40.4 \pm 1.7$ & $41.7 \pm 1.6$ & 3.3 & $4708 \pm 204$ & $4652 \pm 222$ & -1.2 \\
\hline
\end{tabular}



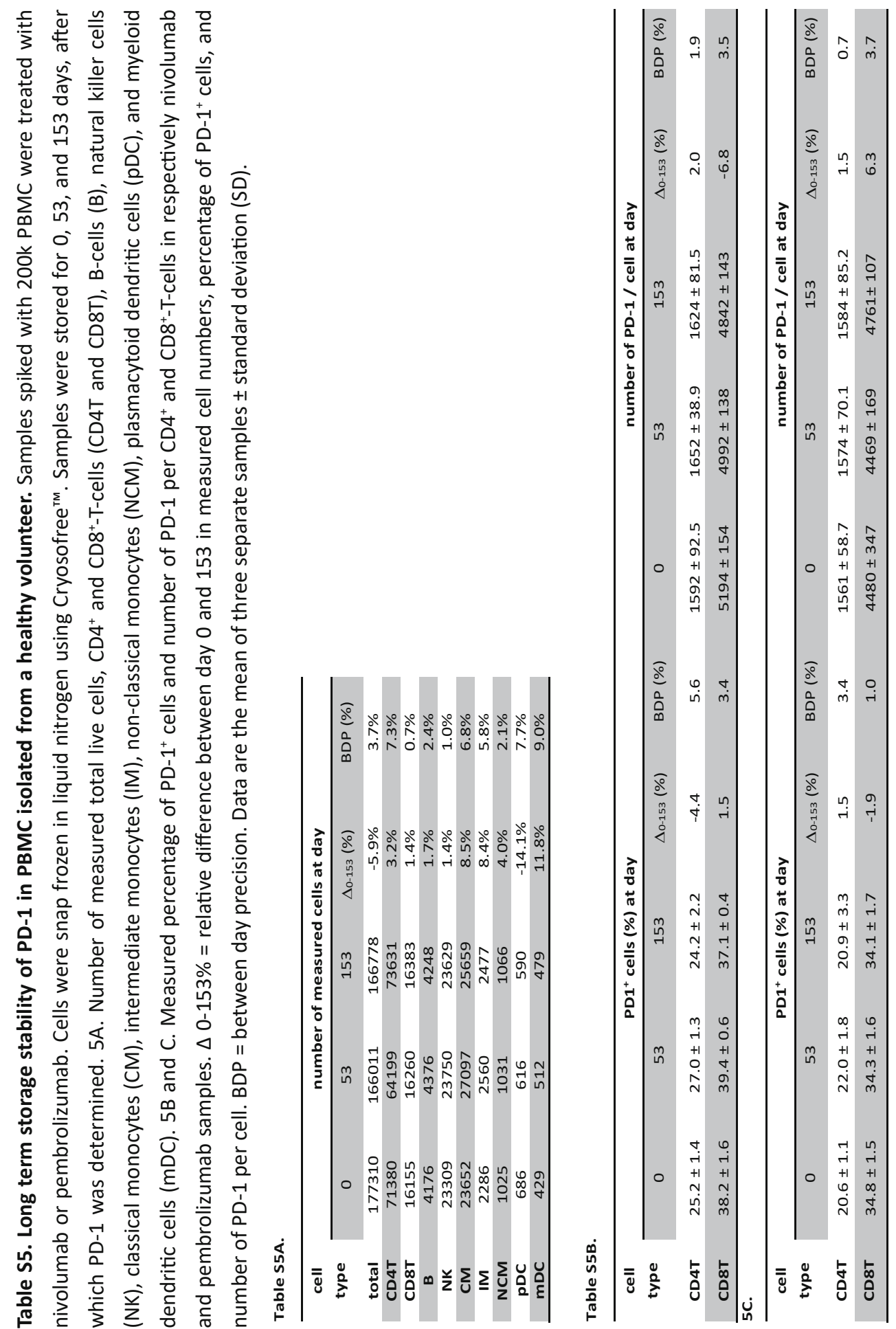
Table S6. Overview of patients included in the study. Advanced cancer patients with indicated tumor type were administered with nivolumab or pembrolizumab, based on their bodyweight $(3 \mathrm{mg} / \mathrm{kg})$, or a flat dose $(\mathrm{mg})$ in two $(q 2 \mathrm{w})$, three $(q 3 \mathrm{w})$ or four $(\mathrm{q} 4 \mathrm{w})$ weekly intervals.

\begin{tabular}{cccc}
\hline cancer type & treatment & dose & schedule \\
\hline melanoma & nivolumab & $480 \mathrm{mg}$ & q4w \\
mesothelioma & nivolumab & $3 \mathrm{mg} / \mathrm{kg}$ & q2w \\
NSCLC & nivolumab & $3 \mathrm{mg} / \mathrm{kg}$ & q2w \\
Mesothelioma & nivolumab & $3 \mathrm{mg} / \mathrm{kg}$ & q4w \\
renal & nivolumab & $480 \mathrm{mg}$ & q4w \\
head and neck & nivolumab & $240 \mathrm{mg}$ & q4w \\
bladder & pembrolizumab & $200 \mathrm{mg}$ & q3w \\
melanoma & pembrolizumab & $200 \mathrm{mg}$ & q3w \\
bladder & pembrolizumab & $200 \mathrm{mg}$ & q3w \\
melanoma & pembrolizumab & $150 \mathrm{mg}$ & q3w \\
melanoma & pembrolizumab & $200 \mathrm{mg}$ & q3w
\end{tabular}
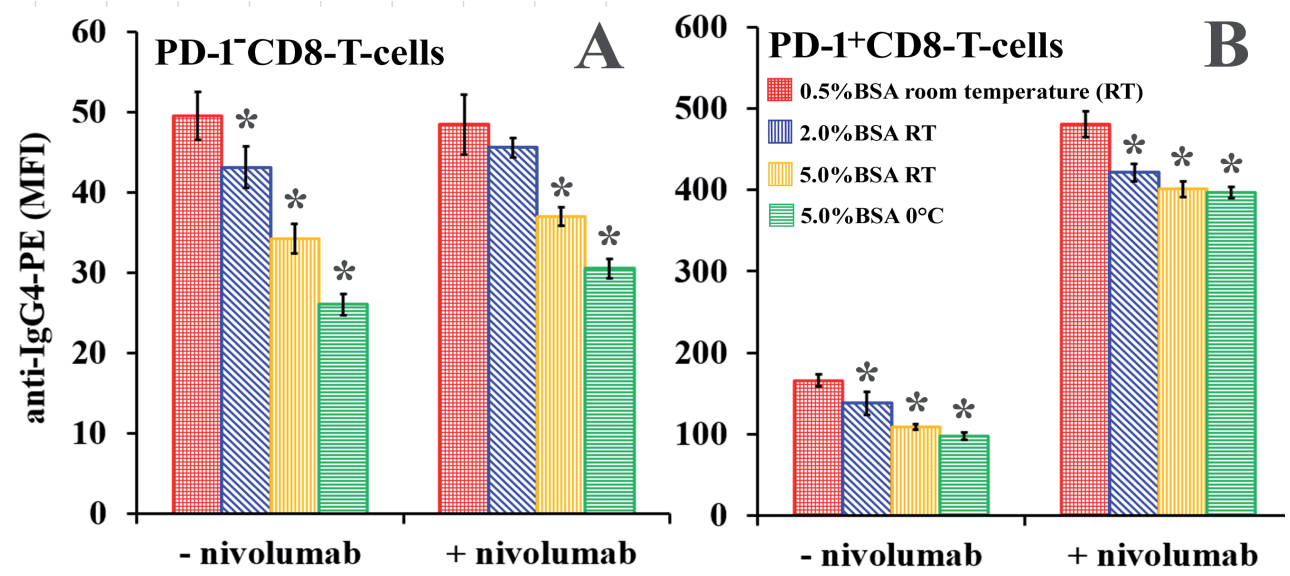

Figure S1. Effect of different incubation conditions on the median fluorescence staining intensity (MFI) of PD1 ${ }^{-}$(A) and PD1 ${ }^{+}$(B) CD8 ${ }^{+}$T-cells by anti-IgG 4 -PE, after pre-incubation with $(+)$ or without (-) $10 \mu \mathrm{g} / \mathrm{ml}$ nivolumab. Results are the mean of three separate samples \pm SD, incubated with beads buffer containing 0.5 (团), 2.0 (\$) , and 5.0\% (四) (w/v\%) bovine serum albumin (BSA) at room temperature and beads buffer with $5 \% \mathrm{BSA}$ at $0^{\circ} \mathrm{C}$ (目). * indicates a significant reduction in MFI relative to $0.5 \% \mathrm{BSA}$. 


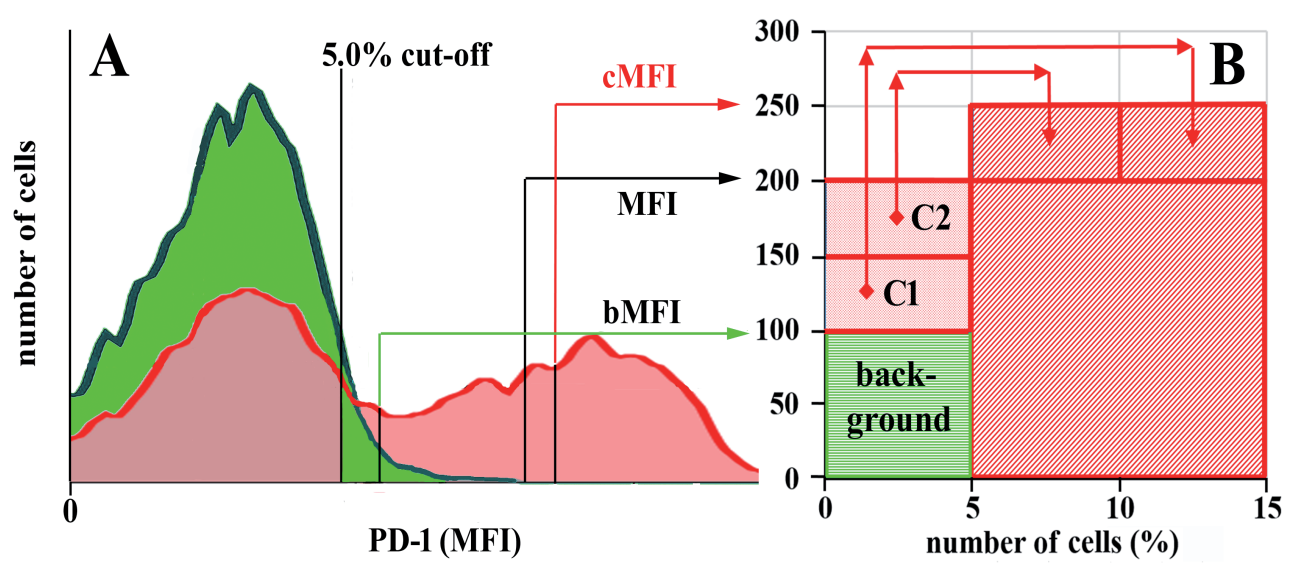

Figure S2. Correction method used for calculation of the specific median fluorescent intensity (MFI) of PD-1. The MFI of PD-1 in cells treated with nivolumab or pembrolizumab is negatively affected by the lower MFI of the background cells, which requires correction. A. Histograms overlays of background (green) and nivolumab (red) treated samples. Cells were qualified as PD- $1^{+}$using $5.0 \%$ cut-off. B. Graphical presentation of the MFI correction procedure for a sample containing $10 \%$ net PD- $1^{+}$cells with a PD-1 MFI of 200 . The $5.0 \%$ background cells have an MFI of 100 (bMFI, 目). The lower MFI of the background cells results in an underestimation of the MFI of the PD $-1^{+}$cells, which was corrected according to our method (cMFI, $\square)$.
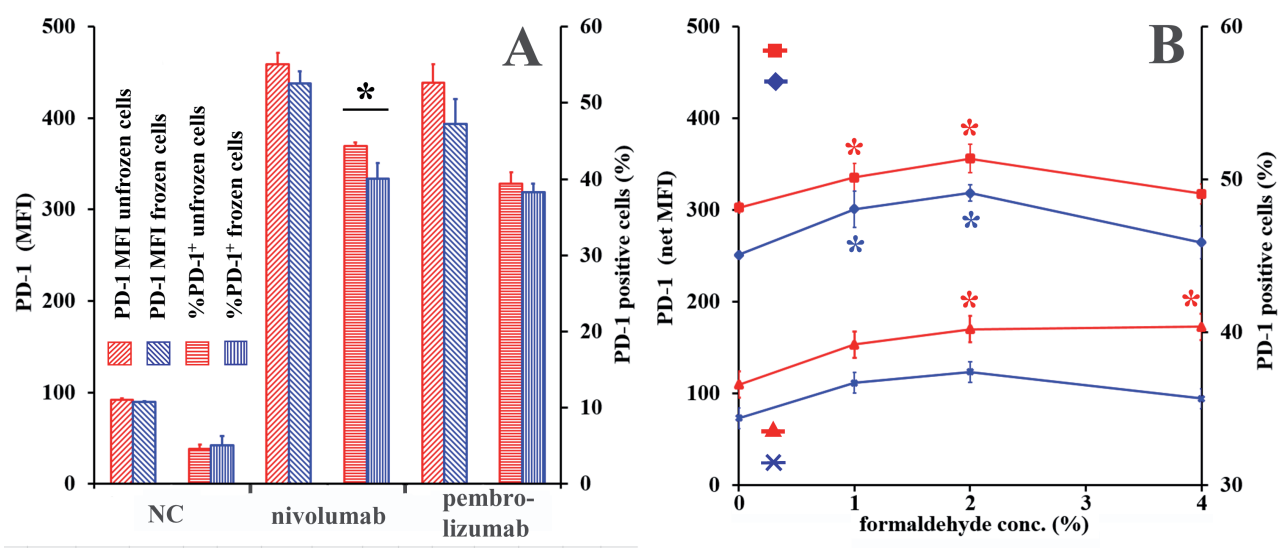

Figure S3. Effect of fixation and cryopreservation on PD-1 (net) median fluorescent intensity (MFI, $1^{\text {st }}$ marker) and number of PD-1 ${ }^{+}$cells (\%PD-1 ${ }^{+}, 2^{\text {nd }}$ marker). A. Effect of snap-freezing with Cryosofree ${ }^{\mathrm{TM}}$ on the PD-1 median fluorescent intensity $(\mathrm{MFI}=\mathbb{\mathbb { N }}$ ) and percentage of PD$1^{+} \mathrm{CD}^{+}$-T-cells ( ) was assessed compared to unfixed and not frozen negative controls (NC, $\left.\mathrm{MFI}=\mathbb{\mathbb { Q }} ; \% \mathrm{PD}-1^{+}=\square\right)$. PBMC from a healthy volunteer were incubated without ( NC) or with

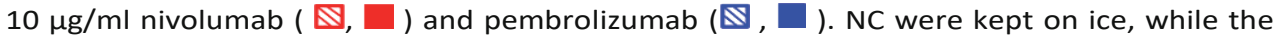
other samples were fixed with $4 \%(w / v \%)$ formaldehyde, followed by snap-freezing in Cryosofree $^{\mathrm{TM}}$. B. Effect of fixation, with different concentrations of formaldehyde on the MFI of PD-1 $(\square,-)$ ) and percentage of PD-1+ cells $(-,-\sim)$ in samples pre-incubated with 10 $\mu \mathrm{g} / \mathrm{ml}$ nivolumab $(\square,-)$ and pembrolizumab $(-, *)$. * indicates a significant difference in $\% \mathrm{PD}-1^{+}$due to Cryosofree ${ }^{\mathrm{TM}}(\mathrm{A})$ or in $\mathrm{MFI}$ and \%PD-1+ ${ }^{+}$relative to unfixed samples (B). 


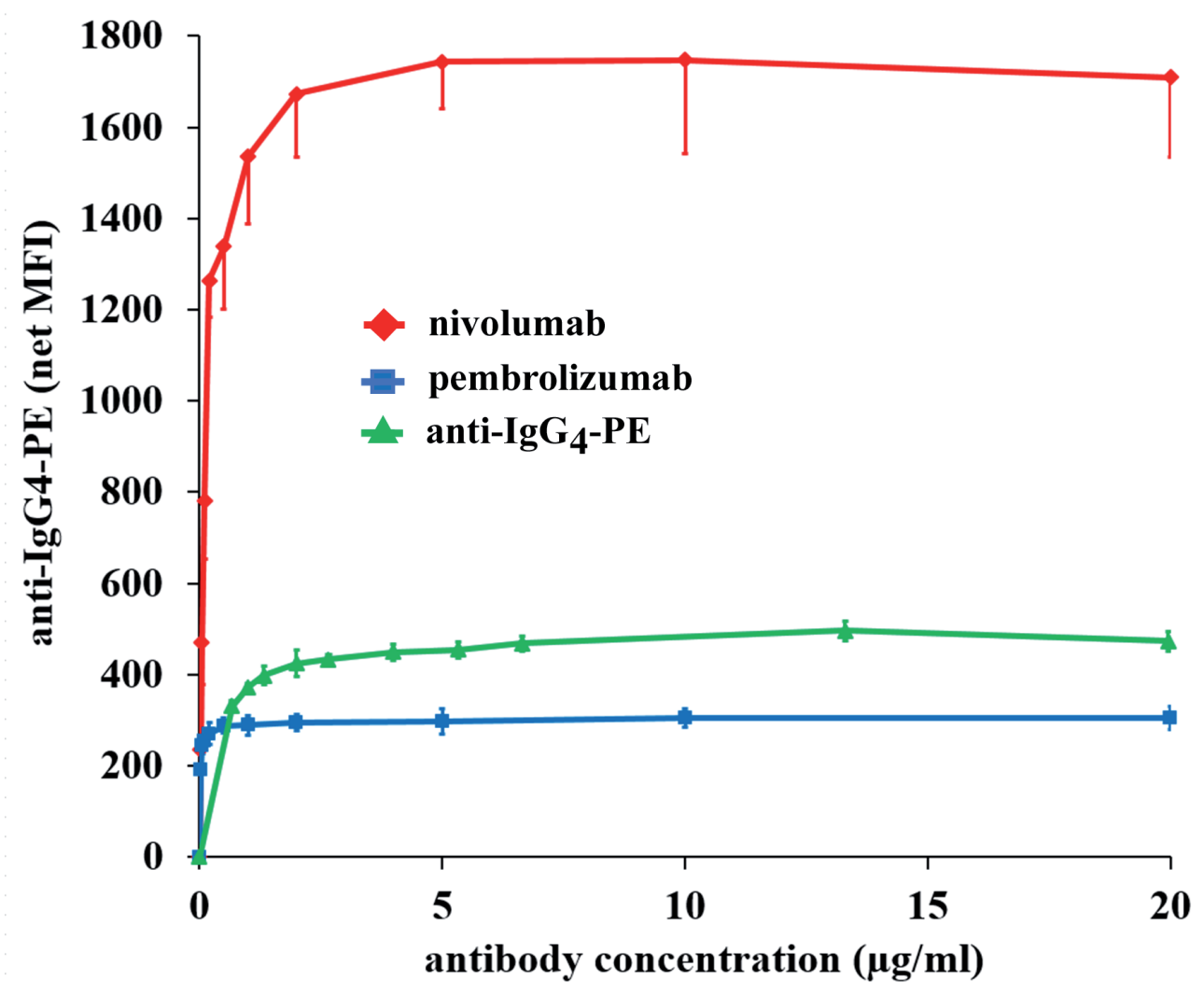

Figure S4. Antibody target saturation curves. Ex vivo growth stimulated or unstimulated peripheral blood mononuclear cells (PBMC) were incubated with indicated concentrations of nivolumab (-) and pembrolizumab (-), respectively. Samples were incubated with 8 $\mu \mathrm{g} / \mathrm{mL}$ of anti-IgG - -PE. PBMC pre-incubated with nivolumab were incubated with indicated concentrations of anti-IgG4-PE ( - ). PBMCs used for each curve were from different healthy volunteers. Results are the mean \pm standard deviation (SD) of three independent samples. 
Development and validation of pharmacodynamic and diagnostic biomarker methods 


\section{CHAPTER 1}

Development and validation of pharmacodynamic and diagnostic cancer biomarker methods

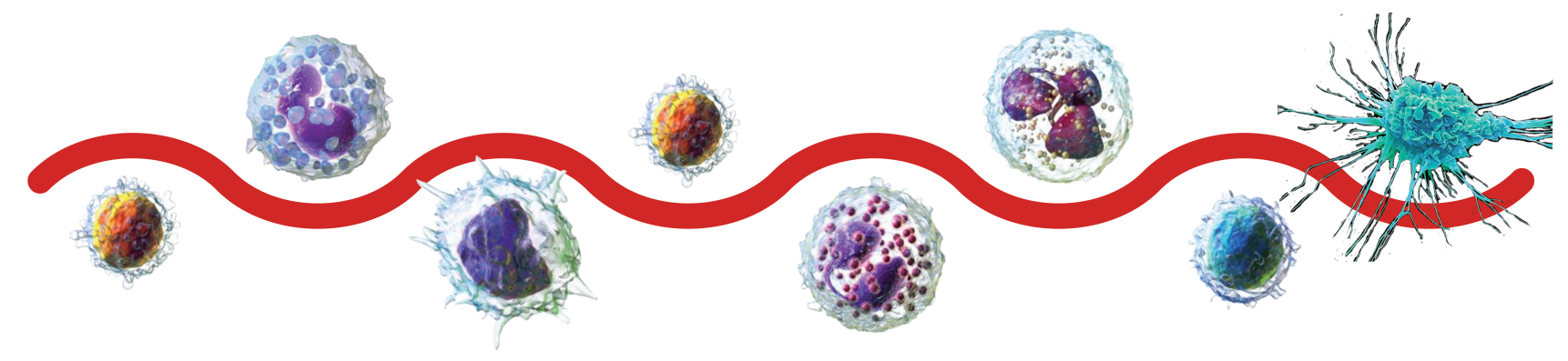

1.8

Method for the Determination of Phosphorylated Extracellular-Signal-Regulated Kinase and DNA in Circulating Tumor Cells

Dick Pluim, Lot A. Devriese, Jos H. Beijnen, Jan H. M. Schelens

Cytometry Part A 2012;81A:664-671 


\section{ABSTRACT}

A simple, selective, and sensitive multiparameter fluorescence activated cell sorting method utilizing density gradient centrifugation and magnetic antibody cell sorting was developed and validated for the determination of phosphorylated extracellular signal-regulated kinase (pERK) and DNA in circulating tumor cells (CTCS). Cell preparation tubes (CPT) were used for peripheral blood collection and density gradient centrifugation, followed by phosphorylation of ERK with epidermal growth factor (EGF). After fixation with formaldehyde and methanol, magnetic anti epithelial cell adhesion molecule (EPCAM) micro-beads were used for the selective isolation of CTCs from the background, consisting of peripheral blood mononuclear cells and platelets. Subsequently, samples were stained with Hoechst 33342, and fluorescent antibodies against EPCAM, CD45, and pERK. Flow cytometry was used for identification and enumeration of CTCS and determination of their pERK and DNA content. The validation parameters included specificity, recovery, linearity, precision, sensitivity, and stability. The lower limit of quantification was two CTCS per $8 \mathrm{ml}$ peripheral blood. Samples were stable for 4 months in storage at $-80^{\circ} \mathrm{C}$. The applicability of the method was demonstrated by successful enumeration of CTCs, and the determination of DNA, and pERK before and after stimulation with EGF in $8 \mathrm{ml}$ peripheral blood samples from patients with metastatic cancer. 


\section{INTRODUCTION}

Metastatic disease is the main reason for mortality in patients with solid tumors. Metastazation is caused by shedding of an estimated one million tumor cells into the bloodstream per gram of tumor tissue per day $(1,2)$. Circulating tumor cell (CTC) quantity is a proven valuable prognostic marker in metastatic breast, colorectal, and prostate cancer (3). The detection of CTCs before adjuvant chemotherapy as well as the persistence of CTCs after the completion of systemic adjuvant treatment has been correlated with an unfavorable clinical outcome (4). However, there is evidence that a significant percentage of CTCs is apoptotic and, therefore, unable to settle in secondary organs $(5,6)$.

For many epithelial cancers, minimally invasive biopsies provide insufficient material for molecular analysis at diagnosis, and tumors are typically not sampled repeatedly during treatment to monitor changes in genetic abnormalities. The molecular profile of CTCs better possibly resembles that of metastatic cells than of the primary tumor, which can be very different from the tumor of origin. Therefore, the pharmacodynamic effects of cytotoxic drugs and molecular targeted anticancer agents might be better tested in CTCs than in the primary tumor (7-10). However, the use of CTCs for molecular profiling has been limited by relatively insensitive detection strategies (11).

Patients with non small cell lung cancer (NSCLC) that are identified with activating mutations in the epidermal growth factor receptor (EGFR) gene in tumor tissue can respond to EGFR tyrosine kinase inhibitors, including gefitinib (Iressa1) and erlotinib (Tarceva1) (12-14). Recent studies have reported expression of growth factor receptors on CTCS of patients with breast and prostate cancer (15-17), and the expression of activated EGFR in CTCs has also been reported $(4,18)$. The cellular effect of activated EGFR is exerted via the ERK signaling pathway which ultimately leads to phosphorylation of ERK. However, the ERK activation status in CTCs in response to targeted drugs remains unknown (4).

In this study, we present the development and validation of a multiparameter fluorescence-activated cell sorting (FACS) method for the quantification of pERK, and the detection of nucleated CTCs isolated from peripheral human blood. Phosphorylation state-specific antibodies (19-24) have recently become available and were used for the quantification of pERK. The applicability of the method was demonstrated in peripheral blood from patients with advanced metastatic breast, 
colon, lung, ovarian, and urothelial cancer. Although we report results for ERK phosphorylation, we believe that this procedure will be more widely applicable to the study of phospho-epitope expression in peripheral blood samples.

\section{MATERIALS AND METHODS}

\section{Reagents and chemicals}

Erlotinib hydrochloride and methanol originated from Roche (Woerden, the Netherlands). The water used was of Milli-Q grade (Millipore). Methanol-free formaldehyde was purchased as a $40 \%$ solution in water from Merck (Darmstadt, Germany). PBS and RPMI medium were purchased from GIBCO BRL (Gaithersburg). EGF and Hoechst33342 were purchased from Sigma (St. Louis). Anti-human EpCAMmicro-beads, magnetic antibody cell sorting (MACS1) columns, Fc-Receptor block (FcR), mouse clone 5B1 $\operatorname{lgG}_{2 a}$ antihuman CD45-fluorescein isothiocyanate (FITC), and mouse clone HEA-125 IgG anti-human EpCAM-phycoerythrin (PE) were purchased from Miltenyi (Bergisch Gladbach, Germany). Rabbit clone D13.14.4E IgG anti-human pERK1/2-Alexa Fluor1647, and isotype rabbit clone DA1E IgG - $^{-}$ Alexa Fluor1647 were purchased from Cell Signalling (Danvers). Perm/WashTM was purchased from Becton Dickinson (Heidelberg, Germany). Beads buffer (BB) was PBS containing $0.5 \%$ fetal calf serum and 2 mM EDTA degassed by sonication for 10 $\min$. All buffers were filtered through $0.2 \mu \mathrm{m}$ filters before use.

\section{Patients and whole blood collection}

For each patient, three $8 \mathrm{ml}$ collection tubes were used containing a Ficoll-Hypaque density fluid separated by a polyester gel barrier from a sodium citrate anticoagulant (BD Vacutainer1 $\mathrm{CPT}^{\mathrm{TM}}$ ). In order to avoid possible contamination by epithelial cells during skin puncture, the first $4 \mathrm{ml}$ of blood were collected in a separate tube for disposal. CTCs were isolated from $8 \mathrm{ml}$ peripheral blood samples of 25 metastatic cancer patients, of which two patients were being treated with an EGFR tyrosine kinase inhibitor. Study participants were informed of the investigational nature of this analysis and had given written informed consent in accordance with institutional and national guidelines. The study protocol was approved by the ethical committee of the Netherlands Cancer Institute. 


\section{Cell culture and spiking experiments}

The two human lung cancer cell lines MOR/P, and A549, and the breast cancer cell line MCF-7 (ATCC, Rockville), were cultured as monolayer in RPMI medium supplemented with

$10 \%$ fetal calf serum. For spiking experiments, cells were counted and sorted by a FACSaria ${ }^{\mathrm{TM}}$ cell sorter (BD Biosciences).

\section{Centrifugation and sample washing}

All centrifugations were performed in $2 \mathrm{ml}$ eppendorf tubes, in a centrifuge equipped with a swing-out rotor at $1,000 \mathrm{~g}$ for $4 \mathrm{~min}$ at $4^{\circ} \mathrm{C}$. After centrifugation, the supernatant was removed with a $1 \mathrm{ml}$ pipet leaving $100 \mu \mathrm{l}$ on the pellet. Samples were washed with $1 \mathrm{ml}$ Perm/Wash buffer, followed by vortex mixing at half speed.

\section{Sample preprocessing}

Cell preparation tubes (CPT) containing $8 \mathrm{ml}$ of peripheral blood were centrifuged in a swing-out rotor at 1,500g for $25 \mathrm{~min}$ at ambient temperature (RT). Next, EGFR was stimulated under the following conditions: after centrifugation the CPT were inverted three times and acclimatized in a water bath for $15 \mathrm{~min}$ at $37^{\circ} \mathrm{C}$. The upper $\mathrm{CPT}$ layer is incubated with $100 \mathrm{ng} / \mathrm{ml} \mathrm{EGF}$ for $5 \mathrm{~min}$ at $37^{\circ} \mathrm{C}$. Next, the upper CPT layer is transferred to a 50-ml Falcon tube (Becton Dickinson, Franklin Lakes) containing

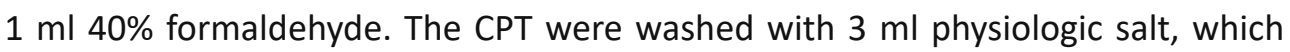
was pooled with the rest of the sample. After vortex mixing at half speed for $10 \mathrm{~s}$, incubation for $15 \mathrm{~min}$ at RT, and addition of $40 \mathrm{ml}$ physiologic salt, samples were centrifuged at $1,000 \mathrm{~g}$ for $10 \mathrm{~min}$ at $4^{\circ} \mathrm{C}$. The supernatant was decanted, followed by placing the tubes upside down on filter paper for $5 \mathrm{~s}$, after which the samples were chilled on ice. Next, the pellets were resuspended in $1 \mathrm{ml}$ of ice-cold $50 \%(\mathrm{v}, \mathrm{v} \%)$ methanol/PBS by vortex mixing for $10 \mathrm{~s}$ at the highest setting. After incubation on ice for exactly $10 \mathrm{~min}$ in prechilled $2 \mathrm{ml}$ Eppendorf tubes, the samples were stored at $-80^{\circ} \mathrm{C}$ for future analysis.

\section{Cell recovery optimization}

A549 cells, expressing approximately 50 times less EpCAM than MOR/P, were used for spiking 15 CPT each containing $8 \mathrm{ml}$ peripheral blood from a healthy volunteer, with 1,000 cells each. After sample preprocessing, samples were blocked with FcR 
for $60 \mathrm{~min}$ at RT, next, $10 \mu \mathrm{l}$ anti-EpCAM micro-beads were added for $30 \mathrm{~min}$ at $0^{\circ} \mathrm{C}$, and for $30,60,120$, and 180 min at RT. After tumor cell enrichment, recovery was determined by FACS analysis. An additional six CPT, each containing $8 \mathrm{ml}$ human plasma from a healthy volunteer were spiked with 1000 A549 $(n=3)$ or MOR/P $(n=$ 3 ) cells and processed for FACS analysis without the EPCAM micro-bead enrichment.

\section{Tumor cell enrichment}

CTCs underwent an immuno-magnetic enrichment using anti-EpCAM micro beads and Fc-R, with the following modifications to the manufacturers instructions: Samples stored at $-80^{\circ} \mathrm{C}$ were defrosted on ice, and after centrifugation supernatant was removed. The pellets were washed twice with $1 \mathrm{ml}$ ice-cold $\mathrm{BB}$. After centrifugation, the pellets were resuspended in the remaining $100 \mu \mathrm{lBB}$, and $40 \mu \mathrm{l} \mathrm{of} \mathrm{FcR} \mathrm{was}$ added for $60 \mathrm{~min}$ at RT. Next, $10 \mu \mathrm{l}$ anti-EpCAM microbeads were added for $1 \mathrm{~h}$ at RT. Samples were washed twice with $1 \mathrm{ml}$ of $B B$, followed by centrifugation. After resuspending the pellets in $500 \mu \mathrm{l}$ of $\mathrm{BB}$, labeled cells were collected on a MACS column. After removal of the column from the magnetic field, the retained $\mathrm{EPCAM}^{+}$ cells were eluted in two separate elution steps using $1 \mathrm{ml} \mathrm{BB}$ each, followed by centrifugation.

\section{(Immuno)fluorescence staining}

The tumor cell enriched samples were stained for intracellular DNA at a final concentration of $5 \mu \mathrm{M}$ Hoechst33342 for $15 \mathrm{~min}$ at RT in the dark. Next, samples were washed twice with $1 \mathrm{ml}$ Perm/Wash, centrifuged, followed by staining with $5 \mu \mathrm{l}$ of anti-CD45-FITC for $15 \mathrm{~min}$ at RT in the dark. Subsequently, samples were stained with $5 \mu \mathrm{l}$ of anti-EPCAM-PE, and $10 \mu \mathrm{l}$ anti-pERK1/2-Alexa Fluor 647 for $1 \mathrm{~h}$ at RT in the dark. Next, unbound antibodies were removed with two $1 \mathrm{ml}$ washes of Perm/Wash, followed by centrifugation. Staining linearity was measured in triplicate in samples spiked with 10,30,100,300, 1,000, 3,000, and 10,000 MOR/P cells in CPT containing $8 \mathrm{ml}$ peripheral blood from a healthy volunteer. Samples were stained with Hoechst33342, anti-EpCAM-PE, and anti-pERK-Alexa647 according to the conditions described above. After removal of unbound antibodies and Hoechst33342 mean fluorescence intensity (MFI) was measured by flow cytometry. 
Flow cytometry

Flow cytometry was performed using a CyAn ADPTM (Beckman Coulter, Brea). Hoechst33342, FITC, PE, and Alexa Fluor 647 were collected through $450 \pm 25 \mathrm{~nm}$, $530 \pm 40 \mathrm{~nm}, 575 \pm 25 \mathrm{~nm}$, and $665 \pm 25 \mathrm{~nm}$ band pass filters, respectively. Data analysis was performed with Summit v4.3.01 software (Dako Cytomation, Fort Collins, CO).

\section{Specificity}

In order to assess the amount of background interference, three CPT containing $8 \mathrm{ml}$ peripheral blood were drawn from 18 different healthy volunteers. The background was defined as the total number of events in Gate 1 of the FSC/SSC density plots (Fig. 1A). Furthermore, we assessed in triplicate, using $8 \mathrm{ml}$ peripheral blood from a healthy volunteer, the influence of different FcR blocking conditions on the amount of background by using $20 \mu \mathrm{l} \mathrm{FcR}$ for $15 \mathrm{~min}$ at $0^{\circ} \mathrm{C}$ and RT, $40 \mu \mathrm{l} \mathrm{FcR} \mathrm{at} \mathrm{RT} \mathrm{for} \mathrm{15,} \mathrm{30,}$ and $60 \mathrm{~min}$, respectively.

\section{Within- and between-day precision and recovery}

A549 and MOR/P cells were spiked at 10, 100, 1,000, and 10,000 cells per $8 \mathrm{ml}$ of peripheral blood in CPT which were immediately preprocessed as described above. Samples were measured in triplicate on 3 consecutive days. The betweenday (BDP) and within-day precision (WDP) were calculated by one-way analysis of variance (ANOVA) for each spike level using the run day as classification variable using the software package SPSS v15.0 for windows (SPSS, Chicago, USA). The day mean square (DayMS), error mean square (ErrMS), and the grand mean (GM) of the observed cell concentrations across run days were used. The WDP\% and BDP\% for each spike level was calculated using the formulas ( $n$ is the number of replicates within each run):

\section{Lower limit of quantification}

The lower limit of quantification (LLOQ) was determined by spiking in sixfold 1, 2, $3,4,5$, and $10 \mathrm{MOR} / \mathrm{P}$ cells in CPT containing $8 \mathrm{ml}$ of peripheral blood from six different healthy volunteers. The LLOQ was defined as the cell concentration that could be determined with a precision of $0-20 \%$, and a recovery between 80 and 
$120 \%$ of the nominal value.

\section{Sample Stability}

Long term storage stability was assessed by spiking $45 \mathrm{CPT}$, containing $8 \mathrm{ml}$ peripheral blood from a healthy volunteer, with 1,400 MOR/P cells each. Three samples per time point were processed and stored in $50 \% \mathrm{MeOH}$ at $-80^{\circ} \mathrm{C}$ for $0,1,7$, $14,30,60,120$, and 180 days until analysis. We also assessed the stability of stained samples in triplicate after storage at $4-7^{\circ} \mathrm{C}$ in the refrigerator for $0,0.25,0.5,1,4$, 24 , and $48 \mathrm{~h}$ until analysis.

\section{CTC morphology}

Stained and processed CTC samples from two colon carcinoma and one NSCLC patient were sorted using a FACSaria. After staining with $0.6 \mu \mathrm{g} / \mathrm{ml}$ Cellmask Orange for $10 \mathrm{~min}$ at RT in the dark, samples were washed and centrifuged five times with $1 \mathrm{ml}$ demineralised water supplemented with 3\% FCS. The pellet was resuspended in the remaining $50 \mu \mathrm{l}$ Wash buffer, transferred to a microscope slide, and dried by vacuum concentration in a SpeedVac (Savant, Farmingdale, NY, USA). After applying $3 \mu \mathrm{l}$ of Vectashield $\mathrm{H}-1000$ (Vector, Burlingame, CA), a round object glass of $1 \mathrm{~cm}$ in diameter was put on top and sealed with nail polish. CTCs were identified and photographed using an Axiovert 200M epifluorescence microscope (Carl Zeiss, Göttlingen, Germany).

\section{Statistical analysis}

Statistical evaluation was performed using the student's t-test unless indicated otherwise. P-values of 0.05 were considered to be significant.

\section{RESULTS}

\section{Method development}

Discrimination of CTCs from the bulk of blood cells was achieved by density gradient centrifugation using CPT. The gel barrier in these tubes separates the blood cells over two compartments. The lower compartment contains red blood cells, granulocytes, and the majority of monocytes. The upper compartment consists of plasma, CTCs, peripheral blood mononuclear cells (PBMCs), and platelets. At this 


$$
\begin{gathered}
W D P \%=\frac{E r r M S^{0.5}}{G M} * 100 \% \\
B D P \%=\left(\frac{\text { DayMS }-E r r M S}{n}\right)^{0.5} * 100 \% \\
\text { Accuracy }=\frac{G M}{\text { nominal cell concentration }} * 100 \% \\
\text { Recovery }=\frac{\text { mean observed cell concentration }}{\text { nominal cell concentration }} * 100 \%
\end{gathered}
$$

stage, we exposed the CTCs to a 5 min pulse of $100 \mathrm{ng} / \mathrm{ml} \mathrm{EGF,} \mathrm{because} \mathrm{this} \mathrm{resulted}$ in a maximal twofold induction of pERK (Supporting Information Fig. 7), which was completely inhibited by erlotinib in time course experiments using MCF-7 tumor cells (data not shown). Then, cells were treated with $50 \%$ methanol for protein denaturation, facilitating detection of $\mathrm{pERK}$ with antibodies. Fixation also enabled long-term storage of samples at $-80^{\circ} \mathrm{C}$.

Further, CTC enrichment from the remaining background was achieved using magnetic anti-human EpCAM micro-beads. In the following steps, we deviated from the manufacturer' instructions: For more specific EpCAM binding and higher recovery of samples with low EpCAM levels, samples were first incubated with 40 $\mu \mathrm{l} \mathrm{FCR}$ at RT for $1 \mathrm{~h}$, followed by incubation with $10 \mu \mathrm{l}$ micro-beads for $1 \mathrm{~h}$ at RT. A further $15.7 \pm 1.1 \%$ increase in recovery was achieved by flushing the CTCs from the MACS columns with an additional $1 \mathrm{ml}$ of BB. With these modifications, the recovery of MOR/P cells was $75 \%$ (Table 1 ) in a remaining background of 15,000 PBMCs and platelets.

Next, the DNA in the cells was stained with Hoechst-33342. Unbound stain was removed by washing the cells with Perm/Wash buffer. This buffer contained saponin, which permeabilizes the cell membrane for intracellular pERK staining with antibodies. In order to remove protein aggregates that can bind nonspecifically to antibodies, which can result in a false positive CTC count, EPCAM, CD45, and 
pERK antibody solutions were centrifuged at $10,000 \mathrm{~g}$ for $10 \mathrm{~min}$ at $4^{\circ} \mathrm{C}$, and all buffers were filtered through $0.2 \mu \mathrm{m}$ syringe filters. FcR and EpCAM microbeads were not centrifuged, because it resulted in a considerably lower antibody concentration and reduced CTC recovery. Identification of the CTCs by FACS using PE against FITC density plots (Fig. 1) was achieved after staining CTCs with antiEpCAM-PE, anti-CD45-FITC, and anti-pERK-Alexa647. DNA was measured as the MFI of Hoechst-33342 and pERK levels were measured as the MFI of pERK-Alexa Fluor 647. During each batch analysis, two positive and two negative quality control (QC) samples were analyzed. The negative and positive QCs consisted of 5 million PBMCs from a healthy volunteer, and an additional 1,000 MOR/P cells in the positive QCs. The QCs were formaldehyde fixed and stably stored for a maximum of 4 months in $50 \%$ methanol/PBS at $-80^{\circ} \mathrm{C}$. The measured MFI values of Alexa- 647 and Hoechst-33342 were normalized against these positive QCs. The background from the two negative QCs was always below the LLOQ, and the recovery of MOR/P cells was always better than $75 \pm 6 \%$ (Table 1). CTCs were considered to be nucleated if the Hoechst-33342 MFI was above the indicated DNA cut-off level for PBMCs from the same sample (Fig. 1E).

\section{Specificity}

Total background levels were highest at $08 \mathrm{C}$ using $20 \mu \mathrm{FcR}$ for 15 min consisting of a total of $367,667 \pm 76,334$ PBMCs and platelets, but decreased significantly (P 50.023 ) to $229,283 \pm 56,293$ at RT. The background was significantly further reduced to 113,002 \pm 46,811 (P 5 0.015), 49,038 $\pm 11,365$ (P 5 0.009), 14,357 \pm 6,931 (P\0.001) by using $40 \mu \mathrm{l} \mathrm{FcR} \mathrm{for} 15 \mathrm{~min}, 30 \mathrm{~min}$, and $60 \mathrm{~min}$, respectively (Supporting Information Fig. 5). We determined that the amount of background counts in the CTC gate during FACS analysis was $0.26 \pm 0.29$ false positive CTCs per $8 \mathrm{ml}$ peripheral blood ( $\mathrm{n}=18$ healthy volunteers in triplicate).

The rabbit clone D13.14.4E IgG anti-human pERK1/2-Alexa Fluor-647 antibody was specific for $\mathrm{PERK}$ because staining of MOR/P cells with the isotype rabbit clone DA1E IgG ${ }_{1}$-Alexa Fluor 647 resulted in about 100 times lower MFI values (Fig. 1F). 


\section{Cell recovery optimization}

The recovery after the CPT enrichment step was $98 \pm 2 \%$ for both A549 and MOR/P cells. The recovery of A549 cells after the micro-beads enrichment step was significantly affected by the temperature and incubation time used for micro-beads binding (Supporting Information Fig. 6). The maximum recovery of A549 cells was $34 \%$ and was reached after $1 \mathrm{~h}$ incubation with micro-beads at RT. No significant increase in recovery was achieved after longer incubation times. Under these conditions, the recovery of MOR/P cells expressing about 50 times more EpCAM than $A 549$ cells was $75 \pm 6 \%$.

\section{Within- and between-day precision and recovery}

The precision and recovery of the method were determined by analyses of samples spiked with MOR/P at four different cell concentrations in triplicate in three consecutive analytical runs. From these results, we calculated the WDP and BDP and recovery (Table 1 ). In all cases, the precision and recoveries were well within the limits that are considered acceptable for bioanalytical methods. An exception was the $34 \%$ recovery of A549.

\section{Lower limit of quantification}

The LLOQ was determined in peripheral blood samples from six different volunteers spiked with a nominal MOR/P cell concentration. The determined LLOQ of the method was two cells in $8 \mathrm{ml}$ of whole blood. At this LLOQ, the recovery was $108 \%$ and the precision $18.8 \%$.

\section{Staining linearity}

Staining linearity was determined in triplicate in samples containing incremental amounts of MOR/P cells spiked in CPT containing $8 \mathrm{ml}$ of peripheral blood of a healthy volunteer. The measured Hoechst-33342 staining was not significantly different over the tested $10-10,000$ MOR/P spike range with an MFI of $409 \pm 30$. Staining of EpCAM and pERK was not significantly affected up to 1,000 cells per sample, with an MFI at spike level 10, of 3,511 \pm 179 for EpCAM, and $320 \pm 11$ for pERK. However, above 1,000 cells per sample, staining of EpCAM and pERK was significantly reduced with an MFI at spike level 10,000 of 2,582 $\pm 66(P=0.002)$ for EpCAM, and $247 \pm 6(P=0.003)$ for $p E R K$. 


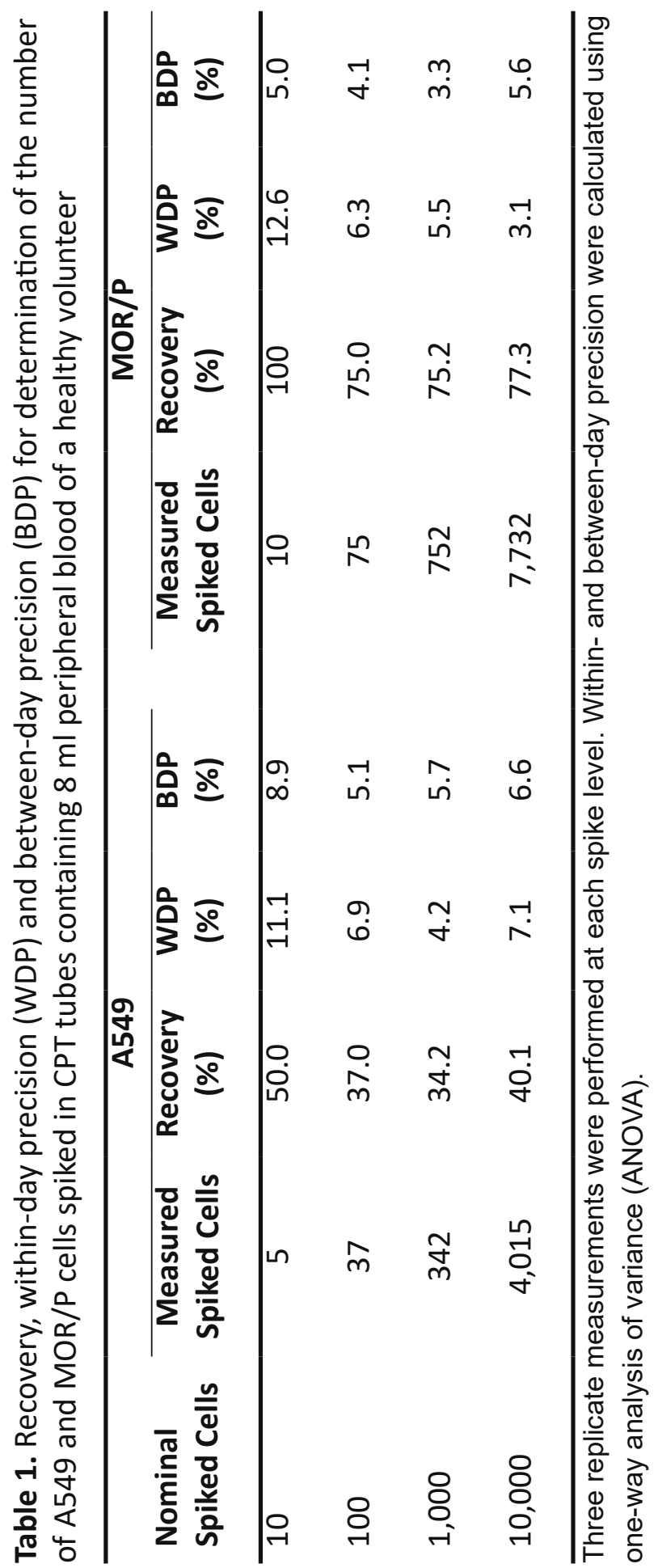




\section{Sample stability}

We determined the stability of EpCAM, CD45, DNA, and cell counts for MOR/P cells spiked in $8 \mathrm{ml}$ peripheral blood samples after storage at $-80^{\circ} \mathrm{C}$ for incremental time periods. All parameters were stable for at least 6 months, except pERK levels which were stable for 4 months. After 6 months, pERK levels were significantly decreased by $10.4 \%(P=0.032)$. Similar results were obtained for the co-isolated lymfocytes and monocytes.

We also assessed the short term stability of stained samples stored at $4^{\circ} \mathrm{C}$ during incremental time periods. The measured MOR/P cell numbers, levels of Hoechst-33342, pERK, EPCAM, and CD45 were stable during the tested $48 \mathrm{~h}$ storage period.

\section{CTC morphology}

CTCs from three different patients were processed and sorted by FACS. DNA stained with Hoechst-33342, and cell membranes stained with Cellmask Orange were visible by epifluorescence microscopy as blue and orange colors, respectively. The diameter of the CTCs varied between 4 and $12 \mu \mathrm{m}$. In about 50\% of the CTCS, DNA was detected, although mostly less and fragmented compared to vital MOR/P cells (Fig. 2A). In some CTCs, membrane blisters were present (Fig. 2B), whereas others resembled apoptotic bodies (Fig. 2C). However, some CTCs had a similar appearance and DNA content as the vital MOR/P control cells (Fig. 2D).

\section{Applicability of method for determination of CTCS and pERK in patient samples}

We determined in threefold the number of CTCs in samples from 25 advanced metastatic cancer patients, which were diagnosed with NSCLC $(n=11)$, colon ( $n=$ $4)$, breast $(n=4)$, urothelial $(n=3)$, ovarium cancer $(n=2)$, and osteosarcoma $(n=$ 1). In $64 \%$ of the patients, the CTC numbers were above LLOQ with a mean of 12.4 CTCs per sample. All three samples from the osteosarcoma patient tested negative for CTCs. The correlation between the measured CTC numbers in two subsequent CPT was significant $(P=0.02)$ with a Pearson correlation coefficient of 0.9476 (Fig. 3).

Furthermore, we determined in triplicate the DNA content and effect of ex vivo 


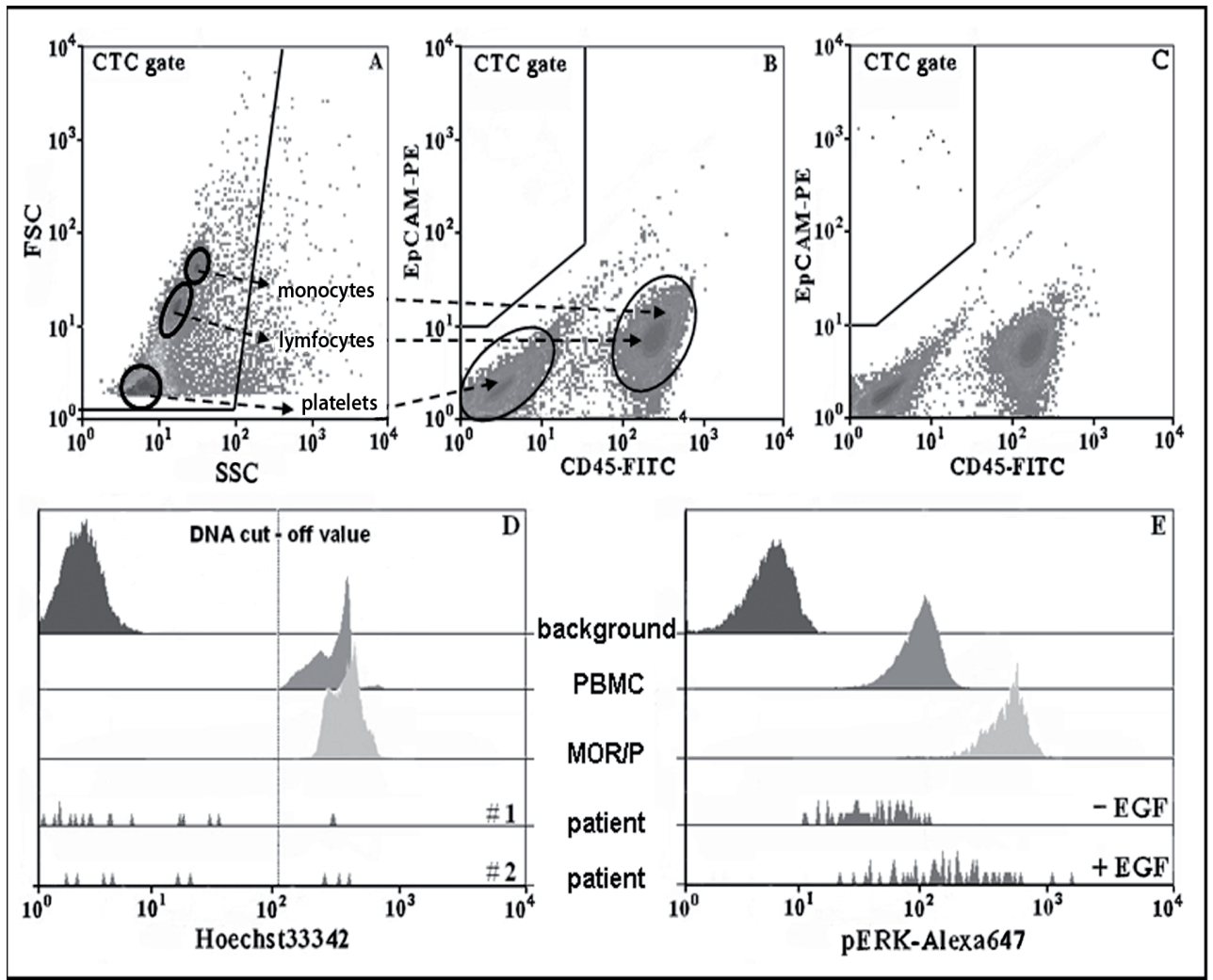

Figure 1. Representative FACS forward against sideward scatter plot (A) with indicated

CTC gate 1 setting. In Figures B (healthy volunteer), C (healthy volunteer spiked with 100 $\mathrm{MOR} / \mathrm{P}$ cells), and $\mathrm{D}$ (patient sample), all events from gate 1 are plotted as EPCAM-PE against CD45-FITC. The used gate settings for recognition of CTCS are $1 \pm 2$, for platelets $1 \pm 3$, and for PBMCs $1 \pm 4$. The Hoechst33342 (E) and pERK (F) MFI histograms together with the used gating strategy are shown for PBMCs, MOR/P, and CTCs from two patient samples treated in vitro with and without EGF. The used Hoechst-33342 MFI cut-off value for identification of nucleated CTCS is indicated (E). Signal specificity of Hoechst-33342 is demonstrated by staining of platelets ( $E$, Background). Staining specificity of $p E R K$ is demonstrated by staining of MOR/P cells with isotype IgG1-Alexa647 ( $F$, Background).

EGF stimulation on pERK levels in CTCs from eight different advanced metastatic patients with the following tumor types: patients 1 and 5 (NSCLC); patients 2, 6, 7 , and 8 (colon cancer); patient 3 (breast cancer); and patient 4 (bladder cancer). Primary tumor biopsies from all eight patients were screened for mutations in EGFR and KRAS: In patients 1 - 5 no mutations were found; after ex vivo incubation of the CPT upper layer with $100 \mathrm{ng} / \mathrm{ml}$ of EGF for $5 \mathrm{~min}$ at $37^{\circ} \mathrm{C}$, a significant 
upregulation of pERK was seen with a factor $1.9(P=0.011), 2.5$ (P 50.024$), 2.1$ $(P=0.035)$, and $3.7(P=0.010)$, respectively (Fig. 4). In tumor tissue of patients $6-8$, activating mutations in K-RAS were found and CTCs from patients 5 and 8 were obtained while receiving treatment with the EGFR tyrosine kinase inhibitor lapatinib. CTCs from these patients did not show a significant increase of pERK following ex vivo EGF stimulation (Fig. 4). The percentage of nucleated CTCs, with a DNA content in the same range as PBMCs, varied between $7 \pm 0.7 \%$ (patient 5 ) and $50 \pm 8.5 \%$ (patient 2), with an average of $21.9 \pm 4.5 \%$.

\section{DISCUSSION}

This is the first report to demonstrate ex vivo EGFR stimulation and subsequent activation of ERK in CTCs. Furthermore, this is the first immunocytochemical FACS method for the quantification of DNA and pERK in CTCs.

Rapid and routine analysis of large batches of formaldehyde fixed samples was feasible after storage in $50 \%$ methanol at $-80^{\circ} \mathrm{C}$. Fixation is necessary because the time interval and manipulations used to eliminate blood cells have the potential to introduce artifacts (25), as PERK is part of a signaling network that responds to the environment and turns over rapidly.

In order to minimize the number of background events after the MACS enrichment step, we reduced nonspecific binding of the magnetic anti-EpCAM antibodies by increasing the incubation time with a larger amount of FC receptor block.

We increased the recovery of cells with low EpCam expression by increasing the incubation time with the magnetic MACS antibodies at ambient temperature, by the addition of a second MACS elution step, and by performing all centrifugations in a swing-out rotor. This is important because cells of high metastatic potential may lose expression of EpCAM during the course of metastatic disease $(26,27)$.

With our method, we found an average of $78 \%$ apoptotic CTCs. Others have reported $50-80 \%$ apoptotic CTCs, depending on histo type, by using the CellSearch ${ }^{\circledR}$ method that does not include a density centrifugation CTC enrichment step (28). This probably means that apoptotic CTCs are retained to the upper compartment of the CPT, despite the increased buoyant density of apoptotic cells (29).

The method was validated using batch-stored fixed MOR/P cells spiked in 
blood from healthy volunteers. Control MOR/P cells were used for assuring proper performance on a daily and run-to-run basis. We showed that the method was able to recover $75 \%$ of MOR/P cells, which was considered acceptable considering the complexity of the assay. We also used A549 cells as a model for low-EpCAM-expressing cells, considering the 50 times lower EpCAM expression in A549 as compared to MOR/P and still found a reasonable recovery of $34 \%$. In our experience, the EpCAM expression in MOR/P is more representative for the average EpCAM expression in human epithelial tumor cells. The method is accurate and reproducible up to two cells per $8 \mathrm{ml}$ peripheral blood (LLOQ). By analyzing different spike levels, we were able to show that the enumeration of CTCs was linear over the whole tested spike range of 10 to 10,000 MOR/P cells. The within-run precision was $12.6 \%$ and the between-run precision was $5.6 \%$. Furthermore, we showed that the detection of the biomarkers EpCAM, DNA, and pERK was linear over a spike range of $10-1,000$ MOR/P cells, which is probably enough for the quantification of biomarkers in CTCs from almost every patient sample.

Long-term stability of samples stored at $-80^{\circ} \mathrm{C}$ was good with no detectable degradation of cell numbers and DNA, and PERK after 6 and 4 months, respectively. Furthermore, cell numbers, Hoechst-33342, and pERK were shown to be stable in samples stored in the refrigerator for up to $48 \mathrm{~h}$.

Our results show that the method can be applied for the enumeration of CTCs, and the determination of DNA and PERK in CTCs from patient samples. We observed CTCs in $64 \%$ of patients, which is in line with other published papers $(30,31)$. As expected, we did not observe CTCs in the patient with osteosarcoma since EpCAM is not expressed on tumors of mesodermal origin (32).

Our results confirm other reports about CTCs exhibiting a high degree of pleomorphism, that is high and low nuclear to cytoplasmic ratios, and early and late apoptotic changes $(6,33)$ These apoptotic characteristics might explain why the presence of CTCs is necessary but not sufficient for the metastatic process to occur (2). Since there is mounting evidence for the importance of DNA content for the clonogenicity and metastatic potential of CTCs $(2,34)$, we believe that monitoring of this biomarker can improve prediction of clinical outcome for patients. Furthermore, we were able to measure pERK in CTCs isolated from patient samples. We found that the expression of $p E R K$ was significantly increased 
in CTCs after ex vivo stimulation of patient samples with EGF. No increase of pERK was seen in CTCs isolated from samples of a patient with NSCLC that was being treated with an EGFR tyrosine kinase inhibitor, and thus counteracts the stimulatory effect of EGF. The same lack of stimulation with EGF was seen in three patients with a K-RAS mutation. Due to this mutation, K-RAS is constitutively active and irresponsive to signals originating from EGFR. It would have been more informative to determine the total ERK to PERK ratio in CTCS and how this relates to the mutational status. However, a suitable primary FACS antibody against ERK was not available.

In conclusion, a method has been developed and validated for the enumeration of CTCs, and the determination of DNA and pERK in CTCs in peripheral blood. The method is straightforward with long-term stability using standard laboratory equipment and techniques, and is suitable for application in clinical trials. We have shown that the method enables reproducible isolation of CTCs in sufficient quantity and with sufficient purity to allow molecular intracellular analyses. It is currently being used for determining DNA and pERK in CTCs in peripheral blood from metastatic lung cancer patients for assessment of the relevance of these biomarkers for predicting disease progression.

\section{ACKNOWLEDGMENTS}

We thank Laura van't Veer and Astrid Bosma for fruitful discussions, and we are grateful to Frank van Diepen and Anita Pfauth, operators at our flow cytometry facility, for their support with the FACS and cell sorting experiments. 


\section{REFERENCES}

1. Liotta LA, Kleinerman J, Saidel GM. Quantitative relationships of intravascular tumor cells, tumor vessels, and pulmonary metastases following tumor implantation. Cancer Res 1974;34:997-1004.

2. Swartz MA, Kristensen CA, Melder RJ, Roberge S, Calautti E, Fukumura D, Jain RK. Cells shed from tumours show reduced clonogenicity, resistance to apoptosis, and in vivo tumorigenicity. $\mathrm{Br}$ J Cancer 1999;81:756-759.

3. Mata M, Raponi M. Circulating tumor cells: Utility for predicting response to anti-EGFR therapies? Expert Rev Mol Diagn 2009;9:115-119.

4. Kallergi G, Agelaki S, Kalykaki A, Stournaras C, Mavroudis D, Georgoulias V. Phosphorylated EGFR and PI3K/ Akt signaling kinases are expressed in circulating tumor cells of breast cancer patients. Breast Cancer Res 2008;10:R80.

5. Rossi E, Basso U, Celadin R, Zilio F, Pucciarelli S, Aieta M, Barile C, Sava T, Bonciarelli G, TumoloS, Ghiotto C, Magro C, Jirillo A, Indraccolo S, Amadori A, Zamarchi; M30 neoepitope expression in epithelial cancer: Quantification of apoptosis in circulating tumor cells by CellSearch analysis. Clin Cancer Res 2010;16:5233-5243.

6. Ren C, Han C, Zhang J, He P, Wang D, Wang B, Zhao P, Zhao X. Detection of apoptotic circulating tumor cells in advanced pancreatic cancer following 5-fluorouracil chemotherapy. Cancer Biol Ther 2011;12:700-706.

7. Guarneri V, Giovannelli S, Ficarra
G, Bettelli S, Maiorana A, Piacentini F, Barbieri E, Dieci MV, D'Amico R, Jovic $G$, Conte P. Comparison of HER-2 and hormone receptor expression in primary breast cancers and asynchronous paired metastases: Impact on patient management. Oncologist 2008;13:838844.

8. Kalikaki A, Koutsopoulos A, Trypaki M, Souglakos J, Stathopoulos E, Georgoulias V, Mavroudis D, Voutsina A. Comparison of EGFR and K-RAS gene status between primary tumors and corresponding metastases in NSCLC. $\mathrm{Br} J$ Cancer 2008;99:923-929.

9. Lower EE, FleishmanS, Cooper A, Zeldis J, Faleck H, Yu Z, Manning D. Efficacy of dexmethylphenidate for the treatment of fatigue after cancer chemotherapy: $A$ randomized clinical trial. J Pain Symptom Manage 2009;38:650-662.

10. Klein CA. Parallel progression of primary tumours and metastases. Nat Rev Cancer 2009;9:302-312.

11. Devriese LA, Voest EE, Beijnen JH, Schellens JH. Circulating tumor cells as pharmacodynamic biomarker in early clinical oncological trials. Cancer Treat Rev 2011;37:579-589.

12. Lynch TJ, Bell DW, Sordella R, Gurubhagavatula S, Okimoto RA, Brannigan BW, Harris PL, Haserlat SM, Supko JG, Haluska FG, Louis DN, Christiani DC, Settleman J, Haber DA. Activating mutations in the epidermal growth factor receptor underlying responsiveness of non-small-cell lung cancer to gefitinib. $\mathrm{N}$ Engl J Med 2004;350:2129-2139. 
13. Paez JG, Janne PA, Lee JC, Tracy S, Greulich H, Gabriel S, Herman P, Kaye FJ, Lindeman N, Boggon TJ, Naoki K, Sasaki $H$, Fujii $Y$, Eck MJ, Sellers WR, Johnson $B E$, Meyerson M. EGFR mutations in lung cancer: Correlation with clinical response to gefitinib therapy. Science 2004;304:1497-1500.

14. Pao W, Miller V, Zakowski M, Doherty J, Politi K, Sarkaria I, Singh B, Heelan R, Rusch V, Fulton L, Mardis E, Kupfer $D$, Wilson $R$, Kris $M$, Varmus $H$. EGF receptor gene mutations are common in lung cancers from "never smokers" and are associated with sensitivity of tumors to gefitinib and erlotinib. Proc Natl Acad Sci USA 2004;101:13306-13311.

15. Kallergi G, Markomanolaki $H$, Giannoukaraki V, Papadaki MA, Strati A, Lianidou ES, Georgoulias V, Mavroudis D, Agelaki S. Hypoxia-inducible factor1alpha and vascular endothelial growth factor expression in circulating tumor cells of breast cancer patients. Breast Cancer Res 2009;11:R84.

16. de Bono JS, Attard G, Adjei A, Pollak MN, Fong PC, Haluska P, Roberts L, Melvin C, Repollet M, Chianese D, Connely M, Terstappen LW, Gualberto A. Potential applications for circulating tumor cells expressing the insulin-like growth factor-I receptor. Clin Cancer Res 2007;13:3611-3616.

17. Hayes DF, Walker TM, Singh B, Vitetta ES, Uhr JW, Gross S, Rao C, Doyle GV, Terstappen LW. Monitoring expression of HER-2 on circulating epithelial cells in patients with advanced breast cancer. Int J Oncol 2002;21:1111-1117.
18. Maheswaran $S$, Sequist LV, Nagrath S, Ulkus L, Brannigan B, Collura CV, Inserra $E$, Diederichs $S$, lafrate AJ, Bell DW, Digumarthy S, Muzikansky A, Irimia D, Settleman J, Tompkins RG, Lynch TJ, Toner M, Haber DA. Detection of mutations in EGFR in circulating lungcancer cells. N Engl J Med 2008;359:366377.

19. Krutzik PO, Nolan GP. Intracellular phospho-protein staining techniques for flow cytometry: Monitoring single cell signaling events. Cytometry A 2003;55: 61-70.

20. Perez OD, Nolan GP. Simultaneous measurement of multiple active kinase states using polychromatic flow cytometry. Nat Biotechnol 2002;20:155162.

21. Chow S, Patel $H$, Hedley DW. Measurement of MAP kinase activation by flow cytometry using phosphospecific antibodies to MEK and ERK: Potential for pharmacodynamic monitoring of signal transduction inhibitors. Cytometry 2001;46: 72-78.

22. Krutzik PO, Irish JM, Nolan GP, Perez OD. Analysis of protein phosphorylation and cellular signaling events by flow cytometry: Techniques and clinical applications. Clin Immunol 2004;110:206-221.

23. Jacobberger JW, Sramkoski RM, Frisa PS, Ye PP, Gottlieb MA, Hedley DW, Shankey TV, Smith BL, Paniagua M, Goolsby CL. Immunoreactivity of Stat5 phosphorylated on tyrosine as a cell-based measure of Bcr/Abl kinase activity. Cytometry A 2003;54:75-88. 
24. Pallis $M$, Seedhouse $C$, Grundy $M$, Russell N. Flow cytometric measurement of phosphorylated STAT5 in AML: Lack of specific association with FLT3 internal tandem duplications. Leuk Res 2003;27:803-805.

25. Chow $S$, Hedley D, Grom P, Magari $R$, Jacobberger JW, Shankey TV. Whole blood fixation and permeabilization protocol with red blood cell lysis for flow cytometry of intracellular phosphorylated epitopes in leukocyte subpopulations. Cytometry 2005;67:4-17.

26. Fuchs IB, Lichtenegger $W$, Buehler $H$, Henrich $W$, Stein $H$, Kleine-Tebbe A, Schaller $G$. The prognostic significance of epithelial-mesenchymal transition in breast cancer. Anticancer Res 2002;22:3415-3419.

27. Danila DC, Pantel K, Fleisher $M$, Scher HI. Circulating tumors cells as biomarkers: Progress toward biomarker qualification. Cancer J 2011;17:438450.

28. Rossi E, Basso U, Celadin R, Zilio F, Pucciarelli S, Aieta M, Barile C, Sava T, Bonciarelli G, Tumolo S, Ghiotto C, Magro C, Jirillo A, Indraccolo $S$, Amadori A, Zamarchi R. M30 neoepitope expression in epithelial cancer: Quantification of apoptosis in circulating tumor cells by CellSearch analysis. Clin Cancer Res 2010;16: 5233-5243.

29. Martin SJ, Bradley JG, Cotter TG. HL-60 cells induced to differentiate towards neutrophils subsequently die via apoptosis. Clin Exp Immunol 1990;79:448-453.
30. Cohen SJ, Punt CJ, lannotti N, Saidman BH, Sabbath KD, Gabrail NY, Picus J, Morse M, Mitchell E, Miller MC, Doyle GV, Tissing H, Terstappen LW, Meropol NJ. Relationship of circulating tumor cells to tumor response, progressionfree survival, and overall survival in patients with metastatic colorectal cancer. J Clin Oncol 2008;26:3213-3221

31. Wong CS, Cheung MT, Ma BB, Pun Hui E, Chan AC, Chan CK, Lee KC, Cheuk W, Lam MY, Wong MC, Chan CM, Chan JK, Chan AT. Isolated tumor cells and circulating CK20 mRNA in pNO colorectal cancer patients. Int J Surg Pathol 2008;16:119-126.

32. Momburg $F$, Moldenhauer G, Hammerling GJ, Moller P. Immunohistochemical study of the expression of a Mr 34,000 human epithelium-specific surface glycoprotein in normal and malignant tissues. Cancer Res 1987;47:2883-2891.

33. Marrinucci $D$, Bethel $K$, Bruce $\mathrm{RH}$, Curry DN, Hsieh B, Humphrey M, Krivacic RT, Kroener J, Kroener L, Ladanyi A, Lazarus NH, Nieva J, Kuhn P. Case study of the morphologic variation of circulating tumor cells. Hum Pathol 2007;38:514-519.

34. Hou JM, Krebs M, Ward T, Sloane R, Priest L, Hughes A, Clack G, Ranson $M$, Blackhall $F$, Dive C. Circulating tumor cells as a window on metastasis biology in lung cancer. 


\section{CHAPTER 2 \\ Clinical and preclinical application of biomarker methods}

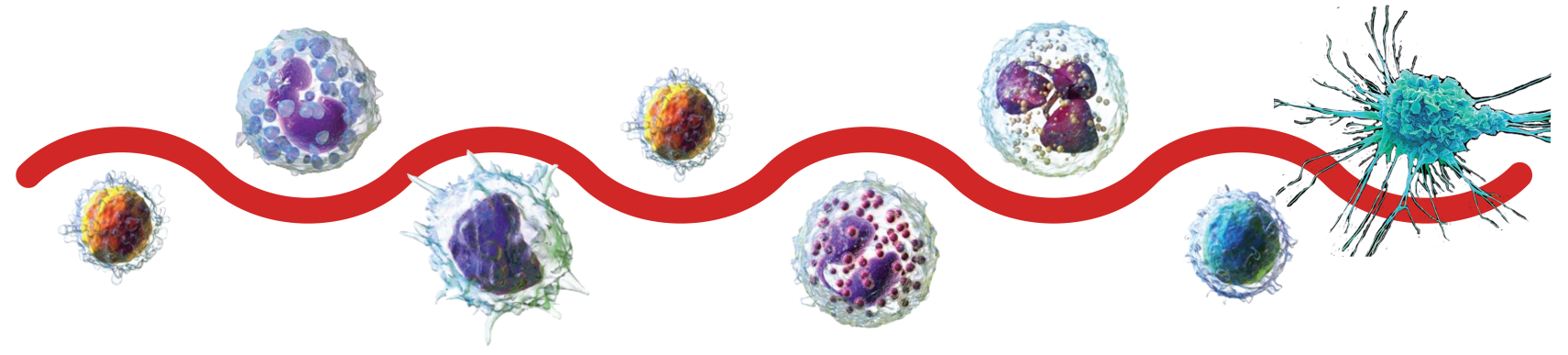

2.1

Pronounced between-subject and circadian

variability in thymidylate synthase and

dihydropyrimidine dehydrogenase enzyme

activity in human volunteers

Bart A.W. Jacobs, Maarten J. Deenen, Dick Pluim, J.G. Coen van Hasselt, Martin D. Krähenbühl, Robin M.J.M. van Geel, Niels de Vries, Hilde Rosing, Didier Meulendijks, Artur M. Burylo, Annemieke Cats, Jos H. Beijnen, Alwin D.R. Huitema, Jan H.M. Schellens

British Journal of Clinical Pharmacology 2016;82:706-716 


\section{ABSTRACT}

Aims: Enzymatic activities of thymidylate synthase (TS) and dihydropyrimidine dehydrogenase (DPD) are important for the tolerability and efficacy of the fluoropyrimidine drugs. In this study, we explored between-subject variability (BSV) and circadian rhythmicity in DPD and TS activity in human volunteers.

Methods: The BSV in DPD activity $(n=20)$ in peripheral blood mononuclear cells (PBMCs) and in plasma, by means of the dihydrouracil (DHU) and uracil (U) plasma levels and DHU:U ratio ( $n=40)$, and TS activity in PBMCs $(n=19)$, were examined. Samples were collected every 4 hours throughout one day for assessment of circadian rhythmicity in DPD and TS activity in PBMCs $(n=12)$ and DHU:U plasma ratios $(n=23)$. In addition, the effects of genetic polymorphisms and gene expression on DPD and TS activity were explored.

Results: Population mean ( \pm SD) DPD activity in PBMCs and DHU:U plasma ratio were $9.2( \pm 2.1) \mathrm{nmol} / \mathrm{mg} / \mathrm{h}$ and $10.6( \pm 2.4)$, respectively. Individual TS activity in PBMCs ranged from $0.024-0.596 \mathrm{nmol} / \mathrm{mg} / \mathrm{h}$. Circadian rhythmicity was demonstrated for all phenotype markers. Between 00:30 - 02:00 h, DPD activity in PBMCs peaked, while the DHU:U plasma ratio and TS activity in PBMCs showed trough activity. Peak-to-trough ratios for TS and DPD activity in PBMCs were 1.62 and 1.69, respectively. For the DHU:U plasma ratio, peak-to-trough ratio was 1.43.

Conclusions: Between-subject and circadian variability in DPD and TS activity were demonstrated. Circadian rhythmicity in DPD might be tissue dependent. The results suggest influence of circadian rhythms on phenotype-guided fluoropyrimidine dosing and support implications for chronotherapy with highdose fluoropyrimidine administration during the night. 


\section{INTRODUCTION}

Anticancer drugs belonging to the group of the fluoropyrimidines are extensively used in the treatment of colorectal, breast and gastric cancer. Most frequently applied fluoropyrimidine drugs are 5-fluorouracil (5-FU) and its oral pre-prodrug capecitabine. After oral administration, capecitabine is rapidly absorbed and via a three-step enzymatic cascade converted into 5-FU. Approximately $80 \%$ of 5-FU is rapidly catabolized by the enzyme dihydropyrimidine dehydrogenase (DPD) to inactive metabolites [1-3]. About $1-3 \%$ of 5-FU is anabolized to active metabolites, of which 5-fluoro-2'-deoxyuridine-5'-monophosphate (FdUMP) possesses the highest anticancer potency [4]. This metabolite inhibits the enzyme thymidylate synthase (TS). Through inhibition of TS, synthesis of deoxythymidine triphosphate (dTTP) is reduced. Depletion of dTTP disrupts DNA synthesis and cell death ensues.

Approximately $10-30 \%$ of all patients treated with fluoropyrimidine-based chemotherapy develops severe, sometimes even lethal, toxicity [5]. Unfortunately, identification of patients at risk of severe toxicity is hampered by the unavailability of sensitive clinical biomarker tests. Genetic polymorphisms in the gene encoding for DPD, DPYD, may result in DPD deficiency. The polymorphisms DPYD*2A and DPYD 2846A $>$ T are proven risk alleles and are strongly associated with fluoropyrimidine-induced severe toxicity [6]. Given the combined frequency of these two mutations of $2-3 \%[7,8]$, an important, but only a small fraction of patients at risk is identified by these two polymorphisms. Polymorphisms in TYMS, the gene encoding TS, have also been associated with fluoropyrimidine-induced toxicity $[6,9]$. However, relevance of these mutations requires clinical validation.

In order to reduce the incidence of fluoropyrimidine-induced toxicity and optimize dosing, more sensitive biomarkers are required. Phenotyping methods could provide increased sensitivity for the identification of patients at risk of fluoropyrimidine-induced toxicity. In order to prevent invasive procedures, DPD activity is often determined in peripheral blood mononuclear cells (PBMCs). Clearance of 5-FU has shown to correlate well with DPD activity in PBMCs (DPDApbmc) [10]. Furthermore, previous studies have shown that approximately $50 \%$ of the patients suffering from severe fluoropyrimidine-induced toxicity had relatively low DPDApbmc [11-13]. In addition, clearance of 5-FU and fluoropyrimidine-induced toxicity are also associated with pre-therapeutic plasma levels of the endogenous DPD substrate uracil (U) in plasma, and the ratio of the reaction product dihydrouracil (DHU) and $U$ in plasma [14-17].

Although application of phenotyping assays seems promising for identification 
of patients at risk, only few medical centers use these methods in routine clinical practice $[18,19]$. Several factors might account for this. The development and validation of accurate and robust phenotyping assays is challenging, which is illustrated by high variability in $U$ and DHU plasma levels among different studies [14]. Importantly, enzymatic activity of DPD and TS might possess circadian rhythms, which impedes interpretation of assay results.

Expression of DPD in PBMCs and the DHU:U plasma ratio have previously shown to peak at 19:00 $\mathrm{h}$ [20]. Others found that human DPDApbmc peaked at the beginning or during the night $[21,22]$. However, lack of a circadian rhythm has also been suggested [23]. TS might also possess a circadian rhythm. In human oral mucosa, TS activity was found to be lowest during the night [24]. Toxicity studies in mice provided evidence that 5-FU-induced toxicity is relatively low when the drug was administered at time of trough TS activity $[25,26]$.

In human patients, a 5-FU dosing regimen that is adapted to anticipated nocturnal peak activity of DPD showed excellent tolerability [27]. Nonetheless, fluoropyrimidine chronotherapy remains controversial because convincing pharmacological data supporting chronotherapy is lacking. In addition, implementation of chronotherapy in routine clinical practice is often impractical.

Taken together, DPD and TS phenotype assays are promising for upfront identification of patients at risk of developing fluoropyrimidine-induced toxicity. To facilitate implementation of pretreatment screening of patients, examination of circadian rhythms in DPD and TS phenotype markers is essential. Moreover, circadian rhythms in DPD and TS activity could provide a rationale for clinical evaluation of fluoropyrimidine chronotherapy in order to improve treatment safety.

The purpose of the current study was to gain insight in the between-subject and circadian variability in DPD and TS enzyme activity in human volunteers. Secondary objectives were to explore the effect of genetic polymorphisms and gene expression on DPD and TS enzyme activities. For these reasons, we performed an observational study in healthy volunteers and determined DPDApbmc, $U$ and DHU plasma levels, TS activity in PBMCs (TSApbmc) using newly developed and validated bioanalytical methods [28,29]. We applied a mixed-effect modeling approach to quantify circadian rhythmicity. 


\section{MATERIALS AND METHODS}

Study design and sample collection

In total, 40 healthy volunteers participated in this study. Included subjects were more than 18 years old and not known with cancer, not treated with investigational drugs in the past 30 days prior to study assessments, and had not undergone surgery within the past 6 months. Age, gender, regular sleep and wake up time were recorded. From 20 volunteers, blood was collected at 9:00 $\mathrm{h}$ for determination of DPDApbmc, TSApbmc, DHU and $U$ plasma levels and DPYD and TYMS gene expression. Of these 20 volunteers, 12 underwent additional blood sampling at 13:00, 17:00, 21:00, 1:00, 5:00, and 9:00 $\mathrm{h}$ the following day to examine circadian variability in DPDApbmc, TSApbmc, DHU and U plasma levels. From the remaining 20 volunteers, we collected samples only for determination of DHU and U plasma levels. Of those 20 volunteers, 9 underwent blood sampling once at 9:00 $\mathrm{h}$ and 11 volunteers were repeatedly sampled at the previously defined time points for evaluation of circadian variability. Thus, circadian variability in DPDApbmc and TSApbmc was assessed in 12 volunteers, and circadian variability in DHU and $U$ plasma levels in 23 volunteers.

In order to take blood samples at night, volunteers were hospitalized. Intravenous cannulas were used for the volunteers participating in the overnight sampling part of this study. Hereby, disturbance of the normal day-night rhythm was limited. The study protocol was approved by the Medical Ethics Committee of the Slotervaart Hospital, Amsterdam, The Netherlands. All volunteers provided written informed consent prior to study assessments.

\section{Determination of DPD and TS activity in PBMCS}

A volume of $8 \mathrm{~mL}$ of peripheral heparinized blood was collected for the assessment of DPDApbmc and TSApbmc. PBMCs were isolated using Ficoll-Paque density gradient centrifugation and stored at $-80^{\circ} \mathrm{C}$ until further analysis $[28,29]$. DPDApbmc and TSApbmc were determined by validated radioassays $[28,29]$. Activity of DPD was expressed by the amount of ${ }^{3} \mathrm{H}$-dihydrothymine formed per mg PBMC protein after one hour of ex vivo incubation $(\mathrm{nmol} / \mathrm{mg} / \mathrm{h}$ ) with the DPD substrate of $3 \mathrm{H}$-thymine [28]. TS activity was expressed by the amount of $5-{ }^{3} \mathrm{H}-2^{\prime}$-deoxyuridine $5^{\prime}$-monophosphate that was metabolized ex vivo per $\mathrm{mg}$ PBMC protein per hour of incubation ( $\mathrm{nmol} / \mathrm{mg} / \mathrm{h}$ ) [29]. PBMC protein levels were corrected for hemoglobin contamination using a spectrophotometric method [30]. 


\section{Quantification of uracil and dihydrouracil plasma levels}

A volume of $4 \mathrm{~mL}$ of heparinized whole blood was centrifuged at $1500 \mathrm{~g}$ for 10 minutes at $4^{\circ} \mathrm{C}$. Isolated plasma was stored at $-20^{\circ} \mathrm{C}$ until further analysis. DHU and $U$ were quantified in plasma using mass spectrometry (Jacobs et al. submitted). After defrosting, a volume of $20 \mu \mathrm{L}$ of internal standard working solution containing $1,3-\mathrm{U}-{ }^{15} \mathrm{~N} 2$ and $5,6-\mathrm{DHU}-{ }^{13} \mathrm{C} 4,{ }^{15} \mathrm{~N} 2$ was added to $300 \mu \mathrm{L}$ plasma. Protein precipitation was performed using $900 \mu \mathrm{L}$ of $\mathrm{MeOH}$ and acetonitrile $(1: 1, v / v)$. Samples were vortex-mixed for $10 \mathrm{~s}$, shaken for $10 \mathrm{~min}$ at $1250 \mathrm{rpm}$ (Labinco, Breda, The Netherlands) and centrifuged at $14.000 \mathrm{rpm}$ for $10 \mathrm{~min}$. Clear supernatants were dried under a stream of nitrogen at $40^{\circ} \mathrm{C}$ and reconstituted in $100 \mu \mathrm{L} \mathrm{0.1 \%} \mathrm{formic} \mathrm{acid} \mathrm{in} \mathrm{water.} \mathrm{U}$ and $\mathrm{DHU}$ plasma levels were determined using an ultra-performance liquid chromatography - tandem mass spectrometry (UPLCMS/MS) system. Chromatographic separation was performed on an Acquity UPLC ${ }^{\circledR}$ HSS T3 (150 x 2.1 mm ID, particle size $1.8 \mu \mathrm{m}$; Waters, Milford, USA) column. Mobile phases consisted of $0.1 \%$ formic acid in UPLC-grade water (eluent A) and $0.1 \%$ formic acid in UPLC-grade acetonitrile (eluent B) at a flow of $0.3 \mathrm{~mL} / \mathrm{min}$. The following gradient was used: 0\% B from 0-3.0 min, 0-90\% B from 3.0-3.2 min, 90\% B from 3.2-3.7 $\mathrm{min}, 0 \%$ B from 3.7-5 min. A Qtrap 5500 triple quadrupole mass spectrometer ( $A B$ Sciex, Framingham, USA) was operated in the negative mode for quantification of $U$ and in the positive mode for quantification of DHU. Selected mass transitions for $U$ and DHU were m/z 110.9 -> m/z 42.0 and m/z 114.9 -> m/z 55.0. Validated concentration ranges for $U$ and $\mathrm{DHU}$ were $1-100 \mathrm{ng} / \mathrm{mL}$ and 10 $1000 \mathrm{ng} / \mathrm{mL}$, respectively.

\section{Gene expression of DPYD and TYMS}

PBMCs were isolated from $8 \mathrm{~mL}$ of whole blood using Vacutainer ${ }^{\circledR}$ cell preparation (CPT) tubes (Becton Dickinson, Franklin Lakes, USA). Tubes were centrifuged at $1800 \mathrm{~g}$ for $20 \mathrm{~min}$ at room temperature. The PBMCs were transferred into a clean $50 \mathrm{~mL}$ tube and washed twice with $\mathrm{NaCl} 0.9 \%$. Then, PBMCs were lysed in RNABee (TelStat, Friendswood, USA) and stored at $-80{ }^{\circ} \mathrm{C}$ until total RNA extraction. Isolation of total RNA was performed according to the RNA-Bee manufacturer's instructions. A quantity of $350 \mathrm{ng}$ of the isolated total mRNA, random primers (Invitrogen) and SuperScript II reverse transcriptase (Invitrogen) were used for the synthesis of cDNA using the following PCR protocol: $25^{\circ} \mathrm{C}$ for $10 \mathrm{~min}, 42{ }^{\circ} \mathrm{C}$ for $50 \mathrm{~min}, 70{ }^{\circ} \mathrm{C}$ for $15 \mathrm{~min}$, refrigeration at $4{ }^{\circ} \mathrm{C}$. Quantification of TYMS and DPYD gene expression was performed in triplicate using SYBR Green PCR Master 
Mix (Applied Biosystems, Foster City, USA) and the 7500 Fast Real-Time PCR (RTPCR) system (Applied Biosystems, Foster City, USA). Relative gene expression was determined using the $2^{-\Delta \Delta C t}$ method [31]. Peptidylprolyl isomerase B (PPIB) was used as housekeeping gene and Human Reference RNA (Stratagene, La Jolla, USA) as external calibrator. RT-PCR primer sequences are available upon request.

\section{Genetic polymorphisms in DPYD and TYMS}

Genomic DNA was isolated from $3 \mathrm{~mL}$ of EDTA blood using the QIAamp DNA mini kit (Qiagen, Valencia, USA). The polymorphisms DPYD*2 and 2846A>T were determined by RT-PCR using allele-specific TaqMan probes (Applied Biosystems, Bleijswijk, The Netherlands) [8]. Polymorphisms within the 5'UTR 28-bp tandem repeat (VNTR) in TYMS were analyzed using Sanger sequencing. Additionally, we screened for the $G>C$ SNPs within the first tandem repeat of the $2 R$ allele. Patients were stratified based on the 28-bp VNTR in TYMS to either the low TYMS expression group $\left(* 2 /{ }^{*} 2, * 2 /{ }^{*} 3 \mathrm{C}\right.$ or $\left.* 3 \mathrm{C} /{ }^{*} 3 \mathrm{C}\right)$ or high TYMS expression group $(* 2 / * 3 G, * 3 C / * 3 G$ or $* 3 G / * 3 G)$. Primer sequences are available upon request.

\section{Mixed-effect modeling of circadian rhythms}

Mixed-effect modeling was applied to describe the circadian rhythms in DPDApbmc, $U$ and DHU plasma levels and TSApbmc using NONMEM (version 7.3.0) [32]. Piraña (version 2.9.1) was used for model management [33]. Circadian rhythms were modeled applying cosine functions as follows:

where $Y$ represents the studied phenotype biomarker, Mesor is the 24-hour mean

$$
Y(t)=\text { Mesor } \times\left\{1+\sum_{i=1}^{n}\left[A M P_{i} \times \cos \left(2 \pi \times i \times \frac{\left[t-P S_{i}\right]}{24}\right)\right]\right\}
$$

value, $A M P_{i}$ is the relative amplitude and $P S_{i}$ is the phase shift (time of peak) for cosine function $i$. The time of day is represented by $t$. Between-subject variability (BSV) on model parameters was described using log-normal models. Residual unexplained variability (RUV) was estimated using additive residual error models. Circadian variability in $U$ and DHU plasma levels was estimated using a single set of parameters for $A M P_{i}$ and $P S_{i}$. Model evaluation was guided by goodnessof-fit (GOF) plots, visual predictive checks (VPC), drop in objective function value (dOFV) and precision of obtained parameter estimates. Model management and 
diagnostics were done using $R$ [34], the Xpose4 package (version 4.5.3) for $R$ and PsN (version 4.2) [33].

\section{Statistical analysis}

Statistical analyses were performed in R (version 3.1.2) [34]. Descriptive statistics were used to describe DPDApbmc, TSApbmc, $U$ and DHU plasma levels and DHU:U plasma ratios. Assessments of normality were done using the Shapiro-Wilk test. Mann-Whitney $U$ tests were applied for comparing continuous variables between subgroups. Pearson correlations were estimated to examine the relationship between DPDApbmc and $U$ plasma levels and the DHU:U plasma ratio. The Pearson and Filon's statistical test was applied to explore the difference between the overlapping correlations of DPDApbmc and U plasma level and of DPDApbmc and DHU:U ratio using the cocor package for $\mathrm{R}$ [35]. Associations between gene expression and DPDApbmc and TSApbmc were explored using the Pearson correlation test. Intra-day variability in DPDApbmc, TSApbmc, DHU:U plasma ratio and $U$ and DHU plasma levels were assessed using repeated measures analysis of variance (rANOVA) tests with Tukey post hoc analysis, unless stated differently. P-values $<0.05$ were considered statistically significant.

\section{RESULTS}

Volunteer characteristics

A total of 40 volunteers ( 21 females) with a mean age of 28.8 years (range: $20.3-$ 49.7 years) were included. Of the 40 volunteers, 39 were Caucasian. Mean (range) wake and sleep times were 7:00 h (6:00-8:30 h) and 23:25 h (21:45-01:50 h). Sample collection for baseline assessment of DPDApbmc, TSApbmc, DHU and $\mathrm{U}$ plasma levels and DPYD and TYMS gene expression was on average at 9:25 $\mathrm{h}$ (range: 8:45-11:15 h).

\section{Baseline characteristics of DPD and TS phenotype markers}

Mean and BSV in TSApbmc, DPDApbmc, DHU:U plasma ratio and $U$ and DHU plasma levels are summarized in Table 1. For one volunteer the amount of isolated PBMC protein was insufficient for TSApbmc analysis. TSApbmc followed a nonnormal distribution $(p<0.001)$, whereas for the other variables this test was not significant. Large BSV in baseline TSApbmc was found as illustrated by a factor 25 
difference between the maximum and minimum observed values.

Intra-day variability in markers for TS and DPD activity

Individual and population average TSApbmc and DPDApbmc are shown in Figure 1. Trough TSApbmc and peak DPDApbmc were observed at 1:00 $\mathrm{h}$ while peak TSApbmc and trough DPDApbmc were both detected at 17:00 $\mathrm{h}$ and 13:00 $\mathrm{h}$, respectively. Peak-to-trough ratio of DPDApbmc was 1.69 and for TSApbmc 1.62. Figure 2 displays the intra-day variability in $\mathrm{U}, \mathrm{DHU}$ and DHU:U in plasma. Peak and trough $U$ plasma levels occurred at 5:00 $\mathrm{h}$ and 17:00 h. Throughout the day, DHU plasma levels showed significant differences with peak levels at 9:00 $\mathrm{h}$ and trough levels at 1:00 h. Peak-to-trough ratios for $\mathrm{U}$ and DHU plasma levels were 1.39 and 1.22. Intra-day variability in $U$ and DHU plasma levels also resulted in clear intra-day variability in DHU:U plasma ratios. Peak and trough DHU:U ratio were detected at $17: 00 \mathrm{~h}$ and $5: 00 \mathrm{~h}$ with a peak-to-trough ratio of 1.43. All examined phenotype markers revealed significant intra-day variability (Table 2 ).

Mixed-effect modeling of circadian rhythms

Table 1. Descriptive statistics for baseline values of thymidylate synthase and dihydropyrimidine dehydrogenase activity in peripheral blood mononuclear cells and plasma levels of uracil (U) and dihydrouracil (DHU), including the DHU:U plasma ratio, in healthy volunteers. Mean time of sample collection was 9:25 h (range: 8:45-11:15 h).

\begin{tabular}{|cccc|}
\hline Variable & $\mathbf{n}$ & Mean $\pm \mathbf{s d}$ & CV $(\%)$ \\
\hline TS activity in PBMCs $(\mathrm{nmol} / \mathrm{mg} / \mathrm{h})$ & 19 & $0.072(0.024-0.596)^{*}$ & - \\
DPD activity in PBMCs (nmol/mg/h) & 20 & $9.2 \pm 2.1$ & 23 \\
\hline DHU:U plasma ratio & 40 & $10.6 \pm 2.4$ & 22 \\
U concentration $(\mathrm{ng} / \mathrm{mL})$ & & $9.8 \pm 2.9$ & 29 \\
DHU concentration $(\mathrm{ng} / \mathrm{mL})$ & & $98 \pm 23.8$ & 24 \\
\hline
\end{tabular}

Abbreviations: TS = thymidylate synthase, DPD = dihydropyrimidine dehydrogenase, PBMCs = peripheral blood mononuclear cells, $\mathrm{DHU}=$ dihydrouracil, $\mathrm{U}=$ uracil, $\mathrm{n}=$ number of subjects, $\mathrm{sd}=$ standard deviation, $\mathrm{CV}=$ coefficient of variation. $*$ Median and range are shown for TS activity, since non-normal distribution was demonstrated. 


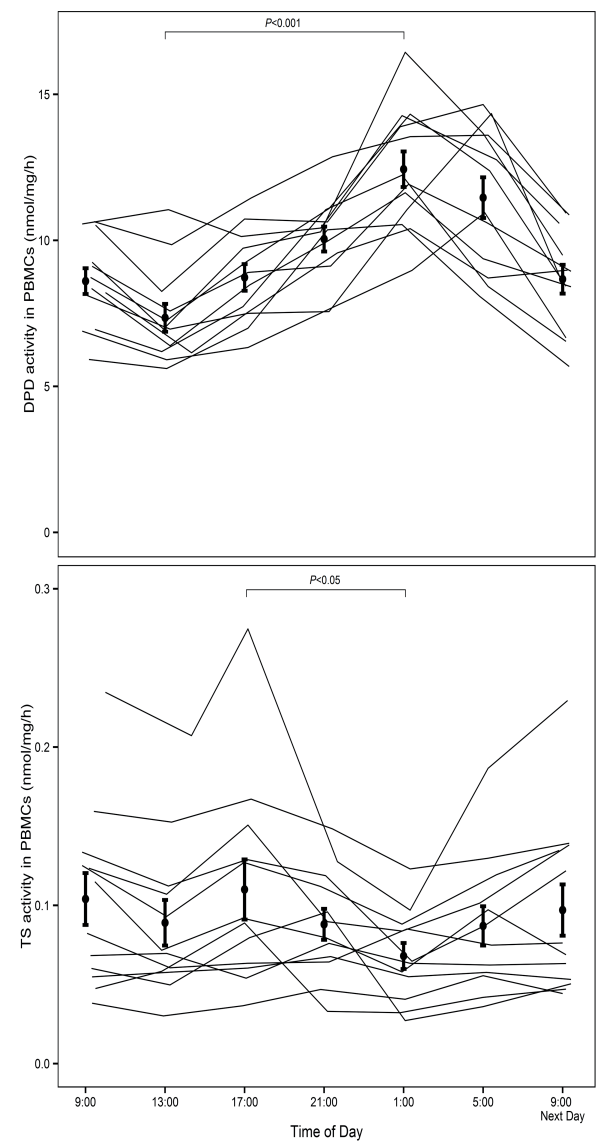

Figure 1. Intraday variability in dihydropyrimidine dehydrogenase (upper panel) and thymidylate synthase activity (lower panel) in peripheral blood mononuclear cells from volunteers $(\mathbf{n}=$ 12). Grey lines represent individual lines for DPD and TS activity. Mean \pm standard error per timepoint are shown by black points and error bars. Differences between peak and trough activities are supported by P-values. Abbreviations: DPD = dihydropyrimidine dehydrogenase; PBMCs = peripheral blood mononuclear cells; TS = thymidylate synthase

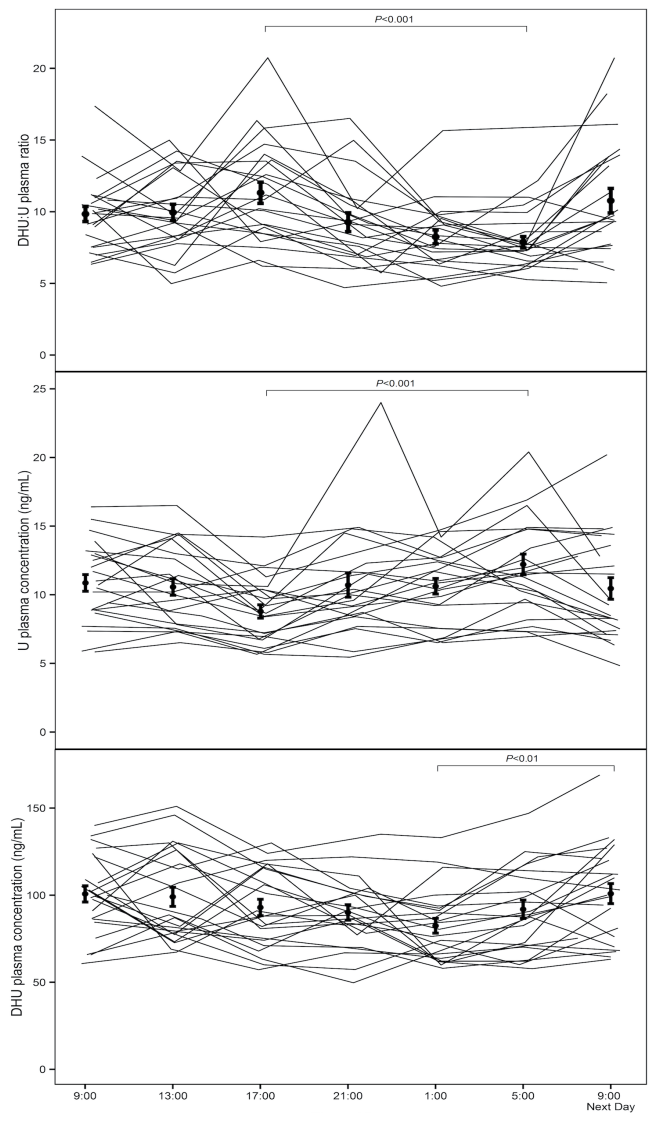

Figure 2. Intraday variability in the dihydrouracil : uracil plasma ratio (upper panel), uracil plasma levels (middle panel) and dihydrouracil plasma levels (lower panel) in 23 healthy volunteers. Grey solid lines represent individual curves. Mean \pm standard error per time point is shown by black points and error bars. Differences between peak and trough levels are supported by P-values. Abbreviations: $\mathrm{DHU}=$ dihydrouracil; $\mathrm{U}=$ uracil. 
Table 2. Results of the repeated measures ANOVA of thymidylate synthase and dihydropyrimidine dehydrogenase activity in peripheral blood mononuclear cells, dihydrouracil:uracil plasma ratio and uracil and dihydrouracil plasma levels in healthy volunteers.

\begin{tabular}{|c|c|c|c|c|c|c|c|}
\hline Variable & $n$ & $\begin{array}{l}\text { Trough } \pm \\
\text { S.E.M. }\end{array}$ & $\begin{array}{l}\text { Peak } \pm \\
\text { S.E.M. }\end{array}$ & $\begin{array}{l}\text { Time of trough } \\
\text { (hh:mm) }\end{array}$ & $\begin{array}{c}\text { Time of } \\
\text { peak } \\
\text { (hh:mm) }\end{array}$ & $\begin{array}{l}\text { Peak: } \\
\text { Trough }\end{array}$ & $\begin{array}{c}\text { p-value of } \\
\text { repeated } \\
\text { measures } \\
\text { ANOVA }\end{array}$ \\
\hline $\begin{array}{l}\text { TS activity in PBMCs } \\
\text { (nmol/mg/h) }\end{array}$ & 12 & $0.068 \pm 0.008$ & $0.110 \pm 0.019^{*}$ & $01: 00 \mathrm{~h}$ & $17: 00 \mathrm{~h}$ & 1.62 & $0.012^{\$}$ \\
\hline $\begin{array}{c}\text { DPD activity in PBMCS } \\
(\mathrm{nmol} / \mathrm{mg} / \mathrm{h})\end{array}$ & 12 & $7.35 \pm 0.48$ & $12.4 \pm 0.61^{* * *}$ & $13: 00 \mathrm{~h}$ & $01: 00 \mathrm{~h}$ & 1.69 & $<0.0001$ \\
\hline DHU:U plasma ratio & 23 & $7.87 \pm 0.40$ & $11.32 \pm 0.74^{* * *}$ & 05:00 h & $17: 00 \mathrm{~h}$ & 1.43 & $<0.0001$ \\
\hline $\begin{array}{l}U \text { concentration } \\
(\mathrm{ng} / \mathrm{mL})\end{array}$ & 23 & $8.78 \pm 0.49$ & $12.21 \pm 0.75^{* * *}$ & $17: 00 \mathrm{~h}$ & $5: 00 \mathrm{~h}$ & 1.39 & 0.0002 \\
\hline $\begin{array}{c}\text { DHU concentration } \\
(\mathrm{ng} / \mathrm{mL})\end{array}$ & 23 & $82.4 \pm 4.2$ & $100.9 \pm 8.8^{* *}$ & $01: 00 \mathrm{~h}$ & $09: 00 \mathrm{~h}$ & 1.22 & 0.0009 \\
\hline
\end{tabular}

Abbreviation: $\mathrm{TS}=$ thymidylate synthase, $\mathrm{DPD}=$ dihydropyrimidine dehydrogenase, $\mathrm{PBMCS}$ = peripheral blood mononuclear cells, $\mathrm{DHU}=$ dihydrouracil, $\mathrm{U}=$ uracil, $\mathrm{n}=$ number of subjects, S.E.M. = standard error of the mean, ANOVA = analysis of variance. Differences between peak and trough levels were based on post hoc test: $p \leq 0.001\left(*^{* *}\right) ; p \leq 0.01\left(*^{*}\right)$; $\mathrm{p} \leq 0.05\left(^{*}\right) ; \mathrm{p}>0.05$ (not significant). ${ }^{\$}$ In case of TS activity in PBMCs, the nonparametric repeated measures ANOVA (Friedman test) with post hoc analysis was applied. 
A mixed-effect modeling approach was applied to quantify circadian variability. A combined model for circadian rhythms in $U$ and DHU plasma levels and DPDApbmc was developed. Base models included BSV terms for mesors of $U$ Mesor $_{U}$ and DHU Mesor ${ }_{D H U}$ plasma levels and DPDApbmc Mesor ${ }_{D P D}$. One cosine function adequately described circadian rhythms in $U$ and DHU plasma levels.

Equation 2 illustrates the function for model prediction of $U$ and DHU plasma levels as function of the time of day $(0-24 \mathrm{~h})$ :

$$
\text { Rhythm }_{U \& D H U}(\mathrm{t})=\mathrm{AMP}_{\mathrm{U} \& D H U} \times \cos \left(2 \pi \frac{\left[\mathrm{t}-\mathrm{PS}_{\mathrm{U} \& \mathrm{DHU}}\right]}{24}\right)
$$

where circadian variability in $U$ and DHU plasma levels is represented by Rhythm $_{U \& D H U^{\prime}}$ the amplitude $A M P_{U \& D H U^{\prime}}$ phase shift by $P S_{U \& D H U}$ and time of day by $t$.

Equation 2 was incorporated in the population model for circadian variability in $U$ and DHU plasma levels, as illustrated by equations 3 and 4 :

$$
\begin{aligned}
& U(t)=\text { Mesor }_{U} \times\left(1+\text { Rhythm }_{U \& D H U}(t)\right)+\varepsilon_{U} \\
& D H U(t)=\text { Mesor }_{D H U} \times\left(1-\text { Rhythm }_{U \& D H U}(t)\right)+\varepsilon_{D H U}
\end{aligned}
$$

In these equations, additive residual errors for $U$ and DHU plasma levels are represented by $\varepsilon_{-} U$ and $\varepsilon_{-} D H U$, with mean zero and variance $\sigma 2$.

The circadian rhythm of DPDApbmc was adequately described using a single cosine function. Covariance between BSV of Mesor ${ }_{U}$ and MesOr $_{D H U}$ was assessed. The estimated correlation coefficient was 0.68 (dOFV=-17.2). In addition, there was a negative correlation between BSV of Mesor $_{U}$ and Mesor $_{D P D}$. The correlation coefficients between BSV of Mesor ${ }_{u}$ and MesOr ${ }_{D H U}$ and BSV of Mesor ${ }_{u}$ and Mesor ${ }_{D P D}$ were included in the final model. Furthermore, there was a positive correlation between RUV in $U$ and DHU plasma levels, which was also included in the final model (dOFV=-9.9).

The optimal model for TSApbmc contained two cosine functions to describe circadian variability. This model was further improved by addition of a single BSV 

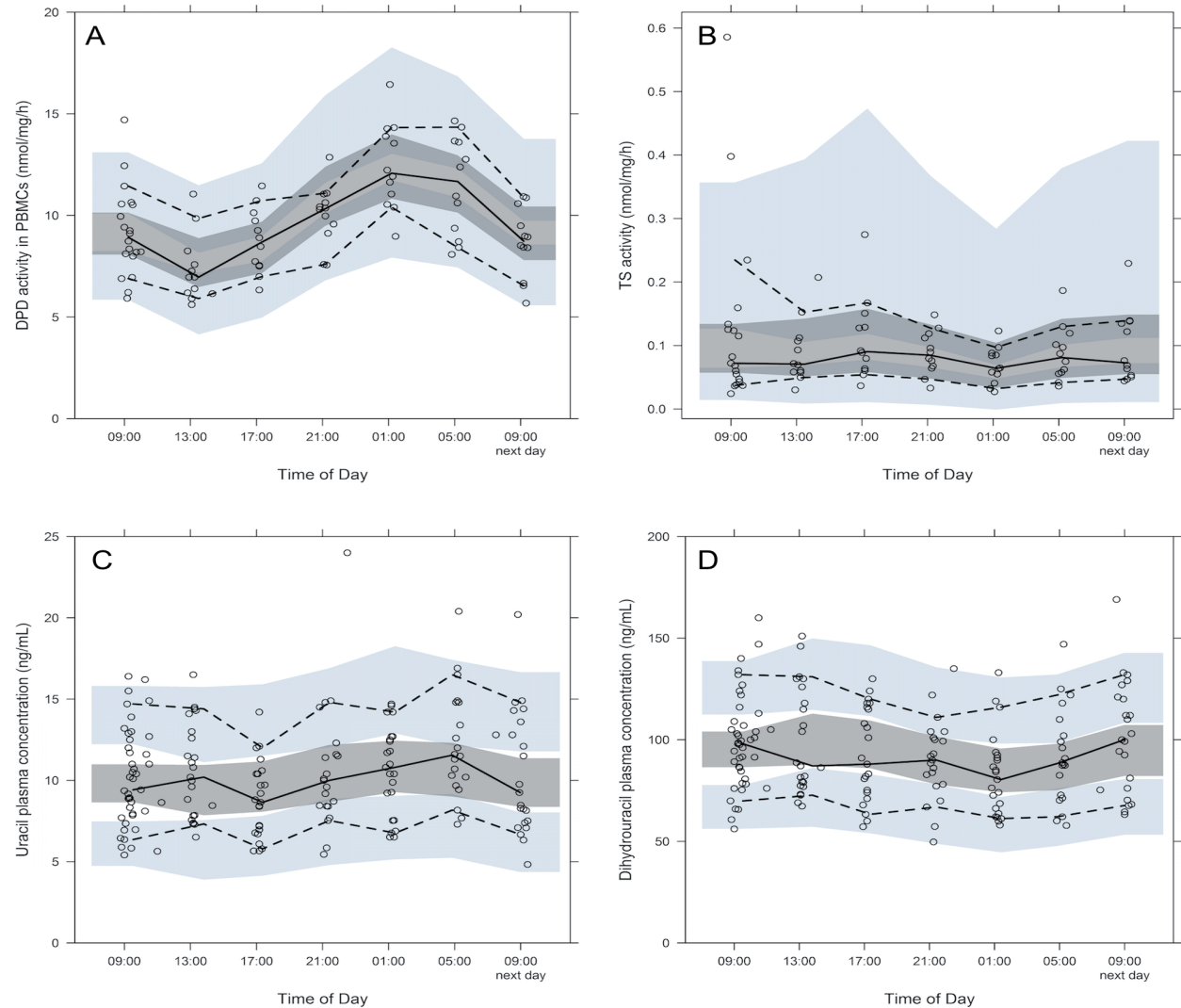

Figure 3. Visual predictive checks for final models for circadian rhythms in dihydropyrimidine dehydrogenase (A) and thymidylate synthase (B) activity in peripheral blood mononuclear cells, and uracil (C) and dihydrouracil (D) plasma levels. Lines represent the 10th percentile, median and 90th percentile of observed data. Shaded areas represent corresponding $95 \%$ confidence intervals of simulated data. Abbreviations: DPD = dihydropyrimidine dehydrogenase; PBMCs = peripheral blood mononuclear cells; TS $=$ thymidylate synthase. 
Table 3. Parameter estimates of the final models of circadian rhythms in uracil and dihydrouracil plasma levels, thymidylate synthase and dihydropyrimidine dehydrogenase activity in peripheral blood mononuclear cells. The circadian rhythm in thymidylate synthase activity was described by two cosine functions, for which separate amplitudes and phase shifts were estimated.

\begin{tabular}{|c|c|c|c|}
\hline Parameter & Estimate & RSE (\%) & \\
\hline \multicolumn{4}{|l|}{ Structural model parameter } \\
\hline Mesoru (ng/mL) & 9.95 & 4.3 & \\
\hline $\operatorname{Mesor}_{\mathrm{DHU}}(\mathrm{ng} / \mathrm{mL})$ & 91.4 & 2.9 & \\
\hline Amplitudeu\&DHu & 0.082 & 15.5 & \\
\hline Phase shiftu\&DHu (hh:mm) & 01:56 & 21.4 & \\
\hline Mesor $_{\text {DPD }}(\mathrm{nmol} / \mathrm{mg} / \mathrm{h})$ & 9.94 & 4.0 & 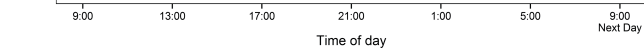 \\
\hline Amplitude DPD & 0.245 & 9.3 & \multirow{12}{*}{$\begin{array}{l}\text { Figure 4. Typical patterns of circadian variability } \\
\text { in dihydropyrimidine dehydrogenase and } \\
\text { thymidylate synthase enzyme activity in } \\
\text { peripheral blood mononuclear cells, and uracil } \\
\text { and dihydrouracil plasma levels in healthy } \\
\text { volunteers. Circadian variability is expressed as a } \\
\text { percentage of the mesor (rhythm-adjusted } \\
\text { mean). } \\
\text { DPD, dihydropyrimidine dehydrogenase; TS, } \\
\text { thymidylate synthase. - Uracil (ng/ml); - - } \\
\text { dihydrouracil (ng/ml); - DPD activity in } \\
\text { PBMCs (nmol/mg/h); . . TS activity in PBMCs } \\
\text { (nmol/mg/h) }\end{array}$} \\
\hline Phase shift ${ }_{D P D}(h h: m m)$ & 01:46 & 18.4 & \\
\hline $\operatorname{Mesor}_{\text {TS }}(\mathrm{nmol} / \mathrm{mg} / \mathrm{h})$ & 0.080 & 19.4 & \\
\hline Amplitudets 1 & 0.129 & 28.9 & \\
\hline Amplitude 2 & 0.106 & 29.6 & \\
\hline Phase shiftтs 1 (hh:mm) & $13: 24$ & 3.1 & \\
\hline Phase shiftTs 2 (hh:mm) & $18: 42$ & 1.1 & \\
\hline $\begin{array}{l}\text { Between-subject variability } \\
\text { Mesoru (CV\%) }\end{array}$ & 24.3 & 10.7 & \\
\hline Mesor $_{\text {DHU }}(\mathrm{CV} \%)$ & 17.8 & 14.3 & \\
\hline MesordpD (CV\%) & 17.5 & 17.8 & \\
\hline MesorTs $_{\text {(CV\%) }}$ & 92.3 & 16.8 & \\
\hline Amplitude $_{\text {Ts }} 1$ and 2 (CV\%) & 56.5 & 33.2 & \\
\hline \multicolumn{4}{|c|}{ Residual unexplained variability } \\
\hline$\sigma_{\text {additive,U }}(\mathrm{ng} / \mathrm{mL})$ & 2.05 & 21.5 & \\
\hline$\sigma_{\text {additive,DHU }}(\mathrm{ng} / \mathrm{mL})$ & 16.2 & 11.8 & \\
\hline$\sigma_{\text {additive,DPD }}(\mathrm{nmol} / \mathrm{mg} / \mathrm{h})$ & 1.14 & 19.5 & \\
\hline$\sigma_{\text {additive,Ts }}(\mathrm{nmol} / \mathrm{mg} / \mathrm{h})$ & 0.014 & 20.3 & \\
\hline \multicolumn{4}{|l|}{ Correlations } \\
\hline$\rho$ (BSV Baseu, BSV Base & 0.68 & - & \\
\hline$\rho$ (BSV Base $e_{U}$, BSV Base $\left._{\mathrm{DPD}}\right)$ & -0.16 & - & \\
\hline$\rho\left(\sigma_{U}, \sigma_{\mathrm{DHU}}\right)$ & 0.26 & - & \\
\hline
\end{tabular}

Abbreviations: Mesor = rhythmadjusted mean, Phase shift $=$ time of peak, $\mathrm{TS}=$ thymidylate synthase, $\mathrm{DPD}=$ dihydropyrimidine dehydrogenase, DHU = dihydrouracil, $\mathrm{U}=$ uracil, $\mathrm{RSE}=$ relative standard error, $\mathrm{CV}=$ coefficient of variation, $\mathrm{BSV}=$ between-subject variability, $\sigma=$ residual variability, $\rho=$ correlation coefficient. 
term on both amplitudes (dOFV=-16.7).

VPCs of the final circadian models are shown in Figure 3. The parameter estimates are given in Table 3. The typical circadian rhythms of the studied phenotype markers are shown in Figure 4. GOF plots are provided as supplementary material (Supplementary Figures S1-4).

\section{Associations between DPD activity in PBMCs and in plasma}

There was a modest but significant negative correlation between DPDApbmc and $U$ plasma levels $\left(r^{2}=0.26 ; p=0.02\right.$; Supplementary Figure S5). There was a trend towards a positive association between DPDApbmc and DHU:U plasma ratio $\left(r^{2}=0.17 ; p=0.07\right)$. Difference in overlapping correlations between DPDApbmc and $\mathrm{U}$ plasma level and of DPDApbmc and DHU:U ratio was not statistically significant.

\section{Associations between TYMS and DPYD genotypes and phenotypes}

There were 10 volunteers with the TYMS low expression genotype and 9 volunteers with the TYMS high expression genotype. Although the average TSApbmc was as expected higher in volunteers with the high expression genotype, the difference was not significant ( $p=0.32$; Supplementary Figure 56$)$. Among the volunteers, we identified one volunteer with the very uncommon $2 \mathrm{RC} / 3 R C$ expression genotype. The proportion of individuals with this genotype was previously reported to be $2 \%$ [36]. TSApbmc in this volunteer was relatively low (0.036 $\mathrm{nmol} / \mathrm{mg} / \mathrm{h}$; Supplementary Figure S6). None of the 40 volunteers was carrier of the DPYD*2A allele, and one volunteer was heterozygous for DPYD $2846 \mathrm{~A}>\mathrm{T}$.

Associations between TS and DPD enzyme activity and gene expression in PBMCs

To assess whether TS and DPD enzyme activity in PBMCs are regulated on a transcriptional level, we explored associations between gene expression and TSApbmc and DPDApbmc (Supplementary Figure S7). There was a strong positive correlation between TSApbmc and TYMS gene expression $\left(r^{2}=0.84 ; p<0.001\right)$. In contrast, a weak, but significant negative correlation was found for DPDApbmc and DPYD gene expression $\left(r^{2}=0.22 ; p=0.04\right)$. 


\section{DISCUSSION}

This study clearly identified and quantified wide BSV and circadian rhythmicity in phenotypic markers of TS and DPD activity. Intra-day variability was noticeable in the presented data. Eventually, we were able to describe circadian rhythms in DPDApbmc, $U$ and DHU plasma levels using in a combined model and rhythmicity in TSApbmc by the sum of two cosine functions. Model parameters were estimated with adequate precision and model diagnostics did not suggest structural deviations. Therefore, this is the first report to successfully describe and fully quantify circadian rhythmicity of TSApbmc, DPDApbmc, $U$ and DHU plasma levels using the mixed-modeling approach.

Although there was a moderate correlation between baseline DPDApbmc and $U$ plasma levels, circadian rhythmicity in DPDApbmc and $U$ and DHU plasma levels clearly suggested two different patterns in DPD activity. Time of peak DPDApbmc was estimated at 01:46 h. However, at that time, we also discovered peak $U$ and trough DHU plasma levels, suggestive for trough DPD activity at the same timepoint. Magnitude of circadian variation was more pronounced for DPDApbmc than for $U$ and DHU plasma levels, which is illustrated by relative amplitudes of 0.245 for DPDApbmc and 0.082 for $U$ and DHU plasma levels. Residual unexplained variability was relatively large in the circadian model for $U$ and $D H U$ in plasma. This indicates that there are unidentified variables, other than circadian rhythmicity, accounting for variability in $\mathrm{U}$ and DHU plasma levels.

Others have also reported circadian rhythmicity on surrogate markers for systemic DPD activity [20,21,37]. Results from these studies show large differences. Jiang et al. determined circadian rhythmicity in DHU:U plasma ratios and DPD protein expression in PBMCs in human volunteers and found peak levels for both markers at approximately 18:40 $\mathrm{h}$. They found an average DHU:U plasma ratio in their study of 5.1 and found a large effect of circadian rhythmicity on this marker, considering the observed peak-to-trough ratio of 3.4 [20]. Compared to our study, they showed more pronounced circadian variability in $U$ and $D H U$ and earlier peak expression of DPD protein in PBMCs. Their average DHU:U plasma ratio is remarkably lower than the average $\mathrm{DHU} U \mathrm{U}$ plasma that we observed. Zeng et al. reported peak DHU:U plasma ratios in patients at 2:30 $\mathrm{h}$ and with a relative amplitude of 0.13 [37]. Although the magnitude of circadian variability of their findings was in line with ours, time of peak is completely opposite to our results. Peak DPDApbmc in patients who were treated with 5-FU was detected around midnight by Harris et al. [21]. Besides the time of peak activity also the magnitude 
of rhythmicity was very close to our results on DPDApbmc.

DPD activity in PBMCs and the DPD phenotype in plasma might be regulated by different mechanisms. Circadian rhythms are generally maintained by a central circadian clock located in the hypothalamus [38]. The circadian clock consists of a transcription-translation based oscillatory feedback mechanism involving a set of genes, called clock genes. Clock proteins control circadian rhythms of other genes by regulating transcriptional processes. However, circadian clocks have been found in several peripheral tissues. This allows for tissue specific regulation of rhythmicity. Surprisingly, circadian clock genes in PBMCs show expression in a circular manner which has been shown to be conserved in cultured PBMCs $[39,40]$. Previous experiments suggested that DPD activity is coordinated by the clock gene PER1 [41], which is one of the genes that show circadian rhythmicity in PBMCs $[39,40]$. Tissue specific regulation of clock genes might cause DPD activity in PBMCs to deviate from DPD activity in other body compartments, which could lead to differences in circadian rhythms for DHU:U in plasma and DPDApbmc. Alternatively, other enzymatic processes might contribute to rhythmicity in $U$ and DHU plasma levels. The enzyme uridine phosphorylase (UP), which degrades uridine to $U$, and the enzyme DPD show opposite circadian rhythms in mice [42]. If these two enzymes also show opposite rhythms in humans this could contribute to circadian variability in $U$ plasma levels. Since DPDApbmc and DHU:U plasma ratio show opposing circadian rhythms, patient samples for DPD phenotyping or therapeutic drug monitoring of 5-FU should preferably be collected at the intersect of both rhythms, which is at approximately 8:00 h and 20:00 h.

Correlation between DPDApbmc and $U$ plasma level and of DPDApbmc and $D H U: U$ ratio were rather weak. These weak correlations could be caused by differences in analytical methods and biological sample matrices. The method for DPD activity in PBMCs is based on ex vivo conversion of the radiolabeled DPD substrate $3 \mathrm{H}$-dihydrothymine and showed to be highly selective for the enzyme DPD [28]. Conversely, enzymes, other than DPD, might contribute to the regulation of $U$ and DHU plasma levels. The enzyme UP is involved in the formation of $U$ and dihydropyrimidinase catalyzes the degradation of DHU. Consequently, BSV in UP and dihydropyrimidinase activity could affect $U$ and DHU plasma levels, which in turn, could attribute to the weak correlation with DPDApbmc. DPD-based adaptive dosing of fluoropyrimidines using the DHU:U plasma ratio could be biased by the involvement of other enzymes. Additional clinical research is needed to evaluate the applicability of DHU:U plasma for DPD- 
based adaptive dosing of fluoropyrimidines.

TSApbmc displayed circadian variability and particularly large BSV. Smaaland et al. discovered a circadian rhythm in bone marrow DNA synthesis of healthy human volunteers. They observed trough DNA synthesis at midnight, a minor peak in DNA synthesis at 8:00 $\mathrm{h}$ and maximum DNA synthesis at 16:00 $\mathrm{h}$ [43]. This is in agreement with the pattern we observed in TSApbmc. Since TS activity is required for DNA synthesis it might be anticipated that these processes are depending on each other and, therefore, show similar patterns.

Strong correlation between TSApbmc and TYMS gene expression in PBMCS clearly suggests that BSV in TS activity is regulated on a transcriptional level. Within cancer tissue, others have found correlations between TS protein and gene expression as well $[44,45]$. One volunteer carried the $G>C$ SNP in the $2 R$ allele and was identified with 2RC/3RC genotype in TYMS. The $2 \mathrm{RC}$ allele has been associated with low TS expression in vitro $[36,46]$. We also found that the TSApbmc for this subject was relatively low. Moreover, we recently showed that patients carrying the $2 \mathrm{RC}$ allele are at strongly increased risk of developing fluoropyrimidine-induced toxicity [9].

DPDpbmc showed a weak negative correlation with DPYD gene expression. A trend towards negative correlation between DPD activity and gene expression was also found in human mucosa tissue [47]. It seems plausible that DPD activity is regulated on a posttranscriptional level, which indicates that DPYD gene expression can not be used for the prediction of the DPD phenotype in PBMCs.

Although various pharmacological methods were used to measure the TS and DPD activity patterns, a drawback of the study might be the relatively small number of individuals. For this reason, we performed mixed-effect modeling to use all available data for full quantitative description of the time course of the markers. Larger studies are needed to assess the associations between DPYD and TYMS polymorphisms and DPD and TS phenotypes more extensively.

Taken together, multiple studies have been performed in order to assess circadian rhythms in DPDApbmc, $U$ and DHU. These studies show differences concerning time of peak levels and magnitude of circadian rhythms. This might be due to limited sample size, variability among populations, and differences in bioanalytical methods. Other factors that are organized in a circadian manner, like exposure to light, intake of food, liver blood flow, body temperature, activity, other enzymes or mediators, may additionally play a role in regulation of circadian rhythmicity of $U$ and DHU plasma levels, TSApbmc and DPDApbmc. 
However, further research is warranted to identify factors that are associated with rhythmicity in DPD and TS.

By extensively validating our developed phenotyping assays we maximized our effort to obtain accurate and representative values for the phenotype markers. We discovered substantial BSV in baseline DPDApbmc, $U$ and DHU plasma levels and large BSV in baseline TSApbmc. Circadian rhythmicity in DPDApbmc was opposite and more prominent compared to rhythmicity in $\mathrm{U}$ and DHU plasma levels. And TSApbmc showed peak activity in the afternoon and trough activity during the night. These results highly suggest possible influence of circadian rhythms on phenotype-guided fluoropyrimidine dosing. Moreover, there might be implications for fluoropyrimidine chronotherapy. Tolerability to fluoropyrimidines in mice has been shown to be largest at time of trough TS and peak DPD activity [26], which should occur during the night according to our results. Levi et al. previously showed superior 5-FU tolerability, when the drug was administered at night [27]. The pharmacological results in the current study support this clinical observation that fluoropyrimidine chronotherapy, with relatively high dose intensity during the night, might show better tolerability.

Capecitabine is usually administered twice daily at a 12-hour interval with equal morning and evening doses. Because of this dosing regimen, circadian rhythms in DPD and TS activity could in particular affect tolerability of capecitabine. We are currently performing a pharmacological study of chronomodulated capecitabine therapy in patients to explore the role of circadian rhythms in DPD and TS activity on treatment tolerability and drug exposure. In this pharmacological study, the morning:evening ratio of the daily capecitabine dose is 3:5 in order to administer high-dose capecitabine in the late evening (http:// www.trialregister.nl, study identifier: NTR4639). In addition, we are exploring the applicability of our phenotype markers with regard to phenotype adjusted fluoropyrimidine treatment in a prospective study (http://www.clinicaltrials. gov, study identifier: NCT02324452). In conclusion, markers for TS and DPD show circadian variability, which offers opportunities for improved fluoropyrimidine treatment safety.

\section{ACKNOWLEDGEMENT}

We would like to thank all the volunteers for their provision of the blood samples needed to conduct this study. 


\section{REFERENCES}

1. Heggie GD, Sommadossi JP, Cross DS, Huster WJ, Diasio RB. Clinical pharmacokinetics of 5-fluorouracil and its metabolites in plasma, urine, and bile. Cancer Res 1987;47:2203-6.

2. Judson IR, Beale PJ, Trigo JM, Aherne $\mathrm{W}$, Crompton $\mathrm{T}$, Jones $\mathrm{D}$, et al. A human capecitabine excretion balance and pharmacokinetic study after administration of a single oral dose of 14C-labelled drug. Invest New Drugs 1999;17:49-56.

3. Thorn CF, Marsh S, Carrillo MW, McLeod $\mathrm{HL}$, Klein TE, Altman RB. PharmGKB summary: fluoropyrimidine pathways. Pharmacogenet Genomics 2011;21:237-42.

4. Longley DB, Harkin DP, Johnston PG. 5-fluorouracil: mechanisms of action and clinical strategies. Nat Rev Cancer 2003;3:330-8.

5. Midgley R, Kerr DJ. Capecitabine: have we got the dose right? Nat Clin Pract Oncol 2009;6:17-24.

6. Rosmarin D, Palles C, Church D, Domingo $E$, Jones A, Johnstone E, et al. Genetic markers of toxicity from capecitabine and other fluorouracil-based regimens: Investigation in the QUASAR2 study, systematic review, and meta-analysis. J Clin Oncol 2014;32:1031-9.

7. Loganayagam A, Arenas Hernandez $M$, Corrigan A, Fairbanks L, Lewis CM, Harper $P$, et al. Pharmacogenetic variants in the DPYD, TYMS, CDA and MTHFR genes are clinically significant predictors of fluoropyrimidine toxicity. Br J Cancer 2013;108:2505-15.

8. Deenen MJ, Tol J, Burylo AM, Doodeman VD, de Boer A, Vincent A, et al. Relationship between single nucleotide polymorphisms and haplotypes in DPYD and toxicity and efficacy of capecitabine in advanced colorectal cancer. Clin Cancer Res 2011;17:3455-68.

9. Meulendijks D, Jacobs BAW, Aliev A, Pluim D, van Werkhoven E, Deenen MJ, et al. Increased risk of severe fluoropyrimidineassociated toxicity in patients carrying a $\mathrm{G}$ to $C$ substitution in the first 28-bp tandem repeat of the thymidylate synthase $2 \mathrm{R}$ allele. Int J Cancer 2015:2-31.

10. Fleming RA, Milano G, Thyss A, Etienne $M C$, Renée N, Schneider M, et al. Correlation between dihydropyrimidine dehydrogenase activity in peripheral mononuclear cells and systemic clearance of fluorouracil in cancer patients. Cancer Res 1992;52:2899-902.

11. Van Kuilenburg $A B P$, Meinsma $R$, Zoetekouw L, Van Gennip AH. Increased risk of grade IV neutropenia after administration of 5-fluorouracil due to a dihydropyrimidine dehydrogenase deficiency: High prevalence of the IVS14+1G>A mutation. Int J Cancer 2002;101:253-8.

12. Milano G, Etienne $M C$, Pierrefite V, Barberi-Heyob M, Deporte-Fety R, Renée N. Dihydropyrimidine dehydrogenase deficiency and fluorouracil-related toxicity. Br J Cancer 1999;79:627-30.

13. van Kuilenburg $A B$, Haasjes J, Richel DJ, Zoetekouw L, Van Lenthe H, De Abreu RA, et al. Clinical implications of dihydropyrimidine dehydrogenase (DPD) deficiency in patients with severe 5-fluorouracil-associated toxicity: identification of new mutations in the DPD gene. Clin Cancer Res 2000;6:470512.

14. Sistonen J, Büchel $B$, Froehlich $T K$, Kummer $D$, Fontana $S$, Joerger $M$, et al. Predicting 5-fluorouracil toxicity: DPD 
genotype and 5,6-dihydrouracil:uracil ratio. Pharmacogenomics 2014;15:1653-66.

15. Zhou ZW, Wang GQ, Wan D Sen, Lu $\mathrm{ZH}$, Chen YB, Li S, et al. The dihydrouracil/ uracil ratios in plasma and toxicities of 5-fluorouracil-based adjuvant chemotherapy in colorectal cancer patients. Chemotherapy 2007;53:127-31.

16. Gamelin $M$, Boisdron-Celle $M$, GuérinMeyer V, Delva R, Lortholary A, Genevieve $F$, et al. Correlation between uracil and dihydrouracil plasma ratio, fluorouracil (5-FU) pharmacokinetic parameters, and tolerance in patients with advanced colorectal cancer: A potential interest for predicting 5-FU toxicity and determining optimal 5-FU dosage. J Clin Oncol 1999;17:1105-10.

17. Boisdron-Celle $M$, Remaud $G$, Traore S, Poirier A, Gamelin L, Morel A, et al. 5-Fluorouracil-related severe toxicity: a comparison of different methods for the pretherapeutic detection of dihydropyrimidine dehydrogenase deficiency. Cancer Lett 2007;249:271-82.

18. Thomas F, Hennebelle I, Delmas C, Lochon I, Dhelens C, Garnier Tixidre C, et al. Genotyping of a family with a novel deleterious DPYD mutation supports the pretherapeutic screening of DPD deficiency with dihydrouracil/uracil ratio. Clin Pharmacol Ther 2016;99:235-42.

19. Launay M, Dahan L, Duval M, Rodallec A, Milano $G$, Duluc $M$, et al. Beating the odds: Efficacy and toxicity of dihydropyrimidine dehydrogenase-driven adaptive dosing of 5-FU in patients with digestive cancer. $\mathrm{Br} J$ Clin Pharmacol 2016;81:124-30.

20. Jiang $\mathrm{H}$, Lu J, Ji J. Circadian rhythm of dihydrouracil/uracil ratios in biological fluids: a potential biomarker for dihydropyrimidine dehydrogenase levels. $\mathrm{Br} J$ Pharmacol 2004;141:616-23.

21. Harris BE, Song R, Soong SJ, Diasio RB. Relationship between dihydropyrimidine dehydrogenase activity and plasma 5-fluorouracil levels with evidence for circadian variation of enzyme activity and plasma drug levels in cancer patients receiving 5 -fluorouracil by protracted continuous infusion. Cancer Res 1990;50:197-201.

22. Petit E, Milano G, Levi F, Thyss A, Bailleul F, Schneider M. Circadian rhythm-varying plasma concentration of 5 -fluorouracil during a five-day continuous venous infusion at a constant rate in cancer patients. Cancer Res 1988;48:1676-9.

23. Van Kuilenburg $A B$, Poorter RL, Peters GJ, Van Gennip AH, Van Lenthe H, Stroomer $\mathrm{AE}$, et al. No circadian variation of dihydropyrimidine dehydrogenase, uridine phosphorylase, beta-alanine, and 5-fluorouracil during continuous infusion of 5-fluorouracil. Adv Exp Med Biol 1998;431:811-6.

24. Bjarnason GA, Jordan RC, Wood $P A$, Li Q, Lincoln DW, Sothern RB, et al. Circadian expression of clock genes in human oral mucosa and skin: association with specific cell-cycle phases. Am J Pathol 2001;158:1793-801.

25. Lincoln DW, Hrushesky WJM, Wood PA. Circadian organization of thymidylate synthase activity in normal tissues: A possible basis for 5-fluorouracil chronotherapeutic advantage. Int J Cancer 2000;88:479-85.

26. Wood PA, Du-Quiton J, You S, Hrushesky 
WJM. Circadian clock coordinates cancer cell cycle progression, thymidylate synthase, and 5-fluorouracil therapeutic index. Mol Cancer Ther 2006;5:2023-33.

27. Lévi F, Zidani R, Misset J. Randomised multicentre trial of chronotherapy with oxaliplatin, fluorouracil, and folinic acid in metastatic colorectal cancer. Lancet 1997;350:681-6.

28. Pluim $D$, Jacobs BAW, Deenen MJ, Ruijter AEM, van Geel RMJM, Burylo AM, et al. Improved pharmacodynamic assay for dihydropyrimidine dehydrogenase activity in peripheral blood mononuclear cells. Bioanalysis 2015;7:519-29.

29. Pluim D, Schilders KAA, Jacobs BAW, Vaartjes D, Beijnen JH, Schellens JHM. Pharmacodynamic assay of thymidylate synthase activity in peripheral blood mononuclear cells. Anal Bioanal Chem 2013;405:2495-503.

30. Pluim $D$, Jacobs $B A W$, Krähenbühl $M D$, Ruijter AEM, Beijnen JH, Schellens JHM. Correction of peripheral blood mononuclear cell cytosolic protein for hemoglobin contamination. Anal Bioanal Chem 2013;405:2391-5.

31. Livak KJ, Schmittgen TD. Analysis of relative gene expression data using realtime quantitative PCR and the 2(-Delta Delta $C(T))$ Method. Methods 2001;25:402-8.

32. Beal $S$, Sheiner L. NONMEM user guides. Ellicott City, Maryland, USA: Icon Development Solutions, 1989.

33. Keizer RJ, Karlsson MO, Hooker A. Modeling and Simulation Workbench for NONMEM: Tutorial on Pirana, PsN, and Xpose. CPT Pharmacometrics Syst Pharmacol 2013;2:e50.
34. R Development Core Team. R: A Language and Environment for Statistical Computing. Vienna, Austria: R Foundation for Statistical Computing, 2016.

35. Diedenhofen B, Musch J. cocor: A Comprehensive Solution for the Statistical Comparison of Correlations. PLoS One 2015;10:e0121945.

36. Gusella M, Bolzonella C, Crepaldi G, Ferrazzi E, Padrini R. A novel $G / C$ singlenucleotide polymorphism in the double 28-bp repeat thymidylate synthase allele. Pharmacogenomics J 2006;6:421-4.

37. Zeng Z-L, Sun J, Guo L, Li S, Wu M, Qiu F, et al. Circadian rhythm in dihydropyrimidine dehydrogenase activity and reduced glutathione content in peripheral blood of nasopharyngeal carcinoma patients. Chronobiol Int 2005;22:741-54.

38. Innominato PF, Lévi FA, Bjarnason GA. Chronotherapy and the molecular clock: Clinical implications in oncology. Adv Drug Deliv Rev 2010;62:979-1001.

39. Boivin DB, James FO, Wu A, ChoPark PF, Xiong $\mathrm{H}$, Sun ZS. Circadian clock genes oscillate in human peripheral blood mononuclear cells. Blood 2003;102:4143-5. 40. Ebisawa $T$, Numazawa $K$, Shimada $H$, Izutsu H, Sasaki T, Kato N, et al. Self-sustained circadian rhythm in cultured human mononuclear cells isolated from peripheral blood. Neurosci Res 2010;66:223-7.

41. Krugluger $W$, Brandstaetter A, Kállay E, Schueller J, Krexner E, Kriwanek S, et al. Regulation of genes of the circadian clock in human colon cancer: reduced period-1 and dihydropyrimidine dehydrogenase transcription correlates in high-grade tumors. Cancer Res 2007;67:7917-22. 
42. Naguib FN, Soong SJ, el Kouni $\mathrm{MH}$. Circadian rhythm of orotate phosphoribosyltransferase, pyrimidine nucleoside phosphorylases and dihydrouracil dehydrogenase in mouse liver. Possible relevance to chemotherapy with 5-fluoropyrimidines. Biochem Pharmacol 1993;45:667-73.

43. Smaaland R, Laerum OD, Lote $K$, Sletvold $\mathrm{O}$, Sothern RB, Bjerknes R. DNA synthesis in human bone marrow is circadian stage dependent. Blood 1991;77:2603-11.

44. Kristensen $\mathrm{MH}$, Weidinger $\mathrm{M}$, Bzorek $\mathrm{M}$, Pedersen $\mathrm{PL}$, Mejer J. Correlation between thymidylate synthase gene variants, RNA and protein levels in primary colorectal adenocarcinomas. J Int Med Res 2010;38:484-97.

45. Monica V, Familiari U, Chiusa L, Rossi G, Novero D, Busso S, et al. Messenger RNA and protein expression of thymidylate synthase and DNA repair genes in thymic tumors. Lung Cancer 2013;79:228-35.

46. Mandola M V, Stoehlmacher J, MullerWeeks S, Cesarone G, Yu MC, Lenz HJ, et al. A novel single nucleotide polymorphism within the $5^{\prime}$ tandem repeat polymorphism of the thymidylate synthase gene abolishes USF-1 binding and alters transcriptional activity. Cancer Res 2003.

47. Uetake H, Ichikawa W, Takechi T, Fukushima M, Nihei Z, Sugihara K. Relationship between intratumoral dihydropyrimidine dehydrogenase activity and gene expression in human colorectal cancer. Clin Cancer Res 1999;5:2836-9. 


\section{SUPPLEMENTARY MATERIAL}

Table S1. The specificity of thymine in heat-treated PBMC lysate protein $(20 \mu \mathrm{g})$.

\begin{tabular}{cccc}
$\begin{array}{c}\text { Nominal thymine } \\
\text { concentration }(\mu \mathrm{M})\end{array}$ & $\begin{array}{c}\text { Average measured thymine } \\
\text { concentration }(\mu \mathrm{M})\end{array}$ & $\begin{array}{c}\text { Deviation } \\
(\%)\end{array}$ & $\begin{array}{c}\mathrm{CV} \\
(\%)\end{array}$ \\
2.5 & 2.49 & -0.3 & 0.2 \\
12.5 & 13.28 & 6.3 & 0.4 \\
50 & 53.24 & 6.5 & 0.2 \\
\hline
\end{tabular}

Abbreviation: PBMC, peripheral blood mononuclear cells; CV, coefficient of variation
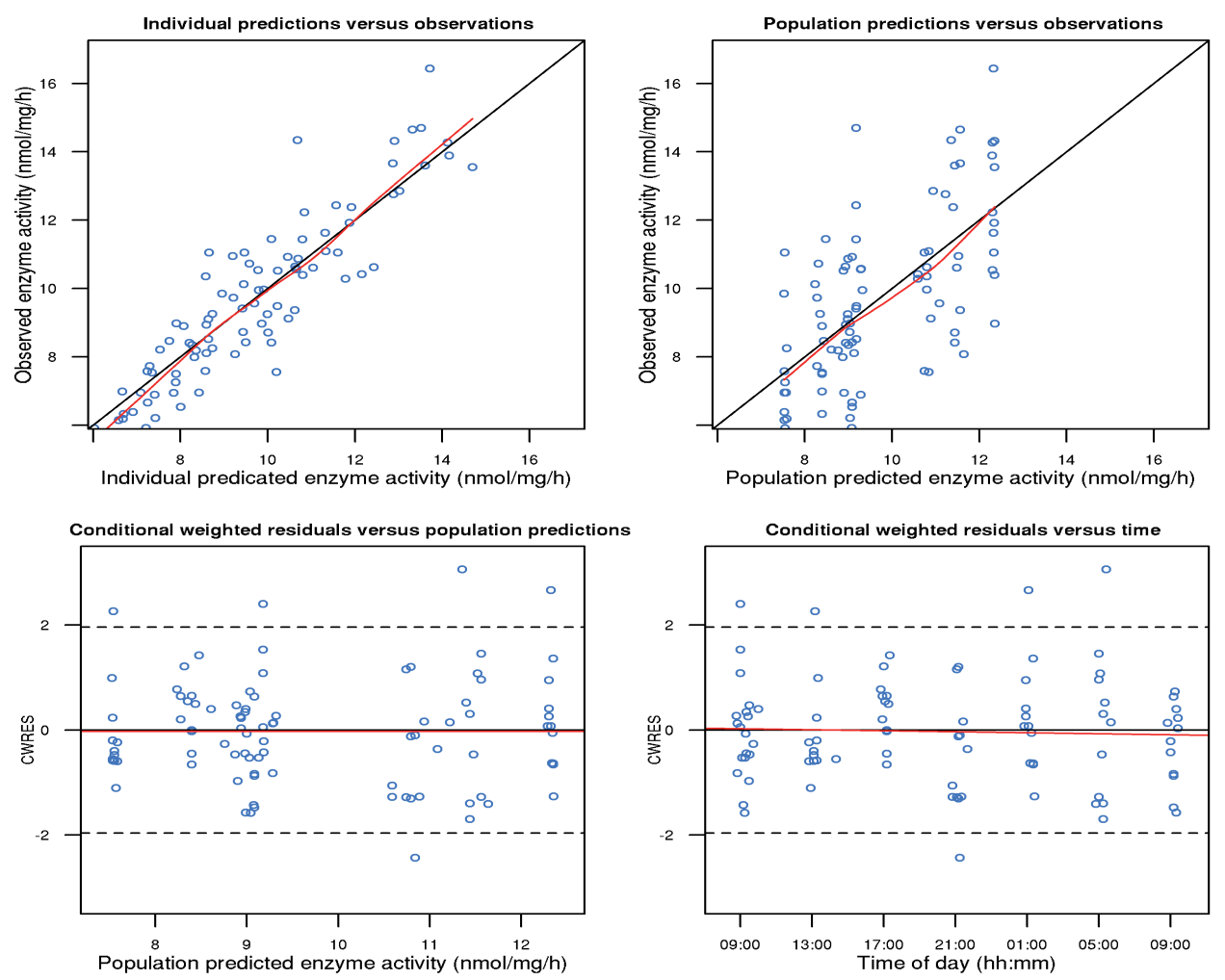

Figure S1. Goodness of fit plots for circadian model predicted dihydropyrimidine dehydrogenase activity in peripheral blood mononuclear cells. Grey dots represented observed data and black lines represent the trend of the data.

Abbreviation: CWRES = conditional weighed residuals. 

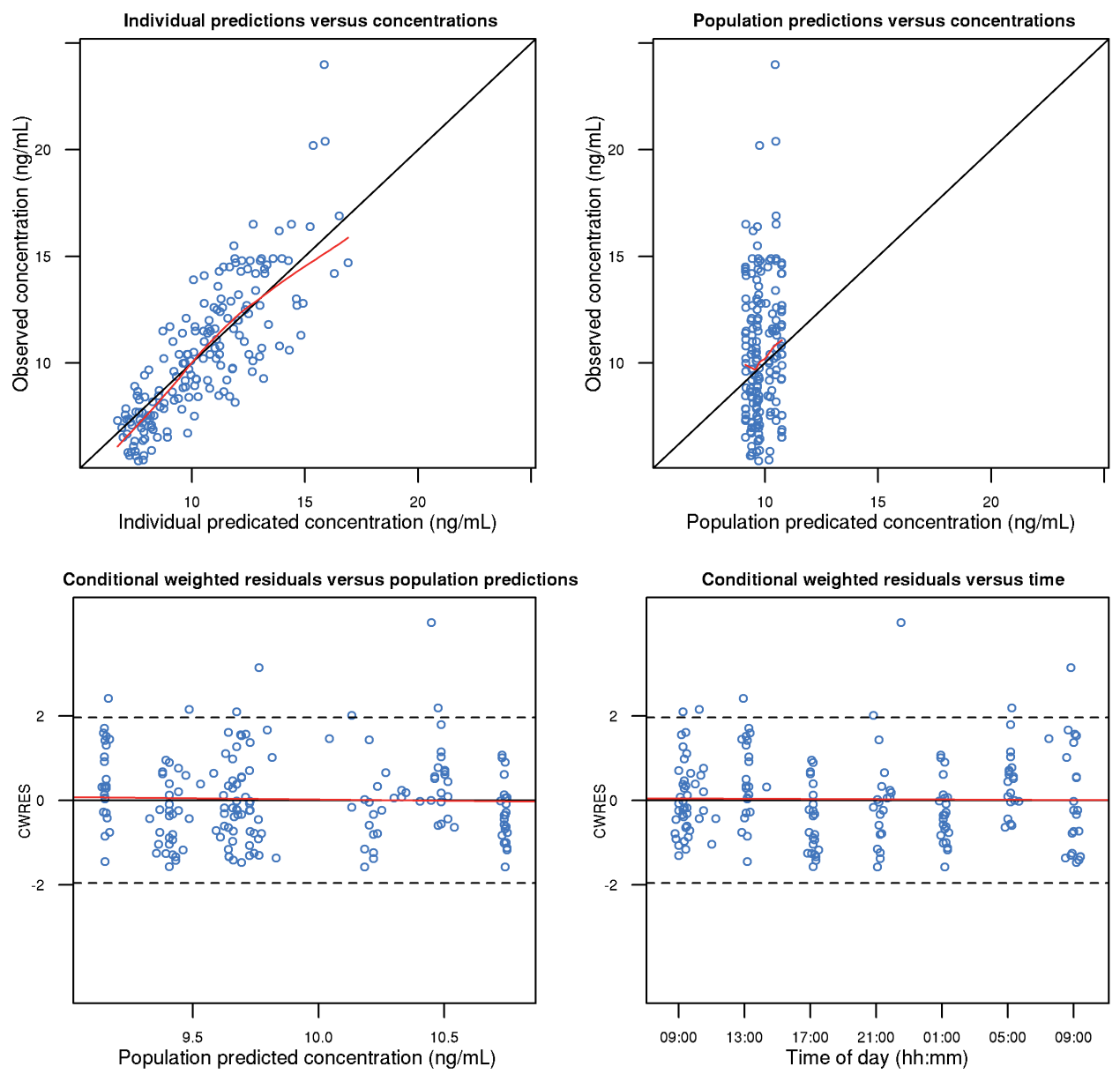

Figure S2. Goodness of fit plots for circadian model predicted uracil plasma levels. Grey dots represented observed data and black lines represent the trend of the data. Abbreviation: CWRES = conditional weighed residuals. 

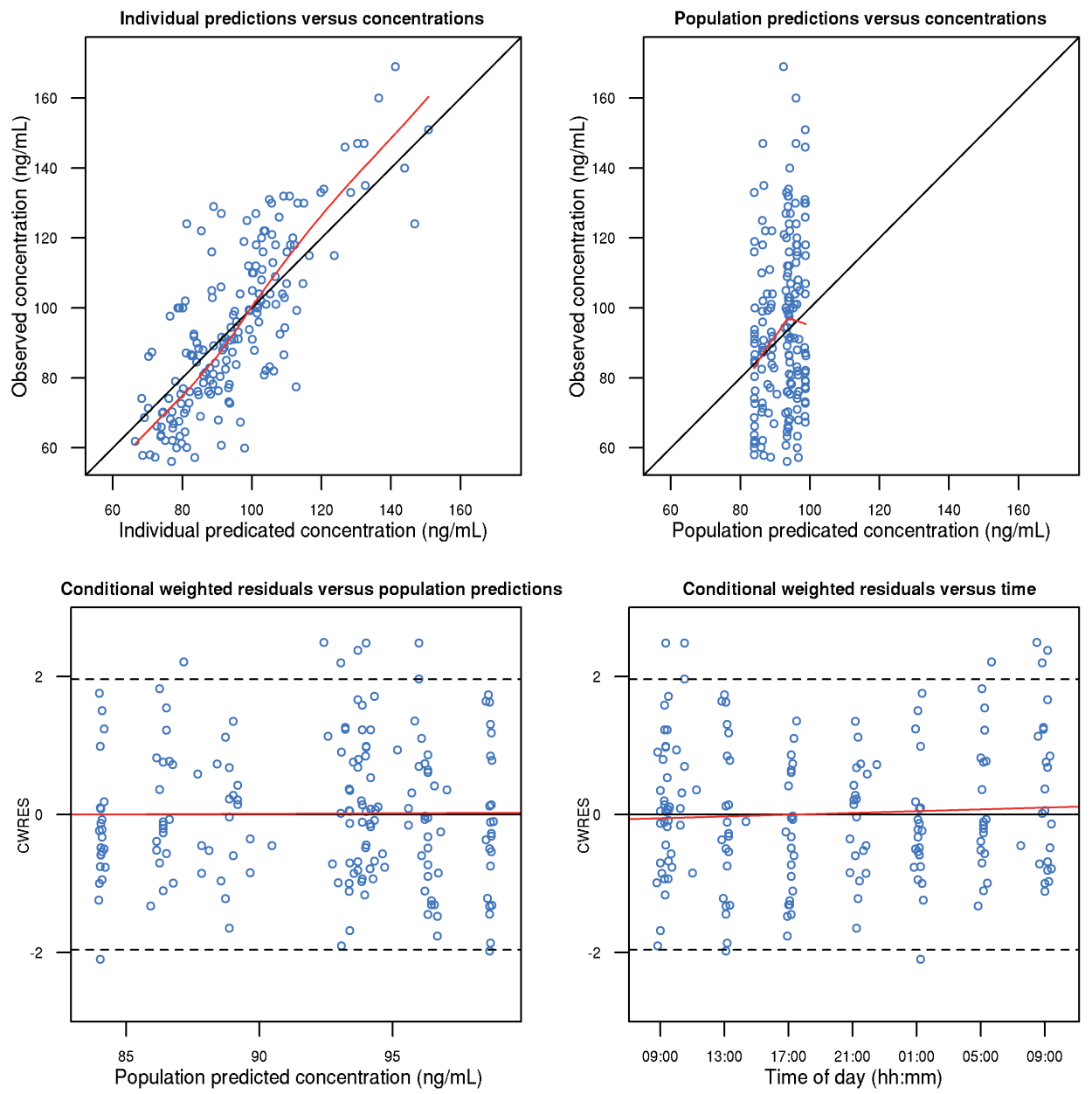

Figure S3. Goodness of fit plots for circadian model predicted dihydrouracil plasma levels. Grey dots represented observed data and black lines represent the trend of the data.

Abbreviation: CWRES = conditional weighed residuals. 

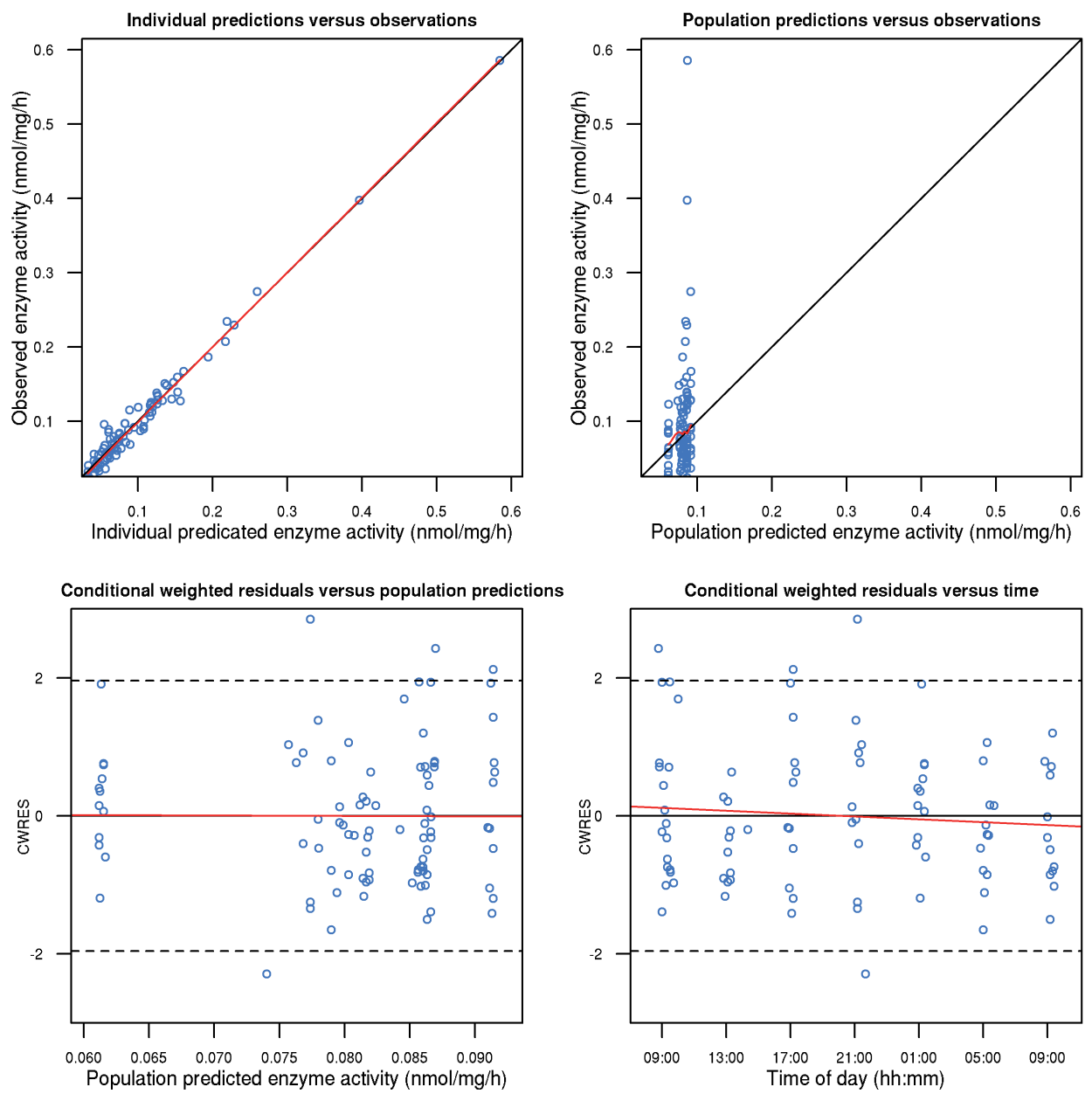

Figure S4. Goodness of fit plots for circadian model predicted thymidylate synthase activity in peripheral blood mononuclear cells. Grey dots represented observed data and black lines represent the trend of the data.

Abbreviation: CWRES = conditional weighed residuals. 


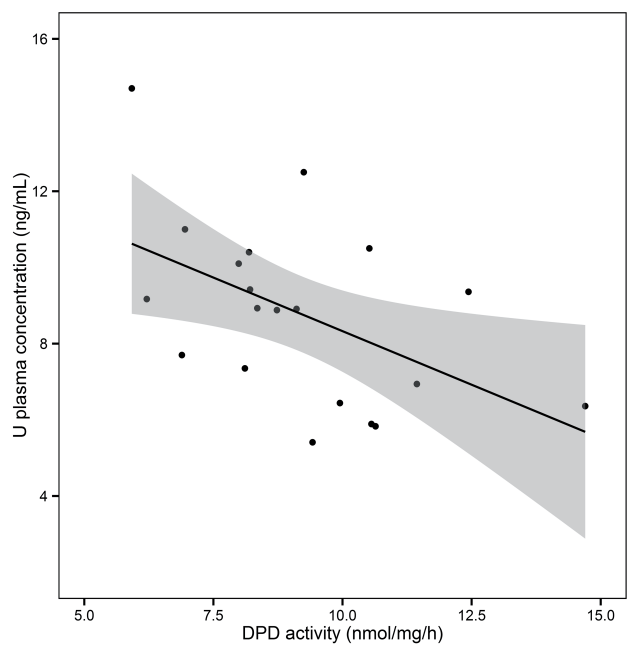

Figure S5. Correlation between baseline dihydropyrimidine dehydrogenase activity in peripheral blood mononuclear cells and uracil plasma levels $\left(r^{2}=0.26, p=0.02\right)$ in 20 healthy volunteers. The shaded area represents the $95 \%$ confidence interval of the line.

Abbreviation: DPD = dihydropyrimidine dehydrogenase, $U$ = uracil.

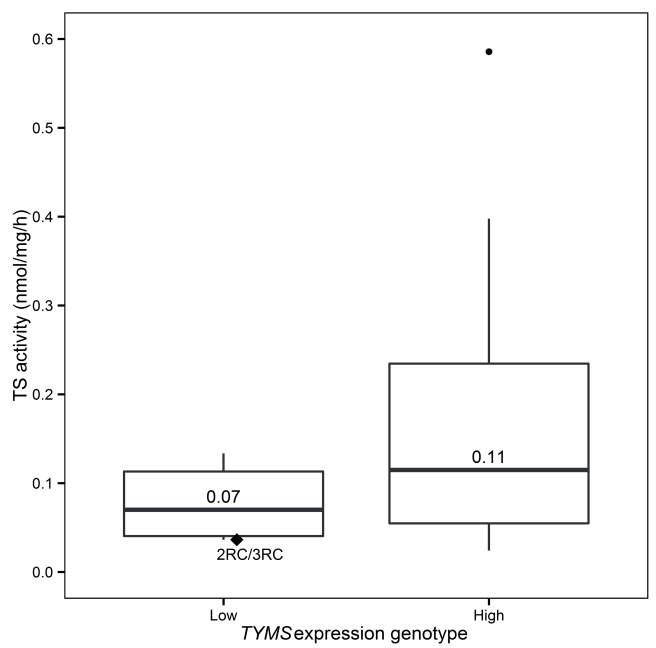

Figure S6. Baseline thymidylate synthase activity in peripheral blood mononuclear cells for low $(n=10)$ and high ( $n=9)$ TYMS expression genotypes. Median TS activity per group is shown in the plot. Range in TS activity was highest for the TYMS high expression group. Difference in TS activity between groups was not statistically significant $(p=0.32)$. TS activity of the volunteer with the $2 \mathrm{RC} / 3 \mathrm{RC}$ genotype is separately shown (black diamond).

Abbreviations: TS = thymidylate synthase. 

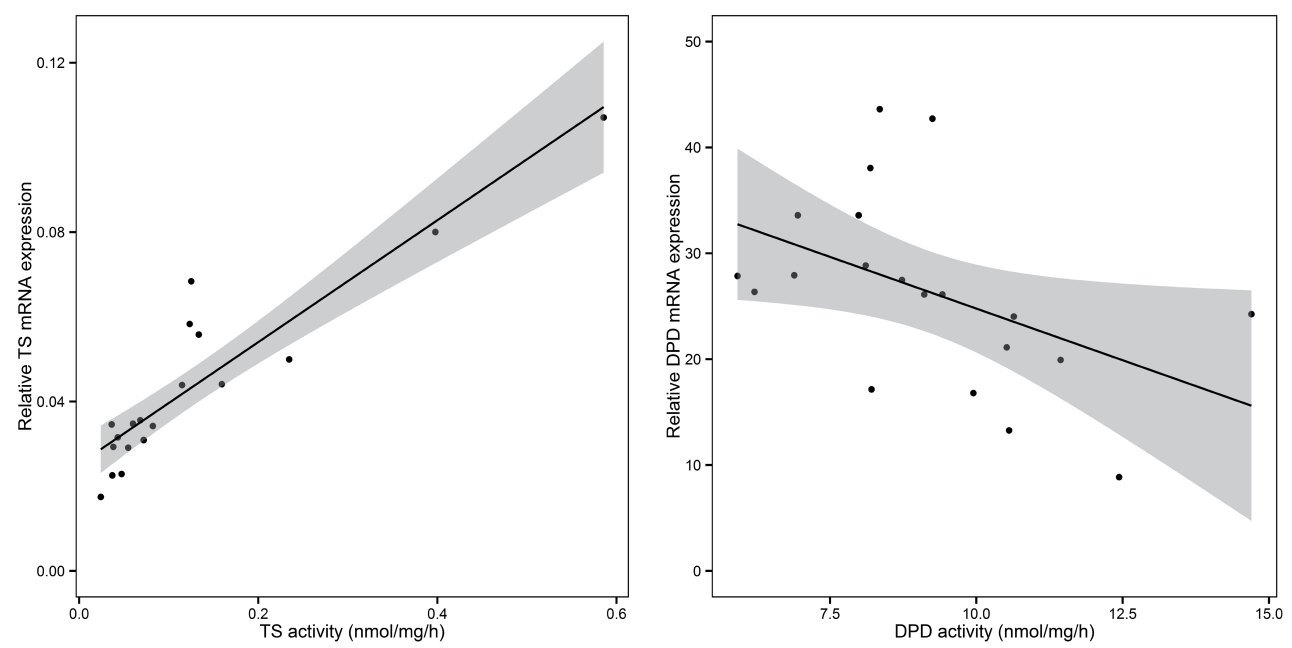

Figure S7. Strong positive correlation between thymidylate synthase activity and gene expression $\left(r^{2}=0.84 ; p<0.001\right)$ (left panel) and weak negative correlation between dihydropyrimidine dehydrogenase activity and gene expression $\left(r^{2}=0.22 ; p=0.04\right)$ (right panel) in human peripheral blood mononuclear cells obtained from 20 healthy volunteers. Shaded areas represent $95 \%$ confidence intervals of the lines.

Abbreviations: $\mathrm{TS}$ = thymidylate synthase, DPD = dihydropyrimidine dehydrogenase. 
Clinical and preclinical application of biomarker methods 


\section{CHAPTER 2 \\ Clinical and preclinical application of biomarker methods}

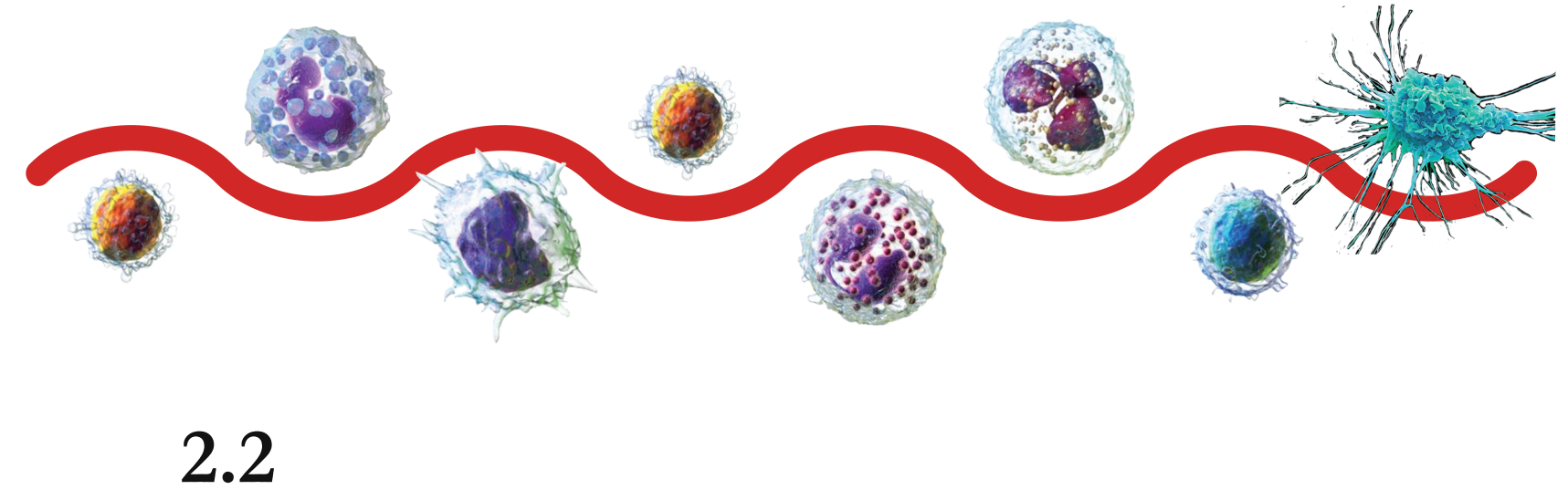

Phase I pharmacological study of continuous chronomodulated capecitabine treatment

Jeroen Roosendaal, Bart A.W. Jacobs, Dick Pluim, Hilde Rosing, Niels de Vries, Erik van Werkhovend, Bastiaan Nuijen, Jos $\mathrm{H}$. Beijnen, Alwin D.R. Huitema, Jan H.M. Schellens, Serena Marchetti

Pharmaceutical Research 2020;37:89-99 


\section{ABSTRACT}

Purpose: Capecitabine is an oral pre-pro-drug of the anti-cancer drug 5 -fluorouracil (5-FU). The biological activity of the 5-FU degrading enzyme, dihydropyrimidine dehydrogenase (DPD), and the target enzyme thymidylate synthase (TS), are subject to circadian rhythmicity in healthy volunteers. The aim of this study was to determine the maximum tolerated dose (MTD), doselimiting toxicity (DLT), safety, pharmacokinetics (PK) and pharmacodynamics (PD) of capecitabine therapy adapted to this circadian rhythm (chronomodulated therapy).

Methods: Patients aged $\geq 18$ years with advanced solid tumours potentially benefitting from capecitabine therapy were enrolled. A classical dose escalation $3+3$ design was applied. Capecitabine was administered daily without interruptions. The daily dose was divided in morning and evening doses that were administered at 9:00 $\mathrm{h}$ and 24:00 $\mathrm{h}$, respectively. The ratio of the morning to the evening dose was 3:5 (morning : evening). PK and PD were examined on treatment days 7 and 8.

Results: A total of 25 patients were enrolled. The MTD of continuous chronomodulated capecitabine therapy was established at 750/1250 mg/m²/ day, and was generally well tolerated. Circadian rhythmicity in the plasma PK of capecitabine, dFCR, dFUR and 5-FU was not demonstrated. TS activity was induced and DPD activity demonstrated circadian rhythmicity during capecitabine treatment.

Conclusion: The MTD of continuous chronomodulated capecitabine treatment allows for a $20 \%$ higher dose intensity compared to the approved regimen (1250 $\mathrm{mg} / \mathrm{m}^{2}$ bi-daily on day 1-14 of every 21-day cycle). Chronomodulated treatment with capecitabine is promising and could lead to improved tolerability and efficacy of capecitabine. 


\section{INTRODUCTION}

Capecitabine is an oral pre-pro-drug of 5-fluorouracil (5-FU) and is frequently used for the treatment of colorectal, breast and gastric cancer. After administration, capecitabine is rapidly and completely absorbed and converted into subsequently 5'-deoxy-5-fluorocytidine (dFCR), 5'-deoxy-5-fluorouridine (dFUR) and 5-FU via a three-step enzymatic pathway involving carboxyl esterase, cytidine deaminase and thymidine phosphorylase (TP), respectively [1]. Approximately $80 \%$ of 5-FU is catabolized to inactive metabolites. A small proportion of 5-FU is intracellularly anabolized to the cytotoxic metabolites 5 -fluorouridine $5^{\prime}$-triphosphate (FUTP), 5-fluoro-2'-deoxyuridine 5'-triphosphate (FdUTP), and 5-fluoro-2'-deoxyuridine 5 '-monophosphate (FdUMP) [2,3]. The main mechanism of action is inhibition of the enzyme thymidylate synthase (TS), which is essential for DNA synthesis $[4,5]$. Dihydropyrimidine dehydrogenase (DPD) is the enzyme that catalyzes 5-FU degradation into dihydro-5-FU. Dihydro-5-FU is eventually converted to fluoro- $\beta$ alanine (FBAL), which is cleared renally $[1,6]$.

The recommended dose (RD) of capecitabine is $1250 \mathrm{mg} / \mathrm{m}^{2}$ twice daily (BID) on day 1-14 of a 21-day cycle [7]. In early clinical phase I studies, both continuous and intermittent dosing regimens were examined $[8,9]$. For continuous capecitabine treatment, the RD was $666 \mathrm{mg} / \mathrm{m}^{2}$ BID [9], which is a $20 \%$ lower dose intensity than for intermittent treatment [8]. Intermittent and continuous treatment schedules have been compared in a phase II clinical trial and showed similar efficacy [10]. Although the intermittent dosing regimen was recommended for further clinical evaluation, diarrhoea, hand-foot syndrome, vomiting, nausea and stomatitis were more frequently reported with the intermittent schedule than the continuous capecitabine treatment [10].

The time of dose administration could also influence tolerability of capecitabine. In previous studies, 5-FU metabolism demonstrated circadian rhythmicity [11-13]. Chronomodulated and constant-rate infusion with intravenous 5-FU have been compared in a randomized trial [14]. Chronomodulation was achieved by nocturnal administration of 5-FU, since peak activity of DPD and trough TS activity were expected during the night. The 5-FU chronomodulated schedule was more effective and less toxic than constant-rate infusion of 5-FU [14].

Recently, we examined the circadian rhythmicity in DPD and TS activity in healthy volunteers [15]. At 2.00 a.m. a peak in DPD activity (which was about 50\% higher compared with afternoon activity) and trough TS activity were reported 
[15]. Adaptation to the circadian rhythm of DPD may result in a more constant 5-FU exposure. This might benefit patients, as exposure to 5-FU at trough TS activity has been associated with improved 5-FU safety and tolerability [16]. Based on these data, we hypothesized that chronomodulated capecitabine therapy would improve treatment tolerability by administering the highest capecitabine dose at night during maximum DPD activity and trough TS activity. Since continuous BID capecitabine treatment was better tolerated than intermittent therapy [10], chronomodulation was expected to result in even better tolerability, which potentially could lead to increased dose intensity.

The aim of this phase I study was to determine the maximum tolerated dose (MTD), dose-limiting toxicity (DLT), pharmacokinetics (PK) and pharmacodynamics (PD) of continuous chronomodulated BID capecitabine therapy.

\section{METHODS}

\section{Patient selection}

Patients aged $\geq 18$ years, with advanced solid tumours potentially benefiting from capecitabine treatment and adequate bone marrow, hepatic and renal function were eligible for enrolment. Patients with known DPD deficiency caused by genetic polymorphisms in DPYD (DPYD*2A or c.2846A $>$ T) were excluded.

\section{Study design}

This was a phase I, open label, dose-escalation study. Patients received capecitabine tablets (150 mg and $500 \mathrm{mg}$ ) on day 1-21 of a 21-day cycle until disease progression, unacceptable toxicity, or patient refusal. Capecitabine was administered with water within 30 minutes after a light meal, both in the morning and late evening. A classical 3+3 dose escalation design was applied. [17] The capecitabine dose was escalated according to five predefined dose levels $\left(1000,1275,1600,2000\right.$ and $2550 \mathrm{mg} / \mathrm{m}^{2}$ total daily dose). The total daily dose was divided in morning and evening doses that were administered at 9:00 $\mathrm{h}$ and 24:00 $\mathrm{h}$ ( $\pm 1 \mathrm{~h}$ ), respectively, according to a 3:5 (morning : evening) ratio, based on the 3:5 ratio in trough to peak DPD activity observed in healthy volunteers [15]. The MTD was expanded to a maximum of 12 patients. DLT period was defined as the first three weeks of treatment. Toxicity was assessed weekly during the first treatment cycle and at the end of each subsequent cycle according to the 
Common Terminology Criteria for Adverse Events (CTC-AE) version 4.03. Tumour response was evaluated every two treatment cycles according to the Response Evaluation Criteria in Solid Tumors (RECIST) version 1.1 [18]. The study protocol was approved by the local ethical committee and was performed in compliance with Good Clinical Practice guidelines and the WHO Declaration of Helsinki. The study was registered in the Dutch Trial Registry (http://www.trialregister.nl, study identifier: NTR4639).

\section{Pharmacokinetic analyses}

In order to examine circadian variability, the plasma PK of capecitabine, dFCR, dFUR, 5-FU, and FBAL were examined during day- and nighttime. Peripheral blood was collected at pre-dose and $0.5,1,1.5,2,3,5,11,15 \mathrm{~h}$ after capecitabine intake at 9:00 $\mathrm{h}$ on day 7 of treatment and during the following night (day 8), 0.5, 1, 1.5, 2, 3, 5 and $9 \mathrm{~h}$ after capecitabine intake at 24:00 h. Blood samples were collected in lithium-heparinized tubes, which were centrifuged for $10 \mathrm{~min}$ at $1500 \mathrm{~g}$ and $4{ }^{\circ} \mathrm{C}$ after collection. Isolated plasma was stored at $-70{ }^{\circ} \mathrm{C}$ until further analysis.

As an exploratory objective, the intracellular PK of FUTP, FdUTP and FdUMP in peripheral blood mononuclear cells (PBMCs) were determined at pre-dose, 1.5 and $3 \mathrm{~h}$ after capecitabine intake at 9:00h on day 7 of treatment. For this, PBMCs were isolated from peripheral heparinized blood using Ficoll-paque density gradient and counted using previously described procedures [19]. Capecitabine and metabolite concentrations were quantified using validated liquid chromatography coupled to tandem mass spectrometric (LC-MS/MS) methods $[19,20]$.

Non-compartmental plasma PK analyses (NCA) were performed using a validated script in $\mathrm{R}$ version 3.3.0 [21]. The following individual PK parameters were extracted: the maximum plasma concentrations $(\mathrm{Cmax})$, the time to reach maximum plasma concentration (tmax), and the area under the plasma concentration-time curve up to $5 \mathrm{~h}$ post-dose (AUCO-5h) for capecitabine, dFCR, dFUR and 5-FU, and the AUC extrapolated to infinity (AUCO-inf) for FBAL. Paired t-tests were performed for statistical comparison of the AUCO-5h after morning and evening administration of capecitabine.

\section{Pharmacodynamic analyses}

Circadian variability in DPD and TS activity were examined. DPD and TS activity in 
PBMCs (DPDApbmc and TSApbmc) were determined at several time points during the day: at pre-dose, 1.5, 11 and $15 \mathrm{~h}$ after capecitabine intake at 9:00 $\mathrm{h}$ on day 7 and $1.5 \mathrm{~h}$ after capecitabine intake at 24:00 h (day 8). In addition, DPDApbmc and TSApbmc were determined at screening (within 3 days before treatment). PBMCs were isolated from peripheral heparinized blood using Ficoll-Paque density gradient centrifugation and stored at $-80{ }^{\circ} \mathrm{C}$ until further analysis. DPDApbmc and TSApbmc were determined using validated radio-assays [22-24].

The applicability of the dihydrouracil to uracil ( $\mathrm{DHU}: \mathrm{U}$ ) ratio in plasma, as a marker for DPD activity, was explored using the same plasma samples as for PK analysis. Uracil and dihydrouracil levels were quantified using a validated LC-MS/ MS method [25], after which DHU:U molar ratios were calculated.

To explore the treatment effect of capecitabine on the TP phenotype, TP activity in PBMCs (TPApbmc) was determined at screening, day 7 at pre-dose (9:00 h), and end of treatment using a previously developed assay. [26]

Variability in DPDApbmc and TSApbmc was examined using repeated measures analysis of variance (rANOVA) and the nonparametric Friedman test, respectively. The difference between TPApbmc at screening and day 7 was examined by the paired t-test. Statistical difference was considered significant at $p$-values $<0.05$.

\section{RESULTS}

In total, 25 patients were enrolled in the study between July 2014 and February 2019, of which 22 patients were evaluable for safety. Patient characteristics are summarized in Table I. The median (range) number of administered treatment cycles was 4 (1-11).

\section{Treatment tolerability}

Overall, continuous chronomodulated capecitabine therapy as well tolerated. The most commonly reported toxicities were fatigue (68\%), hand-foot syndrome $(55 \%)$, nausea (45\%), and diarrhoea (36\%). An overview of the observed adverse events possibly, probably or definitely related to study treatment is summarized in Table II.

A total of six serious adverse events (SAEs) were reported, of which one (i.e., grade 3 diarrhoea) was possibly related to study treatment. Other SAEs were grade 3 lleus $(3 x)$, grade 3 urinary tract infection $(1 x)$, and grade 4 haemorrhage 
Table I. Demographic and disease characteristics.

\begin{tabular}{|c|c|c|}
\hline Characteristic & $\begin{array}{c}\text { Number of } \\
\text { patients }\end{array}$ & $\%$ \\
\hline $\begin{array}{l}\text { Total number of patients } \\
\text { Gender }\end{array}$ & 25 & 100 \\
\hline Male & 11 & 44 \\
\hline Female & 14 & 56 \\
\hline Ethnic origin & & \\
\hline Caucasian & 24 & 96 \\
\hline Creole & 1 & 4 \\
\hline Age & & \\
\hline Median (range), years & \multicolumn{2}{|c|}{$64(40-78)$} \\
\hline \multicolumn{3}{|l|}{ WHO performance status } \\
\hline 0 & 12 & 48 \\
\hline 1 & 12 & 48 \\
\hline 2 & 1 & 4 \\
\hline \multicolumn{3}{|l|}{ Primary tumor type } \\
\hline Colorectal & 10 & 40 \\
\hline$S C L C$ & 2 & 8 \\
\hline Head and neck & 2 & 8 \\
\hline Other & 11 & 44 \\
\hline \multicolumn{3}{|l|}{ Stage of cancer } \\
\hline Locally advanced & 1 & 5 \\
\hline Metastatic & 24 & 95 \\
\hline \multicolumn{3}{|l|}{ Prior treatment } \\
\hline Chemotherapy & 24 & 96 \\
\hline Radiotherapy & 13 & 52 \\
\hline Surgery & 16 & 64 \\
\hline Immunotherapy & 12 & 48 \\
\hline
\end{tabular}


Table II. Treatment-related adverse events in all cycles by dose level. Treatment-related adverse events observed in $\geq 5 \%$ of patients treated with chronomodulated capecitabine or $\geq$ grade 3 .

\begin{tabular}{|c|c|c|c|c|c|c|c|c|c|c|}
\hline \multirow{3}{*}{$\begin{array}{l}\text { Number of patients } \\
\text { CTCAE grade toxicity }\end{array}$} & Dose level 1 & Dose level 2 & \multicolumn{2}{|c|}{ Dose level 3} & \multicolumn{2}{|c|}{ Dose level 4} & \multicolumn{2}{|c|}{ Dose level 5} & \multicolumn{2}{|c|}{ Total } \\
\hline & $n=3$ & $n=3$ & \multicolumn{2}{|l|}{$n=3$} & \multicolumn{2}{|l|}{$n=8$} & \multicolumn{2}{|l|}{$n=5$} & \multicolumn{2}{|c|}{$n=22$} \\
\hline & Gr. 1-2 Gr. 3 & Gr. 1-2 Gr. 3 & Gr. 1-2 & Gr. 3 & Gr. 1-2 & Gr. 3 & Gr. 1-2 & Gr. 3 & $\mathrm{~N}$ & $\%$ \\
\hline \multicolumn{11}{|l|}{ Toxicity } \\
\hline Fatigue & 1 & 2 & 3 & & 6 & & 2 & 1 & 15 & 68 \\
\hline Hand-foot syndrome & & 1 & 1 & & 5 & & 2 & 3 & 12 & 55 \\
\hline Nausea & 1 & 1 & 3 & & 3 & & 2 & & 10 & 45 \\
\hline Diarrhoea & 2 & & & 1 & 1 & & 2 & 2 & 8 & 36 \\
\hline Anorexia & 1 & 1 & 1 & & 2 & & 1 & & 6 & 27 \\
\hline Peripheral sensory neuropathy & & 1 & & & 3 & & 1 & & 5 & 23 \\
\hline Anemia & & & & & 1 & 2 & 1 & & 4 & 18 \\
\hline Vomiting & & & 2 & & 1 & & 1 & & 4 & 18 \\
\hline Blood bilirubin increased & 1 & & 1 & & 1 & & & & 3 & 14 \\
\hline Dry skin & & & & & 2 & & 1 & & 3 & 14 \\
\hline Dysgeusia & & & 1 & & 1 & & 1 & & 3 & 14 \\
\hline Dry mouth & & & & & 1 & & 1 & & 2 & 9 \\
\hline Oral mucositis & & & & & 1 & & 1 & & 2 & 9 \\
\hline Nail discoloration & & & & & & & 2 & & 2 & 9 \\
\hline Neutropenia & & & & & 1 & & 1 & & 2 & 9 \\
\hline Rash & & & 1 & & & & 1 & & 2 & 9 \\
\hline
\end{tabular}

Abbreviations: CTCAE, Common Terminology Criteria for Adverse Events; Gr., grade; $n$, number of subjects. 

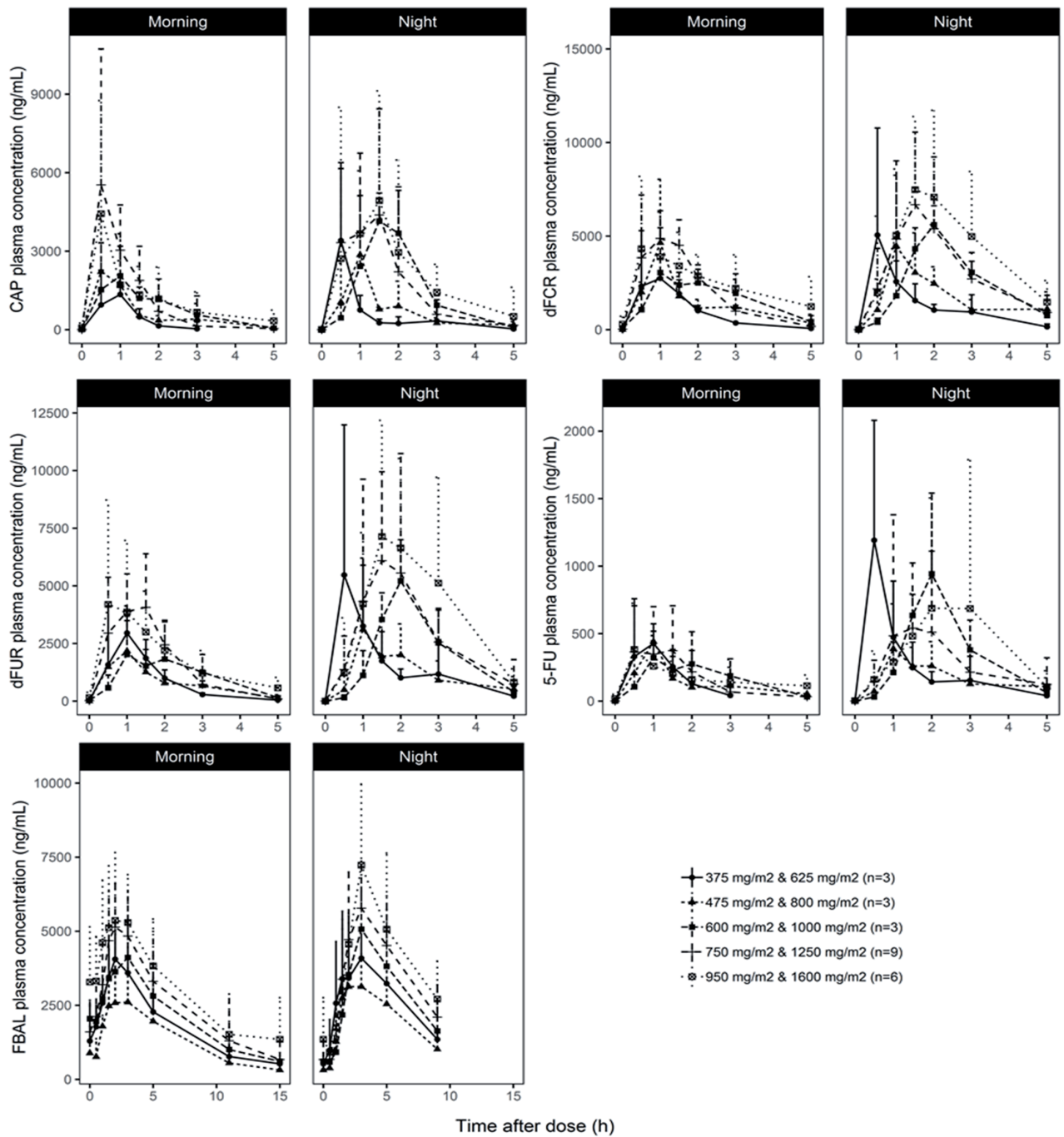

Figure 1. Mean (+SD) plasma concentration-time profiles of capecitabine (CAP), 5'-deoxy5-fluorocytidine (dFCR), 5'-deoxy-5-fluorouridine (dFUR), 5-fluorouracil (5-FU) and fluoro- $\beta$-alanine (FBAL) after dose administration in the morning (at 9:00 h) and at night (24:00 h) for dose level 1-5 on treatment day 7 and 8 , respectively. $(n=24)$ 

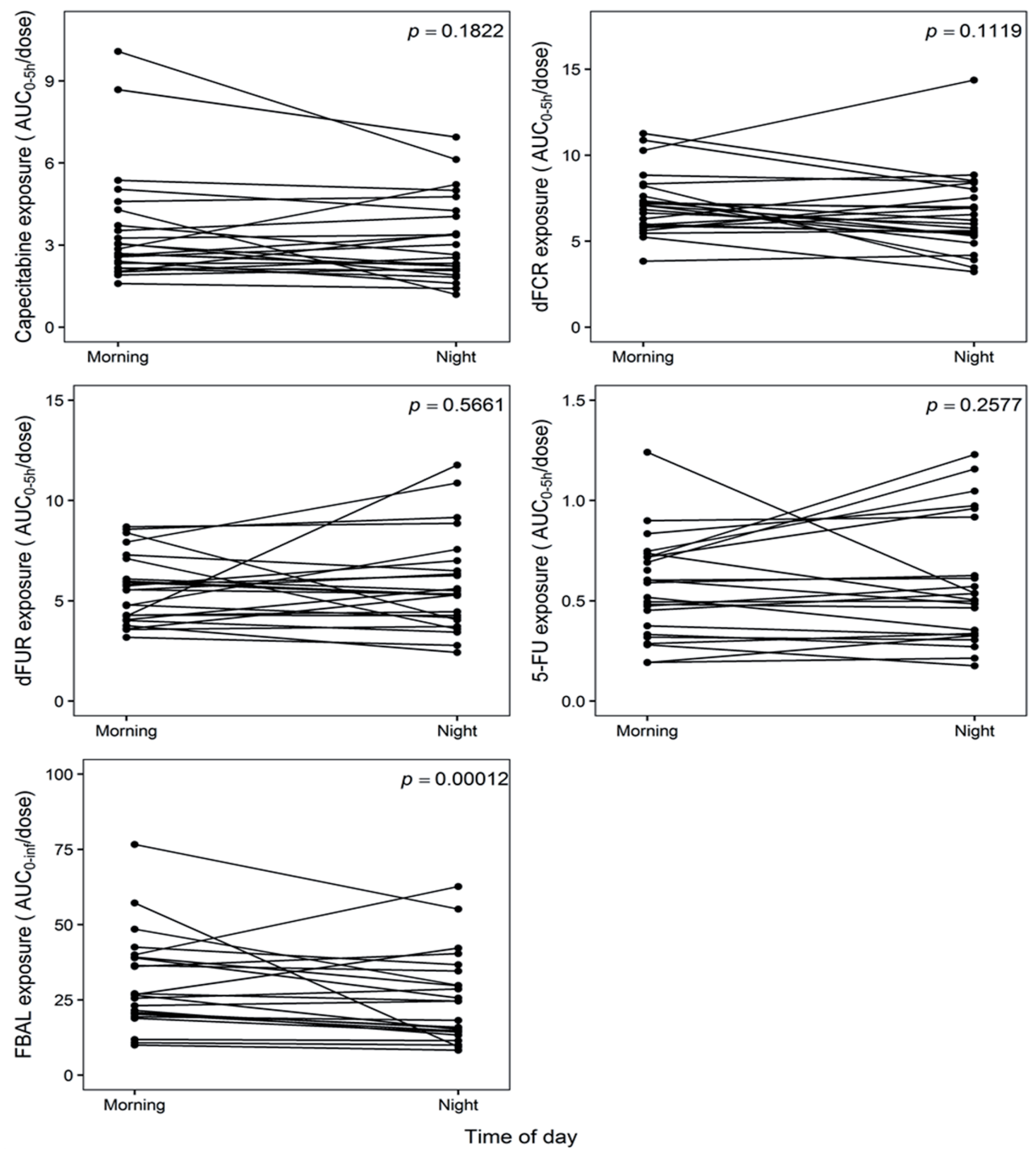

Figure 2. Dose-normalized area under the plasma concentration-time curve up to $5 \mathbf{h}$ (AUC0-5h, $\mu \mathrm{g}^{*} \mathrm{~h} / \mathrm{mL}$ ) for capecitabine (CAP), 5'-deoxy-5-fluorocytidine (dFCR), 5'-deoxy5-fluorouridine (dFUR), 5-fluorouracil (5-FU) and extrapolated from zero to infinity (AUC0-inf) for fluoro- $\beta$-alanine (FBAL) after dose administration in the morning (at 9:00 h) and in night (24:00 h) on treatment day 7 and 8 , respectively $(n=24)$ 


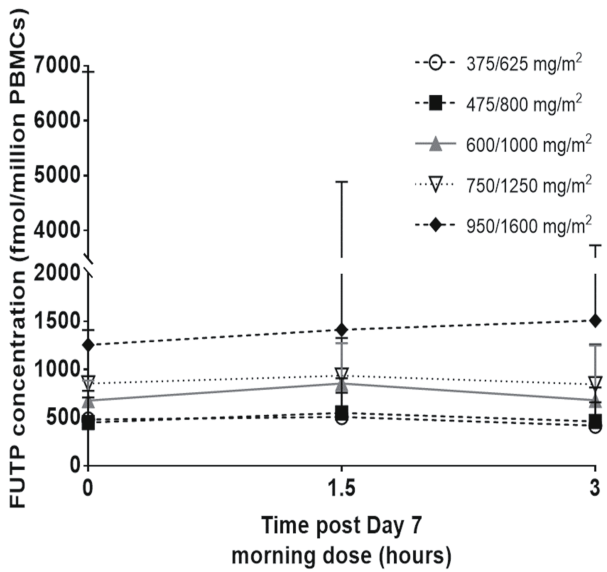

Figure 3. Intracellular peripheral blood mononuclear cell concentrations of 5-fluorouridine-5'-triphosphate (FUTP) after 7 days of chronomodulated capecitabine treatment at indicated morning/evening doses (mean +SD)

Table III. Overview of dose levels and dose-limiting toxicities (DLTs)*

\begin{tabular}{|c|c|c|c|}
\hline $\begin{array}{l}\text { Dose } \\
\text { level }\end{array}$ & $\begin{array}{c}\text { Capecitabine } \\
\left(\mathrm{mg} / \mathrm{m}^{2}\right) \\
\text { at 9:00 h/ } \\
24: 00 \mathrm{~h}\end{array}$ & $\begin{array}{l}\text { Number } \\
\text { of } \\
\text { patients }\end{array}$ & $\begin{array}{c}\text { Patients } \\
\text { experiencing } \\
\text { DLT }\end{array}$ \\
\hline 1 & $375 / 625$ & 3 & None \\
\hline 2 & $475 / 800$ & 3 & None \\
\hline 3 & $600 / 1000$ & 3 & None \\
\hline 4 & $750 / 1250$ & 8 & None \\
\hline 5 & $950 / 1600$ & 5 & 2 \\
\hline
\end{tabular}

* DLT was defined as any of the following events occurring in the first 3 weeks of treatment considered to be at least possibly, probably or definitely related to study treatment: $\geq$ grade 3 non-hematologic toxicity (other than alopecia, inadequately treated nausea, vomiting or diarrhoea), thrombocytopenia grade 4 or grade 3 associated with bleeding events, grade 4 neutropenia, grade 3 febrile neutropenia, $\geq$ grade 3 anaemia, and/or a dose interruption of more than 7 days due to toxicity.

$\S$ A total of 22 patients out of the 25 enrolled were evaluable for safety. One patient in dose level 5 was not evaluable for DLT, due intake of an incorrect capecitabine dose during the first 7 days of treatment. Two patients only received one treatment cycle due to symptomatic deterioration related to quick disease progression. 

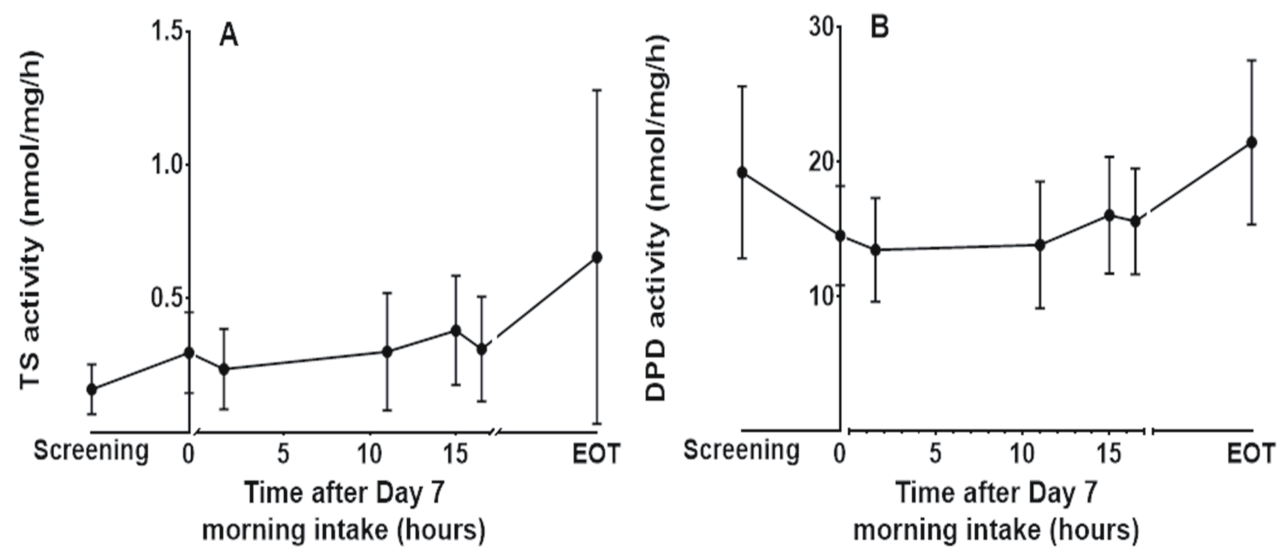

Figure 4. (A) Thymidylate synthase (TS) and (B) dihydropyrimidine dehydrogenase (DPD) activity (mean $\pm S D$ ) in peripheral blood mononuclear at screening, day $7 /$ day 8 , and end of treatment (EOT) in patients receiving chronomodulated capecitabine treatment $(\mathrm{n}=24)$. Capecitabine was administered at $\mathrm{t}=0 \mathrm{~h}$ and $\mathrm{t}=15 \mathrm{~h}$.

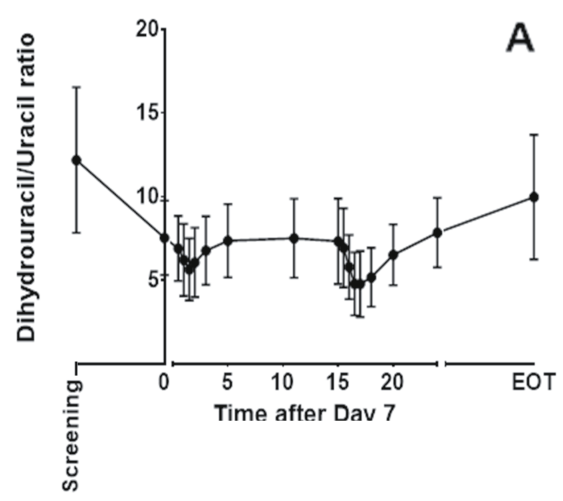

Figure 5. (A) The dihydrouracil:uracil plasma ratio, and (B) uracil and (C) dihydrouracil plasma levels at screening, day $7 /$ day 8 , and end of treatment (EOT) in patients receiving chronomodulated capecitabine treatment (mean $\pm S D, n=24$ ). Capecitabine was administered at $\mathrm{t}=\mathrm{Oh}$ and $t=15 h$.
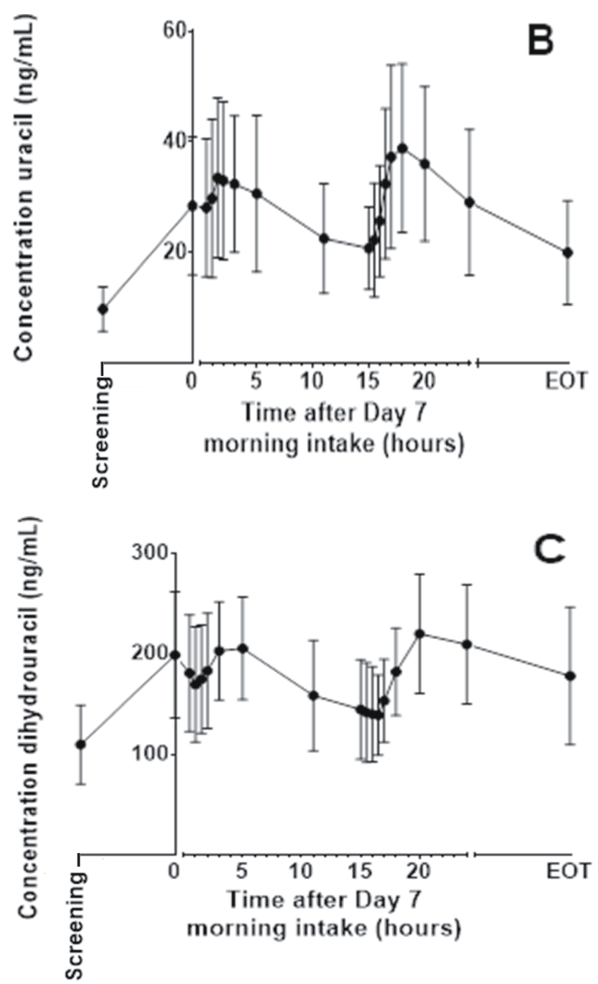
(1x).

A total of 14 dose reductions during treatment were reported in 10 patients, caused by, hand-foot syndrome $(13 x)$, diarrhoea $(1 x)$, and anaemia $(1 x)$. Median time to first dose reduction was 30 days (range 17-70). Dose delays occurred in 4 patients, due to hand-foot syndrome $(4 \mathrm{x})$ and neutropenia (1x).

\section{Dose-limiting toxicity and maximum tolerated dose}

Table III gives an overview of the examined dose levels and experienced DLTs. Three DLTs were observed in two patients at the highest dose level (grade 3 handfoot syndrome $(2 x)$ and grade 3 diarrhoea (1x)). TheMTD was established at 2000 $\mathrm{mg} / \mathrm{m}^{2} /$ day, with no experienced DLTs at this dose level.

\section{Pharmacokinetics}

The mean plasma concentration-time profiles for capecitabine, dFCR, dFUR, 5-FU, and FBAL are shown per dose level and time of day in Fig. 1. Results of the NCA are summarized in Supplementary Table 1. The dose-normalized

AUC0-5h are shown in Fig. 2. As shown in this figure, dosenormalized exposure to capecitabine, dFCR, dFUR and 5-FU were not statistically different between daytime and nighttime. For FBAL, daytime exposure was significantly higher than at night $(p=0.00012)$. Results on the intracellular PKat day 7 are shown in Fig. 3. For all patients, only FUTP was detectable in PBMCs. FUTP concentrations increased per dose level, with a 4.1-fold increase in dose level 5 as compared to dose level 1.

\section{Pharmacodynamics}

TSApbmc is shown in Fig. 4a. The median (range) TSApbmc at screening was 0.134 (0.035-0.584) $\mathrm{nmol} / \mathrm{mg} / \mathrm{h}$ and was significantly induced to $0.301(0.030-0.677$ ) $\mathrm{nmol} / \mathrm{mg} / \mathrm{h}$ on day 7 at 9:00 $\mathrm{h}(\mathrm{p}<0.0001)$. TSApbmc declined again $1.5 \mathrm{~h}$ after the dose administration on day 7 ( $p<0.001)$. Maximum TSApbmc was measured at 15 $\mathrm{h}$ post-dose $(24: 00 \mathrm{~h})$ with median (range) activity of $0.346(0.101-0.729) \mathrm{nmol} /$ $\mathrm{mg} / \mathrm{h}$, which was significantly higher than the observed TSApbmc $1.5 \mathrm{~h}$ after dose administration at 9:00 $\mathrm{h}(\mathrm{p}<0.0001)$.

DPDApbmc is shown in Fig. $4 \mathrm{~b}$. The mean ( $\pm \mathrm{SD}$ ) DPDApbmc at screening was $19.2( \pm 6.4) \mathrm{nmol} / \mathrm{mg} / \mathrm{h}$, which was significantly higher than day 7 at 9:00 $\mathrm{h}(\mathrm{P}<$ 
0.001). Significant intra-day variabilities in DPDApbmc trough and peak activity were observed at 10:30 $\mathrm{h}$ and 24:00 $\mathrm{h}(\mathrm{p}<0.0001)$, and were $13.5( \pm 3.8)$ and 16.1 $( \pm 4.3) \mathrm{nmol} / \mathrm{mg} / \mathrm{h}$, respectively.

The DHU:U ratio (mean \pm SD) in plasma decreased from 12.2 ( \pm 4.4 ) at screening to 7.5 ( \pm 2.2) on day 7 at 09:00 h (Fig. 5). Pronounced intra-day variability was observed, with mean DHU:U ratio trough levels at 10:30 $\mathrm{h}$ and 02:00 h.

There was moderate between-subject variability in TPApbmc at screening with a mean $( \pm S D)$ value of $2676( \pm 1260) \mathrm{nmol} / \mathrm{mg} / \mathrm{h}$. There was no significant change in TPApbmc observed during treatment (Supplementary Fig. 1).

\section{Tumour response evaluation}

Three partial remissions (12\%) in patients with breast, ovarian, and neuroendocrine cancer, respectively, were reported. No complete remissions were observed. Thirteen patients (52\%) had stable disease as best response. Eight patients (33\%) had progressive disease at the first response evaluation.

\section{DISCUSSION}

The present phase I study evaluated MTD, DLT, safety, PK and PD of continuous chronomodulated capecitabine therapy. The total capecitabine dose was stepwise increased from $1000 \mathrm{mg} / \mathrm{m}^{2} /$ day up to $2550 \mathrm{mg} / \mathrm{m}^{2} /$ day. The MTD was established at $2000 \mathrm{mg} / \mathrm{m}^{2} /$ day $\left(750 / 1250 \mathrm{mg} / \mathrm{m}^{2} /\right.$ day), with major observed adverse events being grade 1-2 handfoot syndrome and fatigue. The safety profile overall and at the MTD was in line with previous phase I-III studies of continuous and intermittent capecitabine therapy [9, 10, 28]. The establishedMTD of 2000 $\mathrm{mg} / \mathrm{m}^{2} /$ day exceeds the previously determined recommended daily dose for regular treatment with continuous capecitabine of $1331 \mathrm{mg} / \mathrm{m}^{2} /$ day $(666 \mathrm{mg} /$ $\mathrm{m}^{2}$ BID) [10]. Furthermore, the dose intensity at the MTD was $20 \%$ higher than the dose intensity of the currently approved regimen $\left(1250 \mathrm{mg} / \mathrm{m}^{2}\right.$ BID on day 1-14 of every 21 -day cycle), and even $50 \%$ higher than the dose intensity of the intermittent regimen most often used in clinical practice $\left(1000 \mathrm{mg} / \mathrm{m}^{2}\right.$ on day $1-14$ of every 21-day cycle).

Several chronomodulated treatment strategies for capecitabine have been evaluated in phase II studies [29-33]. In these studies, the total daily capecitabine dose was divided in two or three dosing moments with highest capecitabine 
dose administered between 18:00-20:00 h [30,31], at 23:00 h $[29,32]$, or at 24:00 $\mathrm{h}$ [33]. In these studies, chronomodulated capecitabine was combined with oxaliplatin [29-33], and radiotherapy [33]. The examined chronomodulated capecitabine regimens were well tolerated, except in the study performed by Qvortrup et al. [30]. They did not find improved treatment tolerability of chronomodulated capecitabine in combination with oxaliplatin compared to standard capecitabine plus oxaliplatin [30]. The reason for this could be that $80 \%$ of the capecitabine daily dose was administered between 18:00 and 20:00 h. According to our finding [16], high-dose capecitabine administration between 18:00 and 20:00 $\mathrm{h}$ could be too early to achieve adequate chronomodulation. Indeed, at that time of day, DPD activity is around the baseline value. Due to rapid elimination [2], most of 5-FU is probably degraded before DPD peak activity is encountered. A phase I study of intermittent capecitabine chronotherapy, in which $25 \%$ of daily dose was administered at $8: 00 \mathrm{~h}, 25 \%$ at $18: 00 \mathrm{~h}$ and $50 \%$ at 23:00 $\mathrm{h}$, on day 1-14 of each 21-day cycle, demonstrated good treatment tolerability [34]. At the declared MTD level of $2750 \mathrm{mg}$ capecitabine per day, only one out of nine patients experienced DLT. Our current findings are in line with previously reported results on chronomodulated capecitabine therapy.

In our study circadian rhythmicity in the dose normalized plasma exposure of capecitabine, dFCR, dFURand 5-FUwas not observed. FBAL exposure was significantly higher during daytime. This may be due to relatively high FBAL concentrations already at pre-dose (9:00 h). Most likely, this finding does not have any clinical implications, since FBAL is an inactive metabolite.

In all treated patients, only FUTP concentrations were quantifiable in PBMCs, with no concentrations above the limit of detection for FdUTP and FdUMP. This is in line with previous research, where only FUTP could be quantified after capecitabine therapy. [35] Interestingly, intracellular FUTP concentrations increase per dose level, with highest levels observed in two patients experiencing DLT.

In healthy volunteers, we previously found that DPD activity in PBMCs demonstrated pronounced circadian rhythmicity, while in the liver, this effect was only minor, as measured by the DHU:U ratio in plasma [16]. Circadian rhythmicity might be regulated in a tissue-specificmanner [36]. It could be that DPD activity in liver tissue is not subject to noticeable circadian rhythmicity, explaining the absence of circadian rhythmicity in 5-FU plasma exposure. On the other hand, peripheral 5-FUmetabolism could be regulated in a circadian manner, which could contribute to improved treatment tolerability. 
TSApbmc demonstrated peak activity at night, opposite to the trough activity at night observed in healthy volunteers [16]. TSApbmc was partly inhibited 1.5 $\mathrm{h}$ after each dose of capecitabine. This temporary reduction in TSApbmc is most likely a direct consequence of target inhibition by the intracellularly activated metabolite FdUMP. Previous research demonstrated that TS protein expression is subject to auto-regulation by binding to its own mRNA, preventing protein translation. Binding of FdUMP to TS inhibits this mRNA binding and results in an increase of TS protein levels [37]. As a consequence, capecitabine therapy could lead to TSApbmc upregulation and a disturbance of the circadian rhythm, as observed in this trial.

Although less pronounced than in healthy volunteers, DPDApbmc displayed a circadian rhythm during capecitabine treatment. This finding supports our rationale for capecitabine chronotherapy. The less pronounced DPDApbmc rhythmicity as compared to healthy volunteers may may be caused by capecitabine treatment, or by other factors such as disease status [38]. As for TSApbmc, a partial inhibition of DPDApbmc was observed $1.5 \mathrm{~h}$ after each capecitabine dose. This temporary decrease may be caused by competition between intracellular 5-FU and the ${ }^{3} \mathrm{H}$-Thymine substrate used for the DPDApbmc assay.

Both the DPDApbmc and the DHU:U plasma ratio decreased between screening and day 7 of therapy. In addition, a temporary decrease in the DHU:U plasma ratio was observed following capecitabine administration, inversely related to 5-FU exposure in plasma. This last finding is most likely explained by competition between endogenous uracil and 5-FU for DPD conversion. This potential treatment effect should be taken into account when the DPD phenotype is explored during capecitabine treatment.

\section{CONCLUSION}

Chronomodulation represents a promising strategy as it could lead to improved tolerability and efficacy of capecitabine through achievement of an increased dose intensity in comparison with the currently approved dose regimen. Although questions on PK/PD relationships remain, the results observed in terms of observed MTD by implementation of a chronomodulated capecitabine treatment are encouraging. Additional research is required to evaluate treatment efficacy using the continuous chronomodulated treatment regimen. If further confirmed, 
this concept could lead to development of a delayed release formulation of capecitabine to allow for nocturnal peak exposure to 5-FU in a patient-friendly way. 


\section{REFERENCES}

1. Reigner B, Blesch K, Weidekamm E. Clinical pharmacokinetics of capecitabine. Clin Pharmacokinet 2001;40:85-104.

2. Diasio RB, Harris BE. Clinical pharmacology of 5-fluorouracil. Clin Pharmacokinet 1989;16:215-37.

3. Longley DB, Harkin DP, Johnston PG. 5-fluorouracil: mechanisms of action and clinical strategies. Nat Rev Cancer 2003;3:330-8.

4. Wilson PM, Danenberg P V, Johnston PG, Lenz $\mathrm{H}-\mathrm{J}$, Ladner RD. Standing the test of time: targeting thymidylate biosynthesis in cancer therapy. Nat Rev Clin Oncol Nature Publishing Group; 2014;11:282-98.

5. de Bono JS, Twelves CJ. The oral fluorinated pyrimidines. Invest New Drugs 2001;19:41-59.

6. Judson IR, Beale PJ, Trigo JM, Aherne $\mathrm{W}$, Crompton $\mathrm{T}$, Jones $\mathrm{D}$, et al. A human capecitabine excretion balance and pharmacokinetic study after administration of a single oral dose of 14C-labelled drug. Invest New Drugs 1999;17:49-56.

7. Midgley R, Kerr DJ. Capecitabine: have we got the dose right? Nat Clin Pract Oncol 2009;6:17-24.

8. Mackean $M$, Planting $A$, Twelves $C$, Schellens J, Allman D, Osterwalder B, et al. Phase I and pharmacologic study of intermittent twice-daily oral therapy with capecitabine in patients with advanced and/or metastatic cancer. J Clin Oncol 1998;16:2977-85.
9. Budman DR, Meropol NJ, Reigner B, Creaven PJ, Lichtman SM, Berghorn E, et al. Preliminary studies of a novel oral fluoropyrimidine carbamate: capecitabine. J Clin Oncol 1998;16:1795-802.

10. Van Cutsem E, Findlay M, Osterwalder B, Kocha W, Dalley D, Pazdur R, et al. Capecitabine, an oral fluoropyrimidine carbamate with substantial activity in advanced colorectal cancer: results of a randomized phase II study. J Clin Oncol 2000;18:1337-45.

11. Harris BE, Song R, Soong SJ, Diasio RB. Relationship between dihydropyrimidine dehydrogenase activity and plasma 5-fluorouracil levels with evidence for circadian variation of enzyme activity and plasma drug levels in cancer patients receiving 5 -fluorouracil by protracted continuous infusion. Cancer Res 1990;50:197-201.

12. Petit E, Milano G, Levi F, Thyss A, Bailleul F, Schneider M. Circadian rhythm-varying plasma concentration of 5-fluorouracil during a five-day continuous venous infusion at a constant rate in cancer patients. Cancer Res 1988;48:1676-9.

13. Fleming GF, Schumm P, Friberg G, Ratain MJ, Njiaju UO, Schilsky RL. Circadian variation in plasma 5 -fluorouracil concentrations during a 24 hour constantrate infusion. BMC Cancer 2015;15:1075.

14. Lévi F, Zidani R, Misset J, Organization I. Randomised multicentre trial of chronotherapy with oxaliplatin , fluorouracil , and folinic acid in metastatic colorectal 
cancer. Lancet 1997;350:681-6.

15. Jacobs BAW, Deenen MJ, Pluim D, van Hasselt JGC, Krähenbühl MD, van Geel RMJM, et al. Pronounced between-subject and circadian variability in thymidylate synthase and dihydropyrimidine dehydrogenase enzyme activity in human volunteers. $\mathrm{Br} \mathrm{J}$ Clin Pharmacol 2016;82:706-16

16. Lévi F, Okyar A, Dulong $S$, Innominato PF, Clairambault J. Circadian Timing in Cancer Treatments. Annu Rev Pharmacol Toxicol 2010;50:377-421.

17. Le Tourneau C, Lee JJ, Siu LL. Dose escalation methods in phase $\mathrm{i}$ cancer clinical trials. J. Natl. Cancer Inst 2009;101:708-20.

18. Eisenhauer EA, Therasse $P$, Bogaerts J, Schwartz LH, Sargent D, Ford R, et al. New response evaluation criteria in solid tumours: revised RECIST guideline (version 1.1). Eur J Cancer 2009;45:228-47.

19. Derissen EJB, Hillebrand MJX, Rosing $\mathrm{H}$, Schellens JHM, Beijnen JH. Development of an LC-MS/MS assay for the quantitative determination of the intracellular 5-fluorouracil nucleotides responsible for the anticancer effect of 5-fluorouracil. J Pharm Biomed Anal 2015;110:58-66.

20. Deenen MJ, Rosing $\mathrm{H}$, Hillebrand MJ, Schellens JHM, Beijnen JH. Quantitative determination of capecitabine and its six metabolites in human plasma using liquid chromatography coupled to electrospray tandem mass spectrometry. J Chromatogr B 2013;913-914:30-40.
21. R Development Core Team. R: A Language and Environment for Statistical Computing. Vienna, Austria: R Foundation for Statistical Computing 2016;

22. Pluim $D$, Jacobs $B A$, Deenen $M J$, Ruijter AE, Van Geel RM, Burylo AM, et al. Improved pharmacodynamic assay for dihydropyrimidine dehydrogenase activity in peripheral blood mononuclear cells. Bioanalysis 2015;7:519-29.

23. Pluim D, Schilders KAA, Jacobs BAW, Vaartjes D, Beijnen JH, Schellens JHM. Pharmacodynamic assay of thymidylate synthase activity in peripheral blood mononuclear cells. Anal Bioanal Chem 2013;405:2495-503.

24. Pluim $D$, Jacobs BAW, Krähenbühl MD, Ruijter AEM, Beijnen JH, Schellens JHM. Correction of peripheral blood mononuclear cell cytosolic protein for hemoglobin contamination. Anal Bioanal Chem 2013;405:2391-5.

25. Jacobs BAW, Rosing $\mathrm{H}$, de Vries $\mathrm{N}$, Meulendijks D, Henricks LM, Schellens JHM, et al. Development and validation of a rapid and sensitive UPLC-MS/MS method for determination of uracil and dihydrouracil in human plasma. J Pharm Biomed Anal 2016;126:75-82.

26. Jacobs BAW, Pluim D, van der Laan P, Tzani A, Beijnen JH, Schellens JHM. Development and validation of a quantitative method for thymidine phosphorylase activity in peripheral blood mononuclear cells. Nucleosides, Nucleotides and Nucleic Acids 2018;37:436- 
454.

27. Twelves $C$, Wong $A$, Nowacki MP, Abt $M$, Burris $H$, Carrato $A$, et al. Capecitabine as adjuvant treatment for stage III colon cancer. N Engl J Med 2005;352:2696-704.

28. Innominato PF, Lévi FA, Bjarnason GA. Chronotherapy and the molecular clock: Clinical implications in oncology. Adv Drug Deliv Rev 2010;62:979-1001.

29. Derissen EJB, Jacobs BAW, Huitema ADR, Rosing $H$, Schellens JHM, Beijnen JH. Exploring the intracellular pharmacokinetics of the 5-fluorouracil nucleotides during capecitabine treatment. Br J Clin Pharmacol 2016;81:949-57.

30. Chu E, Koeller DM, Casey JL, Drake JC, Chabner BA, Elwood PC, et al. Autoregulation of human thymidylate synthase messenger RNA translation by thymidylate synthase. Proc Natl Acad Sci 1991;88:8977-81.

31. Mormont MC, Levi F. Cancer chronotherapy: Principles, applications, and perspectives. Cancer 2003;97:155-69. 


\section{SUPPLEMENTARY MATERIAL}
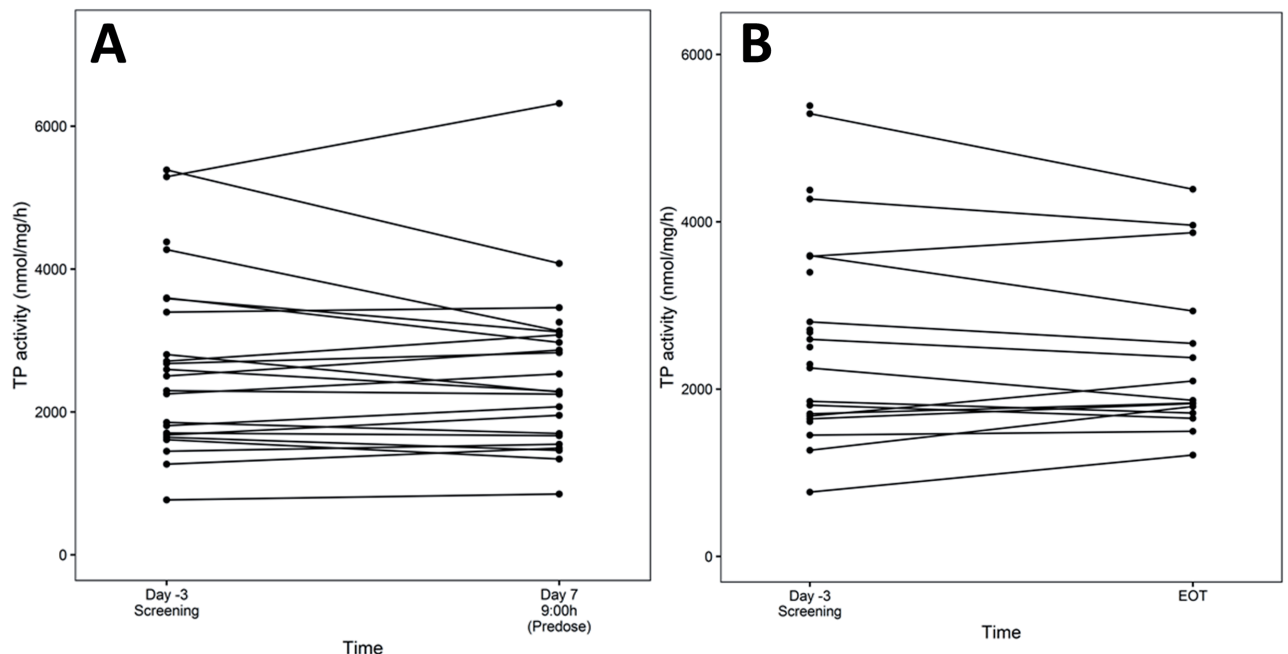

Figure S1. Thymidine phosphorylase (TP) activity in peripheral blood mononuclear cells

(A) at screening (within 3 days prior to treatment) and pre-dose at treatment day 7 , and

(B) at screening and end-of-treatment (EOT) $(n=24)$. 
Clinical and preclinical application of biomarker methods

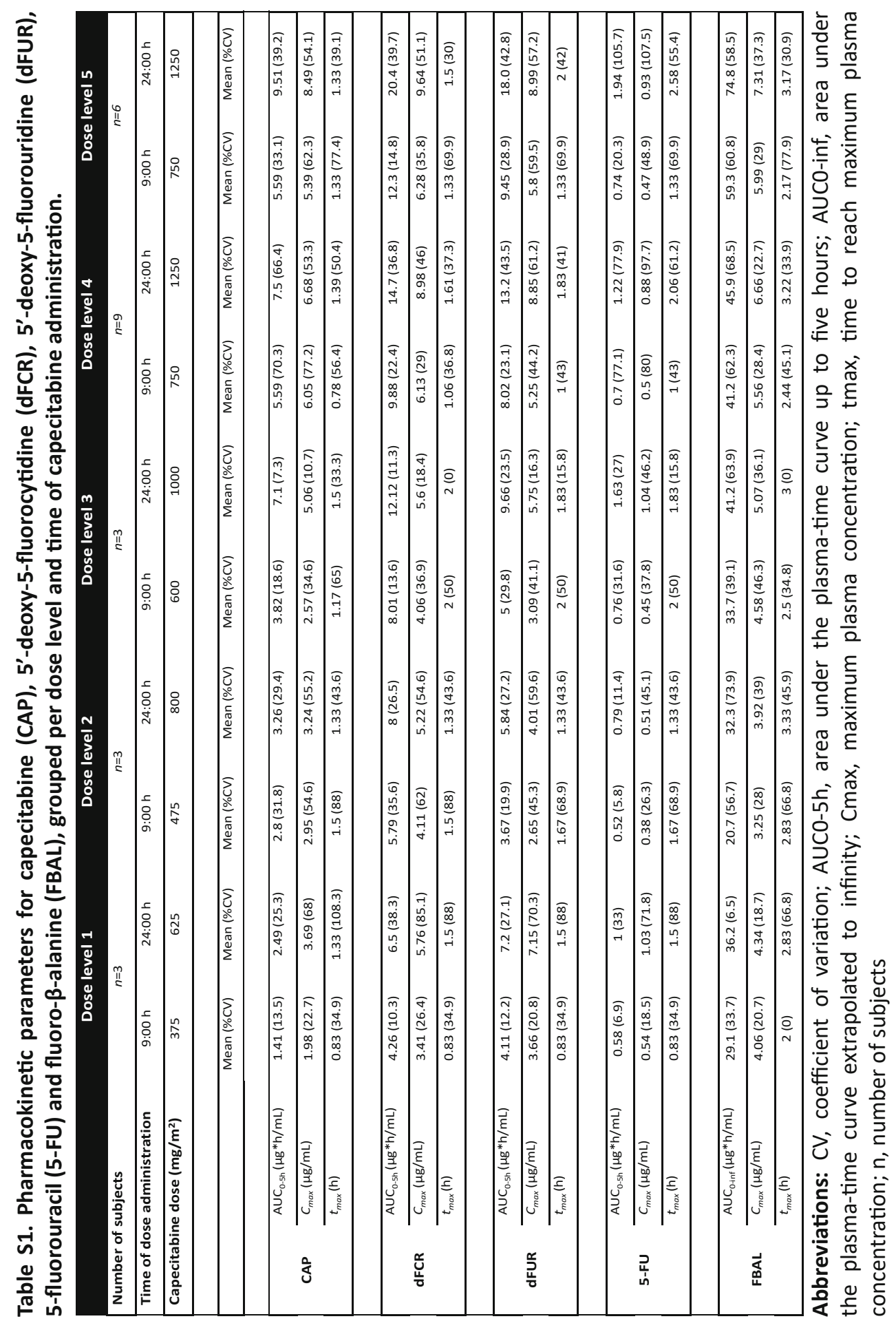




\section{CHAPTER 2 \\ Clinical and preclinical application of biomarker methods}

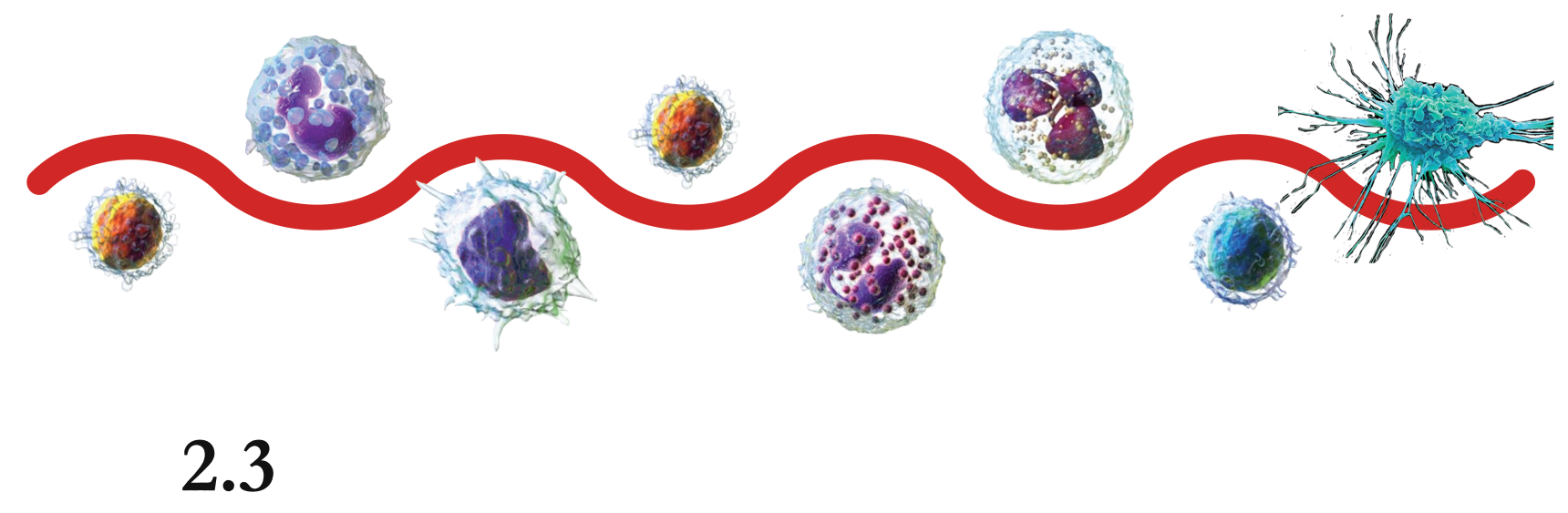

EpCAM-based assays for epithelial tumor cell detection in cerebrospinal fluid

Mark T.J. van Bussel, Dick Pluim, Mijke Bol, Jos H. Beijnen, Jan H. M. Schellens, Dieta Brandsma Journal of Neuro-Oncology 2017;137:1-10 


\section{ABSTRACT}

The diagnosis of leptomeningeal metastases (LM) of solid tumors is complicated due to low sensitivities of both magnetic resonance imaging (MRI) and cytology. MRI has a sensitivity of $76 \%$ for the diagnosis of LM and cerebrospinal fluid (CSF) cytology has a sensitivity of $44-67 \%$ at first lumbar puncture (LP) which increases to $84-91 \%$ upon second CSF sampling. Epithelial cell adhesion molecule (EpCAM) is expressed by solid tumors of epithelial origin like non-small-cell lung cancer, breast cancer or ovarium cancer. Recently, a CELLSEARCH ${ }^{\circledR}$ assay and flow cytometry laboratory techniques have been developed to detect circulating tumor cells (CTCS) of epithelial origin in CSF. These laboratory techniques are based on capture antibodies labelled with different fluorescent tags against EpCAM. In this review, we provide an overview of the available laboratory techniques and diagnostic accuracy for tumor cell detection in CSF. The reported sensitivities of the EpCAM-based CTC assays for the diagnosis of LM across the different studies are highly promising and vary between $76-100 \%$. An overview of the different EpCAM-based techniques for the enumeration of CTCS in the CSF is given and a comparison is made with CSF cytology for the diagnoses of LM from epithelial tumors. 


\section{INTRODUCTION}

Two to eight percent of patients with solid tumors develop LM. Diagnosis of LM is currently based on clinical symptoms and typical contrast enhancement of the leptomeninges on MRI of brain and/or spine. However, MRI has a low sensitivity (76\%) and specificity (77\%) for the diagnosis of LM.[1] When MRI results are inconclusive, a LP is performed to obtain CSF. Sensitivity of CSF cytology, however, is also low: $44-67 \%$ at first LP, increasing to $84-91 \%$ upon second sampling. [2-11] EpCAM is a cell-cell adhesion molecule and a mitogenic signal transducer after regulated intramembrane proteolysis.[11,12] Solid tumors of epithelial origin like non-small-cell lung cancer, breast cancer or ovarium cancer express transmembrane glycoprotein EpCAM (also known as CD326).[13] In blood donors with nonmalignant diseases the background of EpCAM+ cells is extremely low with only $0.3 \%$ having $\geq 2$ CTC per $7.5 \mathrm{~mL}$.[14] EPCAM+ CTCs in blood have been detected in patients with metastasized epithelial tumors, like ovarian cancer, breast cancer and colorectal cancer and prostate and have prognostic value when CTC numbers are higher than 0.3-5 CTC/mL.[15-18] Therefore, multiple research groups started to investigate assays to detect and count EpCAM+ CTCs in CSF in patients with already diagnosed LM or clinically suspected LM. To improve CSF diagnostics, the enumeration of CTCs by flow cytometry and Veridex CELLSEARCH ${ }^{\circledR}$ has been introduced.[4-6,19,20] The CELLSEARCH ${ }^{\circledR}$ assay is an FDA-approved assay to detect and count CTC from solid tumors in blood.[21,22] Currently, two major EpCAM-based techniques have been studied: the CELLSEARCH ${ }^{\circledR}$ technology to detect CTCs in blood which has been adapted to detect CTCs in CSF and flow cytometry assays. In this review, an overview is given of the different assays and their performance in CSF for the enumeration of EpCAM+ CTCs. The EpCAM-based techniques are compared with CSF cytology for the diagnosis of LM from epithelial tumors.

\section{METHODS}

In June 2017, PubMed was searched for studies with the following terms "Cerebrospinal Fluid"[Mesh] and "Neoplastic Cells, Circulating"[Mesh], CELLSEARCH and cerebrospinal fluid or EpCAM and cerebrospinal fluid. The references of the selected articles were also reviewed for inclusion in this review. Articles in which non-EpCAM based assays where used for other tumor types such as melanoma or lymphoma were excluded. Reported CTC numbers in the various 
articles were standardized to cells $/ \mathrm{mL}$, if possible.

\section{RESULTS}

The initial article search resulted in twenty-one, six, and twenty-five hits, respectively. Eight articles were included for data extraction after reviewing of the abstracts. One additional article was included after reviewing the references of the selected articles.

\section{CELLSEARCH technique}

The CELLSEARCH ${ }^{\circledR}$ assay is an FDA-approved assay to detect CTC in blood.[21,22] The CELLSEARCH ${ }^{\circledR}$ system consists of the CellTracks Autoprep, CellTracks Magnest and the CellTracks Analyzer II.[23] First, blood is drawn in the CellSave collection tube which preserves the sample up to 96 hours. Then, the blood is gently mixed with a dedicated dilution buffer provided in the CELLSEARCH ${ }^{\circledR}$ kit and centrifuged at $800 \times \mathrm{g}$ at room temperature for 10 minutes.[24] Subsequently, the sample is transferred to the CellTracks Autoprep part of the CELLSEARCH ${ }^{\circledR}$ System. In the CellTracks Autoprep, the EpCAM+ CTCs are immunomagnetically enriched and the fluorescently labeled antibodies are added. Anti-EpCAM ferrofluid is added to the aspirated plasma/dilution buffer layer to select for cells of epithelial origin by immunomagnetically enrichment.[25] Captured cells are fixed and permeabilized with the CELLSEARCH ${ }^{\circledR}$ proprietary permeabilization reagents and subsequently stained with 4'6-diamidino-2-phenylindole, dihydrochloride (DAPI) for nuclear staining. Anti-CD45-allophycocyan (CD45-APC) was added to label leukocytes and distinguish them from tumor cells. Anti-cytokeratin (CK) 8, 18-Phycoerythrin (PE), and anti-cytokeratin 19 Phycoerythrin (CK-PE) were added to stain the epithelial tumor cells. Next, cells are deposited in the cartridge that is positioned in the CellTracks Magnest. Thereafter, the CellTracks Analyzer II generates images of the cells using filters for DAPI, PE, and APC. Cells that are stained with both DAPI and PE are automatically identified as CTCS and placed in an image gallery. (see for overview of the CellTracks Analyzer II Figure 1A). Finally, a reviewer observes the images and makes the final decision on the identification of CTCs, which are defined as nucleated DAPI+ cells, lacking CD45 and expressing CK-PE. An example of gallery images of tumor cells detected by $\mathrm{CELLSEARCH}^{\circledR}$ in CSF (B1) and peripheral blood (B2) is given in Figure 1B. 


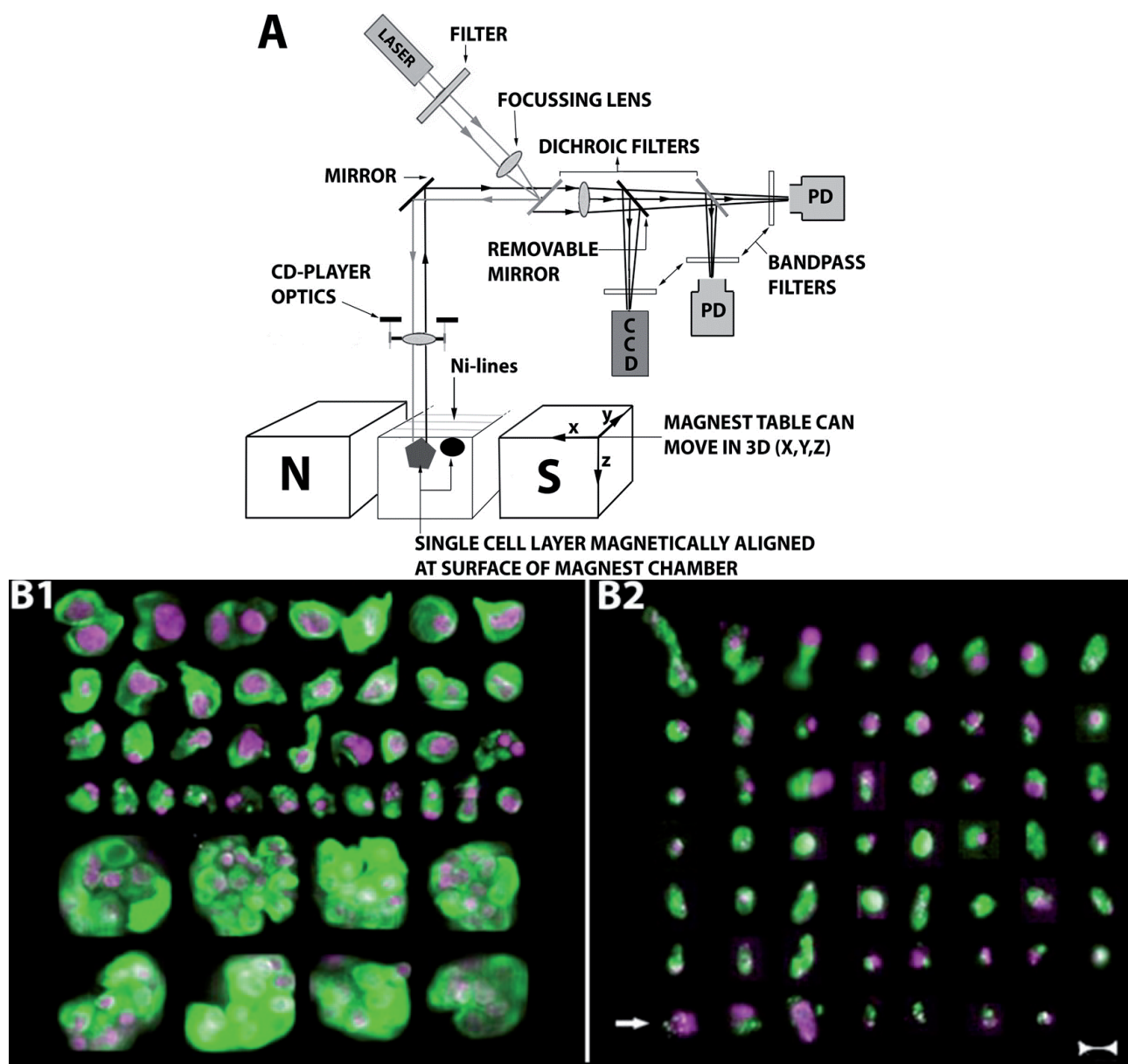

Figure 1. A. Schematic representation of the CellTracks Analyzer II, used in the CellSearch ${ }^{\circledR}$ system.[26]

Cells that have been enriched immunomagnetically and fluorescently labelled in the CellTracks Autoprep machine are magnetically ( $N, \mathrm{~S}=$ magnet North and South) aligned to nickel $(\mathrm{Ni})$ lines at the inner surface of the Magnest chamber. The light from a laser diode is focused onto these cells via a normal CD-player objective. The fluorescent light is collected via the same objective and separated through a combination of filters onto the photodiode detectors (PD). Fluorescent images of the events of interest can be acquired by inserting a removable mirror and band pass filter. The fluorescent light captured by the $C D$ objective is then focused onto the camera (CCD) . The magnets and chamber (Magnest cartridge) are positioned on a computer-controlled stage and the cells cross the laser focus one after another when the stage is moved in the Y-direction. While scanning, a feedback system uses the Ni-lines to keep the laser focused on the aligned cells. 
B. Gallery of images of tumor cells in CSF and peripheral blood using CELLSEARCH ${ }^{\circledR}$ technology.[27] Gallery of images of tumor cells in CSF (B1) and peripheral blood (B2) detected by CELLSEARCH ${ }^{\circledR}$ technology. CTC are defined as $\geq 4 \mu \mathrm{m}$ in diameter, nucleated DAPI+ (purple), CD45-, and CK-PE+ (green). In the CSF sample, CTCs were either found as isolated cells or in clusters. Their morphology was similar to the CTCS found in the peripheral blood but without any apoptotic features, which were present in some of the CTCS in blood samples (arrow, shrunken cell containing CK inclusion). Scale bar is $10 \mu \mathrm{m}$. Abbreviations: $\mathrm{CSF}=$ cerebrospinal fluid, $\mathrm{CTC}=$ circulating tumor cell, $\mathrm{CK}=$ cytokeratin.

Table 1. Overview CELLSEARCH ${ }^{\circledR}$ and flow cytometry studies

\begin{tabular}{|c|c|c|c|c|c|c|c|}
\hline Study & Assay & $\mathbf{N}$ & Patient population & $\begin{array}{c}\text { Median } \\
\text { CTCS/mL } \\
\text { in CSF }\end{array}$ & $\begin{array}{l}\text { CTC range } \\
\text { CTC/mL } \\
\text { in CSF }\end{array}$ & $\begin{array}{l}\text { Modification technique for CSF analysis } \\
\text { CELLSEARCH }{ }^{\circledast} \text { only target of capture antibody / } \\
\text { fluorescent antibody flow cytometry only }\end{array}$ & $\begin{array}{l}\text { Results } \\
\text { control } \\
\text { group }\end{array}$ \\
\hline $\begin{array}{l}\text { Tu et al. } \\
2015^{4}\end{array}$ & $\mathrm{C}$ & 18 & $\begin{array}{l}\text { MRI confirmed LM in lung cancer } \\
\text { (main histological subtype: NSCLC) }\end{array}$ & 157 & $0.2->4000$ & $\begin{array}{l}\text { Darkening the outside of the tube with a black } \\
\text { felt-tip up to the fluid level to mimic the level of } \\
\text { sediment erythrocytes }\end{array}$ & Not reported \\
\hline $\begin{array}{l}\text { Le Rhun et } \\
\text { al. } \\
2012^{19}\end{array}$ & C & 8 & $\begin{array}{l}\text { Confirmed LM/ breast cancer treated } \\
\text { patients }\end{array}$ & 106 & $0.2-2100$ & $\begin{array}{l}\text { Darkening of the outside of the tube with a black } \\
\text { felt-tip up to the fluid level to mimic the level of } \\
\text { sediment erythrocytes }\end{array}$ & Not reported \\
\hline $\begin{array}{l}\text { Lee et al. } \\
2015^{5}\end{array}$ & C & 38 & $\begin{array}{l}\text { Confirmed or suspected LM / breast } \\
\text { cancer }\end{array}$ & 14.9 & $0-9323$ & $\begin{array}{l}\text { Elimination of the centrifugation } \\
\text { step prior to enrichment and the use of the } \\
\text { control mode }{ }^{\mathrm{b}}\end{array}$ & $\begin{array}{l}\mathrm{N}=14^{\mathrm{c}} \\
\text { mean } 0.3 \mathrm{CTC} / \mathrm{mL} \\
\text { median } 0 \mathrm{CTC} / \mathrm{mL}\end{array}$ \\
\hline $\begin{array}{l}\text { Nayak et al. } \\
2013^{6}\end{array}$ & c & 51 & $\begin{array}{l}\text { Clinical suspicion of LM/ solid tumors } \\
\text { (mainly NSCLC and breast cancer) }\end{array}$ & 20.7 & $0.13>150$ & $\begin{array}{l}\text { Elimination of the centrifugation } \\
\text { step prior to enrichment and the use of the } \\
\text { control mode }{ }^{\mathrm{b}}\end{array}$ & $\begin{array}{c}\mathrm{N}=9^{\mathrm{d}} \\
0 \mathrm{CTC} / \mathrm{mL}\end{array}$ \\
\hline $\begin{array}{l}\text { Patel et al. } \\
2011^{20}\end{array}$ & c & 5 & Metastatic breast cancer involving CNS & NA & NA & $\begin{array}{c}\text { CSF suspension } \\
\text { spiked into reconstituted blood }\end{array}$ & $\begin{array}{l}\text { Not } \\
\text { reported }\end{array}$ \\
\hline $\begin{array}{l}\text { Jiang et al. } \\
2017^{7}\end{array}$ & C & 21 & NSCLC patients with suspected LM & 129.3 & $3.6-1985$ & CELLSEARCH $^{\circledast}$ standard procedure & $\begin{array}{c}\text { Not } \\
\text { reported }\end{array}$ \\
\hline $\begin{array}{l}\text { Acosta et al. } \\
2016^{26}\end{array}$ & FC & $6^{a}$ & $\begin{array}{c}\text { Clinical suspicion of LM, previously } \\
\text { diagnosed carcinoma }\end{array}$ & $\begin{array}{c}\text { not } \\
\text { reported }\end{array}$ & $\begin{array}{c}\text { not } \\
\text { reported }\end{array}$ & $\begin{array}{c}\text { EpCAM } \\
\text { (clone Ber-EP4) }\end{array}$ & $\begin{array}{c}\text { Not } \\
\text { reported }\end{array}$ \\
\hline $\begin{array}{l}\text { Milojkovic } \\
\text { Kerklaan et } \\
\text { al. } 2016^{8}\end{array}$ & FC & 29 & $\begin{array}{c}\text { Clinical suspicion of LM but a negative or } \\
\text { inconclusive MRI (primary tumor mainly } \\
\text { breast ( } n=13) \text { and lung cancer }(n=8) \text { ) }\end{array}$ & $\begin{array}{c}316.5 \\
\text { (in LM } \\
\text { patients) }\end{array}$ & $\begin{array}{c}160-4503 \\
\text { (in LM } \\
\text { patients) }\end{array}$ & $\begin{array}{c}\text { EpCAM magnetic beads/ } \\
\text { EpCAM-PE } \\
\text { (HEA-125 (isotype: mouse IgG1)) }\end{array}$ & $\begin{array}{c}\text { Not } \\
\text { reported }\end{array}$ \\
\hline $\begin{array}{l}\text { Lee et al. } \\
2015^{5}\end{array}$ & FC & $32^{f}$ & $\begin{array}{l}\text { Confirmed LM suspected LM / breast } \\
\text { cancer }\end{array}$ & 3.5 & $0-1.634$ & $\begin{array}{c}\text { EpCAM magnetic beads/ } \\
\text { EpCAM-PE (clones MJ37/EBA-1) }\end{array}$ & $\begin{array}{c}\text { Not } \\
\text { reported }\end{array}$ \\
\hline $\begin{array}{l}\text { Subirá et al.g } \\
2015^{10}\end{array}$ & FC & 144 & $\begin{array}{l}\text { Confirmed LM or clinically suspected LM } \\
\text { (primary tumor, mainly breast }(n=38) \\
\text { and lung }(n=24))\end{array}$ & 260 & $\begin{array}{l}10-2210 \\
\text { (interquart } \\
\text { ile range) }\end{array}$ & $\begin{array}{c}\text { EpCAM } \\
\text { (clones BerEP4; and EBA-1)/ } \\
\text { 2-color (fluorescein isothyocyanate, FITC/PE) }\end{array}$ & $\begin{array}{c}\text { Not } \\
\text { reported }\end{array}$ \\
\hline $\begin{array}{l}\text { Subirá et al.g } \\
2012^{9}\end{array}$ & FC & 78 & $\begin{array}{c}\text { Clinically suspected LM and previous } \\
\text { diagnosis of epithelial-cell neoplasia } \\
\text { mainly breast }\end{array}$ & $\begin{array}{c}\text { Not } \\
\text { reported }\end{array}$ & $\begin{array}{c}\text { Not } \\
\text { reported }\end{array}$ & $\begin{array}{c}\text { EpCAM } \\
\text { (clones BerEP4; and EBA-1)/2-color (fluorescein } \\
\text { isothyocyanate, FITC/PE) }\end{array}$ & $\begin{array}{l}\text { Not } \\
\text { reported }\end{array}$ \\
\hline
\end{tabular}

a fluid level = Le Rhun et al. and Tu et al. darkened the outside of the tube with a black felt-tip up to the fluid level to mimic the level of sedimented erythrocytes to allow for the selection of clear CSF $[4,19] .{ }^{b}$ Control mode: a clear suspension of prestained, fixed cancer cells is used and no interface to aspirate the right fluid fraction is needed. Therefore, this mode can be used to aspirate the clear CSF automatically. ${ }^{c}$ Lee et al. included control patients who had a hematologic malignancy but no solid tumor and no clinical findings consistent with LM [5]. ${ }^{d}$ Nayak et al. included control patients with CSF pleocytosis but without solid tumors [6]. ${ }^{\text {e }}$ reconstituted blood $=$ Patel et al. spiked the CSF in blood for calibration of the CELLSEARCH ${ }^{\circledR}$ system [20]. ${ }^{f}$ number of samples instead of number of patients. ${ }^{\mathrm{g}}$ study cohorts are overlapping. Abbreviations: $\mathrm{C}=\mathrm{CELLSEARCH}^{\circledR}$, $\mathrm{FC}=$ flow cytometry, epithelial cell adhesion molecule phycoerythrin= EpCAM-PE, LM = leptomeningeal metastases. 
Table 2. Overview CELLSEARCH ${ }^{\circledR}$ and flow cytometry studies in CSF with reported sensitivity and specificity versus cytology

\begin{tabular}{|c|c|c|c|c|c|c|c|}
\hline Study & Assay & $\mathrm{N}$ & Patient population & $\begin{array}{l}\text { Sensitivity } \\
(95 \% \mathrm{Cl})\end{array}$ & $\begin{array}{l}\text { Specificity } \\
(95 \% \mathrm{Cl})\end{array}$ & $\begin{array}{c}\text { Sensitivity } \\
(95 \% \mathrm{CI}) \\
\text { cytology }\end{array}$ & $\begin{array}{c}\text { Specificity } \\
(95 \% \mathrm{Cl}) \\
\text { cytology }\end{array}$ \\
\hline $\begin{array}{l}\text { Tu et al. } \\
2015^{4}\end{array}$ & C & 18 & MRI confirmed LM / lung cancer & $\begin{array}{c}77.8 \\
(52.4-93.6)\end{array}$ & $\begin{array}{c}100 \\
(47.8-100)\end{array}$ & $\begin{array}{c}44.4 \\
(21.5-69.2)\end{array}$ & Not reported \\
\hline $\begin{array}{l}\text { Lee et al. } \\
2015^{5}\end{array}$ & $\mathrm{C}$ & 38 & Confirmed LM/ suspected LM / breast cancer & $\begin{array}{c}80.95 \\
(58.1-94.4)\end{array}$ & $\begin{array}{c}84.62 \\
(54.5-97.6)\end{array}$ & $\begin{array}{c}66.67 \\
(43.04-85.35)\end{array}$ & $\begin{array}{l}\text { Used as gold } \\
\text { standard } 100\end{array}$ \\
\hline $\begin{array}{l}\text { Nayak et al. } \\
2013^{6}\end{array}$ & C & 51 & $\begin{array}{l}\text { Clinical suspicion of LM/ solid tumors (mainly NSCLC } \\
\text { and breast cancer) }\end{array}$ & $\begin{array}{c}100 \\
(78.1-100)\end{array}$ & $\begin{array}{c}97.2 \\
(85.4-99.9)\end{array}$ & $\begin{array}{c}66.7 \\
(38.3-88.1)\end{array}$ & $\begin{array}{l}\text { Used as gold } \\
\text { standard }\end{array}$ \\
\hline $\begin{array}{l}\text { Jiang et al. } \\
2017^{7}\end{array}$ & C & 21 & NSCLC patients with suspected LM & $\begin{array}{l}95.2 \\
(\mathrm{NA})\end{array}$ & $\begin{array}{l}100 \\
\text { (NA) }\end{array}$ & $\begin{array}{l}57.1 \\
(\mathrm{NA})\end{array}$ & Not reported \\
\hline $\begin{array}{l}\text { Acosta et al } \\
2016^{26}\end{array}$ & $\mathrm{FC}$ & $6^{a}$ & Clinical suspicion of LM previous diagnosed carcinoma & $\begin{array}{l}100 \% \\
(\mathrm{NA})\end{array}$ & $\begin{array}{l}100 \% \\
(\mathrm{NA})\end{array}$ & Not reported & Not reported \\
\hline $\begin{array}{l}\text { Milojkovic } \\
\text { Kerklaan } 2016^{8}\end{array}$ & $\mathrm{FC}$ & 29 & $\begin{array}{l}\text { Clinical suspicion of LM but a negative or inconclusive } \\
\text { MRI, previously diagnosed carcinoma }\end{array}$ & $\begin{array}{c}100 \\
(75-100)\end{array}$ & $\begin{array}{c}100 \\
(79-100)\end{array}$ & $\begin{array}{c}61.5 \\
(32-86)\end{array}$ & $\begin{array}{c}100 \\
(79-100)\end{array}$ \\
\hline $\begin{array}{l}\text { Subirá et al. } \\
2015^{10}\end{array}$ & FC & 144 & $\begin{array}{c}\text { Confirmed LM or } \\
\text { clinically suspected LM }\end{array}$ & $\begin{array}{l}79.8 \\
(\mathrm{NA})\end{array}$ & $\begin{array}{c}84 \\
(\mathrm{NA})\end{array}$ & $\begin{array}{c}50 \\
(\mathrm{NA})\end{array}$ & $\begin{array}{l}100 \\
(\mathrm{NA})\end{array}$ \\
\hline $\begin{array}{l}\text { Subirá et al. }{ }^{b} \\
2012^{9}\end{array}$ & FC & 78 & $\begin{array}{l}\text { Clinically suspected LM and previous diagnosis of } \\
\text { epithelial-cell neoplasia }\end{array}$ & $\begin{array}{c}75.5 \\
(63.5-87.6)\end{array}$ & $\begin{array}{c}96.1 \\
(88.8-100)\end{array}$ & $\begin{array}{c}65.3 \\
(52.0-78.6)\end{array}$ & $\begin{array}{c}100 \\
(100-100)\end{array}$ \\
\hline
\end{tabular}

Abbreviations: $\mathrm{C}=\mathrm{CELLSEARCH}^{\circledR}, \mathrm{FC}=$ flow cytometry, $95 \mathrm{Cl}=95 \%$ confidence interval, $\mathrm{MRI}$ =magnetic resonance imaging, $\mathrm{LM}=$ leptomeningeal metastases, $N A=$ not available, a number of samples instead of number of patients. b study cohorts are overlapping.

In the CELLSEARCH ${ }^{\circledR}$ assay plasma is aspirated based on the optical differences between plasma, buffy coat and erythrocytes. To use the CELLSEARCH ${ }^{\circledR}$ assay in CSF instead of blood, it is necessary to make some modifications to the original method. An overview of the CELLSEARCH ${ }^{\circledR}$ studies using CSF is given in Table 1 . To calibrate the CELLSEARCH ${ }^{\circledR}$ system, the control mode is normally used.[5] In the control mode, a clear suspension of prestained fixed breast cancer cells is used and no separation line to aspirate the right fluid fraction is needed. Therefore, this mode can be used to aspirate the clear CSF automatically. Lee et al. used the control mode and Patel et al. spiked the CSF in blood for calibration of the CELLSEARCH $^{\circledR}$ system.[5,20] Le Rhun et al. and Tu et al. darkened the outside of the tube with a black felt-tip up to the fluid level to mimic the level of sedimented erythrocytes to allow for the selection of the clear CSF.[4,19] The reported sensitivity and specificity for the diagnosis of LM of both types of modified CELLSEARCH ${ }^{\circledR}$ assays for CSF are shown in Table 2. 


\section{FLOW CYTOMETRY}

In fluorescence activated cell sorting systems (FACS) for CTCs enumeration of epithelial origin, different fluorescently labelled EpCAM antibodies are used to stain and count the cells. An overview of the FACS technology is depicted in Figure 2a Milojkovic Kerklaan et al. and Lee et al. used immunomagnetic enrichment with anti-EpCAM MicroBeads prior to FACS analysis.[5,8] To distinguish between CTCs and leukocytes, anti-CD45-fluorescein isothiocyanate (FITC) for leucocyte labeling was added. FACS plots of CSF obtained by this method are shown in Figure $2 \mathrm{~b}$. In addition to these markers, Acosta et al. used anti-CD33 to improve differentiation between monocyte/macrophages/granulocytes (CD45- CD33+ CD326+) and epithelial cells (CD45- CD33- CD326+).[28] Milojkovic Kerklaan et al. and Subirá et al. used Hoechst33258 and DRAQ5, respectively, for nuclear DNA-staining whereas Lee et al. did not use a DNA-dye.[9,10] An overview of flow cytometry studies is given in Table 1 . The reported sensitivity and specificity of these assays for the diagnosis of LM are shown in Table 2.

\section{DISCUSSION}

The diagnosis of LM is hampered by the low sensitivities of its diagnostic tools: MRI of brain and /or spine and CSF cytology. Although CSF cytology still is the gold standard for LM with a reported sensitivity of $44-67 \%$ at the first CSF examination, LM can also be diagnosed by the combination of neurological symptoms compatible with LM and leptomeningeal contrast enhancement in patients with known (metastasized) tumors.[2] The low sensitivity of cytology could be attributed partially to the spill of tumor cells at cytospin preparation. Furthermore, limited sample volume, delayed sample processing and sample collection at a suboptimal site (LP when there are mainly intracranial LM).[29] Leptomeningeal contrast enhancement on MRI has a sensitivity of 76\% for LM.[1] Currently, multiple techniques are used to detect and count EpCAM+ CTCs in CSF to improve the CSF diagnostics for LM in patients with epithelial tumors. The reported results of the EpCAM-based techniques in CSF are highly promising with a detection limit of $0.4 \mathrm{CTC} / \mathrm{mL}$. However, these techniques are not yet fully ready for clinical implementation due to lack of assay standardization and proper multicenter validation studies with adequate control groups. These studies are required for each individual CTC assay before clinical implementation. Furthermore, patients groups that have been investigated so far were rather small ranging from 6 to 

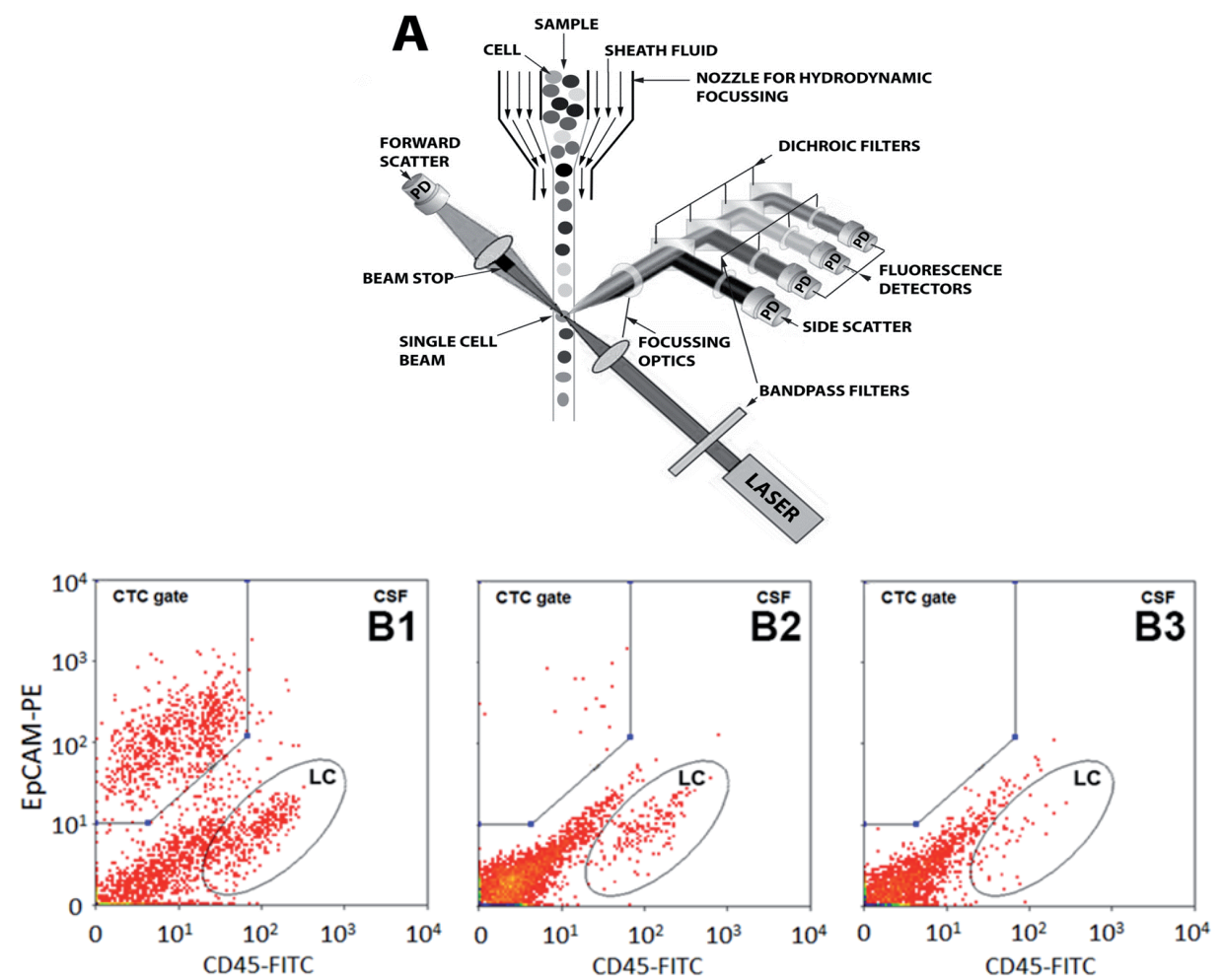

Figure 2. A. Schematic representation of fluorescence activated cell sorting (FACS). Cells in the sample are focused into a stream of single cells by hydrodynamic focusing with sheath fluid. A laser is focused on the middle of this stream. Forward scatter is measured in a straight line opposite the laser beam and is used to distinguish cells on the basis of size. Sideward scatter and fluorescence is measured perpendicular to the laser beam and provide, respectively, information about internal complexity and amount of cell-bound fluorescently labelled antibody or dye. The signals from the photodiode detectors (PD) are processed by a computer using flow cytometry software.

B. Representative examples of epithelial cell adhesion molecule (EpCAM)-based flow cytometry plots of cerebrospinal fluid (CSF) from three individual patients. Circulating tumor cells (CTC) are defined as EpCAM+ and CD45- and will therefore be sorted to the CTC gate. B1: non-small cell lung cancer patient with LM with EpCAM-positive CTCs (162 $\mathrm{CTCs} / \mathrm{mL}$ ); CSF cytology was positive (not shown). B2: breast cancer patient with LM with EpCAM-positive CTCs ( $3 \mathrm{CTCs} / \mathrm{mL}$ ). CSF cytology in this patient was negative (not shown). b3: breast cancer patient without LM. No EpCAM-positive CTCS in CSF. CSF cytology in this patient was also negative (not shown). Abbreviations: FACS= fluorescence activated cell sorting systems, CTC=circulating tumor cell, EpCAM =epithelial cell adhesion molecule, LC=leucocytes. 
144 patients. Sensitivity of the EpCAM based techniques may be lower in larger patients studies suspected for LM as it is known that tumor cells of epithelial origin can lose EpCAM expression due to epithelial to mesenchymal cell transition. [30] This may explain that patients with LM can have positive CSF cytology but no detectable CTCs.[19]

The FDA-approved CELLSEARCH ${ }^{\circledR}$-assay was initially validated in blood in a prospective, double-blind, multicenter clinical trial involving 177 metastatic breast cancer patients at 20 clinical centers.[31]

The reported sensitivities of the EPCAM-based CTC assays for the diagnosis of LM across the different studies are highly promising and vary between 76$100 \%$. However, none of the studied EpCAM assays for the enumeration of CTCs in CSF have yet been shown to be statistically significant better than CSF cytology.[4-10,19,20,28] This can be attributed to the insufficient number of patients ultimately diagnosed with LM in the study cohorts. Furthermore, in order to establish the real value of the new techniques in CSF, standardization of the patient selection process is critical to ensure selection of patients with true diagnostic uncertainty of LM. A patient population with a true diagnostic uncertainty with clinical suspicion of LM was investigated in only two studies. $[6,8]$ All other studies that reported sensitivity for tumor cell detection in CSF also included patients with already proven LM based on MRI and/or CSF cytolog. $[4,5,9,10]$ Future validation studies should be performed in properly defined study populations with a clinical suspicion on LM in prospective, multicenter triple blind (clinician, lab technician and patient) studies. A possible risk in CSF analysis is the detection of CTCs in the CSF due to contamination with blood in a traumatic LP. When high numbers of CTCs per $\mathrm{mL}$ blood are present, contamination of $5 \mathrm{~mL}$ CSF with just a few $\mu \mathrm{L}$ of blood may raise CTC levels above the detection limit, which can possibly effect the specificity of the assay.[14] Therefore, it is recommended to determine CTC-numbers in blood simultaneously with CSF, which up till now only has been done in one study.[8]

The question which technique, CELLSEARCH ${ }^{\circledR}$ or flow cytometry, is optimal to detect epithelial tumor cells in CSF is unresolved as comparable sensitivity and specificity rates can be gained with both methods (Table 2). No direct comparison with adequate power between both methods in patients with a clinical suspicion on $\mathrm{LM}$ has been done hitherto.5 The $\mathrm{CELLSEARCH}^{\circledR}$ method requires specific reviewer training to minimalize inter-reviewer discordant results.[32] Besides, a 
major limitation of the CELLSEARCH ${ }^{\circledR}$ analysis is the requirement of $\mathrm{CELLSEARCH}^{\circledR}$ reagents, CELLSEARCH ${ }^{\circledR}$ laboratory equipment and central laboratories equipped with CellTracks Autoprep, the CellTracks Analyzer II and trained operators. These prerequisites may limit wide-spread application.[23] Flow cytometry assays for CTCs utilize standard flow cytometry equipment, which makes these assays more widely applicable and can potentially shorten the time to LM diagnosis compared to the CELLSEARCH ${ }^{\circledR}$ analysis. Another important merit of flow cytometry is their reliance on a predefined tumor cell gate, which allows fully automatic identification and enumeration of CTCs in CSF. From an analytical perspective it makes sense to perform a pre-enrichment step using magnetic cell sorting with ferrolabelled antibodies against EPCAM to lower the amount of cellular background events. This has been applied in the CELLSEARCH ${ }^{\circledR}$ assay and in some flow cytometry assays.[5,8] An overview of the benefits and drawbacks of flow cytometry and CELLSEARCH assays is given in Table 3.

A critical review of the randomized trials in LM using intra-CSF therapy, of which five of them enrolled patients with solid tumors, revealed that all these studies have methodological limitations with a lack of standardization for the evaluation of treatment response and long time-periods needed for accrual.[33] Also phase one clinical trials in patients with LM with targeted agents failed due to slow patient accrual.[34,35] To improve the accrual rate of (early) LM patients and the reliability of response evaluation in clinical trials, CTC assays in CSF are promising tools as tumor cells can be quantified at very low levels. As LM often has a devastating course with median reported survival between 2-5 months,[36] it is important to include patients with a low CSF tumor burden. A validated and sensitive CTC assay in CSF that can diagnose patients at an early LM stage when CSF cytology is still negative, is crucial. This was demonstrated by MilojkovicKerklaan et al., who reported that the EpCAM-based flow cytometry assay in CSF brings higher sensitivity than CSF cytology for the diagnosis of LM, especially when CTC numbers in the CSF drop below 50 cells/mL.[8] The specificity of the different EpCAM assays varies between $84-100 \%$. Future large scale study cohorts need to reveal the true sensitivity and specificity of CTC assays in CSF. It is of particular interest to determine the optimal cut-off value for the number of CTCs per $\mathrm{mL}$ with an optimal sensitivity and specificity by using Receiver Operating Curves.

CSF cytology is a non-quantitative method with a low sensitivity, which renders the technique insufficient for monitoring of treatment response. A sensitive quantitative technique enables patient treatment response monitoring. 
A decrease in the CTC number would be indicative for a response to treatment. In several articles described in our review, sequential CSF samples from patients have been obtained for treatment monitoring using CTC enumeration.[4,5,19,20] Lee et al. showed that in three of seven patients who had been treated for LM, no CTCs were detectable after treatment. CSF clearance of CTCs was associated with the longest survival with an average of 2 years. 5 Although the number of studies performed so far are limited, CTC enumeration in CSF has the potential to be a sensitive, specific, and quantitative biomarker for evaluating treatment response in LM. The new CTC assays do not only have the potential to be more sensitive, specific and quantitative in the diagnosis and treatment of LM, they also provide the possibility of expanding our knowledge on the pathophysiology of LM. Single cell analysis and the use of other molecular markers in the identification of the cells in the CSF may help to understand why this highly malignant cells metastasize to the CSF. Recently, Cordone et al. (2017) showed the presence of syndecan-1 and MUC-1 overexpression and the putative stem cell markers CD15, CD24, CD44 and CD133 on CTCs in the CSF of breast cancer patients with LM.[37]

In conclusion, we have shown in our review that the EpCAM-based assays are promising new techniques for epithelial tumor cell detection in CSF, although assay standardization and proper multicenter validation studies are needed before clinical implementation. Furthermore, the possibility of detecting (and isolating) low numbers of tumor cells in the CSF using flow cytometry assays opens new ways to further understand why these malignant cells metastasize to the central nervous system. 


\section{REFERENCES}

1. Straathof CS, de Bruin HG, Dippel DW, VechtCJ. The diagnostic accuracy of magnetic resonance imaging and cerebrospinal fluid cytology in leptomeningeal metastasis. J Neurol 1999;246:810-814.

2. Wasserstrom WR, Glass JP, Posner JB. Diagnosis and treatment of leptomeningeal metastases from solid tumors: experience with 90 patients. Cancer 1982;49:759-772.

3. van Oostenbrugge RJ, Twijnstra A. Presenting features and value of diagnostic procedures in leptomeningeal metastases. Neurology 1999;53:382-385.

4. Tu $Q$, Wu X, Le Rhun E, et al. CellSearch technology applied to the detection and quantification of tumor cells in CSF of patients with lung cancer leptomeningeal metastasis. Lung Cancer 2015;90:352-357.

5. Lee JS, Melisko ME, Magbanua MJ, et al. Detection of cerebrospinal fluid tumor cells and its clinical relevance in leptomeningeal metastasis of breast cancer. Breast Cancer Res Treat 2015;154:339-349.

6. Nayak L, Fleisher M, Gonzalez-Espinoza $R$, et al. Rare cell capture technology for the diagnosis of leptomeningeal metastasis in solid tumors. Neurology 2013;80:1598-605; discussion 1603.

7. Jiang BY, Li YS, Guo WB, et al. Detection of Driver and Resistance Mutations in Leptomeningeal Metastases of NSCLC by Next-Generation Sequencing of Cerebrospinal Fluid Circulating Tumor Cells. Clin Cancer Res 2017.

8. Milojkovic Kerklaan B, Pluim D, Bol $M$, et al. EpCAM-based flow cytometry in cerebrospinal fluid greatly improves diagnostic accuracy of leptomeningeal metastases from epithelial tumors. Neuro Oncol 2016;18:855-862.

9. Subira D, Serrano C, Castanon S, et al. Role of flow cytometry immunophenotyping in the diagnosis of leptomeningeal carcinomatosis. Neuro Oncol 2012;14:4352.

10. Subira D, Simo M, Illan J, et al. Diagnostic and prognostic significance of flow cytometry immunophenotyping in patients with leptomeningeal carcinomatosis. Clin Exp Metastasis 2015;32:383-391.

11. Maetzel D, Denzel S, Mack B, et al. Nuclear signalling by tumour-associated antigen EpCAM. Nat Cell Biol 2009;11:162171.

12. Litvinov $S$ V, Velders MP, Bakker $H A$, Fleuren GJ, Warnaar SO. Ep-CAM: a human epithelial antigen is a homophilic cell-cell adhesion molecule. J Cell Biol 1994;125:437446.

13. Went PT, Lugli A, Meier S, et al. Frequent EpCam protein expression in human carcinomas. Hum Pathol 2004;35:122-128.

14. Allard WJ, Matera J, Miller MC, et al. Tumor cells circulate in the peripheral blood of all major carcinomas but not in healthy subjects or patients with nonmalignant diseases. Clin Cancer Res 2004;10:68976904.

15. Zhou Y, Bian B, Yuan X, Xie G, Ma Y, Shen L. Prognostic Value of Circulating Tumor Cells in Ovarian Cancer: A Meta-Analysis. PLoS One 2015;10:e0130873.

16. Lv $Q$, Gong L, Zhang $T$, et al. Prognostic value of circulating tumor cells in metastatic breast cancer: a systemic review and metaanalysis. Clin Transl Oncol 2016;18:322-330. 17. Huang $X$, Gao $P$, Song $Y$, et al. Meta- 
analysis of the prognostic value of circulating tumor cells detected with the CellSearch System in colorectal cancer. BMC Cancer 2015;15:202.

18. Ma X, Xiao Z, Li X, et al. Prognostic role of circulating tumor cells and disseminated tumor cells in patients with prostate cancer: a systematic review and meta-analysis. Tumour Biol 2014;35:5551-5560.

19. Le Rhun E, Massin F, Tu Q, Bonneterre J, Bittencourt Mde C, Faure GC. Development of a new method for identification and quantification in cerebrospinal fluid of malignant cells from breast carcinoma leptomeningeal metastasis. BMC Clin Pathol 2012;12:21.

20. Patel AS, Allen JE, Dicker DT, et al. Identification and enumeration of circulating tumor cells in the cerebrospinal fluid of breast cancer patients with central nervous system metastases. Oncotarget 2011;2:752760.

21. Andree KC, van Dalum G, Terstappen LW. Challenges in circulating tumor cell detection by the CellSearch system. Mol Oncol. 2016;10(3):395-407.

22. CellSearchTM Circulating Tumor Cell Kit Premarket Notification- Expanded Indications for Use- Colorectal. Available at https://www.accessdata.fda.gov/cdrh_ docs/pdf7/k071729.pdf Accessed 21 Mar 2017.

23. de Wit S, van Dalum G, Terstappen LW. Detection of circulating tumor cells. Sci 2014;2014:819362.

24. Cellsearch ${ }^{\circledR}$ Circulating Tumor Cell Kit (Epithelial). Available at http://documents. cellsearchctc.com/pdf/e631600004/ e631600004_EN.pdf Accessed 22 Mar 2017.
25. Riethdorf S, Fritsche $H$, Muller V, et al. Detection of circulating tumor cells in peripheral blood of patients with metastatic breast cancer: a validation study of the CellSearch system. Clin Cancer Res 2007;13:920-928.

26. Tibbe AG, de Grooth BG, Greve J, Dolan GJ, Terstappen LW. Imaging technique implemented in CellTracks system. Cytometry 2002;47:248-255.

27. Reprinted from Lung Cancer: vol. 90 number 2, Tu Q, Wu X, Le Rhun E, Blonski M, Wittwer B, Taillandier L, De Carvalho Bittencourt $M$, Faure GC. CellSearch technology applied to the detection and quantification of tumor cells in CSF of patients with lung cancer leptomeningeal metastasis,Pages No. 352-7 Copyright (2015), with permission from Elsevier.

28. Acosta M, Pereira J, Arroz M. Screening of carcinoma metastasis by flow cytometry: A study of 238 cases. Cytom B Clin Cytom 2016;90:289-294.

29. Glantz MJ, Cole BF, Glantz LK, et al. Cerebrospinal fluid cytology in patients with cancer: minimizing false-negative results. Cancer 1998;82:733-739.

30. Hyun KA, Koo GB, Han H, et al. Epithelialto-mesenchymal transition leads to loss of EpCAM and different physical properties in circulating tumor cells from metastatic breast cancer. Oncotarget 2016;7:2467724687.

31. Hayes DF, Cristofanilli M, Budd GT, et al. Circulating tumor cells at each followup time point during therapy of metastatic breast cancer patients predict progressionfree and overall survival. Clin Cancer Res 2006;12:4218-4224. 
32. Kraan J, Sleijfer S, Strijbos $M H$, et al. External quality assurance of circulating tumor cell enumeration using the CellSearch((R)) system: a feasibility study. Cytom B Clin Cytom 2011;80:112-118.

33. Chamberlain M, Soffietti R, Raizer J, et al. Leptomeningeal metastasis: a Response Assessment in Neuro-Oncology critical review of endpoints and response criteria of published randomized clinical trials. Neuro Oncol 2014;16:1176-1185.

34. Jackman DM, Cioffredi LA, Jacobs L, et al. A phase I trial of high dose gefitinib for patients with leptomeningeal metastases from non-small cell lung cancer. Oncotarget 2015;6:4527-4536.

35. Wu PF, Lin $\mathrm{CH}$, Kuo $\mathrm{CH}$, et al. A pilot study of bevacizumab combined with etoposide and cisplatin in breast cancer patients with leptomeningeal carcinomatosis. BMC Cancer 2015;15:299.

36. Brower J V, Saha S, Rosenberg SA, Hullett CR, lan Robins $H$. Management of leptomeningeal metastases: Prognostic factors and associated outcomes. J Clin Neurosci 2016;27:130-137.

37. Cordone I, Masi S, Summa V, et al. Overexpression of syndecan-1, MUC-1, and putative stem cell markers in breast cancer leptomeningeal metastasis: a cerebrospinal fluid flow cytometry study. Breast Cancer Res 2017;19:46. 
Clinical and preclinical application of biomarker methods 


\section{CHAPTER 2 \\ Clinical and preclinical application of biomarker methods}

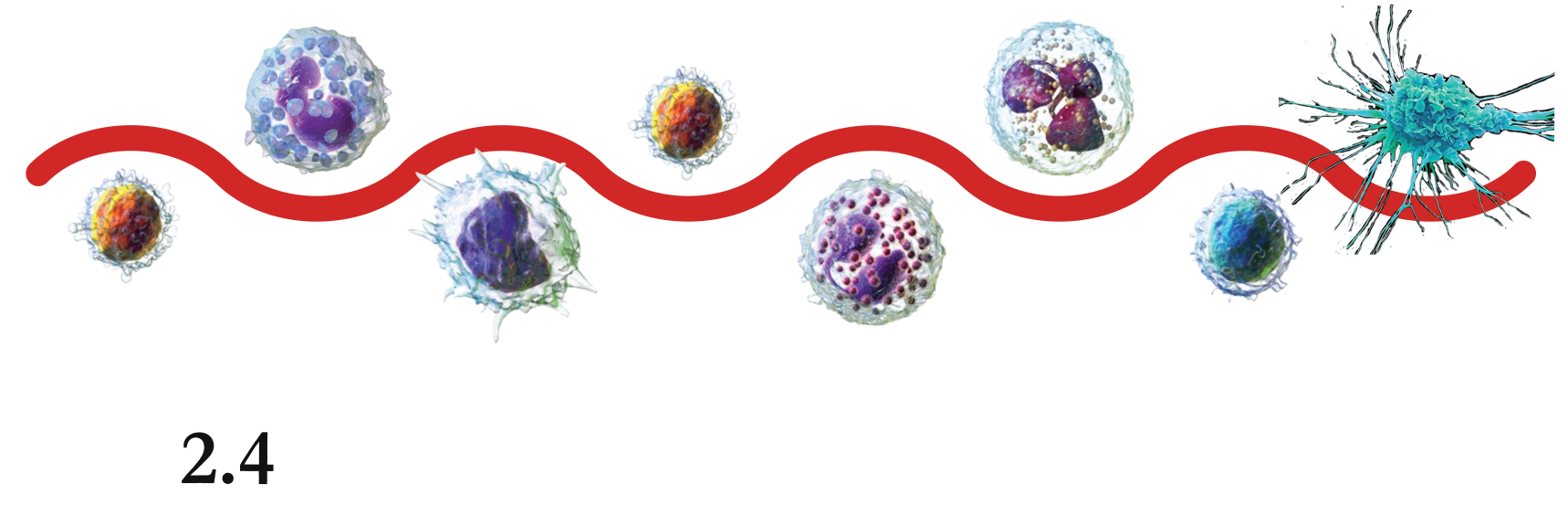

Circulating epithelial tumor cell analysis in

cerebrospinal fluid in patients with

leptomeningeal metastases

Mark T.J. van Bussel, Dick Pluim, Bojana Milojkovic Kerklaan, Mijke Bol, Karolina Sikorska, Dorothé Linders, Daan van den Broek, Jos H. Beijnen, Jan H. M. Schellens, Dieta Brandsma

Neurology 2020;94:521-528 


\section{ABSTRACT}

Objective: The primary objective was to determine the sensitivity and specificity of epithelial cell adhesion molecule (EPCAM) immunoflow cytometry circulating tumor cells (CTC) analysis in cerebrospinal fluid (CSF) in patients with suspected leptomeningeal metastases (LM). The secondary objective was to explore the distribution of driver mutations in the primary tumor, plasma, cell free (cf)CSF and isolated CTC from CSF in non-small cell lung cancer (NSCLC).

Methods: We tested the performance of the CTC assay versus CSF cytology in a prospective study in 81 patients with a clinical suspicion of LM but a nonconfirmatory MRI. In a NSCLC subcohort we analyzed circulating tumor (ct)DNA of the selected driver mutations by digital droplet (dd)PCR.

Results: The sensitivity of the CTC assay was $94 \%$ (95\% Cl 80-99) and the specificity was $100 \%(95 \% \mathrm{Cl} 91-100)$ at the optimal cut-off of $0.9 \mathrm{CTC} / \mathrm{mL}$. The sensitivity of cytology was $76 \%$ ( $95 \% \mathrm{Cl} 58-89$ ). Twelve of the 23 NSCLC patients were epidermal growth factor receptor (EGFR) mutated. All 5 tested patients with LM demonstrated the primary EGFR driver mutation in CfCSF. The driver mutation could also be detected in CTC isolated from CSF.

Conclusion: CTC in CSF are detected with a high sensitivity for the diagnosis of LM. ddPCR can determine EGFR mutations in both CfCSF and isolated CTC from CSF of EGFR mutated NSCLC patients with LM.

Classification of evidence: This study provides Class III evidence that in patients clinically suspected for LM, EpCAM-based flow cytometry analysis of CSF is recommended as part of routine diagnostic workup. 


\section{INTRODUCTION}

Approximately $10 \%$ of patients with solid tumors develop leptomeningeal metastases (LM).[1] The diagnosis of LM can be based on clinical symptoms compatible with LM and typical contrast enhancement of the leptomeninges on MRI brain and/or spine. However, MRI has a low sensitivity (76\%) and specificity (77\%) for the diagnosis of LM.[2] When MRI is normal or results are inconclusive, a lumbar puncture (LP) is performed to obtain cerebrospinal fluid (CSF). Sensitivity of CSF cytology is also low: $44-67 \%$ at first LP, increasing to $84-91 \%$ upon second sampling.[3-11] To improve CSF diagnostics in patients with solid tumors, epithelial cell adhesion molecule (EpCAM) assays have been developed to detect CTC in CSF with reported sensitivities of 76-100\%.[5-11] Here we describe the results of an EpCAM immunoflow cytometry assay in CSF compared to CSF cytology in 81 patients for the diagnosis of LM.

Tumor cell detection in CSF is pivotal for the diagnosis of LM, but ctDNA analysis of CSF can be of additive value for driver mutation detection. Driver mutation determination by circulating tumor DNA (ctDNA) analysis in plasma has clinical utility in epidermal growth factor receptor mutated (EGFR) non-small-cell lung cancer (NSCLC).12 Furthermore, EGFR mutant DNA copy number in CSF can be used for response evaluation.[13] In 6 out of 7 patients with brain metastases from various tumor types, including two EGFR mutated NSCLC patients, ctDNA fragments were detected in the CSF.[14] It is unknown whether the presence of ctDNA in CSF can currently be used to diagnose LM, as ctDNA fragments may also be present in patients with brain metastases only. In the current study, both cellfree ctDNA analysis in CSF and DNA mutation analysis of isolated CTC from CSF is performed to determine the known driver tumor mutations of the primary tumor.

\section{METHODS}

\section{Patients}

The institutional review board of the Netherlands Cancer Institute - Antoni van Leeuwenhoek and the Medical Center Slotervaart approved the study. Written informed consent was obtained from all participants. Patients were consecutively included in the prospective study between October 2012 and Augustus 2018. Patients $\geq 18$ years with a (metastasized) epithelial tumor and clinical suspicion of LM but a normal or inconclusive MRI who had to undergo a diagnostic LP were asked to participate. CSF pressure was measured. Next $20 \mathrm{~mL}$ CSF was collected: 
1x5 mL CSF for cytology, 1x5mL for leukocyte count and biochemical parameters, $1 \times 5 \mathrm{~mL}$ for CTC analysis and $1 \times 5 \mathrm{~mL}$ for CTC isolation. Cytology and CTC analysis were performed by independent operators. Diagnosis of LM was defined as follows: a positive CSF cytology at the initial LP or repeated LP performed within 6 weeks after the initial LP, or a follow-up MRI of the brain or spine performed after the diagnostic LP within 2 months following the first MRI, showing unequivocal evidence of LM and/or progressive neurological symptoms compatible with LM and exclusion of other causes (e.g. infectious meningitis, treatment side effects). Patients with possible or probable LM were classified according to the European Association of Neuro-Oncology - European Society of Medical Oncology (EANOESMO) clinical practice guidelines for LM.[1] The final diagnoses were made by one neurologist (D.B.) who had access to index test results and the reference standard. Non-oncological patients with a clinical indication for a diagnostic LP due to a suspicion on an infectious or auto-immune meningitis or subarachnoid hemorrhage were included for the control group. Exclusion criteria for a LP in both groups were: intracranial or intraspinal tumor with mass effect heralding the risk of herniation during LP and uncorrected thrombocytopenia or coagulation disorders. Patients were interviewed via a follow-up telephone call for evaluation of post-punctional headache at day 3 of the study. The primary objective of the study was to determine the sensitivity and specificity of detection of CTC in patients with epithelial tumors compared to cytology in the CSF, in patients clinically suspected of LM (Class III level of evidence). The secondary objective was to explore the distribution of driver mutations in the primary tumor, plasma, cell free (cf)CSF and isolated CTC from CSF in non-small cell lung cancer (NSCLC). This trial was registered at www.clinicaltrials.gov (NCT01713699).

\section{CTC and ctDNA assays}

We used the same EPCAM immunoflow cytometry assay for CTC detection as the one employed in a previous study.[15,16] In case the CSF-CTC sample (5 $\mathrm{mL}$ ) appeared to be positive, the extra collected CSF-CTC sample $(5 \mathrm{~mL})$ was used to isolate the CTC fraction via fluorescence-activated cell sorting (FACS) for determination of the selected driver mutation of the CTC. Selective driver mutation analysis was performed as a secondary exploratory endpoint. Blood samples were collected in $\mathrm{K}_{2}$ EDTA (ethylene diamine tetra acetic acid) tubes (BD Vacutainer, Franklin Lakes, NJ, USA) and plasma was separated by centrifugation. The cfDNA was extracted using the QIAsymphony DSP circulating DNA Kit. 
(Qiagen, Hilden, Germany). cfDNA of plasma and CSF samples was analysed by the QX200TM Droplet Digital ${ }^{\mathrm{TM}}$ PCR (ddPCR) system (Bio-Rad).[17]

\section{Statistical analysis}

Sample size calculation

The aim of the study was to include 100 patients. The power calculation was performed for sensitivity of the CTC-assay in CSF. A sensitivity of the CSF-CTC assay higher than the reported sensitivity of cytology of $67 \%$ would be of clinical interest.[7] We expected to achieve a sensitivity of 95\% for the CTC-CSF assay. [15] At the start of the trial the prevalence of LM was unknown, but it was set to $20 \%-50 \%$. A sample size of 100 patients has around $92 \%$ power to test the sample sensitivity at the two-sided alpha level of 0.05 . Confidence intervals for the sensitivities and specificities were calculated using Clopper and Pearson method. The best cut-off for the CTC was optimized by maximizing sensitivity and specificity using the $\mathrm{R}$ package OptimalCutpoints. The Standards for Reporting Diagnostic accuracy studies (STARD) were used as a guideline for preparation of the final report.[18]

Data Availability Statement

Data can be requested from the corresponding author. 


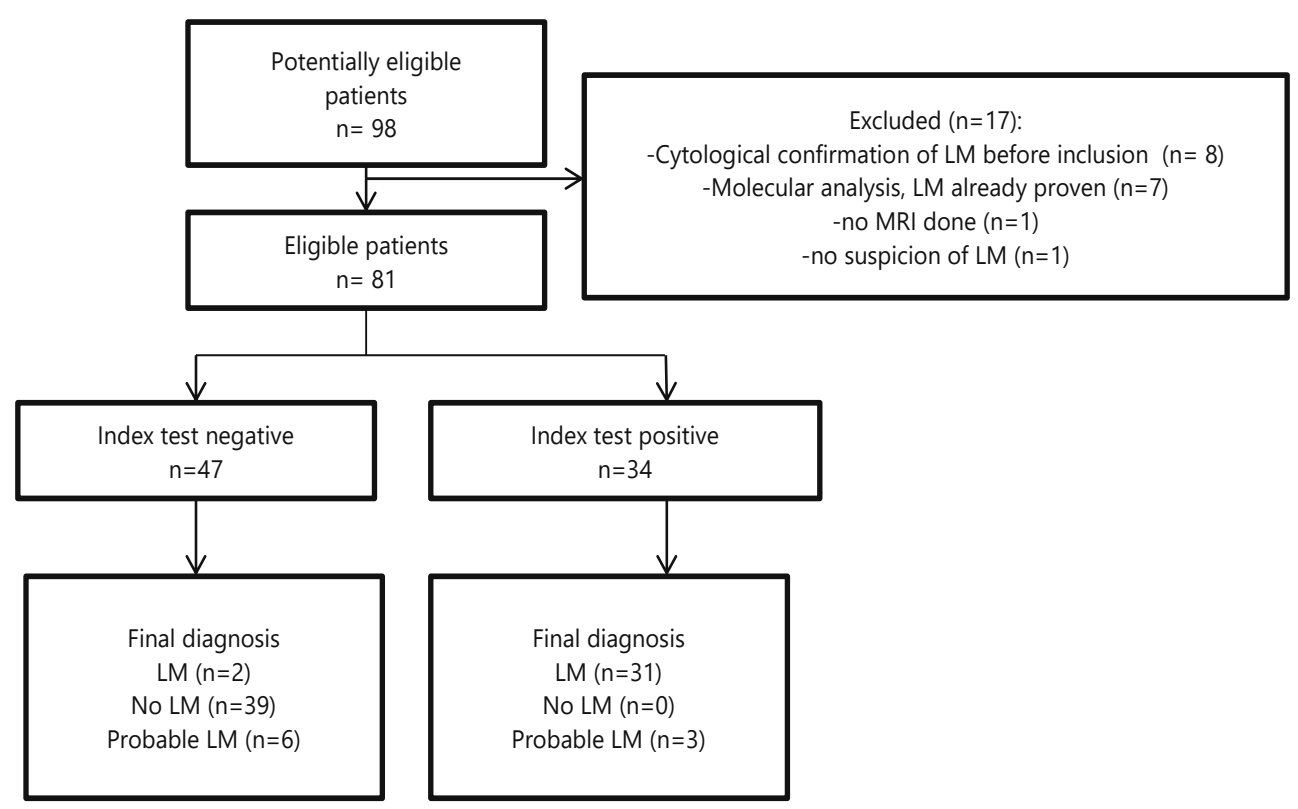

Figure 1. STARD diagram to report flow of participants through the study

Abbreviations: LM=leptomeningeal metastases.

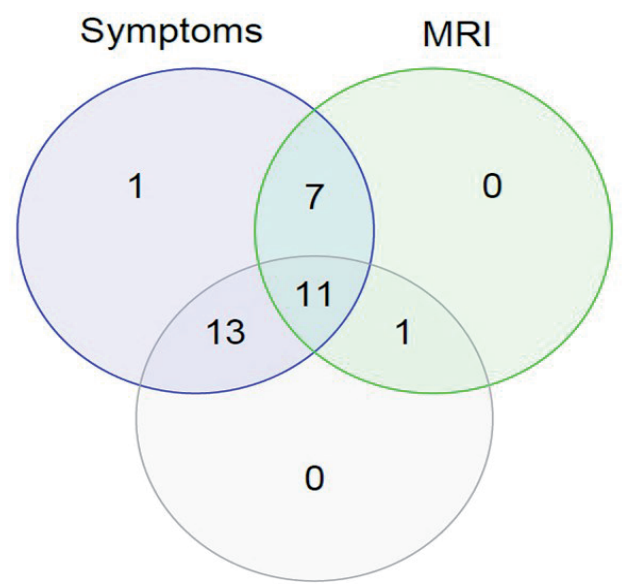

Cytology

Figure 2. Venn diagram of the diagnosis of definitive leptomeningeal metastases based on CSF cytology, MRI and progressive neurological symptoms 


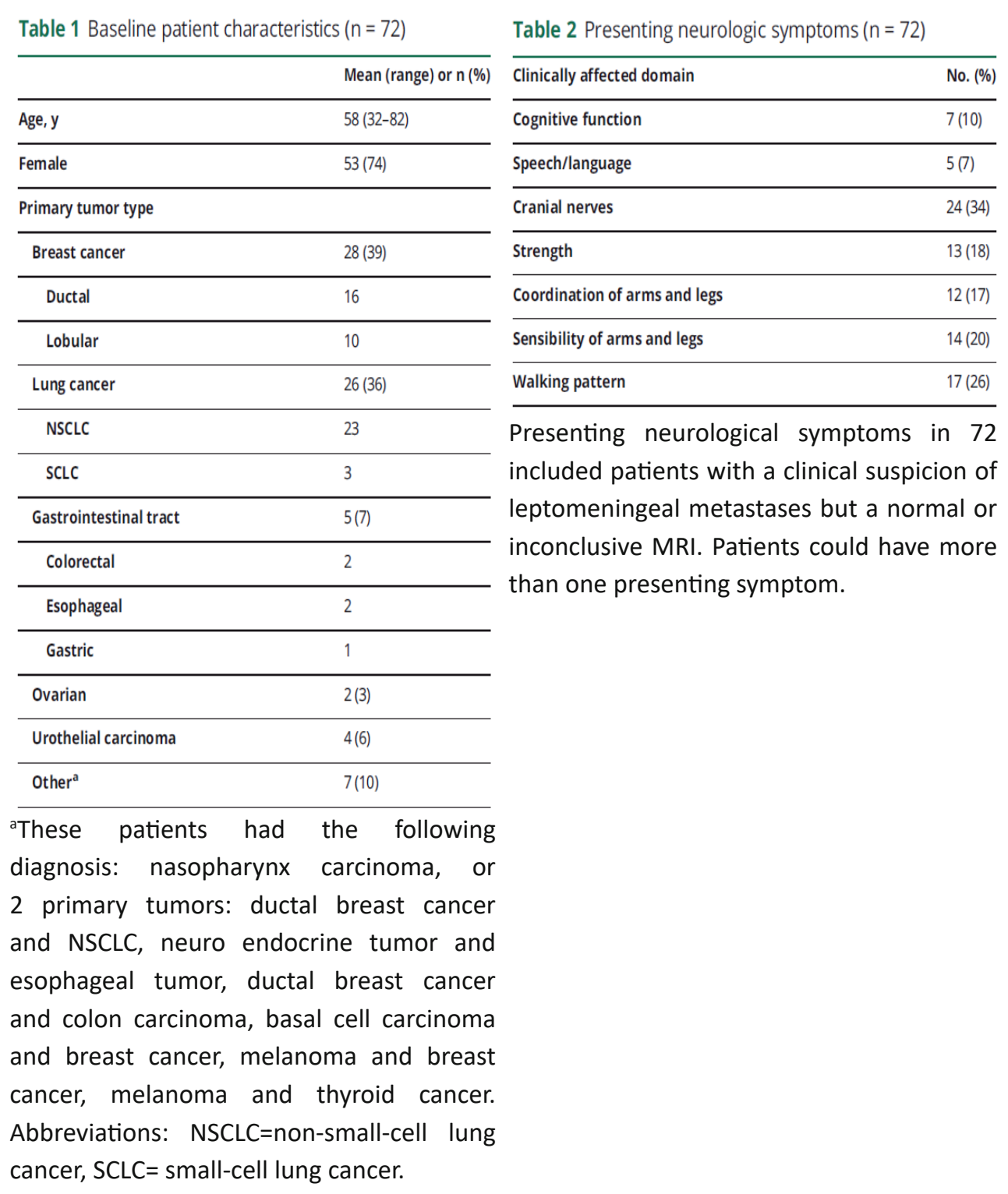


Table 3 Patients with probable and possible leptomeningeal metastases (LM) according to the European Association of Neuro-Oncology (EANO)-European Society of Medical Oncology guidelines

\begin{tabular}{|c|c|c|c|c|c|c|}
\hline Patient & Tumor type & Symptoms & MRI & $\begin{array}{l}\text { CSF } \\
\text { cytology }\end{array}$ & $\begin{array}{l}\mathrm{CTC} / \mathrm{mL} \\
\text { in CSF }\end{array}$ & $\begin{array}{l}\text { EANO LM } \\
\text { classification }\end{array}$ \\
\hline 17 & $\begin{array}{l}\text { NSCLC: EGFR } \\
\text { mutation }\end{array}$ & No typical LM symptoms & $\begin{array}{l}\text { Leptomeningeal contrast- } \\
\text { enhancing lesions }\end{array}$ & Negative & 0 & Possible LM, IIC \\
\hline 26 & Breast cancer & Epilepsy & $\begin{array}{l}\text { Focal leptomeningeal } \\
\text { contrast-enhancing lesion }\end{array}$ & Negative & 3 & Possible LM, IIA \\
\hline 71 & Breast cancer & Headache, increased ICP & $\begin{array}{l}\text { Dural contrast enhancement; } \\
\text { no leptomeningeal contrast } \\
\text { enhancement }\end{array}$ & Negative & 0.6 & $\begin{array}{l}\text { Lack of evidence } \\
\text { for LM, IID }\end{array}$ \\
\hline 86 & $\begin{array}{l}\text { NSCLC: EGFR } \\
\text { mutation }\end{array}$ & Encephalopathy & $\begin{array}{l}\text { No leptomeningeal contrast } \\
\text { enhancement }\end{array}$ & Negative & 49.6 & Possible LM, IID \\
\hline 87 & $\begin{array}{l}\text { NSCLC: EGFR } \\
\text { mutation }\end{array}$ & No typical LM symptoms & $\begin{array}{l}\text { Nodular leptomeningeal } \\
\text { lesions }\end{array}$ & Negative & 3.2 & Possible LM, IIB \\
\hline 88 & $\begin{array}{l}\text { NSCLC: no } \\
\text { EGFR mutation }\end{array}$ & Hearing loss, headache & $\begin{array}{l}\text { Single nodular } \\
\text { leptomeningeal } \\
\text { lesion }\end{array}$ & Negative & 0 & Possible LM, IIB \\
\hline 111 & $\begin{array}{l}\text { NSCLC: EGFR } \\
\text { mutation }\end{array}$ & No neurologic symptoms & $\begin{array}{l}\text { Linear and nodular } \\
\text { leptomeningeal lesions }\end{array}$ & Negative & 0.2 & Possible LM, IIC \\
\hline 129 & $\begin{array}{l}\text { NSCLC: ALK } \\
\text { translocated }\end{array}$ & $\begin{array}{l}\text { Apathy, dysphasia, right-sided } \\
\text { hemiparesis }\end{array}$ & $\begin{array}{l}\text { Linear leptomeningeal } \\
\text { lesions }\end{array}$ & Negative & 0 & Possible LM, IIA \\
\hline 144 & $\begin{array}{l}\text { NSCLC: EGFR } \\
\text { mutation }\end{array}$ & $\begin{array}{l}\text { Cerebellar syndrome, cranial nerve } \\
\text { dysfunction (CN V and CN II right-sided) }\end{array}$ & $\begin{array}{l}\text { Linear and nodular } \\
\text { leptomeningeal } \\
\text { enhancement }\end{array}$ & Negative & 0 & Probable LM, IIC \\
\hline
\end{tabular}

Abbreviations: $\mathrm{LM}=$ leptomeningeal metastases, EANO=European Association of NeuroOncology, ICP = intracranial pressure, NSCLC=non-small-cell lung cancer, $\mathrm{SCLC}=$ small-cell lung cancer, $\mathrm{CTC}=$ circulating tumor cells. EGFR=epidermal growth factor receptor, ALK= Anaplastic lymphoma kinase. 
Table 4 CSF biochemical measures, leukocyte count, and opening pressure

\begin{tabular}{llllll}
\hline $\begin{array}{l}\text { Patient } \\
\text { group }\end{array}$ & $\begin{array}{l}\text { Leukocytosis } \\
\left(>3 / \mathrm{mm}^{3}\right)\end{array}$ & $\begin{array}{l}\text { Increased total protein } \\
(>0.45 \mathrm{~g} / \mathrm{L})\end{array}$ & $\begin{array}{l}\text { Low glucose CSF/serum } \\
\text { ratio }(<0.66)\end{array}$ & $\begin{array}{l}\text { Elevated LDH } \\
(>40 \mathrm{U} / \mathrm{L})\end{array}$ & $\begin{array}{l}\text { Increased CSF opening pressure } \\
\left(>20 \mathrm{~cm} \mathrm{H}_{2} \mathrm{O}\right)\end{array}$ \\
\hline LM $(\mathrm{n}=33)$ & 61 & 85 & 44 & 48 & 52 \\
\hline $\begin{array}{l}\text { Probable LM } \\
(\mathrm{n}=9)\end{array}$ & 0 & 44 & 44 & 0 & 33 \\
\hline No LM(n=39) & 18 & 33 & 67 & 8 & 18 \\
\hline
\end{tabular}

Abbreviations: $\mathrm{LM}=$ leptomeningeal metastases, EGFR= epidermal growth factor receptor, $\mathrm{cf}=$ cell free, $\mathrm{CSF}=$ cerebrospinal fluid, $\mathrm{NSCLC}=$ non-small-cell lung cancer, $\mathrm{CTC}=$ circulating tumor cells.

\section{RESULTS}

In total, 98 patients were potentially eligible for the study as shown in Figure 1, of whom 81 patients with a clinical suspicion of LM were eligible for the assessment of the index test. In 9 patients the LM diagnosis was not definitive but these patients were scored as possible or probable LM or lack of evidence for LM according to the EANO-ESMO guidelines The test characteristics are therefore calculated based on the remaining 72 patients. The baseline characteristics of the remaining 72 patients are shown in Table 1 . The presenting neurological symptoms are depicted in Table 2.

The prevalence of LM in the eligible cohort was $41 \%(n=33)$. The final diagnosis of definitive LM was based on CSF cytology or MRI and/or progressive neurological symptoms compatible with LM as shown in Figure 2. 25 (76\%) patients had positive CSF cytology, 7 (21\%) patients were diagnosed with LM based on both $\mathrm{MRI}$ and progressive neurological symptoms and 1 (3\%) patient was diagnosed with LM based on progressive neurological symptoms only.

In 9 of the 81 patients LM diagnosis was not proven/definitive, but according to the EANO-ESMO LM clinical practice guidelines for LM they were diagnosed with possible or probable LM, as shown in Table 3.1, 12 patients with a nononcological disease were included as a control group. These patients had the following diagnoses: a neurological infectious disease (neuroborreliosis, neurolues, viral myelitis), multiple sclerosis, dementia, neuropathy or a nonneurological disease. 
CSF pressure, cell count and biochemical parameters

CSF pressure was increased $(>20 \mathrm{~cm} \mathrm{H} 2 \mathrm{O}$ ) in $52 \%$ of patients with definitive LM. Increased total protein CSF levels ( $>0.45 \mathrm{~g} / \mathrm{L}$ ) were present in $85 \%$ of patients with LM. Leucocyte CSF counts were increased $(>3 / \mathrm{mm} 3)$ in $61 \%$ of patients with LM. LDH CSF levels were increased (>40 U/L) in $48 \%$ and glucose CSF/serum ratio was decreased $(<0.66)$ in $94 \%$ of patients with LM. $10 \%$ of the patients experienced post lumbar puncture headache.

Diagnostic accuracy of CSF cytology versus EpCAM-based immunoflow cytometry

CSF cytology had a sensitivity of $76 \%(95 \% \mathrm{Cl} 58-89)$ for the diagnosis of LM. The specificity of CSF cytology is $100 \%$ as it is accepted as the gold standard for the diagnosis of LM in this patient population.[6]

For the EpCAM-based immunoflow cytometry assay in CSF a receiver operating characteristic (ROC) analysis was done to define the optimal cut-off value of the CTC number per $\mathrm{mL}$ CSF for the definitive diagnosis of LM. The optimal cut-off value for the flow cytometry assay was $0.86 \mathrm{CTC} / \mathrm{mL}$. This cut-off value provides a sensitivity of $94 \%$ (95\% Cl $80-99)$ and a specificity of $100 \%$ (95\% Cl $91-100)$. The positive predictive value was $100 \%(95 \% \mathrm{Cl} 89$ - 100) and the negative predictive value was $95 \%$ (95\% Cl 83 - 99). The receiver operating characteristic (ROC) Area Under the Curve was 0.98 (95\% Cl 0.94-1). All control patients with nononcological diseases had a CSF-CTC number equal or less than $0.2 \mathrm{CTC} / \mathrm{mL}$.

\section{Driver mutation analysis in NSCLC patients}

NSCLC was the primary tumor in 23 of 72 (32\%) included patients. In 12 of these patients (52\%) an EGFR mutation was present in their primary tumor or metastases. In 10 patients the EGFR driver or resistance mutation was determined in cfDNA CSF samples. In 3 patients without LM the EGFR mutation in cfCSF was not detected. In 5 out of 5 patients with LM the primary EGFR driver mutation was detected in cfCSF. In four of these patients the primary EGFR mutation was detected in CTC from CSF, isolated by immunoflow cytometry. Three of them were positive for the L858R mutation of exon 21 and one had an exon 19 deletion. In two LM patients with a T790M mutation in recurrent tumor or metastasis after 1st line EGFR inhibitor treatment, T790M was assessed in cfCSF. One patient was T790M positive and the other one was negative. In the patient with negative cfCSF for T790M, isolated CTC from CSF were also negative. In 6 out of 8 assessed 
plasma samples from individual EGFR mutated NSCLC patients we detected the primary EGFR driver mutation in cfDNA. The EGFR driver mutation distribution in primary tumor, plasma and CSF is depicted in Table 4.

\section{DISCUSSION}

This prospective clinical diagnostic study shows a high sensitivity of $94 \%$ and specificity of $100 \%$ for the detection of CTC with our EpCAM-based flow cytometry assay in CSF of patients with epithelial tumors and LM. It showed similar results with regard to the sensitivity and specificity in diagnosing LM as previously published for the CELLSEARCH ${ }^{\circledR}$ CTC assay.[19] EpCAM is expressed by tumors of epithelial origin like NSCLC, breast cancer or ovarian cancer.[20] The CELLSEARCH ${ }^{\circledR}$ assay is a FDA-approved assay to detect EpCAM positive CTC in blood and is adapted for use in CSF.[16,21] This method was recommended for use as part of routine LM work-up. However, in the CELLSEARCH ${ }^{\circledR}$ assay CTC are identified by an operator which coincides with inter-reviewer discordant results.[22] To avoid operator bias, immunoflow cytometry CTC assays of the CSF can be used. Our data indicate that the EpCAM-based CTC immunoflow cytometry analysis of CSF is an adequate, alternative method to detect CTC of epithelial tumors in CSF for the diagnosis of LM. Both the CELLSEARCH ${ }^{\circledR}$ CTC assay and our immunoflow cytometry EpCAM assay do not show a 100\% diagnostic accuracy for LM. In studies using the $\mathrm{CELLSEARCH}^{\circledR}$ technique 2 out of 8 patients and 2 out of 81 samples respectively were found with a positive CSF cytology but negative CTC. $[6,23]$ Our series showed two patients with LM who were negative for CTC and CSF cytology. This could be due to loss of EpCAM expression of malignant cells during the metastatic cascade of cells to the CSF.[24] The false-negative findings of EpCAM CTC analysis in patients with positive CSF cytology support the choice for cytology as an additional, non-EpCAM dependent dual diagnostic CSF method for LM. In the past, questions have been raised whether circulating epithelial cells in the blood detected by CELLSEACRHC are indeed CTC.[25] Based on the driver mutation analysis of the EpCAM-positive CTC in CSF and the absence of CTC in CSF both in patients without LM and the non-oncology control patients, we conclude that the EpCAM positive CTC found in CSF are indeed epithelial tumor cells. All diagnostic studies for LM are hampered by the lack of a golden standard for LM in case of negative CSF cytology. When CSF cytology is negative, LM diagnosis is based on an interpretation of progressive neurological symptoms and subsequent MRIs, in our study this was performed by one neurologist (D.B.) experienced in 
LM. A group of 9 patients was scored initially with an uncertain LM diagnosis. We ultimately scored these patients according the EANO/ESMO guidelines as probable LM, possible LM or lack of evidence of LM.[1] In only 3 of 9 patients with possible or probable LM, CSF-CTC were $\geq 0.9 / \mathrm{mL}$ confirming the diagnosis of LM.

EpCAM CTC analysis in CSF is not only a sensitive way to diagnose LM, but is also a quantitative assay and therefore enables patient treatment response monitoring. Thus far, LM-response is based on change of neurological symptoms and MRI and CSF cytological results. Response measurement in LM is hampered by a lack of sensitivity of CSF cytology and validation problems in response measurement of both neurological symptoms and MRI abnormalities in LM, despite ongoing efforts of the Response Assessment in Neuro-Oncology (RANO) LM group.[1,26] In this respect, it will be important to include CTC analysis methods in CSF in future LM studies and determine whether CTC numbers in CSF reflect treatment response and predict survival/prognosis in an accurate way.

In our study we included 23 NSCLC patients of whom 12 having an EGFR mutation in the primary tumor and/or metastases. In NSCLC the prevalence of EGFR driver mutations in the primary tumor is $10-20 \%$ in the Caucasian population.[27] About 90\% of the EGFR mutations are deletions in exon 19 or a L858R substitution mutation in exon 21. EGFR mutated NSCLC can be treated with ATP competitive EGFR tyrosine kinase inhibitors (TKI) of the first generation (erlotinib and gefitinib) or the irreversibly binding second generation TKI (afatinib). The T790M exon 20 substitution is in $50-60 \%$ of the cases the cause of resistance to first- and second-generation EGFR TKIs. The irreversibly binding third generation TKI osimertinib was initially registered for T790M NSCLC only. Recently, osimertinib has become first-line treatment in EGFR mutated NCSLC in case of an exon 19 deletion or L858R mutation.[27] In our study we found the primary EGFR mutation in CFCSF and isolated CTC from CSF in patients with LM. The presence of the driver mutation in the EGFR gene of the CTC isolated from CSF with FACS confirms that we indeed detect cancer cells in the CTC gate of the immunoflow cytometry assay.

Molecular analysis of tumor tissue biopsies, CTC and ctDNA derived from blood of 120 patients with EGFR mutated NSCLC showed an agreement of 95\%.[28] The isolation of tumor cells from CSF using immunoflow cytometry sorting opens the way for more extensive mutation analysis (both driver mutations and resistance mutations) of tumor cells that have metastasized to the CSF. These mutation analyses of CTC in CSF may be used to guide future treatment, in particular in 
those patients with progressive CNS metastases and stable systemic metastases. Furthermore, Next Generation Sequencing of isolated tumor cells from CSF compared to tumor cells isolated from the primary tumor and the systemic metastases may reveal the genetic mechanisms that support cells to metastasize to the CSF.

Further research with larger cohorts of patients with MRI brain (for brain metastases detection), concomitant CTC analysis of CSF (for LM detection) and paired plasma-CSF ctDNA sampling is essential in order to draw conclusions on the clinical utility of the presence of ctDNA in CSF for the diagnosis of LM. In particular patients with brain metastases near the CSF compartment may shed DNA into the CSF suggesting LM, which is not the case according to CTC-CSF analysis (false positive results). ctDNA analysis has an average sensitivity of $66 \%$ (95\% Cl 63-69) and a specificity of $96 \%$ (95\% Cl 83-99) in blood in patients with NSCLC.[12] The sensitivity of ctDNA detection in CSF in NSCLC for the diagnosis of LM is unknown but based on the results in plasma, we would expect a higher false negative rate of ctDNA detection in CSF than for CTC for the diagnosis of LM. Moreover, ctDNA mutation analysis in the CSF cannot be used currently to diagnose LM as ctDNA in CSF has also been detected in patients with brain metastases only.

In conclusion, we recommend including an EpCAM-based CTC method, either our EpCAM immunoflow cytometry assay or the FDA-approved CELLSEARCH ${ }^{\circledR}$ CTC assay, in the diagnostic work-up for patients with a clinical suspicion of LM next to CSF cytology. Driver mutation analysis of cfCSF and isolated CTC from CSF can further be used to guide future therapy of CNS metastases and unravel the pathophysiological and /genetic mechanisms of tumor cells metastasizing to the CSF.

\section{ACKNOWLEDGEMENTS}

We would like to acknowledge NKI-AVL Core Facility Molecular Pathology \& Biobanking (CFMPB) for supplying NKI-AVL Biobank material and/or laboratory support. 


\section{REFERENCES}

1. Le Rhun E, Weller M, Brandsma D, et al. EANO-ESMO Clinical Practice Guidelines for diagnosis, treatment and follow-up of patients with leptomeningeal metastasis from solid tumours. Ann Oncol 2017;28:8499.

2. Straathof CS, de Bruin HG, Dippel DW, Vecht CJ. The diagnostic accuracy of magnetic resonance imaging and cerebrospinal fluid cytology in leptomeningeal metastasis. J Neurol 1999;246:810-814.

3. Wasserstrom WR, Glass JP, Posner JB. Diagnosis and treatment of leptomeningeal metastases from solid tumors: experience with 90 patients. Cancer. 1982;49(4):759772.

4. van Oostenbrugge RJ, Twijnstra A. Presenting features and value of diagnostic procedures in leptomeningeal metastases. Neurology 1999;53:382-385.

5. Tu $Q$, Wu X, Le Rhun E, et al. CellSearch technology applied to the detection and quantification of tumor cells in CSF of patients with lung cancer leptomeningeal metastasis. Lung Cancer 2015;90:352-357.

6. Lee JS, Melisko ME, Magbanua MJ, et al. Detection of cerebrospinal fluid tumor cells and its clinical relevance in leptomeningeal metastasis of breast cancer. Breast Cancer Res Trea. 2015;154:339-349.

7. Nayak L, Fleisher M, Gonzalez-Espinoza $\mathrm{R}$, et al. Rare cell capture technology for the diagnosis of leptomeningeal metastasis in solid tumors. Neurology 2013;80:1598-605; discussion 1603.

8. Jiang B-Y, Li Y-S, Guo W-B, et al. Detection of Driver and Resistance Mutations in Leptomeningeal Metastases of NSCLC by Next-Generation Sequencing of Cerebrospinal Fluid Circulating Tumor Cells. Clin Cancer Res 2017;23:5480-5488.

9. Milojkovic Kerklaan B, Pluim D, Bol $M$, et al. EpCAM-based flow cytometry in cerebrospinal fluid greatly improves diagnostic accuracy of leptomeningeal metastases from epithelial tumors. Neuro Oncol 2016;18:855-862.

10. Subira D, Serrano C, Castanon $\mathrm{S}$, et al. Role of flow cytometry immunophenotyping in the diagnosis of leptomeningeal carcinomatosis. Neuro Oncol 2012;14:43-52.

11. Subira D, Simo $M$, Illan J, et al. Diagnostic and prognostic significance of flow cytometry immunophenotyping in patients with leptomeningeal carcinomatosis. Clin Exp Metastasis 2015;32:383-391.

12. Merker JD, Oxnard GR, Compton C, et al. Circulating Tumor DNA Analysis in Patients With Cancer: American Society of Clinical Oncology and College of American Pathologists Joint Review. J Clin Oncol 2018;36:1631-1641.

13. Ahn MJ, Kim DW, Cho BC, et al. Activity and safety of AZD3759 in EGFR-mutant non-small-cell lung cancer with CNS metastases (BLOOM): a phase 1, openlabel, dose-escalation and dose-expansion study. Lancet Respir Med 2017;5:891-902.

14. Pan W, Gu W, Nagpal S, Gephart $\mathrm{MH}$, Quake SR. Brain tumor mutations 
detected in cerebral spinal fluid. Clin Chem 2015;61:514-522.

15. Pluim D, Devriese LA, Beijnen $\mathrm{JH}$, Schellens JHM. Validation of a multiparameter flow cytometry method for the determination of phosphorylated extracellular-signal-regulated kinase and DNA in circulating tumor cells. Cytometry A 2012;81:664-671.

16. van Bussel MTJ, Pluim $D$, Bol $M$, Beijnen JH, Schellens JHM, Brandsma D. EpCAM-based assays for epithelial tumor cell detection in cerebrospinal fluid. J Neurooncol 2018;137:1-10.

17. van Ginkel JH, van den Broek DA, van Kuik J, et al. Preanalytical blood sample workup for cell-free DNA analysis using Droplet Digital PCR for future molecular cancer diagnostics. Cancer Med 2017;6:2297-2307.

18. Bossuyt PM, Reitsma JB, Bruns DE, et al. STARD 2015: an updated list of essential items for reporting diagnostic accuracy studies. BMJ 2015;351:h5527.

19. Lin $X$, Fleisher $M$, Rosenblum $M$, et al. Cerebrospinal fluid circulating tumor cells: a novel tool to diagnose leptomeningeal metastases from epithelial tumors. Neuro Oncol 2017;19:1248-1254.

20. Went PT, Lugli A, Meier $S$, et al. Frequent EpCam protein expression in human carcinomas. Hum Pathol 2004;35:122-128.

21. Hayes DF, Cristofanilli M, Budd GT, et al. Circulating tumor cells at each followup time point during therapy of metastatic breast cancer patients predict progressionfree and overall survival. Clin Cancer Res.
2006;12(14 Pt 1):4218-4224.

22. Kraan J, Sleijfer S, Strijbos $M H$, et al. External quality assurance of circulating tumor cell enumeration using the CellSearch $\left({ }^{\circledR}\right)$ system: a feasibility study. Cytometry B Clin Cytom 2011;80:112-118.

23. Le Rhun E, Massin F, Tu Q, Bonneterre J, Bittencourt Mde C, Faure GC. Development of a new method for identification and quantification in cerebrospinal fluid of malignant cells from breast carcinoma leptomeningeal metastasis. BMC Clin Pathol. 2012;12:21.

24. Königsberg $R$, Obermayr E, Bises $G$, et al. Detection of EpCAM positive and negative circulating tumor cells in metastatic breast cancer patients. Acta Oncol 2011;50:700-710.

25. Fiegl $M$, Denz H. Circulating epithelial cells in breast cancer. N Engl J Med. 2004;351(23):2452-4; author reply 2452-4.

26. Chamberlain $M$, Junck $L$, Brandsma $D$, et al. Leptomeningeal metastases: A RANO proposal for response criteria. Neuro Oncol 2017;19:484-492.

27. Planchard D, Popat $S$, Kerr K, et al. Metastatic non-small cell lung cancer: ESMO Clinical Practice Guidelines for diagnosis, treatment and follow-up. Ann Oncol 2018;29:192-237.

28. He J, Tan W, Ma J. Circulating tumor cells and DNA for real-time EGFR detection and monitoring of non-small-cell lung cancer. Future Oncol 2017;13:787-797. 
Clinical and preclinical application of biomarker methods 


\section{CHAPTER 2 \\ Clinical and preclinical application of biomarker methods}

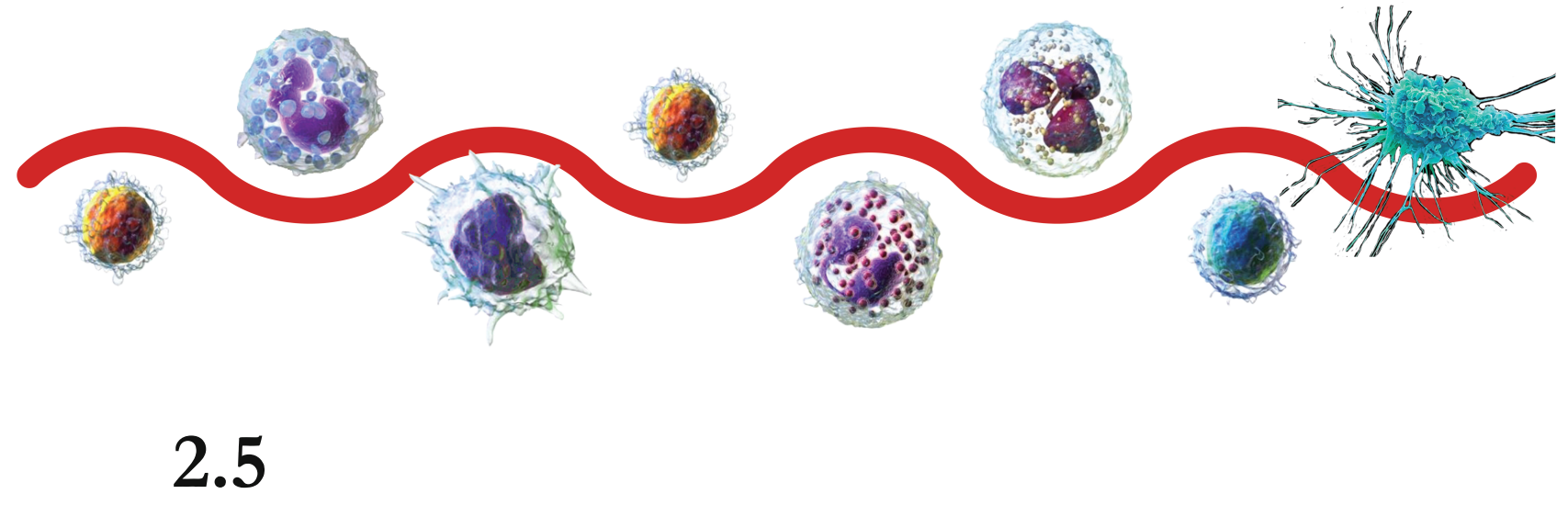

Circulating melanoma cell detection and driver mutation analysis in cerebrospinal fluid in melanoma patients with suspected leptomeningeal metastases

Mark T.J. van Bussel*, Dick Pluim1*, Bojana Milojkovic Kerklaan, Emilie Le Rhun, Mijke Bol, Dorothe Linders, Daan van den Broek, Karolina Sikorska, Annette Compter, Jos H. Beijnen, Jan H.M. Schellens, Dieta Brandsma

*authors contributed equally and share first authorship

Manuscript in preparation. 


\section{ABSTRACT}

Background: To improve CSF diagnostics for LM in melanoma patients, a melanoma-associated chondroitin sulphate proteoglycan (MCSP) /CD146-based circulating melanoma cell (CMC) immunoflow cytometry assay was developed.

Methods: In a multicentre, prospective clinical study, we tested the performance of this assay in 42 patients with clinical suspicion for LM (36: negative/equivocal $\mathrm{MRI}$; 6: typical leptomeningeal contrast enhancement on MRI). CMC in CSF were also enumerated in 10 non-oncological control patients. EANO-ESMO clinical practice guidelines were followed to classify LM diagnosis. Digital droplet PCR (ddPCR) was used to detect BRAFV600E mutation in paired cell free CSF, isolated CMC from CSF and plasma samples in 15 BRAFV600E mutated melanoma patients.

Results: Thirteen patients had confirmed LM by CSF cytology, 1 probable LM, 8 possible LM and 20 no LM. CMC were detected in CSF in 11 of 12 patients with confirmed LM in whom CSF samples were available (1.9-5587 CMC/mL). In one patient no CMC were found. One probable $\mathrm{LM}$ patient had $180 \mathrm{CMC} / \mathrm{mL}$ and 2 of 8 possible LM patients showed 9.8 and $3.5 \mathrm{CMC} / \mathrm{mL}$, respectively. Control and non-LM patients had $\leq 0.3 \mathrm{CMC} / \mathrm{mL}$. Cell-free CSF of all 4 BRAFV600E mutated melanoma patients with confirmed LM showed a BRAFV600E mutation. CMC isolated from CSF in 2 of these patients were also BRAFV600E positive.

Conclusion: The newly developed MCSP/CD146 immunoflow cytometry assay is a promising tool to detect melanoma cells in CSF and diagnose LM. DdPCR can be used to detect BRAFV600E mutations in both cell-free CSF and CMC isolated from CSF.

\section{IMPORTANCE OF STUDY}

The diagnosis of LM is hampered by a lack of sensitivity of MRI and CSF cytology. In this study we show that by using the MCSP/CD146 immunoflow cytometry assay we can detect melanoma cells in CSF of patients with confirmed LM whereas no melanoma cells were found in CSF of patients without LM. BRAFV600E mutations were detected using digital droplet PCR in both cell-free CSF and isolated melanoma cells in CSF. This study holds promise for a more accurate diagnosis of LM from melanoma using enumeration and molecular characterization of melanoma cells in CSF. 


\section{INTRODUCTION}

Patients with leptomeningeal metastases (LM) of melanoma usually have a poor prognosis with a survival of 1.7-2.5 months [1-3]. Melanoma is the primary tumor type in 5-25\% of the patients with LM from solid tumors [4]. In a cohort of 355 patients with stage IV metastatic melanoma with brain metastases, LM was diagnosed on MRI in 11\% of patients [5]. Diagnosis of LM is 'definitive' when CSF cytology is positive and 'probable' at combination of typical clinical symptoms and contrast enhancing (nodular or linear) leptomeningeal lesions on MRI of brain and/or spine in a patient with known (metastatic) cancer. However, clinical assessment may be challenging in the context of concomitant brain metastases and MRI has a low sensitivity (76\%) and specificity (77\%) for the diagnosis of LM in patients with solid tumors [6]. Sensitivity of cerebrospinal fluid (CSF) cytology is also low: $44-67 \%$ at first LP, increasing to $84-91 \%$ upon second sampling [7-15]. Circulating epithelial tumor cells can be quantified by assays which use antibodies against epithelial cell adhesion molecule (EpCAM). These assays show 76-100\% sensitivity for epithelial tumor cell detection in CSF [9-15]. Circulating tumor cell (CTC) analysis in CSF can enable more accurate diagnostics of LM and may also be used to monitor treatment response in LM. Only one case series of two patients with LM from melanoma has been published in which circulating melanoma cells (CMC) in CSF were analyzed with an adapted CELLSEARCH ${ }^{\circledR}$ assay [16]. Melanoma cell adhesion molecule (MCAM) or CD146 was used as a marker in this assay for immuno-magnetical enrichment of CMC [17]. However, the CD146 capture antigen is not completely specific for CMC as endothelial cells and lymphocytes also express CD146 [18,19]. Melanoma chondroitin sulfate proteoglycan (MCSP), also known as high molecular weight melanoma associated antigen (HMWMAA) or neuron glia antigen-2 (NG2), is expressed by $75-100 \%$ of malignant lesions of melanocyte origin [20-22]. MCSP is involved in cell migration and cell proliferation $[23,24]$ and is expressed in fetal skin, abdominal and perineal skin and occasionally in hair follicles and squamous and basal cell carcinomas [20]. It is also expressed in the developing and adult central nervous system [25]. To improve CSF diagnostics in melanoma patients, we developed a MCSP/CD146based immunoflow cytometry assay for CMC detection in CSF. We tested the performance of this assay in CSF of 36 patients with a clinical suspicion on LM but negative or equivocal MRI and in 6 patients with clinical suspicion for LM and typical leptomeningeal contrast enhancement on MRI. Moreover, BRAFV600E mutation analysis was done using digital droplet PCR (ddPCR) in paired plasma 
and cell-free CSF and CMC isolated from CSF samples in 15 BRAFV600E mutated melanoma patients.

\section{Methods and study design}

\section{CMC immunoflow cytometry assay}

The CMC immunoflow cytometry assay development and validation is described in the supplement of this paper. CSF for CMC flow cytometry was collected in a conical $50 \mathrm{~mL}$ tube. After fixation with $4 \%$ formaldehyde samples were washed with $50 \mathrm{~mL}$ physiological saline and centrifuged at $1000 \mathrm{~g}$ for 7 minutes at $4^{\circ} \mathrm{C}$. Pellets were resuspended in $50 \%$ methanol/phosphate buffered saline and stored at $-80^{\circ} \mathrm{C}$ for a maximum of 6 months. CMC measurements were performed in batches. After defrosting on ice, the supernatant was removed and cell pellets were washed twice with ice-cold beads buffer (BB). After centrifugation, pellets were resuspended in the remaining $100 \mu \mathrm{L}$ BB. Next, $40 \mu \mathrm{L}$ of Fc-receptor block was added and samples were incubated for $1 \mathrm{~h}$ at room temperature (RT). Subsequently, a volume of $2.5 \mu \mathrm{L}$ of anti-MCSP-Micro-Beads was added, and samples were incubated for an additional $1 \mathrm{~h}$ at RT. Next, samples were washed twice with $1 \mathrm{~mL}$ of $\mathrm{BB}$, followed by centrifugation. After discarding the supernatant, cell pellets were resuspended in $500 \mu \mathrm{L}$ of BB. Subsequently, labeled cells were separated using a magnetic antibody cell sorting (MACS) column. After removal of the column from the magnetic field, the retained MCSP-positive cells were eluted into $2 \mathrm{~mL}$ eppendorf tubes using two volumes of $1 \mathrm{~mL}$ BB. Next, the CMC enriched samples were stained in $100 \mu \mathrm{L}$ Perm/WashTM (P/W) containing $10 \mu \mathrm{M}$ Hoechst33258, $0.25 \mu \mathrm{L}$ CD146-allophycocyanin (APC), $5 \mu \mathrm{L}$ anti-MCSPphycoerythrin (PE), and $5 \mu \mathrm{L}$ anti-human CD45 fluorescein isothiocyanate (FITC) for $1 \mathrm{~h}$ at RT. After extensive washing with BB, tumor cells were quantified by fluorescent activated cell sorting (FACS).

\section{CMC morphology}

Stained and processed CSF samples from two melanoma patients were sorted using a FACSaria ${ }^{\mathrm{TM}}$ cell sorter with gates set for leucocytes and CMC as shown in Figure $1 \mathrm{~A}$. After centrifugation the cell pellet was resuspended in $100 \mu \mathrm{L}$ of $\mathrm{BB}$ and stained with $5 \mu \mathrm{L}$ of anti-CD45-APC for $1 \mathrm{~h}$ at RT. After washing twice with $1 \mathrm{~mL}$ of $\mathrm{MQ}$, samples were resuspended in $10 \mu \mathrm{L}$ of $\mathrm{MQ}$ and transferred to a microscope slide. The slide was dried for $5 \mathrm{~min}$ at $30^{\circ} \mathrm{C}$ by vacuum concentration 


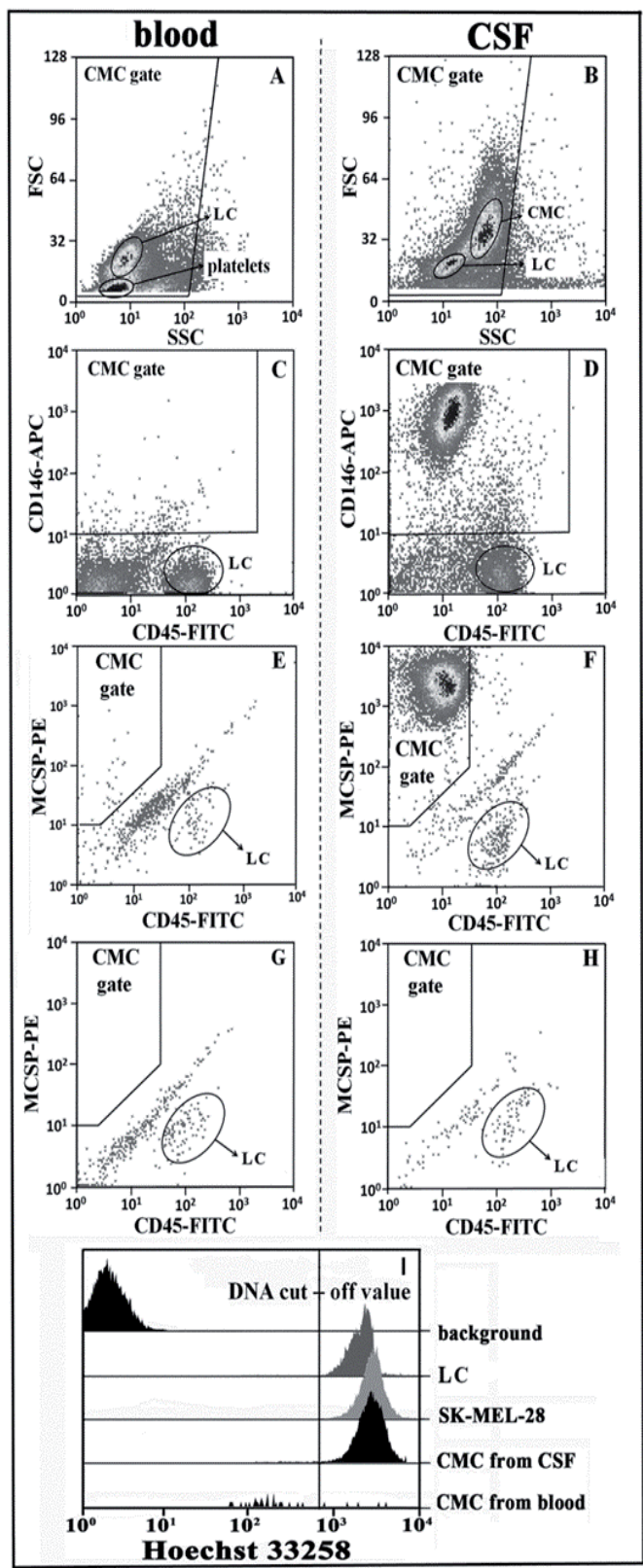

Figure 1a. Fluorescence activated cell sorting plots of CMC in blood and CSF.

Representative fluorescence activated cell sorting (FACS) plots with indicated gate settings used for circulating melanoma cells (CMC) enumeration and DNA content determination. In step 1 ( $A$ and $B$ ), CMC are gated by forward and sideward scatter characteristics for size and cell complexity to eliminate debris. The background DNA, leucocytes (LC), platelets, and CMC isolated from blood and cerebrospinal fluid (CSF) are shown. In step 2 (C and D), CMC are gated for CD146-APC positivity. In step 3 ( $E$ and F) CMC are gated for MCSPPE and CD45-FITC positivity to eliminate platelets and LC (patient with LM). G and $\mathrm{H}$ are FACS plots of blood and CSF from a patient without LM. The DNA cut-off value (I) was used to differentiate between $\mathrm{CMC}$ with low and normal to high DNA content. $\mathrm{CMC}=$ circulating melanoma cells; $\mathrm{LC}=$ leucocytes; FSC = forward scatter; SSC = side scatter; CD146-APC = Cluster of Differentiation 146-AlloPhyCocyanin; CD45-FITC = Cluster of Differentiation45Fluorescein IsoThioCyanate; MCSP$\mathrm{PE}=$ Melanoma Chondroitin Sulfate Proteoglycan-Phycoerythrin. 


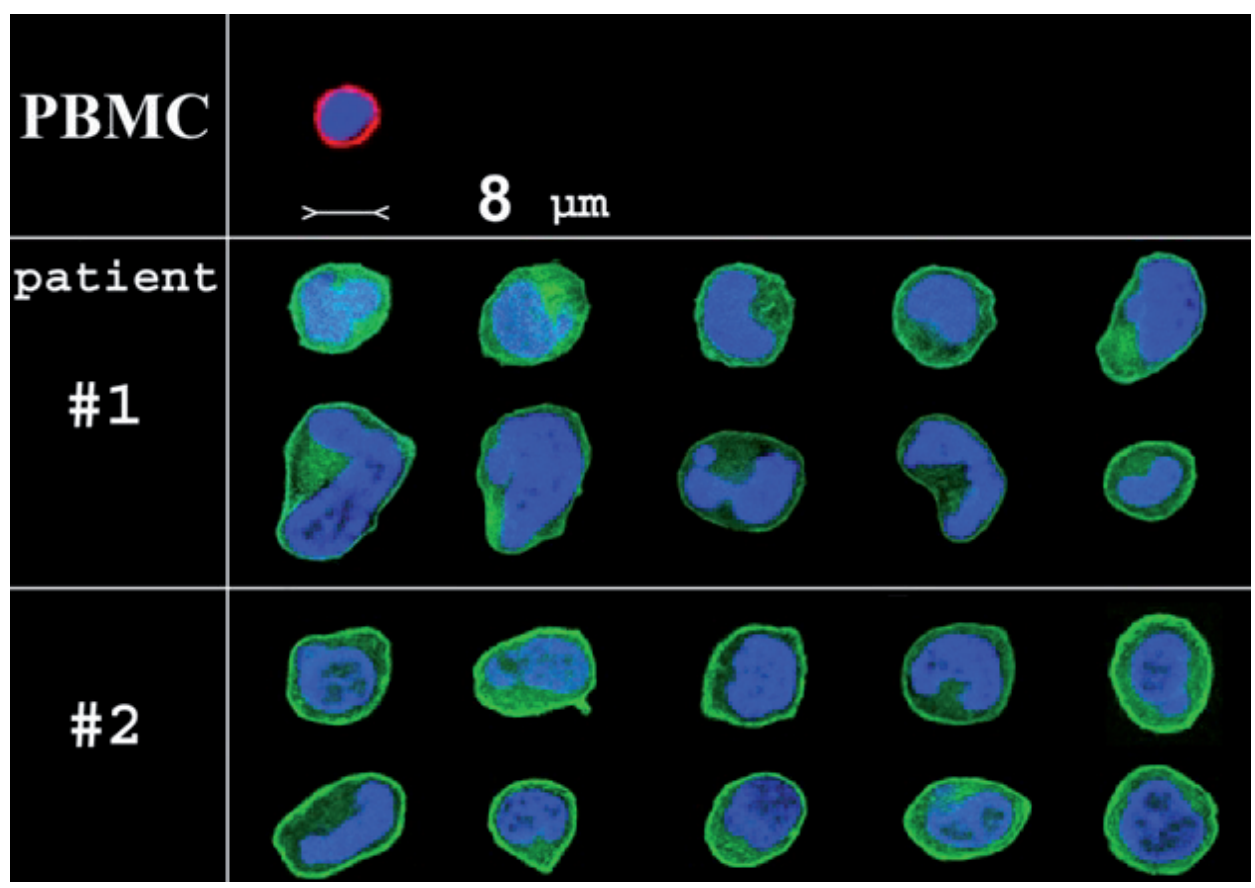

Figure 1b. Morphology of circulating melanoma cells in CSF in two patients. Morphology of representative circulating melanoma cells $(\mathrm{CMC})$, isolated from $5 \mathrm{~mL}$ of cerebrospinal fluid (CSF) from two metastatic melanoma patients with LM (patient \#1 and \#2), sorted by fluorescence-activated cell sorting (FACS) using the CMC gate setting (Fig.1a-F). CD45, Hoechst33258, and MCSP are visible as red, blue, and green colors, respectively. An example of a typical leucocyte sorted by FACS using the leucocytes gate setting (Fig.1a-E) is included. Imaging was performed at 100 times magnification. CD45 = Cluster of Differentiation45; MCSP = Melanoma Chondroitin Sulfate Proteoglycan; PBMC $=$ peripheral blood mononuclear cell. 
in a SpeedVac (Savant, Rarmindale, USA). After applying $3 \mu \mathrm{L}$ of Vectashield $\mathrm{H}-1000$ (Vector, Burlingame, USA) a round object glass of $1 \mathrm{~cm}$ in diameter was put on top and sealed with nail polish. Stained DNA, MCSP, and CD45 were visualized as blue (Hoechst 33258), green (anti-MCSP-PE), and red (anti-CD45-APC) colours, respectively. CMC were identified and photographed using a SP5 confocal fluorescence microscope (Leica, Rijswijk, The Netherlands).

\section{Driver mutation analysis}

CMC from CSF were isolated with a FACSaria' ${ }^{\mathrm{TM}}$ cell sorter. Selective driver mutation analysis of cell free CSF (cFCSF), plasma and CMC isolated from CSF was performed using a QX200 ${ }^{\mathrm{TM}}$ Droplet Digital ${ }^{\mathrm{TM}}$ PCR (ddPCR) (Biorad Laboratories Inc, California, USA). CSF was collected in a Sterilin ${ }^{\mathrm{TM}}$ universal polystyrene container and cfCSF was obtained via centrifugation at $1700 \mathrm{~g}$ for $10 \mathrm{~min}$. Blood samples were collected in $\mathrm{K}_{2}$ EDTA (di-potassium ethylene diamine tetra acetic acid) tubes (Becton Dickinson, Franklin Lakes, USA). Plasma was separated from the blood by centrifugation at $380 \mathrm{~g}$ during $20 \mathrm{~min}$. Cell free plasma was obtained by centrifugation at $20.000 \mathrm{~g}$ during $10 \mathrm{~min}$. CfDNA (cell-free DNA) was extracted using the QIAsymphony DSP circulating DNA Kit. (Qiagen, Hilden, Germany). CfDNA isolated from plasma and CSF was analysed by ddPCR. [26]

\section{Multicenter prospective clinical study}

The institutional review boards of the Netherlands Cancer Institute - Antoni van Leeuwenhoek (Amsterdam, The Netherlands) Medical Center Slotervaart (Amsterdam, The Netherlands) and Oscar Lambret Center (Lille, France) approved the study. Patients $\geq 18$ years with melanoma and a clinical suspicion of LM but negative or equivocal MRI, who had to undergo a diagnostic lumbar puncture (LP) were asked to participate. Six patients were included with neurological symptoms suspicious for LM and typical leptomeningeal (nodular or linear) contrast enhancing lesions on MRI. Written informed consent was obtained from all participants. The diagnosis of LM was defined according to the EANO-ESMO diagnostic criteria for LM. [1] Diagnostic categories were defined as follows: 1. confirmed LM by positive CSF cytology, 2. probable LM based on typical clinical findings and typical (linear or nodular) leptomeningeal contrast-enhancement of leptomeninges on MRI but negative CSF cytology 3. possible LM based on typical clinical signs, a normal MRI and negative CSF cytology or no typical clinical 
signs, typical (linear or nodular) contrast-enhancement on MRI and negative CSF cytology and 4. no LM (lack of evidence) defined as no typical clinical signs, normal MRI and negative CSF cytology. Exclusion criteria were contra-indications for a LP, including intracranial or intraspinal tumor with mass effect heralding the risk of herniation and uncorrected thrombocytopenia or coagulation disorders. Patients were included between October 2012 and August 2018. This study is registered with ClinicalTrials.gov, number NCT01713699. The primary objective of the study was to determine the sensitivity and specificity of the detection of CMC for the diagnosis of LM in patients with melanoma compared to CSF cytology. In this paper the results of an interim analysis are being presented.

\section{RESULTS}

Melanoma cell detection with MCSP/CD146 immunoflow cytometry

Representative FACS plots for CMC detection in blood and CSF using the MCSP/ CD146 immunoflow cytometry assay are depicted in Figure $1 \mathrm{~A}$.

\section{CMC morphology in CSF}

For determining morphology of CMC in CSF, CMC isolated from $5 \mathrm{~mL}$ of CSF from two melanoma patients with confirmed LM were processed and sorted by FACS. A picture of the morphological analysis of CMC in CSF of these two patients is shown in Figure 1B. The diameter of CMC varied between 12 and $22 \mu \mathrm{m}$. Most $\mathrm{CMC}$ had an oval or irregular shape, with lobular nuclei and a fluorescent green membrane due to specific anti-MCSP-PE staining. CMC were easily distinguished from leucocytes, which were smaller with a mean diameter of $8.0 \pm 1.5 \mu \mathrm{m}$, had a rounder shape and condensed nucleus, and a bright red cell membrane due to specific anti-CD45-APC staining. No leucocytes were detected in the CMC gate and vice versa no $\mathrm{CMC}$ were detected in the leucocyte gate. 
Table 1. Baseline characteristics and presenting neurological symptoms of patients suspected for leptomeningeal metastases. Patients can have more than one presenting neurological symptom. BRAF = v-Raf murine sarcoma viral oncogene homolog $B$, NRAS = neuroblastoma RAS viral ( $v$-ras) oncogene homolog protein, $\mathrm{MEK}=$ mitogen-activated protein kinase kinase, $\mathrm{WHO}=$ World Health Organization.

\begin{tabular}{|l|c|}
\hline Mean age in years, [range] & $54(20-83)$ \\
\hline Gender, women $\mathrm{n}(\%)$ & $21(49)$ \\
\hline Type of mutation $\mathrm{n}(\%)$ & \\
- BRAF & $29(69)$ \\
- NRAS & $6(14)$ \\
- other mutation & $2(5)$ \\
- no mutation & $3(7)$ \\
- mutation not determined & $2(5)$ \\
\hline Brain metastases $\mathrm{n}(\%)$ & $19(45)$ \\
\hline Other metastases $\mathrm{n}(\%)$ & \\
- lymphnode & $29(69)$ \\
- lung & $17(41)$ \\
- liver & $7(17)$ \\
- bone & $10(24)$ \\
- skin & $14(33)$ \\
\hline Systemic treatment before inclusion & \\
- BRAF/MEK inhibition & $11(26)$ \\
- immunotherapy & $16(38)$ \\
\hline WHO performance state at inclusion study $\mathrm{n}(\%)$ & \\
-WHO 0-1 & $23(55)$ \\
\hline Presenting neurological symptoms & $\mathrm{n}(\%)$ \\
of clinically affected domain & \\
- cognitive function & $7(17)$ \\
- speech/language & $4(10)$ \\
- cranial nerves & $12(29)$ \\
- strength & $11(29)$ \\
- coordination of arms and legs & $12(31)$ \\
- sensibility of arms and legs & $12(33)$ \\
- walking pattern & $16(43)$ \\
\hline
\end{tabular}



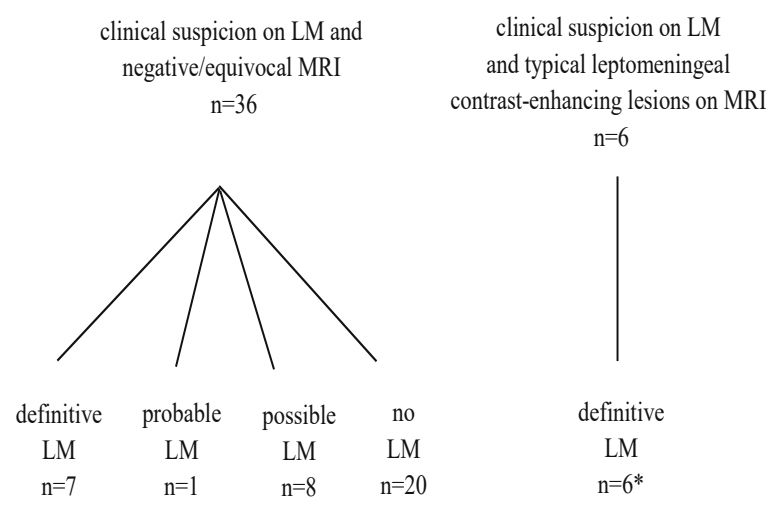
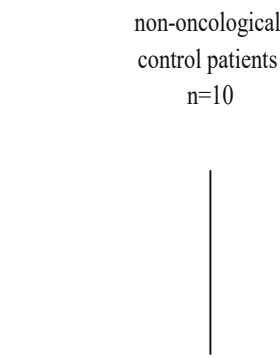

neuroborreliosis, neurolues, viral myelitis, multiple sclerosis, dementia, neuropathy or a non-neurological disease $n=10$

Figure 2. Inclusion of patients in clinical study and final diagnoses. LM was classified according to the EANO-ESMO criteria as definitive LM (CSF cytology proven), probable LM (typical clinical symptoms and typical MRI abnormalities, CSF cytology negative) or possible LM (typical clinical symptoms, no typical MRI abnormalities, CSF cytology negative) and no LM. [1] LM = leptomeningeal metastases; $M R I=$ magnetic resonance imaging; $\mathrm{CMC}=$ Circulating Melanoma Cells; CSF = cerebrospinal fluid. ${ }^{*}$ No CSF available for immunoflow cytometry in 1 patient.

\section{Multicenter prospective clinical study}

In this multicenter, prospective clinical study, 36 patients with a clinical suspicion on LM and a negative or equivocal MRI and 6 patients with a clinical suspicion on LM and typical leptomeningeal contrast-enhancing on MRI were included. The baseline patient characteristics and presenting neurological symptoms of these 42 patients are shown in Table 1 . Ten patients with a non-oncological medical history and suspicion on a neurological disease (e.g. infectious or auto-immune meningitis, subarachnoid hemorrhage) were included.

\section{LM diagnosis and CSF characteristics}

In Figure 2 the inclusion of patients in the clinical study and there final diagnoses is shown. LM diagnosis was confirmed by CSF cytology in 13 of 42 patients. $84 \%$ of these patients had concomitant brain metastases. In $100 \%$ of patients with confirmed LM, leucocytes in CSF were increased $(>3 / \mathrm{mm} 3$ ). Total protein CSF concentration was increased (>0.45 g/L) in $54 \%$ of patients and glucose CSF/serum 


\begin{tabular}{|l|c|}
\hline EANO-ESMO LM diagnosis & Mean (range) CMC/mL in CSF \\
\hline Confirmed LM $(n=12)^{*}$ & $1076(0-5587)$ \\
\hline Probable LM $(n=1)$ & $180(N A)$ \\
\hline Possible LM $(n=8)$ & $1.7(0-9.8)$ \\
\hline No LM $(n=20)$ & $0.11(0-0.3)$ \\
\hline
\end{tabular}

Table 2. Immunoflow cytometry results of CMC enumeration in CSF of patients with the diagnosis of LM according to EANO-ESMO clinical practice guidelines [1]. LM = leptomeningeal metastases; $\mathrm{CMC}=$ Circulating Melanoma Cells; CSF = cerebrospinal fluid; $\mathrm{NA}=$ not applicable. * no CSF sample for immunoflowcytometry was available in one patient.

ratio was decreased in $83 \%$ (glucose CSF/serum ratio <0.66).

In 9 patients the diagnosis probable/possible LM (1 probable LM; 8 possible LM) was made. $33 \%$ of patients had concomitant brain metastases. Leucocytes in CSF were increased in 57\%, total protein CSF concentration was increased in $75 \%$ and glucose CSF/serum ratio was decreased in $100 \%$ of patients. In the remaining 20 patients without LM, $20 \%$ of patients had concomitant brain metastases. Leucocytes were increased in CSF in 37\%, total CSF protein concentration was increased in $58 \%$ and glucose CSF/serum ratio was decreased in $53 \%$ of patients.

\section{CMC immunoflow cytometry results}

Results of CMC detection in the patient groups classified according to the EANOESMO LM criteria are shown in Table 2. Six patients had a clinical suspicion on LM and typical leptomeningeal contrast-enhancement on MRI before the LP was performed. In all 6 patients positive CSF cytology confirmed the diagnosis of LM. In 1 of these patients no CSF was available for CMC enumeration. In the other 5 patients $1.9-3592 \mathrm{CMC} / \mathrm{mL}$ CSF were detected.

In 36 patients a LP was performed because of neurological symptoms suspicious for LM with a negative or equivocal MRI. In 7 of these patients LM was confirmed based on positive CSF cytology: in 6 because of positive CSF cytology at first LP and in 1 patient based on positive CSF cytology at second LP while equivocal CSF cytology results were obtained at first LP. In one of 7 patients with confirmed LM, CMC were negative. In the other 6 patients, CMC numbers in CSF varied from 4.3- $5587 \mathrm{CMC} / \mathrm{mL}$. In the patient with equivocal CSF cytology at first $\mathrm{LP}$ and positive CSF cytology at second $\mathrm{LP}, 42 \mathrm{CMC} / \mathrm{mL}$ were found at first LP and $48 \mathrm{CMC} / \mathrm{mL}$ at second LP.

One patient was diagnosed with probable LM according to the EANO-ESMO 
criteria. In this patient, $180 \mathrm{CMC} / \mathrm{mL}$ in CSF were found. The patient showed stable disease with BRAF- and MEK-inhibition, followed by anti-PD1 treatment during more than 3 years; he finally died 3.5 years after study inclusion, due to progressive metastatic disease, including progressive LM confirmed by MRI. Eight patients were diagnosed with possible LM. Six of these patients showed 0-0.2 CMC/mL. In two possible LM patients $9.8 \mathrm{CMC} / \mathrm{mL}$ and $3.5 \mathrm{CMC} / \mathrm{mL} \mathrm{CSF}$ were found, respectively. The first patient died 9 months later, but it is unknown whether this was due to progressive LM; the other patient died from progression of (concomitant) brain metastases.

Twenty patients with a clinical suspicion on LM but negative or equivocal MRI ultimately did not have LM. All these 20 patients had $\leq 0.3 \mathrm{CMC} / \mathrm{mL}$. Furthermore, 10 patients with a non-oncological medical history with suspicion on a neurological disease and a clinical indication for a LP were included in the study. Final diagnoses were neuroborreliosis, neurolues, viral myelitis, multiple sclerosis,

Table 3. Driver mutation distribution in plasma, cfCSF and CMC isolated from CSF in $\mathbf{1 5}$ BRAFV600E mutated melanoma patients. LM was diagnosed according to the EANOESMO clinical practice guidelines for LM. [1] CfCSF = cell-free cerebrospinal fluid; $C M C=$ circulating melanoma cells; BRAFV600E = v-Raf murine sarcoma viral oncogene homolog $B$; $\mathrm{LM}=$ leptomeningeal metastases; ND = not done.

\begin{tabular}{|l|c|c|c|c|}
\hline $\begin{array}{l}\text { Diagnosis EANO-ESMO } \\
\text { LM criteria } \\
\text { (patient number) }\end{array}$ & $\begin{array}{c}\text { Plasma } \\
\text { BRAFV600E }\end{array}$ & $\begin{array}{c}\text { cfCSF } \\
\text { BRAFV600E }\end{array}$ & $\begin{array}{c}\text { Isolated CMC in CSF } \\
\text { BRAFV600E }\end{array}$ & $\begin{array}{c}\text { CMC/mL } \\
\text { CSF }\end{array}$ \\
\hline Confirmed LM (6) & Not done & Positive & Not done & 42 \\
\hline Confirmed LM (19) & Not done & Positive & Positive & 1834 \\
\hline Confirmed LM (43) & Not done & Positive & Not done & 15 \\
\hline Confirmed LM (72) & Not done & Positive & Positive & 1622 \\
\hline Possible LM (12) & Not done & Negative & - & 0 \\
\hline Possible LM (33) & Not done & Negative & Negative & 9.8 \\
\hline Possible LM (140) & Negative & Negative & - & 0 \\
\hline No LM (1) & Not done & Negative & - & 0 \\
\hline No LM (5) & Not done & Negative & - & 0 \\
\hline No LM (63) & Not done & Negative & - & 0 \\
\hline No LM (113) & Negative & Negative & - & 0.2 \\
\hline No LM (124) & Positive & Negative & - & 0.2 \\
\hline No LM (128) & Positive & Positive & - & 0.2 \\
\hline No LM (135) & Negative & Negative & - & 0.2 \\
\hline No LM (137) & Negative & Negative & - & 0.2 \\
\hline
\end{tabular}


dementia, neuropathy or a non-neurological disease. CMC numbers in the CSF in these 10 control patients were also $\leq 0.3 \mathrm{CMC} / \mathrm{mL}$.

\section{BRAFV600 driver mutation analysis}

In total 29 of the included 42 melanoma patients (67\%) had a BRAFV600E mutation detected in either the primary tumor or metastasis. In a subset of 15 BRAFV600E positive patients in whom plasma and CSF samples were available, BRAFV600E mutation analysis of plasma, cfCSF and CMC isolated from CSF was performed. Results of BRAFV600E mutation analysis are depicted in Table 3. Two out of 6 tested metastatic melanoma patients showed a BRAFV600E mutation in the plasma circulating tumor (ct)DNA. All four patients with confirmed LM showed a BRAFV600E mutation in cfCSF; in three patients with possible LM no BRAFV600E mutation was found in cfCSF ( 2 of 3 patients had $0 \mathrm{CMC} / \mathrm{mL}$ CSF and 1 patient had $9.8 \mathrm{CMC} / \mathrm{mL}$ CSF). BRAFV600E mutation was measured and detected in CMC isolated from CSF of 2 patients with confirmed LM and $1834 \mathrm{CMC} / \mathrm{mL}$ and 1622 $\mathrm{CMC} / \mathrm{mL}$ CSF, respectively.

In one patient with possible LM $(9.8 \mathrm{CMC} / \mathrm{mL})$ no BRAFV600E mutation was found in the isolated CMC from CSF and cFCSF of this patient was also negative. Two other patients with possible $\mathrm{LM}$ and $0 \mathrm{CMC} / \mathrm{mL} \mathrm{CSF}$ also showed no BRAFV600E mutation in cfCSF. 1 out of 17 tested patients without LM was positive for BRAFV600E in cfCSF. This patient (no=128, see table 3 ) had cervical intramedullary metastases.

\section{DISCUSSION}

Our study shows that we can enumerate melanoma cells in CSF by using our MCSP/CD146-based immunoflow cytometry assay. We detected melanoma cells in the CSF in $91 \%$ of patients with confirmed LM with CMC numbers varying from 1.9-5587 CMC/mL. In one of these patients, CMC detection outperformed CSF cytology at first LP: cytology showed equivocal results while at immunoflow cytometry $42 \mathrm{CMC} / \mathrm{mL}$ were found. We consider that CMC are indeed melanoma cells, based on cytomorphological analysis of CMC isolated from CSF, which identified all the FACS events in the CMC gate as melanoma cells (Figure $1 \mathrm{~b}$ ). This is further supported by BRAFV600E mutation detection in isolated CMC from CSF of patients with LM. Moreover, patients with metastatic melanoma without LM and control non-oncological patients showed $\leq 0.3 \mathrm{CMC} / \mathrm{mL} \mathrm{CSF}$. 
Our data suggest that the MCSP/CD146 immunoflow cytometry is a promising CSF tool to diagnose LM in melanoma patients. The dataset is however too small to compare the sensitivity and specificity of immunoflow cytometry with CSF cytology for diagnosing LM. A larger patient cohort is needed to determine the accuracy of our test and to determine the optimal cut-off value of the CMC number in CSF for LM diagnosis. Based on the current small dataset we expect the cut-off value to be $\geq 1 \mathrm{CMC} / \mathrm{mL}$. The group of 9 patients with possible or probable LM in whom CMC were detected in 3 of them $(1.7-180 \mathrm{CMC} / \mathrm{mL})$ is interesting as this could indicate that although the diagnosis LM was not confirmed on the current EANO-ESMO LM criteria, this subgroup of patients may indeed have had LM.

A further important advantage of the presented CMC immunoflow cytometry method is the fact that it is a quantitative assay with possible use for future treatment response monitoring. Moreover, it can be used for driver mutation analysis (e.g. BRAFV600E) of isolated CMC from CSF and opens way for broader mutational analysis of these cells.

Based on the current dataset, the accuracies of MCSP/CD146 immunoflow cytometry and CSF cytology cannot be compared. It is also is not yet known whether our assay outperforms the CELLSEARCH ${ }^{\circledR}$ method in melanoma cell detection in CSF, as there is only one study in two patients showing CMC in CSF with the adapted CELLSEARCH ${ }^{\circledR}$ method [4]. The MCSP/CD146 immunoflow cytometry method uses fixed gate settings and fully automatic CMC identification, which prevents the operator bias of the CELLSEARCH ${ }^{\circledR}$ method $[4,27]$. Furthermore, our method is based on MCSP to immunomagnetically enrich CMC, which is relatively more specific for melanoma than CD146 and eliminates the use of CD34 to discriminate between endothelial cells and CMC [14][18, 19].

In our exploratory driver mutation analysis of CfCSF and isolated CMCs in CSF and plasma, BRAFV600E was detected in cfCSF of all four tested patients with cytology confirmed LM and in isolated CMC from CSF of 2 tested patients with 1622 and $1834 \mathrm{CMC} / \mathrm{mL}$ CSF. In a patient with possible LM and only 9.8 CMC/ $\mathrm{mL} \mathrm{CSF}$, the BRAFV600E mutation could not be detected in isolated CMC. In an earlier published study of 7 melanoma patients treated for LM there was a strong correlation between driver mutation status BRAFV600E detection by ddPCR, CSF cytology and abnormalities on MRI [28]. In another study, ctDNA fragments were detected in the CSF in 6 out of 7 patients with brain metastases from various tumor types, including two melanoma patients [29]. Tumor-derived ctDNA has 
also been detected in CSF of two patients who had brain melanoma metastases without radiographic evidence of leptomeningeal disease [30]. This indicates that it is currently unknown if BRAFV600E mutation detection in CSF is a useful tool to diagnose LM, in particular when there are concomitant brain metastases.

In conclusion, the newly developed CD-146/MCSP immunoflow cytometry assay is a promising tool for detection of melanoma cells in CSF and diagnose LM. Driver mutation analysis with ddPCR can be used to detect BRAFV600E mutation in both cfCSF and CMC isolated from CSF. Both assays need further validation for diagnostic accuracy in a larger patient cohort.

\section{ACKNOWLEDGEMENTS}

We acknowledge the Oscar Lambret Institute for inclusion of patients and the Netherlands Cancer Institute - Antoni van Leeuwenhoek (NKI-AVL) Core Facility Molecular Pathology \& Biobanking (CFMPB) for supplying NKI-AVL biobank material and laboratory support. 


\section{REFERENCES}

1. Le Rhun $E$, Weller $M$, Brandsma $D$, et al. EANO-ESMO Clinical Practice Guidelines for diagnosis, treatment and follow-up of patients with leptomeningeal metastasis from solid tumors. Ann Oncol 2017;28:iv84iv99.

2. Harstad L, Hess KR, Groves MD. Prognostic factors and outcomes in patients with leptomeningeal melanomatosis. Neuro Oncol 2008;10:1010-1018.

3. Geukes Foppen $\mathrm{MH}$, Brandsma D, Blank CU, et al. Targeted treatment and immunotherapy in leptomeningeal metastases from melanoma. Ann Oncol Off J Eur Soc Med Oncol 2016;27:1138-42.

4. Le Rhun E, Taillibert S, Chamberlain MC. Carcinomatous meningitis: Leptomeningeal metastases in solid tumors. Surg Neurol Int2013;4:S265-88.

5. Raizer JJ, Hwu W-J, Panageas KS, et al. Brain and leptomeningeal metastases from cutaneous melanoma: survival outcomes based on clinical features. Neuro Oncol 2008;10:199-207.

6. Straathof CS, de Bruin HG, Dippel DW, Vecht CJ. The diagnostic accuracy of magnetic resonance imaging and cerebrospinal fluid cytology in leptomeningeal metastasis. J Neurol 1999;246:810-814.

7. Wasserstrom WR, Glass JP, Posner JB. Diagnosis and treatment of leptomeningeal metastases from solid tumors: experience with 90 patients. Cancer 1982;49:759-772

8. van Oostenbrugge RJ, Twijnstra A. Presenting features and value of diagnostic procedures in leptomeningeal metastases. Neurology 1999;53:382-385

9. Tu $Q$, Wu X, Le Rhun E, et al. CellSearch technology applied to the detection and quantification of tumor cells in CSF of patients with lung cancer leptomeningeal metastasis. Lung Cancer 2015;90:352-357.

10. Lee JS, Melisko ME, Magbanua MJ, et al. Detection of cerebrospinal fluid tumor cells and its clinical relevance in leptomeningeal metastasis of breast cancer. Breast Cancer Res Treat 2015;154:339-349.

11. Nayak L, Fleisher M, Gonzalez-Espinoza $R$, et al. Rare cell capture technology for the diagnosis of leptomeningeal metastasis in solid tumors. Neurology 2013;80:1598-605.

12. Jiang $B-Y, L i \quad Y-S$, Guo $W-B$, et al. Detection of Driver and Resistance Mutations in Leptomeningeal Metastases of NSCLC by Next-Generation Sequencing of Cerebrospinal Fluid Circulating Tumor Cells. Clin Cancer Res 2017;23:5480-5488.

13. Milojkovic Kerklaan B, Pluim D, Bol $M$, et al. EpCAM-based flow cytometry in cerebrospinal fluid greatly improves diagnostic accuracy of leptomeningeal metastases from epithelial tumors. Neuro Oncol 2016;18:855-862.

14. Subira D, Serrano C, Castanon $\mathrm{S}$, et al. Role of flow cytometry immunophenotyping in the diagnosis of leptomeningeal carcinomatosis. Neuro Oncol 2012;14:43-52.

15. Subira $D$, Simo $M$, Illan J, et al. Diagnostic and prognostic significance of flow cytometry immunophenotyping in patients with leptomeningeal carcinomatosis. Clin Exp Metastasis 
2015;32:383-391.

16. Le Rhun $E$, Tu $Q$, De Carvalho Bittencourt $M$, et al. Detection and quantification of CSF malignant cells by the CellSearch technology in patients with melanoma leptomeningeal metastasis. Med Oncol 2013;30:538.

17. Rao C, Bui $T$, Connelly $M$, et al. Circulating melanoma cells and survival in metastatic melanoma. Int J Oncol 2011;38:755-760.

18. Breuer J, Korpos E, Hannocks M-J, et al. Blockade of MCAM/CD146 impedes CNS infiltration of $T$ cells over the choroid plexus. J Neuroinflammation 2018;15:236.

19. Duda DG, Cohen KS, Di Tomaso E, et al. Differential CD146 expression on circulating versus tissue endothelial cells in rectal cancer patients: Implications for circulating endothelial and progenitor cells as biomarkers for antiangiogenic therapy. J Clin Oncol 2006;24:1449-1453.

20. Natali PG, Giacomini $P$, Russo $C$, et al. Antigenic profile of human melanoma cells. Analysis with monoclonal antibodies to histocompatibility antigens and to melanoma-associated antigens. J Cutan Pathol 1983;10:225-37.

21. de Bruyn $M$, Rybczynska AA, Wei $Y$, et al - Melanoma-associated Chondroitin Sulfate Proteoglycan (MCSP)-targeted delivery of soluble TRAIL potently inhibits melanoma outgrowth in vitro and in vivo. Mol Cancer 2010;9:301.

22. Yadavilli S, Hwang El, Packer RJ, Nazarian J. The Role of NG2 Proteoglycan in Glioma. Transl Oncol 2016;9:57-63.

23. Eisenmann KM, McCarthy JB, Simpson
MA, et al. Melanoma chondroitin sulphate proteoglycan regulates cell spreading through Cdc42, Ack-1 and p130cas. Nat Cell Biol 1999;1:507-13.

24. Yang J, Price MA, Gui $Y L$, et al. Melanoma proteoglycan modifies gene expression to stimulate tumor cell motility, growth, and epithelial-to-mesenchymal transition. Cancer Res 2009;69:7538-7547.

25. Dawson MRL, Levine JM, Reynolds $R$ (2000) NG2-expressing cells in the central nervous system: are they oligodendroglial progenitors? J Neurosci Res 2000;61:471-9.

26. van Ginkel JH, van den Broek DA, van Kuik J, et al. Preanalytical blood sample workup for cell-free DNA analysis using Droplet Digital PCR for future molecular cancer diagnostics. Cancer Med 2017;6:2297-2307.

27. van Bussel MTJ, Pluim $D$, Bol $M$, et al. EpCAM-based assays for epithelial tumor cell detection in cerebrospinal fluid. J Neurooncol 2018;137:1-10.

28. Ballester LY, Glitza Oliva IC, Douse DY, et al. Evaluating Circulating Tumor DNA From the Cerebrospinal Fluid of Patients With Melanoma and Leptomeningeal Disease. J Neuropathol Exp Neurol 2018;77:628-635.

29. Pan W, Gu W, Nagpal S, et al. Brain tumor mutations detected in cerebral spinal fluid. Clin Chem 2015;61:514-22.

30. Momtaz P, Pentsova E, Abdel-Wahab $O$, et al. Quantification of tumor-derived cell free DNA(cfDNA) by digital PCR (DigPCR) in cerebrospinal fluid of patients with BRAFV600 mutated malignancies. Oncotarget 2016;7:85430-85436.

31. Chamberlain $M$, Junck $L$, Brandsma $D$, 
Clinical and preclinical application of biomarker methods

et al. Leptomeningeal metastases: A RANO proposal for response criteria. Neuro Oncol 2017;19:484-492. https://doi.org/10.1093/ neuonc/now183 


\section{SUPPLEMENTARY MATERIAL}

Circulating melanoma cell detection and driver mutation analysis in cerebrospinal fluid in melanoma patients with suspected leptomeningeal metastases.

Development and validation of MCSP/CD146 immunoflow cytometry assay Reagents and chemicals

Milli-Q grade (Millipore, USA) water was used. Phosphate buffered saline (PBS) and RPMI medium were purchased from GIBCO BRL (Gaithersburg, USA). Neutral buffered methanol-free $40 \%$ formaldehyde was prepared from paraformaldehyde purchased from Merck (Darmstadt, Germany). Hoechst33258 was obtained from Sigma (St. Louis, USA). Anti-human MCSP-Micro-Beads, MS Magnetic antibody cell sorting (MACS ${ }^{\circledR}$ ) columns, Fc-Receptor block (FCR), mouse clone 5B1 IgG2a antihuman CD45 labelled with fluorescein isothiocyanate (FITC) or allophycocyanin (APC), mouse clone EP-1 IgG1 MCSP-phycoerythrin (PE), and mouse clone 54110B2 IgG1 CD146-allophycocyanin (APC) were purchased from Miltenyi (Bergisch Gladbach, Germany). Perm/Wash ${ }^{\mathrm{TM}}$ (P/W) was purchased from Becton Dickinson (Heidelberg, Germany). Beads buffer (BB) is s PBS containing $0.5 \%$ bovine serum albumin (BSA) and $2 \mathrm{mM}$ EDTA degassed by sonication for $10 \mathrm{~min}$. All buffers and formaldehyde solution were filtered through $0.22 \mu \mathrm{m}$ filters before use.

\section{Cell culture and spiking experiments}

Human melanoma cell lines M19MEL and SK-MEL-28 (from ATCC, Rockvile, USA) were cultured as monolayer in RPMI medium supplemented with $10 \%$ fetal calf serum. SK-MEL-28 is BRAFV600E mutated and has a MCSP expression of 99.8\%.[1] For spiking experiments cells were counted and sorted by a FACSariaTM cell sorter (BD Biosciences, USA).

\section{Centrifugation and pellet resuspension}

Unless stated otherwise, all centrifugations were performed in $2 \mathrm{~mL}$ eppendorf tubes in a centrifuge equipped with a swing-out rotor at $1,000 \mathrm{~g}$ for $4 \mathrm{~min}$ at $4^{\circ} \mathrm{C}$. After centrifugation the supernatant was removed with a $1 \mathrm{~mL}$ pipet leaving 100 $\mu \mathrm{L}$ on the cell pellet. The pellet was resuspended in the remaining supernatant by vortex mixing at $50 \%$ speed setting. 


\section{Sample pre-processing}

CPT tubes containing $8 \mathrm{~mL}$ of whole blood were centrifuged in a swing-out rotor at 1,500g for $25 \mathrm{~min}$ at room temperature (RT). Next, the upper CPT layer was transferred to a $50 \mathrm{~mL}$ tube. The CPT tubes were washed with $3 \mathrm{~mL}$ physiologic salt, which was pooled with the rest of the sample. CSF was collected in $50 \mathrm{~mL}$ tubes. Sample volume was adjusted to $9 \mathrm{~mL}$ with physiological salt and $1 \mathrm{~mL}$ of $40 \%$ formaldehyde was added. After vortex mixing at half speed for $10 \mathrm{~s}$, samples were incubated for $15 \mathrm{~min}$ at RT. Next, sample volume was adjusted to $50 \mathrm{~mL}$ using physiologic salt, followed by centrifugation at 1,000g for $10 \mathrm{~min}$ at $4^{\circ} \mathrm{C}$. The supernatant was decanted, followed by placing the tubes upside down on filter paper for $5 \mathrm{~s}$, after which the samples were chilled on ice. Next, the cell pellets were resuspended in $1 \mathrm{~mL}$ of ice-cold $50 \%(\mathrm{v}, \mathrm{v} \%)$ methanol/PBS by vortex mixing for $10 \mathrm{~s}$ at the highest setting. The samples were stored at $-80^{\circ} \mathrm{C}$ for future analysis.

\section{Cell recovery optimization}

M19MEL cells were spiked at 10,000 cells in 35 CPT tubes each containing $8 \mathrm{~mL}$ of blood from healthy volunteers. Samples were pre-processed as described above and incubated with $40 \mu \mathrm{L}$ of FcR-block for $1 \mathrm{~h}$ at RT. Next, 24 samples were incubated in triplicate at $0{ }^{\circ} \mathrm{C}$ and $37^{\circ} \mathrm{C}$ for $1 \mathrm{~h}$ with, respectively, $10 \mu \mathrm{L}$, and 0 , $0.25,0.5,1,2.5,5,10 \mu \mathrm{L}$ of anti-MCSP-Micro-Beads. An additional 21 samples were incubated in triplicate at RT with $2.5 \mu \mathrm{L}$ of anti-MCSP-Micro-Beads for 0 , $0.08,0.25,0.5,1,2$, and $4 \mathrm{~h}$. Next, the tumor cells were isolated by tumor cell enrichment (see paragraph below). The input control samples consisted of 10,000 M19MEL cells in $100 \mu \mathrm{L}$ P/W. After immunofluorescent staining, the cell recovery and total event counts were determined by fluorescence-activated cell sorting (FACS).

\section{Tumor cell enrichment}

CMC underwent an immunomagnetic enrichment using anti-MCSP-MicroBeads, and FcR-block, with the following modifications to the manufacturer's protocol: samples stored at $-80^{\circ} \mathrm{C}$ were defrosted on ice. After centrifugation, the supernatant was removed and the cell pellets were washed twice with icecold BB. After centrifugation, the pellets were resuspended in the remaining $100 \mu \mathrm{L}$ BB. Next, $40 \mu \mathrm{L}$ of FcR was added and the samples were incubated for 1 
$\mathrm{h}$ at RT. Subsequently, a volume of $2.5 \mu \mathrm{L}$ of anti-MCSP-Micro-Beads was added, and the samples were incubated for an additional $1 \mathrm{~h}$ at RT. Next, samples were washed twice with $1 \mathrm{~mL}$ of $\mathrm{BB}$, followed by centrifugation. After discarding the supernatant, the cell pellets were resuspended in $500 \mu \mathrm{L}$ of BB. Subsequently, labelled cells were separated using a MACS column. After removal of the column from the magnetic field, the retained MCSP-positive cells were eluted into 2 $\mathrm{mL}$ eppendorf tubes using two volumes of $1 \mathrm{~mL}$ BB. After centrifugation the supernatant was removed and the pellet was resuspended.

\section{Immunofluorescence staining}

The CMC enriched samples were stained in $100 \mu \mathrm{L} P / W$ containing $10 \mu \mathrm{M}$ Hoechst33258, $0.25 \mu \mathrm{L}$ CD146-APC, $5 \mu \mathrm{L}$ anti-MCSP-PE, and $5 \mu \mathrm{L}$ anti-CD45-FITC for $1 \mathrm{~h}$ at RT. Next, samples were washed twice with $1 \mathrm{~mL}$ of P/W followed by centrifugation. CD45, MCSP, CD146 and DNA staining linearity were measured in triplicate in samples spiked with 10,000 SK-MEL-28 cells in CPT tubes containing $8 \mathrm{~mL}$ whole blood from a healthy volunteer. Subsequently, samples were stained with $0,0.25,0.5,1,2,5,10$, and $20 \mu$ of anti-CD45-FITC and anti-MCSP-PE, 0, $0.025,0.05,0.1,0.25,0.5,1.0$, and $2.0 \mu \mathrm{L}$ of anti-CD146-APC, and $10 \mu \mathrm{M}$ of Hoechst33258 for $1 \mathrm{~h}$ at RT. Next, samples were washed twice with $1 \mathrm{~mL} P / \mathrm{W}$ and mean fluorescence intensity (MFI) was measured by FACS.

\section{Fluorescence-activated cell sorting}

Fluorescence-activated cell sorting (FACS) analysis was performed using a CyAn ADP $^{\text {TM }}$ (Beckman Coulter, Brea, USA) and a Becton Dickinson LSR Fortessa ${ }^{\text {TM }}$. Hoechst33258, FITC, PE, and APC were collected through $450 \pm 25 \mathrm{~nm}, 530 \pm 40$ $\mathrm{nm}, 575 \pm 25 \mathrm{~nm}$, and $665 \pm 25 \mathrm{~nm}$ band pass filters, respectively. Data analysis was performed with Summit v4.3.01 software (Dako Cytomation, Fort Collins, USA).

\section{Specificity}

In order to assess the background levels in blood, three CPT tubes containing $8 \mathrm{~mL}$ peripheral blood were drawn from 20 healthy volunteers. Background levels in CSF were determined in non-oncological patients with a suspicion on an infectious or auto-immune meningitis or subarachnoid hemorrhage and a clinical indication for 
a diagnostic lumbar puncture.

Within- and between-day precision and recovery

The between-day (BDP) and within-day precision (WDP) and recovery of the MCSP flow cytometry assay were determined, as described previously. [2] CPT tubes containing $8 \mathrm{~mL}$ of whole blood were spiked with 10,100,1,000, and 5,000 SKMEL-28, and M19MEL cells with 10 times less expression of MCSP.

Lower limit of quantification (LLOQ)

The LLOQ was determined by spiking in six-fold 1, 2, 3, 4, 5, and 10 SK-MEL-28 cells in CPT tubes containing $8 \mathrm{~mL}$ of whole blood from six different healthy volunteers. The LLOQ was defined as the cell concentration that could be determined with a precision of $0-20 \%$, and a recovery between $80-120 \%$ of the nominal value.

\section{Sample stability}

Long term storage stability was assessed by spiking 21 CPT tubes, containing 8 $\mathrm{mL}$ whole blood from a healthy volunteer, with 1000 SK-MEL-28 cells each. Three samples per time point were processed and stored in $50 \% \mathrm{MeOH}$ at $-80^{\circ} \mathrm{C}$ for 0 , $1,14,30,60,180$, and 360 days until analysis. We also assessed the stability of stained samples in triplicate after storage at $4-7^{\circ} \mathrm{C}$ in the refrigerator for 0,4 , and 24 until analysis.

\section{CMC assay validation in blood}

Subjects asked for study participation included 20 healthy volunteers $\geq 21$ years of age, not known with cancer, not treated with investigational or other drugs within 30 days before start of the study, and who had not undergone surgery within the past six months. Blood samples from 11 cancer patients with stage III or IV advanced melanoma were used for determination of the method sensitivity. Patients had not been on treatment for at least 4 weeks before whole blood was drawn for determination of CMC counts. For each subject three $8 \mathrm{~mL}$ cell preparation tubes (BD Vacutainer ${ }^{\circledR}$ CPTTM) were used containing a FicollHypaque density fluid separated by a polyester gel barrier from a sodium citrate anticoagulant. 
Discrimination of CMC from blood cells with red blood cell lysis is impossible due to more than $90 \%$ reduction of MCSP staining (data not shown). Therefore, density gradient centrifugation with CPT tubes was used. The gel barrier in these tubes separates the blood cells over two compartments. The lower compartment contains red blood cells and granulocytes. The upper compartment consists of CMC, leucocytes, and platelets. Further, enrichment of CMC was achieved by MACS using anti-human MCSP-Micro-Beads. For removal of protein aggregates that can bind nonspecifically to antibodies, which resulted in false positive CMC counts (data not shown), all antibody solutions except FcR-block and MCSPMicro Beads were centrifuged at $10,000 \mathrm{~g}$ for $10 \mathrm{~min}$ at $4^{\circ} \mathrm{C}$. Furthermore, buffers were filtered through $0.2 \mu \mathrm{m}$ syringe filters. The use of swing-out rotors for centrifugations prevented the loss of $10 \%$ of cells observed with fixed angle rotors. CMC were identified based on double positivity for MCSP and CD146 in combination with CD45 negativity (Fig. 1A). Release of adherent cells from the culture plates by trypsinisation reduced MCSP recognition by more than $90 \%$

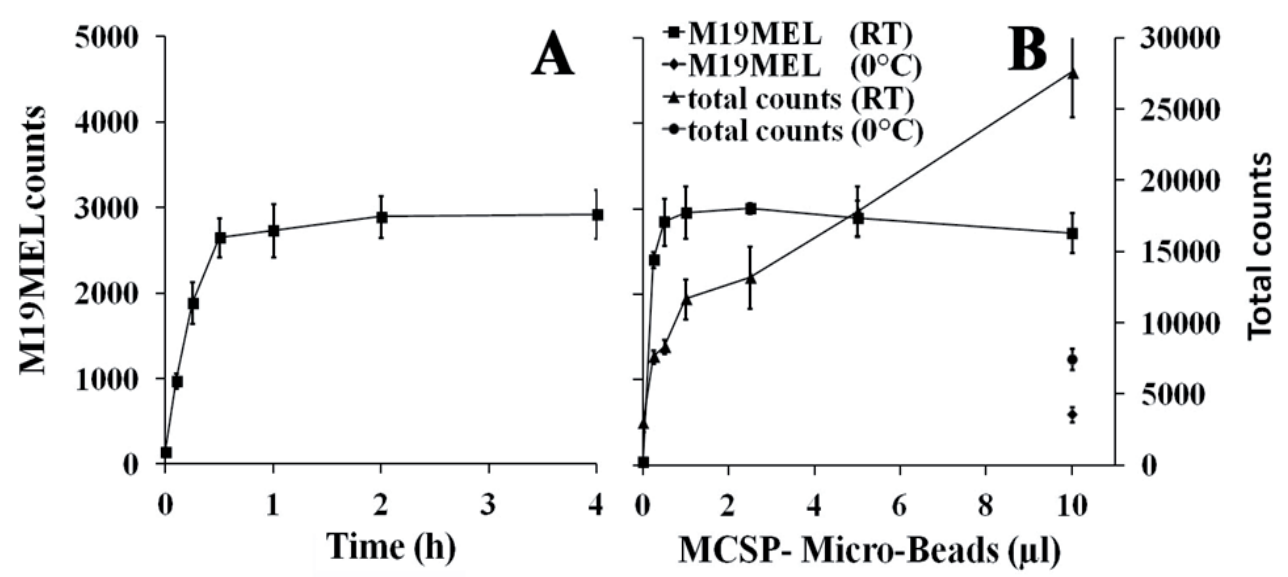

Figure S1. Background events and recovery of M19MEL cells. Total background events and recovery of 10,000 M19MEL cells spiked in $8 \mathrm{~mL}$ peripheral blood from a healthy volunteer, respectively, indicated incubation time using $4 \mu \mathrm{L}$ of anti-MCSP-Micro-Beads (Fig. S1A), or different amounts of anti-MCSP-Micro-Beads (Fig. S1B). Data is expressed as means \pm S.D. of three different samples. 
Table S2. Recovery, within-day precision and between-day precision. Recovery, withinday precision (WDP) and between-day precision (BDP) for determination of the number of SK-MEL-28 and M19MEL cells spiked in cell preparation tubes (CPT) tubes containing $8 \mathrm{~mL}$ peripheral blood from a healthy volunteer. Three replicate measurements were performed at each spike level. Within- and between-day precision were calculated using one-way analysis of variance (ANOVA).

\begin{tabular}{c|c|c|c|c|c|c|c}
\hline \multicolumn{2}{c|}{} & \multicolumn{1}{|c}{ SK-MEL-28 } \\
\hline $\begin{array}{c}\text { Measured } \\
\text { spiked } \\
\text { cells }\end{array}$ & $\begin{array}{c}\text { Recovery } \\
(\%)\end{array}$ & $\begin{array}{c}\text { WDP } \\
\text { (\%) }\end{array}$ & $\begin{array}{c}\text { BDP } \\
\text { (\%) }\end{array}$ & $\begin{array}{c}\text { Measured } \\
\text { spiked } \\
\text { cells }\end{array}$ & $\begin{array}{c}\text { Recovery } \\
(\%)\end{array}$ & $\begin{array}{c}\text { WDP } \\
(\%)\end{array}$ & $\begin{array}{c}\text { BDP } \\
(\%)\end{array}$ \\
\hline 2 & 20 & 9.9 & 7.2 & 8 & 80 & 14.2 & 10.2 \\
\hline 24 & 24 & 11.3 & 6.5 & 74 & 74 & 11.5 & 7.7 \\
\hline 267 & 27 & 14.4 & 10.0 & 72 & 72 & 9.6 & 4.7 \\
\hline 2569 & 26 & 10.8 & 4.8 & 71 & 71 & 10.3 & 5.4 \\
\hline
\end{tabular}

(data not shown). Therefore, we used $10 \mathrm{mM}$ EDTA for $5 \mathrm{~min}$ at $37^{\circ} \mathrm{C}$ to release adherent cells from the culture plates. Negative and positive quality controls were prepared by spiking, respectively, 0 and 1,000 SK-MEL-28 in the upper layer of centrifuged CPT tubes containing $8 \mathrm{~mL}$ of whole blood from a healthy volunteer. Quality Controls (QCS) were formaldehyde fixed and stably stored for a maximum of 360 days in $50 \%$ methanol/PBS at $-80^{\circ} \mathrm{C}$. The background from negative QCs was always $\leq 1$, and the recovery of SK-MEL-28 cells from positive QCs was always $\geq 90 \pm 6 \%$. CMC were considered to be nucleated if the Hoechst33258 MFI was above the indicated DNA cut-off level determined from endogenous leucocytes present in the same sample (Fig. 1A).

\section{Staining Linearity}

Staining linearity was determined in triplicate in samples containing 10,000 SKMEL-28 cells spiked in CPT tubes containing $8 \mathrm{~mL}$ of whole blood from a healthy volunteer. CD146 and MCSP were maximally stained with, respectively, a MFI of $2545 \pm 182$ and $771 \pm 31$ using 0.25 and $5 \mu \mathrm{L}$ of anti-CD146-APC and anti-MCSP$P E$. Staining did not significantly increase at higher antibody concentrations. 
The amount of background counts in the CMC gate during FACS analysis was 4 \pm 0.6 false positive CMC per $8 \mathrm{~mL}$ of whole blood ( $\mathrm{n}=18$ healthy volunteers in triplicate) if MCSP positivity in combination with CD45 negativity were used as criteria for CMC identification after the FS/SSC gating. Specificity strongly improved to $0.3 \pm 0.8 \mathrm{CMC}$ per $8 \mathrm{~mL}$ of whole blood (range $0-1$ ) false positive CMC counts when CD146 positivity was included as marker for CMC identification. All control patients were negative for CMC ( $n=10)$. (Fig. $1 \mathrm{H})$.

\section{Cell recovery optimization}

The recovery of M19MEL cells after the anti-MCSP-Micro-Beads enrichment step was significantly affected by the amount of anti-MCSP-Micro-Beads and incubation temperature (Supplementary Fig. S1). The use of an extra volume of $1 \mathrm{~mL}$ of BB for elution of $\mathrm{CMC}$ from the $\mathrm{MACS}^{\circledR}$ columns resulted in $11 \%$ increase of cell recovery $(P=0.002$, data not shown). The maximum M19MEL recovery of $28.1 \%$ was obtained after $1 \mathrm{~h}$ of incubation (Supplementary Table S1) using $2.5 \mu \mathrm{L}$ of antiMCSP-Micro-Beads (Supplementary Fig. S1B). Under these conditions recovery of SK-MEL-28, with about 10 times higher MCSP levels as compared to M19MEL, was $70-80 \%$ (Supplementary Table S1). Cell recovery did not significantly increase after prolonged incubation, or with more anti-MCSP-Micro-Beads.

\section{Lower limit of quantification (LLOQ)}

The lower limit of quantification (LLOQ) was determined in $8 \mathrm{~mL}$ whole blood samples from six different volunteers spiked with $0,1,2,3,4$, and 5 SK-MEL-28 cells per CPT. The determined LLOQ of the method was 2 cells in $8 \mathrm{~mL}$ of whole blood. At this LLOQ the recovery was $105 \%$ and the precision $16.9 \%$.

\section{Within- and between-day precision and recovery}

The precision and recovery of the method were determined by analyses of samples spiked with SK-MEL-28 at four different cell concentrations in triplicate in three consecutive analytical runs. From these results we calculated the withinday and between-day precision and recovery (Supplementary Table S2). In all cases the precision and recoveries were well within the limits that are considered acceptable for bio-analytical methods. [3] An exception was the low recovery of M19MEL cells. 
Sample stability

We determined the stability of CD146, MCSP, CD45, DNA, and cell counts for SK-MEL-28 cells spiked in $8 \mathrm{~mL}$ whole blood samples after storage at $-80^{\circ} \mathrm{C}$ for incremental time periods. All parameters were stable for at least 12 months. The fluorescent signals from stained CD146, MCSP, CD45, DNA, and SK-MEL-28 cell counts were also stable during the tested $24 \mathrm{~h}$ storage period at $4-7^{\circ} \mathrm{C}$. 


\section{SUPPLEMENTARY}

\section{REFERENCES}

1. $Y u$ L, Favoino $E$, Wang $Y, M a ~ Y$, Deng $X$, Wang $X$. The CSPG4-specific monoclonal antibody enhances and prolongs the effects of the BRAF inhibitor in melanoma cells. Immunol Res 2011;50:294-302.

2. Pluim D, Devriese LA, Beijnen $\mathrm{JH}$, Schellens JHM. Validation of a multiparameter flow cytometry method for the determination of phosphorylated extracellular-signal-regulated kinase and DNA in circulating tumor cells. Cytometry A 2012;81:664-671.

3. Chandran S, Singh RSP. Comparison of various international guidelines for analytical method validation. Pharmazie 2007;62:4-14. 
Clinical and preclinical application of biomarker methods 


\section{CHAPTER 4}

\section{Conclusions and perspectives}

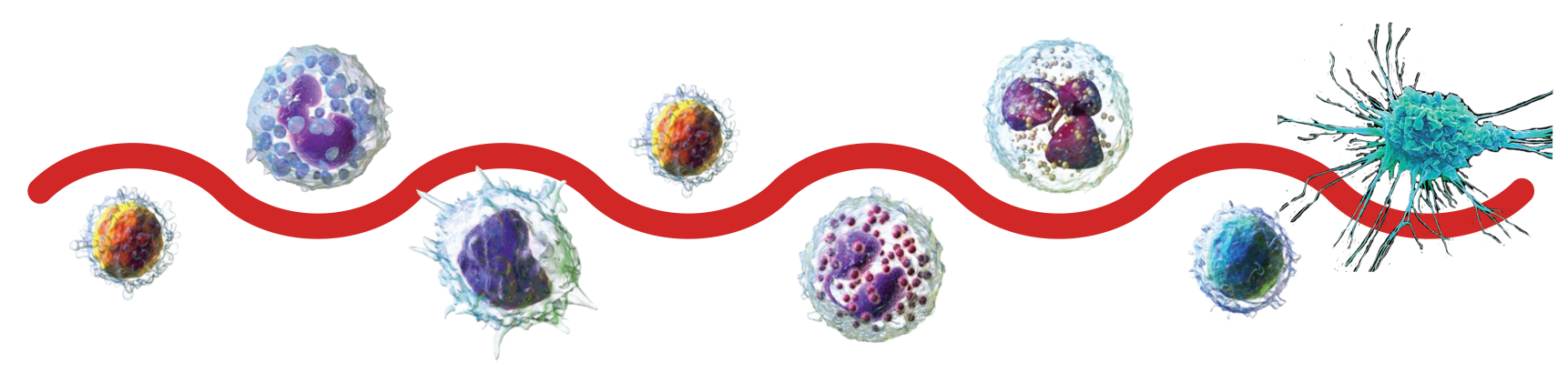

\section{CONCLUSIONS AND PERSPECTIVES}

Biomarkers as biological signposts of cancer have become an essential component of oncology drug development and their importance has even more increased with the advent of therapies targeting specific mechanisms that tumor cells rely on for their growth. Increased knowledge of the molecular pathways of oncogenesis is the main force driving the paradigm shift towards targeted therapies (1-5). Biomarkers are used in clinical trials to find the optimal drug dose, combination of drugs, treatment duration, and for the selection of patients in targeted therapies. The increased use of biomarkers is associated with a higher cancer drug approval rate (6), although, drug approval rates in 2018 were still only $27 \%$. It is promising that the use of biomarkers in clinical cancer trials has grown substantially during the last decade, with just over half of all clinical cancer trials using biomarkers in 2018. However, more extensive use of biomarkers could help to further improve the success rate of clinical cancer trials.

Biomarkers for use in (pre)clinical studies need to be measured with analytical methods that are sensitive, selective, accurate, and stabile. In this thesis, we show the development and validation of seven different biomarker 
methods. We designed these biomarker methods for high sensitivity and low variability to enhance their clinical usefulness. In this regard, Chapter 1.6 provides an illustrative example of a biomarker method that failed during the clinical application due to inadequate sensitivity. This method was developed by the National Cancer Institute (NCI USA) for quantification of poly-adenosine diphosphate ribose (PAR) in peripheral blood mononuclear cells (PBMC) as a measure for PAR polymerase activity. Although, the method did support the clinical development of PARP inhibitors (7-11), it could only detect a median of $53 \%$ (range $49-77 \%$ ) PAR inhibition due to the very low and variable basal PAR levels in PBMC $(12,13)$. It has been suggested that a minimum of $90 \%$ inhibition is required for efficient monotherapy activity (14). We strongly improved the sensitivity, accuracy, stability of the $\mathrm{NCl}$ method by using ex vivo irradiation of the PBMC at $8 \mathrm{~Gy}$ under ice-cold conditions. This resulted in stable PAR levels that were on average 100-fold increased, which enabled the detection of up to a median of 97\% (range 96-98\%) PAR inhibition (15). Chapters 1.8 and 2.5 provide two other illustrative examples of the importance of designing methods for maximal sensitivity. These chapters describe two new methods for the enumeration of circulating epithelial tumor cells and melanoma cells (CTC) in blood and cerebrospinal fluid (CSF). Since, CTC are very rare cells compared with the abundant cellular background of blood or CSF (16), very sensitive methods for their detection are needed. We achieved the high sensitivity needed for CTC detection by using a series of orthogonal enrichment techniques. First, CTCs were isolated from the bulk of other blood cells using Ficoll density gradient centrifugation. Further enrichment was achieved by magnetic cell sorting using an antibody specific for epithelial or melanoma CTC. Finally, flow cytometry was used to separate the fluorescently labeled CTC from the remaining blood cells. Application of these orthogonal enrichment techniques resulted in reliable enumeration of up to just 2 CTC per $8 \mathrm{ml}$ of whole blood.

Low variability is another important requirement for biomarker methods. Therefore, it is important to identify and address potential technical and biological sources of variability. A biological source of variability may for instance be the presence of variable amounts of endogenous compounds that interfere with the biomarker detection. The three biomarker methods described in chapters 2.4-2.6 are illustrative examples of biomarker methods that showed elevated variability due to the presence of large and variable amounts of endogenous hemoglobin that co-isolated with the peripheral blood mononuclear cells (PBMC). The biomarkers in these methods are enzyme activities and are expressed per 
milligram of PBMC cytosolic lysate protein. Therefore any variability in this lysate protein will cause biomarker variability. Although no major variability issues were encountered during the development of these methods using blood of healthy volunteers, clinical application resulted in high within and between patient biomarker variability associated with hemolytic blood sampling. Hemolysis of patients' blood is a regular phenomenon with a frequency of 3-8\% of all samples in cancer trials (17-18). The main technical reasons for hemolysis are drawing of blood from intravenous lines and punctures in veins that are fragile or difficult to access (19). It is known that PBMCs can accumulate free hemoglobin which will affect the protein concentration of PBMC cytosolic lysates (20). The increase in protein concentration of the PBMC lysates due to hemoglobin has a marked effect on the determined enzyme activities. In chapter 2.3 describes a spectrophotometric method to measure the hemoglobin concentration in PBMC lysates. Correction of the PBMC lysate protein, for the amount of hemoglobin present, significantly reduced the biomarker variability. The variability of a biomarker may, however, also be caused by technical reasons. Chapter 2.9 provides an illustrative example of this type of variability, which we encountered during the development of the programmed death-1 (PD-1) biomarker method. We initially used dimethyl sulfoxide (DMSO) for the cryopreservation of isolated PBMC. However, cellular accumulation of DMSO resulted in a substantial and highly variable increase of non-viable cells, which could not be used for the PD-1 analysis due to an elevated level of nonspecific staining. We were able to completely mitigate this source of technical variability by using Cryosofree ${ }^{\mathrm{TM}}$ (Sigma-Aldrich ) as a cryopreservative (21). Cryosofree ${ }^{\mathrm{TM}}$ is a more recently discovered cryopreservative that is much better at keeping cells vital during cryogenic storage mainly because it does not accumulate in cells.

After the development phase, all our biomarker methods were validated in accordance with the recommendations of the Food and Drug Administration (FDA) in their bioanalytical method validation (BMV) guideline from 2018 (22). This FDA guideline, recommends that biomarker methods are validated for specificity, sensitivity, accuracy, linearity, precision, and stability. It is important, to distinguish this analytical validation from the subsequent clinical validation or qualification, that is meant to assess the clinical suitability of the biomarker for identification of a relevant therapeutic effect. Full analytical validation should always be performed, because it will reveal possible issues that may prevent biomarker methods from living up to their expectations during the clinical application. We show in chapter 2.1 that only $13 \%$ of the biomarker methods used in clinical trials 
are fully validated in accordance with the FDA validation guideline. We found that validation was most often lacking for flow cytometry based biomarker methods, which comprised $23 \%$ of all methods used in clinical trials. In this regard, it is important to notice that the FDA validation guideline recommends full validation of chromatography and ligand binding biomarker methods without mentioning other analytical techniques such as flow cytometry. This may explain why flow cytometry methods are relatively less well validated. However, full validation of flow cytometry methods is possible, as we demonstrate in chapters 1.7, 1.8 and 2.5 with 3 different biomarker method used for the enumeration of circulating epithelial tumor cells and melanoma cells, and PD-1 on a panel of blood cell subsets.

We have succesfully applied all our validated biomarker methods in (pre) clinical studies. Briefly, we developed biomarker methods for the determination of DPD, TS, and TP enzyme activities as described in chapters 1.3-1.5, respectively. We developed and validated a method for the correction of these emzyme activities for hemoglobin, as described in chapter 1.2. Subsequently, these methods have been applied in a preclinical human volunteer study (chapter 2.1). We found significant TS and DPD circadian rhythms in this preclinical study, which encouraged us to perform a clinical study to investigate the possible merits of chronomodulated administration of capecitabine, as described in chapter 2.2. Although less pronounced, the DPD circadian rhythm we found during capecitabine treatment supports the rationale for chronomodulated treatment. The chronomodulated capecitabine treatment (CCR) in this study allowed for a $20 \%$ higher dose intensity compared to the approved regimen (1250 mg/m² bi-daily on day 1-14 of every 21 -day cycle). Surprisingly, the clinical study also showed that the circadian rhythm of TS activity was likely affected by capecitabine as the TS activity demonstrated peak activity at night, while trough activity at night was observed in healthy volunteers. Furthermore, we found only limited inhibition of TS activity $1.5 \mathrm{~h}$ after administration of capecitabine and strong upregulation of TS activity during treatment. These findings need further investigation, as they could provide important clues to improve treatment efficacy.

The improved biomarker method for the quantification of PAR described in chapter 1.6 was applied in a clinical study aimed to develop PARP inhibitors as chemo- and radio-sensitizers in combination treatments (23). In these combination treatments, PARP inhibitors are administered at much lower concentrations and for shorter durations, requiring sensitive and robust PAR 
detection methods (24). We found that the PARP inhibitor olaparib, at the maximum tolerated dose of $25 \mathrm{mg}$ bi-daily (tablet formulation), can reach PARP inhibition levels of over $95 \%$ in patients, a dose 10 -fold lower than the recommended monotherapy dose. In another clinical study that used our improved PARP method, patients received low dose olaparib (25 mg bi-daily in tablet formulation) in combination with carboplatin (25). In this study, we found that PAR levels in PBMCs were reduced by $98.7 \% \pm 0.14 \%$ at day eight compared to day one. Both studies are the first to report almost complete inhibition of PARP activity by low dose olaparib treatment.

In chapter 1.7, we demonstrate the clinical application of our novel biomarker method for the determination of PD-1 expression and occupancy by nivolumab and pembrolizumab on a subset of blood cells. Samples were obtained from 6 cancer patients receiving nivolumab and 6 patients receiving pembrolizumab. We found a significant drop in the number of PD-1+ $1^{+}$-cells and the number of PD-1 receptors per T-cell after only one course of nivolumab or pembrolizumab. Further clinical investigation of this possible pharmacodynamic (PD) effect and its association with treatment outcome is warranted. This biomarker method offers efficient determination of multiple biomarkers on a large panel of immune cell subsets in a single experiment that may help to predict treatment outcome.

Lastly, we show in chapter 2.4 that our epithelial CTC method developed for enumeration of CTC in whole blood (Chapter 1.8) can also be used for the enumeration of CTC in cerebrospinal fluid (CSF). In chapter 2.5, we report a new method for the enumeration of circulating melanoma cells in both blood and CSF. In chapters 2.4 and 2.5, we describe the application of these epithelial and melanoma CTC methods for the early detection of CTC in CSF of patients suspected of leptomeningeal metastases (LM). Both methods showed a higher sensitivity and equal specificity compared with cytology, which is still the golden standard for LM diagnosis. The clinical chemistry laboratory of our hospital, Antoni van Leeuwenhoek, has implemented the epithelial CTC method as a standard diagnostic tool for the diagnosis of LM. We plan to further evaluate the merits of these CTC methods for CSF diagnostics compared to cytology in a multi-center setting. CTC analysis in CSF is, however, not only a sensitive way to diagnose LM, but can possibly also be used for patient treatment response monitoring. In that regard, it is important to include our CTC analysis methods in CSF in future LM studies and determine whether CTC numbers in CSF reflect treatment response and predict survival/prognosis in an accurate way. 
In conclusion, we have developed five new or improved pharmacodynamic and two diagnostic biomarker methods. All methods were fully validated in accordance with the recommendations in the FDA validation guideline from 2018 (22). We believe that their successful clinical application emphasizes the benefits of using fully validated PD and diagnostic biomarker methods for the support of clinical studies. 


\section{REFERENCES}

1. van Montfort $\mathrm{RL}$ and Workman $\mathrm{P}$; Structure-based design of molecular cancer therapeutics; Trends Biotechnol 2009;27: 315-328.

2. Collins I and Workman P; New approaches to molecular cancer therapeutics; Nat Chem Biol 2006;2:689-700.

3. Hanahan D. and Weinberg R.A.; The hallmarks of cancer. Cell; 100:57-70.

4. Workman P and de Bono J; Targeted therapeutics for cancer treatment: major progress towards personalised molecular medicine; Curr Opin Pharmacol 2008;8:359362.

5. Stuart D and Sellers WR; Linking somatic genetic alterations in cancer to therapeutics. Curr. Opin. Cell Biol 2009;21:304-310.

6. Pritchard D and Wells C; Raising the Bar: FDA Accelerates the Push Toward Personalized Medicine; J. Precision Medicine; 2019; 5:36-39.

7. Kummar S., Chen A., Ji J. et al.; Phase I study of PARP inhibitor ABT-888 in combination with topotecan in adults with refractory solid tumors and lymphomas.; Cancer Res 2011;71:5626-5634.

8. LoRusso PM, Li J, Burger A et al.; Phase I safety pharmacokinetic and pharmacodynamic study of the poly (ADPribose) polymerase inhibitor veliparib with irinotecan in patients with advanced tumors.; Clin Cancer Res 2016;22:32273237.

9. Rajan A, Carter CA, Kelly RJ et al.; A phase I combination study of olaparib with cisplatin and gemcitabine in adults with solid tumors.; Clin Cancer Res 2012;18:2344-51.

10. Rodler ET, Kurland BF, Griffin $M$ et al.; Phase I study of veliparib (ABT-888) combined with cisplatin and vinorelbine in advanced triple-negative breast cancer and/ or BRCA mutation-associated breast cancer.; Clin Cancer Res 2016;22:2855-2864.

11. Su JM, Thompson P, Adesina A et al.; A phase I trial of veliparib (ABT-888) and temozolomide in children with recurrent CNS tumors: a pediatric brain tumor consortium report.; Neuro Oncol 2014;16: 1661-1668.

12. Ji J., Kinders R.J., Zhang Y. et al.; Modeling pharmacodynamic response to the poly (ADP-Ribose) polymerase inhibitor ABT-888 in human peripheral blood mononuclear cells.; PLoS One 2011;6:e26152.

13. Kummar $S$, Kinders $R$, Gutierrez $M E$ et al.; Phase 0 clinical trial of the poly (ADPribose) polymerase inhibitor ABT-888 in patients with advanced malignancies; J Clin Oncol 2009;27:2705-2711.

14. Curtin $\mathrm{N}$ and Sharma R; PARP inhibitors for cancer therapy; Humana Press 2015.

15. de Haan R, Pluim D, van Triest B, van den Heuvel $M$, Peulen $H$, van Berlo $D$ et al.; Improved pharmacodynamic (PD) assessment of low dose PARP inhibitor PD activity for radiotherapy and chemotherapy combination trials. Radiotherapy and oncology : journal of the European Society for Therapeutic Radiology and Oncology 2018;126:443-449.

16. Bethesda DL.; Blood Groups and Red Cell Antigens; Chapter I: Your complete blood count; National Center for Biotechnology Information 2005.

17. Simundic AM, Topic E, Nikolac N, Lippi $\mathrm{G}$; Hemolysis detection and management of hemolysed specimens. Biochem Med 
(Zagreb) 2010;20:154-159.

18. Lippi G, Plebani M, Di Somma S, Cervellin G; Hemolyzed specimens: a major challenge for emergency departments and clinical laboratories.; Crit Rev Clin Lab Sci 2011; 48:143-153.

19. Lippi G, Mattiuzzi C and Cadamuro J; Is the hemolysis index always suitable for monitoring phlebotomy performance?; J Lab Med 2018;42:67-72.

20. Weaver LK, Hintz-Goldstein KA, Pioli PA, Wardwell K, Qureshi N, Vogel SN, Guyre PM; J Leukoc Biol 2006;80:26-35.

21. Matsumura K, Bae JY, and Hyon SH; Polyampholytes as Cryoprotective Agents for Mammalian Cell Cryopreservation; Cell Transplantation 2010;19:691-699.

22. Food and Drug Administration; Bioanalytical Method Validation Guidance for Industry; 2018 May; http://www.fda. gov/Drugs

23. de Haan $R$, van den Heuvel MM, van Diessen J, Peulen HMU, van Werkhoven $E$, de Langen AJ, Lalezari F, Pluim D, Verwijs-Janssen $M$, Vens $C$, Schellens JHM, Steeghs N, Verheij M, van Triest B; Phase $I$ and Pharmacologic Study of Olaparib in Combination with High-dose Radiotherapy with and without Concurrent Cisplatin for Non-Small Cell Lung Cancer; Clin Cancer Res 2021;27:1256-1266

24. Pujade-Lauraine E, Ledermann JA, Sell $\mathrm{F}$, et al.; Olaparib tablets as maintenance therapy in patients with platinum-sensitive, relapsed ovarian cancer and a BRCA1/2 mutation (SOLO2/ENGOT-Ov21): a doubleblind, randomised, placebo-controlled, phase 3 trial; Lancet Oncol 2021; 22:620-631 25. Geenen JJJ, Dackus GMHE, Schouten PC,
Pluim D, Marchetti S, Sonke GS, Jóźwiak K, Huitema ADR, Beijnen JH, Schellens JHM, Linn SC; A Phase I dose-escalation study of two cycles carboplatin-olaparib followed by olaparib monotherapy in patients with advanced cancer; Int J Cancer 2021;

148:3041-3050 


\section{Appendix}

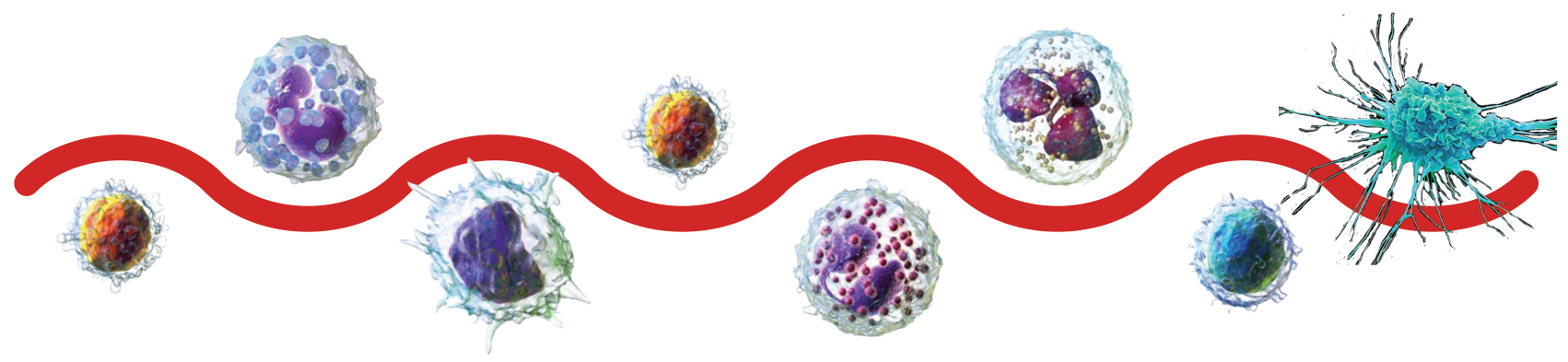

SUMMARY

NEDERLANDSE SAMENVATTING

DANKWOORD

LIST OF PUBLICATIONS

CURRICULUM VITAE 


\section{SUMMARY}

Pharmacodynamic biomarker methods are used to establish whether a cancer drug is hitting its pharmacological target. These methods provide important information to guide the clinical decision making about drug dose and optimal administration schedule. In regard to their importance, only biomarker methods that have passed a full analytical validation should be applied in (pre) clinical studies. Fully validated methods have the best chance to live up to their expectations. In this thesis, we present the development and full validation of new or improved biomarker methods and their application in pre(clinical) studies.

\section{Development and analytical validation of methods for the determination of biomarkers}

This thesis presents the development and analytical validation of 7 biomarker methods designed to support pre(clinical) cancer studies. These methods are based on a wide range of common analytical techniques, such as ligand binding assays, high performance liquid chromatography (HPLC), and flow cytometry. All methods have been validated in accordance with the recommendations of the Food and Drug Adminstration (FDA) in their bio-analytical method validation guideline from 2018, which has been released in preliminary form in 2013.

Chapter 1.1 shows that the majority of biomarker methods used in clinical trials have only partly been validated, which may explain why these methods not always perform in the clinic, as expected. It may also be an important factor in the relatively low approval rate of $27 \%$ for new cancer drugs in 2018.

Chapters 1.2-1.5 are focused on methods for the determination of three enzyme activities that are important for the activation and degradation of fluoropyrimidines. These enzyme activities are normally reported per mass unit of human peripheral blood mononuclear cell (PBMC) cytosolic lysate protein input. However, PBMC cytosolic lysates are highly contaminated by fluctuating amounts of hemoglobin $(\mathrm{Hb})$. Chapter 1.2 presents a method for spectrophotometric measurement of $\mathrm{Hb}$ at $413 \mathrm{~nm}$ to correct for the coisolation of variable amounts of $\mathrm{Hb}$ in the isolates. We showed that correction of the total protein amount in PBMC for the contribution of $\mathrm{Hb}$ significantly improved the method accuracy and variability. In chapter 1.3, the enzyme of interest is thymidylate synthase (TS). TS is the unique enzyme capable of de novo synthesis of $2^{\prime}$-deoxythymidine $5^{\prime}$-monophosphate, which is essential for DNA 
biosynthesis and the key target of fluoropyrimidine treatments. We developed and validated a simple method for the quantification of TS activity in human PBMC. This method is based on the measurement of tritium release from the tritium labeled TS substrate ${ }^{3} \mathrm{H}$-deoxyuridine $5^{\prime}$-monophosphate $\left({ }^{3} \mathrm{H}\right.$-dUMP) by liquid scintillation counting. After the enzyme reaction, remaining ${ }^{3} \mathrm{H}-\mathrm{dUMP}$ is removed by adsorption to activated charcoal. The sensitivity of the method was increased by using lyophilized substrate and optimized charcoal binding conditions to decrease the background level. TS activity was maximized by using a high excess amount of the TS cofactor N5,N10 methylene-(6R,S)-tetrahydrofolate, and by omitting EDTA from the enzyme reactions. In chapter 1.4 a method is reported for the determination of dihydropyrimidine dehydrogenase (DPD) in PBMC. DPD is essential for detoxification of fluoropyrimidines. Patients with a DPD deficiency show decreased clearance of fluoropyrimidines and are at risk of severe fluoropyrimidine-induced toxicity. Therefore, this DPD method may help to individualize fluoropyrimidine treatment based on DPD activity phenotype. DPD phenotype was determined by measuring the amount of released ${ }^{3} \mathrm{H}-5,6$ dihydrothymine by the ex vivo reaction of ${ }^{3} \mathrm{H}$-thymine with DPD in PBMC cytosolic lysates. HPLC with online scintillation radioisotope detection was used for the quantification of the titriated compounds. The accuracy was improved by using the cumulative area of all chromatographic peaks as internal standard. In chapter 1.5, a method is described for the determination of thymidine phosphatase (TP) in PBMC. TP is important for the activation of fluoropyrimidines into cytotoxic metabolites. Patients with high TP activity may experience more fluoropyrimidineinduced toxicity. TP activity phenotype was determined in PBMC cytosolic lysates by the amount of thymine formed from the TP substrate thymidine. HPLC coupled with ultraviolet (UV) detection was used to determine the amount of thymine formed during the reaction step.

Chapter 1.6 concerns the development of a more sensitive method for the assessment of poly ADP-ribose (PAR) polymerase (PARP) activity in human PBMC. PARP inhibitors are currently evaluated as sensitizers in combination with radiotherapy and/or chemotherapy. In these combination trials, PARP inhibitors are active at very low concentrations. Therefore, highly sensitive methods are required for the quantification of PARP activity. Current clinical methods fail to provide such sensitivities. We used ex vivo irradiation to enhance the low basal level of PAR in PBMC. In addition, we found that PAR polymerase was still very active at low temperatures such as $0^{\circ} \mathrm{C}$, while PAR degradation was mostly abolished. Therefore, the combination of irradiation and reaction at low 
temperature resulted in high and stable PAR levels. This "radiation enhanced PAR" (REP) method showed greatly enhanced sensitivity and accuracy. Clinical application of the REP method in a study, combining low dose olaparib with radiotherapy, showed that PAR levels were reduced by more than $95 \%$ at the maximum tolerated dose. In another clinical study, patients received low dose olaparib in combination with carboplatin. In that study PAR levels in PBMCs were reduced by $98.7 \% \pm 0.14 \%$ at day eight compared to day one. Both studies are the first to report almost complete inhibition of PARP activity by low dose olaparib treatment.

Chapter 1.7 is focused on a biomarker method for the support of clinical trials using the immunotherapeutic antibodies nivolumab and pembrolizumab. Checkpoint blockade therapy using nivolumab and pembrolizumab has demonstrated remarkable efficacy against numerous cancer types. Both nivolumab and pembrolizumab block programmed death-1 (PD-1), protein on the surface of immune cells acting as a immune checkpoint molecule. We developed and validated a flow cytometric method to enumerate the number of monocytes, and dendritic, NK, B and T-cells in human blood. The method can also be used to determine the percentage of PD-1 positive cells, PD-1 occupancy, and number of PD-1 molecules on these immune cells. We used cryosofree ${ }^{\mathrm{TM}}$ as a cryopreservative for long term storage of the isolated immune cells. Instead of the more widely used DMSO, Cryosofree ${ }^{\mathrm{TM}}$ does not enter the cells, and therefore it can simply be washed away after thawing of the samples. This resulted in much higher vital immune cell recoveries and reproducibility compared with DMSO. Accuracy was improved by using $2 \%$ formaldehyde to keep nivolumab and pembrolizumab attached to PD-1 during the cryopreservation and washing steps. The detection of nivolumab an pembrolizumab bound to PD-1, by anti-IgG - PE, was very specific and did not require the use of isotype $\operatorname{lgG}_{4}$. We used different standardized fluorescent quantification and quality control beads to enable the reproducible quantification of PD-1 levels. Compared to other methods, our method offers efficient determination of multiple biomarkers on a large panel of immune cell subsets in a single experiment. We established the average within and between subject biological variation of the different PD-1 biomarkers in a healthy volunteer study. The clinical applicability was tested in 6 patients receiving nivolumab, and 5 patients receiving pembrolizumab. In this clinical study, we found for 9 out of 11 patients a significant drop in the number of PD-1 positive T-cells and number of PD-1 receptors per T-cell after just one course of nivolumab or pembrolizumab. 
Chapters 1.8 and 2.5 present two biomarker methods for the detection of circulating epithelial tumor cells and melanoma cells (CTC) in human blood and cerebrospinal fluid (CSF). CTC contribute to the cancer metastasizing process, and their detection has been correlated with an unfavorable clinical outcome. Very sensitive methods are needed for the detection of these very rare cells in the abundant cellular background of blood. Therefore, both CTC biomarker methods use Ficoll density centrifugation for the pre-enrichment of CTC from blood. Further enrichment of CTC was achieved by magnetic antibody cell sorting using labeled antibodies against epithelial cell adhesion molecule (EpCAM), or anti-melanoma chondroitin sulfate proteoglycan (MCSP). The final detection and enumeration of the CTC was accomplished using fluorescently labeled antibodies against EpCAM, MCSP, CD146, and CD45 to distinguish them from the remaining blood cells. We demonstrated that our epithelial CTC detection method can also be used for molecular profiling of the extracellular signal-related kinase (ERK) phosphorylation status in these cells. The ERK pathway is critical in oncogenesis as it regulates cell proliferation, differentiation, and survival. Aberrations in components of the ERK pathway are common in approximately $30 \%$ of human cancers.

\section{Preclinical and clinical application of biomarker methods}

The second chapter of this thesis is focused on the (pre)clinical application of our validated biomarker methods.

Chapter 1.1 describes the application of our methods for the determination of DPD, TS, and TP activities in a healthy human volunteer study. In this study, we found pronounced between-subject and circadian variability in TS and DPD enzyme activity in human volunteers. Based on these results and as described in chapter 1.2, we performed a clinical study with high-dose capecitabine administration during the night. There was no significant change in TP activity observed during treatment. We found partial inhibition of TS activity 1.5 hours after each dose of capecitabine. Furthermore, upregulation of TS activity and a disturbance of the circadian rhythm was observed in this trial. Although less pronounced than in healthy volunteers, DPD activity displayed a circadian rhythm during capecitabine treatment, which supports our rationale for capecitabine chronotherapy. The chronomodulated capecitabine treatment (CCR) in this study allowed for a $20 \%$ higher dose intensity compared to the approved regimen (1250 $\mathrm{mg} / \mathrm{m}^{2}$ bi-daily on day 1-14 of every 21-day cycle).

Chapters 2.3-2.5 are focused on the clinical application of CTC analysis 
methods for the diagnosis of leptomeningeal metastases (LM) in CSF. The golden standard method for diagnosis of LM is CSF cytology. CSF cytology has, however, only a limited sensitivity of $44-67 \%$ at first sampling, increasing to $84-91 \%$ upon second sampling. Chapter 2.3 provides a literature review that shows that the reported sensitivities of the available alternative CSF tumor cell methods and their diagnostic accuracy for tumor cell detection are highly promising in comparison with CSF cytology. Chapters 2.4 and 2.5 describe two clinical studies with patients suspected of LM. In these studies, we found that the sensitivity of CTC detection in CSF using our EPCAM and MCSP based CTC detection methods compared favorably with CSF cytology. The methods show comparable specificities.

Lastly, we provide conclusions and perspectives about the development, validation, and clinical application of biomarker methods. Clinical application of the fully validated biomarker methods described in this thesis has led to a better understanding of the pharmacodynamics of the applied anti-cancer drugs, which may result in more safe and efficient cancer treatment. Furthermore, improved detection of CTC in CSF with our validated CTC analysis methods will enable diagnosis and treatment of LM for more patients. 


\section{NEDERLANDSE SAMENVATTING}

Pharmacodynamische biomarker methoden worden gebruikt om de mate van interactie tussen een antikanker geneesmiddel en zijn pharmacologisch aangrijpingspunt te bepalen. Deze methoden geven belangrijke informatie die leidend zijn voor de klinische besluitvorming omtrent de optimale dosis van het geneesmiddel en het toedieningsschema. Vanwege hun grote belang in de klinische besluitvorming, dienen alleen volledig gevalideerde biomarker methoden toegepast te worden in (pre)klinische studies. Volledig gevalideerde methoden hebben de beste kans om aan hun verwachtingen te voldoen. In dit proefschrift worden nieuwe of verbeterde biomarker methoden, en hun succesvolle toepassing in (pre) klinische studies beschreven.

Ontwikkeling en analytische validatie van methoden voor het bepalen van biomarkers

In het eerste deel van dit proefschrift worden de ontwikkeling en analytische validatie van meerdere biomarker methoden besproken, die zijn ontworpen voor het ondersteunen van (pre)klinische kanker studies. Deze methoden zijn gebaseerd op wijdverspreide basis analytische technieken zoals ligand binding assays, hoge druk vloeistof chromatografie (HPLC), en flow cytometrie. Alle methoden zijn gevalideerd volgens de aanbevelingen van de Food and Drug Administration (FDA) in hun bio-analytische validatie richtlijn uit 2018, die sinds 2013 in voorlopige vorm beschikbaar was.

Hoofdstuk 1.1 laat zien dat de meeste biomarker methoden die gebruikt worden in klinische studies slechts gedeeltelijk zijn gevalideerd. Dit kan mogelijk verklaren waarom deze methoden niet altijd aan hun verwachtingen voldoen. Het zou tevens het lage goedkeuringspercentage van $27 \%$ voor nieuwe antikankermiddelen kunnen verklaren.

Hoofdstukken 1.2-1.5 richten zich op methoden voor de bepaling van de activiteit van drie enzymen die betrokken zijn bij de activatie en afbraak van fluoropyrimidinen. De enzymactiviteit wordt normaal uitgedrukt per eiwitmassa in de cytosolische lysaten van de perifere bloed mononucleaire cellen (PBMC). Echter, de accuraatheid van deze methode wordt negatief beïnvloed door de co-isolatie van grote en variabele hoeveelheden hemoglobine $(\mathrm{Hb})$ in de PBMC lysaten. Hoofdstuk 1.3 behandelt een methode voor de spectrofotometrische bepaling van $\mathrm{Hb}$ bij $413 \mathrm{~nm}$, waarmee gecorrigeerd kan worden voor de 
hoeveelheid hemoglobine in de PBMC lysaten. We laten zien dat toepassing van de $\mathrm{Hb}$ correctie resulteert in een significante toename van de accuratesse, en leidt tot minder variabiliteit van de enzymactiviteitsbepalingen. In hoofdstuk 1.3 belichten we een methode voor de bepaling van de enzymactiviteit van thymidylaat synthase (TS). TS is het enige enzym dat in staat is tot de novo synthese van 2'-deoxythymidine $5^{\prime}$-monophosphate. TS is daarom essentieel voor DNA biosynthese, en het belangrijkste doelwit voor fluoropyrimidine behandelingen. Wij hebben een methode ontwikkeld en gevalideerd voor de bepaling van TS in humane PBMC. De methode is gebaseerd op het meten van de vrijgekomen tritium door de reactie van TS met het substraat ${ }^{3} \mathrm{H}$-deoxyuridine $5^{\prime}$-monophosphate $\left({ }^{3} \mathrm{H}\right.$-dUMP) met behulp van vloeistof scintillatie telling. $\mathrm{Na}$ de reactie wordt het overgebleven ${ }^{3} \mathrm{H}$-dUMP verwijderd door adsorptie aan actieve koolstof. De gevoeligheid van de methode werd verbeterd door gebruik van gevriesdroogd ${ }^{3} \mathrm{H}$-dUMP en optimalisatie van de actieve kool adsorptietijd, resulterend in een sterk verlaagd achtergondsignaal. De TS activiteit werd gemaximaliseerd door het gebruik van een sterke overmaat van de cofactor N5,N10 methylene-(6R,S)-tetrahydrofolaat, en door weglaten van EDTA uit de enzymreacties. In hoofdstuk 1.4 wordt een methode behandeld voor het bepalen van dihydropirimidine dehydrogenase (DPD) in PBMC. DPD is essentieel voor het ontgiften van fluoropyrimidines. Patienten met een tekort aan DPD activiteit hebben een verminderde klaring van fluoropyrimidines en lopen het risico om ernstige fluoropyrimidine gerelateerde toxiciteit te ontwikkelen. Onze DPD methode kan daarom bijdragen aan het verminderen van toxische bijwerkingen van fluoropyrimidine therapie door individueel te doseren op basis van het DPD phenotype. Het DPD phenotype werd bepaald door het meten van de hoeveelheid ${ }^{3} \mathrm{H}$-5,6-dihydrothymine dat vrijkomt bij de ex vivo reactie van ${ }^{3} \mathrm{H}$-thymine met DPD in PBMC cytosolische lysaten. De titrium gelabelde stoffen werden met HPLC en online scintillatie telling gemeten. De accuraatheid van de methode werd verbeterd door het cumulatieve oppervlak van alle chromatografische pieken te gebruiken als interne standaard. In hoofdstuk 1.5 beschrijven we een methode voor het bepalen van thymidine phosphorylase (TP) activiteit in PBMC. TP is een enzym dat zorgt voor de omzetting van fluoropyrimidinen naar actieve cytotoxische metabolieten. Patienten met een hoge TP activiteit kunnen daardoor meer last hebben van fluoropyrimidine-geinduceerde toxiciteit. Het TP activiteitsphenotype werd bepaald in PBMC cytosolische lysaten door de omzetting van het TP substraat thymidine naar thymine te meten met HPLC gekoppeld met ultraviolet licht detectie. 
Hoofdstuk 1.6 gaat over de ontwikkeling van een gevoeliger methode voor de bepaling van poly ADP-ribose (PAR) polymerase (PARP) activiteit in humane PBMC. PARP remmers worden tegenwoordig geëvalueerd als sensibilisatoren in combinatie met radiotherapie en/of chemotherapie. In deze combinatie studies is PARP actief bij zeer lage concentraties. Dit vereist een meetgevoeligheid die de huidige methoden niet kunnen leveren. Wij gebruiken ex vivo bestraling van PBMC om de lage basale PAR levels in PBMC sterk te verhogen. Daarnaast hebben we ontdekt dat PARP nog steeds actief is bij $0^{\circ} \mathrm{C}$, maar dat de afbraak van PAR bij $0^{\circ} \mathrm{C}$ geheel stopt. De combinatie van bestraling en lage temperatuur resulteert daardoor in hoge en stabiele PAR waarden. Deze "radiation enhanced PAR" methode heeft een sterk verbeterde gevoeligheid en accuratesse. De REP methode werd klinisch toegepast in een studie waarbij patienten een lage dosis olaparib kregen toegediend in combinatie met radiotherapie. De gemeten PARP activiteit was meer dan 95\% verlaagd bij behandeling met de maximaal getolereerde dosis olaparib. In een andere klinische studie kregen patienten lage dosis olaparib in combinatie met carboplatin. In die studie kon met de REP methode worden aangetoond dat de PARP activiteit op dag 8 van de behandeling met $98.7 \% \pm 0.14 \%$ was verlaagd ten opzichte van predose olaparib op dag 1 . Beide studies lieten als eerste een bijna complete reductie van PARP activiteit zien bij behandeling met een lage dosis olaparib.

In hoofdstuk 1.7 wordt een flow cytometrische biomarker method besproken voor het ondersteunen van klinisch onderzoek naar nivolumab en pembrolizumab, antilichamen tegen immuuncheckpointeiwitten. Checkpoint blockade therapie met nivolumab en pembrolizumab is zeer effectief gebleken voor de behandeling van vele soorten kanker. Het werkingsmechanisme van zowel nivolumab als pembrolizumab berust op het remmen van een eiwit op het oppervlak van immuuncellen, genaamd programmed death-1 (PD-1), dat functioneert als een receptor checkpoint molekuul. Deze nieuwe methode stelt ons in staat om het aantal monocyten, dendritische, NK-, B-, en T-cellen in humaan bloed te bepalen. Tevens kan met deze methode het percentage PD-1 positieve cellen, PD-1 bezettingsgraad, en het aantal PD-1 receptors per cel bepaald worden. De methode maakt gebruik van Cryosofree $^{\mathrm{TM}}$ als cryoconserveringsmiddel voor de lange termijn opslag van geisoleerde PBMCs. In tegenstelling tot het meer gebruikelijke DMSO, wordt Cryosofree ${ }^{\mathrm{TM}}$ niet door cellen opgenomen en kan daarom na ontdooien van de samples eenvoudig weggewassen worden. Dit resulteert in een hogere recovery van immuun cellen, met als gevolg een betere reproduceerbaarheid en accuratesse van de methode. De accuraatheid van de 
methode kon verder worden verbeterd door het gebruik van $2 \%$ formaldehyde om nivolumab en pembrolizumab aan PD-1 gebonden te houden tijdens de cryoconservering en de wasstappen na het fixeren en kleuren van de cellen met fluorescerende antilichamen. We tonen aan dat de binding tussen het anti-lgG detectie antilichaam en nivolumab of pembrolizumab zeer specifiek is. Voor het kwantificeren van PD-1 gebruiken we standaard fluorescerende kwantificatiebeads en kwaliteitscontrolebeads. Ten opzichte van andere methoden biedt deze methode als voordeel dat er van elk sample meerdere biomarkers gemeten worden in een groot panel van verschillende immuuncellen. We hebben een studie uitgevoerd met gezonde vrijwilligers om de biologische variatie in de biomarkers binnen en tussen individuen te bepalen. De klinische toepasbaarheid werd aangetoond in 6 patienten die met nivolumab werden behandeld, en 5 patienten die pembrolizumab kregen toegediend als standaard kankertherapie. In deze klinische studie vonden we in 9 van de 11 patienten een significante daling van het aantal PD-1 positieve T-cellen en het aantal PD-1 receptoren per T-cell na slechts 1 nivolumab of pembrolizumab kuur.

In de hoofdstukken 1.8 en 2.5 presenteren we twee biomarker methoden voor het detecteren van circulerende epitheliale tumorcellen en melanoomcellen in humaan bloed en CSF. Circulerende tumorcellen dragen bij aan het ontstaan van uitzaaiingen en hun detectie is geassocieerd met een negatieve klinische prognose. Detectie van deze zeer zeldzame circulerende tumorcellen (CTC) in een celrijke vloeistof, zoals bloed, vereist zeer gevoelige meetmethoden. Om dit mogelijk te maken werd eerst een Ficoll gradient gebruikt om het bloed zoveel mogelijk van de CTC te scheiden. Vervolgens werd magnetisch anti-epitheliaal-celadhesie-molecule (EpCAM), of anti-melanoma-chondroitin-sulfaat-proteoglycan (MCSP) aan de samples toegevoegd waarna de CTC van de samples gescheiden werden d.m.v. magnetische antilichaam-cel-sortering. De uiteindelijke detectie en telling van de CTC werd bereikt door de samples te labelen met fluorescerende antilichamen tegen EpCAM, MCSP, CD146, en CD45 om ze vervolgens d.m.v. flowcytometrie te kunnen onderscheiden van de resterende bloedcellen. We tonen aan dat onze methode ook gebruikt kan worden voor het bepalen van de phosphorylatie status van extracellulair-signal-related-kinase (ERK) in CTC. Dit is een potentieel belangrijke biomarker, aangezien het ERK-signaalpad van groot belang is voor de proliferatie, differentiatie, en overleving van tumorcellen. Afwijkingen in onderdelen van het ERK-signaalpad komen voor in ongeveer $30 \%$ van alle tumoren. 


\section{Preklinische en klinische toepassing van biomarker methoden}

Het tweede gedeelte van dit proefschrift is gericht op toepassen van onze gevalideerde biomarker methoden in (pre)klinische studies.

Hoofdstuk 2.1 beschrijft de toepassing van onze methoden voor de bepaling van DPD, TS en TP activiteit in een preklinische studie met gezonde vrijwilligers. In deze studie vonden we een significante circadiaanse variabiliteit in TS en DPD enzymactiviteit. Op basis van deze resultaten, hebben we vervolgens een klinische studie uitgevoerd met hoge-dosis capecitabine gedurende de nacht (hoodstuk 2.2). In deze studie vonden we geen verandering van de TP activiteit gedurende de behandeling. De TS activiteit was echter gedeeltelijk geremd 1.5 uur na toediening van capecitabine. Verder vonden we een toename van TS activiteit en een verstoring van het circadiaans ritme tijdens de studie. Hoewel minder duidelijk dan in de gezonde vrijwilligersstudie, werd in deze studie een identiek circadiaans ritme in DPD activiteit gevonden, die de rationale voor chronogemoduleerd toedienen van capecitabine bevestigt. In deze studie kon dankzij chronogemoduleerde toediening een $20 \%$ hogere capecitabine dosis intensiteit worden bereikt in vergelijking met de goedgekeurde standaard dosering (1250 mg/m² tweemaal daags op dag 1-14 van elke 21-daagse kuur).

Hoofdstukken 2.3-2.5 zijn gericht op de klinische toepassing van CTC detectie in CSF voor de diagnose van leptomeningeale metastasen (LM). De gouden standaard methode voor de diagnose van LM is CSF cytologie. Echter CSF cytologie heeft een beperkte gevoeligheid van $44-67 \%$ bij de eerste lumbaalpunctie, toenemend naar $84-91 \%$ bij de tweede punctie. Het literatuuronderzoek beschreven in hoofdstuk 2.3 laat zien dat de gerapporteerde gevoeligheid van de beschikbare alternatieve CTC detectiemethoden in CSF en hun diagnostische accuraatheid zeer gunstig zijn in vergelijking met cytologie. In de hoofdstukken 2.4 en 2.5 beschrijven we twee klinische studies die wij hebben uitgevoerd bij patienten met een klinische verdenking op LM. In deze studies, vonden we dat de gevoeligheid van CTC detectie in CSF met onze op EpCAM en MCSP gebaseerde CTC detectiemethoden gunstig afstak tegen cytologie, terwijl alle drie methoden een vergelijkbaar hoge specificiteit hebben.

Tenslotte, geven we in het laatste deel van dit proefschrift conclusies en perspectieven voor de ontwikkeling, validatie, en klinische toepassing van biomarker methoden. Klinische toepassing van de volledig gevalideerde biomarker methoden beschreven in dit proefschrift heeft geleid tot een beter begrip van de 
Appendix

pharmacodynamiek van de gebruikte anti-kankermiddelen. Deze opgedane kennis kan mogelijk bijdragen aan meer efficiente en veilige behandelingen. Verder kan de verbeterde detectie van CTC in CSF met onze detectiemethoden leiden tot een betere diagnose en behandeling van meer patienten met LM. 


\section{DANKWOORD}

Het onderzoek beschreven in dit proefschrift is tot stand gekomen dankzij de begeleiding, en samenwerking met vele anderen.

Ten eerste wil ik alle patienten, en gezonde proefpersonen bedanken die vrijwillig hebben deelgenomen aan, respectievelijk, de klinische en preklinische studies. Zonder hen waren de ontwikkeling en klinische toepassing van de biomarker methoden zoals beschreven in dit proefschrift niet mogelijk geweest.

In het bijzonder wil ik Prof. Jan Schellens bedanken voor mijn aanstelling en de prettige samenwerking gedurende de 22 jaar dat ik deel mocht uitmaken van zijn onderzoeksgroep. Jan is een arts-onderzoeker die dankzij zijn grote wetenschappelijke ervaring sterk doordrongen is van de waarde van methode validatie voor hun succesvolle klinische toepassing. Dank voor de grote mate van zelfstandigheid die jij mij hebt geboden bij het uitvoeren van het onderzoek. Dankzij de betrokkenheid van Jan bij een uitgebreid repertoire aan klinische studies was het testen van de klinische toepasbaarheid van onze gevalideerde biomarker methoden nooit een probleem.

Mijn promotor Prof. Jos Beijnen wil ik bedanken voor de mogelijkheid om mijn onderzoek onder zijn begeleiding voort te kunnen zetten. Jos, bedankt voor het vertrouwen en de mogelijkheid die jij hebt geboden om dit promotie onderzoek uit te voeren, wat natuurlijk niet vanzelfsprekend is bij iemand zoals ik met een analisten opleiding. Dank voor het delen van jouw uitgebreide kennis en wetenschappelijke inzichten, die samen met jouw uitgebreide klinischfarmacologische expertise enorm hebben bijgedragen aan dit onderzoek. Daarbij staat in het bijzonder jouw aandacht voor de kwaliteit van het onderzoek aan de basis van de hier beschreven methode validaties.

Mijn co-promotor Dr. Dieta Brandsma wil ik bedanken voor haar grote rol bij de totstandkoming van dit promotieonderzoek. Dieta, ik heb grote waardering voor de wijze waarop jij een drukke baan als neuroloog weet te combineren met het uitvoeren van klinisch wetenschappelijk onderzoek. Jij bent de drijvende kracht achter de klinische validatie en implementatie van de circulerende tumor cel (CTC) analyse methoden voor een betere diagnose van leptomeningeale metastasen (LM). Dankzij jouw inzet wordt een van deze methoden nu al een aantal jaren succesvol toegepast door het Algemeen Klinisch-chemisch Laboratorium (AKL) voor de diagnostiek van LM.

Veel dank gaat ook uit naar alle collega promovendi voor de prettige 
samenwerking. In het bijzonder gaat mijn dank uit naar Serena Marchetti, Rosemarie de Haan, Bojana Kerklaan, Maarten Deenen, Bart Jacobs, Jeroen Roosendaal, Mark van Bussel, Jill Geenen, Gwen Dackus, en Willeke Ros. Dankzij Bojana Kerklaan en Mark van Bussel is het gelukt om de biomarker methoden voor het bepalen van epitheliale CTC in ruggenvocht klinisch te valideren voor de diagnostiek van LM.

Klinisch chemicus Dr. Daan van den Broek (hoofd $A K L$ ), en de altijd zeer behulpzame onderzoekers Tracey Kellow, Vanessa Geldhof, en Selcuk Colak van het AKL wil ik bedanken voor het implementeren van de CTC diagnostiek op het AKL.

Dr. Conchita Vens wil ik bedanken voor onze synergistische samenwerking naar de activiteit van PARP. Conchita staat aan de basis van het concept om bloedcellen buiten het lichaam te bestralen om zo een betere detectie van PARP activiteit mogelijk te maken. Mede hierdoor konden we uiteindelijk een bijna 100-maal gevoeliger methode ontwikkelen voor het meten van PARP activiteit in klinische studies met lage dosis PARP remmers.

De master studenten Kim Schilders, Danielle Vaartjes, Anneloes Ruijter wil ik bedanken voor hun bijdrage aan de ontwikkeling van de DPD en TS methoden, en Iris Miedema voor haar bijdrage aan de PD-1 methode.

Voor de vele bloedafnames bij gezonde vrijwilligers ben ik de altijd zeer behulpzame artsen Kimberley Heinhuis, Sanne Huijberts, Marit Vermunt, Steffie Groenland, en Jill Geenen zeer dankbaar. Dat er wel eens een stoere kerel flauw viel tijdens of soms al voor de bloedafname heeft zeker niet aan jullie gelegen.

Voor het uitvoeren van dit onderzoek heb ik gebruik gemaakt van verschillende NKI onderzoeksfaciliteiten. De zeer kundige en behulpzame flow cytometrie operators Frank van Diepen, Anita Pfauth en Martijn van Baalen ben ik zeer erkentelijk voor de introductiecursussen, oplossen van apparatuur storingen, kalibraties, en het sorteren van tumor cellen. Voor het faciliteren van het onderzoek op het radionucliden lab wil ik de labmanagers Henny van Rooij, Desiree Verwoerd en Theo Lamers bedanken.

We zijn als onderzoeksgroep enkele malen verhuisd naar andere afdelingen binnen het NKI. Dankzij het uitstekende organisatietalent van Hans te Poele (H3), Wouter Nijkamp (B7), en Ellen Wientjes (C2) verliepen deze verhuizingen zonder veel problemen.

Tenslotte gaat mijn dank ook uit naar de office managers Thea Eggenhuizen, Lara Spee, en Mirna Ekelschot-van Diermen voor hun hulp bij alle logistieke zaken. 
Dankwoord

\section{\&}




\section{LIST OF PUBLICATIONS}

1. Pluim D, Beijnen JH. Analytical validation of quantitative pharmacodynamic methods used in clinical cancer studies. Int Arch Clin Pharmacol 2021; 7

2. Duinkerken CW, de Weger VA, Dreschler WA, van der Molen L, Pluim D, Rosing $H$, Nuijen B, Hauptmann M, Beijnen JH, Balm AJM, de Boer JP, Burgers JA, Marchetti S, Schellens JHM, Zuur CL. Transtympanic Sodium Thiosulfate for Prevention of Cisplatin-Induced Ototoxicity: A Randomized Clinical Trial. Otol Neurotol 2021;42:678-685 3. van Eijk M, Pluim D, Dorlo TPC, Marchetti $\mathrm{S}$, Huitema ADR, Beijnen JH. Investigating the influence of relevant pharmacogenetic variants on the pharmacokinetics and pharmacodynamics of orally administered docetaxel combined with ritonavir. Pharmacogenomics J 2021:336-345

4. Geenen JJJ, Dackus GMHE, Schouten PC, Pluim D, Marchetti S, Sonke GS, Jóźwiak K, Huitema ADR, Beijnen JH, Schellens JHM, Linn SC. A Phase I dose-escalation study of two cycles carboplatin-olaparib followed by olaparib monotherapy in patients with advanced cancer. Int J Cancer 2021 Jun 15;148:3041-3050

5. de Haan R, van den Heuvel MM, van Diessen J, Peulen HMU, van Werkhoven $E$, de Langen AJ, Lalezari F, Pluim D, Verwijs-Janssen M, Vens C, Schellens JHM, Steeghs N, Verheij M, van Triest B. Phase I and Pharmacologic Study of Olaparib in Combination with High-dose Radiotherapy with and without Concurrent Cisplatin for Non-Small Cell Lung Cancer. Clin Cancer Res 2021;27:1256-1266

6. Jansen AME, Sriram JD, Pluim D, Maas
RJH, van Groningen H, Piet B, Ter Heine R. Therapeutic Exposure and Successful Response to Pembrolizumab in a Patient With Non-Small-Cell Lung Cancer Despite Significant Renal Loss Due to Paraneoplastic Nephrotic Syndrome. Clin Lung Cancer 2021 Mar;22:220-223

7. Roosendaal J, Jacobs BAW, Pluim D, Rosing $H$, de Vries $N$, van Werkhoven $E$, Nuijen B, Beijnen JH, Huitema ADR, Schellens JHM, Marchetti S. Phase I pharmacological study of continuous chronomodulated capecitabine treatment. Pharm Res 2020 ;37:89

8. van Bussel MTJ, Pluim D, Milojkovic Kerklaan B, Bol M, Sikorska K, Linders DTC, van den Broek $D$, Beijnen JH, Schellens JHM, Brandsma D. Circulating epithelial tumor cell analysis in CSF in patients with leptomeningeal metastases. Neurology 2020;94:521-528

9. Pluim D, Ros W, Miedema IHC, Beijnen $\mathrm{JH}$, Schellens JHM. Multiparameter Flow Cytometry Assay for Quantification of Immune Cell Subsets, PD-1 Expression Levels and PD-1 Receptor Occupancy by Nivolumab and Pembrolizumab. Cytometry Part A 2019;95:1053-1065

10. Siddiqui A, Gollavilli PN, Schwab A, Vazakidou ME, Ersan PG, Ramakrishnan M, Pluim D, Coggins S, Saatci O, Annaratone L, Hm Schellens J, Kim B, Asangani IA, Rasheed SAK, Marchiò C, Sahin O, Ceppi P. Thymidylate synthase maintains the dedifferentiated state of triple negative breast cancers. Cell Death Differ 2019;26:22232236

11. Pluim D, Ros W, van Bussel MTJ, Brandsma D, Beijnen JH, Schellens JHM. Enzyme linked 
immunosorbent assay for the quantification of nivolumab and pembrolizumab in human serum and cerebrospinal fluid. J Pharm Biomed Anal 2019;164:128-134

12. Jacobs $B A W$, Pluim $D$, van der Laan $P$, Tzani A, Beijnen JH, Schellens JHM. Development and validation of a quantitative method for thymidine phosphorylase activity in peripheral blood mononuclear cells. Nucleosides Nucleotides Nucleic Acids 2018;37:436-454

13. Henricks LM, Jacobs BAW, Meulendijks D, Pluim D, van den Broek D, de Vries N, Rosing $H$, Beijnen JH, Huitema ADR, Guchelaar $\mathrm{HJ}$, Cats A, Schellens JHM. Food-effect study on uracil and dihydrouracil plasma levels as marker for dihydropyrimidine dehydrogenase activity in human volunteers. Br J Clin Pharmacol 2018;84:2761-2769

14. van Bussel MTJ, Pluim D, Bol $M$, Beijnen JH, Schellens JHM, Brandsma D. EpCAM-based assays for epithelial tumor cell detection in cerebrospinal fluid. J Neurooncol. 2018;137:1-10

15. de Haan R, Pluim D, van Triest B, van den Heuvel $M$, Peulen $H$, van Berlo D, George J, Verheij M, Schellens JHM, Vens C. Improved pharmacodynamic (PD) assessment of low dose PARP inhibitor PD activity for radiotherapy and chemotherapy combination trials. Radiother Oncol 2018 ;126:443-449

16. Gorelova V, De Lepeleire J, Van Daele J, Pluim D, Meï C, Cuypers A, Leroux O, Rébeillé $F$, Schellens JHM, Blancquaert $D$, Stove CP, Van Der Straeten D. Dihydrofolate Reductase/Thymidylate Synthase FineTunes the Folate Status and Controls Redox Homeostasis in Plants. Plant Cell 2017
;29:2831-2853

17. Leijen S, van Geel RM, Sonke GS, de Jong D, Rosenberg EH, Marchetti S, Pluim D, van Werkhoven E, Rose S, Lee MA, Freshwater T, Beijnen JH, Schellens JH. Phase II Study of WEE1 Inhibitor AZD1775 Plus Carboplatin in Patients With TP53-Mutated Ovarian Cancer Refractory or Resistant to First-Line Therapy Within 3 Months. J Clin Oncol. 2016 ;34:4354-4361

18. Jacobs BA, Deenen MJ, Pluim D, van Hasselt JG, Krähenbühl MD, van Geel RM, de Vries N, Rosing $\mathrm{H}$, Meulendijks D, Burylo AM, Cats $A$, Beijnen JH, Huitema AD, Schellens $\mathrm{JH}$. Pronounced between-subject and circadian variability in thymidylate synthase and dihydropyrimidine dehydrogenase enzyme activity in human volunteers. $\mathrm{Br} \mathrm{J}$ Clin Pharmacol 2016;82:706-16

19. Jacobs BA, Meulenaar J, Rosing $H$, Pluim D, Tibben MM, de Vries $N$, Nuijen B, Huitema AD, Beijnen JH, Schellens JH, Marchetti S. A phase 0 clinical trial of novel candidate extended-release formulations of capecitabine. Cancer Chemother Pharmacol 2016;77:1201-7

20. Meulendijks D, de Groot JW, Los $M$, Boers JE, Beerepoot LV, Polee MB, Beeker A, Portielje JE, Goey SH, de Jong RS, Vanhoutvin SA, Kuiper M, Sikorska K, Pluim D, Beijnen JH, Schellens JH, Grootscholten C, Tesselaar $\mathrm{ME}$, Cats A. Bevacizumab combined with docetaxel, oxaliplatin, and capecitabine, followed by maintenance with capecitabine and bevacizumab, as first-line treatment of patients with advanced HER2-negative gastric cancer: A multicenter phase 2 study Cancer 2016;122:1434-43

21. Milojkovic Kerklaan B, Pluim D, Bol 
M, Hofland I, Westerga J, van Tinteren $\mathrm{H}$, Beijnen JH, Boogerd $\mathrm{W}$, Schellens JH, Brandsma D. EpCAM-based flow cytometry in cerebrospinal fluid greatly improves diagnostic accuracy of leptomeningeal metastases from epithelial tumors. Neuro Oncol 2016;18:855-62

22. Meulendijks $D$, Jacobs BA, Aliev A, Pluim $D$, van Werkhoven E, Deenen MJ, Beijnen $\mathrm{JH}$, Cats $\mathrm{A}$, Schellens JH. Increased risk of severe fluoropyrimidine-associated toxicity in patients carrying a $G$ to $C$ substitution in the first 28-bp tandem repeat of the thymidylate synthase $2 \mathrm{R}$ allele. Int J Cancer 2016;138:245-53

23. Pluim D, Jacobs $B A$, Deenen $M J$, Ruijter $A E$, van Geel RM, Burylo $A M$, Meulendijks D, Beijnen JH, Schellens JH. Improved pharmacodynamic assay for dihydropyrimidine dehydrogenase activity in peripheral blood mononuclear cells. Bioanalysis 2015;7:519-29

24. Leijen $S$, Burgers $S A$, Baas $P$, Pluim D, Tibben $M$, van Werkhoven $E$, Alessio $E$, Sava G, Beijnen JH, Schellens JH. Phase I/II study with ruthenium compound NAMI-A and gemcitabine in patients with non-small cell lung cancer after first line therapy. Invest New Drugs 2015;33:201-14

25. Marchetti S, Pluim D, Beijnen JH, Mazzanti $R$, van Tellingen $O$, Schellens JH. Effect of the drug transporters $A B C B 1$, $A B C C 2$, and $A B C G 2$ on the disposition and brain accumulation of the taxane analog BMS-275,183. Invest New Drugs. 2014 ;32:1083-95

26. Lin F, Marchetti $S$, Pluim D, lusuf $D$, Mazzanti R, Schellens JH, Beijnen JH, van Tellingen $\mathrm{O}$. Abcc4 together with abcb1 and abcg2 form a robust cooperative drug efflux system that restricts the brain entry of camptothecin analogues. Clin Cancer Res 2013;19:2084-95

27. Pluim $D$, Jacobs $B A$, Krähenbühl $M D$, Ruijter $A E$, Beijnen JH, Schellens JH. Correction of peripheral blood mononuclear cell cytosolic protein for hemoglobin contamination. Anal Bioanal Chem. 2013 ;405:2391-5

28. Marchetti S, Pluim D, van Eijndhoven $M$, van Tellingen $O$, Mazzanti R, Beijnen JH, Schellens JH. Effect of the drug transporters $A B C G 2, A b c g 2, A B C B 1$ and $A B C C 2$ on the disposition, brain accumulation and myelotoxicity of the aurora kinase $B$ inhibitor barasertib and its more active form barasertib-hydroxy-QPA. Invest New Drugs 2013;31:1125-35

29. Pluim D, Schilders KA, Jacobs $B A$, Vaartjes D, Beijnen JH, Schellens JH. Pharmacodynamic assay of thymidylate synthase activity in peripheral blood mononuclear cells. Anal Bioanal Chem 2013 405:2495-503

30. Pluim D, Devriese LA, Beijnen $\mathrm{JH}$, Schellens $\mathrm{JH}$. Validation of a multiparameter flow cytometry method for the determination of phosphorylated extracellular-signal-regulated kinase and DNA in circulating tumor cells. Cytometry Part A 2012;81:664-71

31. Pluim D, Beijnen JH, Schellens JH, van Tellingen O. Simultaneous determination of AZD1152 (prodrug) and AZD1152hydroxyquinazoline pyrazol anilide by reversed phase liquid chromatography. J Chromatogr B Analyt Technol Biomed Life Sci. 2009;877:3549-55 
32. Boss DS, Siegel-Lakhai WS, van Egmond-Schoemaker NE, Pluim D, Rosing $\mathrm{H}$, Ten Bokkel Huinink WW, Beijnen JH, Schellens JH. Phase I pharmacokinetic and pharmacodynamic study of Carboplatin and topotecan administered intravenously every 28 days to patients with malignant solid tumors. Clin Cancer Res. 2009;15:4475-83

33. Veltkamp SA, Pluim D, van Eijndhoven MA, Bolijn MJ, Ong FH, Govindarajan $\mathrm{R}$, Unadkat JD, Beijnen JH, Schellens JH. New insights into the pharmacology and cytotoxicity of gemcitabine and 2',2'-difluorodeoxyuridine. Mol Cancer Ther 2008;7:2415-25

34. Veltkamp SA, Jansen RS, Callies S, Pluim D, Visseren-Grul CM, Rosing $H$, KloekerRhoades S, Andre VA, Beijnen JH, Slapak $\mathrm{CA}$, Schellens JH. Oral administration of gemcitabine in patients with refractory tumors: a clinical and pharmacologic study. Clin Cancer Res. 2008;14:3477-86

35. Veltkamp SA, Pluim D, van Tellingen $O$, Beijnen JH, Schellens JH. Ex t e n s i v e metabolism and hepatic accumulation of gemcitabine after multiple oral and intravenous administration in mice. Drug Metab Dispos 2008;36:1606-15

36. Brouwers EE, Tibben MM, Pluim D, Rosing $H$, Boot $H$, Cats $A$, Schellens JH, Beijnen JH. Inductively coupled plasma mass spectrometric analysis of the total amount of platinum in DNA extracts from peripheral blood mononuclear cells and tissue from patients treated with cisplatin. Anal Bioanal Chem 2008;391:577-85

37. Marchetti S, Oostendorp RL, Pluim D, van Eijndhoven $\mathrm{M}$, van Tellingen $\mathrm{O}$, Schinkel $A H$, Versace $R$, Beijnen $J H$, Mazzanti $R$,
Schellens JH. In vitro transport of gimatecan (7-t-butoxyiminomethylcamptothecin) by breast cancer resistance protein, P-glycoprotein, and multidrug resistance protein 2. Mol Cancer Ther 2007;6:3307-13 38. Hoebers FJ, Pluim D, Hart AA, Verheij $\mathrm{M}$, Balm AJ, Fons G, Rasch CR, Schellens JH, Stalpers LJ, Bartelink H, Begg AC. CisplatinDNA adduct formation in patients treated with cisplatin-based chemoradiation: lack of correlation between normal tissues and primary tumor. Cancer Chemother Pharmacol 2008;61:1075-81

39. Breedveld P, Pluim D, Cipriani G, Dahlhaus $F$, van Eijndhoven MA, de Wolf CJ, Kuil A, Beijnen JH, Scheffer GL, Jansen $G$, Borst $P$, Schellens JH. The effect of low $\mathrm{pH}$ on breast cancer resistance protein (ABCG2)mediated transport of methotrexate, 7-hydroxymethotrexate, methotrexate diglutamate, folic acid, mitoxantrone, topotecan, and resveratrol in in vitro drug transport models. Mol Pharmacol 2007 Jan;71:240-9

40. Liedert B, Pluim D, Schellens J, Thomale J. Adduct-specific monoclonal antibodies for the measurement of cisplatin-induced DNA lesions in individual cell nuclei. Nucleic Acids Res 2006;34:47

41. Hoebers FJ, Pluim D, Verheij M, Balm AJ, Bartelink $\mathrm{H}$, Schellens JH, Begg AC. Prediction of treatment outcome by cisplatin-DNA adduct formation in patients with stage III/ IV head and neck squamous cell carcinoma, treated by concurrent cisplatin-radiation (RADPLAT). Int J Cancer 2006;119:750-6

42. Siegel-Lakhai WS, Crul $M$, Zhang S, Sparidans RW, Pluim D, Howes A, Solanki B, Beijnen JH, Schellens JH. 
Phase I and pharmacological study of the farnesyltransferase inhibitor tipifarnib (Zarnestra, R115777) in combination with gemcitabine and cisplatin in patients with advanced solid tumours. Br J Cancer 2005 ;93:1222-9

43. Rademaker-Lakhai JM, Crul M, Pluim D, Sparidans RW, Baas $\mathrm{P}$, Beijnen JH, van Zandwijk N, Schellens JH. Phase I clinical and pharmacologic study of a 2-weekly administration of cisplatin and gemcitabine in patients with advanced non-small cell lung cancer. Anticancer Drugs. 2005;16:1029-36

44. Beumer JH, Hillebrand MJ, Pluim D, Rosing $\mathrm{H}$, Foley $\mathrm{K}$, Yule SM, Schellens $\mathrm{JH}$, Beijnen JH. Human metabolism of $[(14) C]$ indisulam following i.v. infusion in cancer patients. Invest New Drugs 2005 ;23:317-30

45. Breedveld P, Pluim D, Cipriani G, Wielinga $P$, van Tellingen $O$, Schinkel $A H$, Schellens JH. The effect of Bcrp1 (Abcg2) on the in vivo pharmacokinetics and brain penetration of imatinib mesylate (Gleevec): implications for the use of breast cancer resistance protein and P-glycoprotein inhibitors to enable the brain penetration of imatinib in patients. Cancer Res 2005;65:2577-82

46. van Waardenburg $R C$, de Jong $L A$, van Eijndhoven $M A$, Verseyden $C$, Pluim D, Jansen LE, Bjornsti MA, Schellens JH. Platinated DNA adducts enhance poisoning of DNA topoisomerase I by camptothecin. J Biol Chem 2004;279:54502-9

47. Breedveld $P$, Zelcer N, Pluim D, Sönmezer $\mathrm{O}$, Tibben MM, Beijnen JH, Schinkel AH, van Tellingen $\mathrm{O}$, Borst $\mathrm{P}$, Schellens JH.

Mechanism of the pharmacokinetic interaction between methotrexate and benzimidazoles: potential role for breast cancer resistance protein in clinical drugdrug interactions. Cancer Res. 2004;64:580411

48. Rademaker-Lakhai JM, van den Bongard D, Pluim D, Beijnen JH, Schellens JH. A Phase I and pharmacological study with imidazolium-trans-DMSO-imidazoletetrachlororuthenate, a novel ruthenium anticancer agent. Clin Cancer Res 2004;10:3717-27.

49. Rademaker-Lakhai JM, Terret $C$, Howell SB, Baud CM, De Boer RF, Pluim D, Beijnen $\mathrm{JH}$, Schellens JH, Droz JP. A Phase I and pharmacological study of the platinum polymer AP5280 given as an intravenous infusion once every 3 weeks in patients with solid tumors. Clin Cancer Res 2004;10:338695.

50. Pluim D, van Waardenburg RC, Beijnen $\mathrm{JH}$, Schellens JH. Cytotoxicity of the organic ruthenium anticancer drug Nami-A is correlated with DNA binding in four different human tumor cell lines. Cancer Chemother Pharmacol 2004 Jul;54:71-8

51. Zamboni WC, Gervais AC, Egorin MJ, Schellens JH, Zuhowski EG, Pluim D, Joseph E, Hamburger DR, Working PK, Colbern G, Tonda ME, Potter DM, Eiseman JL. Systemic and tumor disposition of platinum after administration of cisplatin or STEALTH liposomal-cisplatin formulations (SPI-077 and SPI-077 B103) in a preclinical tumor model of melanoma. Cancer Chemother Pharmacol 2004;53:329-36

52. Brown DB, Ma MK, Battafarano RJ, Naidu S, Pluim D, Zamboni WC, McLeod HL. Endovascular lung perfusion using high-dose cisplatin: uptake and DNA adduct formation 
in an animal model. Oncol Rep 2004;11:23743

53. Crul $M$, Schoemaker NE, Pluim D, Maliepaard M, Underberg RW, Schot $M$, Sparidans RW, Baas P, Beijnen JH, Van Zandwijk N, Schellens JH. Randomized phase I clinical and pharmacologic study of weekly versus twice-weekly dose-intensive cisplatin and gemcitabine in patients with advanced non-small cell lung cancer. Clin Cancer Res 2003;9:3526-33

54. van den Bongard HJ, Pluim D, Waardenburg RC, Ravic M, Beijnen JH, Schellens JH. In vitro pharmacokinetic study of the novel anticancer agent E7070: red blood cell and plasma protein binding in human blood. Anticancer Drugs 2003;14:405-10

55. Crul $M$, van Waardenburg RC, Bocxe $S$, van Eijndhoven MA, Pluim D, Beijnen $\mathrm{JH}$, Schellens JH. DNA repair mechanisms involved in gemcitabine cytotoxicity and in the interaction between gemcitabine and cisplatin. Biochem Pharmacol 2003 ;65:27582

56. van den Bongard $H J$, Pluim D, Rosing $H$, Nan-Offeringa L, Schot M, Ravic M, Schellens $\mathrm{JH}$, Beijnen $\mathrm{JH}$. An excretion balance and pharmacokinetic study of the novel anticancer agent E7070 in cancer patients. Anticancer Drugs 2002;13:807-14

57. Zamboni WC, Gervais AC, Egorin MJ, Schellens JH, Hamburger DR, Delauter BJ, Grim A, Zuhowski EG, Joseph E, Pluim D, Potter DM, Eiseman JL. Inter- and intratumoral disposition of platinum in solid tumors after administration of cisplatin. Clin Cancer Res 2002;8:2992-9

58. Meerum Terwogt JM, Groenewegen
G, Pluim D, Maliepaard M, Tibben MM, Huisman A, ten Bokkel Huinink WW, Schot M, Welbank $H$, Voest EE, Beijnen JH, Schellens JM. Phase I and pharmacokinetic study of SPI-77, a liposomal encapsulated dosage form of cisplatin. Cancer Chemother Pharmacol 2002;49:201-10

59. Schoemaker NE, Herben VM, de Jong LA, van Waardenburg RC, Pluim D, ten Bokkel Huinink WW, Beijnen JH, Schellens JH. Topoisomerase I levels in white blood cells of patients with ovarian cancer treated with paclitaxel-cisplatin-topotecan in a phase I study. Anticancer Drugs 2002;13:87-91

60. Maliepaard $M$, van Gastelen MA, Tohgo A, Hausheer $\mathrm{FH}$, van Waardenburg RC, de Jong LA, Pluim D, Beijnen JH, Schellens JH. Circumvention of breast cancer resistance protein (BCRP)-mediated resistance to camptothecins in vitro using non-substrate drugs or the BCRP inhibitor GF120918. Clin Cancer Res 2001;7:935-41

61. Pluim D, Maliepaard $M$, van Waardenburg RC, Beijnen JH, Schellens JH. 32P-postlabeling assay for the quantification of the major platinum-DNA adducts. Anal Biochem 1999;275:30-8

62. Maliepaard $M$, van Gastelen MA, de Jong LA, Pluim D, van Waardenburg RC, Ruevekamp-Helmers MC, Floot BG, Schellens JH. Overexpression of the BCRP/ MXR/ABCP gene in a topotecan-selected ovarian tumor cell line. Cancer Res 1999 ;59:4559-63

63. de Graaff $M$, Maliepaard M, Pluim D, Floot BJ, Slaper-Cortenbach IC, Schellens JH. In vitro antagonistic cytotoxic interactions between platinum drugs and taxanes on bone marrow progenitor cell CFU-GM. 
Appendix

Anticancer Drugs 1999;10:213-8

64. Brondijk $\mathrm{TH}$, van der Rest ME, Pluim D, de Vries Y, Stingl K, Poolman B, Konings WN. Catabolite inactivation of wild-type and mutant maltose transport proteins in Saccharomyces cerevisiae. J Biol Chem 1998 ;273:15352-7

65. Faber KN, Keizer-Gunnink I, Pluim D, Harder W, Ab G, Veenhuis M. The N-terminus of amine oxidase of Hansenula polymorpha contains a peroxisomal targeting signal. FEBS Lett 1995;357:115-20 


\section{CURRICULUM VITAE}

Ik ben geboren op 11 september 1970 te Groningen. In 1987 heb ik mijn VWO diploma behaald aan de Rijksscholengemeenschap Winkler Prins te Veendam. In 1992 heb ik de studie HBO-B biotechnologie aan de Rijkshogeschool Groningen afgerond. De afstudeeropdracht betrof het opsporen van het peroxisomaal richtingssignaal aan de $\mathrm{N}$-terminale zijde van amine oxidase in de gist Hansenula polymorpha onder leiding van Prof. Marten Veenhuis van de vakgroep Microbiologie van de Rijksuniversiteit Groningen (RUG) in het Biologisch Centrum te Haren (65). Aansluitend heb ik 1 jaar

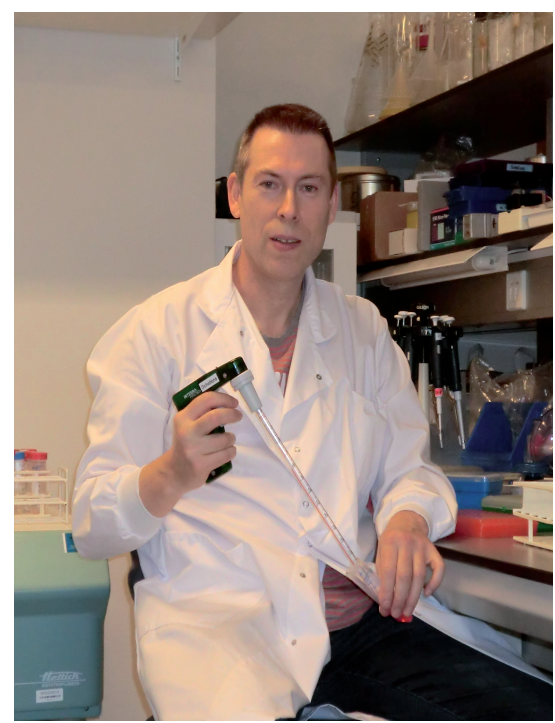
als diensplichtige voor de artillerie gewerkt als vrachtwagenchauffeur aan de Johannes Post kazerne te Havelte. Daarna heb ik tot 1997 gewerkt als research analist voor de afdeling Microbiologie van de Rijks Universiteit Groningen. In die periode heb ik, onder supervisie van Prof. Wil Konings, DNA- en genconstructen gemaakt waarmee we het kataboliet inactivatie signaal van het maltose transport eiwit in de gist Sacharomyces cerevisiae hebben geidentificeerd (64). Begin 1997 ben ik als research analist B begonnen op de afdeling Pharmacologie van het Nederlands Kanker Instituut (NKI) te Amsterdam onder supervisie van Prof. Jan Schellens (tot 2018), en mijn promotor Prof. Jos Beijnen en co-promotor Dieta Brandsma. In deze functie ontwikkel en valideer ik meetmethoden voor het kwantificeren van de mate van interactie van anti-kankermiddelen met hun biologisch aangrijpingspunt in of op de cel, en test ik de klinische toepasbaarheid van deze methoden. De studies beschreven in dit proefschrift zijn gebaseerd op mijn onderzoek van ca. de afgelopen 10 jaar, waarin ik werkzaam was als research analist. 